Maurício Roberto Veronez

\title{
Proposta de um modelo regional para redução do efeito sistemático da ionosfera através do método seqüencial de ajustamento
}

Tese apresentada à Escola de Engenharia de São Carlos, da Universidade de São Paulo, como parte dos requisitos para a obtenção do Título de Doutor em Engenharia Civil: Transportes.

Orientador: Prof. Associado Paulo Cesar Lima Segantine

São Carlos - SP

2004 


\section{DEDICATÓRIA}

À minha mãe guerreira, Dona Bia, pelo amor e dedicação Aos meus irmãos Osni, Rose, Marcelo e Fabiano À minha querida esposa Cleidi 


\section{AGRADECIMENTOS}

A Deus por tudo...

Ao Professor Paulo Cesar Lima Segantine pela orientação e sugestões durante a realização deste trabalho;

À minha esposa Cleidi pelo incentivo nos momentos de maiores dificuldades;

Ao Professor Dr. Joaquim Osório e a Professora Dra. Izabel Osório, ambos da Faculdade de Ciências da Universidade do Porto, pela orientação e críticas, sempre oportunas, durante meu estágio sanduíche naquela instituição;

À Universidade do Vale do Rio dos Sinos - UNISINOS por ter propiciado meu afastamento com bolsa auxílio Doutorado;

Aos professores da UNISINOS Diego e Adriane, pelo apoio durante o meu período de afastamento da instituição;

Ao doutorando Jorge Bessa e aos acadêmicos de Engenharia Geográfica, César e Alex, pela amizade e apoio durante minha estadia na Faculdade de Ciências da Universidade do Porto;

Aos amigos e "irmãos" Sérgio, Rodrigo, Marisa, Uchoa, Tule, Genival, Geraldo, Artur e Cláudia pelo companheirismo durante este período de doutoramento;

Ao amigo Schaal pelas críticas e sugestões valiosas durante a realização deste trabalho;

À Coordenadoria de Aperfeiçoamento de Pessoal de Nível Superior - CAPES, pela concessão da bolsa sanduíche no período de 01/03/2003 a 01/07/2003. 


\section{SUMÁRIO}

RESUMO

ABSTRACT

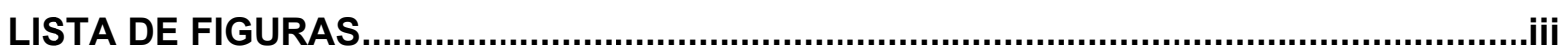

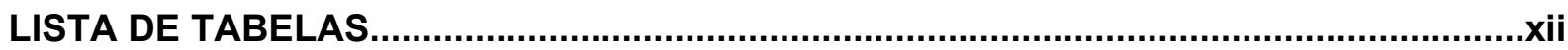

LISTA DE ABREVIATURAS E SIGLAS..........................................................................

LISTA DE SÍMBOLOS..............................................................................................xi

1 INTRODUÇÃO

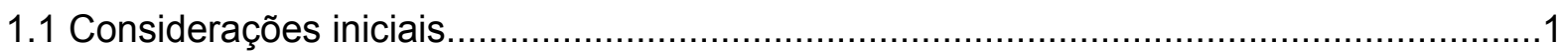

$1.2 \mathrm{O}$ problema

1.3 Delimitação do objeto de estudo e objetivos.................................................................

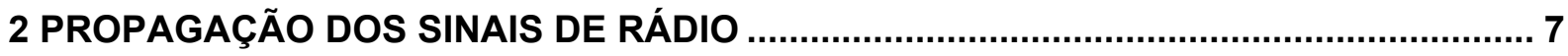

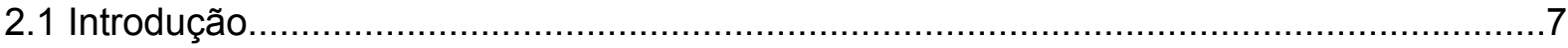

2.2 Principais elementos definidores das ondas eletromagnéticas....................................10

2.3 Representação matemática das ondas.................................................................12

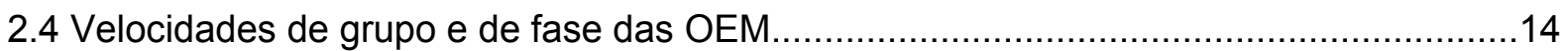

2.4.1 Relação entre velocidade de grupo e velocidade de fase........................................17

2.5 Características dos sinais transmitidos pelos satélites GPS .......................................18

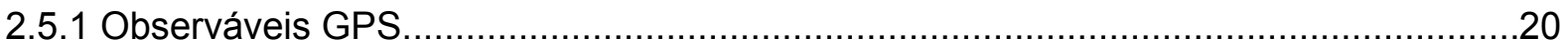

3 A IONOSFERA

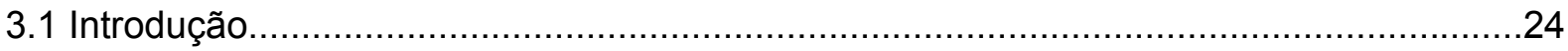

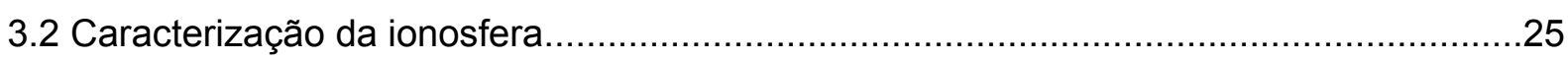

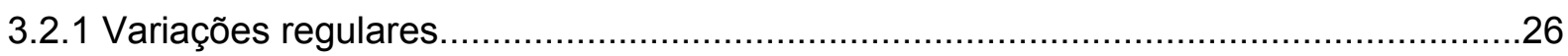

3.2.2 Camadas da ionosfera

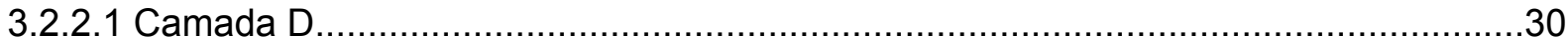

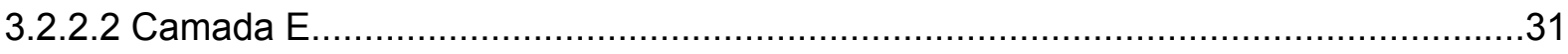

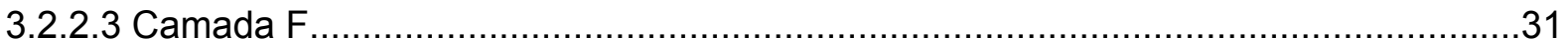

3.3 Propagação dos sinais de rádio através da ionosfera.................................................. 


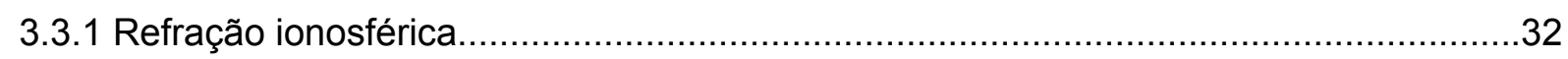

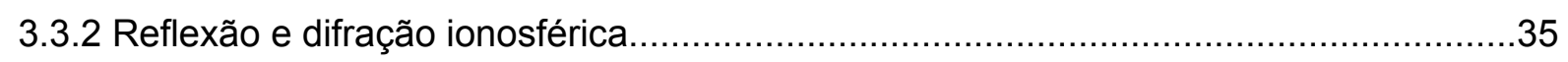

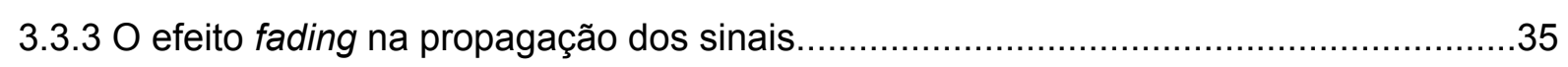

3.4 Outros fenômenos que afetam os sinais de rádio......................................................

4 MODELOS DE MINIMIZAÇÃO DOS EFEITOS IONOSFÉRICOS .................................. 39

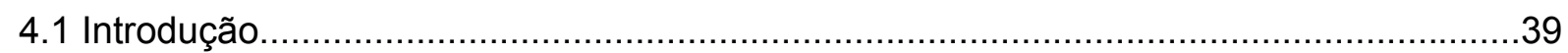

4.2 Correção ionosférica através da solução ionospheric free ...........................................41

4.3 Modelo ionosférico baseado na pseudodistância: Modelo de Klobuchar.........................42

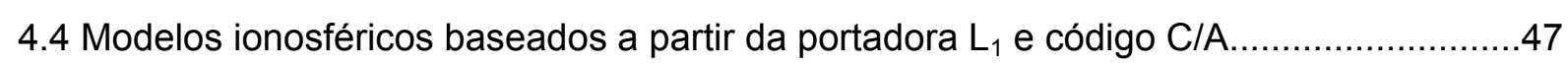

4.4.1 Modelo da lâmina ionosférica......................................................................48

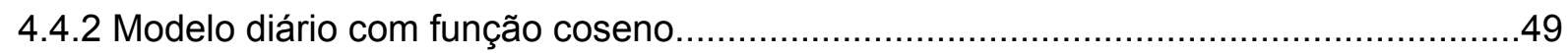

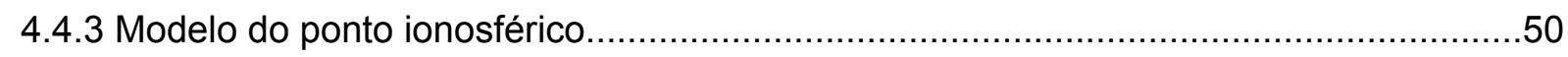

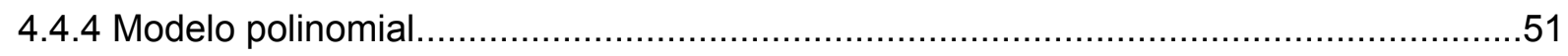

4.5 Modelo ionosférico baseado no código C/A e no código P............................................52

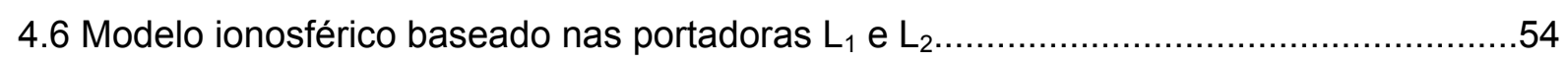

5 AJUSTAMENTO SEQÜENCIAL APLICADO À MINIMIZAÇÃO DOS EFEITOS

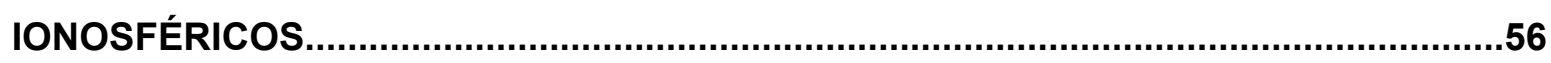

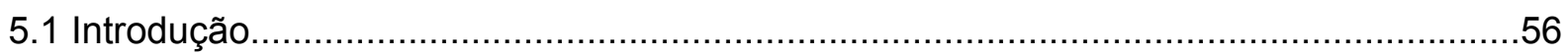

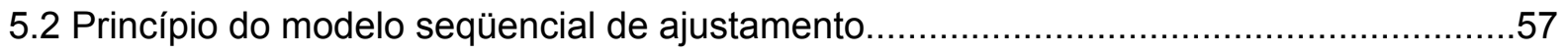

5.3 Estruturação das matrizes do ajustamento de observações.......................................61

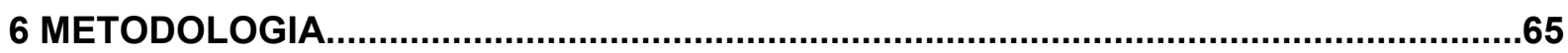

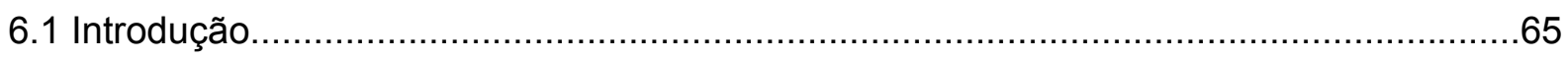

6.2 Procedimentos utilizados na estimativa dos coeficientes do modelo............................67

6.3 Automação na estimativa dos parâmetros: o programa MODEIONO..............................69

6.3.1 Módulo 1 do programa MODEIONO - estruturação de dados......................................69

6.3.2 Módulo 2 do programa MODEIONO - ajustamento dos parâmetros............................70

6.3.3 Módulo 3 do programa MODEIONO - cálculo do atraso ionosférico............................74

6.4 Validação do modelo ionosférico proposto.............................................................. 74

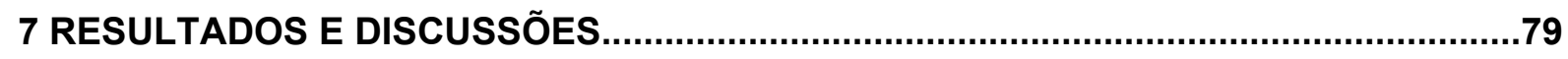

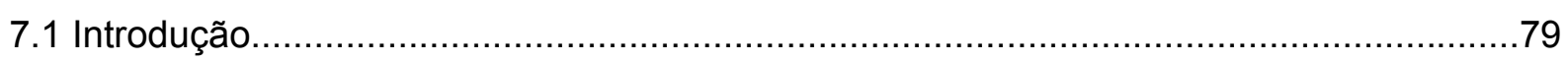

7.2 Coeficientes do modelo referentes ao período do verão............................................. 81

7.2.1 Validação do modelo através de posicionamento Single Point - período

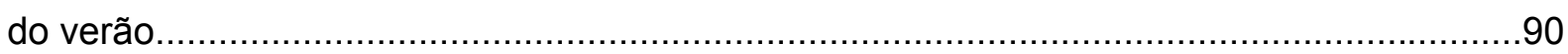

7.2.2 Validação do modelo através de posicionamento relativo - período do verão...........102 
7.3 Coeficientes do modelo referentes ao período do outono.

7.3.1 Validação do modelo através de posicionamento Single Point - período do outono.

7.3.2 Validação do modelo através de posicionamento relativo - período do outono. 129

7.4 Coeficientes do modelo referentes ao período do inverno. 138

7.4.1 Validação do modelo através de posicionamento Single Point - período do inverno 146

7.4.2 Validação do modelo através de posicionamento relativo - período do inverno. 157

7.5 Coeficientes do modelo referentes ao período da primavera. 166

7.5.1 Validação do modelo através de posicionamento Single Point - período da primavera.

7.5.2 Validação do modelo através de posicionamento relativo - período da primavera....185

8 CONCLUSÕES E RECOMENDAÇÕES. 196

8.1 Introdução. 196

8.2 Conclusões. 197

8.3 Recomendações. 199

9 REFERÊNCIAS BIBLIOGRÁFICAS

9.1 Bibliografia complementar.... 


\section{RESUMO}

VERONEZ, M. R. Proposta de um modelo regional para redução do efeito sistemático da ionosfera através do método seqüencial de ajustamento. 2004. 205f. Tese (Doutorado) Escola de Engenharia de São Carlos, Universidade de São Paulo, São Carlos, 2004.

O posicionamento de pontos, com o sistema GPS, tornou-se uma ferramenta importante, aplicável nas mais diferentes áreas do conhecimento. No entanto, em algumas situações, a exigência de elevadas precisões trouxe a inconveniência de um custo elevado na aquisição de receptores de dupla freqüência. Mesmo com os avanços tecnológicos, a ionosfera é uma das fontes de erro que mais afetam o posicionamento de pontos. Para os usuários que possuem equipamentos de dupla freqüência, este erro é modelado com grande eficiência através do processamento de dados com solução iono free. No Brasil, a maioria dos usuários possui equipamentos que captam informações apenas do código C/A e/ou código $C / A$ e portadora $L_{1}$. Neste caso faz-se uso de alguns modelos, como, por exemplo, o de Klobuchar, com redução do erro nos posicionamentos absolutos de, aproximadamente, $50 \%$. Nos posicionamentos relativos, com bases superiores a $20 \mathrm{Km}$, a utilização deste modelo não é a mais indicada. Neste contexto, este trabalho consiste no desenvolvimento de um método que possibilite modelar o atraso ionosférico através de um polinômio do segundo grau, baseado no ajustamento seqüencial de observações. As informações necessárias para esta modelagem são advindas das estações GPS da Rede Brasileira de Monitoramento Contínuo. Isto possibilita, em posicionamentos absolutos, determinar o atraso ionosférico de uma forma mais eficiente que o obtido pelo modelo de Klobuchar. Em posicionamentos relativos, para os usuários de equipamentos de simples freqüência, tal modelagem permite a geração de um código com características semelhantes ao código $\mathrm{P}_{2}$. Assim, com os dados gerados por receptores de uma freqüência, é possível processar vetores de bases longas por meio da solução iono free code. Os resultados obtidos indicam que tal metodologia pode ser uma alternativa eficiente para minimizar o efeito ionosférico no posicionamento de pontos com o sistema GPS. Horizontalmente, através dos métodos de posicionamento Single Point e relativo, respectivamente, o modelo ionosférico proposto proporcionou uma melhoria de $39 \%$ e $26 \%$ se comparado com o modelo de Klobuchar.

Palavras-chave: GPS, ajustamento seqüencial, modelo, ionosfera. 


\section{ABSTRACT}

VERONEZ, M. R. Proposal of a regional model for reduction of the systematic effects of the ionosphere through the sequential adjustment method. 2004. 205f. Thesis (Doctoral) School of Engineering of São Carlos, University of São Paulo, São Carlos-SP, Brazil, 2004.

Point positioning, with GPS, became an important tool applicable to the most different areas of the knowledge. However, in some situations, the requirement of high precisions brought the inconvenience of a high cost in the acquisition of dual receivers frequency. Despite of the technological advances, the ionosphere is one of the error sources that affect most point positioning. For users who have dual equipment frequency, this error is modeled with great efficiency through data processing with the ionosphere free solution. In Brazil the majority of the users has equipments that process C/A code information only and/or C/A code and $L_{1}$ carrier. In this case it is necessary to use some models, for example the Klobuchar model, with error reduction of approximately $50 \%$ in absolute point positioning. In the relative positioning, with baselines longer than $20 \mathrm{Km}$, the use of this model is not indicated. Thus, this work consists in developing a method that makes possible to model the ionospheric delay using a second degree polynomial, based on sequential adjustment of observations. The necessary information for this modeling is obtained from GPS stations that compose the RBMC (Brazilian Network for Continuous Monitoring of GPS). Thus it is possible to determine the ionospheric delay in a more efficient way in absolute positioning than when using the Klobuchar model. In relative positioning, for single frequency users, such modeling allows the generation of a code, with similar characteristics to the $P_{2}$ code. Hence, with data generated by single frequencies, it is possible to process long base line vectors, using the iono free code solution. The results obtained indicate that such methodology can be an efficient alternative to minimize the ionospheric effect in the GPS point positioning. Horizontally, through the methods of positioning Single Point and relative, respectively, the ionospheric model considered provided an improvement of $39 \%$ and $26 \%$ if compared with the Klobuchar model.

Keywords: GPS, sequential adjustment, model, ionosphere. 


\section{LISTA DE FIGURAS}

Figura 2.1 - Processo de geração e detecção das ondas eletromagnéticas.

Figura 2.2 - Componentes de uma onda eletromagnética plana, estacionária no tempo .9

Figura 2.3 - Amplitude e da frequência de um onda eletromagnética. 11

Figura 2.4 - Fase associada aos ângulos do círculo trigonométrico 12

Figura 2.5 - Frentes de onda irradiadas por uma fonte geradora .14

Figura 2.6 - Velocidades de fase e de grupo. 15

Figura 2.7 - Derivação dos sinais transmitidos pelos satélites GPS 18

Figura 3.1 - Divisão da atmosfera em camadas .25

Figura 3.2 - Formação de elétrons livres na camada ionosférica . 28

Figura 3.3 - Densidade de elétrons em diferentes regiões da ionosfera. 29

Figura 3.4 - Ionosfera dividida em camadas. .29

Figura 3.5 - Número médio mensal de manchas solares - período de 1950 a 2000

Figura 4.1 - Ângulo formado entre os vetores "satélite/ponto de observação" e "satélite/centro de massa da Terra".

Figura 4.2 - Ponto ionosférico. 44

Figura 6.1 - Disposição das estações da RBMC. 66

Figura 6.2 - Tela do módulo 1 do programa modeiono. .70

Figura 6.3 - Tela do módulo 2 do programa modeiono 71

Figura 6.4 - Tela do módulo 3 do programa modeiono .74

Figura 6.5 - Trecho do arquivo gerado pelo crinex. .77

Figura 7.1 - Variação horária dos coeficientes do modelo polinomial (dia 5/01). .82

Figura 7.2 - Variação horária dos coeficientes do modelo polinomial (dia 6/01). .82

Figura 7.3 - Variação horária dos coeficientes do modelo polinomial (dia 7/01).....................82

Figura 7.4 - Variação horária dos coeficientes do modelo polinomial (dia 13/01)..................82

Figura 7.5 - Variação horária dos coeficientes do modelo polinomial (dia 14/01)..................82

Figura 7.6 - Variação horária dos coeficientes do modelo polinomial (dia 16/01)..................82

Figura 7.7 - Variação horária dos coeficientes do modelo polinomial (dia 23/01). 83 
Figura 7.8 - Variação horária dos coeficientes do modelo polinomial (dia 24/01) ..................83

Figura 7.9 - Variação horária dos coeficientes do modelo polinomial (dia 25/01)..................83

Figura 7.10 - Variação horária dos coeficientes do modelo polinomial (dia 54/01)...............83

Figura 7.11 - Variação horária dos coeficientes do modelo polinomial (dia 56/01)................83

Figura 7.12 - Variação horária dos coeficientes do modelo polinomial (dia 69/01)................83

Figura 7.13 - Variação horária dos coeficientes do modelo polinomial (dia 72/01)................84

Figura 7.14 - Variação média diária dos coeficientes do modelo polinomial, referente a alguns dias do verão.

Figura 7.15 - Variação horária do erro quadrático horizontal no posicionamento

Single Point do vértice BRAZ - (dia 5/01).

Figura 7.16 - Variação horária do erro vertical no posicionamento Single Point do vértice BRAZ - (dia 5/01)

Figura 7.17 - Variação horária do erro quadrático horizontal no posicionamento Single Point do vértice BRAZ - (dia 6/01).

Figura 7.18 - Variação horária do erro vertical no posicionamento Single Point do vértice BRAZ - (dia 6/01).

Figura 7.19 - Variação horária do erro quadrático horizontal no posicionamento

Single Point do vértice BRAZ - (dia 13/01).

Figura 7.20 - Variação horária do erro vertical no posicionamento Single Point do vértice BRAZ - (dia 13/01).

Figura 7.21 - Variação horária do erro quadrático horizontal no posicionamento

Single Point do vértice BRAZ - (dia 23/01). 96

Figura 7.22 - Variação horária do erro vertical no posicionamento Single Point do vértice BRAZ - (dia 23/01)

Figura 7.23 - Variação horária do erro quadrático horizontal no posicionamento

Single Point do vértice BRAZ - (dia 54/01).

Figura 7.24 - Variação horária do erro vertical no posicionamento Single Point do vértice BRAZ - (dia 54/01).

Figura 7.25 - Variação horária do erro quadrático horizontal no posicionamento

Single Point do vértice BRAZ - (dia 69/01). 99

Figura 7.26 - Variação horária do erro vertical no posicionamento Single Point do vértice BRAZ - (dia 69/01) 100

Figura 7.27 - Variação horária do erro quadrático horizontal no posicionamento Single Point do vértice BRAZ - (dia 72/01). 101 
Figura 7.28 - Variação horária do erro vertical no posicionamento Single Point do vértice BRAZ - (dia 72/01).....

Figura 7.29 - Variação horária do erro quadrático horizontal do vértice UEPP no posicionamento relativo da base PARA - UEPP - (dia 5/01). 103

Figura 7.30 - Variação horária do erro vertical do vértice UEPP no posicionamento relativo da base PARA - UEPP - (dia 5/01). 104

Figura 7.31 - Variação horária do erro quadrático horizontal do vértice UEPP no posicionamento relativo da base PARA - UEPP - (dia 6/01). 105

Figura 7.32 - Variação horária do erro vertical do vértice UEPP no posicionamento relativo da base PARA - UEPP - (dia 6/01).

Figura 7.33 - Variação horária do erro quadrático horizontal do vértice UEPP no posicionamento relativo da base PARA - UEPP - (dia 13/01). 106

Figura 7.34 - Variação horária do erro vertical do vértice UEPP no posicionamento relativo da base PARA - UEPP - (dia 13/01). 106

Figura 7.35 - Variação horária do erro quadrático horizontal do vértice UEPP no posicionamento relativo da base PARA - UEPP - (dia 23/01).

Figura 7.36 - Variação horária do erro vertical do vértice UEPP no posicionamento relativo da base PARA - UEPP - (dia 23/01).

Figura 7.37 - Variação horária do erro quadrático horizontal do vértice UEPP no posicionamento relativo da base PARA - UEPP - (dia 54/01). 108

Figura 7.38 - Variação horária do erro vertical do vértice UEPP no posicionamento relativo da base PARA - UEPP - (dia 54/01). 108

Figura 7.39 - Variação horária do erro quadrático horizontal do vértice UEPP no posicionamento relativo da base PARA - UEPP - (dia 69/01). 109

Figura 7.40 - Variação horária do erro vertical do vértice UEPP no posicionamento relativo da base PARA - UEPP - (dia 69/01) 109

Figura 7.41 - Variação horária do erro quadrático horizontal do vértice UEPP no posicionamento relativo da base PARA - UEPP - (dia 72/01).

Figura 7.42 - Variação horária do erro vertical do vértice UEPP no posicionamento relativo da base PARA - UEPP - (dia 72/01). 110

Figura 7.43 - Variação horária dos coeficientes do modelo polinomial (dia 80/01). 111

Figura 7.44 - Variação horária dos coeficientes do modelo polinomial (dia 94/01). 111

Figura 7.45 - Variação horária dos coeficientes do modelo polinomial (dia 102/01)............112

Figura 7.46 - Variação horária dos coeficientes do modelo polinomial (dia 103/01)............112

Figura 7.47 - Variação horária dos coeficientes do modelo polinomial (dia 104/01)............112

Figura 7.48 - Variação horária dos coeficientes do modelo polinomial (dia 109/01)............112

Figura 7.49 - Variação horária dos coeficientes do modelo polinomial (dia 155/01). 112 
Figura 7.50 - Variação horária dos coeficientes do modelo polinomial (dia 156/01).

Figura 7.51 - Variação horária dos coeficientes do modelo polinomial (dia 157/01).

Figura 7.52 - Variação média diária dos coeficientes do modelo polinomial, referente a alguns dias do outono. 116

Figura 7.53 - Variação horária do erro quadrático horizontal no posicionamento Single Point do vértice BRAZ - (dia 80/01).

Figura 7.54 - Variação horária do erro vertical no posicionamento Single Point do vértice $B R A Z$ - (dia 80/01) 119

Figura 7.55 - Variação horária do erro quadrático horizontal no posicionamento

Single Point do vértice BRAZ - (dia 94/01).

Figura 7.56 - Variação horária do erro vertical no posicionamento Single Point do vértice BRAZ - (dia 94/01).

Figura 7.57 - Variação horária do erro quadrático horizontal no posicionamento Single Point do vértice BRAZ - (dia 103/01).

Figura 7.58 - Variação horária do erro vertical no posicionamento Single Point do vértice $B R A Z$ - (dia 103/01).

Figura 7.59 - Variação horária do erro quadrático horizontal no posicionamento

Single Point do vértice BRAZ - (dia 104/01).

Figura 7.60 - Variação horária do erro vertical no posicionamento Single Point do vértice BRAZ - (dia 104/01).

Figura 7.61 - Variação horária do erro quadrático horizontal no posicionamento

Single Point do vértice BRAZ - (dia 109/01).

Figura 7.62 - Variação horária do erro vertical no posicionamento Single Point do vértice BRAZ - (dia 109/01).

Figura 7.63 - Variação horária do erro quadrático horizontal no posicionamento

Single Point do vértice BRAZ - (dia 155/01). 126

Figura 7.64 - Variação horária do erro vertical no posicionamento Single Point do vértice BRAZ - (dia 155/01).

Figura 7.65 - Variação horária do erro quadrático horizontal no posicionamento Single Point do vértice BRAZ - (dia 157/01)..... 128

Figura 7.66 - Variação horária do erro vertical no posicionamento Single Point do vértice BRAZ - (dia 157/01).

Figura 7.67 - Variação horária do erro quadrático horizontal do vértice UEPP no posicionamento relativo da base PARA - UEPP - (dia 80/01). 130

Figura 7.68 - Variação horária do erro vertical do vértice UEPP no posicionamento relativo da base PARA - UEPP - (dia 80/01). 
Figura 7.69 - Variação horária do erro quadrático horizontal do vértice UEPP no posicionamento relativo da base PARA - UEPP - (dia 94/01).

Figura 7.70 - Variação horária do erro vertical do vértice UEPP no posicionamento relativo da base PARA - UEPP - (dia 94/01).

Figura 7.71 - Variação horária do erro quadrático horizontal do vértice UEPP no posicionamento relativo da base PARA - UEPP - (dia 103/01).

Figura 7.72 - Variação horária do erro vertical do vértice UEPP no posicionamento relativo da base PARA - UEPP - (dia 103/01).

Figura 7.73 - Variação horária do erro quadrático horizontal do vértice UEPP no posicionamento relativo da base PARA - UEPP - (dia 104/01).

Figura 7.74 - Variação horária do erro vertical do vértice UEPP no posicionamento relativo da base PARA - UEPP - (dia 104/01)....

Figura 7.75 - Variação horária do erro quadrático horizontal do vértice UEPP no posicionamento relativo da base PARA - UEPP - (dia 109/01).

Figura 7.76 - Variação horária do erro vertical do vértice UEPP no posicionamento relativo da base PARA - UEPP - (dia 109/01).

Figura 7.77 - Variação horária do erro quadrático horizontal do vértice UEPP no posicionamento relativo da base PARA - UEPP - (dia 155/01).

Figura 7.78 - Variação horária do erro vertical do vértice UEPP no posicionamento relativo da base PARA - UEPP - (dia 155/01).

Figura 7.79 - Variação horária do erro quadrático horizontal do vértice UEPP no posicionamento relativo da base PARA - UEPP - (dia 157/01).

Figura 7.80 - Variação horária do erro vertical do vértice UEPP no posicionamento relativo da base PARA - UEPP - (dia 157/01).

Figura 7.81 - Variação horária dos coeficientes do modelo polinomial (dia 184/01)............138

Figura 7.82 - Variação horária dos coeficientes do modelo polinomial (dia 186/01)............138

Figura 7.83 - Variação horária dos coeficientes do modelo polinomial (dia 193/01)............139

Figura 7.84 - Variação horária dos coeficientes do modelo polinomial (dia 199/01)............139

Figura 7.85 - Variação horária dos coeficientes do modelo polinomial (dia 202/01)............139

Figura 7.86 - Variação horária dos coeficientes do modelo polinomial (dia 204/01).............139

Figura 7.87 - Variação horária dos coeficientes do modelo polinomial (dia 205/01)............139

Figura 7.88 - Variação horária dos coeficientes do modelo polinomial (dia 206/01)............139

Figura 7.89 - Variação horária dos coeficientes do modelo polinomial (dia 207/01)............140

Figura 7.90 - Variação horária dos coeficientes do modelo polinomial (dia 209/01)............140

Figura 7.91 - Variação horária dos coeficientes do modelo polinomial (dia 240/01)............140

Figura 7.92 - Variação média diária dos coeficientes do modelo polinomial, referente a alguns dias do inverno 
Figura 7.93 - Variação horária do erro quadrático horizontal no posicionamento

Single Point do vértice BRAZ - (dia 184/01).....

Figura 7.94 - Variação horária do erro vertical no posicionamento Single Point do vértice BRAZ - (dia 184/01).

Figura 7.95 - Variação horária do erro quadrático horizontal no posicionamento Single Point do vértice BRAZ - (dia 186/01).

Figura 7.96 - Variação horária do erro vertical no posicionamento Single Point do vértice BRAZ - (dia 186/01).

Figura 7.97 - Variação horária do erro quadrático horizontal no posicionamento

Single Point do vértice BRAZ - (dia 193/01).

Figura 7.98 - Variação horária do erro vertical no posicionamento Single Point do vértice BRAZ - (dia 193/01).

Figura 7.99 - Variação horária do erro quadrático horizontal no posicionamento Single Point do vértice BRAZ - (dia 205/01).

Figura 7.100 - Variação horária do erro vertical no posicionamento Single Point do vértice BRAZ - (dia 205/01).

Figura 7.101 - Variação horária do erro quadrático horizontal no posicionamento

Single Point do vértice BRAZ - (dia 207/01).

Figura 7.102 - Variação horária do erro vertical no posicionamento Single Point do vértice BRAZ - (dia 207/01).

Figura 7.103 - Variação horária do erro quadrático horizontal no posicionamento Single Point do vértice BRAZ - (dia 209/01).

Figura 7.104 - Variação horária do erro vertical no posicionamento Single Point do vértice BRAZ - (dia 209/01). 155

Figura 7.105 - Variação horária do erro quadrático horizontal no posicionamento Single Point do vértice BRAZ - (dia 240/01). 156

Figura 7.106 - Variação horária do erro vertical no posicionamento Single Point do vértice BRAZ - (dia 240/01). 156

Figura 7.107 - Variação horária do erro quadrático horizontal do vértice UEPP no posicionamento relativo da base PARA - UEPP - (dia 184/01). 158

Figura 7.108 - Variação horária do erro vertical do vértice UEPP no posicionamento relativo da base PARA - UEPP - (dia 184/01). 159

Figura 7.109 - Variação horária do erro quadrático horizontal do vértice UEPP no posicionamento relativo da base PARA - UEPP - (dia 186/01). 160

Figura 7.110 - Variação horária do erro vertical do vértice UEPP no posicionamento relativo da base PARA - UEPP - (dia 186/01). 
Figura 7.111 - Variação horária do erro quadrático horizontal do vértice UEPP no posicionamento relativo da base PARA - UEPP - (dia 193/01).

Figura 7.112 - Variação horária do erro vertical do vértice UEPP no posicionamento relativo da base PARA - UEPP - (dia 193/01).

Figura 7.113 - Variação horária do erro quadrático horizontal do vértice UEPP no posicionamento relativo da base PARA - UEPP - (dia 205/01)

Figura 7.114 - Variação horária do erro vertical do vértice UEPP no posicionamento relativo da base PARA - UEPP - (dia 205/01)

Figura 7.115 - Variação horária do erro quadrático horizontal do vértice UEPP no posicionamento relativo da base PARA - UEPP - (dia 207/01).

Figura 7.116 - Variação horária do erro vertical do vértice UEPP no posicionamento relativo da base PARA - UEPP - (dia 207/01)

Figura 7.117 - Variação horária do erro quadrático horizontal do vértice UEPP no posicionamento relativo da base PARA - UEPP - (dia 209/01).

Figura 7.118 - Variação horária do erro vertical do vértice UEPP no posicionamento relativo da base PARA - UEPP - (dia 209/01).

Figura 7.119 - Variação horária do erro quadrático horizontal do vértice UEPP no posicionamento relativo da base PARA - UEPP - (dia 240/01). 165

Figura 7.120 - Variação horária do erro vertical do vértice UEPP no posicionamento relativo da base PARA - UEPP - (dia 240/01). 165

Figura 7.121 - Variação horária dos coeficientes do modelo polinomial (dia 298/01)..........166

Figura 7.122 - Variação horária dos coeficientes do modelo polinomial (dia 301/01)..........166

Figura 7.123 - Variação horária dos coeficientes do modelo polinomial (dia 302/01)..........167

Figura 7.124 - Variação horária dos coeficientes do modelo polinomial (dia 312/01)...........167

Figura 7.125 - Variação horária dos coeficientes do modelo polinomial (dia 315/01)..........167

Figura 7.126 - Variação horária dos coeficientes do modelo polinomial (dia 316/01)..........167

Figura 7.127 - Variação horária dos coeficientes do modelo polinomial (dia 318/01)..........167

Figura 7.128 - Variação horária dos coeficientes do modelo polinomial (dia 323/01)...........167

Figura 7.129 - Variação horária dos coeficientes do modelo polinomial (dia 324/01)...........168

Figura 7.130 - Variação horária dos coeficientes do modelo polinomial (dia 327/01)..........168

Figura 7.131 - Variação horária dos coeficientes do modelo polinomial (dia 329/01)..........168

Figura 7.132 - Variação média diária dos coeficientes do modelo polinomial, referente a alguns dias da primavera. 
Figura 7.133 - Variação horária do erro quadrático horizontal no posicionamento Single Point do vértice BRAZ - (dia 298/01).....

Figura 7.134 - Variação horária do erro vertical no posicionamento Single Point do vértice BRAZ - (dia 298/01). 175

Figura 7.135 - Variação horária do erro quadrático horizontal no posicionamento Single Point do vértice BRAZ - (dia 302/01).

Figura 7.136 - Variação horária do erro vertical no posicionamento Single Point do vértice BRAZ - (dia 302/01).

Figura 7.137 - Variação horária do erro quadrático horizontal no posicionamento Single Point do vértice BRAZ - (dia 315/01).....

Figura 7.138 - Variação horária do erro vertical no posicionamento Single Point do vértice BRAZ - (dia 315/01).

Figura 7.139 - Variação horária do erro quadrático horizontal no posicionamento Single Point do vértice BRAZ - (dia 318/01).

Figura 7.140 - Variação horária do erro vertical no posicionamento Single Point do vértice BRAZ - (dia 318/01).

Figura 7.141 - Variação horária do erro quadrático horizontal no posicionamento Single Point do vértice BRAZ - (dia 323/01).

Figura 7.142 - Variação horária do erro vertical no posicionamento Single Point do vértice BRAZ - (dia 323/01).

Figura 7.143 - Variação horária do erro quadrático horizontal no posicionamento Single Point do vértice BRAZ - (dia 327/01).

Figura 7.144 - Variação horária do erro vertical no posicionamento Single Point do vértice BRAZ - (dia 327/01).

Figura 7.145 - Variação horária do erro quadrático horizontal no posicionamento Single Point do vértice BRAZ - (dia 329/01). 184

Figura 7.146 - Variação horária do erro vertical no posicionamento Single Point do vértice BRAZ - (dia 329/01). 184

Figura 7.147 - Variação horária do erro quadrático horizontal do vértice UEPP no posicionamento relativo da base PARA - UEPP - (dia 298/01) 186

Figura 7.148 - Variação horária do erro vertical do vértice UEPP no posicionamento relativo da base PARA - UEPP - (dia 298/01)

Figura 7.149 - Variação horária do erro quadrático horizontal do vértice UEPP no posicionamento relativo da base PARA - UEPP - (dia 302/01). 188

Figura 7.150 - Variação horária do erro vertical do vértice UEPP no posicionamento relativo da base PARA - UEPP - (dia 302/01). 
Figura 7.151 - Variação horária do erro quadrático horizontal do vértice UEPP no posicionamento relativo da base PARA - UEPP - (dia 315/01).

Figura 7.152 - Variação horária do erro vertical do vértice UEPP no posicionamento relativo da base PARA - UEPP - (dia 315/01) 189

Figura 7.153 - Variação horária do erro quadrático horizontal do vértice UEPP no posicionamento relativo da base PARA - UEPP - (dia 318/01). 190

Figura 7.154 - Variação horária do erro vertical do vértice UEPP no posicionamento relativo da base PARA - UEPP - (dia 318/01).

Figura 7.155 - Variação horária do erro quadrático horizontal do vértice UEPP no posicionamento relativo da base PARA - UEPP - (dia 323/01).

Figura 7.156 - Variação horária do erro vertical do vértice UEPP no posicionamento relativo da base PARA - UEPP - (dia 323/01).

Figura 7.157 - Variação horária do erro quadrático horizontal do vértice UEPP no posicionamento relativo da base PARA - UEPP - (dia 327/01).

Figura 7.158 - Variação horária do erro vertical do vértice UEPP no posicionamento relativo da base PARA - UEPP - (dia 327/01).

Figura 7.159 - Variação horária do erro quadrático horizontal do vértice UEPP no posicionamento relativo da base PARA - UEPP - (dia 329/01).

Figura 7.160 - Variação horária do erro vertical do vértice UEPP no posicionamento relativo da base PARA - UEPP - (dia 329/01). 


\section{LISTA DE TABELAS}

Tabela 2.1 - Propriedades das ondas utilizadas em comunicações móveis .9

Tabela 2.2 - Outras faixas de freqüências utilizadas em comunicações móveis 10

Tabela 2.3 - Ângulos associados a um ciclo de sinal senoidal. 11

Tabela 6.1 - Dias a serem utilizados na estimativa dos parâmetros do modelo polinomial no período do verão

Tabela 6.2 - Dias a serem utilizados na estimativa dos parâmetros do modelo polinomial no período do outono.

Tabela 6.3 - Dias a serem utilizados na estimativa dos parâmetros do modelo polinomial no período do inverno

Tabela 6.4 - Dias a serem utilizados na estimativa dos parâmetros do modelo polinomial no período da primavera

Tabela 6.5 - Coordenadas UTM do vértice BRAZ tomadas como verdadeiras no processo de validação do modelo ionosférico proposto no método Single Point.

Tabela 6.6 - Coordenadas UTM do vértice UEPP tomadas como verdadeiras no processo de validação do modelo ionosférico proposto no método relativo.

Tabela 6.7 - Dias do ano a serem utilizados no processamento de informações GPS para analisar a eficiência do modelo ionosférico proposto. 78

Tabela 7.1 - Estatística dos coeficientes do modelo polinomial - (dia 5/01) .84

Tabela 7.2 - Estatística dos coeficientes do modelo polinomial - (dia 6/01) .84

Tabela 7.3 - Estatística dos coeficientes do modelo polinomial - (dia 7/01). .85

Tabela 7.4 - Estatística dos coeficientes do modelo polinomial - (dia 13/01). .85

Tabela 7.5 - Estatística dos coeficientes do modelo polinomial - (dia 14/01). .85

Tabela 7.6 - Estatística dos coeficientes do modelo polinomial - (dia 16/01). .85

Tabela 7.7 - Estatística dos coeficientes do modelo polinomial - (dia 23/01). .86

Tabela 7.8 - Estatística dos coeficientes do modelo polinomial - (dia 24/01). .86 
Tabela 7.9 - Estatística dos coeficientes do modelo polinomial - (dia 25/01).....................86

Tabela 7.10 - Estatística dos coeficientes do modelo polinomial - (dia 54/01).....................86

Tabela 7.11 - Estatística dos coeficientes do modelo polinomial - (dia 56/01)...................87

Tabela 7.12 - Estatística dos coeficientes do modelo polinomial - (dia 69/01).....................87

Tabela 7.13 - Estatística dos coeficientes do modelo polinomial - (dia 72/01) ...................87

Tabela 7.14 - Valores médios dos coeficientes do modelo polinomial referente a alguns

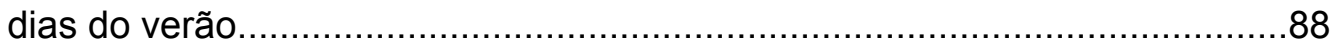

Tabela 7.15 - Erro médio da portadora $L_{1}$ (erro de interfreqüência), devido ao conjunto satélite/receptor, em relação aos dias estudados no verão.

Tabela 7.16 - Erro quadrático horizontal e erro vertical no processamento Single Point do vértice BRAZ para diferentes modelos ionosféricos - (dia 5/01).

Tabela 7.17 - Erro quadrático horizontal e erro vertical no processamento Single Point do vértice BRAZ para diferentes modelos ionosféricos - (dia 6/01).

Tabela 7.18 - Erro quadrático horizontal e erro vertical no processamento Single Point do vértice BRAZ para diferentes modelos ionosféricos - (dia 13/01). 96

Tabela 7.19 - Erro quadrático horizontal e erro vertical no processamento Single Point do vértice BRAZ para diferentes modelos ionosféricos - (dia 23/01).

Tabela 7.20 - Erro quadrático horizontal e erro vertical no processamento Single Point do vértice BRAZ para diferentes modelos ionosféricos - (dia 54/01).

Tabela 7.21 - Erro quadrático horizontal e erro vertical no processamento Single Point do vértice BRAZ para diferentes modelos ionosféricos - (dia 69/01).

Tabela 7.22 - Erro quadrático horizontal e erro vertical no processamento Single Point do vértice BRAZ para diferentes modelos ionosféricos - (dia 72/01). 102

Tabela 7.23 - Erro quadrático horizontal e erro vertical do vértice UEPP no processamento relativo da base PARA - UEPP, para diferentes modelos ionosféricos - (dia 5/01).

Tabela 7.24 - Erro quadrático horizontal e erro vertical do vértice UEPP no processamento relativo da base PARA - UEPP, para diferentes modelos ionosféricos - (dia 6/01).

Tabela 7.25 - Erro quadrático horizontal e erro vertical do vértice UEPP no processamento relativo da base PARA - UEPP, para diferentes modelos ionosféricos - (dia 13/01) 106

Tabela 7.26 - Erro quadrático horizontal e erro vertical do vértice UEPP no processamento relativo da base PARA - UEPP, para diferentes modelos ionosféricos - (dia 23/01) 
Tabela 7.27 - Erro quadrático horizontal e erro vertical do vértice UEPP no processamento relativo da base PARA - UEPP, para diferentes modelos ionosféricos - (dia 54/01).

Tabela 7.28 - Erro quadrático horizontal e erro vertical do vértice UEPP no processamento relativo da base PARA - UEPP, para diferentes modelos ionosféricos - (dia 69/01). 109

Tabela 7.29 - Erro quadrático horizontal e erro vertical do vértice UEPP no processamento relativo da base PARA - UEPP, para diferentes modelos

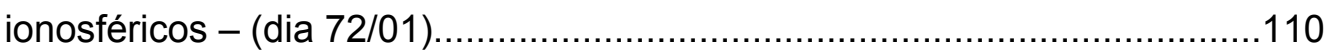

Tabela 7.30 - Estatística dos coeficientes do modelo polinomial - (dia 80/01)...................113

Tabela 7.31 - Estatística dos coeficientes do modelo polinomial - (dia 94/01) ..................113

Tabela 7.32 - Estatística dos coeficientes do modelo polinomial - (dia 102/01).................113

Tabela 7.33 - Estatística dos coeficientes do modelo polinomial - (dia 103/01).................114

Tabela 7.34 - Estatística dos coeficientes do modelo polinomial - (dia 104/01)................114

Tabela 7.35 - Estatística dos coeficientes do modelo polinomial - (dia 109/01).................114

Tabela 7.36 - Estatística dos coeficientes do modelo polinomial - (dia 155/01)................114

Tabela 7.37 - Estatística dos coeficientes do modelo polinomial - (dia 156/01).................115

Tabela 7.38 - Estatística dos coeficientes do modelo polinomial - (dia 157/01)................115

Tabela 7.39 - Valores médios dos coeficientes do modelo polinomial referentes a alguns dias do outono

Tabela 7.40 - Valores médios do erro da portadora $L_{1}$ (erro de interfreqüência), devido ao conjunto satélite/receptor, em relação aos dias estudados no outono.

Tabela 7.41 - Erro quadrático horizontal e erro vertical no processamento Single Point do vértice BRAZ para diferentes modelos ionosféricos - (dia 80/01)..... 120

Tabela 7.42 - Erro quadrático horizontal e erro vertical no processamento Single Point do vértice BRAZ para diferentes modelos ionosféricos - (dia 94/01).

Tabela 7.43 - Erro quadrático horizontal e erro vertical no processamento Single Point do vértice BRAZ para diferentes modelos ionosféricos - (dia 103/01).

Tabela 7.44 - Erro quadrático horizontal e erro vertical no processamento Single Point do vértice BRAZ para diferentes modelos ionosféricos - (dia 104/01).

Tabela 7.45 - Erro quadrático horizontal e erro vertical no processamento Single Point do vértice BRAZ para diferentes modelos ionosféricos - (dia 109/01) 126

Tabela 7.46 - Erro quadrático horizontal e erro vertical no processamento Single Point do vértice BRAZ para diferentes modelos ionosféricos - (dia 155/01).

Tabela 7.47 - Erro quadrático horizontal e erro vertical no processamento Single Point do vértice BRAZ para diferentes modelos ionosféricos - (dia 157/01). 
Tabela 7.48 - Erro quadrático horizontal e erro vertical do vértice UEPP no processamento relativo da base PARA - UEPP, para diferentes modelos ionosféricos - (dia 80/01)

Tabela 7.49 - Erro quadrático horizontal e erro vertical do vértice UEPP no processamento relativo da base PARA - UEPP, para diferentes modelos ionosféricos - (dia 94/01)

Tabela 7.50 - Erro quadrático horizontal e erro vertical do vértice UEPP no processamento relativo da base PARA - UEPP, para diferentes modelos ionosféricos - (dia 103/01).

Tabela 7.51 - Erro quadrático horizontal e erro vertical do vértice UEPP no processamento relativo da base PARA - UEPP, para diferentes modelos ionosféricos - (dia 104/01).

Tabela 7.52 - Erro quadrático horizontal e erro vertical do vértice UEPP no processamento relativo da base PARA - UEPP, para diferentes modelos ionosféricos - (dia 109/01)

Tabela 7.53 - Erro quadrático horizontal e erro vertical do vértice UEPP no processamento relativo da base PARA - UEPP, para diferentes modelos ionosféricos - (dia 155/01). 136

Tabela 7.54 - Erro quadrático horizontal e erro vertical do vértice UEPP no processamento relativo da base PARA - UEPP, para diferentes modelos ionosféricos - (dia 157/01). 137

Tabela 7.55 - Estatística dos coeficientes do modelo polinomial - (dia 184/01). 140

Tabela 7.56 - Estatística dos coeficientes do modelo polinomial - (dia 186/01). 141

Tabela 7.57 - Estatística dos coeficientes do modelo polinomial - (dia 193/01). 141

Tabela 7.58 - Estatística dos coeficientes do modelo polinomial - (dia 199/01). 141

Tabela 7.59 - Estatística dos coeficientes do modelo polinomial - (dia 202/01) 141

Tabela 7.60 - Estatística dos coeficientes do modelo polinomial - (dia 204/01). 142

Tabela 7.61 - Estatística dos coeficientes do modelo polinomial - (dia 205/01). 142

Tabela 7.62 - Estatística dos coeficientes do modelo polinomial - (dia 206/01). 142

Tabela 7.63 - Estatística dos coeficientes do modelo polinomial - (dia 207/01). 142

Tabela 7.64 - Estatística dos coeficientes do modelo polinomial - (dia 209/01). 142

Tabela 7.65 - Estatística dos coeficientes do modelo polinomial - (dia 240/01). 142

Tabela 7.66 - Valores médios dos coeficientes do modelo polinomial referentes a alguns dias do inverno

Tabela 7.67 - Valores médios do erro da portadora $L_{1}$ (erro de interfreqüência), devido ao conjunto satélite/receptor, em relação aos dias estudados no inverno. 
Tabela 7.68 - Erro quadrático horizontal e erro vertical no processamento Single Point do vértice BRAZ para diferentes modelos ionosféricos - (dia 184/01).

Tabela 7.69 - Erro quadrático horizontal e erro vertical no processamento Single Point do vértice BRAZ para diferentes modelos ionosféricos - (dia 186/01).

Tabela 7.70 - Erro quadrático horizontal e erro vertical no processamento Single Point do vértice BRAZ para diferentes modelos ionosféricos - (dia 193/01)

Tabela 7.71 - Erro quadrático horizontal e erro vertical no processamento Single Point do vértice BRAZ para diferentes modelos ionosféricos - (dia 205/01)

Tabela 7.72 - Erro quadrático horizontal e erro vertical no processamento Single Point do vértice BRAZ para diferentes modelos ionosféricos - (dia 207/01).

Tabela 7.73 - Erro quadrático horizontal e erro vertical no processamento Single Point do vértice BRAZ para diferentes modelos ionosféricos - (dia 209/01)....

Tabela 7.74 - Erro quadrático horizontal e erro vertical no processamento Single Point do vértice BRAZ para diferentes modelos ionosféricos - (dia 240/01)

Tabela 7.75 - Erro quadrático horizontal e erro vertical do vértice UEPP no processamento relativo da base PARA - UEPP, para diferentes modelos ionosféricos - (dia 184/01)

Tabela 7.76 - Erro quadrático horizontal e erro vertical do vértice UEPP no processamento relativo da base PARA - UEPP, para diferentes modelos ionosféricos - (dia 186/01).

Tabela 7.77 - Erro quadrático horizontal e erro vertical do vértice UEPP no processamento relativo da base PARA - UEPP, para diferentes modelos ionosféricos - (dia 193/01)....

Tabela 7.78 - Erro quadrático horizontal e erro vertical do vértice UEPP no processamento relativo da base PARA - UEPP, para diferentes modelos ionosféricos - (dia 205/01).

Tabela 7.79 - Erro quadrático horizontal e erro vertical do vértice UEPP no processamento relativo da base PARA - UEPP, para diferentes modelos ionosféricos - (dia 207/01).

Tabela 7.80 - Erro quadrático horizontal e erro vertical do vértice UEPP no processamento relativo da base PARA - UEPP, para diferentes modelos ionosféricos - (dia 209/01).

Tabela 7.81 - Erro quadrático horizontal e erro vertical do vértice UEPP no processamento relativo da base PARA - UEPP, para diferentes modelos

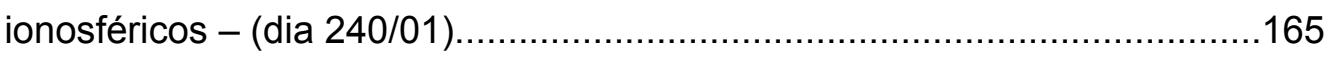

Tabela 7.82 - Estatística dos coeficientes do modelo polinomial - (dia 298/01).................168

Tabela 7.83 - Estatística dos coeficientes do modelo polinomial - (dia 301/01).................169 
Tabela 7.84 - Estatística dos coeficientes do modelo polinomial - (dia 302/01).................169

Tabela 7.85 - Estatística dos coeficientes do modelo polinomial - (dia 312/01).................169

Tabela 7.86 - Estatística dos coeficientes do modelo polinomial - (dia 315/01).................169

Tabela 7.87 - Estatística dos coeficientes do modelo polinomial - (dia 316/01).................170

Tabela 7.88 - Estatística dos coeficientes do modelo polinomial - (dia 318/01).................170

Tabela 7.89 - Estatística dos coeficientes do modelo polinomial - (dia 323/01)..................170

Tabela 7.90 - Estatística dos coeficientes do modelo polinomial - (dia 324/01).................170

Tabela 7.91 - Estatística dos coeficientes do modelo polinomial - (dia 327/01).................171

Tabela 7.92 - Estatística dos coeficientes do modelo polinomial - (dia 329/01).................171

Tabela 7.93 - Valores médios dos coeficientes do modelo polinomial referentes a alguns dias da primavera

Tabela 7.94 - Valores médios do erro da portadora $L_{1}$ (erro de interfreqüência), devido ao conjunto satélite/receptor, em relação aos dias estudados na primavera....173

Tabela 7.95 - Erro quadrático horizontal e erro vertical no processamento Single Point do vértice BRAZ para diferentes modelos ionosféricos - (dia 298/01).........176

Tabela 7.96 - Erro quadrático horizontal e erro vertical no processamento Single Point do vértice BRAZ para diferentes modelos ionosféricos - (dia 302/01).........177

Tabela 7.97 - Erro quadrático horizontal e erro vertical no processamento Single Point do vértice BRAZ para diferentes modelos ionosféricos - (dia 315/01).

Tabela 7.98 - Erro quadrático horizontal e erro vertical no processamento Single Point do vértice BRAZ para diferentes modelos ionosféricos - (dia 318/01). 180

Tabela 7.99 - Erro quadrático horizontal e erro vertical no processamento Single Point do vértice BRAZ para diferentes modelos ionosféricos - (dia 323/01)

Tabela 7.100 - Erro quadrático horizontal e erro vertical no processamento Single Point do vértice BRAZ para diferentes modelos ionosféricos - (dia 327/01).........183

Tabela 7.101 - Erro quadrático horizontal e erro vertical no processamento Single Point do vértice BRAZ para diferentes modelos ionosféricos - (dia 329/01).........185

Tabela 7.102 - Erro quadrático horizontal e erro vertical do vértice UEPP no processamento relativo da base PARA - UEPP, para diferentes modelos ionosféricos - (dia 298/01).

Tabela 7.103 - Erro quadrático horizontal e erro vertical do vértice UEPP no processamento relativo da base PARA - UEPP, para diferentes modelos ionosféricos - (dia 302/01).

Tabela 7.104 - Erro quadrático horizontal e erro vertical do vértice UEPP no processamento relativo da base PARA - UEPP, para diferentes modelos ionosféricos - (dia 315/01)...... 
Tabela 7.105 - Erro quadrático horizontal e erro vertical do vértice UEPP no processamento relativo da base PARA - UEPP, para diferentes modelos ionosféricos - (dia 318/01).

Tabela 7.106 - Erro quadrático horizontal e erro vertical do vértice UEPP no processamento relativo da base PARA - UEPP, para diferentes modelos ionosféricos - (dia 323/01)....

Tabela 7.107 - Erro quadrático horizontal e erro vertical do vértice UEPP no processamento relativo da base PARA - UEPP, para diferentes modelos ionosféricos - (dia 327/01).

Tabela 7.108 - Erro quadrático horizontal e erro vertical do vértice UEPP no processamento relativo da base PARA - UEPP, para diferentes modelos ionosféricos - (dia 329/01).

Tabela 7.109 - Erro médio quadrático horizontal e erro médio quadrático vertical do vértice $B R A Z$, referentes aos dias estudados em cada estação do ano (posicionamento Single Point)

Tabela 7.110 - Erro médio quadrático horizontal e erro médio quadrático vertical do vértice UEPP, referentes aos dias estudados em cada estação do ano (posicionamento relativo) 


\section{LISTA DE ABREVIATURAS E SIGLAS}

\begin{tabular}{|c|c|}
\hline Abreviatura/Sigla & Significado \\
\hline A/S & Anti-Spoofing \\
\hline $\mathrm{C} / \mathrm{A}$ & Coarse Aquisition \\
\hline CODE & Centre for Orbit Determination in Europe \\
\hline DoD & Department Of Defense \\
\hline ESOC & European Space Operations Center \\
\hline EUA & Estados Unidos da América \\
\hline GPS & Global Positioning System \\
\hline IBGE & Instituto Brasileiro de Geografia e Estatística \\
\hline IGS & International GPS Service \\
\hline IONEX & Ionosphere Map Exchange Format \\
\hline $\mathrm{JPL}$ & Jet Propulsion Laboratory \\
\hline $\mathrm{L}_{1}$ & Portadora $L_{1}$ \\
\hline $\mathrm{L}_{2}$ & Portadora $\mathrm{L}_{2}$ \\
\hline LASERCA & Laboratório de Sensoriamento Remoto e Cartografia \\
\hline MMQ & Método dos Mínimos Quadrados \\
\hline MVC & Matriz Variância e Covariância \\
\hline NASA & National Aeronautics and Space Administration \\
\hline OEM & Ondas eletromagnéticas \\
\hline $\mathrm{P}$ & Precise/Protected \\
\hline PPS & Precise Positioning Service \\
\hline
\end{tabular}


RBMC

RINEX

SA

SPS

SIVAM

TECU

TEC

TVEC

UNB

UV
Rede Brasileira de Monitoramento Contínuo

Receiver Independent Exchange Format

Selective Availability

Standard Positioning Service

Sistema de Vigilância da Amazônia

Total Electron Content Unit

Total Electron Content

Total Vertical Electron Content

University of New Brunswick

Ultravioleta 


\section{LISTA DE SÍMBOLOS}

\section{Símbolo}

\section{A}

$\mathrm{A}_{z}$

$$
A_{i}^{\top} \text { (i = } 1 \text { até 2) }
$$

$A_{i}(i=1$ até 2$)$

C

$C_{i}(i=1$ até 6$)$

$\mathrm{dt}^{\mathrm{s}}$

$\mathrm{dt}_{\mathrm{r}}$

e

E

$E_{\text {(conhecido) }}$ e $E_{\text {(calculado) }}$

E'

Erro

E.Q.P

\section{Significado}

amplitude de uma onda eletromagnética.

azimute do satélite em relação à antena receptora.

matriz transposta dos coeficientes do sistema de equações normais, no ajustamento seqüencial.

matriz dos coeficientes do sistema de equações normais, no ajustamento seqüencial.

velocidade da luz no vácuo $(299792458 \mathrm{~m} / \mathrm{s})$.

coeficientes do polinômio de grau 2.

erro de relógio do satélite, em relação ao sistema de tempo GPS.

erro de relógio do receptor, em relação ao sistema de tempo GPS.

carga do elétron.

ângulo de elevação do satélite.

coordenadas UTM - Este conhecida e calculada (aplicando-se um determinado modelo ionosférico), respectivamente.

ângulo de elevação do satélite em relação ao ponto ionosférico.

conjunto: erro sistemático na portadora $L_{1}$ devido ao satélite $e$ erro sistemático na portadora $L_{1}$ devido ao receptor.

erro quadrático no posicionamento quando se utiliza o modelo ionosférico polinomial. 
E.Q.K

E.Q.S

E.M.Q

f

f

$f_{0}$

$\mathrm{F}$

$\mathrm{h}_{\text {(conhecido) }}$ e $\mathrm{h}_{\text {(calculado) }}$

$\mathrm{h}_{\mathrm{m}}$

$\mathrm{h}_{\mathrm{s}}$

$\mathrm{h}_{\mathrm{am}}$

$h_{s, U T}$

$I_{1 r}^{S}$

K e K'

$\mathrm{k}_{\mathrm{i}}$ (i = 1 até 2 )

$L_{i}$ (i = 1 até 2$)$

$m_{e}$

$\mathrm{N}_{\mathrm{L}_{1}}$

$\mathrm{N}_{\mathrm{L}_{2}}$

$\mathrm{N}_{\text {(conhecido) }}$ e $\mathrm{N}_{\text {(calculado) }}$

$\mathrm{n}$

$\mathrm{n}_{\mathrm{e}}$ erro quadrático no posicionamento quando se utiliza o modelo ionosférico de Klobuchar.

erro quadrático no posicionamento quando se utiliza o modelo ionosférico Standard.

erro médio quadrático no posicionamento durante um período de 24 horas.

freqüência de um sinal eletromagnético.

número de graus de liberdade.

freqüência fundamental gerada pelos satélites dos sistema GPS.

fator de obliqüidade.

alturas geométricas conhecida e a advinda do processamento GPS, em relação ao elipsóide WGS-84.

altura média da camada ionosférica.

hora solar local.

hora solar local em que ocorre o atraso ionosférico vertical máximo.

hora solar em relação ao sistema universal de tempo.

correção ionosférica, ao longo do caminho satélite/receptor.

número de ondas.

coeficiente de Lagrange no ajustamento seqüencial.

matriz das observações no ajustamento seqüencial.

massa do elétron.

ambigüidade da portadora $L_{1}$.

ambigüidade da portadora $L_{2}$.

coordenadas UTM - Norte conhecida e calculada (aplicando-se um determinado modelo ionosférico), respectivamente.

índice de refração de um gás ionizado.

densidade de elétrons livres. 
$\mathrm{n}_{\mathrm{F}}$

$\mathrm{n}_{\mathrm{g}}$

$$
n_{i}(i=1 \text { até } 2)
$$

$\mathrm{n}_{\mathrm{r}}$

P

$\mathrm{P}_{\mathrm{t}}$

$P_{i}(i=1$ até 2$)$

r

$\mathrm{R}_{\mathrm{m}}$

$\mathrm{R}_{\mathrm{ir}}^{\mathrm{s}}$

$\mathrm{R}_{2 \mathrm{r}}^{\mathrm{s}}$

$\mathrm{R}_{\mathrm{P} 1}$

$\mathrm{R}_{\mathrm{P} 2}$

$\mathrm{R}$

$\mathrm{R}_{\mathrm{t}}$

$r_{\phi 1}$

$r_{\phi 2}$

$\mathrm{S}_{\phi 1}^{\mathrm{s}}$

$\mathrm{S}_{\phi 2}^{\mathrm{s}}$

$\mathrm{S}_{\mathrm{P} 1}^{\mathrm{s}}$

$\mathrm{S}_{\mathrm{P} 2}^{\mathrm{s}}$

$\mathrm{T}$

TEC

TVEC índice de refração que descreve a propagação fase portadora na ionosfera.

índice de refração que descreve a propagação do código na ionosfera.

número de observações no ajustamento seqüencial.

índice de refração.

densidade de potência a uma determinada distância de uma fonte isotrópica.

potência transmitida.

matriz peso no ajustamento seqüencial.

distância entre a origem da fonte isotrópica e a frente de onda.

raio médio da Terra.

observável pseudodistância na freqüência $f_{1}$.

observável pseudodistância na freqüência $f_{2}$.

erro sistemático na freqüência portadora $\mathrm{f}_{1}$ devido ao receptor.

erro sistemático na freqüência portadora $\mathrm{f}_{2}$ devido ao receptor.

observável pseudodistância.

raio da Terra para o ponto de observação.

erro sistemático na fase da portadora $L_{1}$, devido ao receptor.

erro sistemático na fase da portadora $L_{1}$, devido ao receptor.

erro sistemático na fase da portadora $L_{1}$, devido ao satélite.

erro sistemático na fase da portadora $L_{2}$, devido ao satélite.

erro sistemático na freqüência portadora $f_{1}$ devido ao satélite.

erro sistemático na freqüência portadora $\mathrm{f}_{2}$ devido ao satélite.

período da onda eletromagnética.

total de elétrons livres ao longo da trajetória do sinal GPS.

conteúdo total de elétrons na vertical. 


$t_{U T}$
$t_{r}$
$t^{S}$
$T_{G P S}$
$u^{S}$
$V_{F}$
$V_{G}$
$V_{i}(i=1$ até 2$)$
$X$
$X$
$Z_{r, 0}$
$X_{r, 0}$
$X_{r, 0}$
$V_{\text {conhecido }}$

$\mathrm{X}_{\text {conhecido }}$

$Y_{\text {conhecido }}$

$Z_{\text {conhecido }}$

$\mathrm{X}_{\text {calculado }}$ época da observação no sistema universal de tempo.

hora local do ponto ionosférico.

tempo no instante de recepção do sinal na antena receptora.

tempo no instante da transmissão do sinal no satélite.

tempo GPS da época de observação.

número de parâmetros a serem determinados no ajustamento seqüencial.

velocidade de propagação das ondas eletromagnéticas.

velocidade de fase.

velocidade de grupo.

vetor resíduo no ajustamento seqüencial.

fase em radianos.

Vetor dos parâmetros ajustados.

coordenada cartesiana $\mathrm{X}$ em relação a um sistema de eixos coordenados, com origem no centro de massa da Terra.

coordenada cartesiana $Y$ em relação a um sistema de eixos coordenados, com origem no centro de massa da Terra.

coordenada cartesiana $Z$ em relação a um sistema de eixos coordenados, com origem no centro de massa da Terra.

coordenada cartesiana $\mathrm{X}$, em relação a um sistema de eixos coordenados, com origem no centro de massa da Terra, estabelecida como verdadeira nos cálculos estatísticos.

coordenada cartesiana $\mathrm{Y}$, em relação a um sistema de eixos coordenados, com origem no centro de massa da Terra, estabelecida como verdadeira nos cálculos estatísticos.

coordenada cartesiana $Z$, em relação a um sistema de eixos coordenados, com origem no centro de massa da Terra, estabelecida como verdadeira nos cálculos estatísticos.

coordenada cartesiana $X$, em relação a um sistema de eixos coordenados, com origem no centro de massa da Terra, obtida 
$Y_{\text {calculado }}$

$\mathrm{Z}_{\text {calculado }}$

$\Delta_{\mathrm{N}}$ e $\Delta_{\mathrm{E}}$

$\Delta_{\mathrm{h}}$

$\Delta_{\mathrm{F}}^{\mathrm{IONO}}$

$\Delta_{\mathrm{P}}^{\mathrm{IONO}}$

$\Delta \delta$

$\Delta^{\text {TROPO }}$

$\Delta^{\mathrm{IONO}}$

$\Delta_{\mathrm{V}}^{\mathrm{IONO}}$

$\Delta_{\mathrm{V}, \max }^{\mathrm{IONO}}$

$\Delta_{1 \mathrm{r}}^{\mathrm{IONO}(\mathrm{s})}$

$\Delta_{2 \mathrm{r}}^{\mathrm{IONO}(\mathrm{s})}$ através de processamento GPS com diferentes modelos ionosféricos.

coordenada cartesiana $\mathrm{Y}$, em relação a um sistema de eixos coordenados, com origem no centro de massa da Terra, obtida através de processamento GPS com diferentes modelos ionosféricos.

coordenada cartesiana $Z$, em relação a um sistema de eixos coordenados, com origem no centro de massa da Terra, obtida através de processamento GPS com diferentes modelos ionosféricos.

discrepâncias entre os valores das coordenadas UTM conhecidas e as advindas do processamento GPS, em relação ao elipsóide WGS-84.

discrepância entre a altura geométrica conhecida e a advinda do processamento GPS, em relação ao elipsóide WGS-84.

avanço na fase da portadora.

atraso de grupo na modulação do sinal.

combinação dos erros de relógio do satélite e do receptor.

erro troposférico no posicionamento de pontos com o sistema GPS.

efeito causado pela ionosfera na observável fase da portadora e código C/A ao longo da trajetória do sinal GPS.

efeito causado pela ionosfera na observável fase da portadora e código C/A na posição vertical.

efeito máximo causado pela ionosfera na observável fase da portadora e código C/A na posição vertical.

efeito ionosférico na portadora $L_{1}$ em relação a um determinado satélite e a antena receptora.

efeito ionosférico na portadora $L_{2}$ em relação a um determinado satélite e a antena receptora. 
$\Delta \mathrm{x}$

$\Delta_{Y}$

$\Delta_{\mathrm{Z}}$

$\Delta \sum_{\mathrm{x}}$

$\Delta \omega$

$\Delta \mathrm{K}$

$\phi$

$\phi_{\mathrm{g}}$

$\phi_{\mathrm{m}}$

$\phi^{S}$

$\phi_{\mathrm{r}}$

$\phi_{\mathrm{L}_{1}}$

$\phi_{L_{2}}$

$\phi_{1 \mathrm{r}}^{\mathrm{s}}$

$\phi_{2 r}^{\mathrm{s}}$

$\lambda_{\text {ip }}$

$\lambda_{g}$

$\lambda_{\mathrm{L}_{1}}$

$\lambda_{\mathrm{L}_{2}}$ erro na coordenada $X$ do vértice estabelecido como verdadeiro nos cálculos estatísticos.

erro na coordenada $Y$ do vértice estabelecido como verdadeiro nos cálculos estatísticos.

erro na coordenada $Z$ do vértice estabelecido como verdadeiro nos cálculos estatísticos.

matriz variância covariância dos parâmetros no ajustamento seqüencial.

diferença entre as freqüências angulares de dois grupos de ondas harmônicas.

diferença entre o número de ondas de dois grupos de ondas harmônicas.

função de Lagrange minimizada no ajustamento pelo Método dos Mínimos Quadrados.

latitude da antena receptora.

latitude geomagnética do ponto ionosférico.

fase do sinal gerada pelo satélite;

réplica da fase gerada pelo receptor;

observável fase da portadora $L_{1}$.

observável fase da portadora $L_{2}$.

fase da portadora $L_{1}$ em relação a um determinado satélite e a antena receptora.

fase da portadora $L_{2}$ em relação a um determinado satélite e a antena receptora.

longitude do ponto ionosférico.

longitude da antena receptora.

comprimento de onda da portadora $L_{1}$.

comprimento de onda da portadora $L_{2}$. 
$\beta_{\mathrm{n}}$

$\alpha$

$\alpha_{n}$

$\sigma_{0}^{2}$

$\omega$ e $\omega^{\prime}$

$\chi^{2}$

$\hat{\chi}^{2}$ distância geométrica entre o satélite e a antena receptora.

distância geométrica entre um determinado satélite e a antena receptora.

fase da onda eletromagnética.

latitude do ponto ionosférico.

ângulo formado entre os vetores "satélite/ponto de observação" e "satélite/centro de massa da Terra".

coeficiente do modelo de Klobuchar transmitido pelos satélites nas mensagens de navegação.

nível de significância do teste estatístico.

coeficiente do modelo de Klobuchar transmitido pelos satélites nas mensagens de navegação.

variância a posteriori.

freqüência angular da onda eletromagnética.

valor de Qui Quadrado.

valor de Qui Quadrado teórico, com um grau de confiabilidade de $95 \%$, cujo valor é tabelado. 


\section{Introdução}

\subsection{Considerações iniciais}

A literatura, bem como os trabalhos práticos realizados diariamente com o Global Positioning System (GPS), mostram que várias são as fontes de erros que afetam o posicionamento de pontos. Dentre as principais, destacam-se aquelas relacionadas ao satélite, à refração troposférica e ionosférica, a interrupção do sinal, o multicaminhamento, o centro de fase da antena, o posicionamento da estação de referência para a metodologia de levantamento relativo, o nível de ruído dos receptores e os efeitos de degradação dos sinais.

Segundo (CAMARGO, 1999, p. 1), "com a desativação do efeito "SA" (Selective Availability), que era imposta aos usuários civis pelo Departamento de Defesa dos Estados Unidos, a ionosfera passou a ser a maior fonte de erro no posicionamento de pontos com o sistema GPS".

Todo processo envolvido no posicionamento de pontos com o sistema GPS está diretamente relacionado com a propagação e recepção de sinais eletromagnéticos. Por conveniência, normalmente, a atmosfera é dividida em duas camadas, quais sejam: troposfera e ionosfera. Este fato baseia-se nas condições particulares de propagação dos sinais serem bem diferentes em ambas as camadas.

"A estrutura da atmosfera terrestre está relacionada a diversos parâmetros, cujos valores, geralmente combinados, podem variar sensivelmente em função da hora, da época do ano, da latitude, da longitude e da atividade solar", (CAMARGO, 1999, p. 10).

Os sinais emitidos pelos satélites GPS, em seu caminho até a antena receptora, propagam-se através da atmosfera dinâmica e atravessam camadas de diferentes naturezas e estados variáveis. Assim, sofrem diferentes tipos de influência, que podem provocar variações na direção de propagação, velocidade de propagação, na polarização e na potência do sinal (SEEBER, 2003).

O efeito da ionosfera é proporcional ao Total Electron Content (TEC), que corresponde ao número de elétrons livres presentes ao longo do caminho do satélite até a antena do receptor. O TEC é uma grandeza que afeta muito o posicionamento de pontos, pois o mesmo varia no tempo e no espaço, em função do fluxo de ionização solar, atividade 
magnética, ciclo de manchas solares, estação do ano, hora do dia, localização e direção do raio vetor do satélite (LEICK, 2003). A influência da localização geográfica do usuário no valor do TEC foi comprovada por (SEGANTINE, 2001), através das informações da rede GPS do estado de São Paulo.

Segundo (CAMARGO, 1999), vários modelos têm sido desenvolvidos para estimar a densidade de elétrons. No entanto, é difícil encontrar um que estime o TEC com precisão adequada nos levantamentos geodésicos de precisão.

O erro associado à refração ionosférica é de difícil correção. Segundo (HOFMANNWELLENHOF, 2001), o mais eficiente método de minimizar os efeitos da refração ionosférica é o uso de dois sinais com diferentes freqüências, porque a refração é delas dependente.

As mensagens de navegação, transmitidas pelos satélites do sistema GPS, trazem informações que permitem efetuar correções da ionosfera para receptores GPS de uma freqüência ao utilizar o modelo de Klobuchar (KLOBUCHAR, 1987). Porém, vários estudos realizados mostraram que o modelo de Klobuchar pode remover apenas algo em torno de $50 \%$ do efeito ionosférico (NEWBY E LANGLEY, 1992).

(LEANDRO, 2003), ao verificar o efeito da ionosfera em posicionamento de pontos com o sistema GPS, constatou que, entre os vários modelos ionosféricos estudados, o de Klobuchar proporcionou melhores resultados no processo de determinação de coordenadas, através do método de posicionamento Single Point.

Uma das formas de aumentar a eficiência na remoção dos efeitos ionosféricos no posicionamento de pontos através do sistema GPS é a implementação de modelos regionais a partir de receptores de dupla freqüência.

Pode-se citar vários modelos de correção ionosférica para receptores de uma freqüência:

- Modelo Broadcast ou de Klobuchar;

- Modelo da lâmina ionosférica;

- Modelo diário com função coseno;

- Modelo do ponto ionosférico;

- Modelo polinomial etc.

(CAMARGO, 1999), ao trabalhar com estações da Rede Brasileira de Monitoramento Contínuo (RBMC) ${ }^{1}$, desenvolveu um modelo regional, baseado no princípio matemático em

\footnotetext{
${ }^{1}$ A RBMC utiliza receptores GPS de dupla freqüência, em todas as suas 15 estações.
} 
expansão em série e conseguiu melhorar em até $54,4 \%$ a acurácia em posicionamento de pontos de forma absoluta.

(FONSECA JÚNIOR, 2002), elaborou uma série histórica (no período compreendido entre janeiro de 1997 a dezembro de 2001) do conteúdo total de elétrons, determinado a cada duas horas, em treze estações pertencentes à RBMC. Este trabalho possibilitou uma melhor compreensão da ionosfera no Brasil, servindo de suporte para o desenvolvimento de pesquisas voltadas para aprimoramento de modelos ionosféricos, aplicáveis ao sistema GPS.

Através da RBMC, implementada e gerenciada pela Fundação Instituto Brasileiro de Geografia e Estatística (IBGE), é possível estudar modelos específicos para nossa realidade, notadamente em períodos de alta atividade solar.

\subsection{O problema}

Devido ao alto custo dos receptores de dupla freqüência, a maioria das atividades que envolvem posicionamento de pontos com o sistema GPS é realizada com equipamentos de uma freqüência ou que captam apenas informações do código C/A. Para esses usuários, uma forma das principais formas de minimizar os efeitos ionosféricos é através do modelo de Klobuchar. De acordo com o que foi exposto na introdução e justificativa deste trabalho, o modelo de Klobuchar pode remover algo em torno de 50\% do efeito total ionosférico.

Baseado nisto, a hipótese inicial $\left(\mathrm{H}_{0}\right)$ a ser caracterizada é: o aumento da eficiência no processo de redução do efeito ionosférico através de modelos regionais. Para isto, propõe-se uma nova metodologia, baseada no ajuste de um polinômio do segundo grau a valores de atrasos ionosféricos, obtidos das estações GPS da Rede Brasileira de Monitoramento Contínuo.

A estimativa dos coeficientes do polinômio está amparada no método de ajustamento seqüencial de observações, onde, em posicionamentos absolutos, é determinado o atraso ionosférico de uma forma mais eficiente que o obtido pelo modelo de Klobuchar. Em posicionamentos relativos, para os usuários de equipamentos de simples freqüência, tal modelagem permite a geração de um código com características semelhantes ao código $\mathrm{P}_{2}$. Assim, com os dados gerados por receptores de uma freqüência, é possível processar vetores de bases longas por meio da solução ionosphere free code. 


\subsection{Delimitação do objeto de estudo e objetivos}

Duas campanhas de GPS realizadas no Brasil, denominadas BRASION'91 e BRASION'92, mostraram que as medições realizadas com o sistema GPS na América Central e na América do Sul são afetadas por diversas condições ionosféricas (CAMARGO, 1999).

"Centros de pesquisas da Europa como Centre for Orbit Determination in Europe (CODE) e o European Space Operations Center (ESOC) têm, sistematicamente, produzido mapas do TEC, caracterizando, no continente europeu, o comportamento dos elétrons livres na atmosfera. O mesmo tem acontecido na América do Norte na Universidade de New Brunswick (UNB - Canadá) e o Jet Propulsion Laboratory (JPL) da National Aeronautics and Space Administration (NASA - EUA)" (CAMARGO, 1999, p. 4).

Através desses modelos globais, que possibilitam o mapeamento do comportamento da ionosfera para fins de posicionamento, o International GPS Service (IGS) tem produzido mapas globais da ionosfera. Isto é possível devido à padronização no formato desses mapas chamado de lonosphere Map Exchange Format (IONEX) desenvolvidos por SCHAER et al. (1998).

Este tipo de iniciativa é de fundamental importância para análise do comportamento da ionosfera com o intuito de minimizar erros no posicionamento de pontos através do sistema GPS.

No Brasil, pouquíssimos são os trabalhos desenvolvidos no processo de mapeamento da ionosfera de forma regional para posicionamento de pontos, mas dispõemse de estrutura e dados que possibilitam este tipo de estudo.

A Fundação Instituto Brasileiro de Geografia e Estatística (IBGE) implementou, no Brasil, uma rede de pontos GPS de monitoramento contínuo. Essa rede opera com receptores de dupla freqüência (portadoras $L_{1}$ e $L_{2}$ ), código "C/A" e código "P", localizadas em diferentes cidades do território brasileiro, tais como: Bom Jesus da Lapa/BA (BOMJ), Brasília/DF (BRAZ), Cuiabá/MT (CUIB), Curitiba/PR (PARA), Fortaleza/CE (FORT), Imperatriz/MA (IMPZ), Manaus/AM (MANA), Porto Alegre/RS (POAL), Santa Maria/RS (SMAR), Rio de Janeiro (RIOD), Presidente Prudente (UEPP), Recife/PE (RECF), Salvador/BA (SALV), Crato/CE (CRAT) e Viçosa/MG (VICO). As informações referentes aos dados dessas estações são de domínio público e disponibilizadas pelo IBGE no endereço: (http://www.ibge.gov.br/home/geografia/geodesico/rbmc.shtm). Vale ressaltar que as 
estações de Fortaleza e Brasília fazem parte da rede IGS $^{*}$. De posse delas é possível estabelecer, para as condições brasileiras, um modelo regional que minimize os efeitos da ionosfera para posicionamento de pontos com receptores GPS de uma freqüência.

"Geralmente, quando se trabalha com grande número de observações para a estimativa de parâmetros, é utilizado ajustamento de observações. O ajustamento tem por objetivo estimar, através de modelos matemáticos adequados e também através do Método dos Mínimos Quadrados - MMQ, um valor único para cada uma das incógnitas do problema. Além disso, é possível estimar a precisão de tais incógnitas e a correlação entre elas" (GEMAEL, 1994, p. 15).

Alguns métodos de ajustamento pelo $\mathrm{MMQ}$ podem ser destacados: dos correlatos, paramétrico e combinado. Métodos mais avançados de ajustamento de observações foram desenvolvidos como generalizações do $\mathrm{MMQ}$, tais como o da colocação e o seqüencial.

O método da colocação surgiu no início dos anos 60 para solucionar problemas de interpolação de anomalias gravimétricas. Atualmente a teoria encontra condições próprias ao seu desenvolvimento em outras aplicações (KRAKIWSKY, 1990). Sua grande vantagem em relação aos demais métodos de ajustamento é que, além de ajustar, ao mesmo tempo ele realiza filtragem das observações e interpolação de parâmetros.

O método seqüencial estabelece também um filtro no ajustamento, principalmente em problemas de detecção e correção de perdas de ciclos das ondas portadoras dos sinais GPS.

As informações disponibilizadas pela RBMC possibilitaram a investigação de um modelo para minimização dos efeitos sistemáticos da ionosfera com o intuito de melhorar os resultados no posicionamento de pontos com receptores GPS de uma freqüência.

Assim, o objetivo precípuo deste trabalho foi investigar um modelo regional para correção do atraso ionosférico com intuito de melhorar o posicionamento de pontos realizados com receptores GPS de uma única freqüência.

Mais especificamente objetivou-se:

a) Realizar experimentos com uso de uma função polinomial para modelar o atraso ionosférico;

b) Desenvolver um programa em linguagem Visual Basic 5.0 para estimar os parâmetros do modelo polinomial pelo método de ajustamento seqüencial;

\footnotetext{
*A rede internacional IGS corresponde a um conjunto de quase 200 estações GPS de dupla freqüência, operando continuamente em todos os continentes.
} 
c) Validar o modelo proposto através do processamento de posicionamentos absoluto e relativo, através de análises de erros horizontais e verticais, em processos comparativos com os modelos de Klobuchar e Standard ${ }^{2}$.

Desta forma, para atingir os objetivos supracitados, este trabalho foi dividido na seguinte estrutura:

- Capítulo 2 faz um resumo sobre a propagação dos sinais de rádio;

- Capítulo 3 aborda a estrutura da ionosfera e a sua influência na transmissão dos sinais eletromagnéticos;

- Capítulo 4 especifica os principais modelos matemáticos utilizados no processo de minimização dos efeitos ionosféricos, em posicionamentos de pontos através do sistema GPS;

- Capítulo 5 apresenta o princípio do método de ajustamento seqüencial, aplicado na estimativa dos parâmetros do modelo ionosférico proposto neste trabalho;

- Capítulo 6 especifica a metodologia utilizada no desenvolvimento deste trabalho de pesquisa;

- Capítulo 7 apresenta as discussões acerca dos resultados encontrados;

- Capítulo 8 apresenta as conclusões e recomendações;

- Capítulo 9 especifica as referências bibliográficas que deram suporte em todo processo de execução deste trabalho de pesquisa.

\footnotetext{
${ }^{2}$ O modelo Standard é utilizado no programa SKI - 2.3 da LEICA e, segundo informações que constam em seus catálogos, este modelo é o mesmo que o da Lâmina lonosférica, que será descrito na seção 4.4.1.
} 


\section{Propagação dos sinais de rádio}

Este capítulo apresenta conceitos básicos sobre ondas eletromagnéticas, através de uma linguagem, intencionalmente simplificada, para tornar o texto acessível ao leitor iniciante do sistema GPS. Dentre estes conceitos destacam-se:

- as propriedades das ondas utilizadas em comunicações móveis;

- a definição matemática dos elementos definidores das ondas eletromagnéticas;

- a conceituação e a relação matemática entre velocidade de grupo e velocidade de fase;

- as características dos sinais transmitidos pelos satélites GPS.

\subsection{Introdução}

A radiação eletromagnética ocorre naturalmente no Universo e, como tal, sempre esteve presente na atmosfera terrestre. O Sol, por exemplo, é a fonte natural de radiação eletromagnética mais intensa a que estamos expostos. Por outro lado, o desenvolvimento tecnológico, as mudanças no comportamento social e nos hábitos de trabalho (próprios de uma sociedade em evolução), criaram um ambiente crescentemente exposto a outras fontes artificiais de radiação eletromagnética. Estas fontes foram criadas pelos homens e são, por exemplo, as antenas dos sistemas de telecomunicações, as linhas de alta tensão, aparelhos elétricos etc. Assim, a luz visível, os raios- $x$, as vulgarmente chamadas "ondas de rádio" ou as "micro-ondas" são formas possíveis de radiação eletromagnética, que se propaga pelo espaço com velocidades da ordem de $300.000 \mathrm{~km}$ por segundo.

As ondas eletromagnéticas (OEM) resultam da interação entre um campo elétrico e um campo magnético oscilantes. Uma carga elétrica gerada através de um circuito oscilador conectado em uma antena cria um campo elétrico e o correspondente campo magnético. $O$ campo magnético, por sua vez, cria um campo elétrico, que cria outro campo magnético, e assim sucessivamente. Esses dois campos interagem e criam uma onda eletromagnética, que se propaga no espaço. 
As ondas podem ser captadas por uma antena. As cargas elétricas são forçadas a oscilar através das OEM e a voltagem resultante pode ser detectada por intermédio de um voltímetro. A Figura 2.1 ilustra o processo de geração e detecção das ondas eletromagnéticas.

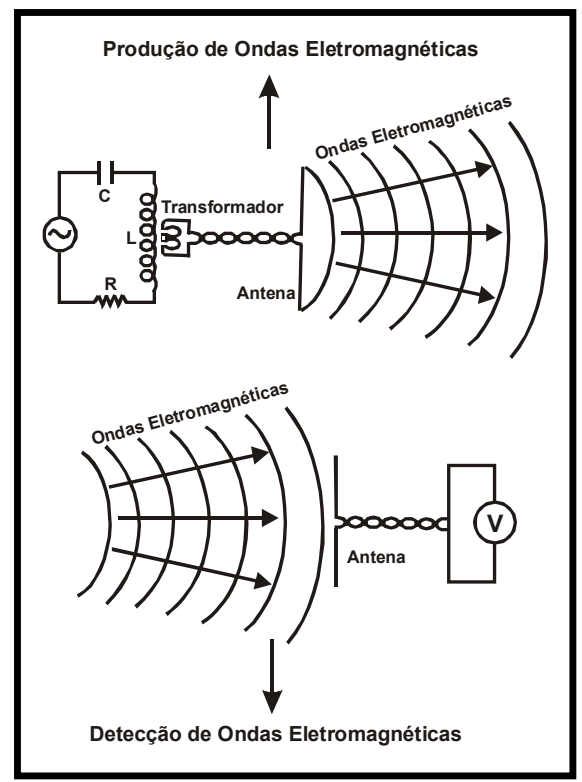

Figura 2.1 - Processo de geração e detecção das ondas eletromagnéticas. Adaptado de (KAGAN, 2002).

As componentes elétrica $(\vec{E})$ e magnética $(\vec{H})$ de uma onda são perpendiculares entre si e fazem um ângulo de $90^{\circ}$ em relação à direção de propagação. A polarização de uma onda de rádio é, geralmente, a mesma do seu campo elétrico. Segundo (ZENG \& MACBETH, 1993), a polarização de uma onda eletromagnética é o modo como oscila o campo elétrico ao longo da direção de propagação.

A relação entre os campos elétrico e magnético de uma onda pode ser observada na Figura 2.2. 


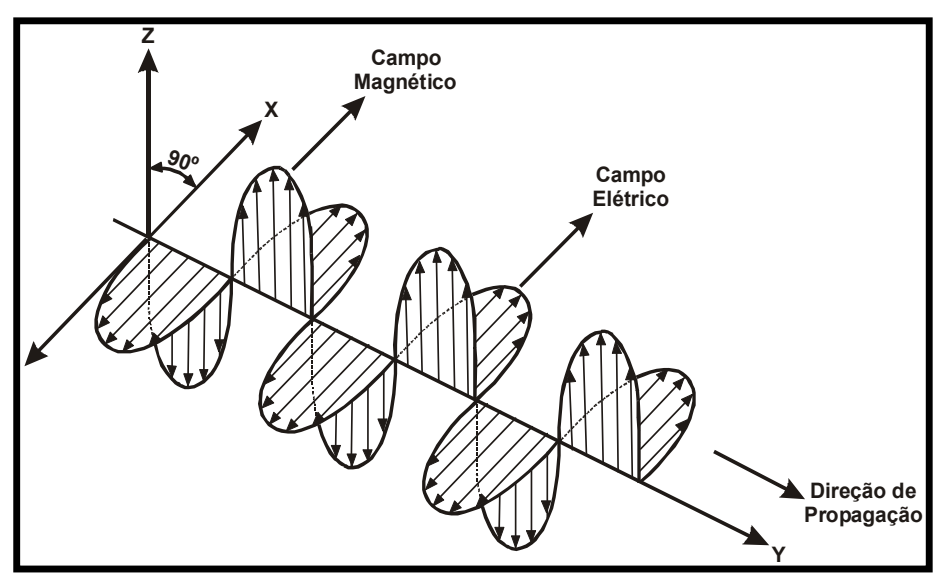

Figura 2.2 - llustração das componentes de uma onda eletromagnética plana, estacionária no tempo.

Devido à não homogeneidade dos componentes físicos e químicos da atmosfera, os sinais de rádio sofrem perturbações que podem comprometer o processo de transmissão de informações. Essas perturbações influenciam a direção, a velocidade de propagação e a potência do sinal.

As características de propagação das ondas de rádio são distintas em relação às bandas de freqüência do espectro eletromagnético, situando-se na faixa entre $3 \mathrm{~Hz}$ e $3000 \mathrm{GHz}$, divididas em 12 bandas. A Tabela 2.1 lista a designação, a classificação, a faixa de freqüência e o comprimento das ondas utilizadas em comunicações móveis.

Tabela 2.1. - Propriedades das ondas utilizadas em comunicações móveis. Adaptado de (FONSECA JÚNIOR, 2002).

\begin{tabular}{|c|c|c|c|c|c|}
\hline \multirow{2}{*}{ Designação } & Classificação & \multicolumn{2}{|c|}{ Faixa de Freqüência } & \multicolumn{2}{c|}{ Comprimento de Onda } \\
\cline { 3 - 6 } & Inferior & Superior & Inferior & Superior \\
\hline ULF & Ultra Low Frequency & $3 \mathrm{~Hz}$ & $30 \mathrm{~Hz}$ & $100.000 \mathrm{Km}$ & $10.000 \mathrm{Km}$ \\
\hline VF & Voice Frequency & $30 \mathrm{~Hz}$ & $300 \mathrm{~Hz}$ & $10.000 \mathrm{Km}$ & $1.000 \mathrm{Km}$ \\
\hline ELF & Extremely Low Frequency & $300 \mathrm{~Hz}$ & $3 \mathrm{KHz}$ & $1.000 \mathrm{Km}$ & $100 \mathrm{Km}$ \\
\hline VLF & Very Low Frequency & $3 \mathrm{KHz}$ & $30 \mathrm{KHz}$ & $100 \mathrm{Km}$ & $10 \mathrm{Km}$ \\
\hline LF & Low Frequency & $30 \mathrm{KHz}$ & $300 \mathrm{KHz}$ & $10 \mathrm{Km}$ & $1 \mathrm{Km}$ \\
\hline MF & Medium Frequency & $300 \mathrm{KHz}$ & $3 \mathrm{MHz}$ & $1 \mathrm{Km}$ & $100 \mathrm{~m}$ \\
\hline $\mathrm{HF}$ & High Frequency & $3 \mathrm{MHz}$ & $30 \mathrm{MHz}$ & $100 \mathrm{~m}$ & $10 \mathrm{~m}$ \\
\hline VHF & Very High Frequency & $30 \mathrm{MHz}$ & $300 \mathrm{MHz}$ & $10 \mathrm{~m}$ & $1 \mathrm{~m}$ \\
\hline UHF & Ultra High Frequency & $300 \mathrm{MHz}$ & $3 \mathrm{GHz}$ & $1 \mathrm{~m}$ & $10 \mathrm{~cm}$ \\
\hline SHF & Super High Frequency & $3 \mathrm{GHz}$ & $30 \mathrm{GHz}$ & $10 \mathrm{~cm}$ & $1 \mathrm{~cm}$ \\
\hline EHF & Extremely High Frequency & $30 \mathrm{GHz}$ & $300 \mathrm{GHz}$ & $1 \mathrm{~cm}$ & $1 \mathrm{~mm}$ \\
\hline
\end{tabular}


Algumas das faixas de freqüências ilustradas na Tabela 2.1 ainda são subdivididas para atender serviços e aplicações específicas. A Tabela 2.2 lista algumas destas subdivisões.

Tabela 2.2. - Outras faixas de freqüências utilizadas em comunicações móveis. Adaptado de http://www.eee.ufrgs.br/ Iguedes/cm/cm6-2.htm e acessado em 21/08/03.

\begin{tabular}{|c|c|c|c|c|}
\hline \multirow{2}{*}{ Designação } & \multicolumn{2}{|c|}{ Faixa de Freqüência } & \multicolumn{2}{c|}{ Comprimento de Onda } \\
\cline { 2 - 5 } & Inferior & Superior & Inferior & Superior \\
\hline Banda L & $1 \mathrm{GHz}$ & $2 \mathrm{GHz}$ & $30 \mathrm{~cm}$ & $15 \mathrm{~cm}$ \\
\hline Banda S & $2 \mathrm{GHz}$ & $4 \mathrm{GHz}$ & $15 \mathrm{~cm}$ & $7,50 \mathrm{~cm}$ \\
\hline Banda C & $4 \mathrm{GHz}$ & $8 \mathrm{GHz}$ & $7,50 \mathrm{~cm}$ & $3,75 \mathrm{~cm}$ \\
\hline Banda X & $8 \mathrm{GHz}$ & $12 \mathrm{GHz}$ & $3,75 \mathrm{~cm}$ & $2,50 \mathrm{~cm}$ \\
\hline Banda Ku & $12 \mathrm{GHz}$ & $18 \mathrm{GHz}$ & $2,50 \mathrm{~cm}$ & $1,67 \mathrm{~cm}$ \\
\hline Banda K & $18 \mathrm{GHz}$ & $27 \mathrm{GHz}$ & $1,67 \mathrm{~cm}$ & $1,11 \mathrm{~cm}$ \\
\hline Banda Ka & $27 \mathrm{GHz}$ & $40 \mathrm{GHz}$ & $1,11 \mathrm{~cm}$ & $7,50 \mathrm{~mm}$ \\
\hline Banda mm & $40 \mathrm{GHz}$ & $300 \mathrm{GHz}$ & $7,50 \mathrm{~mm}$ & $1,00 \mathrm{~mm}$ \\
\hline
\end{tabular}

\subsection{Principais elementos definidores das ondas eletromagnéticas}

Nos sinais eletromagnéticos, a partir de sua formação, pode-se definir os seguintes elementos:

- amplitude

- freqüência

- fase

A amplitude é a medida da altura da onda para voltagem positiva ou para voltagem negativa. Ao iniciar na voltagem zero, a onda cresce, atinge a crista máxima, decresce, se anula, atinge sua crista negativa e volta a crescer até se anular novamente. Essa seqüência compõe um ciclo. Como os sinais são grandezas elétricas, a unidade de amplitude é dada em volt $(\mathrm{V})$ ou milésimos de volt $(\mathrm{mV})$.

A freqüência corresponde ao número de ciclos ou movimentos ondulatórios realizados em um certo intervalo de tempo, normalmente dado em segundo. Na Figura 2.3, além de estar caracterizada a amplitude de um sinal, é possível, também, verificar o comportamento da freqüência. Se, por exemplo, a onda realizou um movimento completo em um segundo, dizemos que a mesma tem uma freqüência de 1 ciclo/segundo ou 1 Hertz 
(1Hz). Na mesma figura, é possível verificar a onda completando 3 ciclos em 1 segundo. Neste caso a sua freqüência é 3 vezes maior, ou seja: 3 ciclos/segundo ou (3Hz).

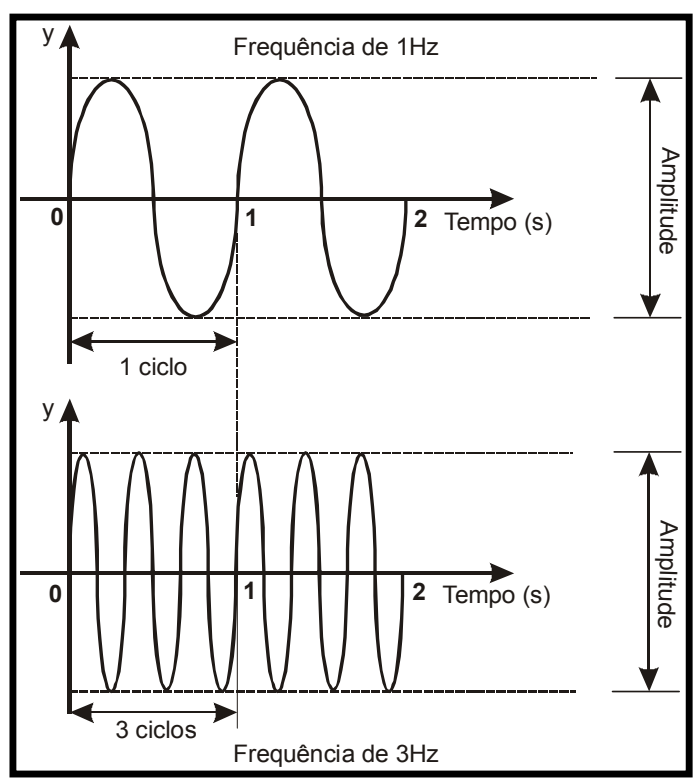

Figura 2.3 - Amplitude e freqüência de uma onda eletromagnética.

No que se refere ao conceito de fase, o mesmo está diretamente relacionado com o ângulo inicial que o sinal assume no instante $t=0$. Para entender melhor a fase de um sinal, é necessário, primeiramente, conhecer os diversos ângulos que uma onda senoidal ocupa ao percorrer um ciclo. Ao lembrar do círculo trigonométrico, usado em Matemática, e ao associá-lo a um ciclo de sinal senoidal, pode-se observar na Tabela 2.3 e na Figura 2.4 exemplos dos diversos ângulos descritos.

Tabela 2.3. - Ângulos associados a um ciclo de sinal senoidal

\begin{tabular}{|c|c|}
\hline Tempo (s) & Ângulo Associado \\
\hline 0,0 & $0^{\circ}$ \\
\hline 0,5 & $45^{\circ}$ \\
\hline 1,0 & $90^{\circ}$ \\
\hline 1,5 & $135^{\circ}$ \\
\hline 2,0 & $180^{\circ}$ \\
\hline 2,5 & $225^{\circ}$ \\
\hline 3,0 & $270^{\circ}$ \\
\hline 3,5 & $315^{\circ}$ \\
\hline
\end{tabular}




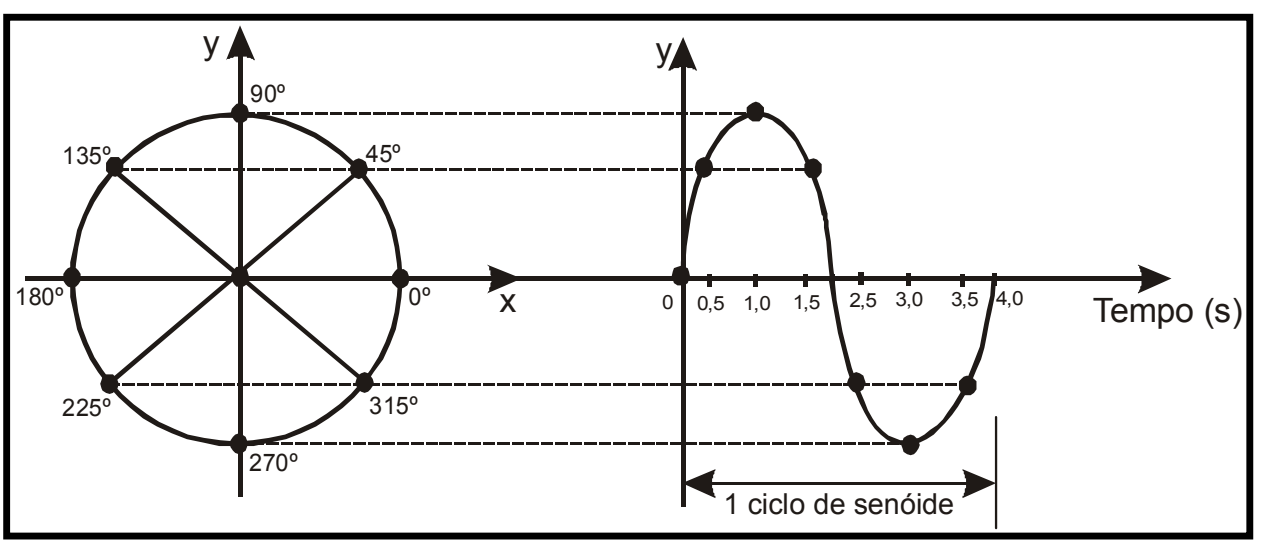

Figura 2.4 - Fase associada aos ângulos do círculo trigonométrico.

\subsection{Representação matemática das ondas}

Como as ondas são periódicas e oscilatórias, elas podem, usualmente, ser representadas através de uma simples função seno ou coseno. As equações, a seguir, representam uma onda em uma única dimensão.

\section{a) função periódica de uma OEM}

$$
y=A \cdot \operatorname{sen}\left(\varphi_{0}-\omega \cdot t\right)
$$

onde:

- "A" corresponde à amplitude da onda;

- $\omega$ corresponde à freqüência angular das OEM;

- "t" corresponde ao tempo;

- $\varphi_{0}$ corresponde à fase inicial da onda;

b) número de onda

$$
\begin{aligned}
& K=\left(\frac{2 \cdot \pi}{\lambda}\right) \\
& \lambda=\left(\frac{c}{f}\right)
\end{aligned}
$$

onde: 
- "K" corresponde ao número de OEM;

- $\lambda$ corresponde ao comprimento de onda;

- "c" corresponde à velocidade de propagação da luz no vácuo. O seu valor corresponde a $299792458 \mathrm{~m} / \mathrm{s}$, para uso em trabalhos de geodésia (MCCARTHY, 1996 apud FONSECA JÚNIOR, 2002);

- "f" corresponde à freqüência do sinal;

c) freqüência angular de uma OEM

$$
\begin{aligned}
& \omega=\left(\frac{2 \cdot \pi}{T}\right) \\
& T=\left(\frac{1}{f}\right)
\end{aligned}
$$

onde:

- $\omega$ corresponde à freqüência angular das OEM;

- "T" corresponde ao período da OEM;

- "f" corresponde à freqüência do sinal;

d) velocidade de propagação de uma OEM

$$
v=\left(\frac{\omega}{K}\right)
$$

onde:

- "v" corresponde à velocidade de propagação das OEM;

- $\omega$ corresponde à freqüência angular das OEM;

- "K" corresponde ao número de OEM.

\section{e) densidade de potência de uma OEM}

É importante salientar que, no espaço, as OEM espalham-se uniformemente em todas as direções, a determinar frentes de onda, cuja potência, em relação à origem de sua fonte geradora, diminui de uma forma inversamente proporcional ao quadrado da distância. A Figura 2.5 ilustra a situação. 


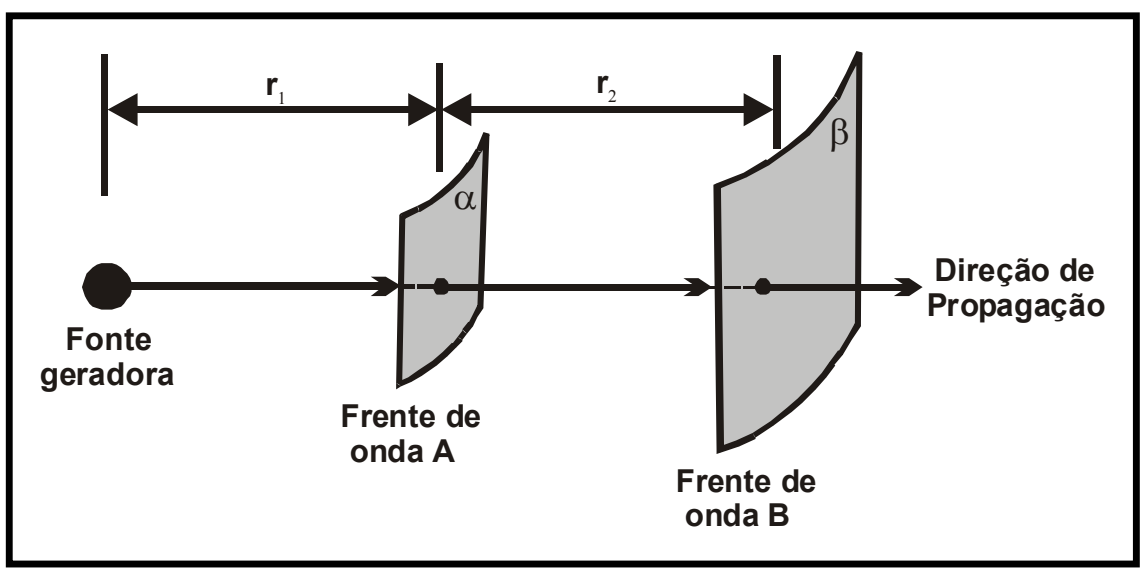

Figura 2.5 - Frentes de ondas irradiadas por uma fonte geradora.

O enfraquecimento da OEM é um fenômeno puramente geométrico, e sua intensidade é dada por:

$$
P=\frac{P_{t}}{4 \cdot \pi \cdot r^{2}}
$$

onde:

- "P" corresponde à densidade de potência à distância "r" de uma fonte isotrópica ${ }^{3}$, em $\mathrm{W} / \mathrm{m}^{2}$

- "r" corresponde à distância entre a origem da fonte isotrópica e a frente de onda;

- $P_{t}$ corresponde à potência transmitida, em W.

\subsection{Velocidades de grupo e de fase das OEM}

A velocidade de propagação $v=\left(\frac{\omega}{K}\right)$, de uma onda harmônica, de comprimento de onda $\lambda=\left(\frac{2 \cdot \pi}{K}\right)$, e freqüência $f=\left(\frac{\omega}{2 \cdot \pi}\right)$, é chamada velocidade de fase.

De acordo com (SLAWINSKI, 1996), a velocidade de grupo, também conhecida como velocidade de raio, é aquela com a qual a energia de uma frente de onda se propaga. Em outras palavras, a velocidade de grupo é aplicada à soma de um conjunto de ondas que se propaga em um meio dispersivo. A Figura 2.6 ilustra a situação.

\footnotetext{
${ }^{3}$ Uma fonte isotrópica é aquela que irradia energia, uniformemente, em todas as direções.
} 


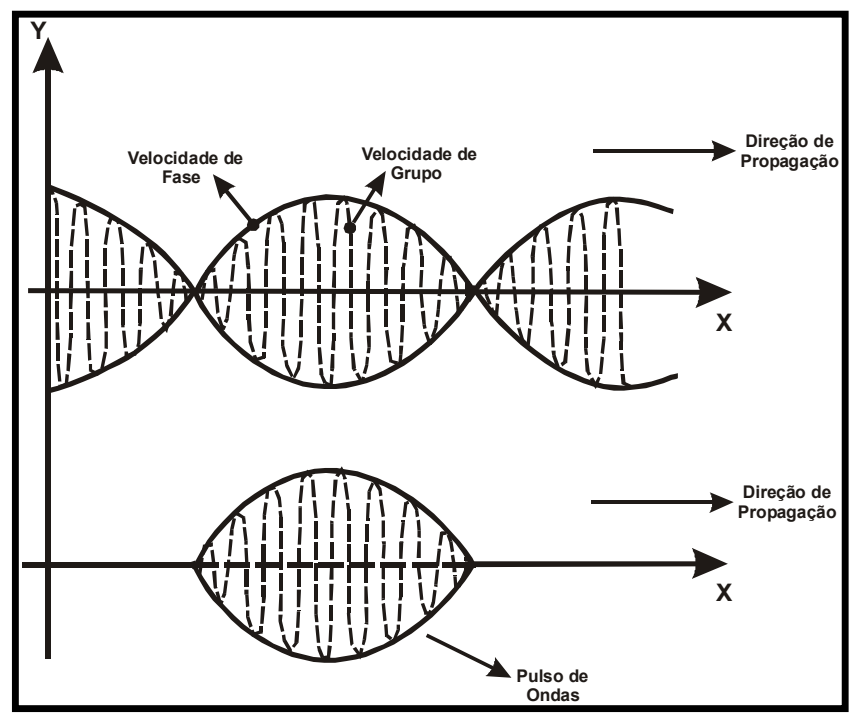

Figura 2.6 - Velocidade de fase e de grupo.

Se a velocidade de propagação for independente da freqüência, diz-se que o meio pelo qual se propagam as ondas é não dispersivo. Então, todas as ondas que compõem o pulso se deslocam com a mesma velocidade. Neste caso, a informação viaja à velocidade de fase, que é idêntica à velocidade de grupo. Em um meio dispersivo, cada onda que compõe o pulso se desloca com uma velocidade diferente. Assim, a velocidade do pulso não é igual à velocidade de fase (ROKHLIN et al, 1986).

Para discutir o que se entende por velocidade de grupo, considere o exemplo da onda constituída pela superposição de duas ondas harmônicas de mesma amplitude "A", mas de freqüências angulares $\omega^{\prime}$ e $\omega$ muito próximas.

$$
y(x, t)=A \cdot \operatorname{sen}(K \cdot x-\omega \cdot t)+A \cdot \operatorname{sen}\left(K^{\prime} \cdot x-\omega^{\prime} \cdot t\right)
$$

onde:

- "A" corresponde à amplitude da onda;

- $\omega$ e $\omega^{\prime}$ correspondem às freqüências angulares da primeira e segunda onda harmônica, respectivamente;

- "t" corresponde ao tempo;

- K e K' correspondem ao número de onda referente à primeira e segunda função harmônica, respectivamente.

Pela trigonometria, tem-se a igualdade: 


$$
\operatorname{sen}(A)+\operatorname{sen}(B)=2 \cdot \operatorname{sen}\left[\frac{1}{2} \cdot(A+B)\right] \cdot \cos \left[\frac{1}{2} \cdot(A-B)\right]
$$

Assim, a equação (2.8) fica:

$$
y(x, t)=2 \cdot A \cdot \cos \left[\left(\frac{K^{\prime}-K}{2}\right) \cdot x-\left(\frac{\omega^{\prime}-\omega}{2}\right) \cdot t\right] \cdot \operatorname{sen}\left[\left(\frac{K^{\prime}+K}{2}\right) \cdot x-\left(\frac{\omega^{\prime}+\omega}{2}\right) \cdot t\right]
$$

Como $\omega^{\prime}$ e $\omega$ são quase iguais, então:

$$
\left(\omega^{\prime}+\omega\right) \cong 2 \cdot \omega \text { e }\left(K^{\prime}+K\right) \cong 2 \cdot K
$$

Ao utilizar-se as aproximações da equação (2.11) na (2.10), tem-se:

$$
y(x, t)=2 \cdot A \cdot \cos \left[\left(\frac{K^{\prime}-K}{2}\right) \cdot x-\left(\frac{\omega^{\prime}-\omega}{2}\right) \cdot t\right] \cdot \operatorname{sen}(K \cdot x-\omega \cdot t)
$$

$\mathrm{Na}$ equação (2.12), a grandeza $\operatorname{sen}(\mathrm{K} \cdot \mathrm{x}-\omega \cdot \mathrm{t})$ representa um movimento ondulatório, com amplitude modulada igual a $2 \cdot A \cdot \cos \left[\left(\frac{K^{\prime}-K}{2}\right) \cdot x-\left(\frac{\omega^{\prime}-\omega}{2}\right) \cdot t\right]$. Na Figura (2.6), pode-se observar o movimento ondulatório através da linha contínua, enquanto que a linha tracejada representa a amplitude modulada, que corresponde a um movimento ondulatório que se propaga com a velocidade de grupo, cujo valor é obtido pela equação (2.14).

$$
\begin{gathered}
V_{G}=\left(\frac{\omega^{\prime}-\omega}{K^{\prime}-K}\right) \\
V_{G}=\left(\frac{\Delta \omega}{\Delta K}\right) \cong\left(\frac{d \omega}{d K}\right)
\end{gathered}
$$

onde:

- $\mathrm{V}_{\mathrm{G}}$ corresponde à velocidade de grupo;

- $\Delta \omega$ corresponde à diferença entre as freqüências angulares da primeira e segunda onda harmônica;

- $\Delta \mathrm{K}$ corresponde a diferença entre o número de onda, representadas pelas duas funções harmônicas. 


\subsubsection{Relação entre velocidade de grupo e velocidade de fase}

Demonstra-se, a seguir, a relação matemática existente entre velocidade de grupo e de fase. O desenvolvimento desta relação foi baseado em (BRILLOUIN and SOMMERFELD, 1960).

A velocidade de grupo é a velocidade com a qual a energia se propaga, definida por:

$$
\mathrm{V}_{\mathrm{G}}=\left(\frac{\mathrm{d} \omega}{\mathrm{dK}}\right)
$$

Um parâmetro muito importante no processo de propagação de sinais é o índice de refração. A refração ocorre quando uma OEM passa obliquamente de um meio para outro. Esse índice pode ser obtido por:

$$
\mathrm{n}_{\mathrm{r}}=\left(\frac{\mathrm{c}}{\mathrm{V}_{\mathrm{F}}}\right)=\left(\frac{\mathrm{c} \cdot \mathrm{K}}{\omega}\right)
$$

onde:

- $\mathrm{n}_{\mathrm{r}}$ corresponde ao índice de refração;

- "c" corresponde à velocidade da luz;

- $\mathrm{V}_{\mathrm{F}}$ corresponde à velocidade de fase;

- $\omega$ corresponde à freqüência angular;

• "K" corresponde ao número de onda.

Ao derivar o índice de refração em relação à freqüência angular, tem-se a relação $V_{G}=f\left(V_{F}\right)$.

$$
\begin{aligned}
& \frac{\mathrm{dn}_{\mathrm{r}}}{\mathrm{d} \omega}=-\frac{\mathrm{c} \cdot \mathrm{K}}{\omega^{2}}+\frac{\mathrm{c}}{\omega} \cdot \frac{\mathrm{dK}}{\mathrm{d} \omega} \\
& \frac{\mathrm{dn}_{\mathrm{r}}}{\mathrm{d} \omega}=\frac{\mathrm{c}}{\omega} \cdot\left(\frac{\mathrm{dK}}{\mathrm{d} \omega}-\frac{\mathrm{K}}{\omega}\right) \\
& \frac{\mathrm{dn}_{\mathrm{r}}}{\mathrm{d} \omega}=\frac{\mathrm{c}}{\omega} \cdot\left(\frac{1}{\mathrm{~V}_{\mathrm{G}}}-\frac{1}{\mathrm{~V}_{\mathrm{F}}}\right)
\end{aligned}
$$




$$
V_{G}=\frac{V_{F}}{1+\left(\frac{\omega}{c} \cdot V_{F} \cdot \frac{d n_{r}}{d \omega}\right)}
$$

onde:

- $\mathrm{V}_{\mathrm{G}}$ corresponde à velocidade de grupo;

- $\mathrm{V}_{\mathrm{F}}$ corresponde à velocidade de fase;

- $\omega$ corresponde à freqüência angular;

- "c" corresponde à velocidade da luz;

- $\mathrm{n}_{\mathrm{r}}$ corresponde ao índice de refração;

- $\frac{d n_{r}}{d \omega}$ corresponde à derivada do índice de refração em relação à freqüência angular.

\subsection{Características dos sinais transmitidos pelos satélites GPS}

O posicionamento de pontos com o sistema GPS está baseado na transmissão de OEM por uma rede de satélites em órbita, em uma altitude de, aproximadamente, 20000 quilômetros em relação à superfície física da Terra.

Os sinais transmitidos pelos satélites GPS são derivados a partir de uma freqüência fundamental $f_{0}(10,23 \mathrm{MHz})$, altamente estável devido a osciladores atômicos com estabilidade de $10^{-12}$ e $10^{-13}$ (relógios de césio e de rubídio) (HOFMANN-WELLENHOF, 2001). A Figura 2.7 ilustra como são derivados os sinais transmitidos pelos satélites GPS.

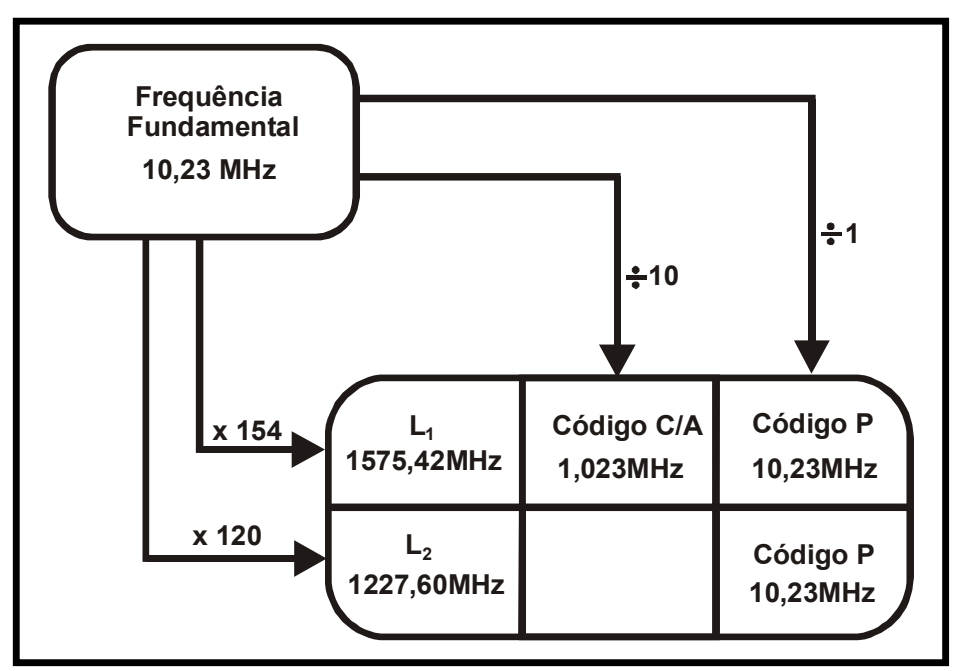

Figura 2.7 - Derivação dos sinais transmitidos pelos satélites GPS. Adaptado de (MONICO, 1998). 
Os satélites transmitem, constantemente, duas ondas portadoras que estão na banda $L$ (usada para rádio). $A$ onda portadora $L_{1}$ é transmitida à freqüência de $1575,42 \mathrm{MHz}$ e contém dois códigos modulados: o código de aquisição livre $(C / A)$ - Coarse/Acquisition, modulado à freqüência de $1,023 \mathrm{MHz}$ e o código $(\mathrm{P})$ - Precise/Protected, modulado à freqüência de $10,23 \mathrm{MHz}$. A onda portadora $L_{2}$ é transmitida à freqüência de $1227,60 \mathrm{MHz}$ e contém apenas o código $P$.

As portadoras $L_{1}$ e $L_{2}$ possuem comprimentos de onda de aproximadamente $19,03 \mathrm{~cm}$ e 24,42cm, respectivamente. Os códigos C/A e $P$ possuem comprimentos de onda de aproximadamente 293,05m e 29,31m, respectivamente (LEICK, 2003). Essas portadoras são moduladas com mensagem de navegação que contém informações necessárias à determinação da posição do satélite. O Departamento de Defesa dos EUA disponibiliza dois tipos de serviço de posicionamento:

- Serviço de Posicionamento Padrão (SPS - Standard Positioning Service) que está disponível para toda a comunidade civil; opera apenas em $L_{1}$ e é usado na aquisição inicial dos sinais do satélite, através da sintonia do código C/A. Até maio de 2000 , quando este código era afetado pelo efeito S/A, permitia aos usuários obter precisões horizontais e verticais na ordem dos 100 e 156 metros, respectivamente.

- Serviço de Posicionamento Preciso (PPS), que está disponível apenas para usuários autorizados pelo governo dos EUA; opera em $L_{1}$ e $L_{2}$, através do código $P(Y)$, e permite obter precisões de 22 e 27 metros, com um intervalo de confiança de 95\% para posicionamento horizontal e vertical, respectivamente (DoD, 2001).

O objetivo inicial do Departamento de Defesa dos Estados Unidos (DoD), era disponibilizar dois serviços com precisões diferenciadas. O SPS foi idealizado para proporcionar navegação em tempo real com exatidão muito inferior ao proporcionado pelo PPS, mas verificou-se que os receptores, usando apenas o código C/A, proporcionavam exatidão muito próxima dos que usavam o código $P$. Como resultado, o DoD implementou uma técnica para limitar a precisão do sistema, aos usuários autorizados. Esta técnica implementada foi a A/S (Anti-Spoofing) com o propósito de negar aos civis e potências militares hostis $o$ acesso ao código $P$. Este sistema criptografa o código $P$ através de um sinal chamado código $\mathrm{Y}$. Apenas os receptores militares conseguem decifrar o código $\mathrm{Y}$. 


\subsubsection{Observáveis GPS}

Dentre as principais observáveis derivadas dos sinais transmitidos pelos satélites GPS, e que são utilizadas no processo de determinação de coordenadas geodésicas, destacam-se: medições de pseudodistâncias obtidas através do código (C/A e/ou P) e a fase da onda portadora $\left(L_{1}\right.$ ou $L_{1}$ e $\left.L_{2}\right)$.

\section{a) Pseudodistância}

A pseudodistância corresponde a uma distância entre antena receptora e antena do satélite. Essa grandeza está diretamente relacionada com o tempo de transmissão e recepção de um sinal eletromagnético que se propaga pela atmosfera com a velocidade da luz. Os relógios dos satélites são de padrões atômicos ao passo que os dos receptores são de qualidade muito inferior, o que acarreta um não sincronismo entre estes relógios. Por este motivo que a pseudodistância recebe este nome.

A pseudodistância simplificada pode ser obtida através da seguinte equação:

$$
R_{r}^{s}=c \cdot\left(t_{r}-t^{s}\right)
$$

onde:

- $\mathrm{R}_{\mathrm{r}}^{\mathrm{s}}$ corresponde à pseudodistância;

- "c" corresponde à velocidade da luz no vácuo;

- $t_{r}$ corresponde ao tempo no instante de recepção do sinal na antena receptora;

- $\mathrm{t}^{\mathrm{S}}$ corresponde ao tempo no instante da transmissão do sinal no satélite.

Quando se relacionam os relógios do satélite e do receptor, com o sistema de tempo GPS, tem-se:

$$
\begin{aligned}
& \mathrm{T}_{\mathrm{GPS}}^{\mathrm{s}}=\mathrm{t}^{\mathrm{s}}-\mathrm{dt}^{\mathrm{s}} \\
& \mathrm{T}_{\mathrm{GPS} \mathrm{r}}=\mathrm{t}_{\mathrm{r}}-\mathrm{dt}_{\mathrm{r}}
\end{aligned}
$$

onde: 
- $\mathrm{dt}^{\mathrm{S}}$ corresponde ao erro de relógio do satélite, em relação ao sistema de tempo GPS, no instante $t^{s}$;

- $\mathrm{dt}_{\mathrm{r}}$ corresponde ao erro de relógio do satélite, em relação ao sistema de tempo GPS, no instante $t_{r}$.

Ao substituir as equações (2.19) e (2.20) na (2.18), tem-se:

$$
R_{r}^{s}=c \cdot\left(T_{G P S_{r}}-T_{G P S}^{s}\right)+c \cdot\left(d t_{r}-d t^{s}\right)
$$

O sinal, ao se propagar pela atmosfera, sofre influência da troposfera e ionosfera. Assim, a equação (2.21) fica:

$$
\mathrm{R}_{\mathrm{r}}^{\mathrm{s}}=\rho_{\mathrm{r}}^{\mathrm{s}}+\mathrm{C} \cdot\left(\mathrm{dt}_{\mathrm{r}}-\mathrm{dt}^{\mathrm{s}}\right)+\Delta^{\mathrm{IONO}}+\Delta^{\mathrm{TROPO}}+\varepsilon
$$

onde:

- $\mathrm{R}_{\mathrm{r}}^{\mathrm{s}}$ corresponde à pseudodistância;

- "c" corresponde à velocidade da luz no vácuo;

- $\left(\mathrm{dt}_{\mathrm{r}}-\mathrm{dt}^{\mathrm{s}}\right)=\Delta \delta$ corresponde ao conjunto: erros dos relógios do receptor e do satélite;

- $\Delta^{\mathrm{IONO}}$ corresponde ao efeito da ionosfera causado no sinal;

- $\Delta^{\text {TROPO }}$ corresponde ao efeito da troposfera causado no sinal;

- $\rho_{\mathrm{r}}^{\mathrm{s}}$ corresponde à distância geométrica entre a antena do satélite e a antena receptora;

- $\varepsilon$ corresponde a erros sistemáticos e aleatórios não modelados.

Observa-se na equação (2.22) que o sinal que acompanha o termo $\Delta^{\mathrm{IONO}}$ é positivo devido ao fato do código sofrer um atraso ao se propagar pela ionosfera. $O$ atraso do código e o avanço da fase serão mostrados de uma forma mais detalhada no próximo capítulo, na seção 3.3.1, que trata da questão sobre refração ionosférica.

A distância geométrica entre a antena do satélite e a antena receptora pode ser obtida por: 


$$
\rho_{r}^{s}=\sqrt{\left(X^{s}-X_{r}\right)^{2}+\left(Y^{s}-Y_{r}\right)^{2}+\left(Z^{s}-Z_{r}\right)^{2}}
$$

as quais:

- $X^{S}, Y^{S}, Z^{S}$ correspondem às coordenadas cartesianas dos satélites, em relação a um sistema ortogonal geocêntrico;

- $X_{r}, Y_{r}, Z_{r}$ correspondem às coordenadas cartesianas da antena receptora, em relação ao mesmo sistema ortogonal geocêntrico.

\section{b) Fase da onda portadora}

Segundo (CAMARGO, 1999 p. 68-69) "a medida da fase da portadora é obtida, através da diferença entre a fase do sinal recebido do satélite $\left(\phi^{\mathrm{S}}\right)$ e sua réplica gerada pelo receptor $\left(\phi_{\mathrm{r}}\right)$. A observação é, portanto, a parte fracional de um ciclo. Na primeira medição, não se sabe o número inteiro de ciclos $\left(\mathrm{N}_{r}^{s}\right)$, designado de ambigüidade, entre a antena receptora e o satélite. A partir daí, o receptor realiza a contagem de ciclos inteiros, até a época seguinte. Isto faz com que a medida da fase da onda portadora seja ambígua, com relação a um número de ciclos inteiros, envolvidos entre o receptor e os satélites na primeira época de observação".

A fase observada, no instante da recepção, é dada por (REMONDI, 1984):

$$
\phi_{r}^{s}=\phi^{s}-\phi_{r}+N_{r}^{s}
$$

Uma equação similar à (2.22) pode ser escrita:

$$
\lambda \cdot \phi_{\mathrm{r}}^{s}=\rho_{\mathrm{r}}^{\mathrm{s}}+\mathrm{c} \cdot\left(\mathrm{dt}_{\mathrm{r}}-\mathrm{dt}^{\mathrm{s}}\right)-\Delta^{\mathrm{INO}}+\Delta^{\mathrm{TROPO}}+\lambda \cdot \mathrm{N}_{\mathrm{r}}^{\mathrm{s}}+\varepsilon
$$

onde:

- $\phi_{r}^{s}$ corresponde à medida da fase da portadora, em ciclos;

- $\phi^{S}$ é a fase do sinal gerada pelo satélite;

- $\phi_{\mathrm{r}}$ é a réplica da fase gerada pelo receptor;

- $\lambda$ corresponde ao comprimento de onda;

- "c" corresponde à velocidade da luz no vácuo;

- $\left(\mathrm{dt}_{\mathrm{r}}-\mathrm{dt}^{\mathrm{s}}\right)=\Delta \delta$ corresponde ao conjunto: erros dos relógios do receptor e do satélite; 
- $\Delta^{\mathrm{IONO}}$ corresponde ao efeito da ionosfera causado no sinal;

- $\Delta^{\mathrm{TROPO}}$ corresponde ao efeito da troposfera causado no sinal;

- $\rho_{\mathrm{r}}^{\mathrm{s}}$ corresponde à distância geométrica entre a antena do satélite e a antena receptora;

- $\mathrm{N}_{r}^{s}$ corresponde à ambigüidade da fase;

- $\varepsilon$ corresponde a erros sistemáticos e aleatórios não modelados.

Observa-se na equação (2.25) que o sinal que acompanha o termo $\Delta^{\text {IONO }}$ é negativo, devido ao fato da fase sofrer um avanço ao se propagar pela ionosfera.

Todos os conceitos abordados nos itens anteriores estão correlacionados com o que será discutido no próximo capítulo: a estrutura da ionosfera e de que forma a mesma influencia a propagação dos sinais de rádio. 


\section{A lonosfera}

Neste capítulo serão abordadas as características da estrutura da ionosfera, a mostrar:

- os principais fatores que propiciam o processo de ionização na ionosfera;

- a sua divisão em camadas;

- a propagação dos sinais de rádio através da ionosfera, com a modelagem matemática que resulta na obtenção do índice de refração do código e da fase portadora;

- os principais efeitos que a ionosfera pode provocar na propagação dos sinais.

\subsection{Introdução}

As ondas de rádio sofrem muitas influências ao atravessarem a atmosfera terrestre devido à sua falta de uniformidade. Vários fatores podem influenciar as condições de propagação do sinal, tanto positiva como negativamente. Alguns desses fatores são: altitude, localização geográfica, hora local, estação do ano, etc.

A atmosfera terrestre é composta essencialmente por: nitrogênio (78\%), oxigênio (21\%), argônio (1\%) e por outros gases raros. O vapor de água pode chegar a $5 \%$ da atmosfera em determinadas condições. Esta proporção de gases é mantida até uma altitude aproximada de $80 \mathrm{~km}$, altitude em que a composição da mistura começa mudar (SCHLESINGER, 1997).

Nas altitudes mais elevadas predominam os gases hélio e hidrogênio. A radiação solar atua direta e indiretamente em todos os níveis da atmosfera. Próximo à superfície da Terra, o aquecimento solar controla todos os aspectos do clima, gerando vento, chuva e outros fenômenos. A atmosfera, que atinge mais de $1000 \mathrm{~km}$ de altitude, está dividida em zonas. A troposfera situa-se entre a superfície da Terra e uma altitude de $12 \mathrm{~km}$. A temperatura nessa região decresce rapidamente com a altitude. Formam-se nuvens e pode existir muita turbulência devido a variações na temperatura, pressão e densidade. Estas 
condições podem ter efeito pronunciado na propagação de ondas de rádio (SCHLESINGER, 1997).

Entre 12 e $50 \mathrm{~km}$ estão a estratosfera e a camada de ozônio. Cerca de $99 \%$ dos gases atmosféricos situam-se nessas duas camadas. A temperatura na estratosfera é quase sempre constante, e existe pouquíssimo vapor de água. Esta camada quase não influencia a propagação de ondas de rádio, por ser relativamente calma e com poucas variações de temperatura (HALK, 2001).

Entre $50 \mathrm{~km}$ até cerca de $1000 \mathrm{~km}$ está a ionosfera, notável pelos seus efeitos na propagação das ondas de rádio. Nessas altitudes, o oxigênio e o nitrogênio predominam a pressões muito baixas. Os raios UV e $X$ ionizam esses gases e criam uma região onde existem íons com uma relativa abundância (HALK, 2001). A Figura 3.1 ilustra a atmosfera dividida em camadas.

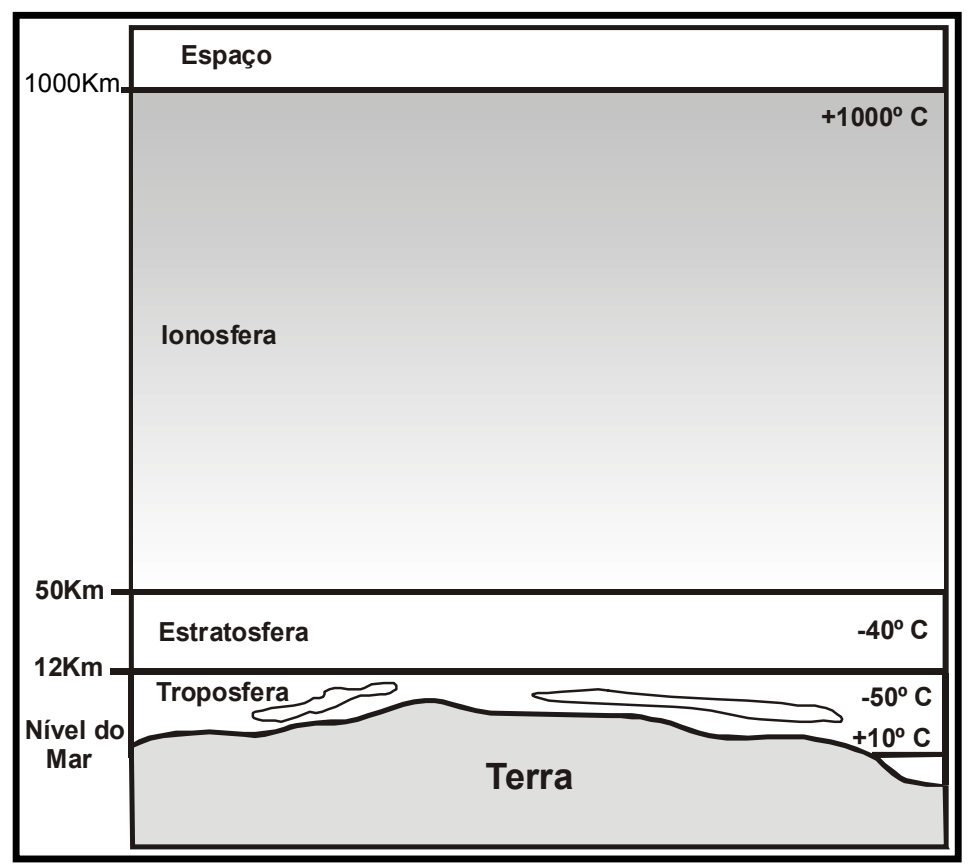

Figura 3.1 - Divisão da atmosfera em camadas. Adaptado de http://www.rep.pt/wave propagation.htm e acessado em 10/05/03.

\subsection{Caracterização da ionosfera}

Segundo (RISHBETH E GARRIOTT, 1969), a ionosfera terrestre é resultado da interação entre os componentes atômicos e moleculares da nossa atmosfera com as fontes ionizantes solares e cósmicas. Dentre essas fontes destacam-se a radiação solar na faixa do ultravioleta e os raios cósmicos. Como os seres humanos não sobreviveriam sem que esses tipos de radiações fossem filtradas, a ionosfera torna-se uma espécie de escudo protetor da biosfera terrestre. 
A ionosfera desempenha um papel importante nas comunicações via satélite, pois fenômenos ionosféricos como as bolhas de plasma podem atenuar ou interferir no sinal propagado ao longo delas, a ponto de provocar erro na leitura do sinal recebido ou mesmo perda de sinal. Hoje se sabe bastante sobre a forma como a ionosfera e seus fenômenos se relacionam com as ondas eletromagnéticas que por ela se propagam (BUDDEN, 1966). De acordo com (DENARDINI, 1999), esses fenômenos e irregularidades, como os eletrojatos equatoriais, ainda não foram totalmente explicados.

Em algumas ocasiões, uma explosão solar é acompanhada pelo espalhamento de partículas de energia (principalmente prótons e elétrons). Outra possibilidade é que as explosões solares ocorram acompanhadas pela ejeção de gigantescas nuvens de plasma. Essas nuvens viajam com o vento solar através do espaço interplanetário, algumas vezes alcançam a Terra e provocam perturbações globais e anomalias no campo magnético terrestre.

As propriedades da ionosfera variam com as coordenadas geográficas ou geomagnéticas, hora local, altitude, estação do ano, ciclo de manchas solares e tempestades geomagnéticas (OSÓRIO, 1992).

A ionosfera é a camada mais importante da atmosfera terrestre para as comunicações via ondas de rádio a longa distância, cuja existência depende diretamente da radiação solar. O movimento da Terra em relação ao Sol, ou a mudança na atividade solar, pode resultar em variações na ionosfera. Estas variações classificam-se em dois tipos:

- as que ocorrem regularmente e podem ser previstas com alguma precisão;

- as que são irregulares e que resultam de um comportamento anormal do sol e, portanto, não podem ser previstas.

Tanto as variações regulares como irregulares tem efeitos importantes na propagação de ondas rádio. Como as variações irregulares não podem ser previstas o texto abordará com maior detalhe as variações regulares.

\subsubsection{Variações regulares}

As variações regulares podem ser divididas em quatro grandes classes: ciclo de 11 anos, sazonais, ciclo de 27 dias e diárias. 


\section{a) Ciclo de 11 anos}

As manchas solares podem aparecer a qualquer instante e o tempo de vida das mesmas é variável. O ciclo de aproximadamente onze anos é um ciclo regular de atividade solar com um mínimo e um máximo de manchas conforme ilustrará mais adiante a figura 3.6 .

\section{b) Variações sazonais}

As variações sazonais estão diretamente relacionadas com a inclinação dos raios solares, resultantes do movimento de translação da Terra em torno do Sol. Esse fato proporciona diferentes graus de ionização da ionosfera durante as quatro estações do ano, sendo mais evidenciado nos equinócios e no verão no hemisfério sul.

\section{c) Ciclo de 27 dias}

O número de manchas solares muda constantemente: desaparecem umas e aparecem outras. Como o Sol possui movimento de rotação, essas manchas são visíveis a intervalos de 27 dias, que é aproximadamente o tempo que o Sol demora a dar uma volta completa em torno do seu eixo.

\section{d) Variações diárias}

A radiação UV cria pequenas concentrações de ozônio entre 10 e $50 \mathrm{~km}$ de altitude. A maior parte desta radiação é absorvida nesse processo e não chega à Terra. Em altitudes ainda maiores, a radiação U.V ioniza, parcialmente, os gases da atmosfera. Elétrons liberados por átomos de gás recombinam-se com íons positivos para reconstituir átomos neutros. A Figura 3.2 ilustra esse processo.

No ambiente rarefeito das grandes altitudes, os átomos encontram-se distantes uns dos outros e os gases podem manter-se ionizados durante horas. Em altitudes menores, a recombinação acontece mais rapidamente. 


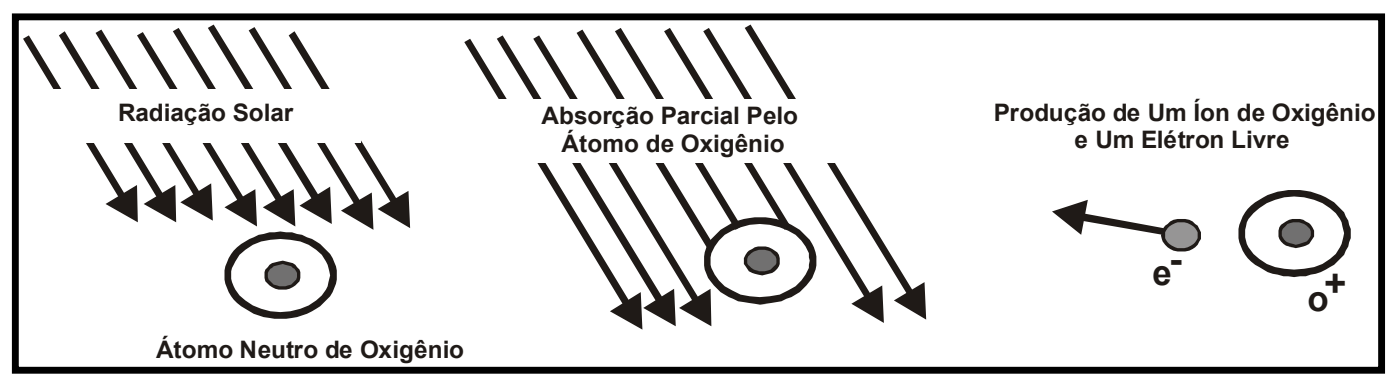

Figura 3.2 - Formação de elétrons livres na camada ionosférica. Adaptado de http://w3.nrl.navy.mil/projects/haarp/ion1.html e acessado em 08/12/02.

Recombinação é o processo oposto à ionização. Ocorre quando elétrons livres e íons positivos colidem, combinam-se, a resultar átomos eletricamente neutros. Tal como a ionização, a recombinação depende da hora do dia. Entre o inicio da manhã e o fim da tarde, o ritmo de ionização excede o ritmo de recombinação. Durante este período, as camadas ionizadas atingem máxima densidade e exercem maior influência nas ondas de rádio.

No entanto, ao anoitecer, o ritmo de recombinação excede o de ionização e causam a diminuição da densidade das camadas ionizadas. Ao longo da noite, a densidade continua a diminuir, e atinge ponto mínimo antes do nascer do sol.

\subsubsection{Camadas da lonosfera}

"Admite-se que a ionosfera seja formada por três regiões $D, E, F$, respectivamente, na seqüência em que aumenta a altitude e a concentração de íons. Cada região contém, muitas vezes, diversas camadas. Por exemplo, a região $F$, para épocas de alta ionização, durante o dia, na estação de verão, divide-se em duas ou mais regiões, designadas $F_{1}$ e $F_{2}$ ", (WEBSTER, 1993 apud CAMARGO, 1999, p. 12). A Figura 3.3 ilustra a densidade de elétrons para as diferentes camadas ionosféricas. 


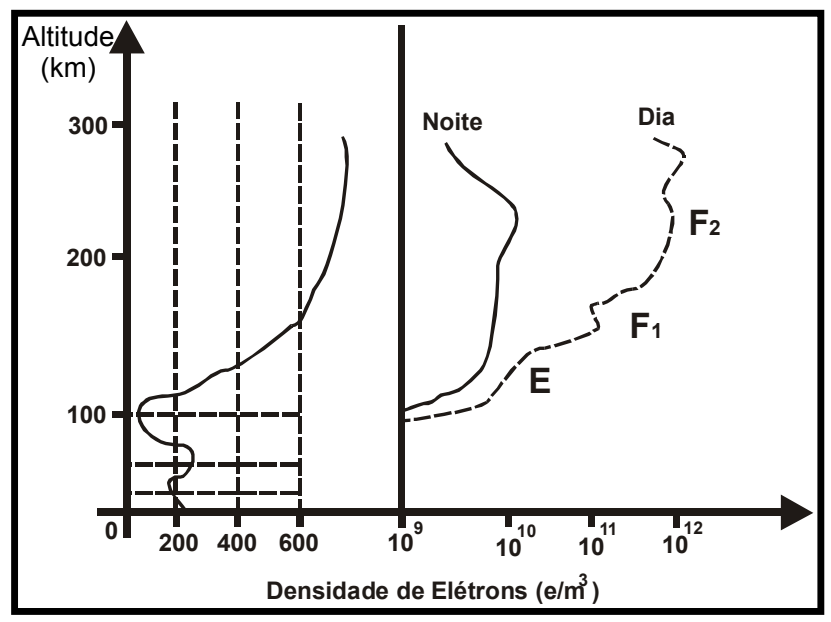

Figura 3.3 - Densidade de elétrons das diferentes regiões da ionosfera. Adaptado de http:|lww.icsl.ucla.edu/ cbiswas/nov97isl/index.htm e acessado em 09/12/02.

A presença ou ausência dessas camadas na ionosfera e a sua altitude varia com a posição do Sol. Ao meio dia, a radiação na ionosfera é máxima, enquanto à noite é mínima. Quando a radiação desaparece, a maior parte das partículas que estavam ionizadas recombinam-se. No espaço de tempo entre estas duas condições, a posição e número de camadas ionizadas da ionosfera mudam. A Figura 3.4 ilustra a ionosfera dividida em camadas.

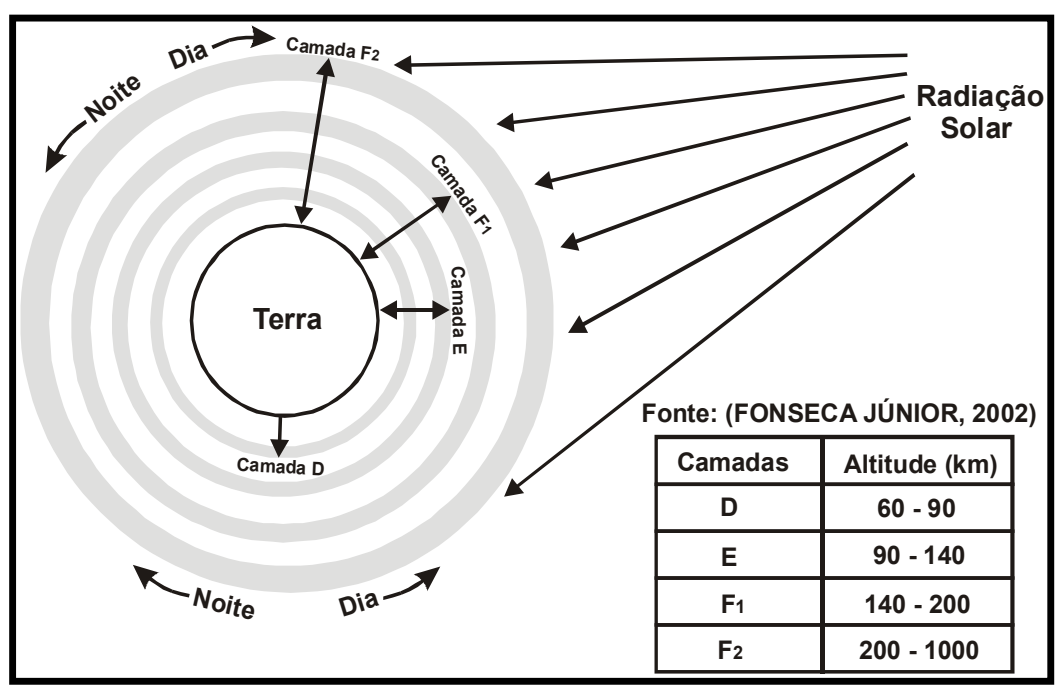

Figura 3.4 - lonosfera dividida em camadas. Adaptado de http://www.rep.pt/wave propagation.htm e acessado em 10/05/03. 


\subsubsection{Camada D}

(DENARDINI, 1999, p. 29-30) cita que "a camada D tem sua localização na faixa de aproximadamente 60 a $90 \mathrm{~km}$ de altitude. Ela é a parte mais complexa da ionosfera do ponto de vista químico. Isso se deve a dois fatores principais: essa região está sob uma alta pressão da coluna de ar e sofre ionização devido a várias fontes. Alguns dos principais agentes ionizantes dessa região são listados a seguir:

1) a linha Lyman- $\alpha$ que penetra abaixo de $95 \mathrm{~km}$ e ioniza a espécie minoritária óxido nítrico (NO);

2) o U.V ioniza outros constituintes minoritários e excita o oxigênio molecular no estado $\mathrm{O}_{2}$;

3) os Raios-X ionizam todos os constituintes;

4) os raios cósmicos afetam toda a baixa atmosfera, tornando-se a maior fonte de ionização em alturas abaixo de $95 \mathrm{~km}$;

5) partículas energéticas do Sol ou de origem auroral ionizam a região $D$ em altas latitudes;

6) partículas energéticas do cinturão de radiação ionizam a região da anomalia do Atlântico Sul, ou seja, a região brasileira".

Durante a noite e devido a sua baixa altitude, a camada $D$ recebe uma quantidade menor de radiação em relação às demais camadas, o que ocasiona redução no processo de ionização.

Para freqüências muito baixas, a camada $D$ e o solo atuam como um guia de ondas, a tornar possível a comunicação através do uso de grandes antenas e emissores muito potentes. A camada $D$ absorve as freqüências médias e baixas, o que limita o alcance diurno para cerca de $400 \mathrm{~km}$. A partir de uma freqüência de $3 \mathrm{MHz}$, a camada $\mathrm{D}$ começa a perder as características absorventes.

Após o pôr do sol, a camada $D$ desaparece por causa da rápida recombinação dos íns. Comunicações em baixa e média freqüência tornam-se possíveis. É por essa razão que as estações em onda média se comportam de forma diferente à noite. 


\subsubsection{Camada $E$}

A camada E situa-se, aproximadamente, entre 90 e $140 \mathrm{~km}$ de altitude. Segundo (KOMJANTHY, 1997 apud FONSECA JÚNIOR, 2002, p. 24-25) "o comportamento da camada $E$ depende do nível de atividade e do ângulo zenital do Sol. Ela é livre de distúrbios, diferentemente das camadas $D$ e $F$, e só está presente durante o dia. Na realidade, essa camada não desaparece completamente à noite, porém, para efeitos práticos, geralmente se assume que a densidade de elétrons cai a zero no período noturno. A fonte primária de ionização é a emissão de raios- $X$ do Sol, resultando em diferentes densidades de elétrons que indicam o ciclo solar, as variações sazonais e as variações diárias."

De acordo com (HAWK, 2001), às vezes, na região da camada $E$, tempestades, explosões solares, chuvas de meteoros, atividades geomagnéticas, etc, causam ionização sobre determinadas áreas, o que acarreta formação de outra camada chamada ESPORÁDICA E. Essa camada afeta de forma significativa a propagação de ondas de rádio, podendo ocorrer durante o dia e a noite e variando, notadamente, com a latitude. Essa camada pode ser tão fina que as ondas de rádio a penetram facilmente, e são refratadas pelas camadas superiores, ou pode ser fortemente ionizada e estender-se por centenas de quilômetros.

\subsubsection{Camada F}

Segundo (KUZNETSOV et al, 1998), a camada F encontra-se, aproximadamente, entre 140 e $390 \mathrm{~km}$ de altitude. Durante o dia, a camada $F$ separa-se em duas camadas, $F_{1}$ e $F_{2}$. Geralmente, durante a noite, a camada $F_{1}$ desaparece. A camada $F$ produz o máximo de ionização após o meio dia, mas os efeitos do ciclo diário são menos pronunciados que nas camadas $\mathrm{D}$ e $\mathrm{E}$. Os átomos da camada $\mathrm{F}$ permanecem ionizados por um longo período, após o por do Sol, e durante o pico de atividade solar podem permanecer ionizados durante toda à noite.

\subsection{Propagação dos sinais de rádio através da ionosfera}

É possível perceber, através dos itens anteriores, a complexidade da estrutura da ionosfera em termos de composição. Devido a isso, as ondas de rádio, ao se propagarem pela ionosfera, podem ser absorvidas, refratadas, refletidas e difratadas. Pelo fato da refração ionosférica ser o principal parâmetro a afetar os sinais transmitidos pelos satélites do sistema GPS, a mesma será abordada com maior detalhe. 


\subsubsection{Refração ionosférica}

A refração é definida como a modificação da forma ou direção de uma onda que, ao passar através de uma interface que separa dois meios, tem, em cada um deles, diferentes velocidades de propagação. Em outras palavras, a refração ocorre quando uma onda eletromagnética passa obliquamente de um meio para outro.

A quantidade de refração que uma onda de rádio sofre ao atravessar a camada ionosférica depende da densidade de ionização da camada e da freqüência da onda.

A seguir, será descrita a modelagem matemática, com propósito de estabelecer o índice de refração da ionosfera. Esta modelagem foi baseada em (FONSECA JÚNIOR, 2002).

O efeito da ionosfera, na propagação de OEM, está diretamente relacionado ao Conteúdo Total de Elétrons - TEC.

$$
T E C=\int_{s}^{r} n_{e}(s) d s
$$

onde:

- $\mathrm{n}_{\mathrm{e}}$ corresponde à densidade de elétrons livres.

A integral representada pela equação 3.1 quantifica o número total de elétrons que estão inclusos em uma coluna cilíndrica com sessão transversal de $1 \mathrm{~m}^{2}$ de área, e que se estende ao longo do caminho " $s$ ", entre o satélite " $S$ " e uma antena receptora "r". A unidade de medida é Total Electron Content Unit (TECU).

$$
1 \mathrm{TECU}=1 \times 10^{16} \mathrm{el} / \mathrm{m}^{2}
$$

O conteúdo total de elétrons na vertical (TVEC), é mostrado na equação (3.2).

$$
\text { TVEC }=\text { TEC } \cdot\left(\frac{1-R_{m}^{2} \cdot \operatorname{sen}^{2}\left(E^{\prime}\right)}{\left(R_{m}+h_{m}\right)}\right)
$$

onde:

- TVEC corresponde ao conteúdo total de elétrons na vertical;

- TEC corresponde ao conteúdo total de elétrons na direção do sinal; 
- $\mathrm{R}_{\mathrm{m}}$ corresponde ao raio médio da Terra;

- $h_{m}$ corresponde à altitude média da camada ionosférica;

- $E^{\prime}$ corresponde ao ângulo de elevação entre o trajeto percorrido pelo sinal e o plano do horizonte na altitude média $\mathrm{h}_{\mathrm{m}}$.

A equação (3.3) permite calcular o índice de refração n para um gás ionizado:

$$
n^{2}=1-n_{e} \cdot\left(\frac{C^{2} \cdot e^{2}}{\pi \cdot f^{2} \cdot m_{e}}\right)
$$

onde:

- "n" corresponde ao índice de refração de um gás ionizado;

- $\mathrm{n}_{\mathrm{e}}$ corresponde à densidade de elétrons livres;

- "e" corresponde à carga do elétron;

- $\mathrm{m}_{\mathrm{e}}$ corresponde à massa do elétron;

- "f" corresponde à freqüência do sinal;

- $C=40,3$ corresponde aos parâmetros constantes da equação.

Ao substituir os valores constantes na equação (3.3), tem-se:

$$
\mathrm{n}=1-\frac{40,3 \cdot \mathrm{n}_{\mathrm{e}}}{\mathrm{f}^{2}}
$$

Ao fazer $c_{2}=-(40,3) \cdot n_{e}$ tem-se:

$$
\mathrm{n}=1+\frac{\mathrm{C}_{2}}{\mathrm{f}^{2}}
$$

De acordo com (SEEBER, 1993 apud FONSECA JUNIOR, 2002, p.17), "a influência da ionosfera na propagação de sinais de rádio tem como principal característica a dispersão. O coeficiente de refração que descreve a propagação da fase pode ser escrito como um desenvolvimento em série."

$$
n_{F}=1+\frac{C_{2}}{f^{2}}+\frac{C_{3}}{f^{2}}+\frac{C_{4}}{f^{2}}+\cdots
$$


onde:

- $\mathrm{n}_{\mathrm{F}}$ corresponde ao índice de refração que descreve a propagação da fase da onda portadora;

- $\mathrm{c}_{\mathrm{i}}(\mathrm{i}=1$ até $\mathrm{n})$ corresponde aos coeficientes da expansão em série;

- f corresponde a freqüência do sinal.

Como $c_{2}=-(40,3) \cdot n_{e}$ e, ao desprezar os termos de ordem superior, tem-se:

$$
n_{F}=1-\frac{40,3 \cdot n_{e}}{f^{2}}
$$

Segundo (WELLS, 1974), o índice de refração, que descreve a propagação do código na ionosfera, pode ser descrito pela equação abaixo.

$$
n_{g}=n_{F}+f \cdot \frac{d n_{F}}{d f}
$$

onde:

- $\mathrm{n}_{\mathrm{g}}$ corresponde ao índice de refração que descreve a propagação do código na ionosfera;

- $\mathrm{n}_{\mathrm{F}}$ corresponde ao índice de refração que descreve a propagação da fase da portadora na ionosfera;

- f corresponde à freqüência do sinal.

Ao derivar a equação (3.6) tem-se:

$$
\frac{d n_{F}}{d f}=\frac{2 \cdot c_{2}}{f^{3}}-\frac{3 \cdot c_{3}}{f^{4}}-\frac{4 \cdot c_{4}}{f^{5}}-\cdots
$$

Ao substituir a equação (3.9) na (3.8), tem-se:

$$
n_{g}=n_{F}-\frac{2 \cdot c_{2}}{f^{2}}-\frac{3 \cdot c_{3}}{f^{3}}-\frac{4 \cdot c_{4}}{f^{4}}-\cdots
$$

Ao substituir a equação (3.6) na (3.10), tem-se:

$$
n_{g}=1-\frac{c_{2}}{f^{2}}-\frac{2 \cdot c_{3}}{f^{3}}-\frac{3 \cdot c_{4}}{f^{4}}-\cdots
$$


Como $c_{2}=-(40,3) \cdot n_{e}$ e, ao desprezar os termos de ordem superior, tem-se:

$$
n_{g}=1+\frac{40,3 \cdot n_{e}}{f^{2}}
$$

Ao observar as equações (3.7) e (3.12), verifica-se porque, ao se propagar pela ionosfera, o código sofre um atraso e a fase sofre um avanço, em magnitudes aproximadamente iguais.

\subsubsection{Reflexão e difração ionosférica}

De acordo com (DABAS, 2000), a reflexão ionosférica acontece quando certas ondas de rádio atingem uma fina e alta camada ionizada da ionosfera. Apesar das ondas serem refratadas, algumas delas retornam à Terra de forma tão rápida que parece tratar-se de reflexão. Para que a reflexão ionosférica aconteça, a espessura da camada ionizada não pode ser maior que um comprimento de onda. Como as camadas ionizadas geralmente têm vários quilômetros de espessura, a reflexão ionosférica acontece com ondas longas.

De acordo com (POOLE, 1999), a difração é a capacidade que as ondas eletromagnéticas têm de contornarem obstáculos. Isso só é possível se o comprimento de onda for maior que o diâmetro do obstáculo.

\subsubsection{O efeito fading na propagação dos sinais}

Como já foi visto anteriormente, mudanças na ionosfera podem produzir distorções na propagação de ondas rádio. Um dos problemas mais sérios na recepção de sinais de rádio é a variação na intensidade do sinal, fenômeno conhecido como fading (ou, em português, desvanecimento).

Segundo (BHATTACHARYA et al, 1998), são várias as condições que produzem o fading. Quando uma onda de rádio é refratada pela ionosfera, podem ocorrer mudanças aleatórias na polarização da onda, a causar mudanças na intensidade do sinal recebido. $O$ fading causado por absorção estende-se por um período mais longo que para outros tipos de fading, já que a absorção ocorre lentamente (GIEFER, 2001). 


\subsection{Outros fenômenos que afetam os sinais de rádio}

Embora as variações diárias na ionosfera tenham o efeito mais pronunciado nos sinais de rádio, outros fenômenos importantes podem ser destacados: manchas solares, perturbações ionosféricas repentinas, tempestades ionosféricas, cintilação e campo magnético da Terra.

\section{a) Manchas solares}

Uma das mais notáveis ocorrências na superfície do Sol é o aparecimento e desaparecimento de manchas escuras e irregulares conhecidas como manchas solares. Crê-se que nas manchas solares ocorrem violentas erupções solares e caracterizam-se por causarem fortes campos magnéticos. Estas explosões causam variações no grau de ionização da ionosfera. As manchas solares tendem a aparecer em dois ciclos: cada 27 dias e a cada 11 anos (KUZNETSOV et al, 1998). A Figura 3.5 ilustra o número médio mensal de manchas solares que ocorreram no período de 1950 até 2004.

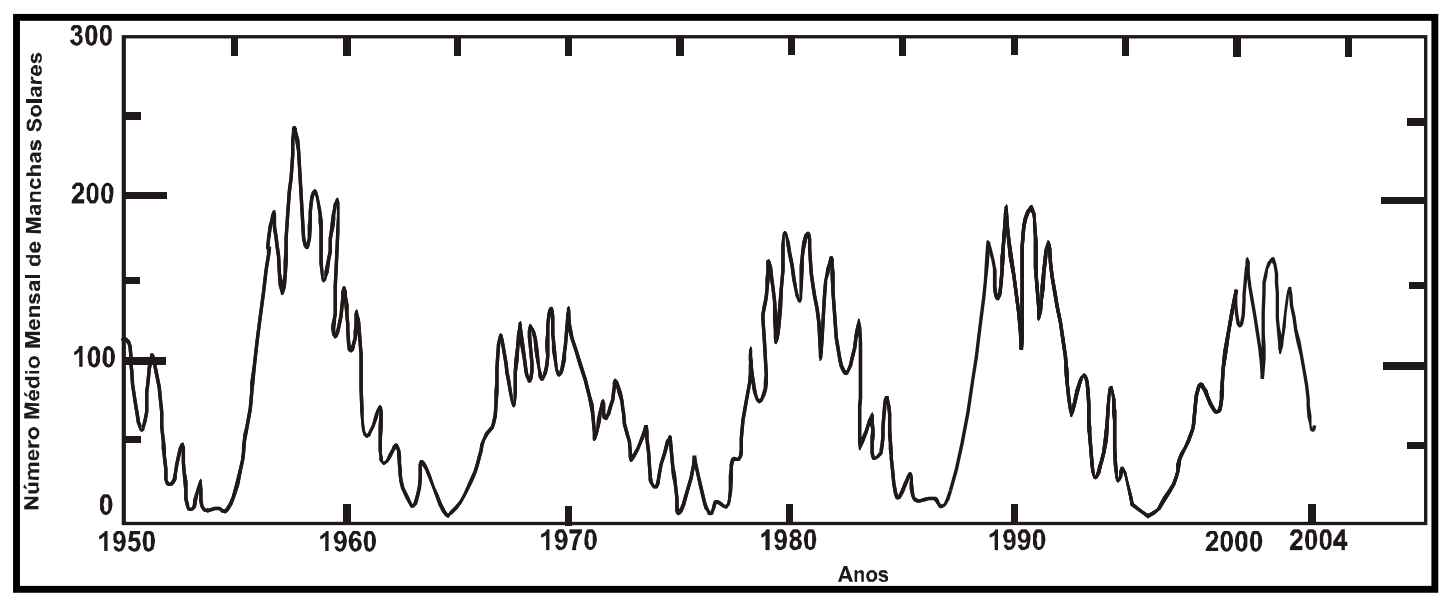

Figura 3.5 - Número médio mensal de manchas solares - período de 1950 a 2004.

Adaptado de http://science.msfc.nasa.gov/ssl/pad/solar/images/zurich.gif e acessado em 14/07/03.

\section{b) Perturbação ionosférica repentina}

Esse fenômeno pode acontecer de forma repentina e sua duração varia entre alguns minutos e algumas horas. Quando essas perturbações acontecem, as comunicações à longa distância tornam-se praticamente impossíveis. Muitas vezes, dá a impressão que o receptor avariou. A causa desse fato ocorre devido à erupção solar, que produz uma quantidade alta de radiação U.V que não é absorvida pelas camadas $F_{1}, F_{2}$ ou $E$. Em vez disso, causa aumento da densidade de ionização da camada D. Como resultado, freqüências acima de 1 ou 2MHz são completamente absorvidas (HAWK, 2001). 


\section{c) Tempestades ionosféricas}

Essas tempestades são causadas por perturbações no campo magnético da Terra. Estão associadas a erupções solares e ao ciclo de 27 dias, ou seja, com o movimento de rotação do Sol. Essas tempestades afetam, sobretudo, a camada $F_{2}$, reduzem a densidade de ionização e tornam as freqüências críticas mais baixas que o normal, (KUZNETSOV et al, 1998).

\section{d) Cintilação}

"A cintilação pode ser descrita como uma rápida variação na amplitude e fase dos sinais que são recebidos de fontes extras ionosféricas, causada pelas estruturas irregulares de plasma com escalas de centenas de metros" (WANNINGER, 1992 apud FONSECA JÚNIOR, 2002 p. 28). "Isso ocorre preferencialmente, na faixa de $+30^{\circ}$ a $-30^{\circ}$ de latitude sendo que os eventos de maior intensidade ocorrem na zona entre $+10^{\circ}$ a $-10^{\circ}$ de latitude a partir da linha do equador geomagnético" (WANNINGER, 1993 apud FONSECA JÚNIOR, 2002 p. 28). "Os efeitos provocados pela cintilação atingem o máximo entre setembro e março na América, África e Índia, porém, no mesmo período, na região do Oceano Pacífico a cintilação é mínima. Entre abril e setembro é oposta. No Brasil, assim como em todo o continente americano, o período de ocorrências máximas está compreendido entre setembro e março e o período de compreendido entre abril e agosto apresenta pouquíssimos eventos relacionados à cintilação" (CAMPOS et al., 1993 apud FONSECA JÚNIOR, 2002 p. 28).

\section{e) Campo magnético da Terra}

"O campo magnético da Terra, com 99\% derivado do seu interior, se comporta como o campo magnético de um dipolo, colocado no centro da Terra e inclinado de aproximadamente 11,5 graus, em relação ao eixo de rotação, e que não passa exatamente pelo seu centro. O campo magnético em torno da Terra forma as linhas de força geomagnéticas, mais potentes nos pólos do que no equador, provocando mudanças nas partículas carregadas na atmosfera, as quais giram em torno dela; e a razão depende da intensidade do campo, massa e carga das partículas. Maiores mudanças ocorrem no pólo, devido à intensidade do campo magnético ser maior. O vento solar, interagindo com o campo geomagnético, faz com que as linhas sejam comprimidas ao lado da Terra voltado para o Sol e estendidas do outro lado, provocando variações na densidade de elétrons, que também ocorrem, devido às tempestades geomagnéticas" (CAMARGO, 1999 p. 31 a 32). 
No próximo capítulo, serão discutidos os principais modelos matemáticos utilizados no processo de correção do efeito sistemático da ionosfera, em posicionamento de pontos com o sistema GPS.

A caracterização da ionosfera, discutida neste capítulo, além de ter possibilitado um melhor entendimento na formulação matemática dos modelos ionosféricos, que serão abordados no próximo capítulo, proporciona um embasamento teórico para discussão e análise dos resultados obtidos neste trabalho. 


\section{Modelos de correção dos efeitos ionosféricos}

Neste capítulo serão discutidos os principais modelos matemáticos utilizados no processo de minimização dos efeitos ionosféricos, passíveis de serem utilizados em posicionamento de pontos com o sistema GPS. Dentre estes modelos destacam-se:

- correção ionosférica através da solução ionospheric free;

- modelo de Klobuchar,

- modelos ionosféricos baseados a partir da portadora $L_{1}$ e código $C / A$;

- modelo ionosférico baseado no código C/A e no código P;

- modelo ionosférico baseado nas portadoras $L_{1}$ e $L_{2}$.

\subsection{Introdução}

Nos capítulos anteriores, pôde-se perceber que a ionosfera influencia o processo de transmissão dos sinais de rádio, devido a um fato primordial: o processo de formação de elétrons e íons que ocorre em suas diferentes camadas.

No caso específico do sistema GPS, esses elétrons livres presentes nas camadas ionosféricas podem influenciar de forma significativa o processo de determinação de coordenadas geodésicas. Vários modelos matemáticos foram desenvolvidos com o intuito de minimizar esse problema. Por ser a quantidade de elétrons livres, presentes na ionosfera, dependente da freqüência do sinal, para aqueles usuários que possuem equipamentos GPS de dupla freqüência $\left(L_{1}, L_{2}\right.$, códigos $C / A$ e $\left.P\right)$, o efeito ionosférico pode ser minimizado de uma forma bastante eficiente, através de uma combinação linear entre as fases das portadoras ou entre as pseudodistâncias.

Uma combinação linear entre as fases das portadoras $\phi_{1}$ e $\phi_{2}$ é apresentada por (WÜBBENA, 1989):

$$
\mathrm{L}_{\mathrm{i}}=\phi_{(\mathrm{n}, \mathrm{m})}=\mathrm{n} \cdot \phi_{1}+\mathrm{m} \cdot \phi_{2}
$$


onde:

- $L_{i}$ corresponde à combinação linear entre as fases das portadoras $\phi_{1}$ e $\phi_{2}$;

- n e m são coeficientes inteiros;

- $\phi_{1}$ corresponde à fase medida da portadora $\mathrm{L}_{1}$;

- $\phi_{2}$ corresponde à fase medida da portadora $L_{2}$.

Através de uma relação entre tempo, fase e freqüência, tem-se:

$$
\begin{aligned}
& t=\frac{\phi_{i}}{f_{i}} \\
& \phi_{i}=t \cdot f_{i}
\end{aligned}
$$

Ao substituir a equação (4.3) na (4.1), tem-se:

$$
L_{i}=n \cdot f_{1} \cdot t+m \cdot f_{2} \cdot t
$$

onde:

- $\mathrm{L}_{\mathrm{i}}$ corresponde à combinação linear entre as fases das portadoras $\phi_{1}$ e $\phi_{2}$;

- n e m são coeficientes inteiros;

- $f_{1}$ corresponde à freqüência da portadora $L_{1}$;

- $f_{2}$ corresponde à freqüência da portadora $L_{2}$;

- t corresponde ao tempo.

A nova freqüência e o novo comprimento de onda da combinação linear são expressos por:

$$
\begin{gathered}
\mathrm{f}_{(\mathrm{n}, \mathrm{m})}=\mathrm{n} \cdot \mathrm{f}_{1}+\mathrm{m} \cdot \mathrm{f}_{2} \\
\lambda_{(\mathrm{n}, \mathrm{m})}=\frac{\mathrm{c}}{\mathrm{f}_{(\mathrm{n}, \mathrm{m})}}
\end{gathered}
$$

onde: 
- $f_{(n, m)}$ corresponde à freqüência derivada da combinação linear;

- $\lambda_{(\mathrm{n}, \mathrm{m})}$ corresponde ao comprimento de onda derivado da combinação linear;

- "c" corresponde à velocidade da luz no vácuo.

\subsection{Correção ionosférica através da solução ionospheric free}

Um dos principais objetivos da realização de combinações lineares entre as observáveis GPS é a minimização dos efeitos ionosféricos em posicionamento de pontos.

As combinações lineares mais simples, e que são utilizadas na maioria dos programas de processamento de dados, são: wide lane $\left(L_{w}\right)$ e narrow lane $\left(L_{n}\right)$.

A observável obtida com a wide lane é resultante da combinação linear $(n=1)$ e $(m=-1)$ e a narrow lane é derivada da combinação $(n=m=1)$.

$$
\begin{aligned}
& \mathrm{L}_{\mathrm{w}}=\phi_{1}-\phi_{2} \\
& \mathrm{~L}_{\mathrm{N}}=\phi_{1}+\phi_{2}
\end{aligned}
$$

onde:

- $L_{w}$ corresponde à combinação linear wide lane;

- $L_{N}$ corresponde à combinação linear narrow lane;

Baseado nas equações (4.5) e (4.6), os comprimentos de onda para as combinações wide lane e narrow lane são, respectivamente: $\lambda_{\mathrm{w}}=86,2 \mathrm{~cm}$ e $\lambda_{\mathrm{N}}=10,7 \mathrm{~cm}$.

A solução do tipo narrow lane dificulta o processo de resolução da ambigüidade para bases longas, devido ao baixo valor de seu comprimento de onda resultante do processo de combinação linear das observáveis $L_{1}$ e $L_{2}$, (SEEBER, 2003).

De acordo com (WÜBBENA, 1989), o efeito da ionosfera na combinação linear das fases da portadora $L_{1}$ e $L_{2}$ pode ser obtido por:

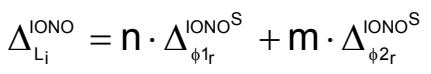

$$
\begin{aligned}
& \Delta_{\phi 1_{\mathrm{r}}}^{\mathrm{INNO}}=\frac{-40,3 \cdot \text { TEC }}{f_{1}}
\end{aligned}
$$




$$
\Delta_{\phi 2_{\mathrm{r}}}^{\mathrm{\text {ONOS }}}=\frac{-40,3 \cdot \text { TEC }}{f_{2}}
$$

onde:

- $\Delta_{\mathrm{L}_{\mathrm{i}}}^{\text {INO }}$ corresponde ao efeito da ionosfera na observável resultante da combinação linear entre $L_{1}$ e $L_{2}$;

- $\Delta_{\phi 1 \mathrm{r}}^{\mathrm{ION0} S}$ corresponde ao efeito da ionosfera na observável $L_{1}$, em relação a um determinado satélite e à antena receptora;

- $\Delta_{\phi 2 \mathrm{r}}^{\mathrm{ION0^{S }}}$ corresponde ao efeito da ionosfera na observável $L_{2}$, em relação a um determinado satélite e à antena receptora;

- n e m são coeficientes inteiros;

- $f_{1}$ e $f_{2}$ correspondem às freqüências das portadoras $L_{1}$ e $L_{2}$, respectivamente;

- TEC corresponde à quantidade de elétrons livres na ionosfera ao longo da trajetória: satélite/antena receptora.

Ao substituir as equações (4.10) e (4.11) na (4.9), tem-se a equação que permite calcular o efeito ionosférico, resultante na combinação linear entre as portadoras $L_{1}$ e $L_{2}$.

$$
\Delta_{L_{\mathrm{i}}}^{\mathrm{INO}}=\frac{-40,3 \cdot T E C}{f_{1} \cdot f_{2}} \cdot\left(n \cdot f_{2}+m \cdot f_{1}\right)
$$

A seguir, serão discutidos os principais modelos ionosféricos utilizados pelos usuários de receptores GPS de uma única freqüência ou por aqueles usuários de receptores que captam apenas o código C/A.

\subsection{Modelo ionosférico baseado na pseudodistância: Modelo de Klobuchar}

Segundo (LEICK, 2003), o modelo de Klobuchar compensa de 50\% a $60 \%$ do efeito da ionosfera no posicionamento de pontos com o sistema GPS.

Para utilizar este modelo há a necessidade de se conhecer: a latitude e a longitude geodésicas aproximadas do local de observação $\left(\phi_{g}\right.$ e $\left.\lambda_{g}\right)$, ângulo de elevação $(E)$ e azimute $\left(A_{z}\right)$ de cada satélite em relação à antena do receptor e os coeficientes $\alpha_{n}$ e $\beta_{n}(n=0 \ldots 3)$ que 
são transmitidos no arquivo de navegação. Os ângulos são representados em radianos e o tempo em segundos.

As etapas de cálculo são baseadas em (KLOBUCHAR, 1987), conforme descritas a seguir:

a) Cálculo da grandeza $(\psi)$

$$
\psi=\left[0,0137 \cdot\left(\frac{\mathrm{E}}{\pi}+0,11\right)-0,022\right] \cdot \pi
$$

onde:

- $\psi$ corresponde ao ângulo formado entre os vetores "satélite/ponto de observação" e "satélite/centro de massa da Terra". A Figura 4.1 ilustra esta grandeza.

- "E" corresponde ao ângulo de elevação do satélite.

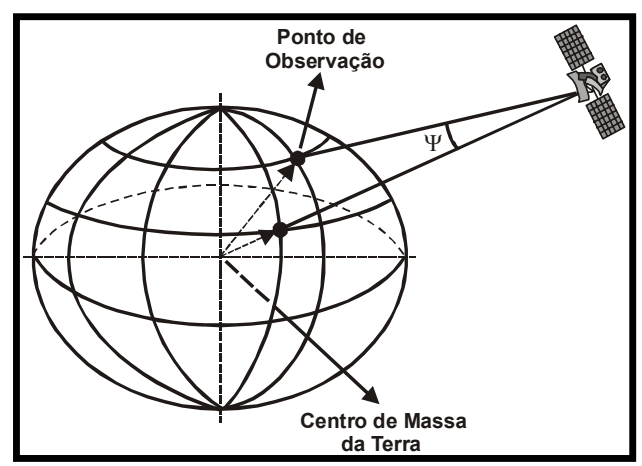

Figura 4.1 - Ângulo formado entre os vetores "satélite/ponto de observação" e "satélite/centro de massa da Terra"

\section{b) Cálculo da latitude do ponto ionosférico $\left(\phi^{*}\right)$}

Segundo (CAMARGO, 1999), o ponto ionosférico corresponde ao ponto formado pela interseção do vetor satélite/antena receptora e a camada ionosférica de altitude média igual a $h_{m}$. No modelo Klobuchar, adota-se $h_{m}$ igual a $350 \mathrm{Km}$. Esta grandeza pode ser visualizada na Figura 4.2 e sua latitude é obtida segundo a equação 4.14. 


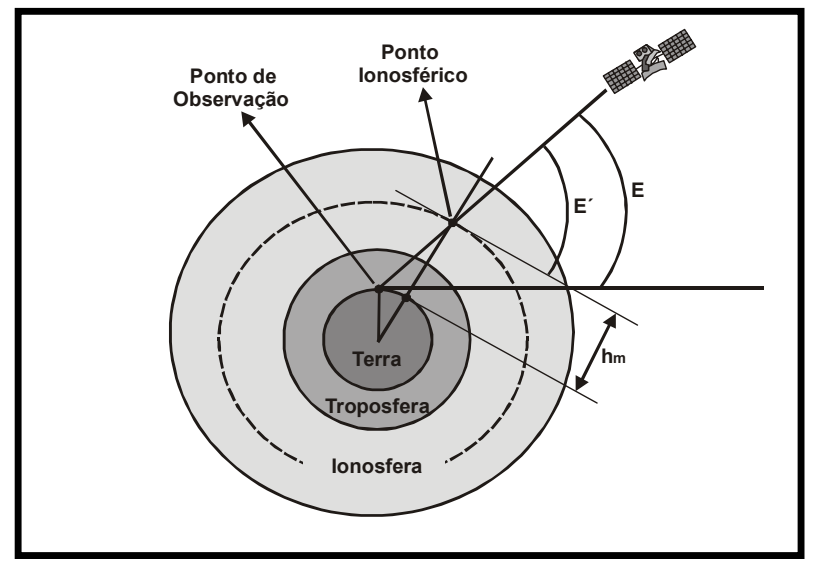

Figura 4.2 - Ponto ionosférico. Adaptado de (LEICK, 2003).

$$
\phi^{*}=\phi_{g}+\psi \cdot \cos \left(\mathrm{A}_{z}\right)
$$

onde:

- $\phi^{*}$ corresponde à latitude do ponto ionosférico;

- $\phi_{\mathrm{g}}$ corresponde à latitude da antena receptora;

- $\psi$ grandeza definida pela equação 4.13;

- $\mathrm{A}_{\mathrm{z}}$ corresponde ao azimute do satélite em relação à antena receptora.

\section{c) Cálculo da longitude do ponto ionosférico $\left(\lambda^{*}\right)$}

A longitude do ponto ionosférico pode ser calculada segundo a equação (4.15).

$$
\lambda^{*}=\lambda_{g}+\left(\frac{\phi_{g} \cdot \operatorname{sen}\left(A_{z}\right)}{\cos \left(\phi^{*}\right)}\right)
$$

onde:

- $\lambda^{*}$ corresponde à longitude do ponto ionosférico;

- $\phi_{g}$ e $\lambda_{g}$ correspondem, respectivamente, à latitude e à longitude da antena receptora;

- $\phi^{*}$ corresponde à latitude do ponto ionosférico;

- $A_{z}$ corresponde ao azimute do satélite em relação à antena receptora. 
d) Cálculo da latitude geomagnética do ponto ionosférico $\left(\phi_{m}\right)$

A latitude geomagnética no ponto ionosférico pode ser obtida pela equação (4.16).

$$
\phi_{\mathrm{m}}=\phi^{*}+0,064 \cdot \pi \cdot \cos \left(\lambda^{*}-1,617 \cdot \pi\right)
$$

onde:

- $\phi_{\mathrm{m}}$ corresponde à latitude geomagnética do ponto ionosférico;

- $\phi^{*}$ corresponde à latitude do ponto ionosférico;

- $\lambda^{*}$ corresponde à longitude do ponto ionosférico.

e) Cálculo da hora local no ponto ionosférico (t)

A hora local no ponto ionosférico pode ser obtida pela equação (4.17).

$$
\mathrm{t}=\frac{4,32 \cdot 10^{4}}{\pi} \cdot \lambda^{*}+\mathrm{T}_{\mathrm{GPS}}
$$

onde:

- "t" corresponde à hora local no ponto ionosférico;

- $\lambda^{*}$ corresponde à longitude no ponto ionosférico;

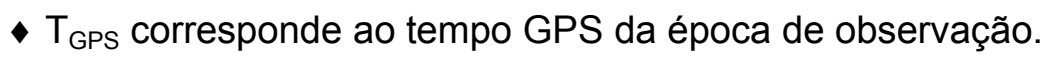

Se $t>86400$, usar $t=(t-86400)$, ou

Se $t<0$, usar $t=(t+86400)$.

\section{f) Cálculo do fator de obliqüidade (F)}

O fator de obliqüidade pode ser obtido pela equação (4.18).

$$
F=1+16 \cdot\left(0,53-\frac{E}{\pi}\right)^{3}
$$

onde:

- "F" corresponde ao fator de obliqüidade;

- "E" corresponde ao ângulo de elevação do satélite. 


\section{g) Cálculo da correção ionosférica $\left(\Delta_{\mathrm{L}^{\mathrm{T}}}^{\mathrm{ONN} \mathrm{S}^{\mathrm{S}}}\right)$}

A correção ionosférica pode ser obtida segundo as equações (4.19), (4.20) e (4.21).

$$
x=\frac{2 \pi(t-50400)}{\sum_{n=0}^{3} \beta_{n} \phi_{m}^{n}}
$$

onde:

- "x" corresponde à fase em radianos;

- "t" corresponde à hora local do ponto ionosférico;

- $\beta_{\mathrm{n}}$ corresponde a um coeficiente do modelo transmitido pelos satélites nas mensagens de navegação;

- $\phi_{\mathrm{m}}$ corresponde à latitude geomagnética do ponto ionosférico;

$$
\text { Se }|\mathrm{x}|>1,57 \quad \Delta_{\mathrm{Li}}^{\mathrm{ONN}}=\mathrm{F} \cdot 5 \cdot 10^{-9}
$$

ou,

$$
\text { Se }|x|<1,57 \quad \Delta_{L r^{r}}^{\mathrm{IONO^{S }}}=F \cdot\left[5 \cdot 10^{-9}+\left(\sum_{n=0}^{3} \alpha_{n} \cdot \phi_{m}^{n}\right) \cdot\left(1-\frac{x^{2}}{2}+\frac{x^{4}}{24}\right)\right]
$$

onde:

- $\Delta_{\mathrm{L}^{\mathrm{T}}}^{\mathrm{ON} \mathrm{S}}$ corresponde à correção ionosférica, ao longo do caminho satélite/receptor na portadora $L_{1}$;

- "x" corresponde à fase em radianos;

- "c" corresponde à velocidade da luz no vácuo;

- "F" corresponde ao fator de obliqüidade;

- $\alpha_{n}$ corresponde à um coeficiente do modelo transmitido pelos satélites nas mensagens de navegação;

- $\phi_{\mathrm{m}}$ corresponde à latitude geomagnética do ponto ionosférico. 


\subsection{Modelos ionosféricos baseados a partir da portadora $L_{1}$ e código $C / A$}

A ionosfera é um meio dispersivo em relação aos sinais GPS, a causar efeitos distintos sobre a pseudodistância e a fase da portadora. A pseudodistância sofre um atraso de grupo e a portadora sofre um avanço de fase, possuindo esses dois efeitos o mesmo valor absoluto, conforme mostra a equação (4.22).

$$
\Delta_{\mathrm{F}}^{\mathrm{IONO}}=-\Delta_{\mathrm{P}}^{\mathrm{IONO}}
$$

onde:

- $\Delta_{\mathrm{F}}^{\mathrm{IONO}}$ corresponde ao avanço de fase sofrido pela portadora;

- $\Delta_{\mathrm{P}}^{\mathrm{IONO}}$ corresponde ao atraso de grupo sofrido pela pseudodistância.

Sendo assim, é possível relacionar as equações de código e fase da portadora a fim de determinar os efeitos causados pela ionosfera nas observações GPS. As equações de observação de pseudodistância e da fase da portadora, em unidades métricas, para uma mesma época são mostradas pelas equações (4.23) e (4.24):

$$
\begin{gathered}
\mathrm{R}=\rho+\mathrm{c} \cdot \Delta \delta+\Delta^{\mathrm{IONO}}+\Delta^{\mathrm{TROPO}} \\
\lambda_{\mathrm{L} 1} \cdot \phi_{\mathrm{L} 1}=\rho+\mathrm{c} \cdot \Delta \delta+\lambda_{\mathrm{L} 1} \cdot \mathrm{N}_{\mathrm{L} 1}-\Delta^{\mathrm{IONO}}+\Delta^{\mathrm{TROPO}}
\end{gathered}
$$

onde:

- "R" representa à observável pseudodistância, em metros;

- $\phi_{\mathrm{L} 1}$ representa à observável fase da portadora $L_{1}$;

- $\rho$ representa à distância geométrica entre o satélite e a antena receptora, em metros;

- "c" representa à velocidade da luz no vácuo, em metros por segundo;

- $\Delta \delta$ representa à combinação dos erros de relógio do satélite e do receptor, em segundos;

- $\lambda_{\mathrm{L} 1}$ representa o comprimento de onda da portadora $L_{1}$, em metros;

- $\mathrm{N}_{\mathrm{L} 1}$ representa à ambigüidade da portadora $\mathrm{L}_{1}$; 
- $\Delta^{\mathrm{IONO}}$ representa o efeito causado pela ionosfera, em metros;

- $\Delta^{\mathrm{TROPO}}$ representa o efeito causado pela troposfera, em metros.

Nestas equações não foram considerados os erros sistemáticos de hardware do satélite e do receptor para as medições das observáveis. A diferença entre as equações (4.23) e a (4.24) resulta em:

$$
\mathrm{R}-\lambda_{\mathrm{L} 1} \cdot \phi_{\mathrm{L} 1}=2 \cdot \Delta^{\mathrm{IONO}}-\lambda_{\mathrm{L} 1} \cdot \mathrm{N}_{\mathrm{L} 1}
$$

Assim, uma vez realizada uma série de observações, é possível determinar o atraso ionosférico a partir das observáveis.

\subsubsection{Modelo da lâmina ionosférica}

Segundo (LEICK, 2003), este é um dos modelos ionosféricos mais simples, pois considera a ionosfera, para um receptor isolado, como uma lâmina de espessura constante que possui distribuição homogênea de elétrons livres. Neste modelo é desconsiderada a curvatura da Terra. $\mathrm{O}$ atraso vertical, $\Delta_{\mathrm{V}}^{\mathrm{IONO}}$, e o atraso ao longo da trajetória, $\Delta^{\mathrm{IONO}}$, são relacionados conforme a equação (4.26).

$$
\Delta^{\mathrm{IONO}}=\frac{\Delta_{\mathrm{V}}^{\mathrm{IONO}}}{\operatorname{sen}(\mathrm{E})}
$$

onde:

- $\Delta^{\mathrm{IONO}}$ representa o efeito causado pela ionosfera ao longo da trajetória do sinal;

- $\Delta_{\mathrm{V}}^{\mathrm{IONO}}$ representa o efeito causado pela ionosfera na direção vertical;

- "E" representa o ângulo de elevação do satélite em relação à antena receptora.

Ao substituir a equação (4.26) na (4.25), tem-se:

$$
\mathrm{R}-\lambda_{\mathrm{L} 1} \cdot \phi_{\mathrm{L} 1}=2 \cdot\left(\frac{\Delta_{\mathrm{V}}^{\mathrm{IONO}}}{\operatorname{sen}(\mathrm{E})}\right)-\lambda_{\mathrm{L} 1} \cdot \mathrm{N}_{\mathrm{L} 1}
$$


Assim, o modelo possui duas variáveis: o atraso ionosférico vertical $\Delta_{\mathrm{V}}^{\mathrm{IONO}}$ e a ambigüidade da portadora $\mathrm{N}_{\mathrm{L} 1}$. Com uma série de observações de um mesmo satélite é possível, então, determinar-se as incógnitas através da aplicação do Método dos Mínimos Quadrados (MMQ).

\subsubsection{Modelo diário com função coseno}

Este modelo leva em consideração a rotação da Terra (e, conseqüentemente, o movimento diário aparente do sol, em relação ao local de observação) o que o torna um pouco mais refinado que o modelo da lâmina ionosférica. Neste modelo, o atraso ionosférico é dependente de um atraso ionosférico máximo, ambos relacionados a uma função coseno, de acordo com a equação (4.28):

$$
\Delta_{\mathrm{V}}^{\mathrm{IONO}}=\Delta_{\mathrm{V}, \max }^{\mathrm{IONO}} \cdot \cos \left(\mathrm{h}_{\mathrm{s}}-\mathrm{h}_{\mathrm{am}}\right)
$$

onde:

- $\Delta_{\mathrm{V}}^{\mathrm{IONO}}$ representa o atraso ionosférico vertical;

- $\Delta_{\mathrm{V}, \max }^{\mathrm{IONO}}$ representa o atraso ionosférico vertical máximo;

- $\mathrm{h}_{\mathrm{s}}$ representa à hora solar local;

- $\mathrm{h}_{\mathrm{am}}$ representa à hora solar local em que ocorre o atraso ionosférico vertical máximo.

De acordo com (KLOBUCHAR, 1987), o atraso máximo ocorre próximo às $14 \mathrm{~h}$ do horário solar local; entretanto, este valor pode variar em função da estação do ano, da latitude e das condições de atividade solar. De acordo com o (OBSERVATÓRIO NACIONAL, 1998), a passagem meridiana do Sol em Greenwich ocorre próximo às $12 \mathrm{~h}$ do sistema universal de tempo. Ao considerar este horário como padrão, pode-se calcular a hora solar local de acordo com a equação (4.29).

$$
\mathrm{h}_{\mathrm{s}, \mathrm{UT}}=\frac{\lambda_{\mathrm{g}}}{15}+\mathrm{t}_{\mathrm{UT}}
$$

onde: 
- $h_{\mathrm{s}, U \mathrm{ut}}$ representa à hora solar local;

- $\lambda_{\mathrm{g}}$ representa à longitude do local de observação;

- $t_{\mathrm{UT}}$ representa à época da observação no sistema universal de tempo.

Ao adotar a hora de máximo atraso adotar (14h), a equação (4.28) fica:

$$
\Delta_{\mathrm{V}}^{\mathrm{IONO}}=\Delta_{\mathrm{V}, \max }^{\mathrm{IONO}} \cdot \cos \left(\mathrm{h}_{\mathrm{s}, \mathrm{UT}}-14\right)
$$

Substituindo a equação (4.30) na (4.27), tem-se:

$$
\mathrm{R}-\lambda_{\mathrm{L} 1} \cdot \phi_{\mathrm{L} 1}=2 \cdot\left[\frac{\Delta_{\mathrm{v}, \max }^{\mathrm{IONO}} \cdot \cos \left(\mathrm{h}_{\mathrm{s}, \mathrm{UT}}-14\right)}{\operatorname{sen}(\mathrm{E})}\right]-\lambda_{\mathrm{L} 1} \cdot \mathrm{N}_{\mathrm{L} 1}
$$

Assim, através da equação (4.31), pode-se obter $\left(\Delta_{\mathrm{v}, \max }^{\mathrm{IONO}}\right)$ e a ambigüidade da portadora através do MMQ.

\subsubsection{Modelo do ponto ionosférico}

Este modelo possui o mesmo princípio do modelo da lâmina ionosférica, porém, utiliza o ângulo de elevação do satélite em relação ao ponto ionosférico.

Como a camada $F_{2}$ (camada da ionosfera com maior densidade de elétrons livres) situa-se, aproximadamente, em altitudes entre 350 e $450 \mathrm{~km}$, utiliza-se, geralmente, como altitude média para o ponto ionosférico $\left(\mathrm{h}_{\mathrm{m}}\right)$, o valor de $350 \mathrm{~km}$. O modelo é expresso pela equação (4.32).

$$
\Delta^{\mathrm{IONO}}=\frac{\Delta_{\mathrm{V}}^{\mathrm{IONO}}}{\operatorname{sen}\left(\mathrm{E}^{\prime}\right)}
$$

onde:

- $\Delta^{\mathrm{IONO}}$ representa o efeito causado pela ionosfera ao longo da trajetória do sinal;

- $\Delta_{\mathrm{V}}^{\mathrm{IONO}}$ representa o efeito causado pela ionosfera na direção vertical;

- E' representa o ângulo de elevação do satélite em relação ao ponto ionosférico.

A grandeza E' pode ser calculada de acordo com a equação (4.33). 


$$
\operatorname{sen}\left(E^{\prime}\right)=\frac{R_{t}}{R_{t}+h_{m}} \cdot \operatorname{sen}(E)
$$

onde:

- E' representa o ângulo de elevação do satélite em relação ao ponto ionosférico;

- E representa o ângulo de elevação do satélite em relação à antena receptora;

- $\mathrm{R}_{\mathrm{t}}$ representa o raio da Terra para o ponto de observação;

- $h_{m}$ representa à altitude média da camada ionosférica.

A grandeza $R_{t}$ pode ser calculada segundo a equação (4.34):

$$
R_{t}=\sqrt{X_{r, 0}^{2}+Y_{r, 0}^{2}+Z_{r, 0}^{2}}
$$

onde:

- $\mathrm{R}_{\mathrm{t}}$ representa o raio da Terra para o ponto de observação;

- $\mathrm{X}_{\mathrm{r}, 0}, \mathrm{Y}_{\mathrm{r}, 0}, \mathrm{Z}_{\mathrm{r}, 0}$ representam as coordenadas cartesianas do ponto de observação, em relação a um sistema de eixos coordenados com origem no centro de massa da Terra.

Substituindo a equação (4.32) na (4.25), tem-se:

$$
R-\lambda_{L 1} \cdot \phi_{L 1}=2 \cdot\left(\frac{\Delta_{V}^{\mathrm{IONO}}}{\operatorname{sen}\left(E^{\prime}\right)}\right)+\lambda_{\mathrm{L} 1} \cdot \mathrm{N}_{\mathrm{L} 1}
$$

\subsubsection{Modelo polinomial}

Segundo (LEICK, 2003), outros modelos mais sofisticados podem ser utilizados para minimização dos efeitos ionosféricos. Dentre eles pode-se citar o polinômio proposto por (COCO et al, 1991), conforme mostrado pela equação (4.36).

$$
\Delta^{\mathrm{IONO}}=\mathrm{C}_{1}+\mathrm{C}_{2} \cdot\left(\phi^{*}\right)+\mathrm{C}_{3} \cdot\left(\lambda^{*}\right)+\mathrm{C}_{4} \cdot\left(\phi^{*}\right)^{2}+\mathrm{C}_{5} \cdot\left(\lambda^{*}\right)^{2}+\mathrm{C}_{6} \cdot\left(\phi^{*}\right) \cdot\left(\lambda^{*}\right)
$$

onde: 
- $\Delta^{\mathrm{IONO}}$ representa o efeito causado pela ionosfera ao longo da trajetória do sinal;

- $\mathrm{C}_{1}, \mathrm{C}_{2}, \mathrm{C}_{3}, \mathrm{C}_{4}, \mathrm{C}_{5}$ e $\mathrm{C}_{6}$ representam os coeficientes do polinômio a serem determinados;

- $\phi^{*}$ e $\lambda^{*}$ correspondem, respectivamente, à latitude e longitude do ponto ionosférico.

A latitude e a longitude do ponto ionosférico podem ser calculadas segundo as equações (6.14) e (6.15), reproduzidas em (4.37) e (4.38), respectivamente.

$$
\begin{gathered}
\phi^{*}=\phi_{g}+\psi \cdot \cos \left(A_{z}\right) \\
\lambda^{*}=\lambda_{g}+\left(\frac{\phi_{g} \cdot \operatorname{sen}\left(A_{z}\right)}{\cos \left(\phi^{*}\right)}\right)
\end{gathered}
$$

Substituindo a equação (4.36) na (4.25), tem-se:

$$
R-\lambda_{\mathrm{L} 1} \cdot \phi_{\mathrm{L} 1}=2 \cdot\left[\mathrm{C}_{1}+\mathrm{C}_{2} \cdot\left(\phi^{*}\right)+\mathrm{C}_{3} \cdot\left(\lambda^{*}\right)+\mathrm{C}_{4} \cdot\left(\phi^{*}\right)^{2}+\mathrm{C}_{5} \cdot\left(\lambda^{*}\right)^{2}+\mathrm{C}_{6} \cdot\left(\phi^{*}\right) \cdot\left(\lambda^{*}\right)\right]-\lambda_{\mathrm{L} 1} \cdot \mathrm{N}_{\mathrm{L} 1}
$$

Através de ajustamento de observações é possível estimar os coeficientes $\left(C_{1} \ldots \ldots C_{6}\right)$ bem como a ambigüidade $\mathrm{N}_{\mathrm{L} 1}$, o que possibilita minimizar os efeitos ionosféricos nas observações GPS.

\subsection{Modelo ionosférico baseado no código C/A e no código $P$}

$\mathrm{Na}$ combinação dos modelos, tanto o erro devido à refração troposférica quanto o erro devido ao não sincronismo do relógio do satélite e do receptor não são considerados, pois os mesmos são eliminados no processo de diferenciação entre as medições do código C/A e o código P (CAMARGO, 1999).

As equações simplificadas para as pseudodistâncias, em ambas as freqüências portadoras ( $f_{1}$ e $\left.f_{2}\right)$, são dadas pelas equações (4.38) e (4.39).

$$
\begin{aligned}
& R_{1 r}^{s}=\rho_{r}^{s}+\Delta_{1 r}^{\mathrm{ONN} S}+S_{P 1}^{s}+r_{P 1} \\
& R_{2 r}^{s}=\rho_{r}^{s}+\Delta_{2 r}^{10 N O^{S}}+S_{P 2}^{s}+r_{P 2}
\end{aligned}
$$

onde:

- $R_{\mathrm{ir}}^{\mathrm{s}}$ e $\mathrm{R}_{2 \mathrm{r}}^{\mathrm{s}}$ representam as observáveis pseudodistâncias nas freqüências portadoras $f_{1}$ e $f_{2}$, respectivamente, em relação a um determinado satélite e à antena receptora, em metros; 
- $\rho_{\mathrm{r}}^{\mathrm{s}}$ representa a distância geométrica entre um determinado satélite e à antena receptora, em metros;

- $\Delta_{1 \mathrm{r}}^{\mathrm{IONO}} \mathrm{S}^{\mathrm{S}}$ e $\Delta_{2 \mathrm{r}}^{\mathrm{ION \textrm {N } ^ { \mathrm { S } }}}$ representam os atrasos ionosféricos das observáveis pseudodistâncias, nas freqüências portadoras $f_{1}$ e $f_{2}$, respectivamente, em relação a um determinado satélite e à antena receptora, em metros;

- $S_{\mathrm{P} 1}^{\mathrm{s}}$ e $S_{\mathrm{P} 2}^{\mathrm{s}}$ representam os erros sistemáticos nas freqüências portadoras $f_{1}$ e $f_{2}$, respectivamente, devido ao satélite;

- $r_{P 1}$ e $r_{P 2}$ representam os erros sistemáticos nas freqüências portadoras $f_{1}$ e $f_{2}$, respectivamente, devido ao receptor.

Segundo (HOFMANN-WELLENHOF, 2001), o atraso ionosférico $\Delta_{\mathrm{ir}}^{\mathrm{ONO} \mathrm{s}}(\mathrm{i}=1,2)$ é proporcional ao TEC ao longo do caminho do sinal e inversamente proporcional ao quadrado da freqüência $\mathrm{f}_{\mathrm{i}}$, de acordo com a equação 4.40 .

$$
\Delta_{\text {ir }}^{\text {IONOS }}=\frac{40,3 \cdot \text { TEC }}{f_{i}^{2}}
$$

onde:

- "TEC" corresponde ao total de elétrons livres na camada ionosférica.

Fazendo uma diferenciação entre as equações (4.39) e a (4.38), tem-se:

$$
\left(R_{2 r}^{s}-R_{1 r}^{s}\right)=\left(\Delta_{2 r}^{\mathrm{ONOS}}-\Delta_{1 r}^{\mathrm{ONO} S}\right)+\left(S_{\mathrm{P} 2}^{\mathrm{s}}-\mathrm{S}_{\mathrm{P} 1}^{\mathrm{s}}\right)+\left(\mathrm{r}_{\mathrm{P} 2}-\mathrm{r}_{\mathrm{P} 1}\right)
$$

No entanto, tem-se que:

$$
\begin{gathered}
\left(\Delta_{2 \mathrm{r}}^{\mathrm{ONO}}-\Delta_{1 \mathrm{r}}^{\mathrm{ONO} \mathrm{S}^{\mathrm{S}}}\right)=40,3 \cdot \mathrm{TEC} \cdot \frac{\left(\mathrm{f}_{1}^{2}-\mathrm{f}_{2}^{2}\right)}{\mathrm{f}_{1}^{2} \cdot \mathrm{f}_{2}^{2}} \\
\left(\Delta_{2 \mathrm{r}}^{\mathrm{IONO} S}-\Delta_{1 \mathrm{r}}^{\mathrm{IONN} S}\right)=\Delta_{1 \mathrm{r}}^{\mathrm{IONN} S} \cdot\left(\frac{\mathrm{f}_{1}^{2}-\mathrm{f}_{2}^{2}}{\mathrm{f}_{2}^{2}}\right)
\end{gathered}
$$

Substituindo a (4.42) na (4.41), tem-se a equação (4.43), que é básica para o cálculo da correção ionosférica baseada em medição da pseudodistância com receptores de dupla freqüência. 


$$
\left(R_{2 r}^{s}-R_{1 r}^{s}\right)=\left(\frac{f_{1}^{2}-f_{2}^{2}}{f_{2}^{2}}\right) \cdot\left(\Delta_{1 r}^{\text {IONOS }}\right)+\left(S_{P 2}^{s}-S_{P 1}^{s}\right)+\left(r_{P 2}-r_{P 1}\right)
$$

O termo $\Delta_{1 \text { ros }}^{\mathrm{oNo}}$ da equação (4.43) pode ser obtido por qualquer um dos modelos apresentados no subitem 4.4 .

\subsection{Modelo ionosférico baseado nas portadoras $L_{1}$ e $L_{2}$}

As equações simplificadas para as fases, em ambas as freqüências portadoras $\left(f_{1}\right.$ e $\left.f_{2}\right)$, são expressas pelas equações (4.44) e (4.45).

$$
\begin{aligned}
& \lambda_{\mathrm{L} 1} \cdot \phi_{\mathrm{L} 1 \mathrm{r}}^{\mathrm{S}}=\rho_{\mathrm{r}}^{\mathrm{S}}-\Delta_{\phi 1 \mathrm{r}}^{\mathrm{ION} \mathrm{N}^{\mathrm{S}}}+\lambda_{\mathrm{L} 1} \cdot \mathrm{N}_{\mathrm{L} 1 \mathrm{r}}^{\mathrm{S}}+\mathrm{S}_{\phi 1}^{\mathrm{s}}+r_{\phi 1} \\
& \lambda_{\mathrm{L} 2} \cdot \phi_{\mathrm{L} 2 \mathrm{r}}^{\mathrm{s}}=\rho_{\mathrm{r}}^{\mathrm{s}}-\Delta_{\phi 2 \mathrm{r}}^{\mathrm{IONN}}+\lambda_{\mathrm{L} 2} \cdot \mathrm{N}_{\mathrm{L} 2 \mathrm{~s}}^{\mathrm{s}}+\mathrm{S}_{\phi 2}^{\mathrm{s}}+r_{\phi 2}
\end{aligned}
$$

onde:

- $\lambda_{\mathrm{L} 1}$ e $\lambda_{\mathrm{L} 2}$ representam os comprimentos de onda das portadoras $L_{1}$ e $L_{2}$, em metros, respectivamente;

- $N_{L 1}$ e $N_{L 2}$ representam as ambigüidades das portadora $L_{1}$ e $L_{2}$, respectivamente;

- $\phi_{1 r}^{s}$ e $\phi_{2 r}^{s}$ representam as fases das portadoras $L_{1}$ e $L_{2}$, respectivamente, em relação a um determinado satélite e a antena receptora, em ciclos;

- $\rho_{r}^{s}$ representa a distância geométrica entre um determinado satélite e a antena receptora, em metros;

- $\Delta_{\phi 1 \mathrm{r}}^{\mathrm{loN} \mathrm{O}^{\mathrm{S}}}$ e $\Delta_{\phi 2 \mathrm{r}}^{\mathrm{loN} \mathrm{S}^{\mathrm{S}}}$ representam os efeitos ionosféricos nas portadoras $L_{1}$ e $L_{2}$, respectivamente, em relação a um determinado satélite e a antena receptora, em metros;

- $S_{\phi 1}^{s}$ e $S_{\phi 2}^{s}$ representam os erros sistemáticos nas fases das portadoras $L_{1}$ e $L_{2}$, respectivamente, devido ao satélite;

- $r_{\phi 1}$ e $r_{\phi 2}$ representam os erros sistemáticos nas fases das portadoras $L_{1}$ e $L_{2}$, respectivamente, devido ao receptor; 
Ao fazer a diferenciação entre as equações (4.45) e a (4.44) tem-se a (4.46), que representa a equação básica para cálculo da correção ionosférica.

$$
\left(\lambda_{\mathrm{L} 1} \cdot \phi_{\mathrm{L} 1 \mathrm{r}}^{\mathrm{s}}-\lambda_{\mathrm{L} 2} \cdot \phi_{\mathrm{L} 2 \mathrm{r}}^{\mathrm{s}}\right)=\left(\frac{\mathrm{f}_{1}^{2}-\mathrm{f}_{2}^{2}}{\mathrm{f}_{2}^{2}}\right) \cdot \Delta_{\phi 1 \mathrm{Ir}}^{\mathrm{OON} \mathrm{S}}-\left[\left(\lambda_{\mathrm{L} 2} \cdot \mathrm{N}_{2 \mathrm{r}}^{\mathrm{s}}-\lambda_{\mathrm{L} 1} \cdot \mathrm{N}_{1 \mathrm{r}}^{\mathrm{s}}\right)+\left(\mathrm{S}_{\phi 2}^{\mathrm{s}}-\mathrm{S}_{\phi 1}^{\mathrm{s}}\right)+\left(\mathrm{r}_{\phi 2}-\mathrm{r}_{\phi 1}\right)\right]
$$

O termo $\Delta_{\phi 1 \mathrm{r}}^{\mathrm{oN} \mathrm{S}^{\mathrm{S}}}$ da equação (4.46) pode ser obtido por qualquer um dos modelos apresentados no subitem 4.4 .

A equação (4.46) apresenta um sério problema no processo de ajustamento de observações, haja vista que as fases das portadoras $L_{1}$ e $L_{2}$ sempre estão sujeitas a perdas de ciclos, a aumentar, conseqüentemente, o número de incógnitas sempre que este fato ocorrer.

No próximo capítulo, será discutido o processo de ajustamento seqüencial de observações aplicado na modelagem ionosférica. 


\section{Ajustamento seqüencial aplicado à minimização dos efeitos ionosféricos}

Neste capítulo será discutido o princípio do ajustamento seqüencial de observações, aplicado aos modelos ionosféricos regionais, enfatizando:

- as etapas a serem desenvolvidas no processo de ajustamento seqüencial;

- o modelo polinomial aplicado à modelagem ionosférica;

- a estruturação das principais matrizes a serem utilizadas no processo de ajustamento seqüencial de observações.

\subsection{Introdução}

As principais formas de minimização dos efeitos ionosféricos, no processo de posicionamento de pontos com o sistema GPS, foram discutidas no Capítulo 4. Para os usuários de equipamentos GPS, que trabalham com programas comerciais e que só captam informações do código C/A, o modelo ionosférico mais eficiente a ser utilizado é o de Klobuchar. Para os usuários que possuem equipamentos de uma freqüência (portadora $L_{1} e$ código $\mathrm{C} / \mathrm{A}$ ), além do modelo de Klobuchar, outras formas eficientes são possíveis para minimizar o efeito ionosférico como, por exemplo, realizar uma combinação entre as observáveis. Para os usuários de equipamentos de dupla freqüência (portadoras $L_{1}$ e $L_{2}$, códigos C/A e P), a forma mais eficiente de minimizar o efeito ionosférico é através da solução iono free.

Quando se pensa em modelos regionais, existe a possibilidade de melhorar a eficiência na minimização dos efeitos ionosféricos através de determinação de parâmetros matemáticos, os quais podem ser utilizados para beneficiar os usuários de equipamentos de simples freqüência e/ou código C/A. A determinação desses parâmetros é baseada nas observáveis de equipamentos GPS de dupla freqüência, que compõem uma rede de monitoramento contínuo. 
Por ser o atraso e/ou avanço ionosférico uma função dos sinais transmitidos pelos satélites GPS, através de um conjunto de estações de monitoramento contínuo de dupla freqüência é possível estabelecer funções do tipo:

$$
\begin{gathered}
\left(R_{2 r}^{S}-R_{1 r}^{S}\right)=\left(\frac{f_{1}^{2}-f_{2}^{2}}{f_{2}^{2}}\right) \cdot\left(\Delta_{1 r}^{\mathrm{ONNO}}\right)+\left(S_{P_{2}}^{S}-S_{P_{1}}^{S}\right)+\left(r_{P_{2}}-r_{P_{1}}\right) \\
\left(\lambda_{L_{1}} \cdot \phi_{L_{1} r}^{S}-\lambda_{L_{2}} \cdot \phi_{L_{2} r}^{S}\right)=\left(\frac{f_{1}^{2}-f_{2}^{2}}{f_{2}^{2}}\right) \cdot \Delta_{\phi_{1} r}^{\mathrm{IONO}}-\left[\left(\lambda_{L_{2}} \cdot N_{2 r}^{S}-\lambda_{L_{1}} \cdot N_{1 r}^{S}\right)+\left(S_{\phi_{2}}^{S}-S_{\phi_{1}}^{S}\right)+\left(r_{\phi_{2}}-r_{\phi_{1}}\right)\right]
\end{gathered}
$$

Os efeitos ionosféricos ( $\Delta_{1 \mathrm{r}}^{\mathrm{ONNS}}$ e $\Delta_{\phi, \mathrm{r}}^{\mathrm{IONS}}$ ), ilustrados nas equações (5.1) e (5.2), podem ser modelados através de várias funções matemáticas, descritas no capítulo 4. Ao analisar as potencialidades de cada função, optou-se em utilizar o modelo polinomial, baseado nas medições da pseudodistância segundo a equação (5.1). Para tanto, na estimativa dos parâmetros do modelo polinomial, utilizou-se o método de ajustamento de observações seqüencial baseado em (ANTUNES, 1996). Este processo é uma derivação do M.M.Q, com uma grande vantagem: o ajustamento não ocorre de forma global e sim época a época e possibilita eliminar a influência de observações ruidosas na estimativa dos parâmetros.

Segundo (ANTUNES, 1996), o conceito da solução seqüencial baseia-se na divisão do conjunto das observações em grupos, com os quais executa-se um tratamento matemático seqüencial de ajustamento, onde nos grupos já ajustados (dos quais resulta uma estimativa da solução) acrescenta-se um novo grupo de observações. Este acréscimo origina uma correção à estimativa já existente, mantendo-se a correlação entre grupos.

\subsection{Princípio do modelo seqüencial de ajustamento}

Para simplificar a dedução do modelo matemático assume-se que o conjunto de observações é formado apenas por dois grupos, conforme as equações do método paramétrico elucidadas pelas equações a seguir.

$$
\begin{gathered}
\left(A_{1}^{\top} \cdot P_{1} \cdot A_{1}\right) \cdot X+\left(A_{1}^{\top} \cdot P_{1} \cdot L_{1}\right)=0 \\
V_{1}=A_{1} \cdot X+L_{1} \\
\left(A_{2}^{\top} \cdot P_{2} \cdot A_{2}\right) \cdot X+\left(A_{2}^{\top} \cdot P_{2} \cdot L_{2}\right)=0 \\
V_{2}=A_{2} \cdot X+L_{2}
\end{gathered}
$$


em que:

- $A_{1}^{\top}$ e $A_{2}^{\top}$ correspondem às matrizes transpostas dos coeficientes do sistema de equações normais, para o primeiro e segundo grupo de observações, respectivamente;

- $A_{1}$ e $A_{2}$ correspondem às matrizes dos coeficientes do sistema de equações normais, para o primeiro e segundo grupo de observações, respectivamente;

- $\mathrm{P}_{1}$ e $\mathrm{P}_{2}$ correspondem às matrizes pesos do primeiro e do segundo grupo de observações, respectivamente;

- $L_{1}$ e $L_{2}$ correspondem às matrizes de observações do primeiro e do segundo grupo de observações, respectivamente;

- $\mathrm{V}_{1}$ e $\mathrm{V}_{2}$ correspondem aos vetores dos resíduos do primeiro e do segundo grupo de observações, respectivamente;

- "X" corresponde à matriz dos parâmetros ajustados.

A função de Lagrange a ser minimizada assume a seguinte estrutura:

$$
\phi=\mathrm{V}_{1}^{\top} \cdot \mathrm{P}_{1} \cdot \mathrm{V}_{1}+\mathrm{V}_{2}^{\top} \cdot \mathrm{P}_{2} \cdot \mathrm{V}_{2}-2 \cdot \mathrm{k}_{1}^{\top} \cdot\left(\mathrm{A}_{1} \cdot \mathrm{X}+\mathrm{L}_{1}-\mathrm{V}_{1}\right)-2 \cdot \mathrm{k}_{2}^{\top} \cdot\left(\mathrm{A}_{2} \cdot \mathrm{X}+\mathrm{L}_{2}-\mathrm{V}_{2}\right)=\min
$$

as quais:

- $\mathrm{k}_{1}$ e $\mathrm{k}_{2}$ correspondem aos multiplicadores de Lagrange do primeiro e do segundo grupo de observações, respectivamente.

Igualando a zero as derivadas parciais da função " $\phi$ ” em relação a $\bigvee_{1}, V_{2}, X, k_{1}$ e $k_{2}$, tem-se:

$$
\begin{gathered}
\mathrm{P}_{1} \cdot \mathrm{V}_{1}+\mathrm{k}_{1}=0 \\
\mathrm{P}_{2} \cdot \mathrm{V}_{2}+\mathrm{k}_{2}=0 \\
\mathrm{~A}_{1}^{\top} \cdot \mathrm{k}_{1}+\mathrm{A}_{2}^{\top} \cdot \mathrm{k}_{2}=0 \\
\mathrm{~A}_{1} \cdot \mathrm{X}+\mathrm{L}_{1}-\mathrm{V}_{1}=0 \\
\mathrm{~A}_{2} \cdot \mathrm{X}+\mathrm{L}_{2}-\mathrm{V}_{2}=0
\end{gathered}
$$

Isolando as variáveis $V_{1}$ e $V_{2}$ das equações (5.8) e (5.9), tem-se: 


$$
\begin{aligned}
& V_{1}=-\left(P_{1}\right)^{-1} \cdot k_{1} \\
& V_{2}=-\left(P_{2}\right)^{-1} \cdot k_{2}
\end{aligned}
$$

Substituindo a equação (5.13) na (5.11) e a (5.14) na (5.12), tem-se:

$$
\begin{aligned}
& A_{1} \cdot X+L_{1}+\left(P_{1}\right)^{-1} \cdot k_{1}=0 \\
& A_{2} \cdot X+L_{2}+\left(P_{2}\right)^{-1} \cdot k_{2}=0
\end{aligned}
$$

Isolando o valor de $k_{1}$ na equação (5.15) tem-se:

$$
k_{1}=-\left(P_{1} \cdot A_{1} \cdot X\right)-\left(P_{1} \cdot L_{1}\right)
$$

Substituindo a equação (5.17) na (5.10), tem-se:

$$
\left(A_{1}^{\top} \cdot P_{1} \cdot A_{1}\right) \cdot X+\left(A_{1}^{\top} \cdot P_{1} \cdot L_{1}\right)-A_{2}^{\top} \cdot k_{2}=0
$$

Isolando o valor de X na equação (5.18), tem-se:

$$
\begin{gathered}
X=-\left(A_{1}^{\top} \cdot P_{1} \cdot A_{1}\right)^{-1} \cdot\left(A_{1}^{\top} \cdot P_{1} \cdot L_{1}\right)+\left(A_{1}^{\top} \cdot P_{1} \cdot A_{1}\right)^{-1} \cdot\left(A_{2}^{\top} \cdot k_{2}\right) \\
X=X_{1}+\left(A_{1}^{\top} \cdot P_{1} \cdot A_{1}\right)^{-1} \cdot\left(A_{2}^{\top} \cdot k_{2}\right)
\end{gathered}
$$

Fazendo $N_{1}=\left(A_{1}^{\top} \cdot P_{1} \cdot A_{1}\right)$ tem-se:

$$
\begin{gathered}
X=\mathrm{X}_{1}+\left(\mathrm{N}_{1}\right)^{-1} \cdot\left(\mathrm{A}_{2}^{\top} \cdot \mathrm{k}_{2}\right) \\
\mathrm{X}=\mathrm{X}_{1}+\Delta \mathrm{X} \\
\Delta \mathrm{X}=\left(\mathrm{N}_{1}\right)^{-1} \cdot\left(\mathrm{A}_{2}^{\top} \cdot \mathrm{K}_{2}\right)
\end{gathered}
$$

Para estabelecer uma expressão para k2, basta substituir a equação (5.20) na (5.16).

$$
\begin{gathered}
A_{2} \cdot\left(X_{1}+\left(N_{1}\right)^{-1} \cdot\left(A_{2}^{\top} \cdot k_{2}\right)\right)+L_{2}+\left(P_{2}\right)^{-1} \cdot k_{2}=0 \\
A_{2} \cdot X_{1}+A_{2} \cdot\left(N_{1}\right)^{-1} \cdot A_{2}^{\top} \cdot k_{2}+L_{2}+\left(P_{2}\right)^{-1} \cdot k_{2}=0 \\
\left(A_{2} \cdot\left(N_{1}\right)^{-1} \cdot A_{2}^{\top}+\left(P_{2}\right)^{-1}\right) \cdot k_{2}=-A_{2} \cdot X_{1}-L_{2} \\
k_{2}=-\left(A_{2} \cdot\left(N_{1}\right)^{-1} \cdot A_{2}^{\top}+\left(P_{2}\right)^{-1}\right)^{-1} \cdot\left(A_{2} \cdot X_{1}+L_{2}\right)
\end{gathered}
$$


Finalmente, a Matriz Variância Covariância dos parâmetros ajustados pode ser obtida por:

$$
\begin{gathered}
\Sigma_{\mathrm{x}}=\Sigma_{\mathrm{x} 1}+\Delta \Sigma_{\mathrm{x}} \\
\Delta \Sigma_{\mathrm{x}}=\hat{\sigma}_{0}^{2} \cdot\left(\mathrm{N}_{1}\right)^{-1} \cdot \mathrm{A}_{2}^{\top} \cdot\left[\left(\mathrm{P}_{2}\right)^{-1}+\mathrm{A}_{2} \cdot\left(\mathrm{N}_{1}\right)^{-1} \cdot \mathrm{A}_{2}^{\top}\right]^{-1} \cdot \mathrm{A}_{2} \cdot\left(\mathrm{N}_{1}\right)^{-1} \\
\hat{\sigma}_{0}^{2}=\frac{\left(\mathrm{V}_{1}^{\top} \cdot \mathrm{P}_{1} \cdot \mathrm{V}_{1}\right)+\left(\mathrm{X}^{\top} \cdot \mathrm{A}_{2}^{\top} \cdot \mathrm{P}_{2} \cdot \mathrm{L}_{2}\right)+\left(\Delta \mathrm{X}^{\top} \cdot \mathrm{A}_{1}^{\top} \cdot \mathrm{P}_{1} \cdot \mathrm{L}_{1}\right)+\left(\mathrm{L}_{2}^{\top} \cdot \mathrm{P}_{2} \cdot \mathrm{L}_{2}\right)}{\mathrm{n}_{1}+\mathrm{n}_{2}+\mathrm{U}}
\end{gathered}
$$

onde:

- $\mathrm{n}_{1}$ corresponde ao número de observações utilizado no primeiro grupo do sistema de equações;

- $\mathrm{n}_{2}$ corresponde ao número de observações utilizado no segundo grupo do sistema de equações;

- u corresponde ao número de parâmetros a serem determinados;

- $\hat{\sigma}_{0}^{2}$ corresponde à variância de unidade de peso a posteriori;

- $\Sigma_{x}$ corresponde a Matriz Variância Covariância dos parâmetros ajustados, referente ao ajustamento seqüencial;

- $\Sigma_{x_{1}}$ corresponde a Matriz Variância Covariância dos parâmetros ajustados, referente ao primeiro grupo de observações;

- $\Delta \Sigma_{\mathrm{x}}$ corresponde ao acréscimo que deve ser somado à matriz variância covariância dos parâmetros ajustados, no processo do ajustamento seqüencial.

Para resumir todo o processo, ao considerar um conjunto de observações, a determinação da solução final do ajustamento passa pela execução de "n" etapas sucessivas, onde, para cada uma delas, é determinada uma solução atualizada. Em cada etapa, são sempre considerados dois blocos: um bloco $\mathrm{B}_{1}$, constituído por todas as observações já processadas, e um bloco $B_{2}$, formado pelas observações adicionais. As variâncias a posteriori dos dois blocos são calculadas. Para verificar a existência de observações ruidosas, é realizado um teste estatístico entre as variâncias, com um determinado nível de confiabilidade, e, se constatado o problema, estas observações são descartadas. O esquema abaixo ilustra todo o processo envolvido. 


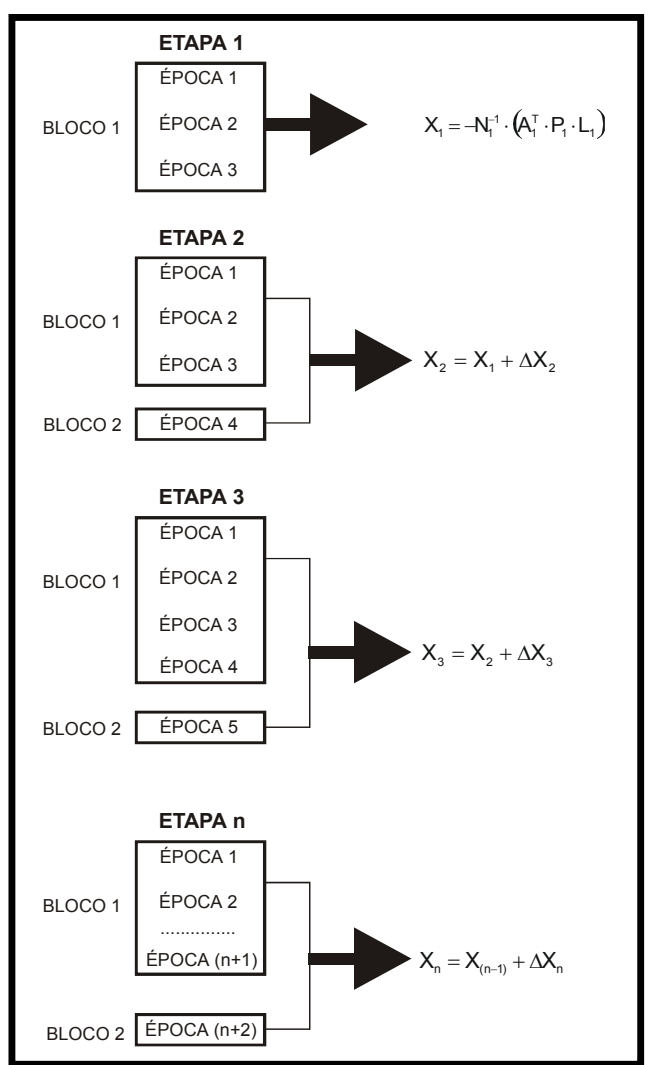

\subsection{Estruturação das matrizes do ajustamento de observações}

O modelo utilizado neste trabalho é representado pela equação abaixo:

$$
\left(R_{2 r}^{S}-R_{1 r}^{S}\right)=\left(\frac{f_{1}^{2}-f_{2}^{2}}{f_{2}^{2}}\right) \cdot\left(\Delta_{1 r}^{I O N O}\right)+\left(S_{P_{2}}^{S}-S_{P_{1}}^{S}\right)+\left(r_{P_{2}}-r_{P_{1}}\right)
$$

O efeito ionosférico foi modelado segundo um polinômio de segunda ordem, conforme ilustra a equação (5.27):

$$
\Delta_{1 \mathrm{r}}^{\mathrm{INOS}}=\mathrm{C}_{1}+\mathrm{C}_{2} \cdot\left(\phi^{*}\right)+\mathrm{C}_{3} \cdot\left(\lambda^{*}\right)+\mathrm{C}_{4} \cdot\left(\phi^{*}\right)^{2}+\mathrm{C}_{5} \cdot\left(\lambda^{*}\right)^{2}+\mathrm{C}_{6} \cdot\left(\phi^{*}\right) \cdot\left(\lambda^{*}\right)
$$

Ao substituir a equação (5.27) na (5.26), tem-se:

$$
\begin{aligned}
\left(R_{2 r}^{S}-R_{1 r}^{S}\right) & =\left(\frac{f_{1}^{2}-f_{2}^{2}}{f_{2}^{2}}\right) \cdot\left[C_{1}+C_{2} \cdot\left(\phi^{*}\right)+C_{3} \cdot\left(\lambda^{*}\right)+C_{4} \cdot\left(\phi^{*}\right)^{2}+C_{5} \cdot\left(\lambda^{*}\right)^{2}+C_{6} \cdot\left(\phi^{*}\right) \cdot\left(\lambda^{*}\right)\right]+ \\
& +\left(S_{P_{2}}^{S}-S_{P_{1}}^{S}\right)+\left(r_{P_{2}}-r_{P_{1}}\right)
\end{aligned}
$$


Ao considerar a equação 5.28 , é possível estruturar as principais matrizes a serem utilizadas no processo de ajustamento de observações: a matriz dos coeficientes "A", a matriz de observações "L" e a matriz Variância e Covariância das observações (MVC).

Para cada um dos receptores "r" e satélites "S" envolvidos no processo, para uma única época, tem-se:

$$
\begin{aligned}
& \begin{array}{lllllllllllllll}
C_{1} & C_{2} & C_{3} & C_{4} & C_{5} & C_{6} & r_{1} & r_{2} & \ldots & r_{n} & S_{1} & S_{2} & \ldots & S_{n}
\end{array}
\end{aligned}
$$

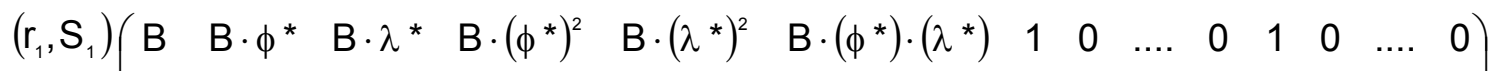

$$
\begin{aligned}
& \begin{array}{c|cccccccccccccc}
\cdots & \ldots & \ldots & \ldots & \ldots & \ldots & \ldots & 1 & 0 & \ldots & 0 & 0 & 1 & \ldots & 0
\end{array}
\end{aligned}
$$

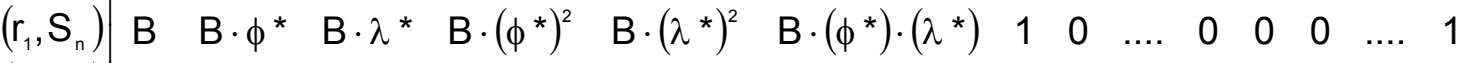

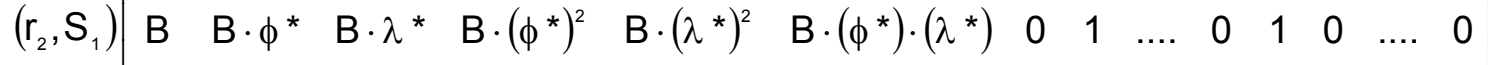

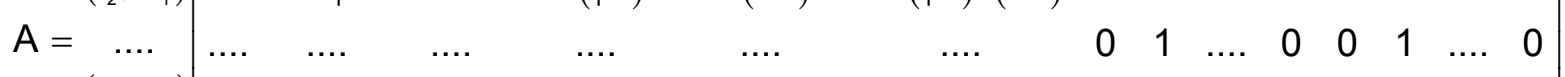

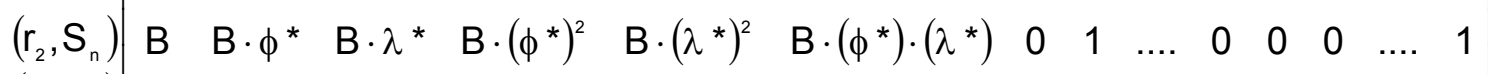

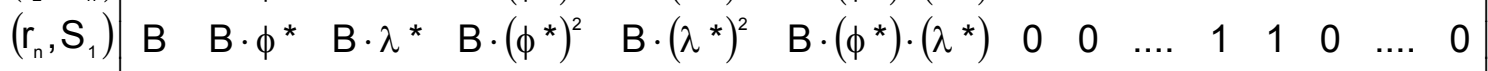

$$
\begin{aligned}
& \left.\begin{array}{c}
\left(r_{n}, S_{n}\right) \\
\cdots
\end{array} \quad \begin{array}{cccccccccccccc}
\ldots \cdot \phi^{*} & B \cdot \lambda^{*} & B \cdot\left(\phi^{*}\right)^{2} & B \cdot\left(\lambda^{*}\right)^{2} & B \cdot\left(\phi^{*}\right) \cdot\left(\lambda^{*}\right) & 0 & 0 & \ldots & 1 & 0 & 0 & \ldots & 1
\end{array}\right)
\end{aligned}
$$

A grandeza "B", presente na matriz A, corresponde a:

$$
\begin{gathered}
B=\left(\frac{f_{1}^{2}-f_{2}^{2}}{f_{2}^{2}}\right) \\
L=\left(\begin{array}{c}
\left(R_{2}^{s_{1}}-R_{1}^{s_{1}}\right)_{r_{11}} \\
\cdots \cdots \cdots \\
\left(R_{2}^{s_{n}}-R_{1}^{s_{n}}\right)_{r_{1}} \\
\left(R_{2}^{s_{1}}-R_{1}^{s_{1}}\right)_{r_{2}} \\
\cdots \cdots \cdots \\
\left(R_{2}^{s_{n}}-R_{1}^{s_{n}}\right)_{r_{2}} \\
\left(R_{2}^{s_{1}}-R_{1}^{s_{1}}\right)_{r_{n}} \\
\cdots \cdots \cdots \\
\left(R_{2}^{s_{n}}-R_{1}^{s_{n}}\right)_{r_{n}}
\end{array}\right)
\end{gathered}
$$

Considerando que a combinação linear das observações seja independente, a MVC das observações será diagonal. Segundo (CAMARGO, 1999), os desvios padrão para as pseudodistâncias (C/A e P) são $1 \mathrm{~m}$ e $1,5 \mathrm{~m}$, respectivamente. Propagando os erros para estes valores, tem-se, como elemento da diagonal da MVC das observações, o valor de $3,25 \mathrm{~m}^{2}$.

Ao analisar a matriz "A", percebeu-se que a matriz $N=(A \cdot P \cdot A)$ não possui inversa, ou seja, é uma matriz singular. 
Para solucionar este problema da singularidade da matriz "N", existem algumas possibilidades:

\section{a) Possibilidade 1 - aplicar injunções}

Neste caso, haveria a necessidade de conhecer os erros sistemáticos (devido à portadora $L_{1}$ ) de um dos satélites ou de um dos receptores da RBMC, utilizados na modelagem matemática. Estes tipos de erros não são conhecidos com grande precisão. Neste caso, o uso de injunções poderia trazer problemas na estimativa dos parâmetros do modelo polinomial.

\section{b) Possibilidade 2 - utilização de inversas generalizadas}

Também conhecidas como pseudo-inversas, ou inversa de Moore Penrose, as inversas generalizadas são utilizadas para tentar solucionar o problema da singularidade de uma determinada matriz. (MOURA, 1980) comprovou que este tipo de solução proporcionou bons resultados em aerotriangulações fotogramétricas.

(SILVA e GRIPP JÚNIOR, 1996) comprovaram, através de vários testes realizados, que a solução de inversas generalizadas em levantamentos topográficos levaram a sofisticados algoritmos sem utilidade prática, uma vez que os mesmos são frágeis quando aplicados em dados heterogêneos.

Este tipo de solução, para solucionar o problema do trabalho em questão, poderia inviabilizar o desenvolvimento do programa no processo de ajustamento dos parâmetros do modelo polinomial.

Este trabalho não tem o objetivo de aprofundar sobre o tema inversas generalizadas. Para um maior entendimento do assunto, é aconselhável a pesquisa nas seguintes referências: (BEN-ISRAEL \& GREVILLE, 1974) e (GEMAEL, 1994).

\section{c) Possibilidade 3 - simplificação do modelo matemático}

Neste caso, optou-se por este tratamento, pois não é objetivo do trabalho determinar, de forma isolada, o conjunto de erros devido à portadora $L_{1}$. Ou seja, ao invés de considerar Erro $=\left(S_{P_{2}}^{s}-S_{P_{1}}^{s}\right)+\left(r_{P_{2}}-r_{P_{1}}\right)$, agrupou-se este parâmetro da seguinte forma: Erro $=\left(\left(S_{P_{2}}^{S}-S_{P_{1}}^{S}\right)+\left(r_{P_{2}}-r_{P_{1}}\right)\right)$. Ao utilizar este procedimento, resolve-se o problema da singularidade da matriz N. Assim, a matriz A do ajustamento de observações fica: 


$$
\begin{aligned}
& \begin{array}{llllllllll}
\mathrm{C}_{1} & \mathrm{C}_{2} & \mathrm{C}_{3} & \mathrm{C}_{4} & \mathrm{C}_{5} & \mathrm{C}_{6} & \mathrm{~S}_{1} \mathrm{~S}_{2} & \ldots & \mathrm{S}_{\mathrm{n}}
\end{array}
\end{aligned}
$$

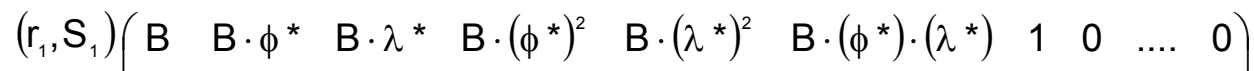

$$
\begin{aligned}
& \begin{array}{lllllllllll}
\ldots . . & \ldots & \ldots & \ldots & \ldots & \ldots & \ldots & 0 & 1 & \ldots & 0
\end{array}
\end{aligned}
$$

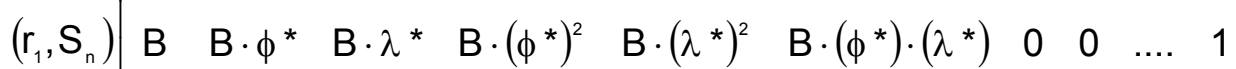

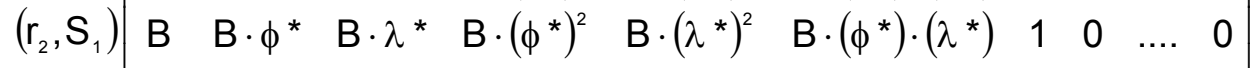

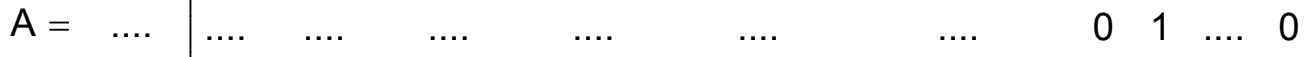

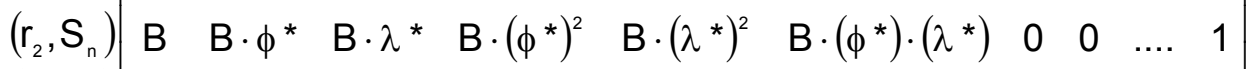

$$
\begin{aligned}
& \left(r_{n}, S_{1}\right) \quad B \quad B \cdot \phi^{*} B \cdot \lambda^{*} B \cdot\left(\phi^{*}\right)^{2} \quad B \cdot\left(\lambda^{*}\right)^{2} \quad B \cdot\left(\phi^{*}\right) \cdot\left(\lambda^{*}\right) \quad 1 \quad 0 \quad \ldots .0
\end{aligned}
$$

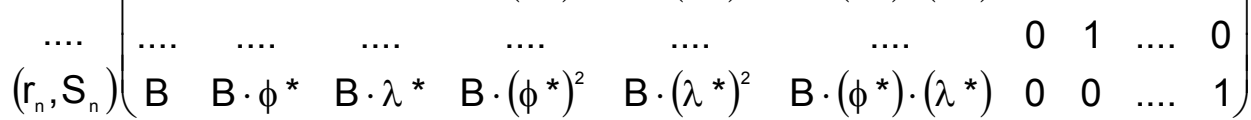

No próximo capítulo será discutido o método que foi utilizado neste trabalho. 


\section{Materiais e Métodos}

Neste capítulo será detalhado o procedimento metodológico utilizado durante o desenvolvimento deste trabalho de pesquisa, enfatizando:

- a delimitação da área de estudo, através da definição das estações da RBMC utilizadas;

- o detalhamento do programa MODEIONO, desenvolvido exclusivamente para modelagem ionosférica;

- os programas que serviram de apoio para concretização dos objetivos desta pesquisa .

\subsection{Introdução}

Os capítulos anteriores mostraram que os sinais transmitidos pelos satélites do sistema GPS, ao se propagarem pela atmosfera, sofrem grande influência da ionosfera, acarretando um avanço na propagação da fase da portadora e um atraso na propagação do código. Conseqüentemente, esses efeitos influenciam de forma significativa na exatidão do posicionamento de pontos com esse sistema.

Segundo (HOFMANN-WELLENHOF, 2001), a técnica mais eficiente para correção do efeito da refração ionosférica é baseada em medições da pseudodistância ou da fase da portadora, obtidas por receptores de dupla freqüência. (CAMARGO, 1999) utilizou essa técnica e comprovou que, na estimativa dos coeficientes do modelo estudado, o resultado do ajustamento com pseudodistância foi o que apresentou melhor precisão para os parâmetros estimados. Essa melhora na precisão se deve: a portadora $L_{2}$, por ser um sinal mais fraco do que a portadora $L_{1}$, está mais sujeita a perdas de ciclos. Este fato proporciona uma redução no número de observações utilizadas no processo de ajustamento, acarretando a obtenção da precisão dos parâmetros estimados com qualidade inferior da obtida com a pseudodistância. 
Sendo assim, optou-se em estimar os parâmetros do modelo polinomial a partir dos dados referentes à pseudodistância, advinda dos códigos $\mathrm{P}_{2}$ e $\mathrm{C} / \mathrm{A}$. Toda a teoria matemática utilizada neste processo foi exposta nos capítulos 4 e 5 . Logo, o modelo utilizado é expresso por:

$\left(R_{2 r}^{S}-R_{1 r}^{S}\right)=\left(\frac{f_{1}^{2}-f_{2}^{2}}{f_{2}^{2}}\right) \cdot\left[C_{1}+C_{2} \cdot\left(\phi^{*}\right)+C_{3} \cdot\left(\lambda^{*}\right)+C_{4} \cdot\left(\phi^{*}\right)^{2}+C_{5} \cdot\left(\lambda^{*}\right)^{2}+C_{6} \cdot\left(\phi^{*}\right) \cdot\left(\lambda^{*}\right)\right]+(E r r o)^{S}$

De acordo com a equação (6.1), verifica-se que o conjunto de erros $\left(S_{P_{2}}^{s}-S_{P_{1}}^{s}\right)$ e $\left(r_{P_{2}}-r_{P_{1}}\right)$ não foram separados na modelagem matemática. Optou-se por este processo devido ao exposto na seção 5.3:

As informações utilizadas na estimativa dos parâmetros do modelo ionosférico foram advindas das estações da RBMC, referentes ao ano de 2000/2001, disponibilizadas para toda comunidade pelo IBGE. A Figura 6.1 ilustra a disposição destas estações.

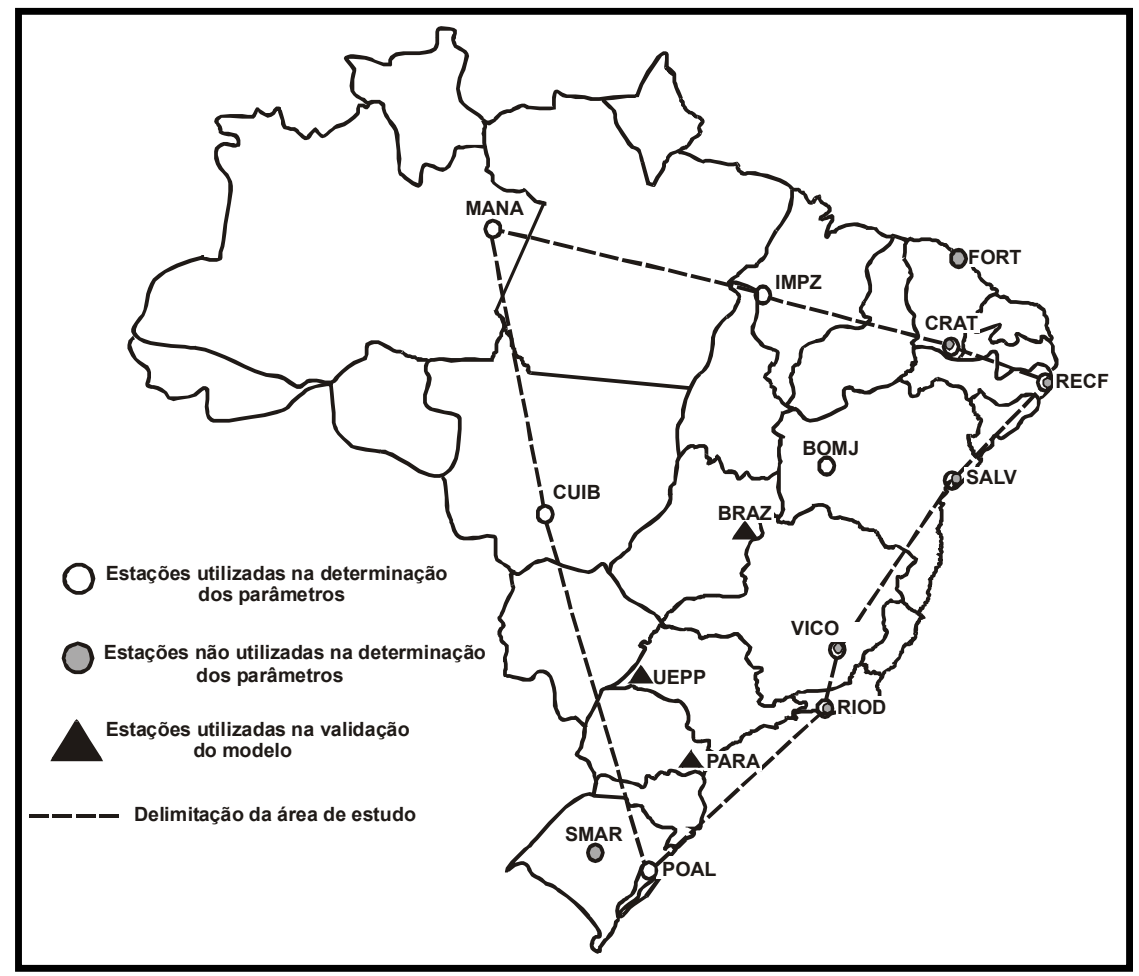

Figura 6.1 - Disposição das estações da RBMC: Adaptado de

http://www.ibge.gov.br/home/geografia/geodesico/rbmc.shtm e acessado em $(10 / 04 / 2003)$.

Optou-se por trabalhar com os dados referentes ao ano de 2001 pelo fato da ocorrência de uma intensa atividade solar neste período.

As estações de Fortaleza e de Santa Maria não participaram do processo de determinação dos parâmetros do modelo polinomial. A estação de Fortaleza, por algum 
motivo, teve muitas perdas de informações referentes à portadora $L_{2}$ e ao código $P_{2}$, o que poderia comprometer o processo de ajustamento de observações. A estação de Santa Maria também não foi utilizada, pois entrou em operação somente no final do ano de 2001.

\subsection{Procedimentos utilizados na estimativa dos coeficientes do modelo}

A estimativa dos parâmetros do modelo polinomial se deu através de um ajustamento seqüencial de observações, de acordo com a teoria exposta no Capítulo 5. Para verificar o comportamento temporal dos parâmetros, optou-se pelos seguintes procedimentos:

a) Determinação diária baseada em informações das estações da RBMC, referentes a alguns dias das quatro estações do ano;

b) Determinação em intervalos horários, durante o período de 24 horas;

Para a definição dos dias utilizados, realizou-se um estudo dos dados das estações da RBMC, de tal forma que fossem aproveitadas somente as estações que tivessem informações completas durante o período de 24 horas. As Tabelas $6.1,6.2,6.3$ e 6.4 ilustram os dias utilizados na estimativa dos parâmetros.

Tabela 6.1 - Dias utilizados na estimativa dos parâmetros do modelo polinomial no período do verão.

\begin{tabular}{|c|c|c|c|c|c|c|c|c|c|c|c|c|c|}
\hline & \multicolumn{13}{|c|}{ Dias do Ano (Verão - 355 a 78) } \\
\hline & 5 & 6 & 7 & 13 & 14 & 16 & 23 & 24 & 25 & 54 & 56 & 69 & 72 \\
\hline \multicolumn{14}{|l|}{ BRAZ } \\
\hline CUIB & $X$ & $\mathbf{X}$ & $X$ & $X$ & $X$ & $\mathbf{X}$ & $\mathbf{X}$ & $\mathbf{X}$ & $X$ & $\mathbf{X}$ & $\mathbf{X}$ & $X$ & $\mathbf{X}$ \\
\hline \multicolumn{14}{|l|}{ PARA $^{*}$} \\
\hline CRATO & $\mathbf{X}$ & $\mathbf{X}$ & $\mathbf{X}$ & $\mathbf{X}$ & $\mathbf{X}$ & $\mathbf{X}$ & $\mathbf{X}$ & $\mathbf{X}$ & $\mathbf{X}$ & $\mathbf{X}$ & $\mathbf{X}$ & $\mathbf{X}$ & $\mathbf{X}$ \\
\hline VICO & $\mathbf{X}$ & $\mathbf{X}$ & $\mathbf{X}$ & $\mathbf{X}$ & $\mathbf{X}$ & $\mathbf{X}$ & $\mathbf{X}$ & $\mathbf{X}$ & $\mathbf{X}$ & $\mathbf{X}$ & $\mathbf{X}$ & $\mathbf{X}$ & $\mathbf{X}$ \\
\hline IMPZ & $\mathbf{x}$ & $\mathbf{X}$ & $\mathbf{X}$ & $\mathbf{X}$ & $\mathbf{X}$ & $\mathbf{X}$ & $\mathbf{X}$ & $\mathbf{X}$ & $\mathbf{X}$ & $\mathbf{X}$ & $\mathbf{X}$ & $\mathbf{X}$ & $\mathbf{X}$ \\
\hline \multicolumn{14}{|l|}{ UEPP * } \\
\hline POAL & $\mathbf{x}$ & $X$ & $X$ & $X$ & & $X$ & $X$ & $X$ & $X$ & $X$ & $X$ & $X$ & $X$ \\
\hline RECF & $x$ & $x$ & $x$ & $X$ & $X$ & $\mathbf{X}$ & $X$ & $X$ & $X$ & $X$ & $X$ & $\mathbf{X}$ & $X$ \\
\hline SALV & $x$ & $x$ & $x$ & $X$ & $X$ & $X$ & $X$ & $X$ & $X$ & $X$ & $X$ & 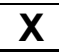 & $X$ \\
\hline
\end{tabular}

\footnotetext{
*As estações BRAZ, PARA e UEPP não participaram do processo de estimativa dos parâmetros, pois foram utilizadas na validação do modelo através dos métodos de posicionamentos Single Point e relativo.
} 
Tabela 6.2 - Dias utilizados na estimativa dos parâmetros do modelo polinomial no período do outono.

\begin{tabular}{|l|c|c|c|c|c|c|c|c|c|}
\cline { 2 - 10 } \multicolumn{1}{c|}{} & \multicolumn{10}{c|}{ Dias do Ano - (Outono - 79 a 171) } \\
\cline { 2 - 10 } \multicolumn{1}{c|}{} & 80 & 94 & 102 & 103 & 104 & 109 & 155 & 156 & 157 \\
\hline BRAZ & & & & & & & & & \\
\hline CUIB & $\mathrm{X}$ & $\mathrm{X}$ & $\mathrm{X}$ & $\mathrm{X}$ & $\mathrm{X}$ & $\mathrm{X}$ & $\mathrm{X}$ & $\mathrm{X}$ & $\mathrm{X}$ \\
\hline PARA & & & & & & & & & \\
\hline CRATO & $\mathrm{X}$ & $\mathrm{X}$ & $\mathrm{X}$ & $\mathrm{X}$ & $\mathrm{X}$ & $\mathrm{X}$ & $\mathrm{X}$ & $\mathrm{X}$ & $\mathrm{X}$ \\
\hline VICO & $\mathrm{X}$ & $\mathrm{X}$ & $\mathrm{X}$ & $\mathrm{X}$ & $\mathrm{X}$ & $\mathrm{X}$ & $\mathrm{X}$ & $\mathrm{X}$ & $\mathrm{X}$ \\
\hline IMPZ & $\mathrm{X}$ & $\mathrm{X}$ & $\mathrm{X}$ & $\mathrm{X}$ & $\mathrm{X}$ & $\mathrm{X}$ & $\mathrm{X}$ & $\mathrm{X}$ & $\mathrm{X}$ \\
\hline UEPP & & & & & & & & & \\
\hline POAL & $\mathrm{X}$ & $\mathrm{X}$ & $\mathrm{X}$ & $\mathrm{X}$ & $\mathrm{X}$ & $\mathrm{X}$ & $\mathrm{X}$ & $\mathrm{X}$ & $\mathrm{X}$ \\
\hline RIOD & $\mathrm{X}$ & $\mathrm{X}$ & $\mathrm{X}$ & $\mathrm{X}$ & $\mathrm{X}$ & $\mathrm{X}$ & $\mathrm{X}$ & $\mathrm{X}$ & $\mathrm{X}$ \\
\hline RECF & $\mathrm{X}$ & $\mathrm{X}$ & $\mathrm{X}$ & $\mathrm{X}$ & $\mathrm{X}$ & $\mathrm{X}$ & $\mathrm{X}$ & $\mathrm{X}$ & $\mathrm{X}$ \\
\hline SALV & $\mathrm{X}$ & $\mathrm{X}$ & $\mathrm{X}$ & $\mathrm{X}$ & $\mathrm{X}$ & $\mathrm{X}$ & $\mathrm{X}$ & $\mathrm{X}$ & $\mathrm{X}$ \\
\hline
\end{tabular}

Tabela 6.3 - Dias utilizados na estimativa dos parâmetros do modelo polinomial no período do inverno.

\begin{tabular}{|c|c|c|c|c|c|c|c|c|c|c|c|}
\hline & \multicolumn{11}{|c|}{ Dias do Ano - (Inverno - 172 a 264) } \\
\hline & 184 & 186 & 193 & 199 & 202 & 204 & 205 & 206 & 207 & 209 & 240 \\
\hline \multicolumn{12}{|l|}{ BRAZ } \\
\hline CUIB & $\mathbf{X}$ & $\mathbf{X}$ & $x$ & $X$ & $X$ & $X$ & $X$ & $X$ & $X$ & $X$ & $\mathbf{X}$ \\
\hline \multicolumn{12}{|l|}{ PARA } \\
\hline CRATO & $\mathbf{X}$ & $\mathbf{X}$ & $\mathbf{X}$ & $\mathbf{X}$ & $\mathbf{X}$ & $\mathbf{X}$ & $\mathbf{X}$ & $\mathbf{X}$ & $\mathbf{X}$ & $\mathbf{X}$ & $\mathbf{X}$ \\
\hline VICO & $\mathbf{X}$ & $\mathbf{X}$ & $\mathbf{X}$ & $\mathbf{X}$ & $\mathbf{X}$ & & & & $\mathbf{X}$ & $\mathbf{X}$ & $\mathbf{X}$ \\
\hline IMPZ & $\mathbf{X}$ & $\mathbf{X}$ & $\mathbf{X}$ & $\mathbf{X}$ & $\mathbf{X}$ & $\mathbf{X}$ & $\mathbf{X}$ & $\mathbf{X}$ & $\mathbf{X}$ & $\mathbf{X}$ & $\mathbf{X}$ \\
\hline MANA & $\mathbf{X}$ & $\mathbf{X}$ & $\mathbf{X}$ & $\mathbf{X}$ & $X$ & $X$ & $X$ & $X$ & $X$ & $X$ & $X$ \\
\hline \multicolumn{12}{|l|}{ UEPP } \\
\hline POAL & $\mathbf{X}$ & $\mathbf{X}$ & $\mathbf{X}$ & $X$ & $X$ & $X$ & $\mathbf{X}$ & $\mathbf{X}$ & $X$ & $x$ & $x$ \\
\hline RIOD & & & & & & & & $\bar{X}$ & $\bar{X}$ & $x$ & $X$ \\
\hline RECF & $\mathbf{X}$ & $\mathbf{X}$ & $\mathbf{X}$ & $\mathbf{X}$ & $\mathbf{X}$ & $\mathbf{X}$ & $\mathbf{X}$ & $\mathbf{X}$ & $X$ & $X$ & $x$ \\
\hline SALV & $X$ & $\mathbf{X}$ & $\mathbf{X}$ & $\mathbf{X}$ & & $X$ & $X$ & $\mathbf{X}$ & $X$ & $X$ & $X$ \\
\hline
\end{tabular}


Tabela 6.4 - Dias utilizados na estimativa dos parâmetros do modelo polinomial no período da primavera.

\begin{tabular}{|l|c|c|c|c|c|c|c|c|c|c|c|}
\cline { 2 - 11 } \multicolumn{1}{c|}{} & \multicolumn{10}{c|}{ Dias do Ano - (Primavera - 265 a 354) } \\
\cline { 2 - 7 } & 298 & 301 & 302 & 312 & 315 & 316 & 318 & 323 & 324 & 327 & 329 \\
\hline BRAZ & & & & & & & & & & & \\
\hline CUIB & $\mathrm{X}$ & $\mathrm{X}$ & $\mathrm{X}$ & $\mathrm{X}$ & & & $\mathrm{X}$ & & $\mathrm{X}$ & $\mathrm{X}$ & $\mathrm{X}$ \\
\hline PARA & & & & & & & & & & & \\
\hline CRATO & $\mathrm{X}$ & $\mathrm{X}$ & $\mathrm{X}$ & $\mathrm{X}$ & $\mathrm{X}$ & & $\mathrm{X}$ & $\mathrm{X}$ & $\mathrm{X}$ & $\mathrm{X}$ & $\mathrm{X}$ \\
\hline VICO & $\mathrm{X}$ & $\mathrm{X}$ & $\mathrm{X}$ & $\mathrm{X}$ & $\mathrm{X}$ & $\mathrm{X}$ & $\mathrm{X}$ & $\mathrm{X}$ & $\mathrm{X}$ & $\mathrm{X}$ & $\mathrm{X}$ \\
\hline IMPZ & $\mathrm{X}$ & $\mathrm{X}$ & $\mathrm{X}$ & $\mathrm{X}$ & $\mathrm{X}$ & $\mathrm{X}$ & $\mathrm{X}$ & $\mathrm{X}$ & $\mathrm{X}$ & $\mathrm{X}$ & $\mathrm{X}$ \\
\hline MANA & $\mathrm{X}$ & $\mathrm{X}$ & $\mathrm{X}$ & $\mathrm{X}$ & $\mathrm{X}$ & $\mathrm{X}$ & $\mathrm{X}$ & & $\mathrm{X}$ & $\mathrm{X}$ & $\mathrm{X}$ \\
\hline UEPP & & & & & & & & & & & \\
\hline POAL & $\mathrm{X}$ & $\mathrm{X}$ & $\mathrm{X}$ & $\mathrm{X}$ & $\mathrm{X}$ & $\mathrm{X}$ & $\mathrm{X}$ & $\mathrm{X}$ & $\mathrm{X}$ & $\mathrm{X}$ & $\mathrm{X}$ \\
\hline RIOD & $\mathrm{X}$ & $\mathrm{X}$ & $\mathrm{X}$ & $\mathrm{X}$ & $\mathrm{X}$ & $\mathrm{X}$ & $\mathrm{X}$ & $\mathrm{X}$ & $\mathrm{X}$ & $\mathrm{X}$ & $\mathrm{X}$ \\
\hline RECF & $\mathrm{X}$ & $\mathrm{X}$ & $\mathrm{X}$ & $\mathrm{X}$ & $\mathrm{X}$ & $\mathrm{X}$ & $\mathrm{X}$ & $\mathrm{X}$ & $\mathrm{X}$ & $\mathrm{X}$ & $\mathrm{X}$ \\
\hline BOMJ & $\mathrm{X}$ & $\mathrm{X}$ & $\mathrm{X}$ & $\mathrm{X}$ & $\mathrm{X}$ & $\mathrm{X}$ & $\mathrm{X}$ & $\mathrm{X}$ & $\mathrm{X}$ & $\mathrm{X}$ & $\mathrm{X}$ \\
\hline SALV & $\mathrm{X}$ & $\mathrm{X}$ & $\mathrm{X}$ & $\mathrm{X}$ & $\mathrm{X}$ & $\mathrm{X}$ & $\mathrm{X}$ & $\mathrm{X}$ & $\mathrm{X}$ & & \\
\hline
\end{tabular}

\subsection{Automação na estimativa dos parâmetros: o programa MODEIONO}

Com o objetivo de facilitar o desenvolvimento desta tese, desenvolveu-se um programa em linguagem Visual Basic-5.0, chamado MODEIONO, composto por três módulos:

- Módulo 1 - estruturação dos dados de entrada;

- Módulo 2 - ajustamento dos parâmetros do modelo polinomial;

- Módulo 3 - cálculo do atraso ionosférico e geração do arquivo RINEX com a observável de interesse corrigida.

A seguir, serão detalhados todos os módulos do programa MODEIONO.

\subsubsection{Módulo 1 do programa MODEIONO - estruturação de dados}

O primeiro módulo do programa permite estabelecer a entrada de dados, referente aos arquivos RINEX de observações das estações da RBMC, bem como o arquivo de efemérides precisas no formato SP3. O programa executa uma interpolação de Lagrange, com o objetivo de obter as coordenadas dos satélites em intervalos de tempo compatíveis com o arquivo RINEX de observação das estações da RBMC. Novamente, é importante salientar que em nenhum momento foram utilizadas as estações de Fortaleza e de Santa Maria no processo de determinação dos parâmetros do modelo polinomial. 
De posse destes dados, o programa estrutura estas informações e calcula a latitude e a longitude do ponto ionosférico, época a época, em um período de 1 hora. O programa possibilita a estruturação das informações em outros intervalos diferentes de um período de 1 hora. Nesta etapa, é gerado um arquivo estruturado, com as informações necessárias para elaborar as matrizes do ajustamento de observações. A Figura 6.2 ilustra a tela de entrada do programa.

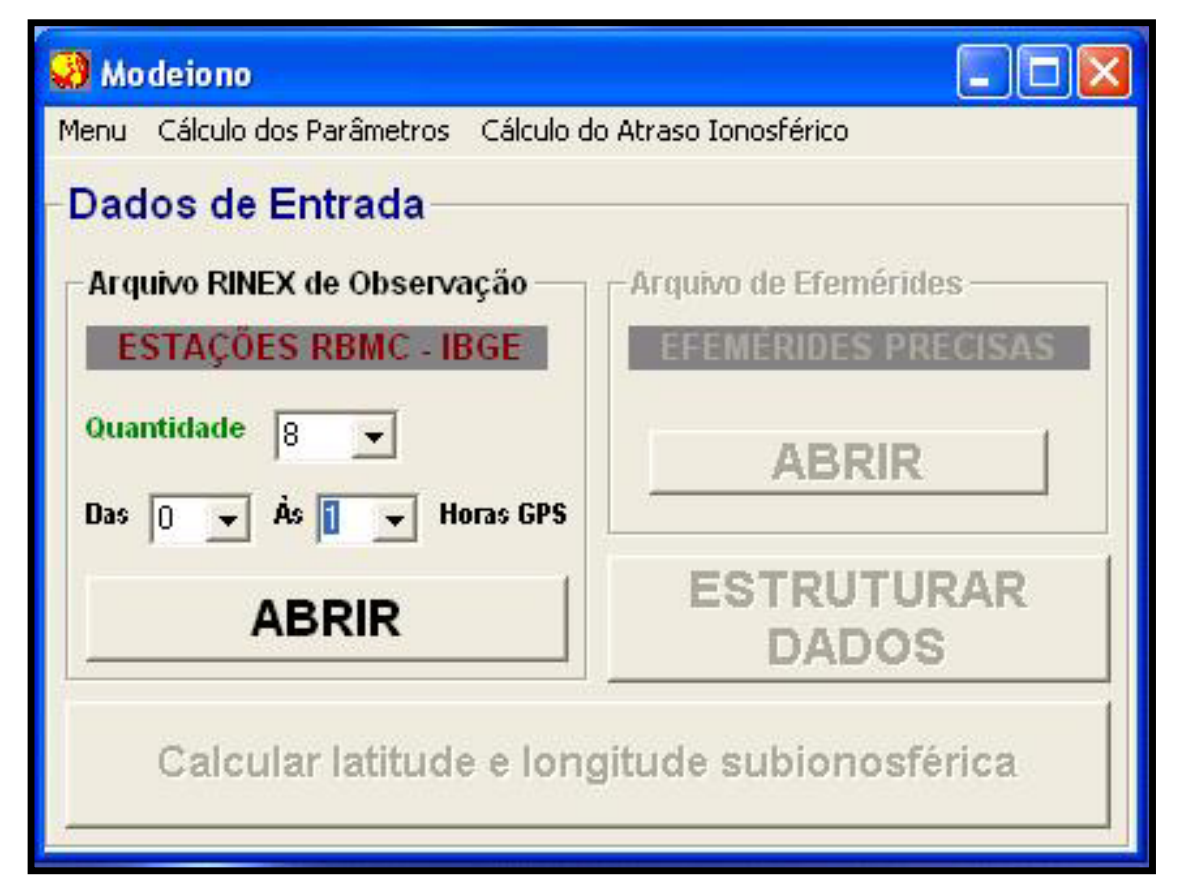

Figura 6.2 - Tela do módulo 1 do programa MODEIONO.

\subsubsection{Módulo 2 do programa MODEIONO - cálculo dos parâmetros}

De posse do arquivo estruturado de dados, o módulo 2 do programa executa o ajustamento de observações. Como foi visto no Capítulo 7, no ajustamento seqüencial, ao considerar um conjunto de observações, a determinação da solução final dos parâmetros passa pela execução de " $n$ " etapas sucessivas, onde, para cada uma delas, é determinada uma solução atualizada. A Figura 6.3 ilustra a tela do medulo 2 do programa MODEIONO. 


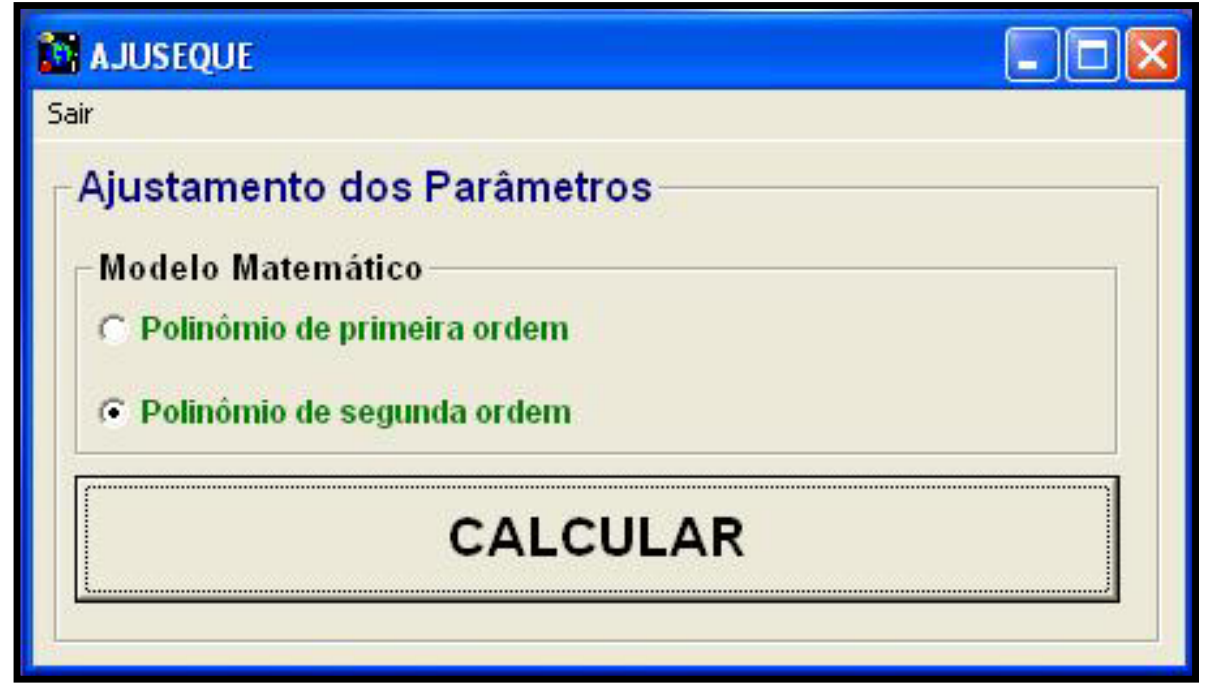

Figura 6.3 - Tela do módulo 2 do programa MODEIONO.

Na primeira etapa do ajustamento seqüencial, é determinada uma primeira solução para os parâmetros do modelo, com um número de épocas que implique redundância de informações para realização do ajustamento, conforme as equações:

$$
\begin{gathered}
\mathrm{X}_{1}=-\left(\mathrm{A}_{1}^{\top} \cdot \mathrm{P}_{1} \cdot \mathrm{A}_{1}\right)^{-1} \cdot\left(\mathrm{A}_{1}^{\top} \cdot \mathrm{P}_{1} \cdot \mathrm{L}_{1}\right) \\
\mathrm{N}_{1}=\left(\mathrm{A}_{1}^{\top} \cdot \mathrm{P}_{1} \cdot \mathrm{A}_{1}\right) \\
\Sigma_{\mathrm{x}_{1}}=\sigma_{0}^{2} \cdot\left(\mathrm{N}_{1}\right)^{-1} \\
\hat{\sigma}_{0_{1}}^{2}=\left(\frac{\mathrm{V}_{1}^{\top} \cdot \mathrm{P}_{1} \cdot \mathrm{V}_{1}}{\mathrm{n}_{1}-\mathrm{u}}\right)
\end{gathered}
$$

onde:

- $\mathrm{X}_{1}$ corresponde ao vetor solução, referente ao primeiro bloco de observações;

- $\mathrm{A}_{1}^{\top}$ corresponde à matriz transposta dos coeficientes do sistema de equações normais, referente ao primeiro bloco de observações;

- $A_{1}$ corresponde à matriz dos coeficientes do sistema de equações normais, referente ao primeiro bloco de observações;

- $\mathrm{P}_{1}$ corresponde à matriz peso, referente ao primeiro bloco de observações;

- $\mathrm{L}_{1}$ corresponde à matriz de observações, referente ao primeiro bloco; 
- $\Sigma_{x_{1}}$ corresponde à matriz variância covariância dos parâmetros ajustados, referente ao primeiro bloco de observações;

- $\mathrm{V}_{1}$ corresponde ao vetor dos resíduos, referente ao primeiro bloco de observações;

- $\mathrm{V}_{1}^{\top}$ corresponde ao vetor dos resíduos transposto, referente ao primeiro bloco de observações;

- $\mathrm{n}_{1}$ corresponde ao número de observações referente ao primeiro bloco;

- u corresponde ao número de parâmetros ajustados;

- $\sigma_{0}^{2}$ corresponde à variância a priori;

- $\hat{\sigma}_{0_{1}}^{2}$ corresponde à variância a posteriori, referente ao primeiro bloco de observações.

Uma vez realizada a primeira etapa do ajustamento, dá-se início ao ajustamento seqüencial, onde são acrescentadas observações, época a época, determinando soluções atualizadas para os parâmetros do modelo, conforme equações abaixo:

$$
\begin{gathered}
\mathrm{X}_{2}=\mathrm{X}_{1}+\Delta \mathrm{X}_{2} \\
\Delta \mathrm{X}_{2}=\left(\mathrm{N}_{1}\right)^{-1} \cdot\left(\mathrm{A}_{2}^{\top} \cdot \mathrm{k}_{2}\right) \\
\mathrm{k}_{2}=-\left(\mathrm{A}_{2} \cdot\left(\mathrm{N}_{1}\right)^{-1} \cdot \mathrm{A}_{2}^{\top}+\left(\mathrm{P}_{2}\right)^{-1}\right)^{-1} \cdot\left(\mathrm{A}_{2} \cdot \mathrm{X}_{1}+\mathrm{L}_{2}\right) \\
\Sigma_{\mathrm{X}_{2}}=\Sigma_{\mathrm{X}_{1}}+\Delta \Sigma_{\mathrm{X}} \\
\Delta \Sigma_{\mathrm{X}}=\hat{\sigma}_{0}^{2} \cdot\left(\mathrm{N}_{1}\right)^{-1} \cdot \mathrm{A}_{2}^{\top} \cdot\left[\left(\mathrm{P}_{2}\right)^{-1}+\mathrm{A}_{2} \cdot\left(\mathrm{N}_{1}\right)^{-1} \cdot \mathrm{A}_{2}^{\top}\right]^{-1} \cdot \mathrm{A}_{2} \cdot\left(\mathrm{N}_{1}\right)^{-1} \\
\hat{\sigma}_{0_{2}}^{2}=\frac{\left(\mathrm{V}_{1}^{\top} \cdot \mathrm{P}_{1} \cdot \mathrm{V}_{1}\right)+\left(\mathrm{X}^{\top} \cdot \mathrm{A}_{2}^{\top} \cdot \mathrm{P}_{2} \cdot \mathrm{L}_{2}\right)+\left(\Delta \mathrm{X}^{\top} \cdot \mathrm{A}_{1}^{\top} \cdot \mathrm{P}_{1} \cdot \mathrm{L}_{1}\right)+\left(\mathrm{L}_{2}^{\top} \cdot \mathrm{P}_{2} \cdot \mathrm{L}_{2}\right)}{\mathrm{n}_{1}+\mathrm{n}_{2}+\mathrm{U}}
\end{gathered}
$$

Ao acrescentar observações no ajustamento seqüencial, o programa realiza um teste estatístico de Qui Quadrado $\left(\chi^{2}\right)$ entre às variâncias a posteriori, referentes ao primeiro e segundo bloco de observações. Por definição, a distribuição de Qui Quadrado é:

$$
\chi^{2}=\left(\frac{\hat{\sigma}_{0_{2}}^{2}}{\hat{\sigma}_{01}^{2}}\right) \cdot f
$$


onde:

- $\hat{\sigma}_{0_{2}}^{2}$ corresponde à variância a posteriori, referente ao segundo bloco de observações.

- $\hat{\sigma}_{0_{1}}^{2}$ corresponde à variância a posteriori, referente ao primeiro bloco de observações.

- $\chi^{2}$ corresponde à distribuição de Qui Quadrado;

- "f" corresponde ao número de graus de liberdade.

A distribuição de $\left(\chi^{2}\right)$ possui duas características importantes:

a) a simetria diminui à medida que diminui o grau de liberdade;

b) ela tende para a distribuição normal à medida que o grau de liberdade aumenta.

O programa utiliza um grau de confiabilidade de $95 \%$ na realização deste teste estatístico. Assim, tem-se:

$$
\hat{\chi}_{\left(f, \frac{\alpha}{2}\right)}^{2} \leq \chi^{2} \leq \hat{\chi}_{\left(f, 1-\frac{\alpha}{2}\right)}^{2}
$$

onde:

- $\chi^{2}$ corresponde ao valor de Qui Quadrado obtido pela equação (6.12);

- $\hat{\chi}^{2}$ corresponde ao valor de Qui Quadrado teórico, com um grau de confiabilidade de $95 \%$, cujo valor é tabelado;

- $\alpha$ corresponde ao nível de significância do teste estatístico;

- "f" corresponde ao número de graus de liberdade.

Neste caso o critério de rejeição das observações que são acrescentadas no ajustamento seqüencial segue a distribuição de Qui Quadrado, segundo a equação (6.13).

Todo este processo se repete seqüencialmente, de acordo com as equações supracitadas, e pode ser melhor entendido segundo o esquema mostrado na seção 5.2 do Capítulo 5.

Após todo o processamento, o módulo 2 do programa gera um arquivo no formato ".TXT" com os parâmetros do polinômio, bem como o conjunto de erros da portadora $L_{1}$, referentes aos satélites e às antenas receptoras: $\left(\left(S_{P_{2}}^{s}-S_{P_{1}}^{s}\right)+\left(r_{P_{2}}-r_{P_{1}}\right)\right)$. 


\subsubsection{Módulo 3 do programa MODEIONO - cálculo do atraso ionosférico}

O terceiro módulo do programa possibilita a leitura do arquivo RINEX de observação, do arquivo de efemérides precisas e do arquivo solução, obtido no módulo 2. Neste etapa, no momento da leitura do arquivo de efemérides precisas, é utilizada uma interpolação de Lagrange para determinar as coordenadas dos satélites, em um intervalo compatível com o arquivo RINEX de observação.

Estruturadas todas estas etapas, calcula-se o atraso ionosférico, gerando um arquivo com um determinado padrão, com a observável de interesse corrigida do efeito ionosférico. De posse deste arquivo padrão, utiliza-se o programa CRINEX ${ }^{4}$ para gerar um novo arquivo RINEX de observação. A Figura 6.3 ilustra a tela de entrada do terceiro módulo do programa MODEIONO.

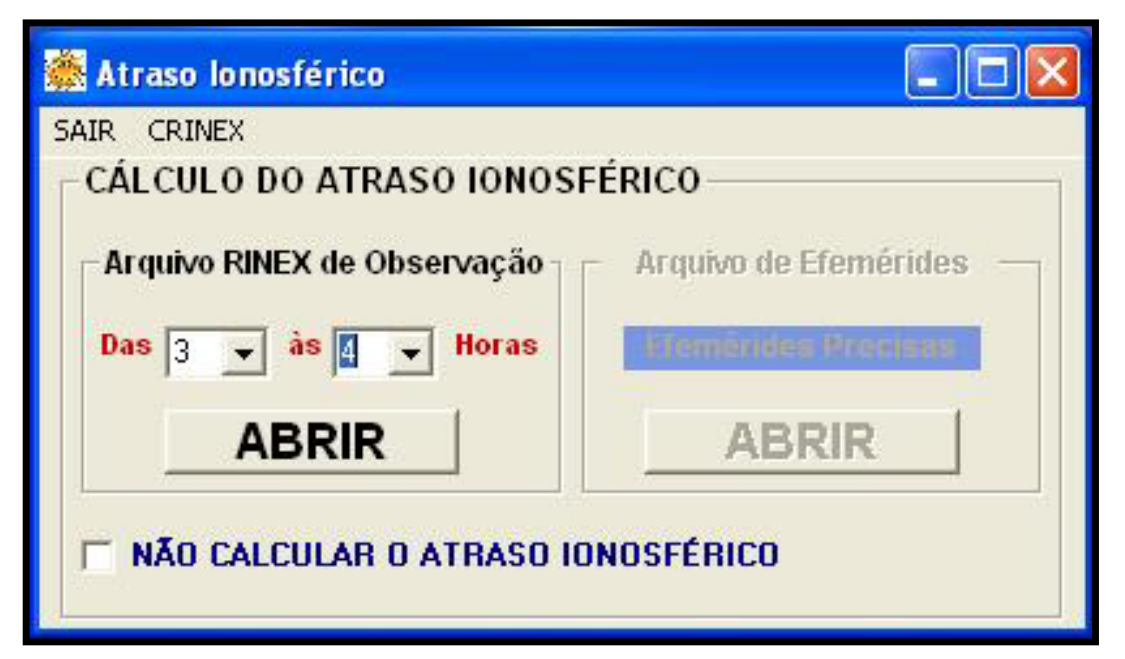

Figura 6.4 - Tela do módulo 3 do programa MODEIONO.

De posse dos coeficientes do modelo, obtidos diariamente e de hora em hora, foi possível verificar o comportamento da ionosfera, bem como testá-los em um processo de validação, através de posicionamento de pontos de forma absoluta e relativa.

\subsection{Validação do modelo ionosférico proposto}

O processo de validação do modelo proposto está amparado em processamento de pontos GPS através de duas metodologias:

\footnotetext{
${ }^{4}$ O programa CRINEX foi desenvolvido por LEANDRO (2003). O programa permite, através de um arquivo fonte, que contém as observáveis de interesse (código C/A e/ou código $P$ e/ou portadora $L_{1}$ e/ou portadora $L_{2}$ ), escrever um arquivo RINEX na versão 2.10 .
} 


\section{a) Processamento de observações GPS baseado na metodologia Single Point}

Nesta etapa utilizou-se o seguinte critério para testar a eficiência do modelo proposto: o vértice $B R A Z$, pertencente à RBMC, que não participou da estimativa dos parâmetros do modelo polinomial, foi processado de forma absoluta, em intervalos de uma hora, onde o efeito ionosférico foi atenuado através do modelo de Klobuchar, modelo Standard, e modelo ionosférico proposto neste trabalho. Nesta última metodologia, o código C/A foi corrigido, através do módulo 3 do programa MODEIONO, e, através do programa CRINEX, gerou-se um novo arquivo RINEX com a observável minimizada do efeito ionosférico. Neste caso, o arquivo RINEX gerado pelo programa CRINEX foi processado sem habilitar nenhum modelo ionosférico. Durante o processamento, nas três metodologias, foram utilizadas as efemérides transmitidas.

O modelo Standard, que compõe o programa SKI - 2.3 da LEICA, é compatível com o modelo da lâmina ionosférica, apresentado no item 4.4 .1 do capítulo 4.

Os programas utilizados para processar o vértice BRAZ foram: SKI - 2.3 da LEICA e GPSurvey - 2.35 da Trimble. As análises de discrepâncias foram realizadas segundo as equações:

$$
\begin{aligned}
& \Delta_{\mathrm{N}}=\mathrm{N}_{\text {(conhecido) }}-\mathrm{N}_{\text {(calculado) }} \\
& \Delta_{\mathrm{E}}=\mathrm{E}_{\text {(conhecido) }}-\mathrm{E}_{\text {(calculado) }} \\
& \Delta_{\mathrm{h}}=\mathrm{h}_{\text {(conhecido) }}-\mathrm{h}_{\text {(calculado) }}
\end{aligned}
$$

onde:

- $\Delta_{\mathrm{N}}$ e $\Delta_{\mathrm{E}}$ correspondem às discrepâncias entre os valores das coordenadas UTM conhecidas e as advindas do processamento GPS, em relação ao elipsóide WGS-84;

- $\Delta_{\mathrm{h}}$ corresponde à discrepância entre a altura geométrica conhecida e a advinda do processamento GPS, em relação ao elipsóide WGS-84;

- $\mathrm{N}_{\text {(conhecido) }}$ e $\mathrm{N}_{\text {(calculado) }}$ correspondem às coordenadas UTM - Norte conhecida e calculada (aplicando-se um determinado modelo ionosférico), respectivamente;

- $E_{\text {(conhecido) }}$ e $E_{\text {(calculado) }}$ correspondem às coordenadas UTM - Este conhecida e calculada (aplicando-se um determinado modelo ionosférico), respectivamente;

- $\mathrm{h}_{\text {(conhecido) }}$ e $\mathrm{h}_{\text {(calculado) }}$ correspondem às alturas geométricas conhecida e a advinda do processamento GPS, em relação ao elipsóide WGS-84. 
As coordenadas UTM do vértice BRAZ tomadas como verdadeiras no processo de validação do modelo são listadas na tabela 6.5 .

Tabela 6.5 - Coordenadas UTM do vértice BRAZ tomadas como verdadeiras no processo de validação do modelo ionosférico proposto no método Single Point.

\begin{tabular}{|c|c|c|c|}
\hline \multirow{2}{*}{$\begin{array}{c}\text { Nome do } \\
\text { Vértice }\end{array}$} & \multicolumn{3}{|c|}{ Coordenadas UTM - WGS-84 (M.C -45 $)$} \\
\cline { 2 - 4 } & $\mathbf{N}(\mathbf{m})$ & $\mathbf{E}(\mathbf{m})$ & $\mathbf{h}(\mathbf{m})$ \\
\hline BRAZ & $8.234 .747,061$ & $191.901,872$ & 1105,949 \\
\hline
\end{tabular}

\section{b) Processamento de observações GPS baseado na metodologia relativa}

O procedimento utilizado é semelhante à etapa do item "a", onde se processou uma base longa de aproximadamente 420 quilômetros formada pelos vértices PARA - UEPP. Processou-se apenas código, simulando uma situação daqueles usuários que só possuem receptores GPS de simples freqüência. O vértice PARA foi considerado como fixo, e os modelos ionosféricos aplicados foram Klobuchar e Standard.

No que se refere ao modelo proposto neste trabalho, o procedimento utilizado nesta etapa diferencia um pouco da metodologia descrita no item "a". Ao invés de corrigir o atraso do código $C / A$, criou-se um código $P$, para ambas estações, muito próximo do real. Isto pode se verificado pelas equações abaixo:

$$
\text { Atraso }=\left(R_{2 r}^{s}-R_{1 r}^{s}\right)
$$

O termo do lado esquerdo da equação (6.17) foi modelado através dos procedimentos descritos no item 6.3. Neste caso, o código $P$ pode ser recriado segundo a equação:

$$
P_{(\text {Gerado })}=R_{1 \mathrm{r}}^{\mathrm{S}}+\left(\frac{\mathrm{f}_{1}^{2}-\mathrm{f}_{2}^{2}}{\mathrm{f}_{2}^{2}}\right) \cdot\left[\mathrm{C}_{1}+\mathrm{C}_{2} \cdot\left(\phi^{*}\right)+\mathrm{C}_{3} \cdot\left(\lambda^{*}\right)+\mathrm{C}_{4} \cdot\left(\phi^{*}\right)^{2}+\mathrm{C}_{5} \cdot\left(\lambda^{*}\right)^{2}+\mathrm{C}_{6} \cdot\left(\phi^{*}\right) \cdot\left(\lambda^{*}\right)\right]+(\text { Erro })^{\mathrm{S}}
$$

Através do programa CRINEX, gerou-se um arquivo RINEX de observação com as observáveis: portadora $L_{1}$, código $C / A$ e código $P$. A Figura 6.4 ilustra um trecho do arquivo RINEX gerado pelo programa CRINEX. 


\begin{tabular}{|c|c|c|c|c|}
\hline 2.10 & \multicolumn{3}{|c|}{ OBSERVAÇ̃̃o $\quad$ G (GPS) } & RINEX VERSION / TYPE \\
\hline \multicolumn{4}{|c|}{ Módulo CRINEX V.1 por Rodrigo Figueiredo Leandro } & COMMENT \\
\hline \multicolumn{4}{|c|}{ MÓDULO CRINEX V.1 } & PGM / RUN BY / DATE \\
\hline \multicolumn{4}{|c|}{$\begin{array}{l}\star \star \star \\
12\end{array}$} & $\begin{array}{l}\text { COMMENT } \\
\text { MARKER NAME }\end{array}$ \\
\hline IBGE/BRASIL & IBGE/BRASI & & & OBSERVER / AGENCY \\
\hline 16594 & TRIMBLE 40 & Nav 7.29 & $9 \mathrm{Sig} 3.07$ & REC \# / TYPE / VERS \\
\hline 00071000 & DORNE MARG & KGOLIN T & & ANT \# / TYPE \\
\hline \multicolumn{4}{|c|}{$4115018.4035-4550644.3682-1741446.2819$} & APPROX POSITION XYZ \\
\hline $\begin{array}{r}4115018.4035 \\
0.0080\end{array}$ & 0.0000 & 0.0000 & & ANTENNA: DELTA H/E/N \\
\hline $1 \quad 1$ & & & & WAVELENGTH FACT L1/2 \\
\hline L1 & P2 & & & $\#$ / TYPES OF OBSERV \\
\hline 2001 & 23 & 0.1150000 & GPS & $\begin{array}{l}\text { TIME OF FIRST OBS } \\
\text { END OF HEADER }\end{array}$ \\
\hline $\begin{array}{lllll}1 & 2 & 23 & 12 & 0\end{array}$ & $0 \quad 0.1150000 \quad 0$ & $\begin{array}{lllll}3 & 14 & 18 & 21 & 22\end{array}$ & $\begin{array}{llll}25 & 28 & 29 & 31\end{array}$ & \\
\hline 1588112.202 & 55089330.373 & $3 \quad 55089338.580$ & & \\
\hline $\begin{array}{l}11318966.359 \\
40014657.725\end{array}$ & $\begin{array}{l}55838653.576 \\
58375514.662\end{array}$ & $\begin{array}{l}55838661.889 \\
58375526.596\end{array}$ & & \\
\hline 23791771.077 & 56851190.108 & 56851201.397 & & \\
\hline 30780327.202 & 58489766.756 & 58489778.525 & & \\
\hline-253536.925 & 58091841.811 & 58091852.572 & & \\
\hline 20505346.151 & 58915814.397 & 58915826.565 & & \\
\hline 748623.074 & 54683853.701 & 54683861.428 & & \\
\hline-2748845.972 & 56866993.248 & 56867002.662 & & \\
\hline${ }^{1} 22312{ }^{0}$ & $\begin{array}{lrr}0 & 15.1150000 & 0 \\
55096620.740\end{array}$ & $\begin{array}{llllll}9 & 3 & 14 & 18 & 21 & 22 \\
10 & & 55096628 & .889\end{array}$ & $25 \quad 282931$ & \\
\hline 11379621.814 & 55850195.904 & 55850204.451 & & \\
\hline 40079532.834 & 58387860.506 & 58387874.150 & & \\
\hline 23854911.236 & 56863205.561 & 56863216.990 & & \\
\hline 30836718.896 & 58500498.318 & 58500508.799 & & \\
\hline-257341.234 & 58091118.006 & 58091129.213 & & \\
\hline 20559894.385 & 58926195.100 & 58926208.592 & & \\
\hline 791142.941 & 54691944.725 & 54691952.475 & & \\
\hline-2751115.702 & 56866561.139 & 56866570.108 & & \\
\hline
\end{tabular}

Figura 6.5 - Trecho do arquivo RINEX gerado pelo CRINEX.

Neste caso, processou-se a base PARA - UEPP através do modelo ionosférico lono Free à base do código $\mathrm{C} / \mathrm{A}$ e código $\mathrm{P}$.

O processamento da base foi realizado em intervalos de 3 em 3 horas e foram utilizados os programas: SKI - 2.31 da LEICA e o Trimble Geomatics Office - 1.01.

As análises das discrepâncias foram às mesmas descritas no item "a". As coordenadas UTM do vértice UEPP tomadas como verdadeiras no processo de validação do modelo são listadas na tabela 6.6.

Tabela 6.6 - Coordenadas UTM do vértice UEPP tomadas como verdadeiras no processo de validação do modelo ionosférico proposto no método relativo.

\begin{tabular}{|c|c|c|c|}
\hline \multirow{2}{*}{$\begin{array}{c}\text { Nome do } \\
\text { Vértice }\end{array}$} & \multicolumn{3}{|c|}{ Coordenadas UTM - WGS-84 (M.C -510) } \\
\cline { 2 - 4 } & $\mathbf{N}(\mathbf{m})$ & $\mathbf{E}(\mathbf{m})$ & $\mathbf{h}(\mathbf{m})$ \\
\hline UEPP & $7.553 .844,315$ & $457.866,720$ & 431,038 \\
\hline
\end{tabular}

Os dias utilizados no processamento GPS, nas metodologias Single Point e relativa, listadas na Tabela 6.5 . 
Tabela 6.7 - Dias do ano utilizados no processamento de informações GPS para analisar a eficiência do modelo ionosférico proposto.

\begin{tabular}{|c|c|c|c|c|c|c|c|c|c|c|c|c|c|c|}
\hline & \multicolumn{14}{|c|}{ Dias do Ano } \\
\hline & \multicolumn{7}{|c|}{ Verão } & \multicolumn{7}{|c|}{ Outono } \\
\hline & 5 & 6 & 13 & 23 & 54 & 69 & 72 & 80 & 94 & 103 & 104 & 109 & 155 & 157 \\
\hline Single Point & $\bar{x}$ & $\bar{x}$ & $\bar{X}$ & $\bar{X}$ & $\bar{X}$ & $\bar{x}$ & $\bar{X}$ & $\bar{X}$ & $\bar{X}$ & $\bar{x}$ & $\bar{x}$ & $\bar{x}$ & $\bar{x}$ & $\bar{X}$ \\
\hline \multirow[t]{3}{*}{ Relativo } & $\mathbf{X}$ & $\mathbf{X}$ & $\mathbf{X}$ & $\mathbf{X}$ & $\mathbf{X}$ & $\mathbf{X}$ & $\mathbf{X}$ & $\mathbf{X}$ & $\mathbf{X}$ & $\mathbf{X}$ & $\mathbf{X}$ & $\mathbf{X}$ & $\mathbf{X}$ & $\mathbf{X}$ \\
\hline & \multicolumn{7}{|c|}{ Inverno } & \multicolumn{7}{|c|}{ Primavera } \\
\hline & 184 & 185 & $\overline{186}$ & $\overline{193}$ & 194 & 199 & 202 & 298 & 302 & 315 & 318 & 323 & 327 & 329 \\
\hline \begin{tabular}{|l|} 
Single Point \\
\end{tabular} & $\bar{x}$ & $\bar{x}$ & $\bar{x}$ & $\bar{x}$ & $\bar{x}$ & $\mathbf{X}$ & $\bar{x}$ & $\bar{x}$ & $\mathbf{X}$ & $\bar{x}$ & $\mathbf{X}$ & $\bar{x}$ & $\bar{x}$ & $\mathbf{X}$ \\
\hline Relativo & $\mathbf{X}$ & $\mathbf{X}$ & $\mathbf{X}$ & $\mathbf{X}$ & $\mathbf{X}$ & $\mathbf{X}$ & $\mathbf{X}$ & $\mathbf{X}$ & $\mathbf{X}$ & $\mathbf{X}$ & $\mathbf{X}$ & $\mathbf{X}$ & $\mathbf{X}$ & $\mathbf{X}$ \\
\hline
\end{tabular}

No próximo capítulo, serão apresentados os resultados obtidos neste trabalho, através de análises e discussões. 


\section{Resultados e discussões}

Neste capítulo serão apresentados os resultados obtidos nesta pesquisa, estruturados da seguinte maneira:

- o processamento dos coeficientes do modelo foi estruturado através de gráficos e, alguns dados estatísticos importantes, através de tabelas. Para verificar o comportamento sazonal da ionosfera o processamento ocorreu, separadamente, de acordo com as quatro estações do ano;

- a validação do modelo proposto foi obtida através de processamento de informações GPS, de acordo com os métodos Single Point e relativo. No método Single Point o vértice utilizado foi o BRAZ e no relativo processou-se a base PARAUEPP, fixando o vértice PARA. Como as coordenadas destes vértices são conhecidas, foi possível verificar o erro no posicionamento através do modelo proposto em um processo comparativo com os de Klobuchar e Standard. Analisouse neste procedimento tanto o erro horizontal quanto o erro vertical, segundo as quatro estações do ano.

\subsection{Introdução}

Conforme já comentado no capítulo anterior, o processamento dos coeficientes foi realizado pelo programa MODEIONO, através de um ajustamento seqüencial de observações, durante todo o dia, em intervalos de 1 hora. De posse destes resultados foi possível verificar o comportamento da ionosfera durante todo o período do dia e testar o modelo através dos posicionamentos Single Point e relativo.

No método Single Point, o vértice utilizado na validação do modelo foi o de nome BRAZ e no método relativo considerou-se como fixo o vértice PARA e processou-se a base PARA-UEPP. Todos estes vértices fazem parte da RBMC e não foram incluídos no processo de determinação dos coeficientes.

Para validar o modelo proposto procedeu-se da seguinte forma: 


\section{a) Processamento Single Point}

- Processamento do vértice BRAZ, em intervalos de 1 hora, através do programa GPSurvey-2.35, com o modelo de Klobuchar habilitado;

- Processamento do vértice BRAZ, em intervalos de 1 hora, através do programa SKI-2.3, com o modelo Standard habilitado;

- Processamento do vértice BRAZ, em intervalos de 1 hora, através da correção do código C/A pelo modelo regional proposto. Neste caso o processamento foi realizado também com o programa GPSurvey-2.35 sem habilitar nenhum modelo ionosférico.

Como as coordenadas do vértice BRAZ são conhecidas, a verificação da eficiência de cada modelo se deu através da determinação do erro médio quadrático, referentes às suas coordenadas no sistema de projeção UTM, referente ao elipsóide WGS-84.

\section{b) Processamento relativo}

Nesta etapa, o procedimento utilizado difere do exposto no item anterior. Optou-se em testar os modelos através do processamento de uma base longa, de aproximadamente 430 quilômetros, segundo os seguintes critérios:

- Processamento somente da base PARA-UEPP usando-se o código em intervalos de 3 horas, através do programa Trimble Geomatics Office 1.01, com o modelo de Klobuchar habilitado;

- Processamento da base PARA-UEPP usando-se o código em intervalos de 3 horas, através do programa SKI-2.3, com o modelo Standard habilitado;

- Processamento somente código da base PARA-UEPP, em intervalos de 3 horas, através do modelo regional proposto. Neste caso, utilizou-se a média dos coeficientes referente ao intervalo de processamento. Por ser o atraso ionosférico função da diferença entre código $P$ e código $C / A$, optou-se em recriar o código $P$ ao invés de corrigir o código C/A. Assim, gerou-se um arquivo RINEX com as observáveis portadora $L_{1}$, códigos C/A e P. Através desta metodologia, foi possível processar a base PARA-UEPP com solução do tipo iono-free apenas com códigos. O software utilizado foi o Trimble Geomatics Office 1.01. 
Com o mesmo critério do item "a", a verificação da eficiência de cada modelo se deu através da determinação do erro médio quadrático do vértice UEPP.

Tanto na metodologia Single Point, quanto na relativa, utilizou-se no processamento as efemérides transmitidas.

\subsection{Coeficientes do modelo polinomial no período do verão}

É importante salientar que, nos gráficos que serão ilustrados a seguir, o eixo $X$ representa o intervalo de processamento utilizado, em horas. $O$ valor 0 significa o intervalo de 0 a 1 hora GPS, o valor 2 significa o intervalo de 2 a 3 horas GPS, e assim, sucessivamente, até o valor 22, que representa o intervalo 22 a 23 horas GPS. Em relação ao eixo $\mathrm{Y}$, a variação de escala é a mesma para os coeficientes $\mathrm{C}_{2}$ a $\mathrm{C}_{6}$. Para os gráficos que ilustram a variação do coeficiente $C_{1}$, o eixo $Y$ possui uma escala diferente dos demais gráficos, devido a sua amplitude de variação ser superior às dos demais coeficientes.

As tabelas 7.1 a 7.13 listam os valores médios diários de cada coeficiente, os respectivos desvios padrão, bem como os valores máximos e mínimos de cada coeficiente.

Através das figuras 7.1 a 7.13 e das tabelas 7.1 a 7.13 , percebe-se que a ionosfera influencia a propagação do sinal, tanto em um período de 24 horas, quanto entre um dia e outro. Estas variações dos coeficientes se devem a vários fatores, conforme foi explicado de forma detalhada nos capítulos 4 e 5 deste trabalho.

Neste período, as maiores variações encontradas nos coeficientes estão compreendidas entre 17 e 20 horas GPS (14 às 17 horas locais), período este, muitas vezes, com uma maior concentração de elétrons livres presentes na ionosfera. O coeficiente que apresentou uma maior variação foi o $\mathrm{C}_{1}$, com um valor mínimo de 12,862 e máximo de 14,000 , com um desvio padrão médio de $\pm 0,617$. Já o coeficiente que apresentou um menor desvio padrão foi o $\mathrm{C}_{4}$ com um valor de $\pm 0,098$.

No que se refere ao ajustamento seqüencial, baseado no procedimento estatístico descrito no capítulo 8 , o mesmo proporcionou um índice de rejeição das observáveis de aproximadamente $35 \%$. Através desta estatística, não é possível concluir se todas estas observáveis rejeitadas estavam sob a influência da ionosfera, já que o código $P_{2}$, normalmente, é um sinal muito fraco, com muitas perdas de informações.

A seguir, serão apresentados todos os resultados do processamento dos coeficientes no período do verão estudado. 


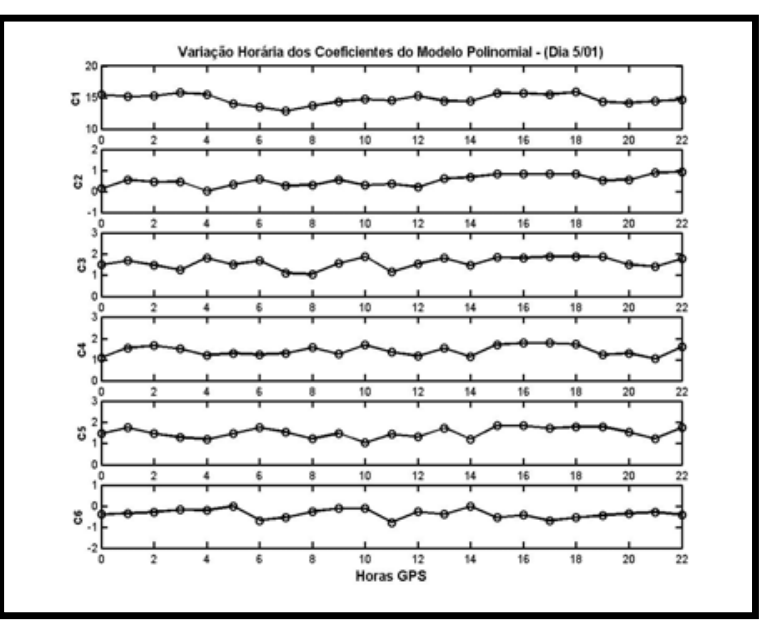

Figura 7.1 - Variação horária dos coeficientes do modelo polinomial (dia 5/01)

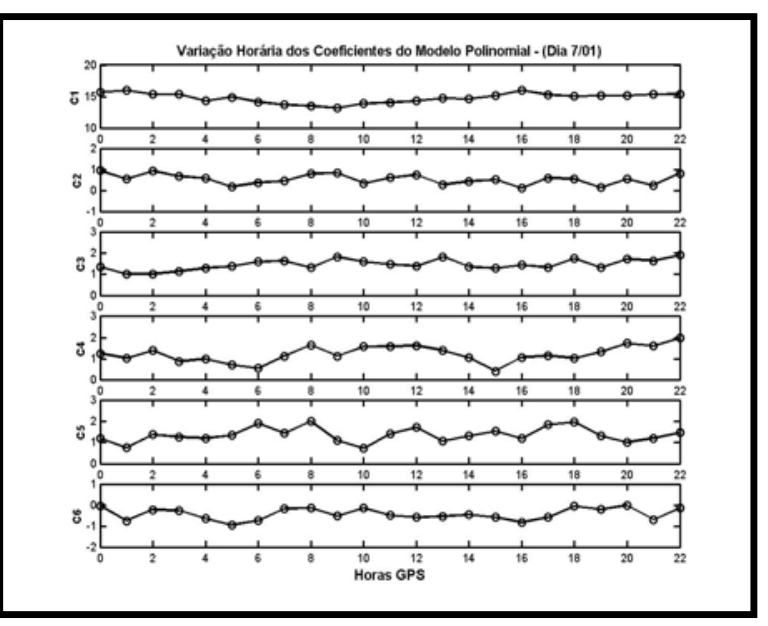

Figura 7.3 - Variação horária dos coeficientes do modelo polinomial (dia 7/01)

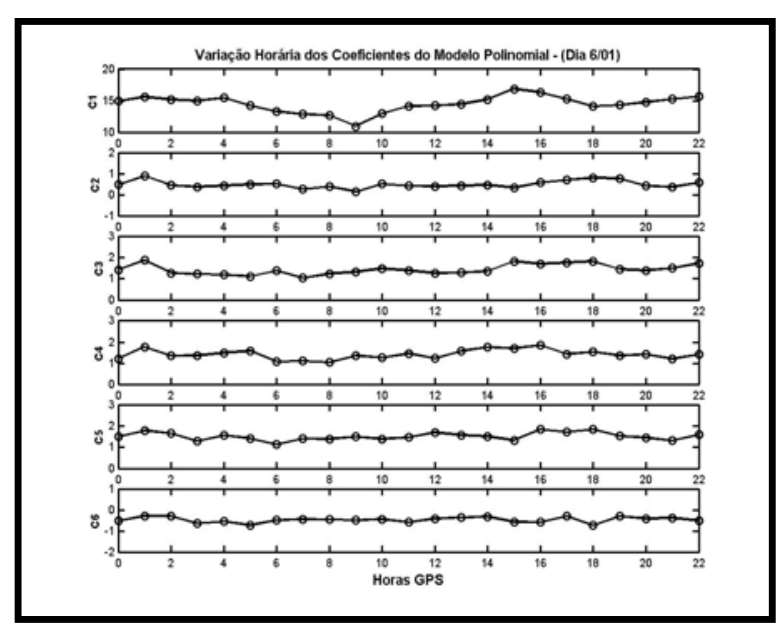

Figura 7.2 - Variação horária dos coeficientes do modelo polinomial (dia 6/01)

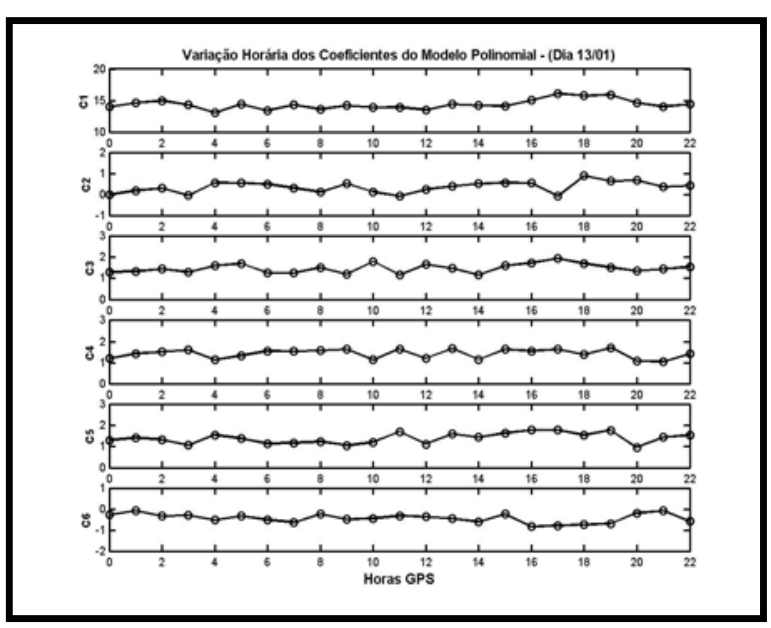

Figura 7.4 - Variação horária dos coeficientes do modelo polinomial (dia 13/01)

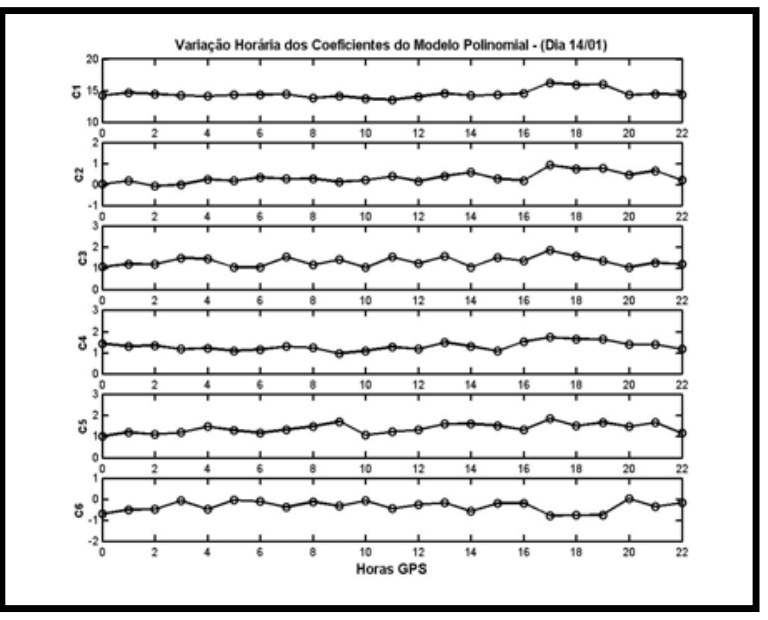

Figura 7.5 - Variação horária dos coeficientes do modelo polinomial (dia 14/01)

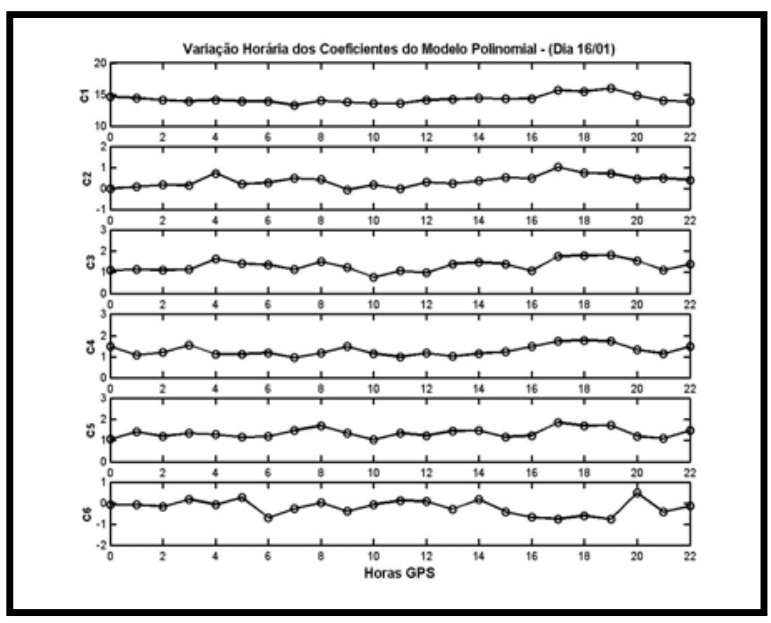

Figura 7.6 - Variação horária dos coeficientes do modelo polinomial (dia 16/01) 


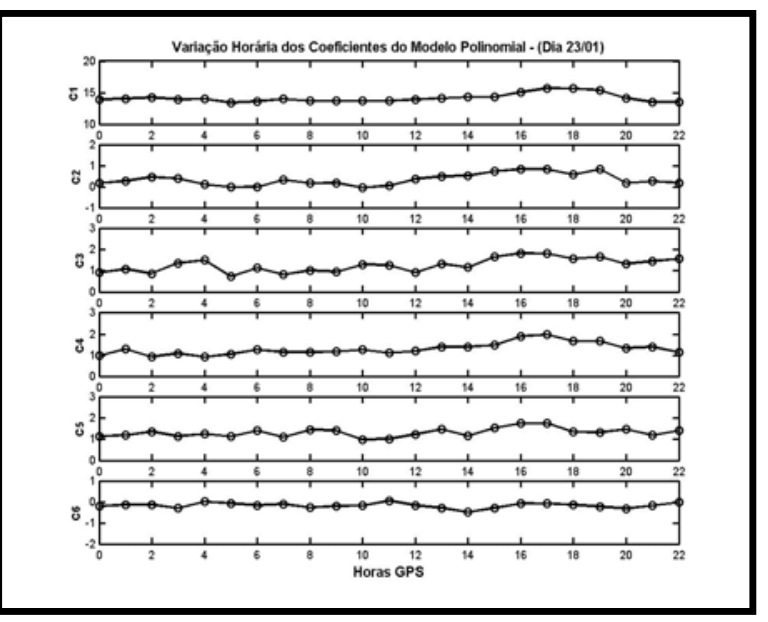

Figura 7.7 - Variação horária dos coeficientes do modelo polinomial (dia 23/01)

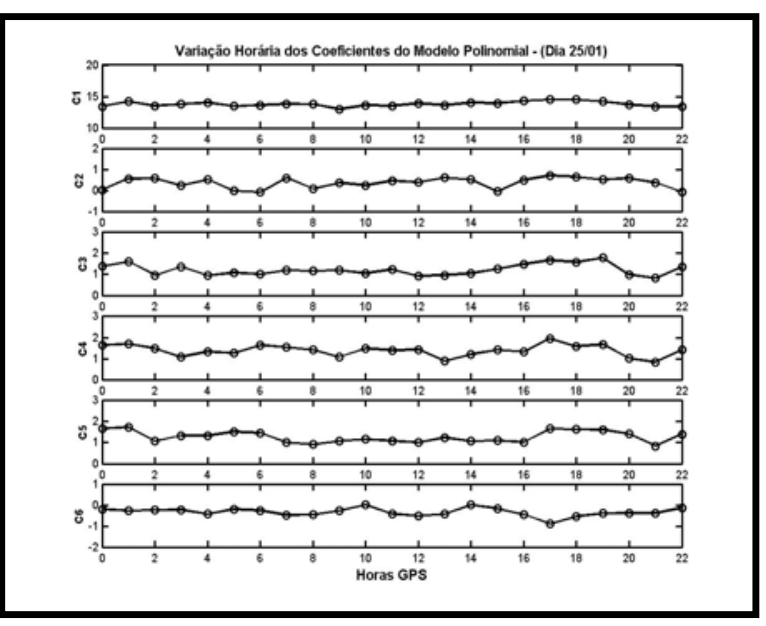

Figura 7.9 - Variação horária dos coeficientes do modelo polinomial (dia 25/01)

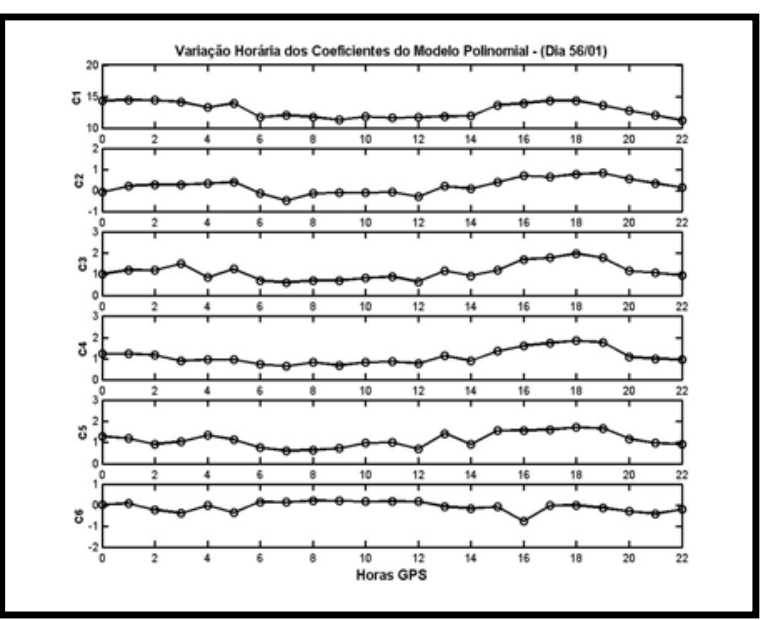

Figura 7.11 - Variação horária dos coeficientes do modelo polinomial (dia 56/01)

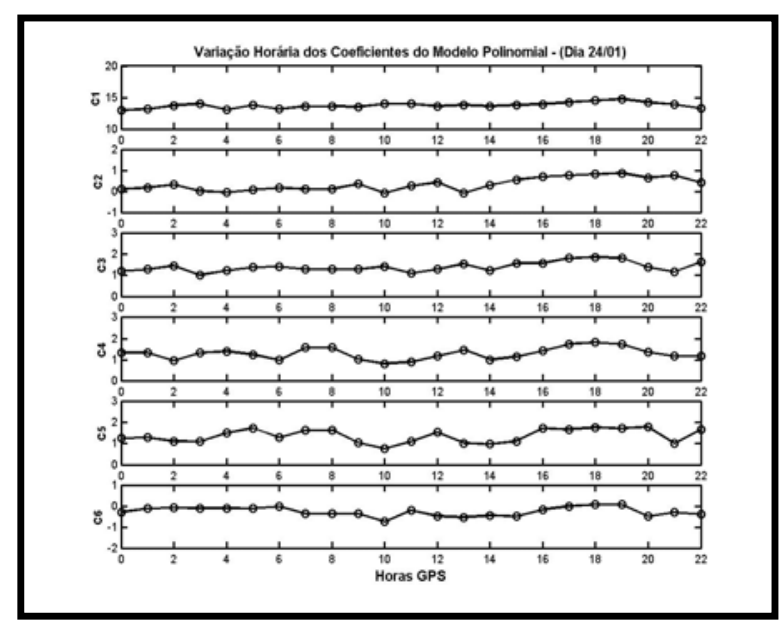

Figura 7.8 - Variação horária dos coeficientes do modelo polinomial (dia 24/01)

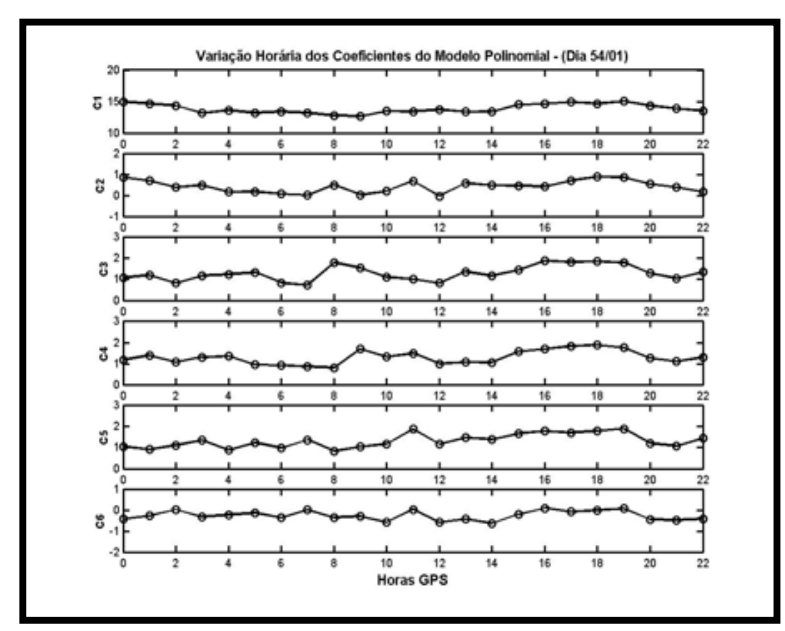

Figura 7.10 - Variação horária dos coeficientes do modelo polinomial (dia 54/01)

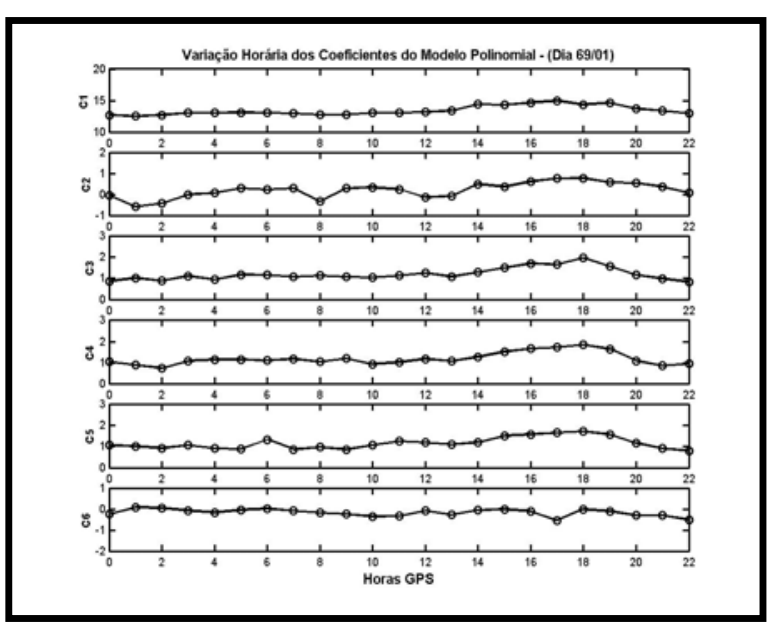

Figura 7.12 - Variação horária dos coeficientes do modelo polinomial (dia 69/01) 


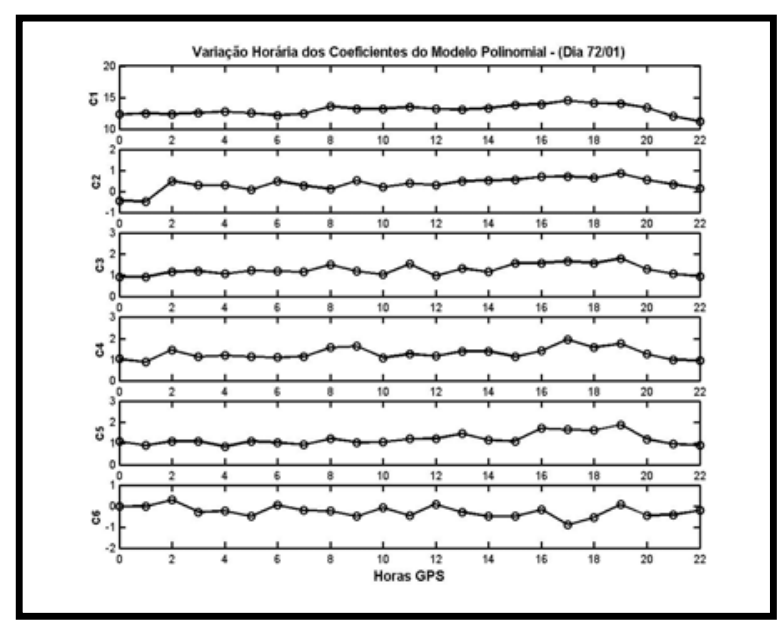

Figura 7.13 - Variação horária dos coeficientes do modelo polinomial

(dia 72/01)

Tabela 7.1 - Estatística dos coeficientes do modelo polinomial - (dia 5/01)

\begin{tabular}{|c|c|c|c|c|}
\hline Coeficientes & Valor Médio & Desvio Padrão & Valor Mínimo & Valor Máximo \\
\hline $\mathbf{C}_{\mathbf{1}}$ & 14,731 & $\pm 0,608$ & 12,842 & 15,833 \\
\hline $\mathbf{C}_{\mathbf{2}}$ & 0,519 & $\pm 0,255$ & 0,019 & 0,907 \\
\hline $\mathbf{C}_{\mathbf{3}}$ & 1,583 & $\pm 0,263$ & 1,042 & 1,886 \\
\hline $\mathbf{C}_{\mathbf{4}}$ & 1,428 & $\pm 0,239$ & 1,042 & 1,790 \\
\hline $\mathbf{C}_{5}$ & 1,513 & $\pm 0,243$ & 1,025 & 1,832 \\
\hline $\mathbf{C}_{\mathbf{6}}$ & $-0,362$ & $\pm 0,211$ & $-0,785$ & $-0,001$ \\
\hline
\end{tabular}

Tabela 7.2 - Estatística dos coeficientes do modelo polinomial - (dia 6/01)

\begin{tabular}{|c|c|c|c|c|}
\hline Coeficientes & Valor Médio & Desvio Padrão & Valor Mínimo & Valor Máximo \\
\hline $\mathbf{C}_{\mathbf{1}}$ & 14,498 & $\pm 1,115$ & 10,927 & 16,858 \\
\hline $\mathbf{C}_{\mathbf{2}}$ & 0,487 & $\pm 0,174$ & 0,152 & 0,900 \\
\hline $\mathbf{C}_{\mathbf{3}}$ & 1,431 & $\pm 0,240$ & 1,035 & 1,868 \\
\hline $\mathbf{C}_{\mathbf{4}}$ & 1,417 & $\pm 0,225$ & 1,043 & 1,851 \\
\hline $\mathbf{C}_{\mathbf{5}}$ & 1,510 & $\pm 0,181$ & 1,128 & 1,834 \\
\hline $\mathbf{C}_{\mathbf{6}}$ & $-0,473$ & $\pm 0,132$ & $-0,727$ & $-0,290$ \\
\hline
\end{tabular}


Tabela 7.3 - Estatística dos coeficientes do modelo polinomial - (dia 7/01)

\begin{tabular}{|c|c|c|c|c|}
\hline Coeficientes & Valor Médio & Desvio Padrão & Valor Mínimo & Valor Máximo \\
\hline $\mathbf{C}_{\mathbf{1}}$ & 14,783 & $\pm 0,582$ & 13,134 & 15,974 \\
\hline $\mathbf{C}_{\mathbf{2}}$ & 0,529 & $\pm 0,245$ & 0,103 & 0,940 \\
\hline $\mathbf{C}_{\mathbf{3}}$ & 1,454 & $\pm 0,247$ & 1,013 & 1,891 \\
\hline $\mathbf{C}_{\mathbf{4}}$ & 1,221 & $\pm 0,393$ & 0,402 & 1,982 \\
\hline $\mathbf{C}_{\mathbf{5}}$ & 1,356 & $\pm 0,347$ & 0,718 & 1,996 \\
\hline $\mathbf{C}_{\mathbf{6}}$ & $-0,425$ & $\pm 0,282$ & $-0,945$ & $-0,013$ \\
\hline
\end{tabular}

Tabela 7.4 - Estatística dos coeficientes do modelo polinomial - (dia 13/01)

\begin{tabular}{|c|c|c|c|c|}
\hline Coeficientes & Valor Médio & Desvio Padrão & Valor Mínimo & Valor Máximo \\
\hline $\mathbf{C}_{\mathbf{1}}$ & 14,388 & $\pm 0,565$ & 13,097 & 16,099 \\
\hline $\mathbf{C}_{\mathbf{2}}$ & 0,348 & $\pm 0,261$ & $-0,083$ & 0,884 \\
\hline $\mathbf{C}_{\mathbf{3}}$ & 1,466 & $\pm 0,215$ & 1,152 & 1,921 \\
\hline $\mathbf{C}_{\mathbf{4}}$ & 1,424 & $\pm 0,217$ & 1,060 & 1,709 \\
\hline $\mathbf{C}_{\mathbf{5}}$ & 1,391 & $\pm 0,251$ & 0,952 & 1,778 \\
\hline $\mathbf{C}_{\mathbf{6}}$ & $-0,441$ & $\pm 0,214$ & $-0,844$ & $-0,085$ \\
\hline
\end{tabular}

Tabela 7.5 - Estatística dos coeficientes do modelo polinomial - (dia 14/01)

\begin{tabular}{|c|c|c|c|c|}
\hline Coeficientes & Valor Médio & Desvio Padrão & Valor Mínimo & Valor Máximo \\
\hline $\mathbf{C}_{\mathbf{1}}$ & 14,459 & $\pm 0,479$ & 13,511 & 16,213 \\
\hline $\mathbf{C}_{\mathbf{2}}$ & 0,319 & $\pm 0,260$ & $-0,091$ & 0,910 \\
\hline $\mathbf{C}_{\mathbf{3}}$ & 1,304 & $\pm 0,225$ & 1,027 & 1,851 \\
\hline $\mathbf{C}_{\mathbf{4}}$ & 1,306 & $\pm 0,198$ & 0,966 & 1,720 \\
\hline $\mathbf{C}_{5}$ & 1,380 & $\pm 0,226$ & 1,013 & 1,826 \\
\hline $\mathbf{C}_{6}$ & $-0,353$ & $\pm 0,250$ & $-0,796$ & 0,008 \\
\hline
\end{tabular}

Tabela 7.6 - Estatística dos coeficientes do modelo polinomial - (dia 16/01)

\begin{tabular}{|c|c|c|c|c|}
\hline Coeficientes & Valor Médio & Desvio Padrão & Valor Mínimo & Valor Máximo \\
\hline $\mathbf{C}_{\mathbf{1}}$ & 14,286 & $\pm 0,466$ & 13,319 & 15,948 \\
\hline $\mathbf{C}_{\mathbf{2}}$ & 0,354 & $\pm 0,271$ & $-0,075$ & 1,000 \\
\hline $\mathbf{C}_{\mathbf{3}}$ & 1,306 & $\pm 0,277$ & 0,768 & 1,796 \\
\hline $\mathbf{C}_{\mathbf{4}}$ & 1,290 & $\pm 0,249$ & 0,954 & 1,777 \\
\hline $\mathbf{C}_{\mathbf{5}}$ & 1,350 & $\pm 0,223$ & 1,037 & 1,841 \\
\hline $\mathbf{C}_{\mathbf{6}}$ & $-0,200$ & $\pm 0,349$ & $-0,768$ & 0,476 \\
\hline
\end{tabular}


Tabela 7.7 - Estatística dos coeficientes do modelo polinomial - (dia 23/01)

\begin{tabular}{|c|c|c|c|c|}
\hline Coeficientes & Valor Médio & Desvio Padrão & Valor Mínimo & Valor Máximo \\
\hline $\mathbf{C}_{\mathbf{1}}$ & 14,146 & $\pm 0,470$ & 13,415 & 15,706 \\
\hline $\mathbf{C}_{\mathbf{2}}$ & 0,339 & $\pm 0,280$ & $-0,058$ & 0,842 \\
\hline $\mathbf{C}_{\mathbf{3}}$ & 1,261 & $\pm 0,326$ & 0,712 & 1,820 \\
\hline $\mathbf{C}_{\mathbf{4}}$ & 1,299 & $\pm 0,285$ & 0,907 & 1,983 \\
\hline $\mathbf{C}_{\mathbf{5}}$ & 1,309 & $\pm 0,203$ & 0,988 & 1,745 \\
\hline $\mathbf{C}_{\mathbf{6}}$ & $-0,172$ & $\pm 0,120$ & $-0,486$ & 0,053 \\
\hline
\end{tabular}

Tabela 7.8 - Estatística dos coeficientes do modelo polinomial - (dia 24/01)

\begin{tabular}{|c|c|c|c|c|}
\hline Coeficientes & Valor Médio & Desvio Padrão & Valor Mínimo & Valor Máximo \\
\hline $\mathbf{C}_{\mathbf{1}}$ & 13,753 & $\pm 0,257$ & 13,018 & 14,782 \\
\hline $\mathbf{C}_{\mathbf{2}}$ & 0,336 & $\pm 0,305$ & $-0,082$ & 0,869 \\
\hline $\mathbf{C}_{\mathbf{3}}$ & 1,390 & $\pm 0,228$ & 1,009 & 1,842 \\
\hline $\mathbf{C}_{\mathbf{4}}$ & 1,287 & $\pm 0,281$ & 0,807 & 1,820 \\
\hline $\mathbf{C}_{5}$ & 1,357 & $\pm 0,321$ & 0,754 & 1,785 \\
\hline $\mathbf{C}_{\mathbf{6}}$ & $-0,263$ & $\pm 0,217$ & $-0,748$ & 0,073 \\
\hline
\end{tabular}

Tabela 7.9 - Estatística dos coeficientes do modelo polinomial - (dia 25/01)

\begin{tabular}{|c|c|c|c|c|}
\hline Coeficientes & Valor Médio & Desvio Padrão & Valor Mínimo & Valor Máximo \\
\hline $\mathbf{C}_{\mathbf{1}}$ & 13,798 & $\pm 0,179$ & 12,974 & 14,501 \\
\hline $\mathbf{C}_{\mathbf{2}}$ & 0,358 & $\pm 0,258$ & $-0,090$ & 0,708 \\
\hline $\mathbf{C}_{\mathbf{3}}$ & 1,211 & $\pm 0,267$ & 0,810 & 1,771 \\
\hline $\mathbf{C}_{\mathbf{4}}$ & 1,385 & $\pm 0,275$ & 0,833 & 1,962 \\
\hline $\mathbf{C}_{\mathbf{5}}$ & 1,262 & $\pm 0,270$ & 0,826 & 1,717 \\
\hline $\mathbf{C}_{\mathbf{6}}$ & $-0,335$ & $\pm 0,198$ & $-0,899$ & 0,015 \\
\hline
\end{tabular}

Tabela 7.10 - Estatística dos coeficientes do modelo polinomial - (dia 54/01)

\begin{tabular}{|c|c|c|c|c|}
\hline Coeficientes & Valor Médio & Desvio Padrão & Valor Mínimo & Valor Máximo \\
\hline $\mathbf{C}_{\mathbf{1}}$ & 13,861 & $\pm 0,530$ & 12,657 & 15,047 \\
\hline $\mathbf{C}_{\mathbf{2}}$ & 0,423 & $\pm 0,285$ & $-0,031$ & 0,889 \\
\hline $\mathbf{C}_{\mathbf{3}}$ & 1,283 & $\pm 0,354$ & 0,721 & 1,861 \\
\hline $\mathbf{C}_{\mathbf{4}}$ & 1,299 & $\pm 0,324$ & 0,800 & 1,878 \\
\hline $\mathbf{C}_{\mathbf{5}}$ & 1,315 & $\pm 0,329$ & 0,834 & 1,887 \\
\hline $\mathbf{C}_{\boldsymbol{6}}$ & $-0,260$ & $\pm 0,226$ & $-0,639$ & 0,094 \\
\hline
\end{tabular}


Tabela 7.11 - Estatística dos coeficientes do modelo polinomial - (dia 56/01)

\begin{tabular}{|c|c|c|c|c|}
\hline Coeficientes & Valor Médio & Desvio Padrão & Valor Mínimo & Valor Máximo \\
\hline $\mathbf{C}_{\mathbf{1}}$ & 12,862 & $\pm 1,005$ & 11,217 & 14,446 \\
\hline $\mathbf{C}_{\mathbf{2}}$ & 0,199 & $\pm 0,351$ & $-0,490$ & 0,817 \\
\hline $\mathbf{C}_{\mathbf{3}}$ & 1,116 & $\pm 0,394$ & 0,612 & 1,975 \\
\hline $\mathbf{C}_{\mathbf{4}}$ & 1,093 & $\pm 0,356$ & 0,637 & 1,851 \\
\hline $\mathbf{C}_{\mathbf{5}}$ & 1,120 & $\pm 0,346$ & 0,610 & 1,702 \\
\hline $\mathbf{C}_{\mathbf{6}}$ & $-0,082$ & $\pm 0,247$ & $-0,768$ & 0,207 \\
\hline
\end{tabular}

Tabela 7.12 - Estatística dos coeficientes do modelo polinomial - (dia 69/01)

\begin{tabular}{|c|c|c|c|c|}
\hline Coeficientes & Valor Médio & Desvio Padrão & Valor Mínimo & Valor Máximo \\
\hline $\mathbf{C}_{\mathbf{1}}$ & 13,415 & $\pm 0,543$ & 12,538 & 14,965 \\
\hline $\mathbf{C}_{\mathbf{2}}$ & 0,205 & $\pm 0,362$ & $-0,587$ & 0,772 \\
\hline $\mathbf{C}_{\mathbf{3}}$ & 1,193 & $\pm 0,295$ & 0,827 & 1,975 \\
\hline $\mathbf{C}_{\mathbf{4}}$ & 1,188 & $\pm 0,295$ & 0,742 & 1,851 \\
\hline $\mathbf{C}_{\mathbf{5}}$ & 1,150 & $\pm 0,277$ & 0,802 & 1,702 \\
\hline $\mathbf{C}_{\mathbf{6}}$ & $-0,167$ & $\pm 0,170$ & $-0,539$ & 0,081 \\
\hline
\end{tabular}

Tabela 7.13 - Estatística dos coeficientes do modelo polinomial - (dia 72/01)

\begin{tabular}{|c|c|c|c|c|}
\hline Coeficientes & Valor Médio & Desvio Padrão & Valor Mínimo & Valor Máximo \\
\hline $\mathbf{C}_{\mathbf{1}}$ & 13,026 & $\pm 0,595$ & 11,217 & 14,501 \\
\hline $\mathbf{C}_{\mathbf{2}}$ & 0,345 & $\pm 0,327$ & $-0,480$ & 0,872 \\
\hline $\mathbf{C}_{\mathbf{3}}$ & 1,259 & $\pm 0,258$ & 0,921 & 1,792 \\
\hline $\mathbf{C}_{\mathbf{4}}$ & 1,291 & $\pm 0,274$ & 0,882 & 1,962 \\
\hline $\mathbf{C}_{\mathbf{5}}$ & 1,199 & $\pm 0,278$ & 0,857 & 1,887 \\
\hline $\mathbf{C}_{\mathbf{6}}$ & $-0,260$ & $\pm 0,270$ & $-0,899$ & 0,293 \\
\hline
\end{tabular}

A Figura 7.14 ilustra os valores médios diários dos coeficientes do modelo polinomial durante alguns dias do verão. Percebe-se que o comportamento dos coeficientes neste período é bastante regular, salvo o $\mathrm{C}_{1}$, que apresentou uma variação entre os valores máximo e mínimo de 1,921. Para os demais coeficientes, o comportamento desta variação permaneceu, praticamente, constante. 


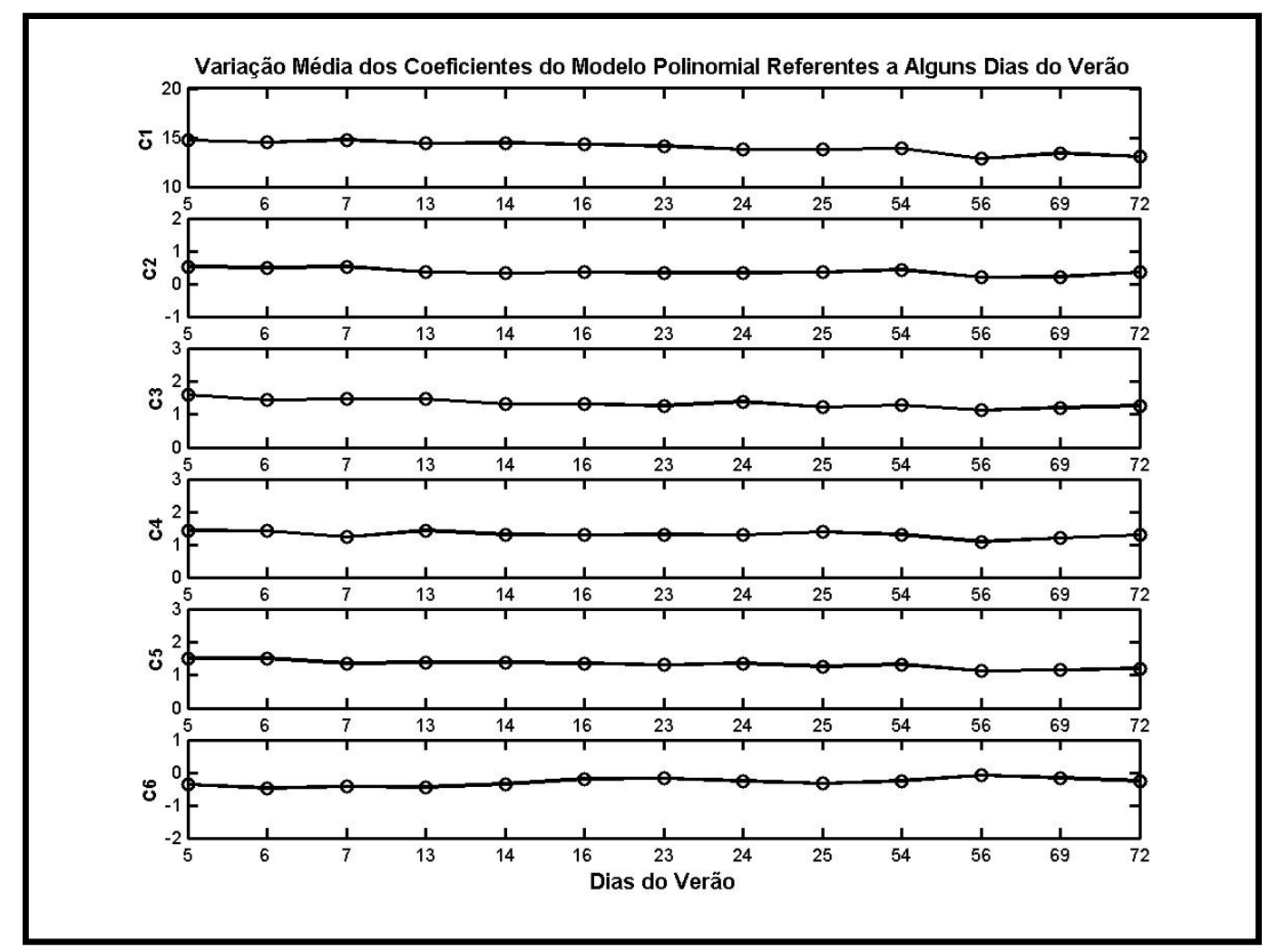

Figura 7.14 - Variação média diária dos coeficientes do modelo polinomial, referente a alguns dias do verão.

A Tabela 7.14 ilustra a estatística dos coeficientes neste período do verão. As colunas "Valor Médio" e "Desvio Padrão" correspondem, respectivamente, à média dos coeficientes e à média dos desvios padrão, em relação aos 13 dias estudados.

Tabela 7.14 - Valores médios dos coeficientes do modelo polinomial referentes a alguns dias do verão

\begin{tabular}{|c|c|c|c|c|}
\hline Coeficientes & Valor Médio & Desvio Padrão & Valor Mínimo & Valor Máximo \\
\hline $\mathbf{C}_{\mathbf{1}}$ & 14,000 & $\pm 0,569$ & 12,862 & 14,783 \\
\hline $\mathbf{C}_{\mathbf{2}}$ & 0,366 & $\pm 0,279$ & 0,199 & 0,529 \\
\hline $\mathbf{C}_{\mathbf{3}}$ & 1,327 & $\pm 0,276$ & 1,116 & 1,583 \\
\hline $\mathbf{C}_{\mathbf{4}}$ & 1,302 & $\pm 0,277$ & 1,093 & 1,428 \\
\hline $\mathbf{C}_{\mathbf{5}}$ & 1,324 & $\pm 0,269$ & 1,120 & 1,513 \\
\hline $\mathbf{C}_{\mathbf{6}}$ & $-0,292$ & $\pm 0,222$ & $-0,473$ & $-0,082$ \\
\hline
\end{tabular}


No que se refere ao erro da portadora $L_{1}$ (erro de interfreqüência), devido ao conjunto satélite e receptor - $(E \text { rro })^{S}=\left(\left(S_{P_{2}}-S_{P_{1}}\right)+\left(r_{P 2}-r_{P 1}\right)\right)^{s}$, os maiores desvios estão relacionados às passagens dos satélites PRN-4 e PRN-18. Este fato se deve a uma grande perda de informações do código $\mathrm{P}_{2}$ destes dois satélites. A tabela 7.15 lista os valores destes erros.

Tabela 7.15 - Valores médios do erro da portadora $L_{1}$ (erro de interfreqüência), devido ao conjunto satélite/receptor, em relação aos dias estudados no verão.

\begin{tabular}{|c|c|c|}
\cline { 2 - 3 } \multicolumn{1}{c|}{} & \multicolumn{2}{c|}{$(\text { Erro })^{\mathrm{s}}=\left(\left(\mathrm{S}_{\mathrm{P} 2}-\mathrm{S}_{\mathrm{P} 1}\right)+\left(\mathrm{r}_{\mathrm{P} 2}-\mathrm{r}_{\mathrm{P} 1}\right)\right)^{\mathrm{s}}$} \\
\hline Satélites & Valor Médio $(\mathbf{m})$ & Desvio Padrão $(\mathbf{m})$ \\
\hline PRN-1 & 1,296 & $\pm 0,625$ \\
\hline PRN-2 & 2,244 & $\pm 0,490$ \\
\hline PRN-3 & 1,667 & $\pm 0,459$ \\
\hline PRN-4 & 2,242 & $\pm 1,203$ \\
\hline PRN-5 & 1,579 & $\pm 0,631$ \\
\hline PRN-6 & 1,498 & $\pm 0,620$ \\
\hline PRN-7 & 2,021 & $\pm 0,715$ \\
\hline PRN-8 & 2,015 & $\pm 0,558$ \\
\hline PRN-9 & 1,562 & $\pm 0,644$ \\
\hline PRN-10 & 1,959 & $\pm 0,775$ \\
\hline PRN-11 & 1,422 & $\pm 0,328$ \\
\hline PRN-13 & 1,937 & $\pm 0,589$ \\
\hline PRN-14 & 1,773 & $\pm 0,478$ \\
\hline PRN-15 & 1,637 & $\pm 0,245$ \\
\hline PRN-17 & 1,729 & $\pm 0,749$ \\
\hline PRN-18 & 1,992 & $\pm 1,093$ \\
\hline PRN-19 & 1,849 & $\pm 0,597$ \\
\hline PRN-20 & 1,721 & $\pm 0,565$ \\
\hline PRN-21 & 1,873 & $\pm 0,500$ \\
\hline PRN-22 & 1,843 & $\pm 0,679$ \\
\hline PRN-23 & 1,497 & $\pm 0,619$ \\
\hline PRN-24 & 1,681 & $\pm 0,615$ \\
\hline PRN-25 & 1,841 & $\pm 0,598$ \\
\hline PRN-26 & 2,014 & $\pm 0,551$ \\
\hline PRN-27 & 2,010 & $\pm 0,549$ \\
\hline PRN-28 & 1,885 & $\pm 0,642$ \\
\hline PRN-29 & 1,469 & $\pm 0,267$ \\
\hline PRN-30 & 1,499 & $\pm 0,624$ \\
\hline PRN-31 & 1,849 & $\pm 0,446$ \\
\hline
\end{tabular}




\subsubsection{Validação do modelo através de posicionamento Single Point - período do verão}

Nesta seção optou-se em comparar o modelo polinomial com o de Klobuchar e o Standard pelo fato dos mesmos serem os mais utilizados nos pacotes de programas comerciais de processamento GPS.

Optou-se em verificar os erros no processamento GPS de forma separada, ou seja: erro horizontal através de coordenadas UTM e o erro vertical através das alturas geométricas ou elipsoidais. As siglas E.Q.H.P, E.Q.H.K, E.Q.H.S, E.M.Q, E.V.P, E.V.K, E.V.S, que aparecerão nas figuras e tabelas mostradas a seguir, significam:

- E.Q.H.P - corresponde ao erro quadrático horizontal no posicionamento quando se utiliza o modelo ionosférico polinomial;

- E.Q.H.K - corresponde ao erro quadrático horizontal no posicionamento quando se utiliza o modelo ionosférico de Klobuchar;

- E.Q.H.S - corresponde ao erro quadrático horizontal no posicionamento quando se utiliza o modelo ionosférico Standard;

- E.M.Q - corresponde ao erro médio quadrático no posicionamento durante um período de 24 horas.

- E.V.P - corresponde ao erro vertical no posicionamento quando se utiliza o modelo ionosférico polinomial;

- E.V.K - corresponde ao erro vertical no posicionamento quando se utiliza o modelo ionosférico de Klobuchar;

- E.V.S - corresponde ao erro vertical no posicionamento quando se utiliza o modelo ionosférico Standard; 
O vértice utilizado no processamento Single Point foi o BRAZ. Os dados foram processados em intervalos de 1 hora e o vértice não participou da determinação dos parâmetros do modelo polinomial. No processamento foram utilizados os programas GPSurvey - 2.35, onde foi acionado o modelo de Klobuchar, e o SKI - 2.3, onde foi acionado o modelo Standard. No que se refere ao modelo polinomial, como já explicado em itens anteriores, não foi acionado nenhum modelo ionosférico no processamento, pelo fato de ter realizado a correção da observável código C/A no arquivo RINEX. As efemérides utilizadas neste processo foram as transmitidas.

Em todos os procedimentos, o modelo troposférico utilizado foi o de Hopfield e com um ângulo de elevação dos satélites maior ou igual a 15 graus.

Através das Figuras 7.15 a 7.28 e das tabelas 7.16 a 7.22 , pode-se perceber que 0 modelo Standard não é tão eficaz se comparado com os modelos de Klobuchar e polinomial. Ao analisar o posicionamento horizontal, o modelo polinomial proporcionou bons resultados se comparado com o modelo de Klobuchar e com o Standard. No período do verão estudado, através do modelo polinomial, o dia 5 foi o único que apresentou um erro médio diário superior a 2 metros. O erro ficou abaixo deste valor nos demais dias. No que se refere ao erro vertical, o modelo polinomial também se mostrou mais eficiente que o de Klobuchar e o Standard. Verifica-se que o modelo Standard é bastante instável na determinação vertical do ponto, tendo variações superiores a 20 metros. Isto pode ser verificado nos dias 5,6 e 23.

Tanto horizontal, quanto vertical, verificou-se nos intervalos entre 0 e 6 e 22 e 23 horas GPS, que os erros apresentaram variações distintas das demais faixas de intervalo. Além da influência da ionosfera, um outro fato que também contribuiu para estas discrepâncias é que nestas faixas de intervalo o código C/A apresentou muitos ruídos. Este fato pode estar associado a algum problema eletrônico ao iniciar e finalizar um arquivo de observação.

Através de uma análise de eficiência, neste período de verão estudado, o posicionamento através do modelo polinomial proporcionou um erro horizontal médio quadrático de $1,748 \mathrm{~m}$, enquanto que, através do modelo de Klobuchar, este erro foi de 2,934m, e 5,831m através do Standard. Esta melhora foi de 40,4\% se comparado com o de Klobuchar. Se a análise for realizada no posicionamento vertical, os erros médios quadráticos ocorridos foram 2,982m, 5,100m e 7,837m, através do uso dos modelos polinomial, Klobuchar e Standard, respectivamente. A melhora em relação ao de Klobuchar foi de $41,5 \%$. 


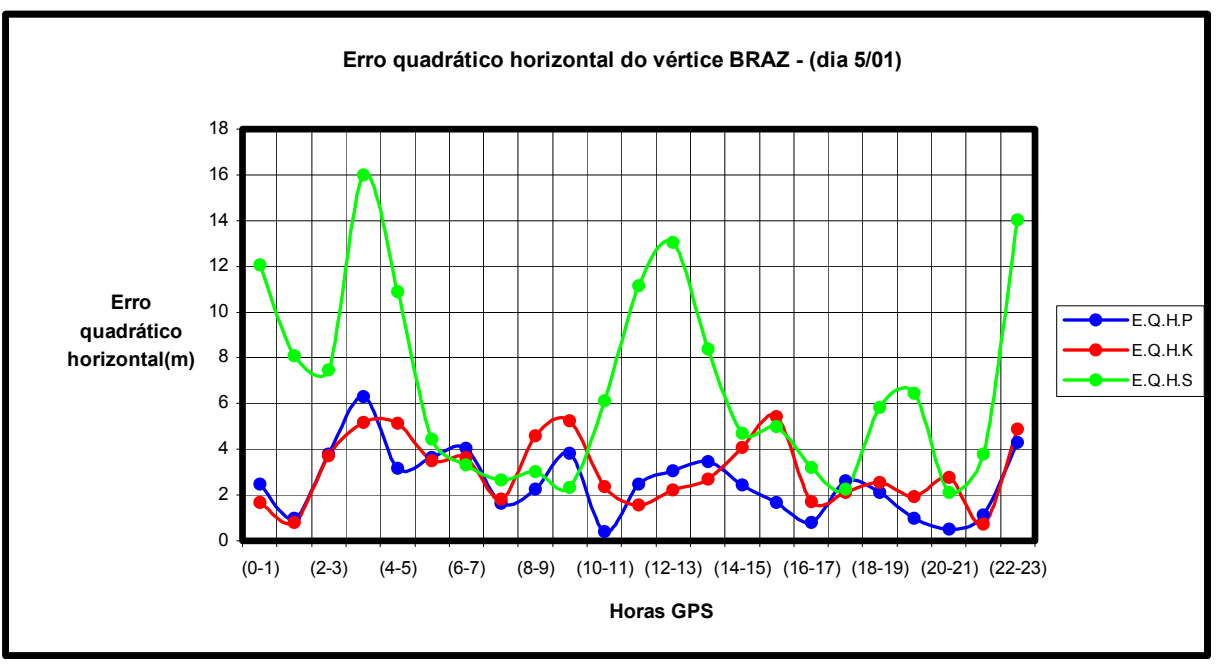

Figura 7.15 - Variação horária do erro quadrático horizontal no posicionamento Single Point do vértice $B R A Z$ - (dia 5/01)

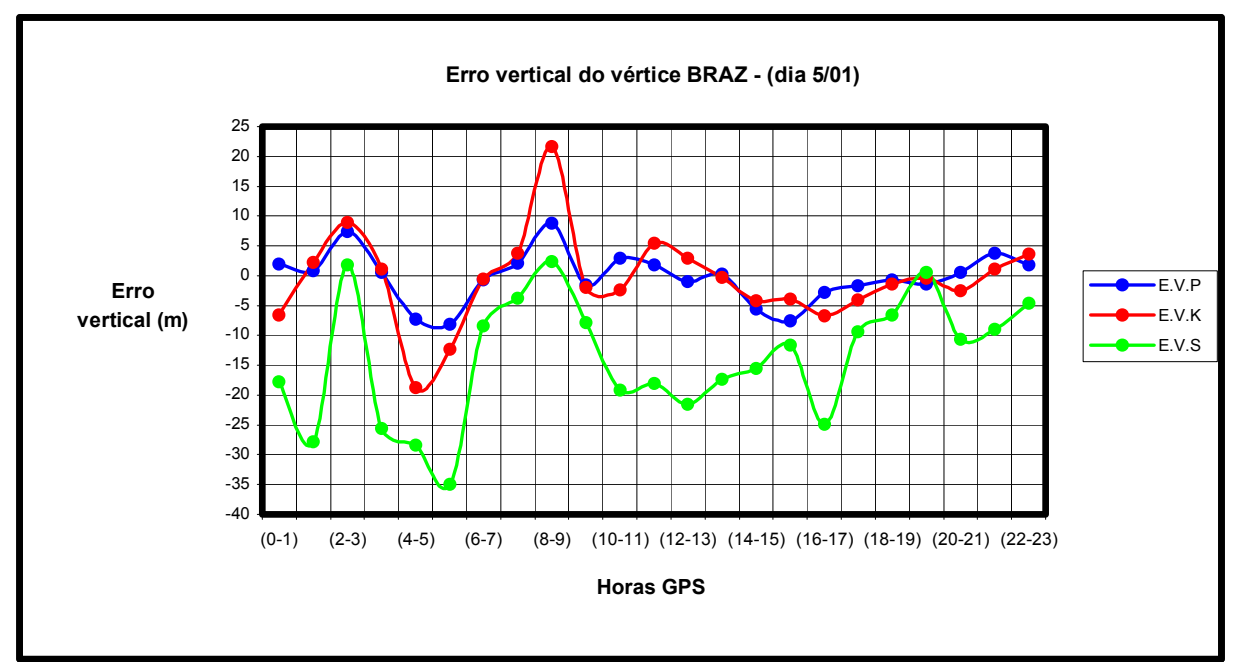

Figura 7.16 - Variação horária do erro vertical no posicionamento Single Point do vértice $B R A Z$ - (dia 5/01) 
Tabela 7.16 - Erro quadrático horizontal e erro vertical no processamento Single Point do vértice BRAZ para diferentes modelos ionosféricos - (dia 5/01).

\begin{tabular}{|c|c|c|c|c|c|c|}
\cline { 2 - 7 } \multicolumn{1}{c|}{} & \multicolumn{2}{c|}{ Erro Quadrático Horizontal (m) } & \multicolumn{3}{c|}{ Erro Vertical (m) } \\
\hline Horas & E.Q.H.P & E.Q.H.K & E.Q.H.S & E.V.P & E.V.K & E.V.S \\
\hline $\mathbf{( 0 - 1 )}$ & 2,470 & 1,662 & 12,046 & 1,894 & $-6,556$ & $-17,801$ \\
\hline $\mathbf{( 1 - 2 )}$ & 0,997 & 0,805 & 8,083 & 0,817 & 2,180 & $-27,905$ \\
\hline $\mathbf{( 2 - 3 )}$ & 3,784 & 3,714 & 7,453 & 7,347 & 8,904 & 1,770 \\
\hline $\mathbf{( 3 - 4 )}$ & 6,291 & 5,176 & 15,986 & 0,511 & 1,090 & $-25,541$ \\
\hline $\mathbf{( 4 - 5 )}$ & 3,161 & 5,137 & 10,879 & $-7,335$ & $-18,795$ & $-28,347$ \\
\hline $\mathbf{( 5 - 6 )}$ & 3,643 & 3,492 & 4,433 & $-8,169$ & $-12,363$ & $-35,016$ \\
\hline $\mathbf{( 6 - 7 )}$ & 4,036 & 3,633 & 3,303 & $-0,725$ & $-0,586$ & $-8,456$ \\
\hline $\mathbf{( 7 - 8 )}$ & 1,653 & 1,814 & 2,670 & 2,103 & 3,726 & $-3,755$ \\
\hline $\mathbf{( 8 - 9 )}$ & 2,269 & 4,583 & 3,016 & 8,785 & 21,583 & 2,361 \\
\hline $\mathbf{( 9 - 1 0 )}$ & 3,830 & 5,240 & 2,339 & $-1,499$ & $-2,001$ & $-7,908$ \\
\hline $\mathbf{( 1 0 - 1 1 )}$ & 0,417 & 2,361 & 6,123 & 2,900 & $-2,330$ & $-19,106$ \\
\hline $\mathbf{( 1 1 - 1 2 )}$ & 2,460 & 1,563 & 11,149 & 1,827 & 5,373 & $-18,013$ \\
\hline $\mathbf{( 1 2 - 1 3 )}$ & 3,043 & 2,227 & 13,038 & $-0,992$ & 2,906 & $-21,577$ \\
\hline $\mathbf{( 1 3 - 1 4 )}$ & 3,457 & 2,685 & 8,390 & 0,304 & $-0,260$ & $-17,381$ \\
\hline $\mathbf{( 1 4 - 1 5 )}$ & 2,458 & 4,078 & 4,715 & $-5,611$ & $-4,210$ & $-15,584$ \\
\hline $\mathbf{( 1 5 - 1 6 )}$ & 1,682 & 5,412 & 4,984 & $-7,599$ & $-3,923$ & $-11,649$ \\
\hline $\mathbf{( 1 6 - 1 7 )}$ & 0,805 & 1,731 & 3,215 & $-2,846$ & $-6,801$ & $-24,944$ \\
\hline $\mathbf{( 1 7 - 1 8 )}$ & 2,613 & 2,130 & 2,273 & $-1,651$ & $-4,042$ & $-9,363$ \\
\hline $\mathbf{( 1 8 - 1 9 )}$ & 2,132 & 2,550 & 5,839 & $-0,752$ & $-1,424$ & $-6,645$ \\
\hline $\mathbf{( 1 9 - 2 0 )}$ & 0,988 & 1,927 & 6,431 & $-1,468$ & $-0,408$ & 0,527 \\
\hline $\mathbf{( 2 0 - 2 1 )}$ & 0,512 & 2,782 & 2,105 & 0,514 & $-2,538$ & $-10,576$ \\
\hline $\mathbf{( 2 1 - 2 2 )}$ & 1,117 & 0,713 & 3,799 & 3,703 & 1,132 & $-9,027$ \\
\hline $\mathbf{( 2 2 - 2 3 )}$ & 4,315 & 4,882 & 14,019 & 1,777 & 3,580 & $-4,704$ \\
\hline E.M.Q & $\mathbf{2 , 5 2 8}$ & $\mathbf{3 , 0 5 6}$ & $\mathbf{6 , 7 9 5}$ & $\mathbf{3 , 0 9 3}$ & $\mathbf{5 , 0 7 4}$ & $\mathbf{1 4 , 2 5 9}$ \\
\hline Desvio Padrão & $\pm \mathbf{1 . 4 4 0}$ & $\pm \mathbf{1 . 4 8 6}$ & $\pm \mathbf{4 . 1 8 7}$ & $\pm \mathbf{4 . 2 3 5}$ & $\pm \mathbf{7 . 5 9 4}$ & $\pm \mathbf{1 0 . 2 8 1}$ \\
\hline & & & & & &
\end{tabular}

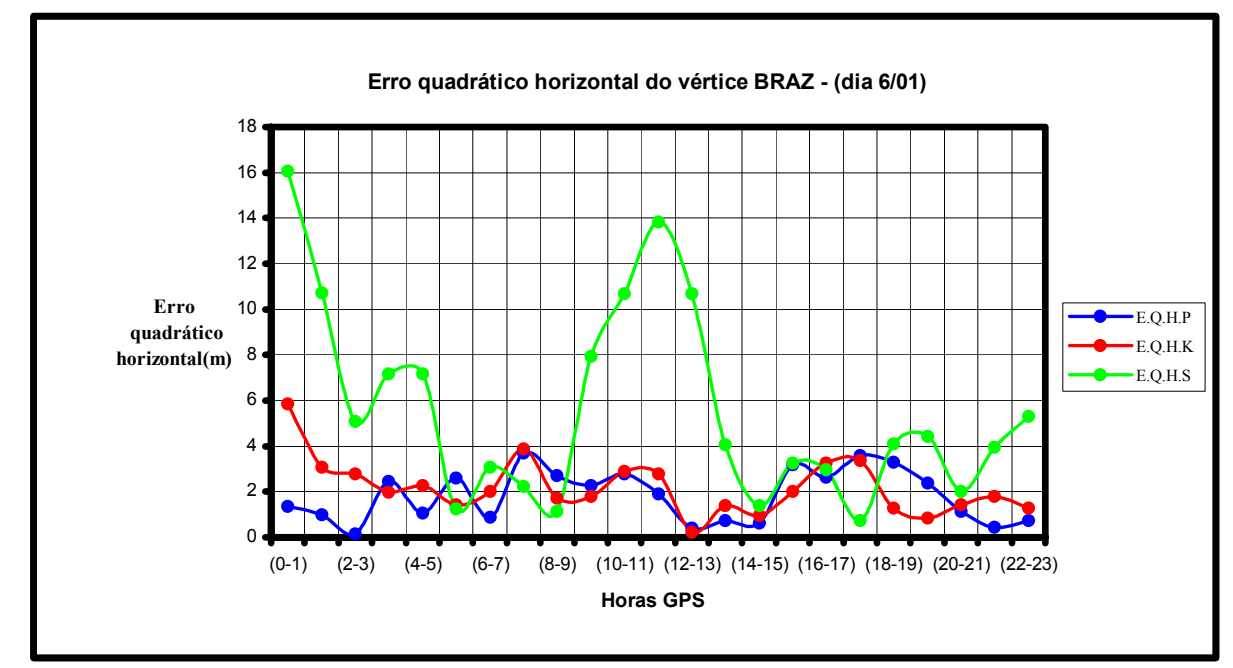

Figura 7.17 - Variação horária do erro quadrático horizontal no posicionamento Single Point do vértice $B R A Z$ - (dia 6/01) 


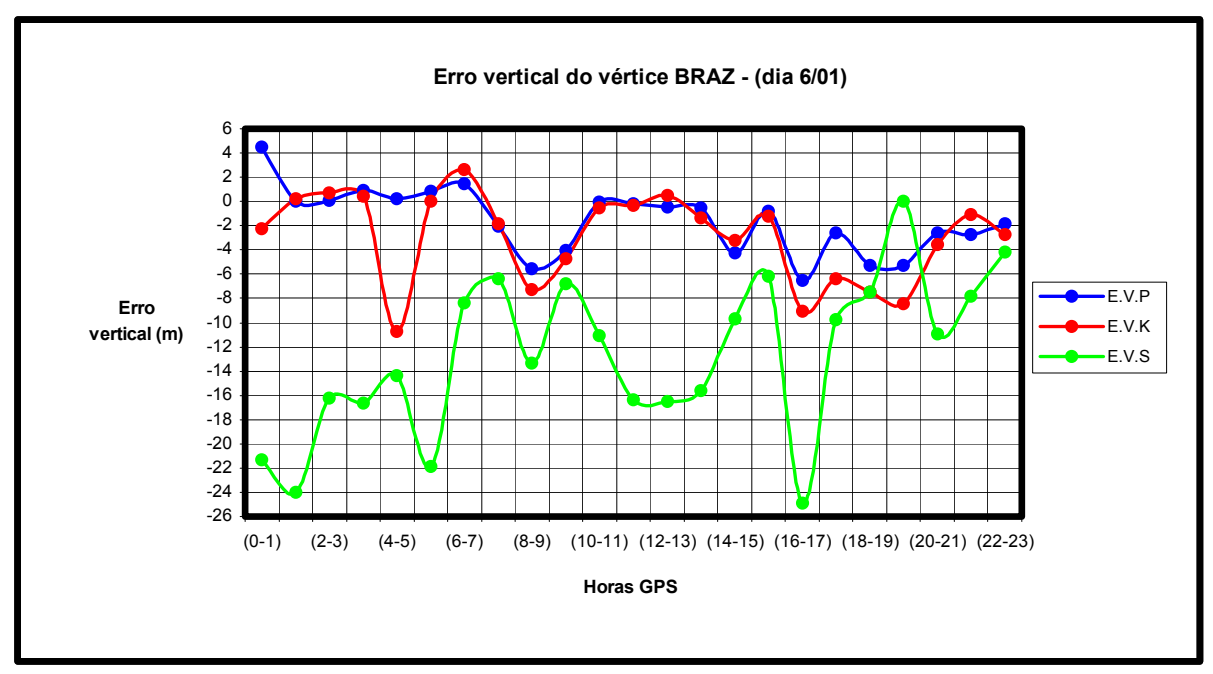

Figura 7.18 - Variação horária do erro vertical no posicionamento Single Point do vértice BRAZ - (dia 6/01)

Tabela 7.17 - Erro quadrático horizontal e erro vertical no processamento Single Point do vértice BRAZ para diferentes modelos ionosféricos - (dia 6/01).

\begin{tabular}{|c|c|c|c|c|c|c|}
\cline { 2 - 7 } \multicolumn{1}{c|}{} & \multicolumn{2}{c|}{ Erro Quadrático Horizontal (m) } & \multicolumn{3}{c|}{ Erro Vertical (m) } \\
\hline Horas & E.Q.H.P & E.Q.H.K & E.Q.H.S & E.V.P & E.V.K & E.V.S \\
\hline $\mathbf{( 0 - 1 )}$ & 1,347 & 5,872 & 16,058 & 4,494 & $-2,281$ & $-21,350$ \\
\hline $\mathbf{( 1 - 2 )}$ & 0,990 & 3,091 & 10,710 & 0,020 & 0,203 & $-24,004$ \\
\hline $\mathbf{( 2 - 3 )}$ & 0,130 & 2,770 & 5,073 & 0,106 & 0,690 & $-16,254$ \\
\hline $\mathbf{( 3 - 4 )}$ & 2,441 & 1,967 & 7,159 & 0,877 & 0,456 & $-16,669$ \\
\hline $\mathbf{( 4 - 5 )}$ & 1,044 & 2,253 & 7,185 & 0,204 & $-10,713$ & $-14,384$ \\
\hline $\mathbf{( 5 - 6 )}$ & 2,607 & 1,409 & 1,262 & 0,842 & 0,033 & $-21,884$ \\
\hline $\mathbf{( 6 - 7 )}$ & 0,883 & 1,997 & 3,080 & 1,481 & 2,631 & $-8,364$ \\
\hline $\mathbf{( 7 - 8 )}$ & 3,694 & 3,880 & 2,249 & $-2,075$ & $-1,820$ & $-6,362$ \\
\hline $\mathbf{( 8 - 9 )}$ & 2,708 & 1,737 & 1,119 & $-5,537$ & $-7,267$ & $-13,367$ \\
\hline $\mathbf{( 9 - 1 0 )}$ & 2,253 & 1,805 & 7,950 & $-4,033$ & $-4,751$ & $-6,789$ \\
\hline $\mathbf{( 1 0 - 1 1 )}$ & 2,776 & 2,890 & 10,671 & $-0,033$ & $-0,541$ & $-11,083$ \\
\hline $\mathbf{( 1 1 - 1 2 )}$ & 1,892 & 2,780 & 13,824 & $-0,200$ & $-0,311$ & $-16,381$ \\
\hline $\mathbf{( 1 2 - 1 3 )}$ & 0,396 & 0,224 & 10,692 & $-0,443$ & 0,485 & $-16,525$ \\
\hline $\mathbf{( 1 3 - 1 4 )}$ & 0,718 & 1,376 & 4,074 & $-0,540$ & $-1,396$ & $-15,582$ \\
\hline $\mathbf{( 1 4 - 1 5 )}$ & 0,623 & 0,950 & 1,386 & $-4,263$ & $-3,207$ & $-9,706$ \\
\hline $\mathbf{( 1 5 - 1 6 )}$ & 3,190 & 2,026 & 3,248 & $-0,786$ & $-1,243$ & $-6,161$ \\
\hline $\mathbf{( 1 6 - 1 7 )}$ & 2,647 & 3,270 & 2,955 & $-6,547$ & $-9,088$ & $-24,928$ \\
\hline$(\mathbf{1 7 - 1 8})$ & 3,592 & 3,369 & 0,731 & $-2,615$ & $-6,419$ & $-9,778$ \\
\hline $\mathbf{( 1 8 - 1 9 )}$ & 3,296 & 1,285 & 4,092 & $-5,264$ & $-7,458$ & $-7,495$ \\
\hline $\mathbf{( 1 9 - 2 0 )}$ & 2,386 & 0,850 & 4,418 & $-5,282$ & $-8,440$ & 0,037 \\
\hline $\mathbf{( 2 0 - 2 1 )}$ & 1,142 & 1,433 & 2,001 & $-2,586$ & $-3,569$ & $-10,895$ \\
\hline $\mathbf{( 2 1 - 2 2 )}$ & 0,437 & 1,792 & 3,963 & $-2,706$ & $-1,064$ & $-7,866$ \\
\hline $\mathbf{( 2 2 - 2 3 )}$ & 0,735 & 1,266 & 5,306 & $-1,813$ & $-2,744$ & $-4,212$ \\
\hline E.M.Q & $\mathbf{1 , 8 2 3}$ & $\mathbf{2 , 1 8 7}$ & $\mathbf{5 , 6 1 8}$ & $\mathbf{2 , 2 9 3}$ & $\mathbf{3 , 3 4 0}$ & $\mathbf{1 2 , 6 1 2}$ \\
\hline Desvio Padrão & $\pm \mathbf{1 . 1 3 0}$ & $\pm \mathbf{1 . 2 1 2}$ & $\pm \mathbf{4 . 2 5 2}$ & $\pm \mathbf{2 . 6 8 4}$ & $\pm \mathbf{3 . 6 4 8}$ & $\pm \mathbf{6 . 5 6 9}$ \\
\hline
\end{tabular}




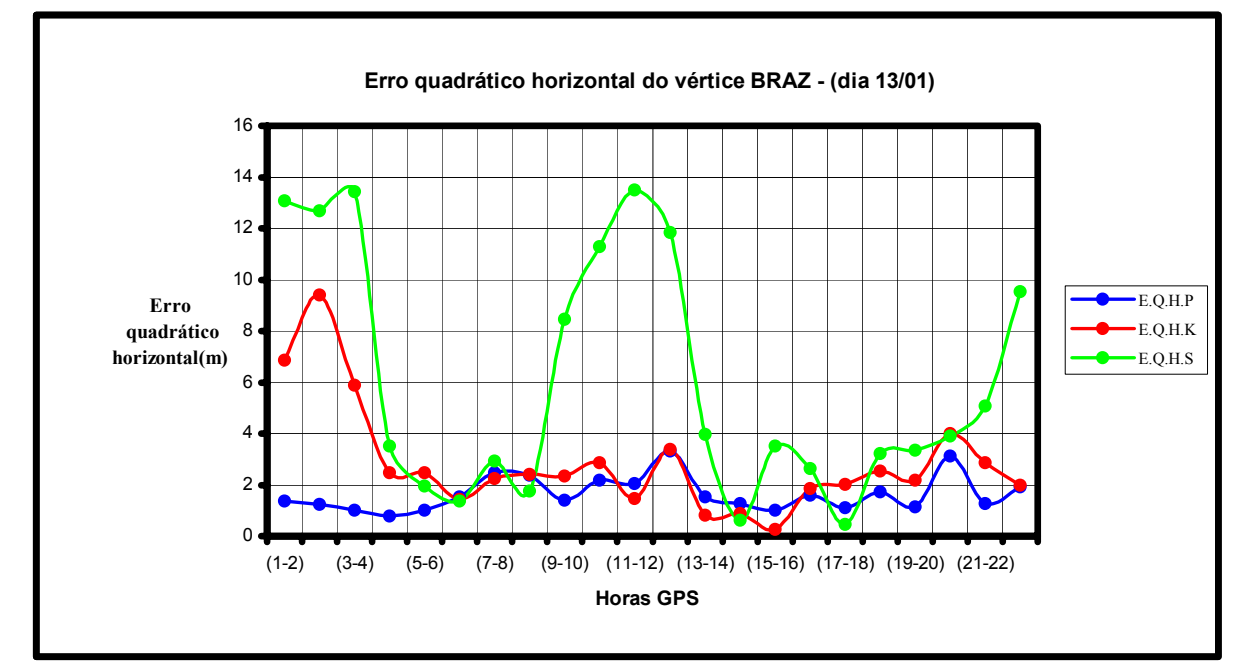

Figura 7.19 - Variação horária do erro quadrático horizontal no posicionamento Single Point do vértice BRAZ - (dia 13/01)

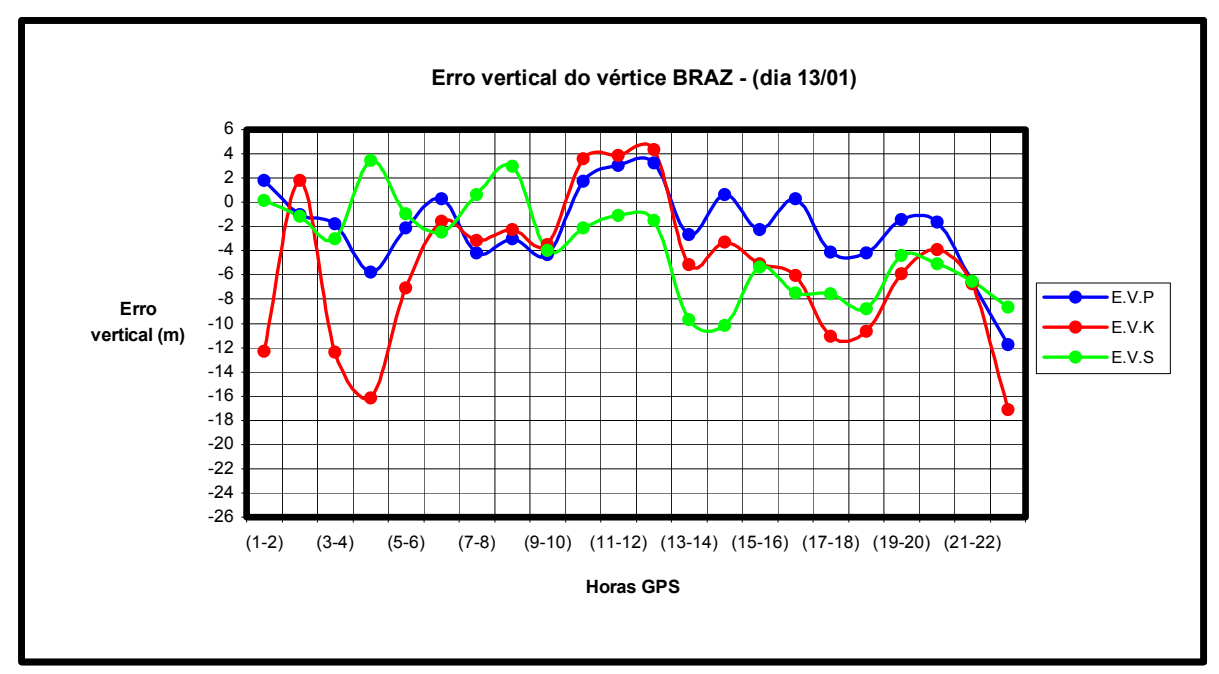

Figura 7.20 - Variação horária do erro vertical no posicionamento Single Point do vértice $B R A Z$ - (dia 13/01) 
Tabela 7.18 - Erro quadrático horizontal e erro vertical no processamento Single Point do vértice BRAZ para diferentes modelos ionosféricos - (dia 13/01).

\begin{tabular}{|c|c|c|c|c|c|c|}
\cline { 2 - 7 } \multicolumn{1}{c|}{} & \multicolumn{2}{c|}{ Erro Quadrático Horizontal (m) } & \multicolumn{3}{c|}{ Erro Vertical (m) } \\
\hline Horas & E.Q.H.P & E.Q.H.K & E.Q.H.S & E.V.P & E.V.K & E.V.S \\
\hline $\mathbf{( 1 - 2 )}$ & 1,375 & 6,859 & 13,083 & 1,784 & $-12,323$ & 0,161 \\
\hline $\mathbf{( 2 - 3 )}$ & 1,235 & 9,384 & 12,680 & $-1,023$ & 1,798 & $-1,130$ \\
\hline $\mathbf{( 3 - 4 )}$ & 1,000 & 5,898 & 13,424 & $-1,759$ & $-12,401$ & $-3,049$ \\
\hline $\mathbf{( 4 - 5 )}$ & 0,768 & 2,481 & 3,497 & $-5,780$ & $-16,137$ & 3,435 \\
\hline $\mathbf{( 5 - 6 )}$ & 1,021 & 2,459 & 1,952 & $-2,109$ & $-7,058$ & $-0,928$ \\
\hline $\mathbf{( 6 - 7 )}$ & 1,527 & 1,421 & 1,376 & 0,271 & $-1,594$ & $-2,467$ \\
\hline $\mathbf{( 7 - 8 )}$ & 2,466 & 2,237 & 2,918 & $-4,165$ & $-3,177$ & 0,608 \\
\hline $\mathbf{( 8 - 9 )}$ & 2,370 & 2,400 & 1,767 & $-3,045$ & $-2,291$ & 2,949 \\
\hline $\mathbf{( 9 - 1 0 )}$ & 1,399 & 2,337 & 8,459 & $-4,354$ & $-3,471$ & $-3,989$ \\
\hline $\mathbf{( 1 0 - 1 1 )}$ & 2,182 & 2,871 & 11,278 & 1,745 & 3,602 & $-2,154$ \\
\hline $\mathbf{( 1 1 - 1 2 )}$ & 2,042 & 1,476 & 13,494 & 3,049 & 3,844 & $-1,065$ \\
\hline $\mathbf{( 1 2 - 1 3 )}$ & 3,306 & 3,398 & 11,835 & 3,249 & 4,330 & $-1,469$ \\
\hline $\mathbf{( 1 3 - 1 4 )}$ & 1,543 & 0,812 & 3,968 & $-2,675$ & $-5,116$ & $-9,714$ \\
\hline $\mathbf{( 1 4 - 1 5 )}$ & 1,272 & 0,862 & 0,617 & 0,616 & $-3,319$ & $-10,156$ \\
\hline $\mathbf{( 1 5 - 1 6 )}$ & 1,024 & 0,247 & 3,519 & $-2,275$ & $-5,049$ & $-5,388$ \\
\hline $\mathbf{( 1 6 - 1 7})$ & 1,594 & 1,863 & 2,628 & 0,313 & $-6,044$ & $-7,502$ \\
\hline $\mathbf{( 1 7 - 1 8 )}$ & 1,096 & 2,024 & 0,469 & $-4,143$ & $-11,056$ & $-7,548$ \\
\hline $\mathbf{( 1 8 - 1 9 )}$ & 1,718 & 2,543 & 3,219 & $-4,188$ & $-10,635$ & $-8,810$ \\
\hline $\mathbf{( 1 9 - 2 0 )}$ & 1,140 & 2,173 & 3,336 & $-1,441$ & $-5,931$ & $-4,359$ \\
\hline $\mathbf{( 2 0 - 2 1 )}$ & 3,108 & 3,997 & 3,900 & $-1,647$ & $-3,889$ & $-5,047$ \\
\hline $\mathbf{( 2 1 - 2 2 )}$ & 1,272 & 2,852 & 5,080 & $-6,593$ & $-6,727$ & $-6,546$ \\
\hline $\mathbf{( 2 2 - 2 3 )}$ & 1,905 & 1,980 & 9,542 & $-11,781$ & $-17,115$ & $-8,675$ \\
\hline E.M.Q & $\mathbf{1 , 6 5 3}$ & $\mathbf{2 , 8 4 4}$ & $\mathbf{6 , 0 0 2}$ & $\mathbf{3 , 0 9 1}$ & $\mathbf{6 , 6 7 8}$ & $\mathbf{4 , 4 1 6}$ \\
\hline Desvio Padrão & $\pm \mathbf{0 . 6 8 1}$ & $\pm \mathbf{2 . 1 0 0}$ & $\pm \mathbf{4 . 6 7 7}$ & $\pm \mathbf{3 . 4 6 6}$ & $\pm \mathbf{6 . 0 4 2}$ & $\pm \mathbf{3 . 9 6 6}$ \\
\hline
\end{tabular}

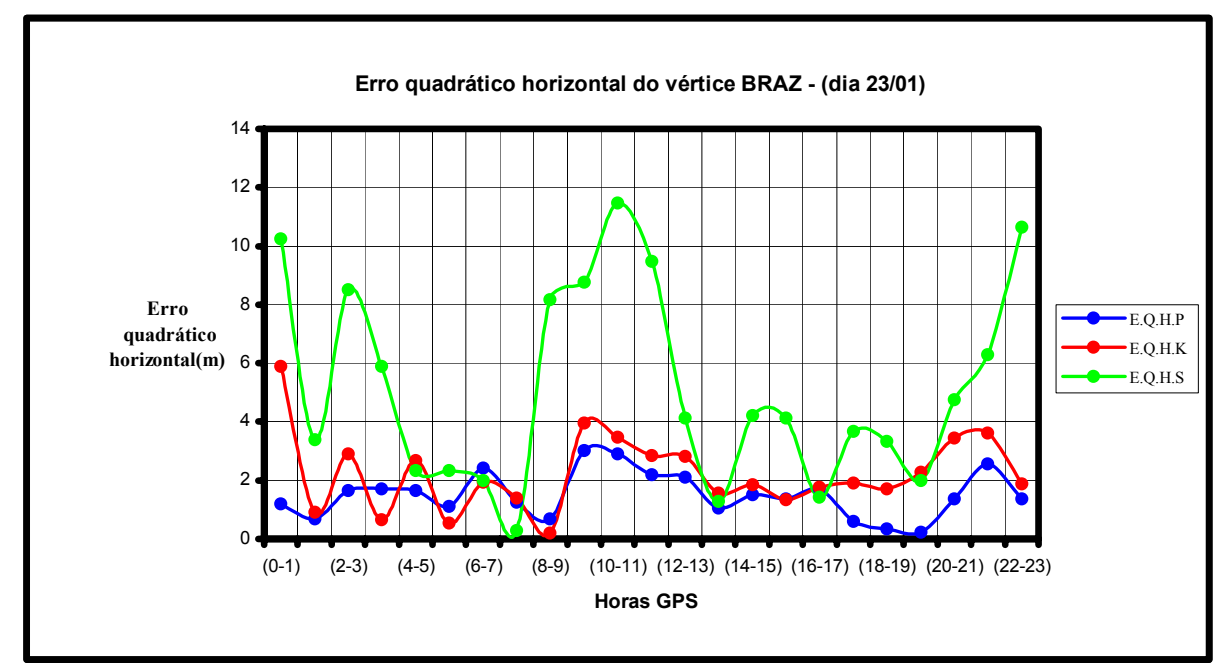

Figura 7.21 - Variação horária do erro quadrático horizontal no posicionamento Single Point do vértice BRAZ - (dia 23/01) 


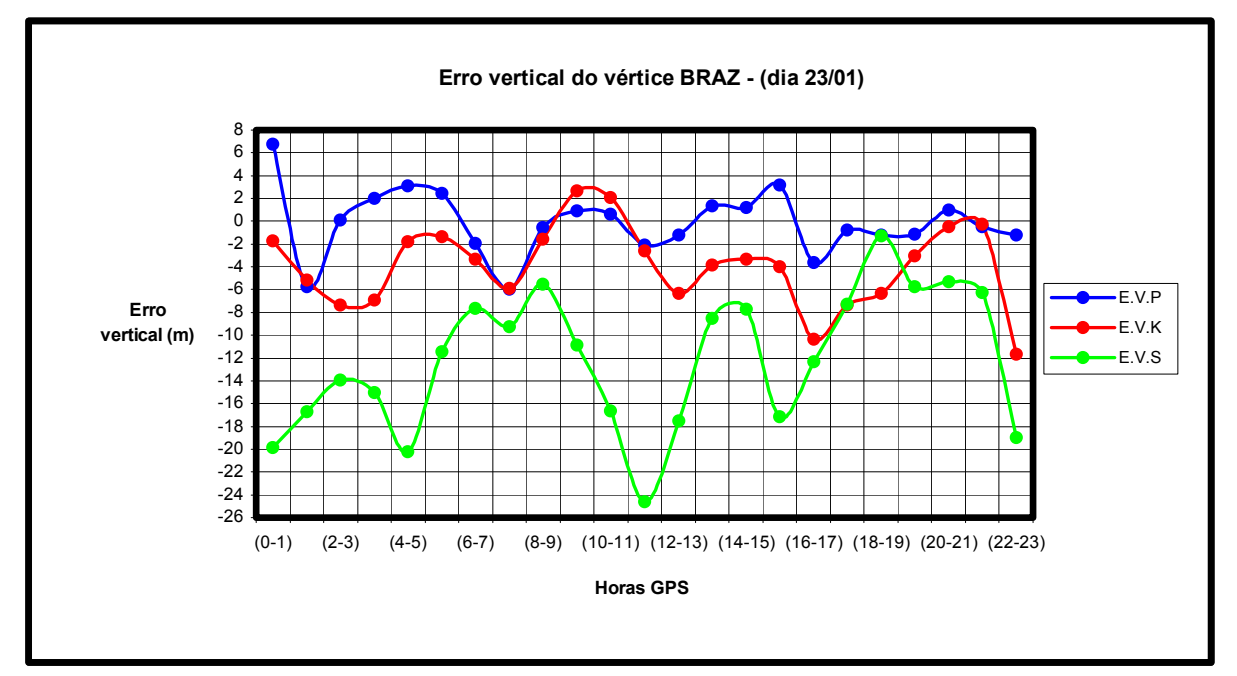

Figura 7.22 - Variação horária do erro vertical no posicionamento Single Point do vértice BRAZ - (dia 23/01)

Tabela 7.19 - Erro quadrático horizontal e erro vertical no processamento Single Point do vértice BRAZ para diferentes modelos ionosféricos - (dia 23/01).

\begin{tabular}{|c|c|c|c|c|c|c|}
\cline { 2 - 7 } \multicolumn{1}{c|}{} & \multicolumn{2}{c|}{ Erro Quadrático Horizontal (m) } & \multicolumn{3}{c|}{ Erro Vertical (m) } \\
\hline Horas & E.Q.H.P & E.Q.H.K & E.Q.H.S & E.V.P & E.V.K & E.V.S \\
\hline $\mathbf{( 1 - 2 )}$ & 1,206 & 5,894 & 10,235 & 6,758 & $-1,705$ & $-19,847$ \\
\hline $\mathbf{( 2 - 3 )}$ & 0,695 & 0,924 & 3,392 & $-5,755$ & $-5,149$ & $-16,702$ \\
\hline $\mathbf{( 3 - 4 )}$ & 1,637 & 2,912 & 8,513 & 0,138 & $-7,388$ & $-13,948$ \\
\hline $\mathbf{( 4 - 5 )}$ & 1,701 & 0,646 & 5,895 & 2,029 & $-6,894$ & $-15,017$ \\
\hline $\mathbf{( 5 - 6 )}$ & 1,638 & 2,678 & 2,345 & 3,122 & $-1,802$ & $-20,225$ \\
\hline $\mathbf{( 6 - 7 )}$ & 1,120 & 0,538 & 2,331 & 2,412 & $-1,386$ & $-11,429$ \\
\hline $\mathbf{( 7 - 8 )}$ & 2,413 & 1,936 & 2,003 & $-1,965$ & $-3,317$ & $-7,641$ \\
\hline $\mathbf{( 8 - 9 )}$ & 1,247 & 1,403 & 0,281 & $-5,986$ & $-5,908$ & $-9,233$ \\
\hline $\mathbf{( 9 - 1 0 )}$ & 0,672 & 0,203 & 8,176 & $-0,544$ & $-1,612$ & $-5,520$ \\
\hline $\mathbf{( 1 0 - 1 1 )}$ & 3,003 & 3,964 & 8,768 & 0,940 & 2,668 & $-10,835$ \\
\hline $\mathbf{( 1 1 - 1 2 )}$ & 2,911 & 3,474 & 11,468 & 0,620 & 2,092 & $-16,646$ \\
\hline $\mathbf{( 1 2 - 1 3 )}$ & 2,202 & 2,854 & 9,481 & $-2,070$ & $-2,601$ & $-24,597$ \\
\hline $\mathbf{( 1 3 - 1 4 )}$ & 2,115 & 2,815 & 4,132 & $-1,220$ & $-6,333$ & $-17,552$ \\
\hline $\mathbf{( 1 4 - 1 5 )}$ & 1,056 & 1,558 & 1,286 & 1,367 & $-3,822$ & $-8,528$ \\
\hline $\mathbf{( 1 5 - 1 6 )}$ & 1,504 & 1,847 & 4,210 & 1,188 & $-3,343$ & $-7,734$ \\
\hline $\mathbf{( 1 6 - 1 7 )}$ & 1,356 & 1,346 & 4,113 & 3,170 & $-3,961$ & $-17,140$ \\
\hline $\mathbf{( 1 7 - 1 8 )}$ & 1,718 & 1,760 & 1,426 & $-3,619$ & $-10,371$ & $-12,302$ \\
\hline $\mathbf{( 1 8 - 1 9 )}$ & 0,602 & 1,910 & 3,673 & $-0,787$ & $-7,357$ & $-7,288$ \\
\hline $\mathbf{( 1 9 - 2 0 )}$ & 0,328 & 1,707 & 3,319 & $-1,225$ & $-6,366$ & $-1,288$ \\
\hline $\mathbf{( 2 0 - 2 1 )}$ & 0,234 & 2,286 & 1,995 & $-1,112$ & $-3,031$ & $-5,757$ \\
\hline $\mathbf{( 2 1 - 2 2})$ & 1,360 & 3,455 & 4,762 & 0,979 & $-0,461$ & $-5,328$ \\
\hline $\mathbf{( 2 2 - 2 3 )}$ & 2,562 & 3,612 & 6,292 & $-0,506$ & $-0,231$ & $-6,256$ \\
\hline E.M.Q & $\mathbf{1 , 5 0 6}$ & $\mathbf{2 , 2 4 3}$ & $\mathbf{5 , 1 6 2}$ & $\mathbf{2 , 1 1 9}$ & $\mathbf{4 , 3 2 5}$ & $\mathbf{1 2 , 1 6 5}$ \\
\hline Desvio Padrão & $\pm \mathbf{0 . 7 6 5}$ & $\pm \mathbf{1 . 2 9 4}$ & $\pm \mathbf{3 . 3 7 1}$ & $\pm \mathbf{2 . 8 4 1}$ & $\pm \mathbf{3 . 5 7 5}$ & $\pm \mathbf{6 . 0 4 5}$ \\
\hline
\end{tabular}




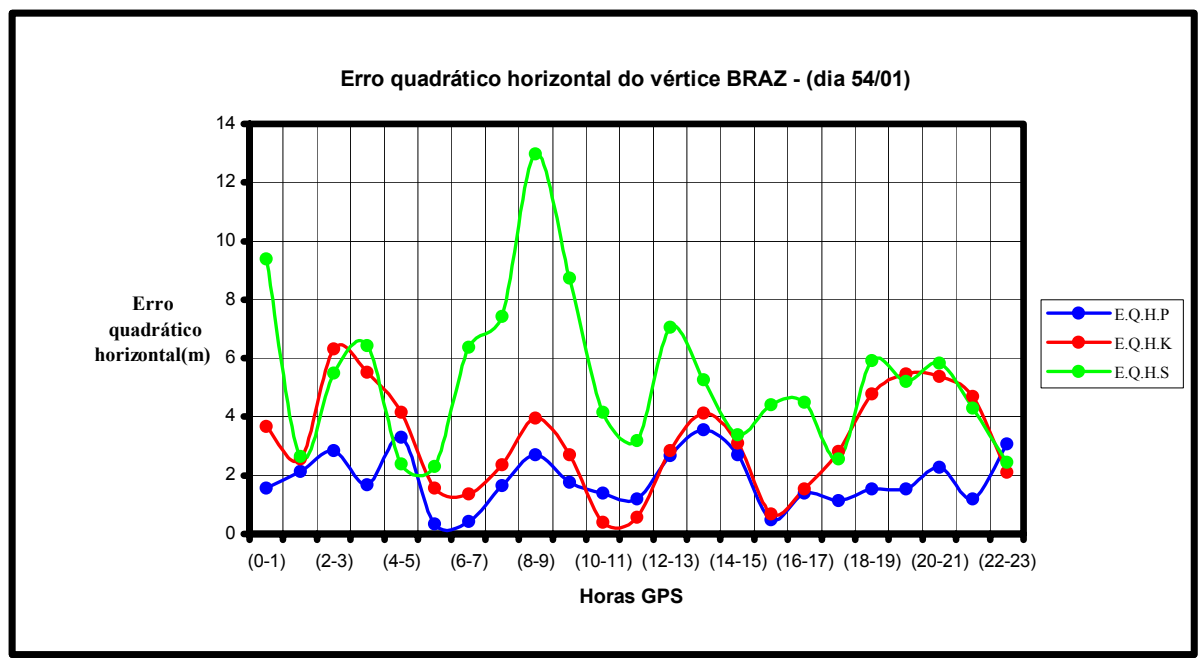

Figura 7.23 - Variação horária do erro quadrático horizontal no posicionamento Single Point do vértice BRAZ - (dia 54/01)

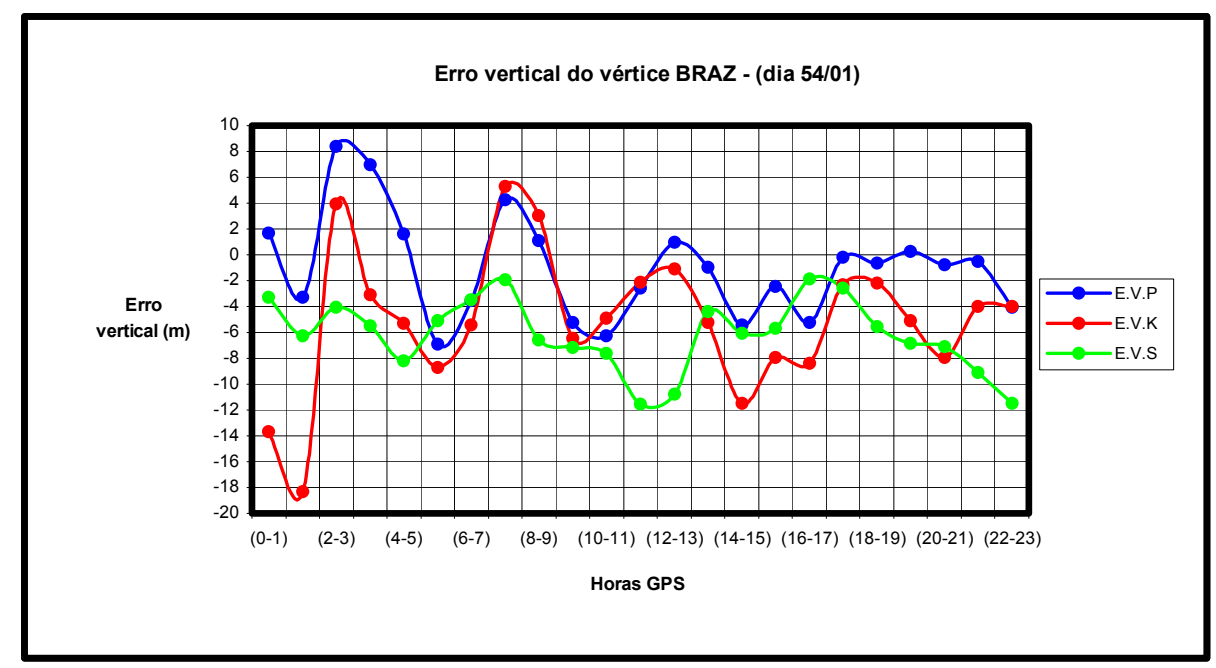

Figura 7.24 - Variação horária do erro vertical no posicionamento Single Point do vértice $\mathrm{BRAZ}$ - (dia 54/01) 
Tabela 7.20 - Erro quadrático horizontal e erro vertical no processamento Single Point do vértice BRAZ para diferentes modelos ionosféricos - (dia 54/01).

\begin{tabular}{|c|c|c|c|c|c|c|}
\cline { 2 - 7 } \multicolumn{1}{c|}{} & \multicolumn{2}{c|}{ Erro Quadrático Horizontal (m) } & \multicolumn{3}{c|}{ Erro Vertical (m) } \\
\hline Horas & E.Q.H.P & E.Q.H.K & E.Q.H.S & E.V.P & E.V.K & E.V.S \\
\hline $\mathbf{( 1 - 2 )}$ & 1,552 & 3,683 & 9,384 & 1,655 & $-13,705$ & $-3,317$ \\
\hline $\mathbf{( 2 - 3 )}$ & 2,137 & 2,569 & 2,638 & $-3,260$ & $-18,292$ & $-6,228$ \\
\hline $\mathbf{( 3 - 4 )}$ & 2,838 & 6,309 & 5,504 & 8,399 & 3,965 & $-4,067$ \\
\hline $\mathbf{( 4 - 5 )}$ & 1,684 & 5,525 & 6,435 & 6,943 & $-3,110$ & $-5,480$ \\
\hline $\mathbf{( 5 - 6 )}$ & 3,291 & 4,143 & 2,400 & 1,592 & $-5,298$ & $-8,170$ \\
\hline $\mathbf{( 6 - 7 )}$ & 0,330 & 1,574 & 2,307 & $-6,922$ & $-8,717$ & $-5,129$ \\
\hline $\mathbf{( 7 - 8 )}$ & 0,414 & 1,353 & 6,376 & $-3,531$ & $-5,447$ & $-3,497$ \\
\hline $\mathbf{( 8 - 9 )}$ & 1,655 & 2,370 & 7,439 & 4,236 & 5,304 & $-1,964$ \\
\hline $\mathbf{( 9 - 1 0 )}$ & 2,689 & 3,948 & 12,969 & 1,122 & 3,018 & $-6,559$ \\
\hline $\mathbf{( 1 0 - 1 1 )}$ & 1,772 & 2,702 & 8,724 & $-5,197$ & $-6,463$ & $-7,189$ \\
\hline $\mathbf{( 1 1 - 1 2 )}$ & 1,391 & 0,386 & 4,145 & $-6,249$ & $-4,888$ & $-7,607$ \\
\hline $\mathbf{( 1 2 - 1 3 )}$ & 1,202 & 0,556 & 3,186 & $-2,602$ & $-2,105$ & $-11,570$ \\
\hline $\mathbf{( 1 3 - 1 4 )}$ & 2,686 & 2,834 & 7,044 & 0,992 & $-1,083$ & $-10,757$ \\
\hline $\mathbf{( 1 4 - 1 5 )}$ & 3,562 & 4,136 & 5,278 & $-0,947$ & $-5,253$ & $-4,379$ \\
\hline $\mathbf{( 1 5 - 1 6 )}$ & 2,692 & 3,089 & 3,394 & $-5,405$ & $-11,456$ & $-6,041$ \\
\hline $\mathbf{( 1 6 - 1 7})$ & 0,496 & 0,693 & 4,409 & $-2,475$ & $-7,962$ & $-5,667$ \\
\hline $\mathbf{( 1 7 - 1 8 )}$ & 1,390 & 1,539 & 4,508 & $-5,245$ & $-8,366$ & $-1,862$ \\
\hline $\mathbf{( 1 8 - 1 9 )}$ & 1,136 & 2,803 & 2,558 & $-0,168$ & $-2,323$ & $-2,600$ \\
\hline $\mathbf{( 1 9 - 2 0 )}$ & 1,528 & 4,767 & 5,929 & $-0,626$ & $-2,194$ & $-5,551$ \\
\hline $\mathbf{( 2 0 - 2 1 )}$ & 1,534 & 5,468 & 5,212 & 0,241 & $-5,083$ & $-6,847$ \\
\hline $\mathbf{( 2 1 - 2 2 )}$ & $\mathbf{2}, 265$ & 5,389 & 5,847 & $-0,777$ & $-7,929$ & $-7,117$ \\
\hline $\mathbf{( 2 2 - 2 3 )}$ & 1,196 & 4,704 & 4,298 & $-0,532$ & $-3,991$ & $-9,083$ \\
\hline E.M.Q & $\mathbf{1 , 8 4 9}$ & $\mathbf{3 , 1 5 8}$ & $\mathbf{5 , 3 2 3}$ & $\mathbf{3 , 1 8 2}$ & $\mathbf{6 , 0 8 4}$ & $\mathbf{6 , 1 8 2}$ \\
\hline Desvio Padrão & $\pm \mathbf{0 . 9 1 0}$ & $\pm \mathbf{1 . 7 2 0}$ & $\pm \mathbf{2 . 6 1 1}$ & $\pm \mathbf{3 . 9 7 2}$ & $\pm \mathbf{5 . 3 7 0}$ & $\pm \mathbf{2 . 7 7 9}$ \\
\hline
\end{tabular}

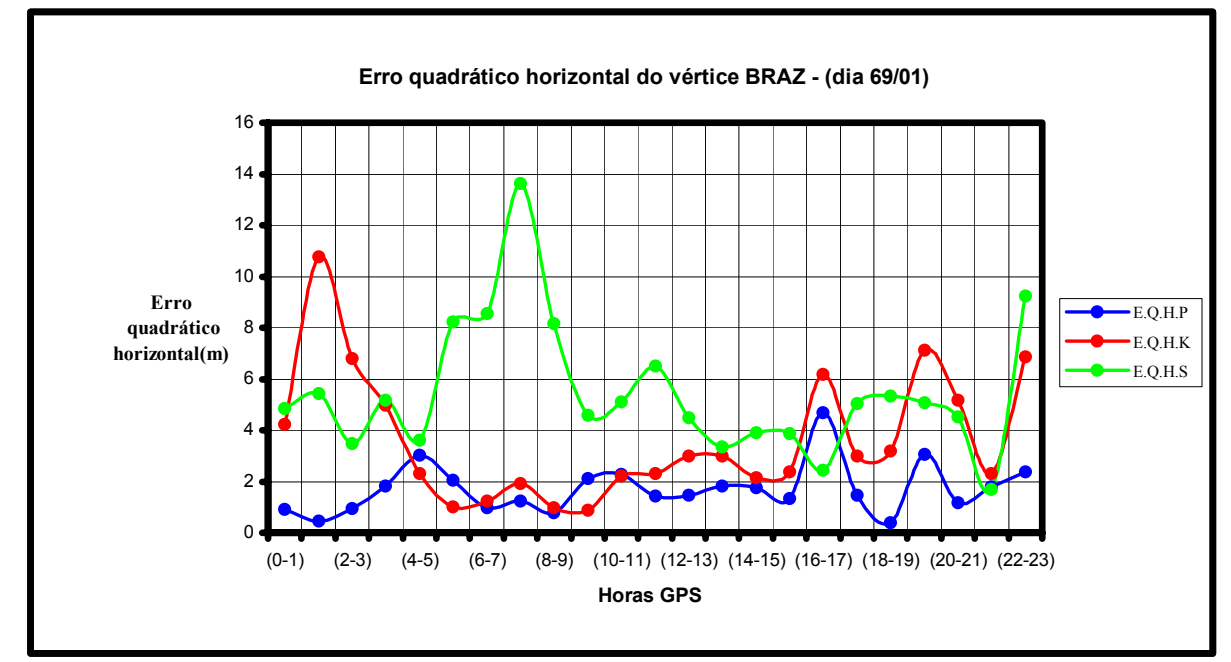

Figura 7.25 - Variação horária do erro quadrático horizontal no posicionamento Single Point do vértice BRAZ - (dia 69/01) 


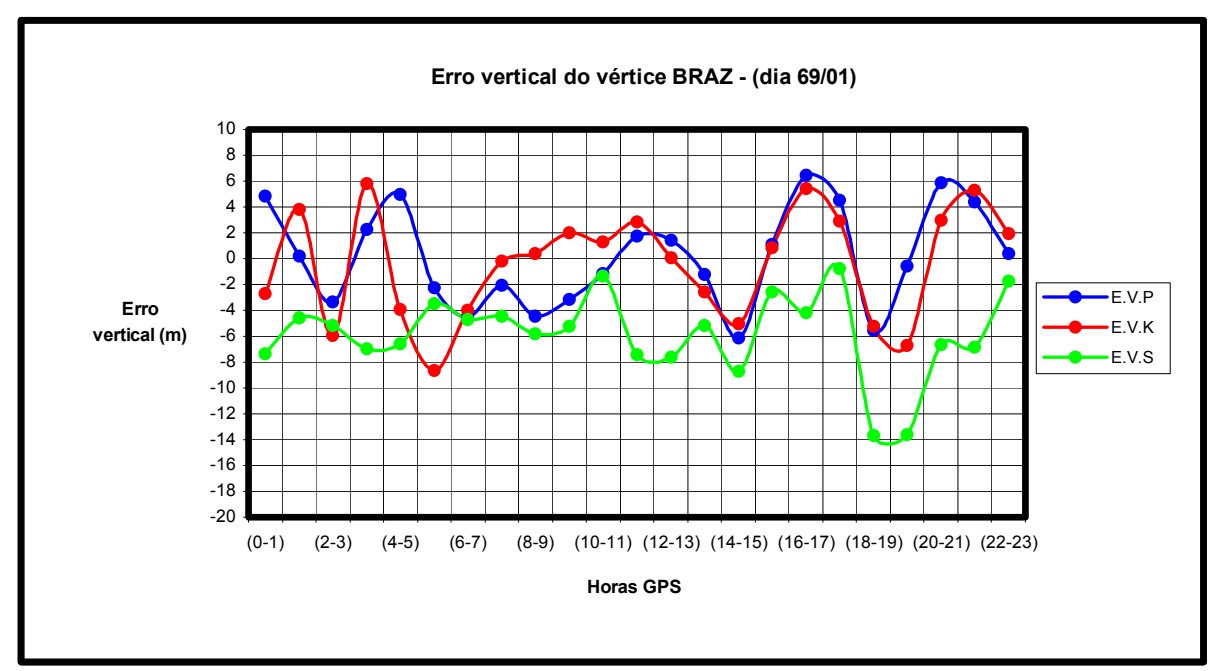

Figura 7.26 - Variação horária do erro vertical no posicionamento Single Point do vértice BRAZ - (dia 69/01)

Tabela 7.21 - Erro quadrático horizontal e erro vertical no processamento Single Point do vértice BRAZ para diferentes modelos ionosféricos - (dia 69/01).

\begin{tabular}{|c|c|c|c|c|c|c|}
\cline { 2 - 7 } \multicolumn{1}{c|}{} & \multicolumn{2}{c|}{ Erro Quadrático Horizontal (m) } & \multicolumn{3}{c|}{ Erro Vertical (m) } \\
\hline Horas & E.Q.H.P & E.Q.H.K & E.Q.H.S & E.V.P & E.V.K & E.V.S \\
\hline $\mathbf{( 1 - 2 )}$ & 0,916 & 4,223 & 4,840 & 4,846 & $-2,704$ & $-7,356$ \\
\hline $\mathbf{( 2 - 3 )}$ & 0,462 & 10,780 & 5,445 & 0,216 & 3,782 & $-4,550$ \\
\hline $\mathbf{( 3 - 4 )}$ & 0,954 & 6,805 & 3,495 & $-3,348$ & $-5,924$ & $-5,153$ \\
\hline $\mathbf{( 4 - 5 )}$ & 1,807 & 4,969 & 5,178 & 2,255 & 5,776 & $-6,940$ \\
\hline $\mathbf{( 5 - 6 )}$ & 3,015 & 2,310 & 3,601 & 4,942 & $-3,924$ & $-6,580$ \\
\hline $\mathbf{( 6 - 7 )}$ & 2,036 & 1,018 & 8,218 & $-2,273$ & $-8,675$ & $-3,488$ \\
\hline $\mathbf{( 7 - 8 )}$ & 0,961 & 1,221 & 8,540 & $-4,490$ & $-3,980$ & $-4,735$ \\
\hline $\mathbf{( 8 - 9 )}$ & 1,243 & 1,921 & 13,629 & $-2,083$ & $-0,179$ & $-4,432$ \\
\hline $\mathbf{( 9 - 1 0 )}$ & 0,793 & 0,965 & 8,165 & $-4,456$ & 0,405 & $-5,781$ \\
\hline $\mathbf{( 1 0 - 1 1 )}$ & 2,121 & 0,890 & 4,570 & $-3,140$ & 1,995 & $-5,207$ \\
\hline $\mathbf{( 1 1 - 1 2 )}$ & 2,274 & 2,216 & 5,102 & $-1,184$ & 1,299 & $-1,339$ \\
\hline $\mathbf{( 1 2 - 1 3 )}$ & 1,441 & 2,302 & 6,516 & 1,730 & 2,842 & $-7,451$ \\
\hline $\mathbf{( 1 3 - 1 4 )}$ & 1,478 & 2,996 & 4,487 & 1,408 & 0,091 & $-7,595$ \\
\hline $\mathbf{( 1 4 - 1 5 )}$ & 1,814 & 2,996 & 3,365 & $-1,203$ & $-2,589$ & $-5,156$ \\
\hline $\mathbf{( 1 5 - 1 6 )}$ & 1,747 & 2,157 & 3,904 & $-6,141$ & $-5,058$ & $-8,739$ \\
\hline $\mathbf{( 1 6 - 1 7 )}$ & 1,339 & 2,373 & 3,871 & 1,105 & 0,806 & $-2,599$ \\
\hline $\mathbf{( 1 7 - 1 8 )}$ & 4,683 & 6,174 & 2,433 & 6,449 & 5,415 & $-4,203$ \\
\hline $\mathbf{( 1 8 - 1 9 )}$ & 1,448 & 2,985 & 5,050 & 4,527 & 2,931 & $-0,785$ \\
\hline $\mathbf{( 1 9 - 2 0 )}$ & 0,382 & 3,201 & 5,340 & $-5,570$ & $-5,207$ & $-13,686$ \\
\hline $\mathbf{( 2 0 - 2 1 )}$ & 3,068 & $\mathbf{7}) 112$ & 5,083 & $-0,573$ & $-6,701$ & $-13,585$ \\
\hline $\mathbf{( 2 1 - 2 2 )}$ & 1,172 & 5,163 & 4,521 & 5,867 & 2,966 & $-6,659$ \\
\hline $\mathbf{( 2 2 - 2 3 )}$ & 1,789 & 2,309 & 1,685 & 4,363 & 5,274 & $-6,838$ \\
\hline E.M.Q & $\mathbf{1 , 7 1 0}$ & $\mathbf{3 , 6 5 1}$ & $\mathbf{5 , 4 9 0}$ & $\mathbf{3 , 1 5 6}$ & $\mathbf{3 , 4 9 8}$ & $\mathbf{5 , 8 5 2}$ \\
\hline Desvio Padrão & $\pm \mathbf{0 . 9 5 9}$ & $\pm \mathbf{2 . 4 9 9}$ & $\pm \mathbf{2 . 6 1 2}$ & $\pm \mathbf{3 . 7 9 5}$ & $\pm \mathbf{4 . 2 1 0}$ & $\pm \mathbf{3 . 2 2 5}$ \\
\hline
\end{tabular}




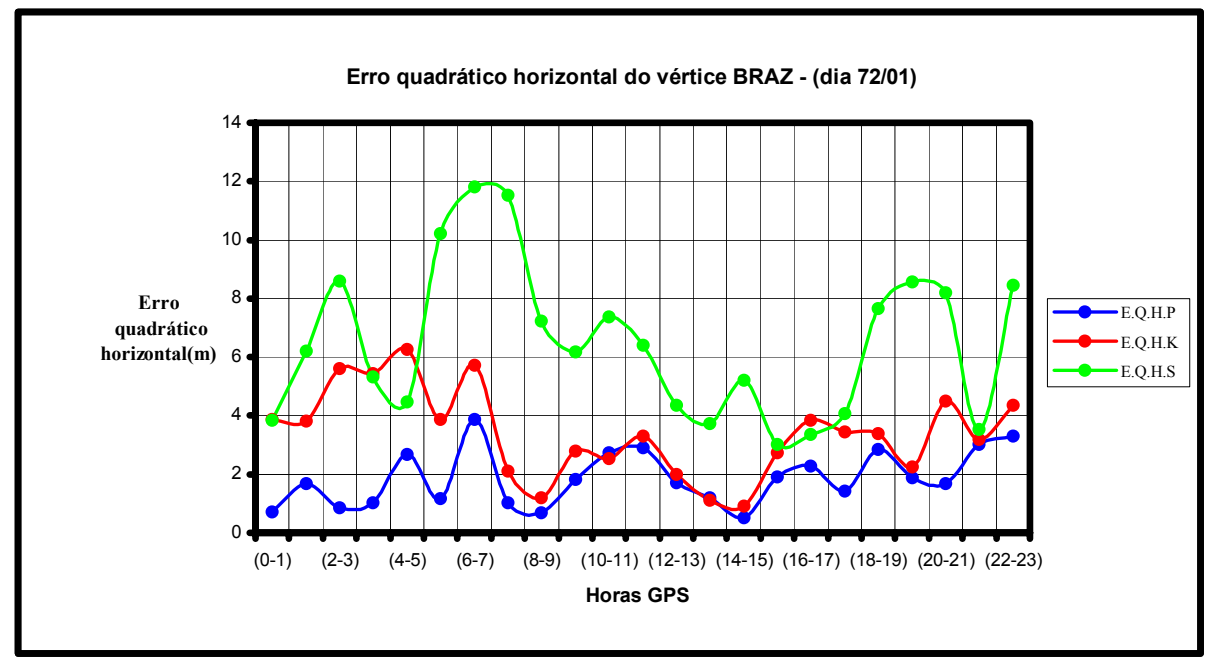

Figura 7.27 - Variação horária do erro quadrático horizontal no posicionamento Single Point do vértice BRAZ - (dia 72/01)

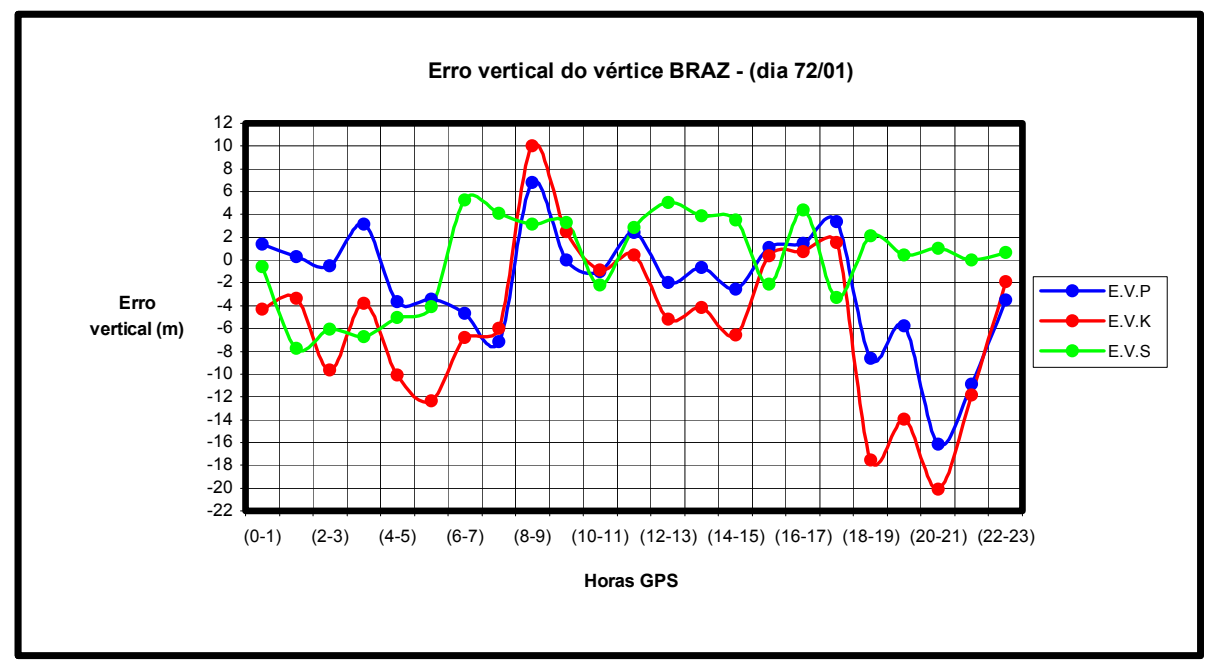

Figura 7.28 - Variação horária do erro vertical no posicionamento Single Point do vértice $B R A Z$ - (dia 72/01) 
Tabela 7.22 - Erro quadrático horizontal e erro vertical no processamento Single Point do vértice BRAZ para diferentes modelos ionosféricos - (dia 72/01).

\begin{tabular}{|c|c|c|c|c|c|c|}
\cline { 2 - 7 } \multicolumn{1}{c|}{} & \multicolumn{2}{c|}{ Erro Quadrático Horizontal (m) } & \multicolumn{3}{c|}{ Erro Vertical (m) } \\
\hline Horas & E.Q.H.P & E.Q.H.K & E.Q.H.S & E.V.P & E.V.K & E.V.S \\
\hline $\mathbf{( 1 - 2 )}$ & 0,710 & 3,875 & 3,838 & 1,417 & $-4,313$ & $-0,609$ \\
\hline $\mathbf{( 2 - 3 )}$ & 1,673 & 3,823 & 6,189 & 0,317 & $-3,352$ & $-7,714$ \\
\hline $\mathbf{( 3 - 4 )}$ & 0,864 & 5,612 & 8,594 & $-0,508$ & $-9,675$ & $-6,082$ \\
\hline $\mathbf{( 4 - 5 )}$ & 1,032 & 5,432 & 5,307 & 3,116 & $-3,810$ & $-6,749$ \\
\hline $\mathbf{( 5 - 6 )}$ & 2,664 & 6,272 & 4,469 & $-3,659$ & $-10,078$ & $-5,047$ \\
\hline $\mathbf{( 6 - 7 )}$ & 1,174 & 3,858 & 10,204 & $-3,447$ & $-12,339$ & $-4,080$ \\
\hline $\mathbf{( 7 - 8 )}$ & 3,875 & 5,724 & 11,823 & $-4,681$ & $-6,756$ & 5,308 \\
\hline $\mathbf{( 8 - 9 )}$ & 1,018 & 2,098 & 11,524 & $-7,154$ & $-5,980$ & 4,096 \\
\hline $\mathbf{( 9 - 1 0 )}$ & 0,670 & 1,183 & 7,214 & 6,833 & 10,026 & 3,163 \\
\hline $\mathbf{( 1 0 - 1 1 )}$ & 1,822 & 2,794 & 6,174 & $-0,006$ & 2,505 & 3,298 \\
\hline $\mathbf{( 1 1 - 1 2 )}$ & 2,745 & 2,532 & 7,384 & $-1,020$ & $-0,879$ & $-2,217$ \\
\hline $\mathbf{( 1 2 - 1 3 )}$ & 2,900 & 3,292 & 6,389 & 2,403 & 0,478 & 2,872 \\
\hline $\mathbf{( 1 3 - 1 4 )}$ & 1,705 & 2,001 & 4,340 & $-1,995$ & $-5,154$ & 5,057 \\
\hline $\mathbf{( 1 4 - 1 5 )}$ & 1,199 & 1,103 & 3,714 & $-0,655$ & $-4,155$ & 3,914 \\
\hline $\mathbf{( 1 5 - 1 6 )}$ & 0,509 & 0,907 & 5,212 & $-2,583$ & $-6,592$ & 3,482 \\
\hline $\mathbf{( 1 6 - 1 7 )}$ & 1,901 & 2,735 & 3,011 & 1,084 & 0,373 & $-2,119$ \\
\hline $\mathbf{( 1 7 - 1 8 )}$ & 2,270 & 3,846 & 3,360 & 1,471 & 0,753 & 4,375 \\
\hline$(\mathbf{1 8 - 1 9 )}$ & 1,435 & 3,457 & 4,066 & 3,369 & 1,576 & $-3,284$ \\
\hline $\mathbf{( 1 9 - 2 0 )}$ & 2,840 & 3,377 & $\mathbf{7 , 6 6 8}$ & $-8,649$ & $-17,541$ & 2,139 \\
\hline $\mathbf{( 2 0 - 2 1 )}$ & 1,891 & 2,257 & 8,571 & $-5,760$ & $-13,988$ & 0,477 \\
\hline $\mathbf{( 2 1 - 2 2 )}$ & 1,678 & 4,509 & 8,189 & $-16,132$ & $-20,120$ & 1,007 \\
\hline $\mathbf{( 2 2 - 2 3 )}$ & 3,015 & 3,185 & 3,526 & $-10,853$ & $-11,864$ & $-0,017$ \\
\hline E.M.Q & $\mathbf{1 , 8 6 5}$ & $\mathbf{3 , 4 0 1}$ & $\mathbf{6 , 4 8 8}$ & $\mathbf{3 , 9 4 0}$ & $\mathbf{6 , 7 0 5}$ & $\mathbf{3 , 3 8 0}$ \\
\hline Desvio Padrão & $\pm \mathbf{0 . 9 3 5}$ & $\pm \mathbf{1 . 4 8 7}$ & $\pm \mathbf{2 . 6 0 3}$ & $\pm \mathbf{5 . 1 2 0}$ & $\pm \mathbf{6 . 9 6 9}$ & $\pm \mathbf{4 . 0 2 9}$ \\
\hline
\end{tabular}

\subsubsection{Validação do modelo através de posicionamento relativo - período do verão}

A base utilizada neste experimento foi PARA-UEPP, de aproximadamente $430 \mathrm{~km}$. Optou-se por uma base longa, justamente para verificar o quanto a metodologia proposta pode ser eficiente quando se utiliza equipamentos de simples freqüência.

O procedimento utilizado foi o mesmo que no posicionamento Single Point, com processamento em intervalos de 3 horas. Será possível notar mais à frente, através dos gráficos e tabelas, que o comportamento dos erros quadráticos são parecidos se comparados com o posicionamento Single Point.

O intervalo com maior disparidade nos erros foi entre 0 às 6 da hora GPS. Justamente, neste intervalo, verificou-se muitos ruídos nas observáveis.

O modelo polinomial, através da metodologia de não corrigir o código $\mathrm{C} / \mathrm{A}$ e sim, através da modelagem, recriar o código $\mathrm{P}$, proporcionou melhores resultados, tanto horizontalmente, quanto verticalmente, se comparado com os modelos de Klobuchar e Standard. Ao reescrever um arquivo RINEX, com as observáveis da portadora $L_{1}$, códigos 
$\mathrm{C} / \mathrm{A}$ e $\mathrm{P}$, foi possível utilizar um modelo ionosférico mais eficiente através da solução ionofree code. Esta solução proporcionou desvios padrão constantes para os erros quadráticos do vértice UEPP, durante todo o período do dia, principalmente durante os intervalos 0 às 3 e 21 às 23 horas GPS.

O erro quadrático médio no posicionamento horizontal do vértice UEPP, foi de 0,259m, 0,720m e 0,930m, ao utilizar os modelos: polinomial, Klobuchar e Standard, respectivamente. Se comparado com o de Klobuchar, o modelo polinomial proporcionou uma melhora de $64 \%$. Ao analisar o erro vertical os erros médios quadráticos foram de $0,685 \mathrm{~m}, 0,886 \mathrm{~m}$ e $1,057 \mathrm{~m}$, ao utilizar os modelos: polinomial, Klobuchar e Standard, respectivamente. Neste caso, se comparado com o de Klobuchar a melhora foi de, aproximadamente, $23 \%$.

É importante salientar que esta melhora são valores médios diários, e que, se verificar mais à frente, através dos gráficos e tabelas, entre os intervalos de 6 às 21 horas GPS, praticamente, os três modelos estudados proporcionaram os mesmos resultados, com uma leve melhora no modelo polinomial.

A seguir serão apresentados todos os resultados referentes ao posicionamento relativo, durante o período do verão estudado.

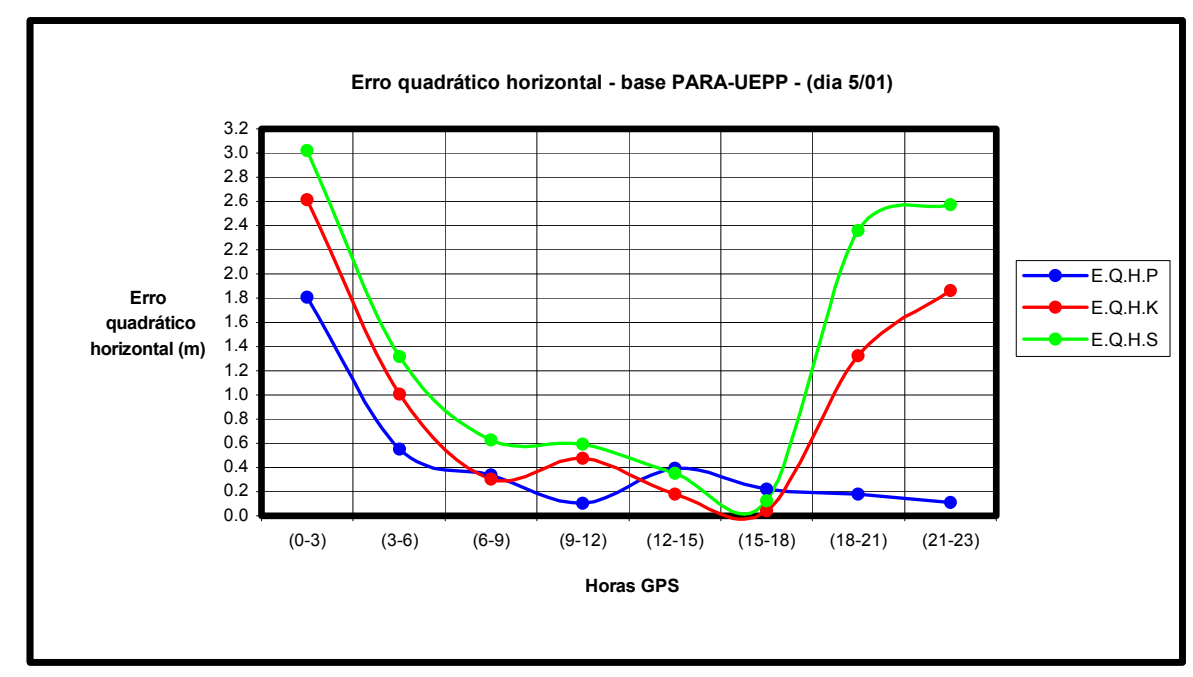

Figura 7.29 - Variação horária do erro quadrático horizontal do vértice UEPP no posicionamento relativo da base PARA - UEPP - (dia 5/01). 


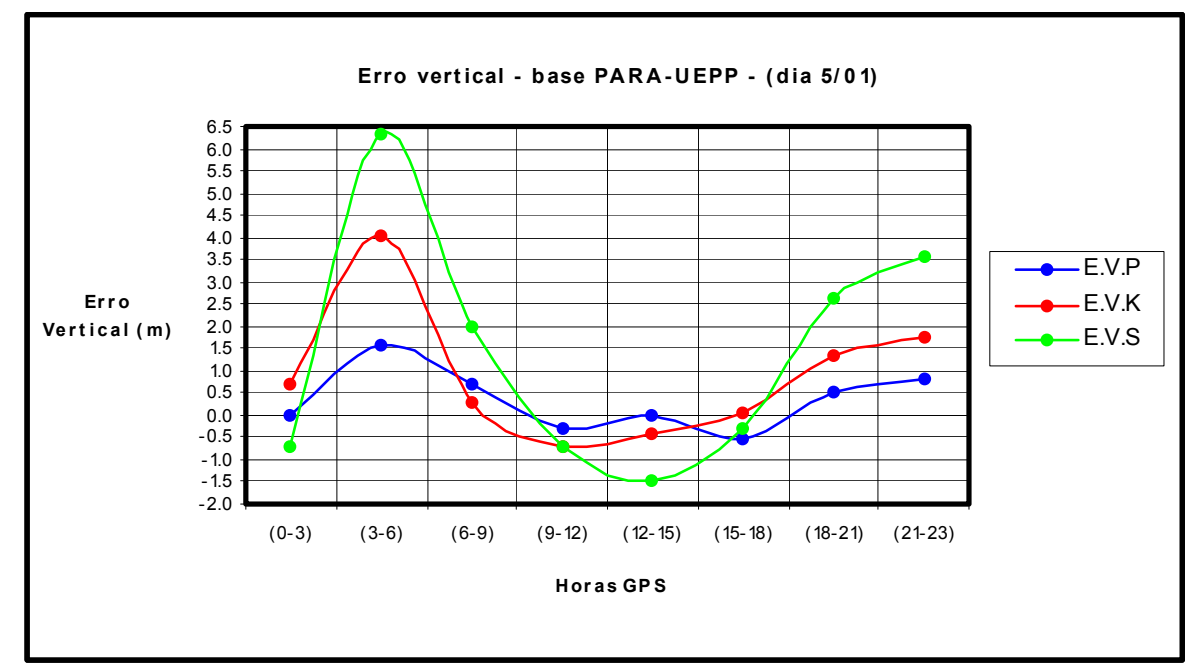

Figura 7.30 - Variação horária do erro vertical do vértice UEPP no posicionamento relativo da base PARA - UEPP - (dia 5/01).

Tabela 7.23 - Erro quadrático horizontal e erro vertical do vértice UEPP no processamento relativo da base PARA - UEPP, para diferentes modelos ionosféricos - (dia 5/01).

\begin{tabular}{|c|c|c|c|c|c|c|}
\cline { 2 - 7 } \multicolumn{1}{c|}{} & \multicolumn{3}{c|}{ Erro Quadrático Horizontal (m) } & \multicolumn{3}{c|}{ Erro Vertical (m) } \\
\hline Horas & E.Q.H.P & E.Q.H.K & E.Q.H.S & E.V.P & E.V.K & E.V.S \\
\hline $\mathbf{( 0 - 3 )}$ & 1,810 & 2,612 & 3,018 & 0,015 & 0,696 & $-0,692$ \\
\hline $\mathbf{( 3 - 6 )}$ & 0,554 & 1,009 & 1,320 & 1,601 & 4,032 & 6,345 \\
\hline $\mathbf{( 6 - 9 )}$ & 0,337 & 0,304 & 0,630 & 0,668 & 0,292 & 2,014 \\
\hline $\mathbf{( 9 - 1 2 )}$ & 0,103 & 0,475 & 0,596 & $-0,322$ & $-0,690$ & $-0,739$ \\
\hline $\mathbf{( 1 2 - 1 5 )}$ & 0,396 & 0,180 & 0,353 & 0,004 & $-0,399$ & $-1,496$ \\
\hline$(\mathbf{1 5 - 1 8 )}$ & 0,219 & 0,039 & 0,127 & $-0,532$ & 0,064 & $-0,289$ \\
\hline$(\mathbf{1 8 - 2 1 )}$ & 0,178 & 1,325 & 2,356 & 0,495 & 1,355 & 2,627 \\
\hline $\mathbf{( 2 1 - 2 3 )}$ & 0,110 & 1,863 & 2,573 & 0,842 & 1,729 & 3,552 \\
\hline E.M.Q & $\mathbf{0 , 4 6 3}$ & $\mathbf{0 , 9 7 6}$ & $\mathbf{1 , 3 7 2}$ & $\mathbf{0 , 5 6 0}$ & $\mathbf{1 , 1 5 7}$ & $\mathbf{2 , 2 1 9}$ \\
\hline Desvio Padrão & $\pm \mathbf{0 . 5 6 5}$ & $\pm \mathbf{0 . 9 1 0}$ & $\pm \mathbf{1 . 1 2 5}$ & $\pm \mathbf{0 . 6 9 6}$ & $\pm \mathbf{1 . 5 1 3}$ & $\pm \mathbf{2 . 7 0 3}$ \\
\hline
\end{tabular}




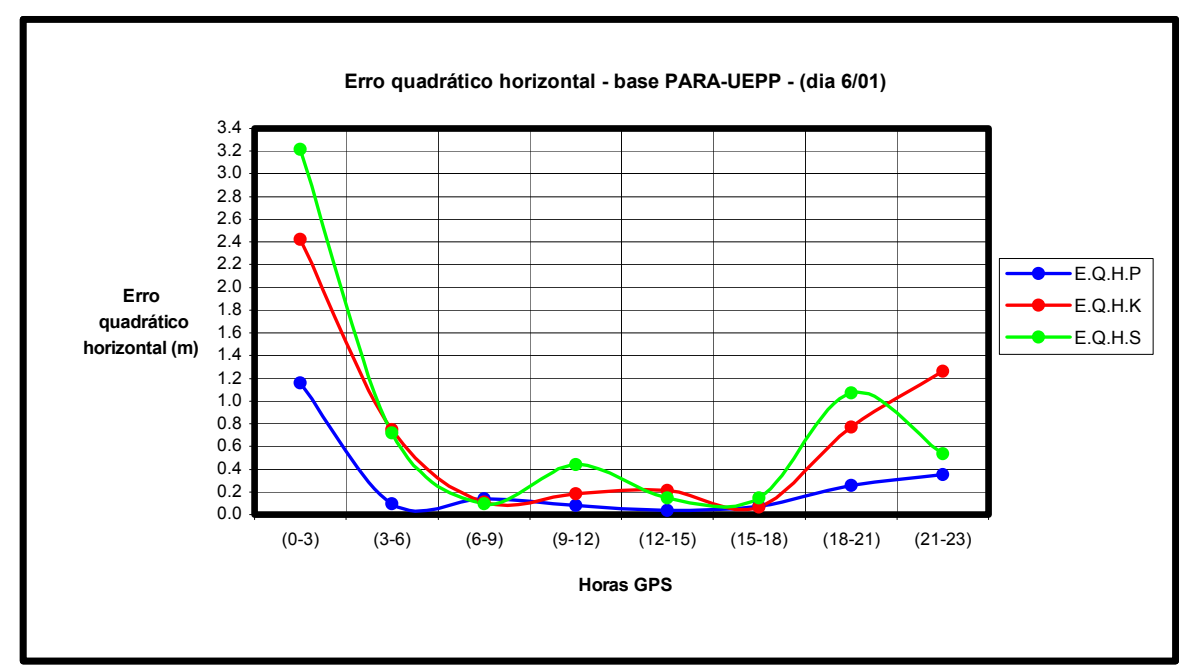

Figura 7.31 - Variação horária do erro quadrático horizontal do vértice UEPP no posicionamento relativo da base PARA - UEPP - (dia 6/01).

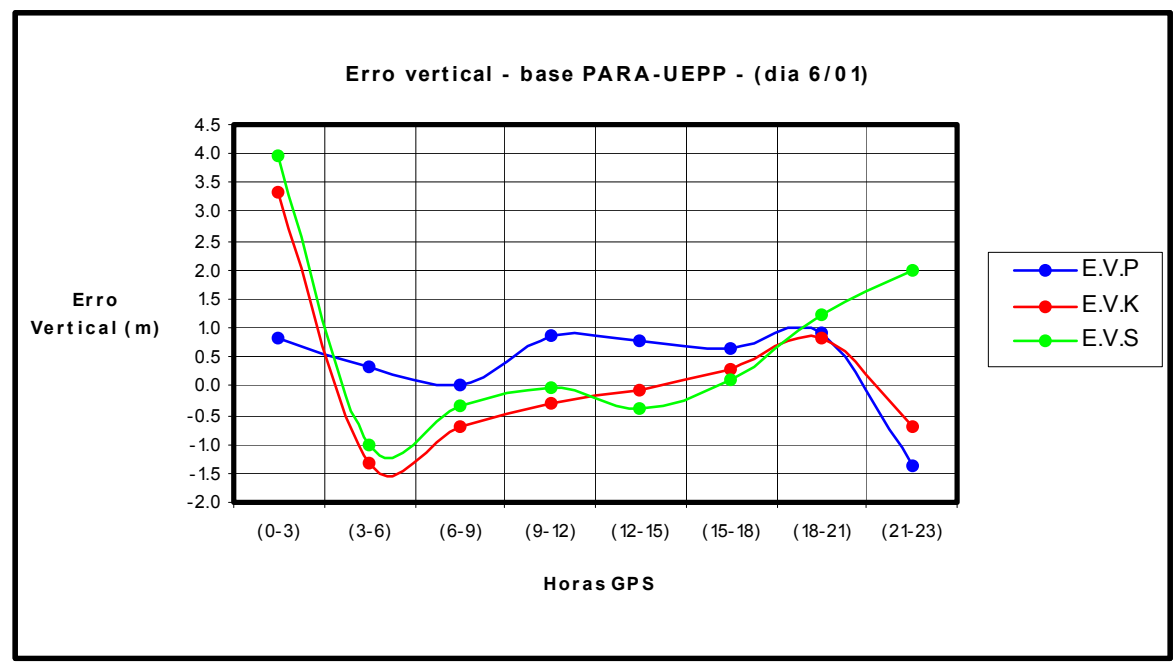

Figura 7.32 - Variação horária do erro vertical do vértice UEPP no posicionamento relativo da base PARA - UEPP - (dia 6/01).

Tabela 7.24 - Erro quadrático horizontal e erro vertical do vértice UEPP no processamento relativo da base PARA - UEPP, para diferentes modelos ionosféricos - (dia 6/01).

\begin{tabular}{|c|c|c|c|c|c|c|}
\cline { 2 - 7 } \multicolumn{1}{c|}{} & \multicolumn{3}{c|}{ Erro Quadrático Horizontal (m) } & \multicolumn{3}{c|}{ Erro Vertical (m) } \\
\hline Horas & E.Q.H.P & E.Q.H.K & E.Q.H.S & E.V.P & E.V.K & E.V.S \\
\hline $\mathbf{( 0 - 3 )}$ & 1,159 & 2,421 & 3,219 & 0,829 & 3,352 & 3,983 \\
\hline $\mathbf{( 3 - 6 )}$ & 0,095 & 0,749 & 0,718 & 0,323 & $-1,307$ & $-1,027$ \\
\hline $\mathbf{( 6 - 9 )}$ & 0,142 & 0,111 & 0,098 & 0,026 & $-0,678$ & $-0,356$ \\
\hline $\mathbf{( 9 - 1 2 )}$ & 0,082 & 0,185 & 0,442 & 0,871 & $-0,298$ & $-0,044$ \\
\hline $\mathbf{( 1 2 - 1 5 )}$ & 0,038 & 0,211 & 0,147 & 0,775 & $-0,054$ & $-0,388$ \\
\hline $\mathbf{( 1 5 - 1 8 )}$ & 0,077 & 0,066 & 0,145 & 0,632 & 0,270 & 0,103 \\
\hline $\mathbf{( 1 8 - 2 1 )}$ & 0,254 & 0,768 & 1,070 & 0,917 & 0,842 & 1,240 \\
\hline $\mathbf{( 2 1 - 2 3 )}$ & 0,351 & 1,260 & 0,534 & $-1,386$ & $-0,707$ & 1,972 \\
\hline E.M.Q & $\mathbf{0 , 2 7 5}$ & $\mathbf{0 , 7 2 1}$ & $\mathbf{0 , 7 9 7}$ & $\mathbf{0 , 7 2 0}$ & $\mathbf{0 , 9 3 8}$ & $\mathbf{1 , 1 3 9}$ \\
\hline Desvio Padrão & $\pm \mathbf{0 . 3 7 2}$ & $\pm \mathbf{0 . 8 0 5}$ & $\pm \mathbf{1 . 0 3 4}$ & $\pm \mathbf{0 . 7 7 4}$ & $\pm \mathbf{1 . 4 4 1}$ & $\pm \mathbf{1 . 6 4 2}$ \\
\hline
\end{tabular}




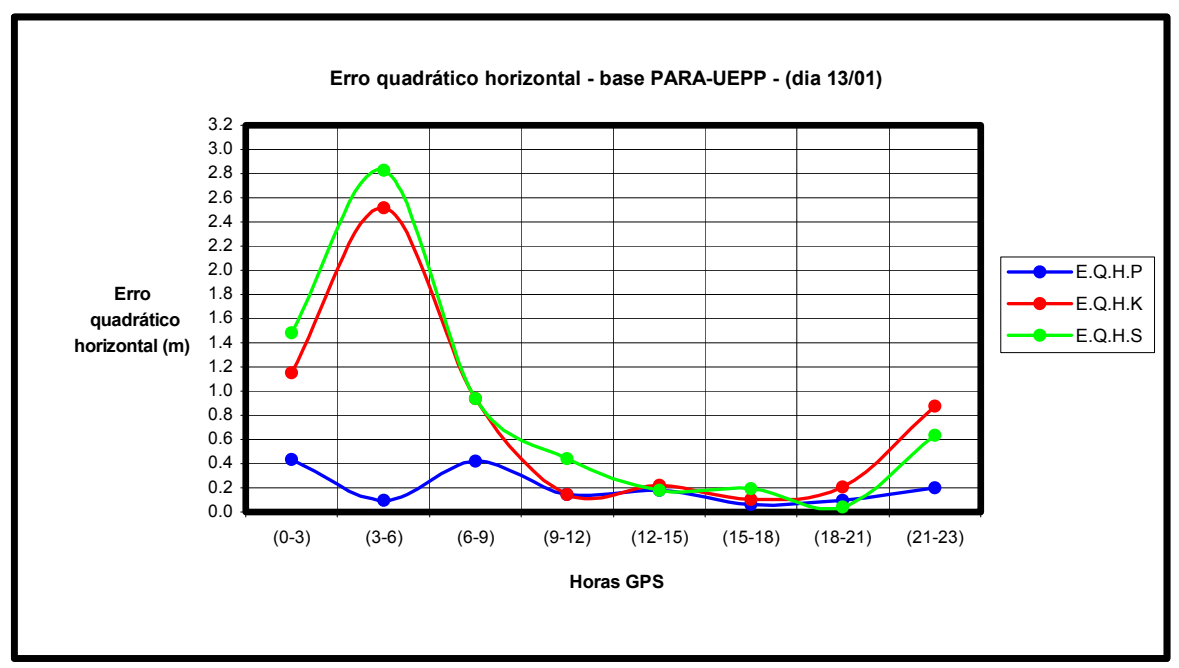

Figura 7.33 - Variação horária do erro quadrático horizontal do vértice UEPP no posicionamento relativo da base PARA - UEPP - (dia 13/01).

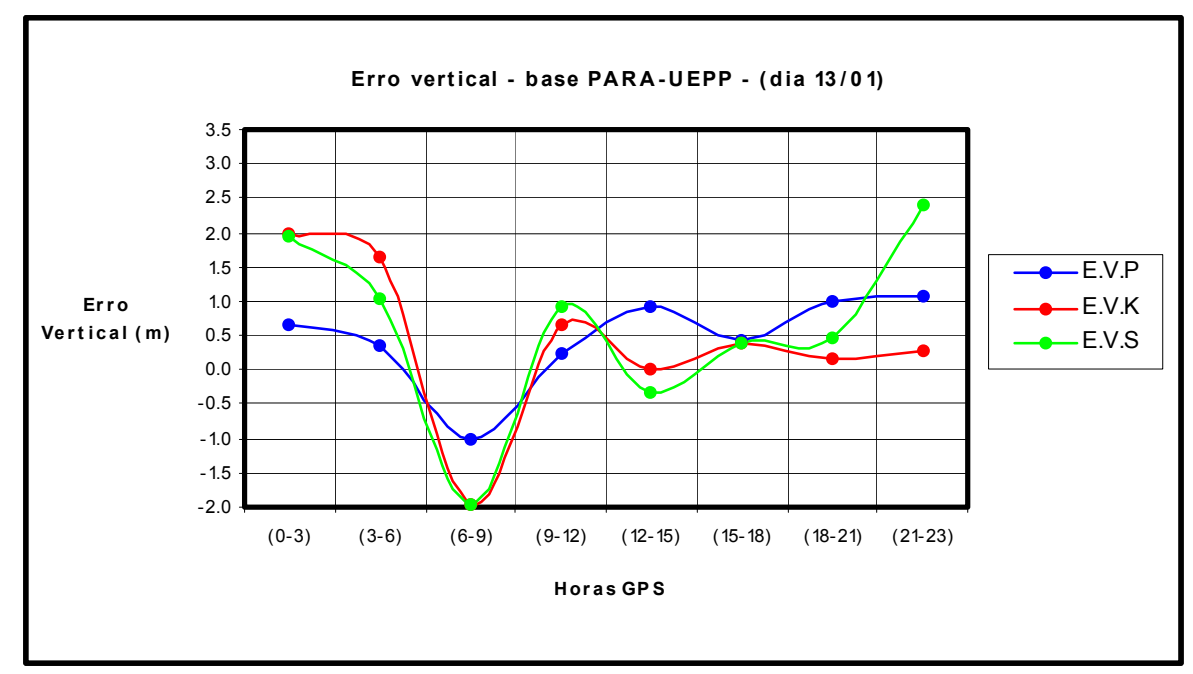

Figura 7.34 - Variação horária do erro vertical do vértice UEPP no posicionamento relativo da base PARA - UEPP - (dia 13/01).

Tabela 7.25 - Erro quadrático horizontal e erro vertical do vértice UEPP no processamento relativo da base PARA - UEPP, para diferentes modelos ionosféricos - (dia 13/01).

\begin{tabular}{|c|c|c|c|c|c|c|}
\cline { 2 - 7 } \multicolumn{1}{c|}{} & \multicolumn{3}{c|}{ Erro Quadrático Horizontal (m) } & \multicolumn{3}{c|}{ Erro Vertical (m) } \\
\hline Horas & E.Q.H.P & E.Q.H.K & E.Q.H.S & E.V.P & E.V.K & E.V.S \\
\hline $\mathbf{( 0 - 3 )}$ & 0,431 & 1,154 & 1,483 & 0,647 & 1,966 & 1,933 \\
\hline $\mathbf{( 3 - 6 )}$ & 0,095 & 2,515 & 2,828 & 0,349 & 1,653 & 1,053 \\
\hline $\mathbf{( 6 - 9 )}$ & 0,418 & 0,936 & 0,941 & $-1,015$ & $-1,952$ & $-1,969$ \\
\hline $\mathbf{( 9 - 1 2 )}$ & 0,146 & 0,142 & 0,440 & 0,220 & 0,640 & 0,904 \\
\hline$(\mathbf{1 2 - 1 5 )}$ & 0,178 & 0,224 & 0,181 & 0,930 & 0,015 & $-0,337$ \\
\hline$(\mathbf{1 5 - 1 8})$ & 0,065 & 0,102 & 0,193 & 0,434 & 0,403 & 0,396 \\
\hline $\mathbf{( 1 8 - 2 1 )}$ & 0,098 & 0,208 & 0,044 & 0,995 & 0,174 & 0,477 \\
\hline $\mathbf{( 2 1 - 2 3 )}$ & 0,203 & 0,876 & 0,633 & 1,089 & 0,294 & 2,396 \\
\hline E.M.Q & $\mathbf{0 , 2 0 4}$ & $\mathbf{0 , 7 7 0}$ & $\mathbf{0 , 8 4 3}$ & $\mathbf{0 , 7 1 0}$ & $\mathbf{0 , 8 8 7}$ & $\mathbf{1 , 1 8 3}$ \\
\hline Desvio Padrão & $\pm \mathbf{0 . 1 4 3}$ & $\pm \mathbf{0 . 8 1 8}$ & $\pm \mathbf{0 . 9 3 1}$ & $\pm \mathbf{0 . 6 7 4}$ & $\pm \mathbf{1 . 1 8 5}$ & $\pm \mathbf{1 . 3 5 4}$ \\
\hline
\end{tabular}




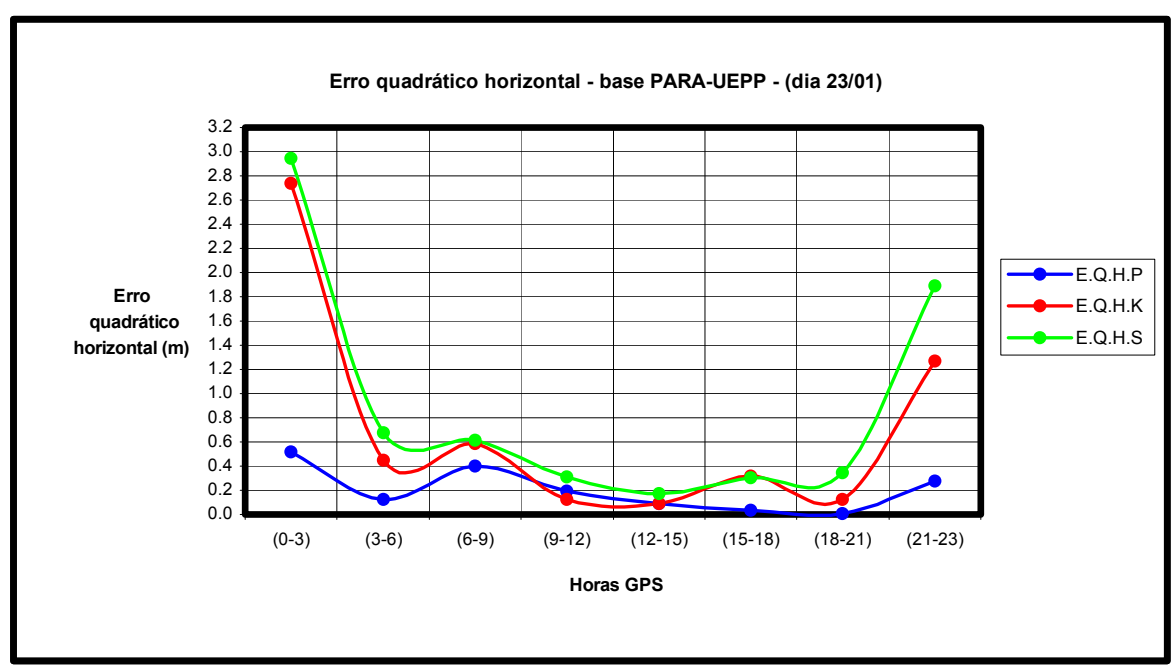

Figura 7.35 - Variação horária do erro quadrático horizontal do vértice UEPP no posicionamento relativo da base PARA - UEPP - (dia 23/01).

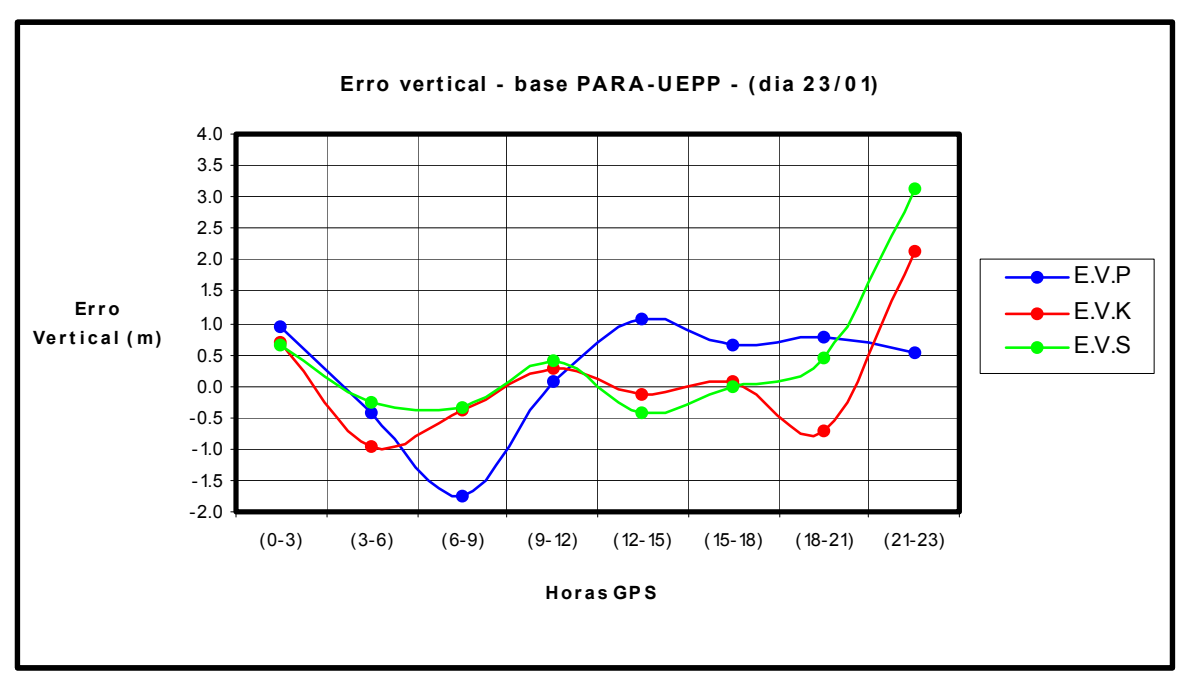

Figura 7.36 - Variação horária do erro vertical do vértice UEPP no posicionamento relativo da base PARA - UEPP - (dia 23/01).

Tabela 7.26 - Erro quadrático horizontal e erro vertical do vértice UEPP no processamento relativo da base PARA - UEPP, para diferentes modelos ionosféricos - (dia 23/01).

\begin{tabular}{|c|c|c|c|c|c|c|}
\cline { 2 - 7 } \multicolumn{1}{c|}{} & \multicolumn{3}{c|}{ Erro Quadrático Horizontal (m) } & \multicolumn{3}{c|}{ Erro Vertical (m) } \\
\hline Horas & E.Q.H.P & E.Q.H.K & E.Q.H.S & E.V.P & E.V.K & E.V.S \\
\hline $\mathbf{( 0 - 3 )}$ & 0,517 & 2,736 & 2,944 & 0,946 & 0,675 & 0,644 \\
\hline $\mathbf{( 3 - 6 )}$ & 0,124 & 0,451 & 0,675 & $-0,436$ & $-0,955$ & $-0,264$ \\
\hline $\mathbf{( 6 - 9 )}$ & 0,397 & 0,584 & 0,616 & $-1,761$ & $-0,394$ & $-0,337$ \\
\hline $\mathbf{( 9 - 1 2 )}$ & 0,194 & 0,125 & 0,307 & 0,071 & 0,279 & 0,391 \\
\hline $\mathbf{( 1 2 - 1 5 )}$ & 0,089 & 0,090 & 0,172 & 1,059 & $-0,147$ & $-0,430$ \\
\hline $\mathbf{( 1 5 - 1 8 )}$ & 0,033 & 0,319 & 0,305 & 0,636 & 0,059 & $-0,008$ \\
\hline $\mathbf{( 1 8 - 2 1 )}$ & 0,010 & 0,127 & 0,348 & 0,762 & $-0,701$ & 0,426 \\
\hline $\mathbf{( 2 1 - 2 3 )}$ & 0,278 & 1,272 & 1,890 & 0,541 & 2,125 & 3,134 \\
\hline E.M.Q & $\mathbf{0 , 2 0 5}$ & $\mathbf{0 , 7 1 3}$ & $\mathbf{0 , 9 0 7}$ & $\mathbf{0 , 7 7 7}$ & $\mathbf{0 , 6 6 7}$ & $\mathbf{0 , 7 0 4}$ \\
\hline Desvio padrão & $\pm \mathbf{0 . 1 8 0}$ & $\pm \mathbf{0 . 9 0 4}$ & $\pm \mathbf{0 . 9 8 8}$ & $\pm \mathbf{0 . 9 3 9}$ & $\pm \mathbf{0 . 9 6 5}$ & $\pm \mathbf{1 . 1 5 6}$ \\
\hline
\end{tabular}




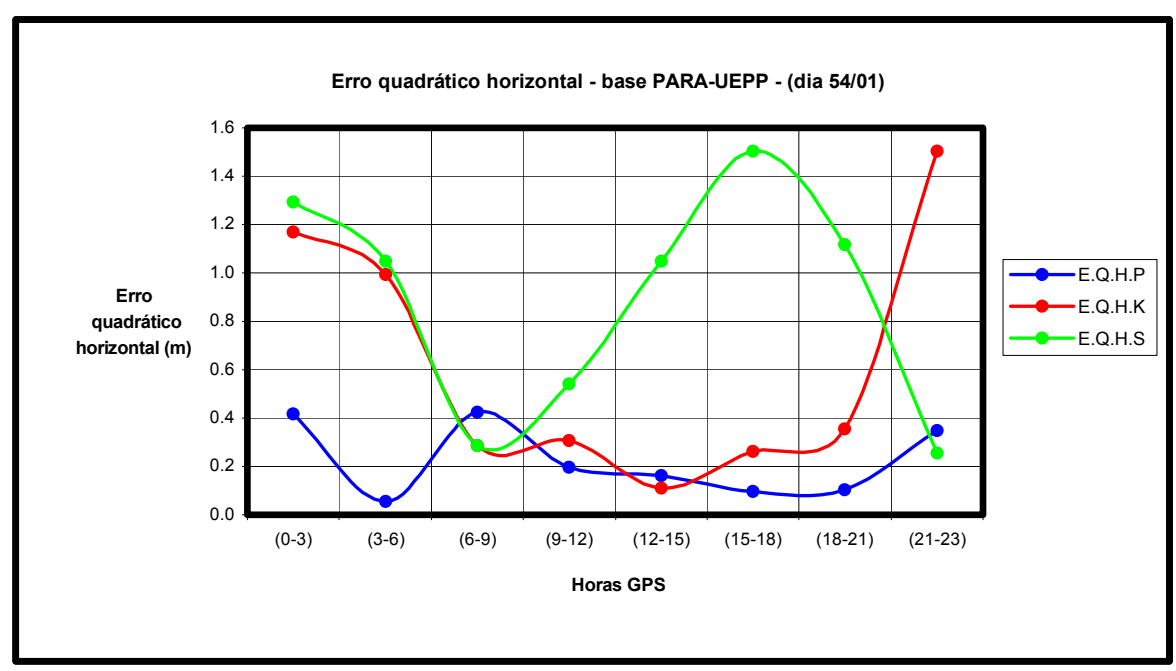

Figura 7.37 - Variação horária do erro quadrático horizontal do vértice UEPP no posicionamento relativo da base PARA - UEPP - (dia 54/01).

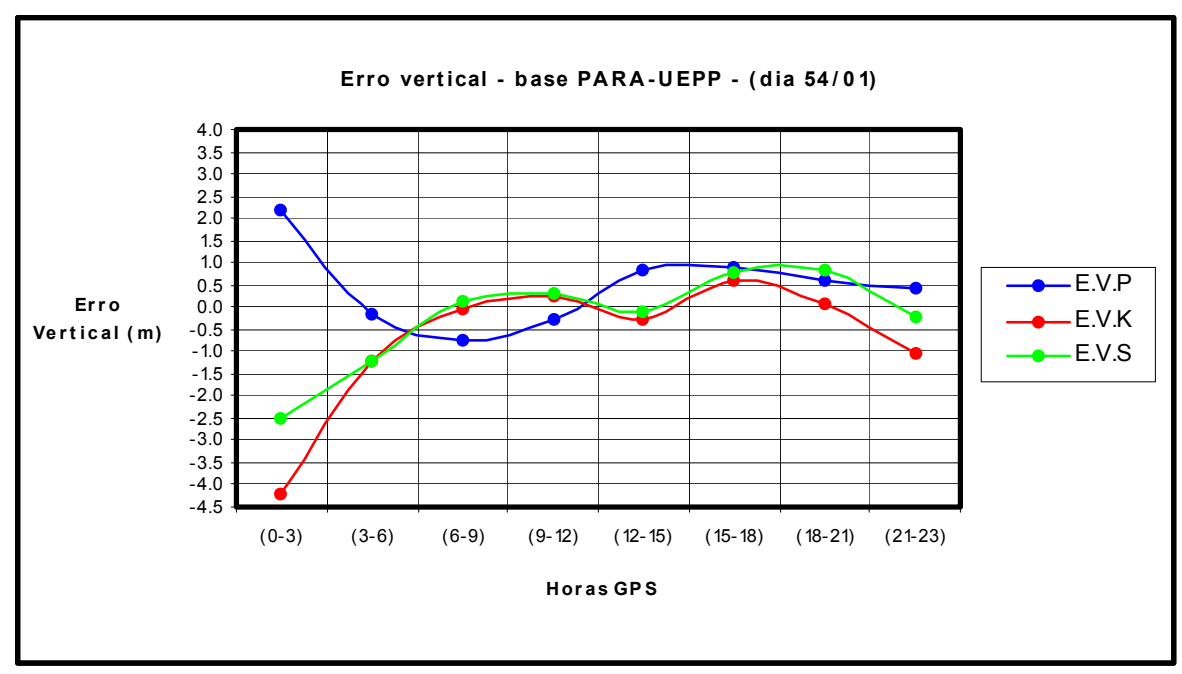

Figura 7.38 - Variação horária do erro vertical no posicionamento relativo da base PARA - UEPP - (dia 54/01).

Tabela 7.27 - Erro quadrático horizontal e erro vertical do vértice UEPP no processamento relativo da base PARA - UEPP, para diferentes modelos ionosféricos - (dia 54/01).

\begin{tabular}{|c|c|c|c|c|c|c|}
\cline { 2 - 7 } \multicolumn{1}{c|}{} & \multicolumn{3}{c|}{ Erro Quadrático Horizontal (m) } & \multicolumn{3}{c|}{ Erro Vertical (m) } \\
\hline Horas & E.Q.H.P & E.Q.H.K & E.Q.H.S & E.V.P & E.V.K & E.V.S \\
\hline $\mathbf{( 0 - 3 )}$ & 0,417 & 1,169 & 1,292 & 2,187 & $-4,193$ & $-2,529$ \\
\hline $\mathbf{( 3 - 6 )}$ & 0,055 & 0,993 & 1,047 & $-0,156$ & $-1,210$ & $-1,240$ \\
\hline $\mathbf{( 6 - 9 )}$ & 0,423 & 0,287 & 0,285 & $-0,743$ & $-0,056$ & 0,138 \\
\hline $\mathbf{( 9 - 1 2 )}$ & 0,196 & 0,307 & 0,542 & $-0,291$ & 0,243 & 0,320 \\
\hline $\mathbf{( 1 2 - 1 5 )}$ & 0,162 & 0,109 & 1,048 & 0,814 & $-0,275$ & $-0,132$ \\
\hline$(\mathbf{1 5 - 1 8 )}$ & 0,098 & 0,261 & 1,502 & 0,865 & 0,629 & 0,774 \\
\hline $\mathbf{( 1 8 - 2 1 )}$ & 0,103 & 0,356 & 1,116 & 0,592 & 0,078 & 0,813 \\
\hline $\mathbf{( 2 1 - 2 3 )}$ & 0,348 & 1,503 & 0,255 & 0,447 & $-1,070$ & $-0,235$ \\
\hline E.M.Q & $\mathbf{0 , 2 2 5}$ & $\mathbf{0 , 6 2 3}$ & $\mathbf{0 , 8 8 6}$ & $\mathbf{0 , 7 6 2}$ & $\mathbf{0 , 9 6 9}$ & $\mathbf{0 , 7 7 3}$ \\
\hline Desvio Padrão & $\pm \mathbf{0 . 1 4 9}$ & $\pm \mathbf{0 . 5 1 9}$ & $\pm \mathbf{0 . 4 6 7}$ & $\pm \mathbf{0 . 9 0 1}$ & $\pm \mathbf{1 . 5 3 3}$ & $\pm \mathbf{1 . 1 2 4}$ \\
\hline
\end{tabular}




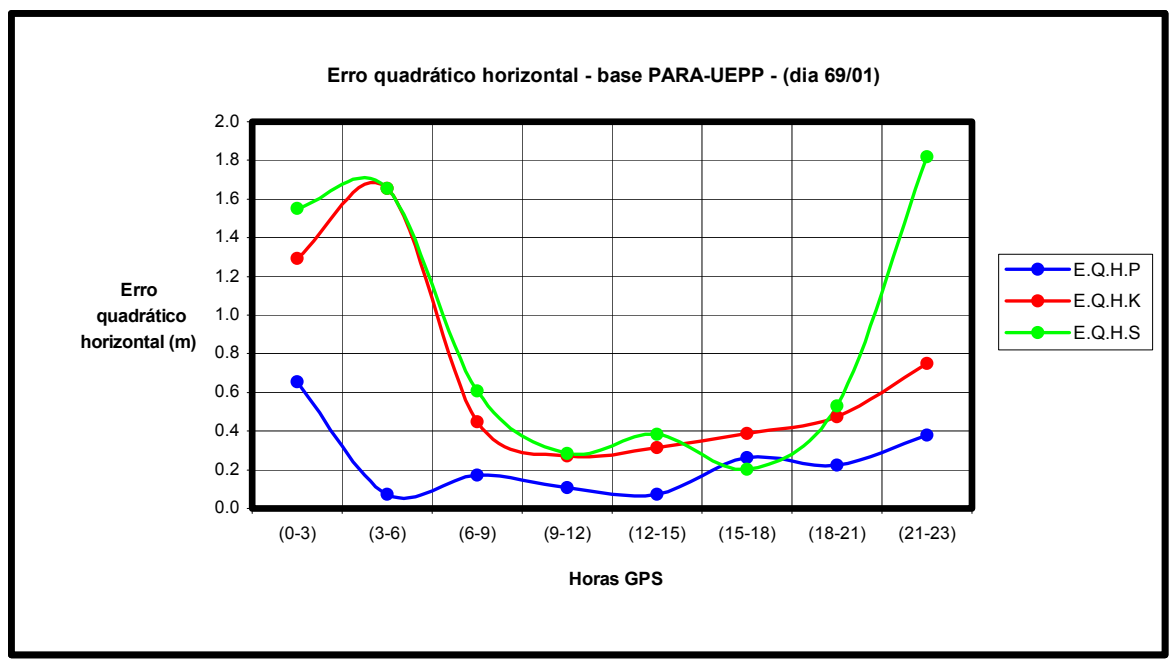

Figura 7.39 - Variação horária do erro quadrático horizontal do vértice UEPP no posicionamento relativo da base PARA - UEPP - (dia 69/01).

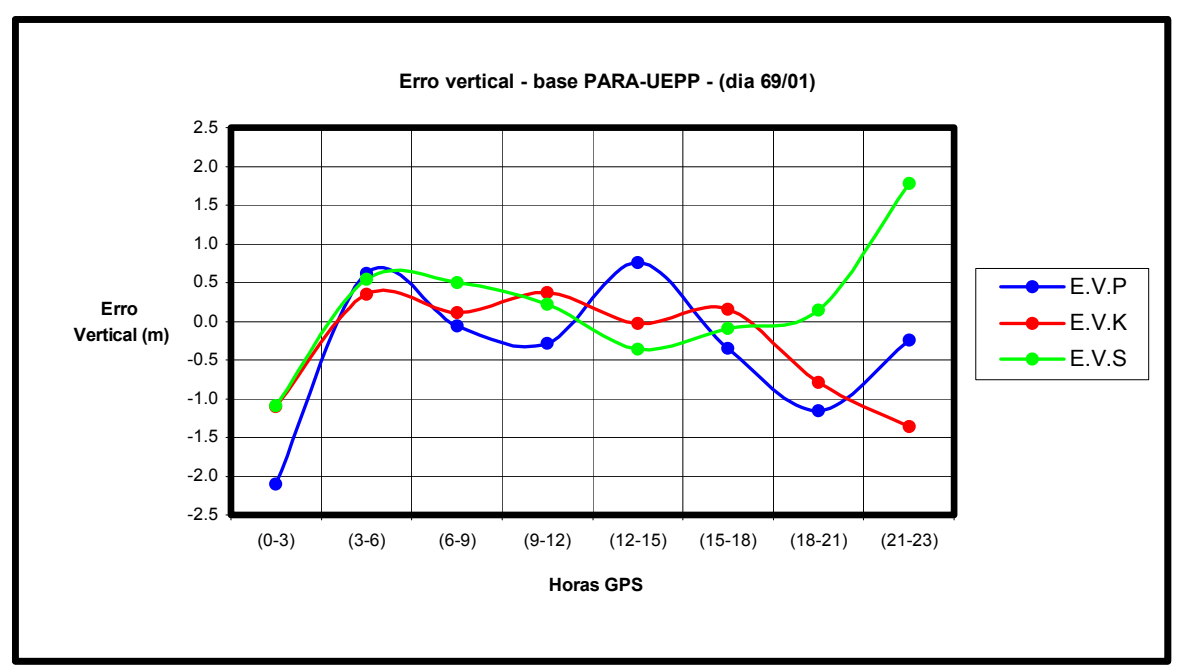

Figura 7.40 - Variação horária do erro vertical do vértice UEPP no posicionamento relativo da base PARA - UEPP - (dia 69/01).

Tabela 7.28 - Erro quadrático horizontal e erro vertical do vértice UEPP no processamento relativo da base PARA - UEPP, para diferentes modelos ionosféricos - (dia 69/01).

\begin{tabular}{|c|c|c|c|c|c|c|}
\cline { 2 - 7 } \multicolumn{1}{c|}{} & \multicolumn{3}{c|}{ Erro Quadrático Horizontal (m) } & \multicolumn{3}{c|}{ Erro Vertical (m) } \\
\hline Horas & E.Q.H.P & E.Q.H.K & E.Q.H.S & E.V.P & E.V.K & E.V.S \\
\hline $\mathbf{( 0 - 3 )}$ & 0,654 & 1,294 & 1,550 & $-2,097$ & $-1,098$ & $-1,096$ \\
\hline $\mathbf{( 3 - 6 )}$ & 0,075 & 1,655 & 1,653 & 0,613 & 0,350 & 0,540 \\
\hline $\mathbf{( 6 - 9 )}$ & 0,172 & 0,450 & 0,609 & $-0,058$ & 0,117 & 0,501 \\
\hline $\mathbf{( 9 - 1 2 )}$ & 0,110 & 0,272 & 0,283 & $-0,281$ & 0,374 & 0,218 \\
\hline $\mathbf{( 1 2 - 1 5 )}$ & 0,074 & 0,316 & 0,383 & 0,754 & $-0,022$ & $-0,363$ \\
\hline$(\mathbf{1 5 - 1 8 )}$ & 0,263 & 0,386 & 0,203 & $-0,354$ & 0,154 & $-0,088$ \\
\hline $\mathbf{( 1 8 - 2 1 )}$ & 0,224 & 0,473 & 0,532 & $-1,152$ & $-0,789$ & 0,143 \\
\hline $\mathbf{( 2 1 - 2 3 )}$ & 0,378 & 0,748 & 1,818 & $-0,241$ & $-1,356$ & 1,783 \\
\hline E.M.Q & $\mathbf{0 , 2 4 4}$ & $\mathbf{0 , 6 9 9}$ & $\mathbf{0 , 8 7 9}$ & $\mathbf{0 , 6 9 4}$ & $\mathbf{0 , 5 3 3}$ & $\mathbf{0 , 5 9 1}$ \\
\hline Desvio Padrão & $\pm \mathbf{0 . 1 9 6}$ & $\pm \mathbf{0 . 5 0 9}$ & $\pm \mathbf{0 . 6 7 4}$ & $\pm \mathbf{0 . 9 2 1}$ & $\pm \mathbf{0 . 6 8 9}$ & $\pm \mathbf{0 . 8 2 8}$ \\
\hline
\end{tabular}




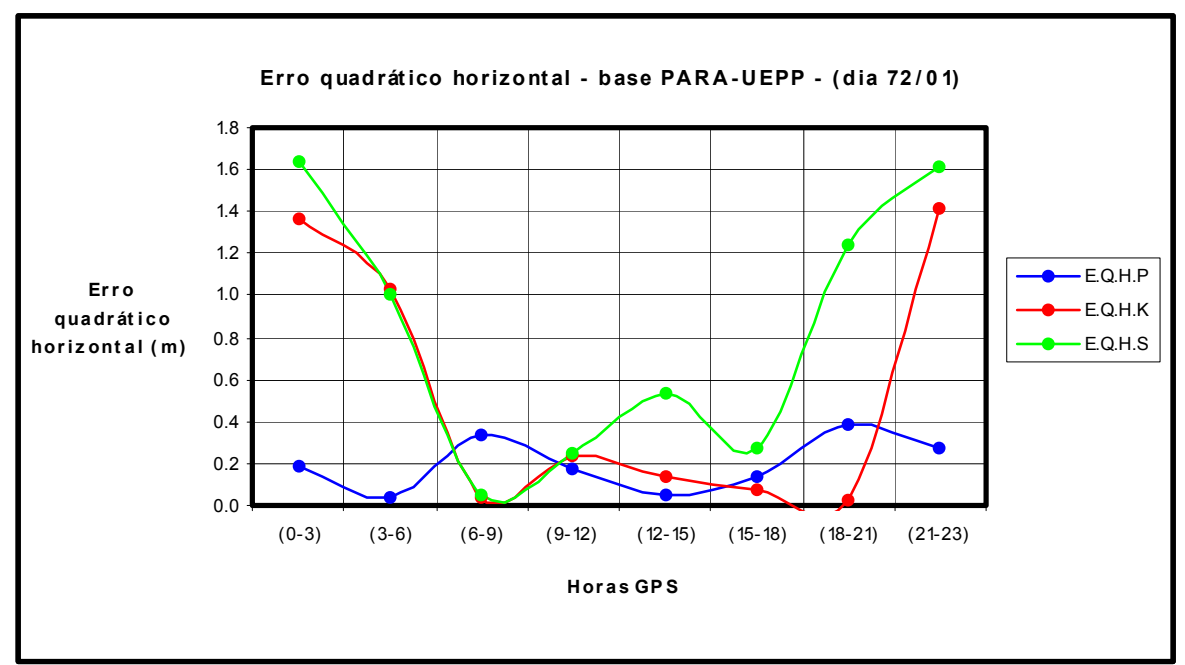

Figura 7.41 - Variação horária do erro quadrático horizontal do vértice UEPP no posicionamento relativo da base PARA - UEPP - (dia 72/01).

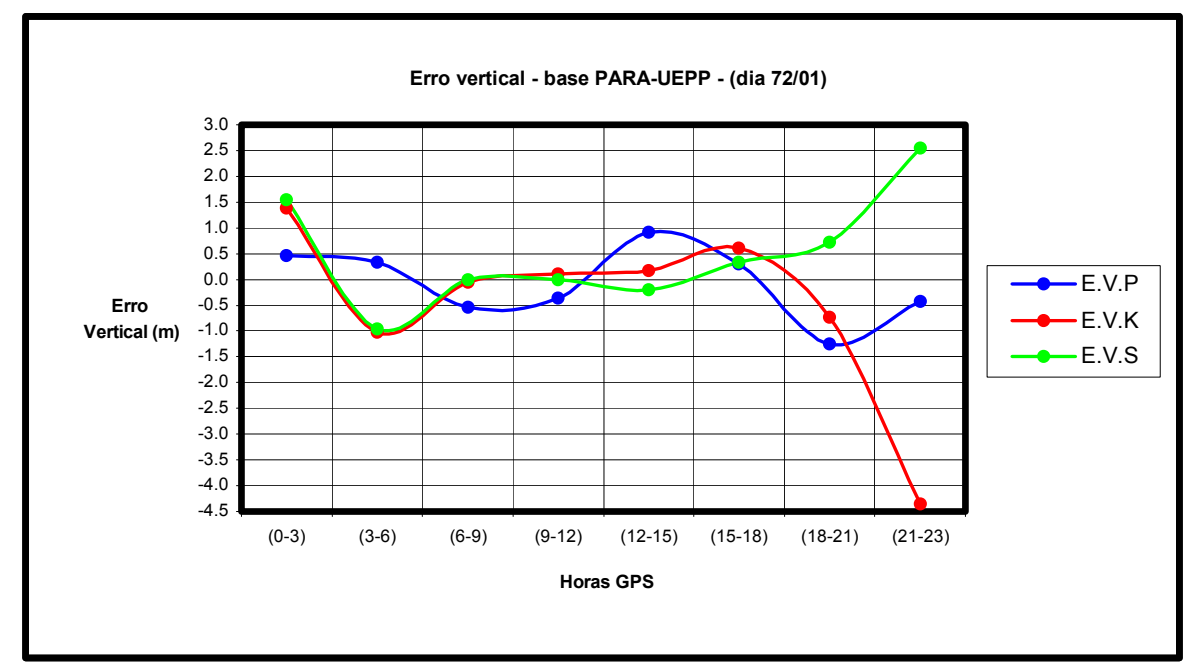

Figura 7.42 - Variação horária do erro vertical do vértice UEPP no posicionamento relativo da base PARA - UEPP - (dia 72/01).

Tabela 7.29 - Erro quadrático horizontal e erro vertical do vértice UEPP no processamento relativo da base PARA - UEPP, para diferentes modelos ionosféricos - (dia 72/01).

\begin{tabular}{|c|c|c|c|c|c|c|}
\cline { 2 - 7 } \multicolumn{1}{c|}{} & \multicolumn{3}{c|}{ Erro Quadrático Horizontal (m) } & \multicolumn{3}{c|}{ Erro Vertical (m) } \\
\hline Horas & E.Q.H.P & E.Q.H.K & E.Q.H.S & E.V.P & E.V.K & E.V.S \\
\hline $\mathbf{( 0 - 3 )}$ & 0,188 & 1,365 & 1,633 & 0,469 & 1,384 & 1,541 \\
\hline $\mathbf{( 3 - 6 )}$ & 0,043 & 1,033 & 1,001 & 0,336 & $-1,024$ & $-0,966$ \\
\hline $\mathbf{( 6 - 9 )}$ & 0,331 & 0,039 & 0,053 & $-0,541$ & $-0,051$ & $-0,014$ \\
\hline $\mathbf{( 9 - 1 2 )}$ & 0,179 & 0,232 & 0,244 & $-0,356$ & 0,109 & $-0,006$ \\
\hline $\mathbf{( 1 2 - 1 5 )}$ & 0,052 & 0,133 & 0,529 & 0,915 & 0,173 & $-0,203$ \\
\hline$(\mathbf{1 5 - 1 8 )}$ & 0,134 & 0,069 & 0,268 & 0,295 & 0,600 & 0,328 \\
\hline $\mathbf{( 1 8 - 2 1 )}$ & 0,379 & 0,026 & 1,247 & $-1,251$ & $-0,726$ & 0,720 \\
\hline $\mathbf{( 2 1 - 2 3 )}$ & 0,271 & 1,409 & 1,609 & $-0,424$ & $-4,347$ & 2,551 \\
\hline E.M.Q & $\mathbf{0 , 1 9 7}$ & $\mathbf{0 , 5 3 8}$ & $\mathbf{0 , 8 2 3}$ & $\mathbf{0 , 5 7 3}$ & $\mathbf{1 , 0 5 2}$ & $\mathbf{0 , 7 9 1}$ \\
\hline Desvio Padrão & $\pm \mathbf{0 . 1 2 3}$ & $\pm \mathbf{0 . 6 1 8}$ & $\pm \mathbf{0 . 6 3 3}$ & $\pm \mathbf{0 . 6 9 5}$ & $\pm \mathbf{1 . 7 2 8}$ & $\pm \mathbf{1 . 1 0 4}$ \\
\hline
\end{tabular}




\subsection{Coeficientes do modelo referentes ao período do outono}

Ao analisar os valores dos coeficientes ao longo de todo o período do dia, o coeficiente $C_{1}$ foi o que apresentou uma maior discrepância, principalmente nos dias 80 e 157, onde, as variações entre os valores máximo e mínimo, foram de 5,482 e 3,560, respectivamente. Este fato proporcionou um aumento no valor de seu desvio padrão, se comparado com os demais dias. Estas variações mostram o quanto a ionosfera é dinâmica ao longo do dia, onde, mesmo com modelos matemáticos sofisticados, não é possível eliminar por completo a sua influência nas observáveis GPS. As maiores variações ocorreram no intervalo entre 17 e 20 horas GPS.

Através das figuras 7.43 a 7.51 e das tabelas 7.30 a 7.38 , percebe-se que a ionosfera influenciou a propagação dos sinais GPS de uma maneira mais acentuada, se comparado com o período do verão. A obtenção de valores distintos para os coeficientes em relação às duas estações do ano, mostra o comportamento sazonal da ionosfera.

No que se refere ao ajustamento seqüencial, o mesmo proporcionou um índice de rejeição das observáveis semelhante ao período do verão, de aproximadamente $32 \%$. Os maiores índices de rejeições das observáveis foram constatados nos dias 80, 109 e 157, justamente o período de maior desvio padrão encontrado para o coeficiente $C_{1}$.

A seguir, serão apresentados todos os resultados do processamento dos coeficientes, no período do outono estudado.

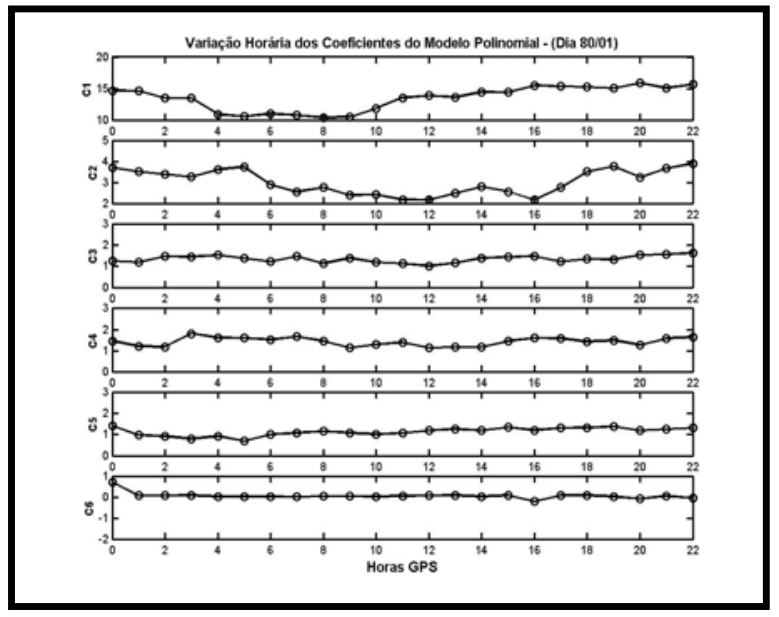

Figura 7.43 - Variação horária dos coeficientes do modelo polinomial (dia 80/01)

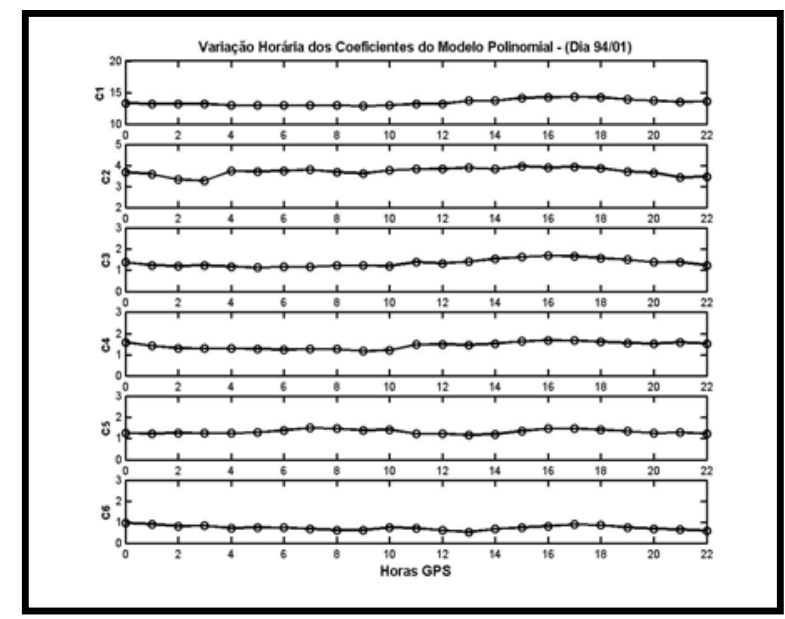

Figura 7.44 - Variação horária dos coeficientes do modelo polinomial (dia 94/01) 


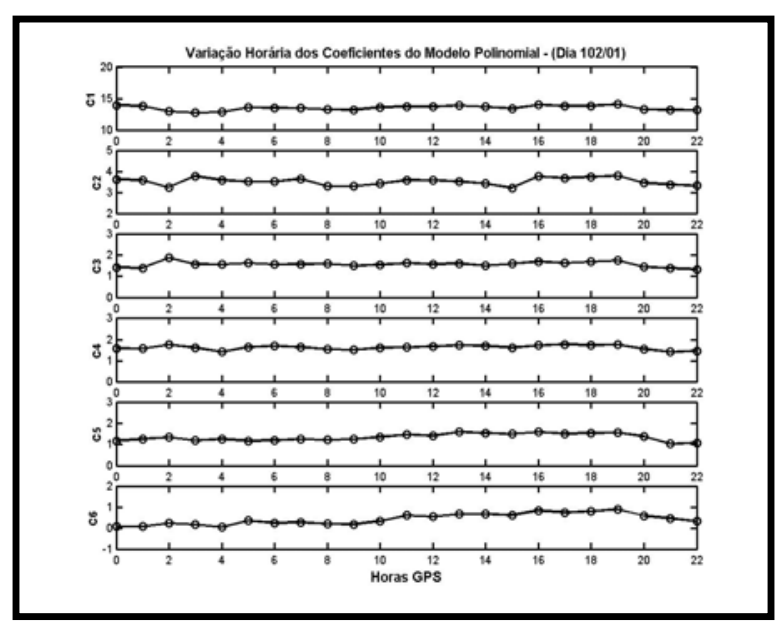

Figura 7.45 - Variação horária dos coeficientes do modelo polinomial (dia 102/01)

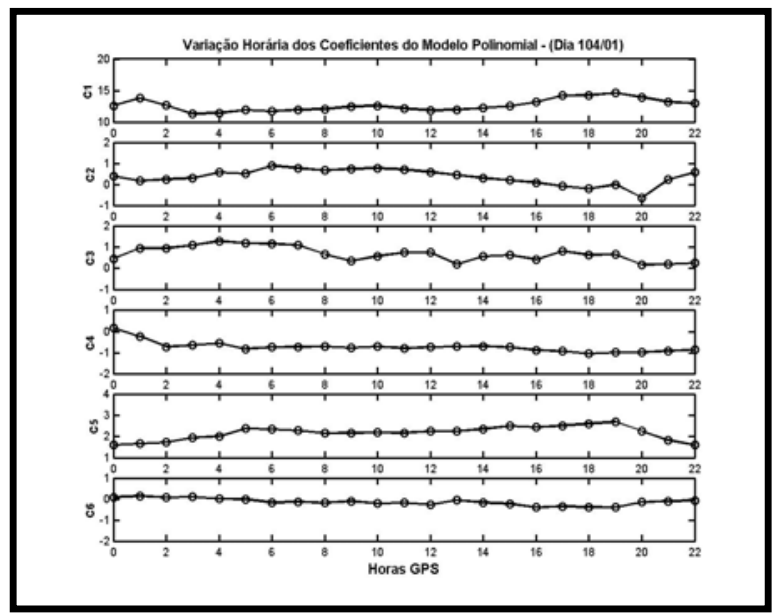

Figura 7.47 - Variação horária dos coeficientes do modelo polinomial (dia 104/01)

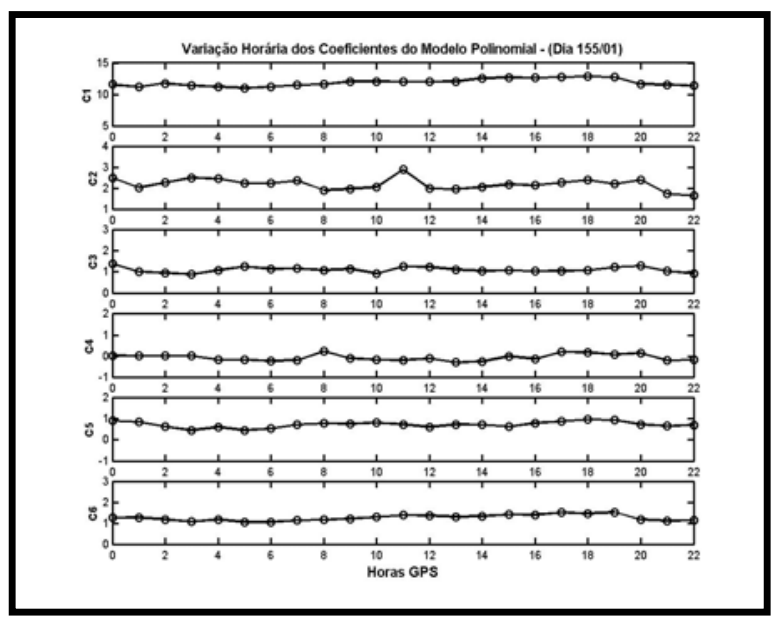

Figura 7.49 - Variação horária dos coeficientes do modelo polinomial (dia 155/01)

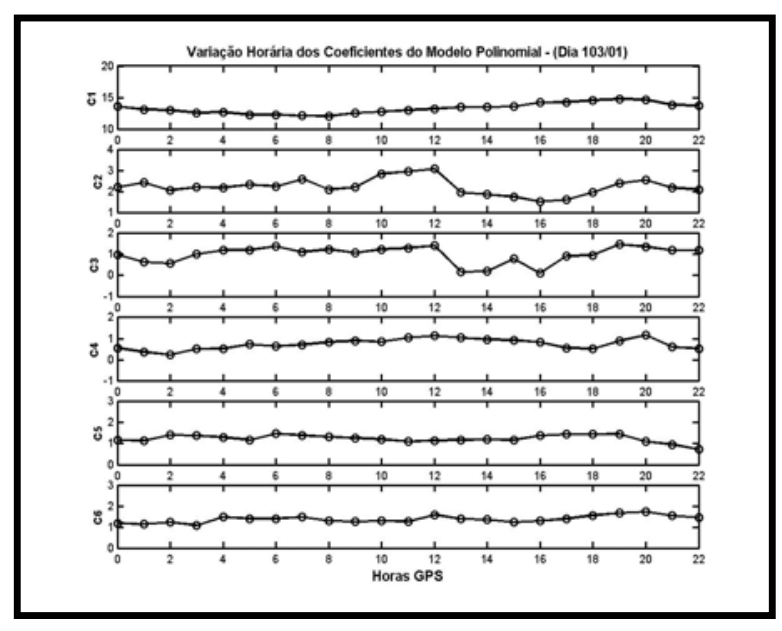

Figura 7.46 - Variação horária dos coeficientes do modelo polinomial (dia 103/01)

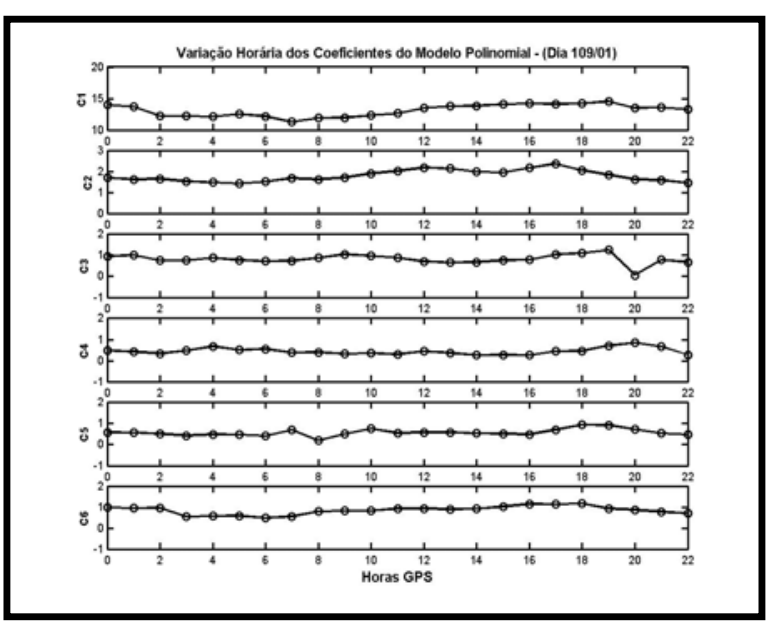

Figura 7.48 - Variação horária dos coeficientes do modelo polinomial (dia 109/01)

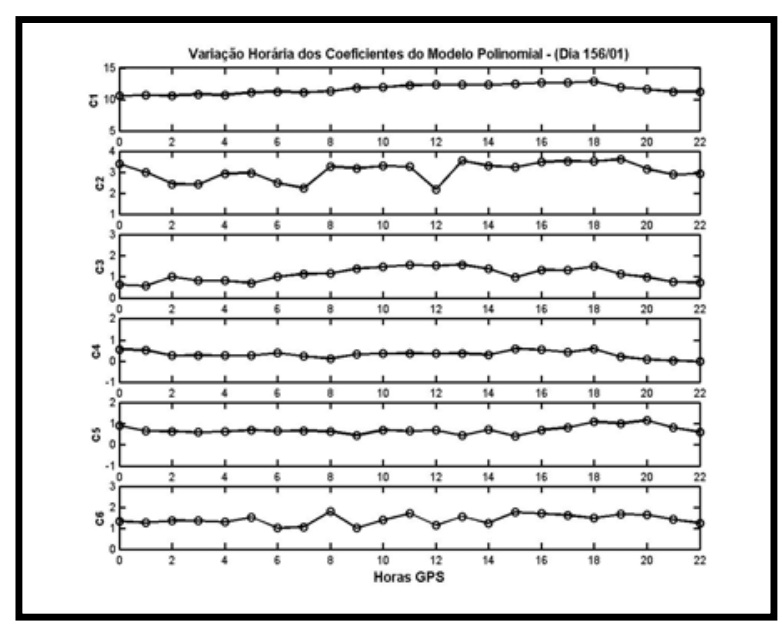

Figura 7.50 - Variação horária dos coeficientes do modelo polinomial (dia 156/01) 


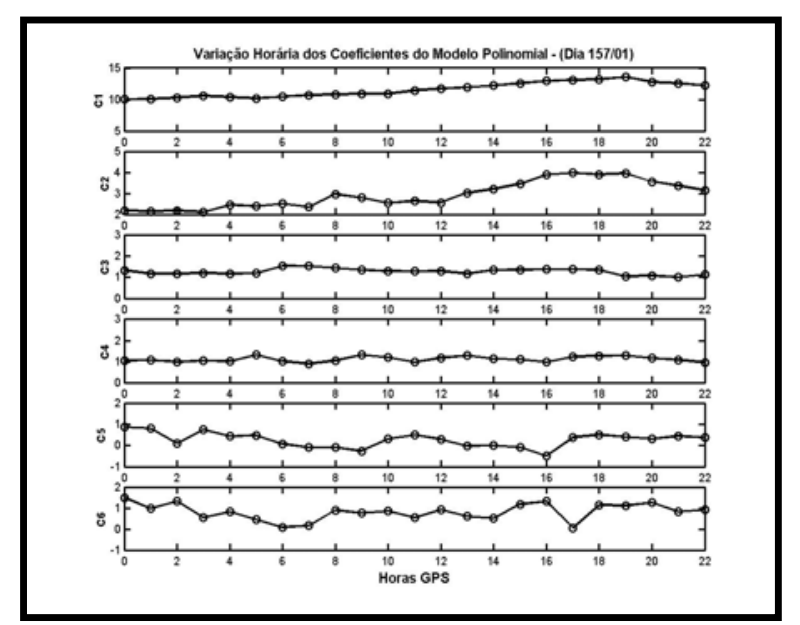

Figura 7.51 - Variação horária dos coeficientes do modelo polinomial (dia 157/01)

Tabela 7.30 - Estatística dos coeficientes do modelo polinomial - (dia 80/01)

\begin{tabular}{|c|c|c|c|c|}
\hline Coeficientes & Valor Médio & Desvio Padrão & Valor Mínimo & Valor Máximo \\
\hline $\mathbf{C}_{\mathbf{1}}$ & 13,462 & $\pm 1,612$ & 10,375 & 15,857 \\
\hline $\mathbf{C}_{\mathbf{2}}$ & 3,016 & $\pm 0,589$ & 2,159 & 3,893 \\
\hline $\mathbf{C}_{\mathbf{3}}$ & 1,337 & $\pm 0,164$ & 1,006 & 1,631 \\
\hline $\mathbf{C}_{\mathbf{4}}$ & 1,430 & $\pm 0,199$ & 1,128 & 1,812 \\
\hline $\mathbf{C}_{\mathbf{5}}$ & 1,129 & $\pm 0,189$ & 0,691 & 1,411 \\
\hline $\mathbf{C}_{\mathbf{6}}$ & 0,057 & $\pm 0,154$ & $-0,209$ & 0,694 \\
\hline
\end{tabular}

Tabela 7.31 - Estatística dos coeficientes do modelo polinomial - (dia 94/01)

\begin{tabular}{|c|c|c|c|c|}
\hline Coeficientes & Valor Médio & Desvio Padrão & Valor Mínimo & Valor Máximo \\
\hline $\mathbf{C}_{\mathbf{1}}$ & 13,424 & $\pm 0,178$ & 12,833 & 14,289 \\
\hline $\mathbf{C}_{\mathbf{2}}$ & 3,700 & $\pm 0,186$ & 3,273 & 3,954 \\
\hline $\mathbf{C}_{\mathbf{3}}$ & 1,343 & $\pm 0,176$ & 1,121 & 1,678 \\
\hline $\mathbf{C}_{\mathbf{4}}$ & 1,436 & $\pm 0,163$ & 1,162 & 1,685 \\
\hline $\mathbf{C}_{\mathbf{5}}$ & 1,313 & $\pm 0,101$ & 1,166 & 1,490 \\
\hline $\mathbf{C}_{\mathbf{6}}$ & 0,730 & $\pm 0,110$ & 0,517 & 0,967 \\
\hline
\end{tabular}

Tabela 7.32 - Estatística dos coeficientes do modelo polinomial - (dia 102/01)

\begin{tabular}{|c|c|c|c|c|}
\hline Coeficientes & Valor Médio & Desvio Padrão & Valor Mínimo & Valor Máximo \\
\hline $\mathbf{C}_{\mathbf{1}}$ & 13,505 & $\pm 0,179$ & 12,743 & 14,096 \\
\hline $\mathbf{C}_{\mathbf{2}}$ & 3,518 & $\pm 0,176$ & 3,211 & 3,792 \\
\hline $\mathbf{C}_{\mathbf{3}}$ & 1,559 & $\pm 0,125$ & 1,316 & 1,865 \\
\hline $\mathbf{C}_{\mathbf{4}}$ & 1,624 & $\pm 0,108$ & 1,406 & 1,770 \\
\hline $\mathbf{C}_{5}$ & 1,339 & $\pm 0,172$ & 1,022 & 1,588 \\
\hline $\mathbf{C}_{\mathbf{6}}$ & 0,429 & $\pm 0,267$ & 0,043 & 0,899 \\
\hline
\end{tabular}


Tabela 7.33 - Estatística dos coeficientes do modelo polinomial - (dia 103/01)

\begin{tabular}{|c|c|c|c|c|}
\hline Coeficientes & Valor Médio & Desvio Padrão & Valor Mínimo & Valor Máximo \\
\hline $\mathbf{C}_{\mathbf{1}}$ & 13,282 & $\pm 0,532$ & 12,036 & 14,752 \\
\hline $\mathbf{C}_{\mathbf{2}}$ & 2,223 & $\pm 0,393$ & 1,502 & 3,076 \\
\hline $\mathbf{C}_{\mathbf{3}}$ & 0,968 & $\pm 0,400$ & 0,088 & 1,449 \\
\hline $\mathbf{C}_{\mathbf{4}}$ & 0,739 & $\pm 0,249$ & 0,230 & 1,157 \\
\hline $\mathbf{C}_{\mathbf{5}}$ & 1,231 & $\pm 0,179$ & 0,713 & 1,466 \\
\hline $\mathbf{C}_{\mathbf{6}}$ & 1,376 & $\pm 0,167$ & 1,079 & 1,734 \\
\hline
\end{tabular}

Tabela 7.34 - Estatística dos coeficientes do modelo polinomial - (dia 104/01)

\begin{tabular}{|c|c|c|c|c|}
\hline Coeficientes & Valor Médio & Desvio Padrão & Valor Mínimo & Valor Máximo \\
\hline $\mathbf{C}_{\mathbf{1}}$ & 12,670 & $\pm 0,643$ & 11,337 & 14,592 \\
\hline $\mathbf{C}_{\mathbf{2}}$ & 0,359 & $\pm 0,369$ & $-0,640$ & 0,896 \\
\hline $\mathbf{C}_{\mathbf{3}}$ & 0,678 & $\pm 0,340$ & 0,161 & 1,285 \\
\hline $\mathbf{C}_{\mathbf{4}}$ & $-0,730$ & $\pm 0,262$ & $-1,059$ & 0,182 \\
\hline $\mathbf{C}_{\mathbf{5}}$ & 2,167 & $\pm 0,315$ & 1,596 & 2,700 \\
\hline $\mathbf{C}_{\mathbf{6}}$ & $-0,136$ & $\pm 0,160$ & $-0,396$ & 0,151 \\
\hline
\end{tabular}

Tabela 7.35 - Estatística dos coeficientes do modelo polinomial - (dia 109/01)

\begin{tabular}{|c|c|c|c|c|}
\hline Coeficientes & Valor Médio & Desvio Padrão & Valor Mínimo & Valor Máximo \\
\hline $\mathbf{C}_{\mathbf{1}}$ & 13,111 & $\pm 0,650$ & 11,289 & 14,559 \\
\hline $\mathbf{C}_{\mathbf{2}}$ & 1,787 & $\pm 0,272$ & 1,409 & 2,371 \\
\hline $\mathbf{C}_{\mathbf{3}}$ & 0,805 & $\pm 0,226$ & 0,051 & 1,228 \\
\hline $\mathbf{C}_{\mathbf{4}}$ & 0,444 & $\pm 0,158$ & 0,255 & 0,845 \\
\hline $\mathbf{C}_{5}$ & 0,560 & $\pm 0,161$ & 0,186 & 0,926 \\
\hline $\mathbf{C}_{\mathbf{6}}$ & 0,846 & $\pm 0,198$ & 0,474 & 1,163 \\
\hline
\end{tabular}

Tabela 7.36 - Estatística dos coeficientes do modelo polinomial - (dia 155/01)

\begin{tabular}{|c|c|c|c|c|}
\hline Coeficientes & Valor Médio & Desvio Padrão & Valor Mínimo & Valor Máximo \\
\hline $\mathbf{C}_{\mathbf{1}}$ & 11,882 & $\pm 0,277$ & 11,011 & 12,817 \\
\hline $\mathbf{C}_{\mathbf{2}}$ & 2,182 & $\pm 0,276$ & 1,639 & 2,894 \\
\hline $\mathbf{C}_{\mathbf{3}}$ & 1,094 & $\pm 0,125$ & 0,870 & 1,366 \\
\hline $\mathbf{C}_{\mathbf{4}}$ & $-0,069$ & $\pm 0,157$ & $-0,309$ & 0,219 \\
\hline $\mathbf{C}_{5}$ & 0,712 & $\pm 0,140$ & 0,443 & 0,964 \\
\hline $\mathbf{C}_{6}$ & 1,260 & $\pm 0,143$ & 1,054 & 1,530 \\
\hline
\end{tabular}


Tabela 7.37 - Estatística dos coeficientes do modelo polinomial - (dia 156/01)

\begin{tabular}{|c|c|c|c|c|}
\hline Coeficientes & Valor Médio & Desvio Padrão & Valor Mínimo & Valor Máximo \\
\hline $\mathbf{C}_{\mathbf{1}}$ & 11,631 & $\pm 0,435$ & 10,572 & 12,825 \\
\hline $\mathbf{C}_{\mathbf{2}}$ & 3,051 & $\pm 0,439$ & 2,157 & 3,625 \\
\hline $\mathbf{C}_{\mathbf{3}}$ & 1,101 & $\pm 0,323$ & 0,561 & 1,568 \\
\hline $\mathbf{C}_{\mathbf{4}}$ & 0,318 & $\pm 0,172$ & $-0,020$ & 0,587 \\
\hline $\mathbf{C}_{\mathbf{5}}$ & 0,705 & $\pm 0,191$ & 0,409 & 1,161 \\
\hline $\mathbf{C}_{\mathbf{6}}$ & 1,414 & $\pm 0,240$ & 1,002 & 1,787 \\
\hline
\end{tabular}

Tabela 7.38 - Estatística dos coeficientes do modelo polinomial - (dia 157/01)

\begin{tabular}{|c|c|c|c|c|}
\hline Coeficientes & Valor Médio & Desvio Padrão & Valor Mínimo & Valor Máximo \\
\hline $\mathbf{C}_{\mathbf{1}}$ & 11,544 & $\pm 0,856$ & 10,013 & 13,573 \\
\hline $\mathbf{C}_{\mathbf{2}}$ & 2,926 & $\pm 0,633$ & 2,117 & 3,973 \\
\hline $\mathbf{C}_{\mathbf{3}}$ & 1,265 & $\pm 0,141$ & 1,005 & 1,538 \\
\hline $\mathbf{C}_{\mathbf{4}}$ & 1,115 & $\pm 0,127$ & 0,904 & 1,319 \\
\hline $\mathbf{C}_{\mathbf{5}}$ & 0,256 & $\pm 0,344$ & $-0,502$ & 0,857 \\
\hline $\mathbf{C}_{\mathbf{6}}$ & 0,814 & $\pm 0,399$ & 0,055 & 1,494 \\
\hline
\end{tabular}

A Figura 7.52 ilustra os valores médios diários dos coeficientes do modelo polinomial durante alguns dias do outono. Percebe-se que no dia 104, os valores dos coeficientes $\mathrm{C}_{2}$ a $\mathrm{C}_{6}$ apresentaram uma discrepância em relação aos demais dias. Este fato, provavelmente, está relacionado à estação de Recife, pois a mesma teve uma interrupção do arquivo de observação a partir das 14 horas GPS. Após este período, esta estação não participou do ajustamento dos parâmetros. 


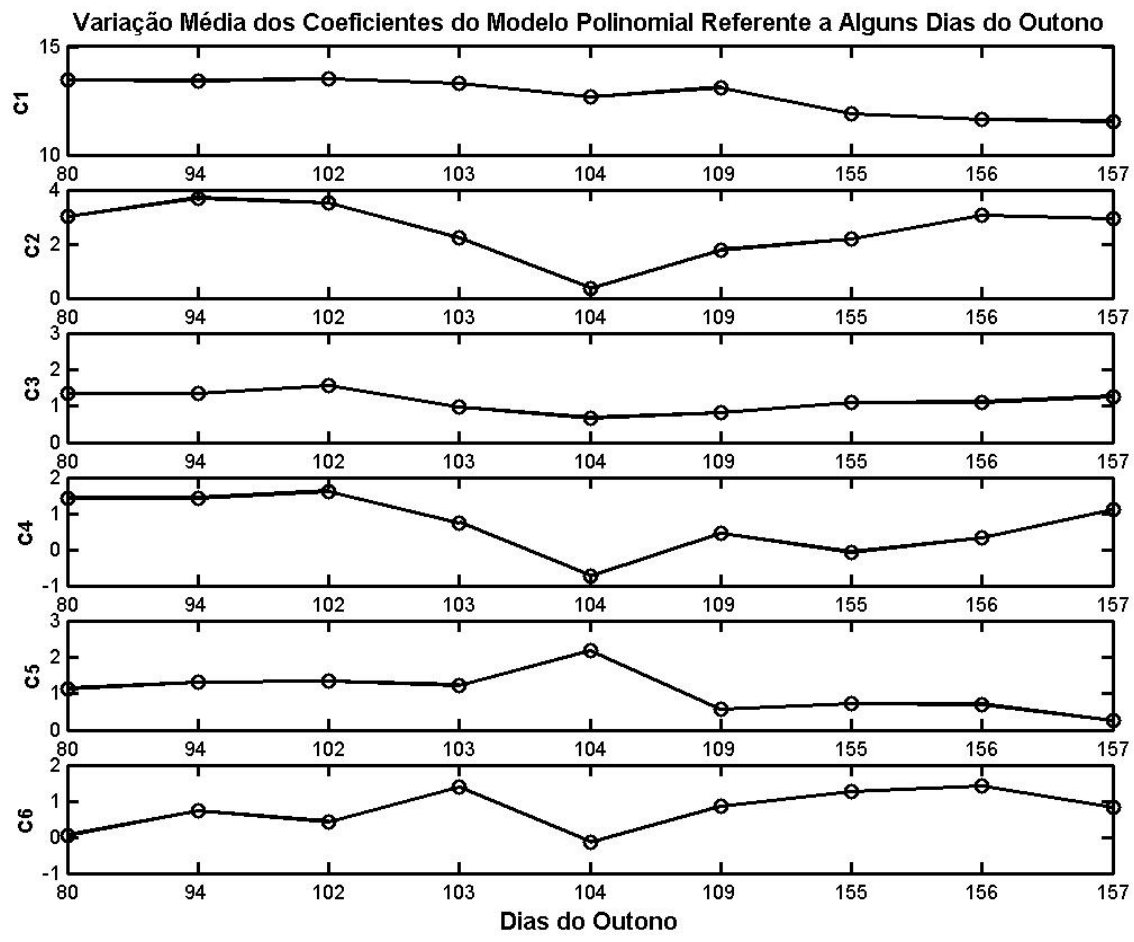

Figura 7.52 - Variação média diária dos coeficientes do modelo polinomial, referente a alguns dias do outono.

A Tabela 7.39 ilustra a estatística dos coeficientes neste período do outono. As colunas "Valor Médio" e "Desvio Padrão" correspondem, respectivamente, a média dos coeficientes e a média dos desvios padrão, em relação aos 9 dias estudados. Percebe-se que estes valores médios são menores dos obtidos no período do verão, o que mostra, como dito anteriormente, o comportamento sazonal da ionosfera.

Tabela 7.39 - Valores médios dos coeficientes do modelo polinomial referentes a alguns dias do outono

\begin{tabular}{|c|c|c|c|c|}
\hline Coeficientes & Valor Médio & Desvio Padrão & Valor Mínimo & Valor Máximo \\
\hline $\mathbf{C}_{\mathbf{1}}$ & 12,723 & $\pm 0,585$ & 11,544 & 13,505 \\
\hline $\mathbf{C}_{\mathbf{2}}$ & 2,529 & $\pm 0,370$ & 0,359 & 3,700 \\
\hline $\mathbf{C}_{\mathbf{3}}$ & 1,128 & $\pm 0,224$ & 0,678 & 1,559 \\
\hline $\mathbf{C}_{\mathbf{4}}$ & 0,701 & $\pm 0,142$ & $-0,730$ & 1,624 \\
\hline $\mathbf{C}_{\mathbf{5}}$ & 1,046 & $\pm 0,199$ & 0,256 & 2,167 \\
\hline $\mathbf{C}_{\mathbf{6}}$ & 0,754 & $\pm 0,204$ & $-0,136$ & 1,414 \\
\hline
\end{tabular}


A Tabela 7.40 ilustra os valores médios para o erro da portadora $L_{1}$ (erro de interfreqüência), bem como os respectivos desvios padrão médios referentes ao período do outono. Neste período, no dia 109, o desvio padrão obtido para o erro de interfreqüência do satélite PRN-5 foi superior que a média obtida no período: 1,3m. Não houve variação significativa destes erros, se comparado com o período do verão.

Tabela 7.40 - Valores médios do erro da portadora $L_{1}$ (erro de interfreqüência), devido ao conjunto satélite/receptor, em relação aos dias estudados no outono.

\begin{tabular}{|c|c|c|}
\cline { 2 - 3 } \multicolumn{1}{c|}{} & \multicolumn{2}{c|}{$(\text { Erro })^{\mathrm{s}}=\left(\left(\mathrm{S}_{\mathrm{P} 2}-\mathrm{S}_{\mathrm{P} 1}\right)+\left(\mathrm{r}_{\mathrm{P} 2}-\mathrm{r}_{\mathrm{P} 1}\right)\right)^{\mathrm{s}}$} \\
\hline Satélites & Valor Médio $(\mathbf{m})$ & Desvio Padrão $(\mathbf{m})$ \\
\hline PRN-1 & 1,105 & $\pm 0,443$ \\
\hline PRN-2 & 2,499 & $\pm 0,582$ \\
\hline PRN-3 & 1,929 & $\pm 0,708$ \\
\hline PRN-4 & 2,203 & $\pm 0,758$ \\
\hline PRN-5 & 2,128 & $\pm 0,794$ \\
\hline PRN-6 & 1,753 & $\pm 0,705$ \\
\hline PRN-7 & 2,275 & $\pm 0,696$ \\
\hline PRN-8 & 2,123 & $\pm 0,538$ \\
\hline PRN-9 & 2,195 & $\pm 0,647$ \\
\hline PRN-10 & 2,207 & $\pm 0,625$ \\
\hline PRN-11 & 1,768 & $\pm 0,617$ \\
\hline PRN-13 & 2,068 & $\pm 0,349$ \\
\hline PRN-14 & 1,591 & $\pm 0,574$ \\
\hline PRN-15 & 1,600 & $\pm 0,497$ \\
\hline PRN-17 & 1,660 & $\pm 0,532$ \\
\hline PRN-18 & 1,523 & $\pm 0,603$ \\
\hline PRN-20 & 1,713 & $\pm 0,480$ \\
\hline PRN-21 & 1,752 & $\pm 0,508$ \\
\hline PRN-22 & 1,728 & $\pm 0,628$ \\
\hline PRN-23 & 1,389 & $\pm 0,575$ \\
\hline PRN-24 & 2,296 & $\pm 0,657$ \\
\hline PRN-25 & 1,730 & $\pm 0,500$ \\
\hline PRN-26 & 2,240 & $\pm 0,480$ \\
\hline PRN-27 & 2,011 & $\pm 0,582$ \\
\hline PRN-28 & 1,920 & $\pm 0,476$ \\
\hline PRN-29 & 1,439 & $\pm 0,624$ \\
\hline PRN-30 & 1,814 & $\pm 0,771$ \\
\hline PRN-31 & 1,903 & $\pm 0,537$ \\
\hline
\end{tabular}




\subsubsection{Validação do modelo através de posicionamento Single Point - período do outono}

Durante este período, o modelo polinomial mostrou o mesmo comportamento no processo de minimização do efeito ionosférico, se comparado com o verão. Em relação ao posicionamento horizontal, o erro médio quadrático diário, foi sempre inferior a 2,2 metros. Este valor é muito próximo em relação ao verão, cujo valor foi inferior a 2,5 metros. Durante todo o período do dia, o erro manteve-se praticamente constante, sempre com valores inferiores a 4 metros, presenciados sempre no intervalo de 17 a 20 horas GPS.

O modelo de Klobuchar, ao analisar o erro médio quadrático horizontal, mesmo por ter proporcionado variações mais constantes, se comparado com o período do verão, o mesmo acarretou picos superiores a 5 metros em alguns intervalos, como de 0 a 6 e 17 a 20 horas GPS. No intervalo de 0 a 6 horas, além do efeito ionosférico, constatou-se observações muito ruidosas para o código C/A.

O modelo Standard, conforme já observado, é muito instável durante todo o período do dia, onde proporcionou erros sempre superiores aos modelos polinomial e de Klobuchar. Algumas vezes, constatou-se erros horizontais de aproximadamente 6 metros, e, entre os intervalos de 0 a 6 e 17 a 20 horas GPS, erros superiores a 9 metros.

Ao analisar os sete dias de processamento, os valores médios do erro horizontal, foram:

- E.M.Q.H.P $=1,773 \mathrm{~m} \pm 0,933 \mathrm{~m}$

- E.M.Q.H.K = 2,738m $\pm 1,179 m$

- E.M.Q.H.S = 3,318m $\pm 1,671 \mathrm{~m}$

O modelo polinomial proporcionou, em média, uma melhora de $0,965 \mathrm{~m}$ e 1,545m, em relação aos modelos de Klobuchar e Standard, respectivamente.

Em relação ao erro vertical, o modelo polinomial também proporcionou melhores resultados que os de Klobuchar e o Standard. Em média, esta melhora não foi tão evidente se comparado com o período do verão. Nos sete dias de processamento os valores médios foram: 
- E.M.Q.V.K = 3,112m $\pm 3,069 m$

- E.M.Q.V.S $=3,269 \mathrm{~m} \pm 2,447 \mathrm{~m}$

A melhora foi, em média, 0,500m e 0,657m, em relação aos modelos de Klobuchar e Standard, respectivamente.

A seguir, serão apresentados todos os resultados do posicionamento Single Point do vértice BRAZ, referentes a alguns dias do outono.

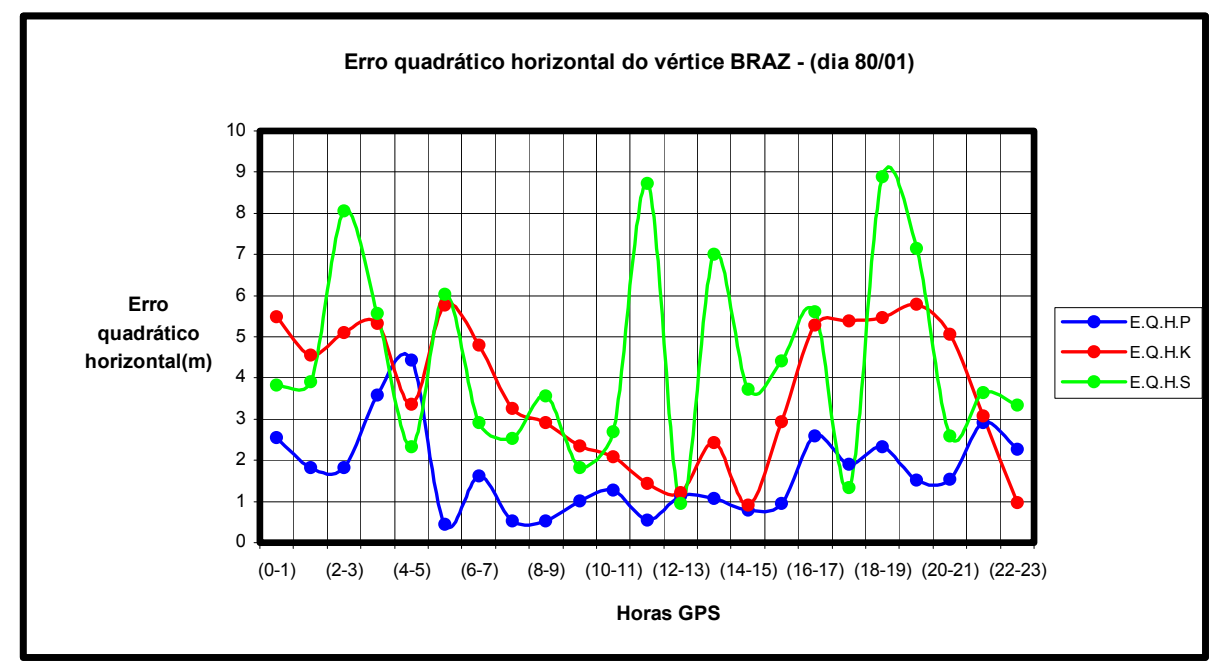

Figura 7.53 - Variação horária do erro quadrático horizontal no posicionamento Single Point do vértice BRAZ - (dia 80/01)

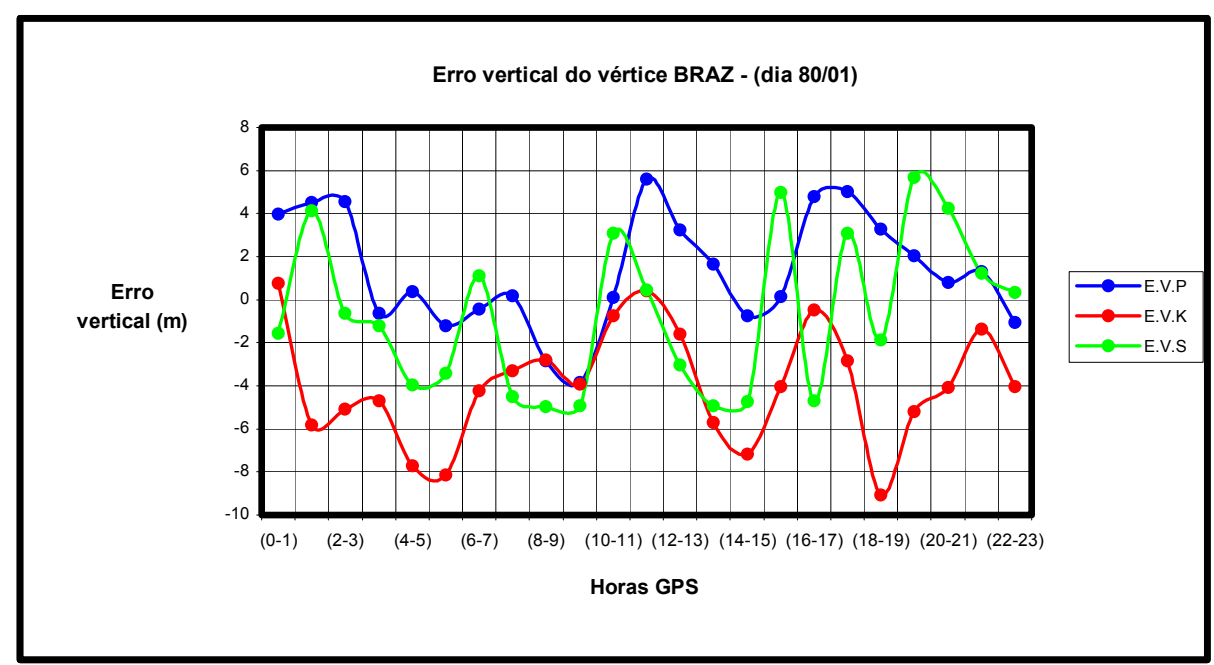

Figura 7.54 - Variação horária do erro vertical no posicionamento Single Point do vértice $\mathrm{BRAZ}$ - (dia 80/01) 
Tabela 7.41 - Erro quadrático horizontal e erro vertical no processamento Single Point do vértice BRAZ para diferentes modelos ionosféricos - (dia 80/01).

\begin{tabular}{|c|c|c|c|c|c|c|}
\cline { 2 - 7 } \multicolumn{1}{c|}{} & \multicolumn{2}{c|}{ Erro Quadrático Horizontal (m) } & \multicolumn{3}{c|}{ Erro Vertical (m) } \\
\hline Horas & E.Q.H.P & E.Q.H.K & E.Q.H.S & E.V.P & E.V.K & E.V.S \\
\hline $\mathbf{( 0 - 1 )}$ & 2,553 & 5,483 & 3,824 & 3,986 & 0,770 & $-1,572$ \\
\hline $\mathbf{( 1 - 2 )}$ & 1,820 & 4,564 & 3,912 & 4,518 & $-5,801$ & 4,141 \\
\hline $\mathbf{( 2 - 3 )}$ & 1,815 & 5,110 & 8,065 & 4,548 & $-5,101$ & $-0,647$ \\
\hline $\mathbf{( 3 - 4 )}$ & 3,588 & 5,315 & 5,573 & $-0,621$ & $-4,678$ & $-1,226$ \\
\hline $\mathbf{( 4 - 5 )}$ & 4,439 & 3,364 & 2,323 & 0,370 & $-7,711$ & $-3,942$ \\
\hline $\mathbf{( 5 - 6 )}$ & 0,439 & 5,763 & 6,039 & $-1,207$ & $-8,130$ & $-3,430$ \\
\hline $\mathbf{( 6 - 7 )}$ & 1,624 & 4,807 & 2,906 & $-0,441$ & $-4,236$ & 1,114 \\
\hline $\mathbf{( 7 - 8 )}$ & 0,535 & 3,249 & 2,526 & 0,193 & $-3,307$ & $-4,511$ \\
\hline $\mathbf{( 8 - 9 )}$ & 0,529 & 2,925 & 3,561 & $-2,847$ & $-2,784$ & $-4,952$ \\
\hline $\mathbf{( 9 - 1 0 )}$ & 1,022 & 2,349 & 1,821 & $-3,836$ & $-3,935$ & $-4,916$ \\
\hline $\mathbf{( 1 0 - 1 1 )}$ & 1,275 & 2,094 & 2,698 & 0,121 & $-0,764$ & 3,093 \\
\hline $\mathbf{( 1 1 - 1 2 )}$ & 0,537 & 1,433 & 8,724 & 5,601 & 0,402 & 0,435 \\
\hline $\mathbf{( 1 2 - 1 3 )}$ & 1,139 & 1,224 & 0,953 & 3,247 & $-1,596$ & $-3,024$ \\
\hline $\mathbf{( 1 3 - 1 4 )}$ & 1,070 & 2,420 & 7,010 & 1,667 & $-5,704$ & $-4,920$ \\
\hline $\mathbf{( 1 4 - 1 5 )}$ & 0,790 & 0,911 & 3,724 & $-0,740$ & $-7,165$ & $-4,736$ \\
\hline $\mathbf{( 1 5 - 1 6 )}$ & 0,948 & 2,934 & 4,414 & 0,143 & $-4,044$ & 4,968 \\
\hline $\mathbf{( 1 6 - 1 7 )}$ & 2,584 & 5,289 & 5,609 & 4,798 & $-0,466$ & $-4,699$ \\
\hline $\mathbf{( 1 7 - 1 8 )}$ & 1,897 & 5,385 & 1,338 & 5,029 & $-2,855$ & 3,079 \\
\hline $\mathbf{( 1 8 - 1 9 )}$ & 2,322 & 5,456 & 8,890 & 3,258 & $-9,053$ & $-1,868$ \\
\hline $\mathbf{( 1 9 - 2 0 )}$ & 1,519 & 5,787 & $\mathbf{7}) 154$ & 2,036 & $-5,206$ & 5,691 \\
\hline $\mathbf{( 2 0 - 2 1 )}$ & 1,537 & 5,057 & 2,583 & 0,808 & $-4,063$ & 4,247 \\
\hline $\mathbf{( 2 1 - 2 2 )}$ & 2,910 & 3,077 & 3,635 & 1,301 & $-1,377$ & 1,227 \\
\hline $\mathbf{( 2 2 - 2 3 )}$ & 2,275 & 0,968 & 3,333 & $-1,049$ & $-4,037$ & 0,327 \\
\hline E.M.Q & $\mathbf{1 , 7 0 3}$ & $\mathbf{3 , 6 9 4}$ & $\mathbf{4 , 3 7 5}$ & $\mathbf{2 , 2 7 7}$ & $\mathbf{4 , 0 5 1}$ & $\mathbf{3 , 1 6 4}$ \\
\hline Desvio Padrão & $\pm \mathbf{1 , 0 2 9}$ & $\pm \mathbf{1 , 6 9 3}$ & $\pm \mathbf{2 , 3 3 4}$ & $\pm \mathbf{2 , 6 3 1}$ & $\pm \mathbf{2 , 6 6 9}$ & $\pm \mathbf{3 , 6 0 0}$ \\
\hline & & & & & & \\
\hline
\end{tabular}

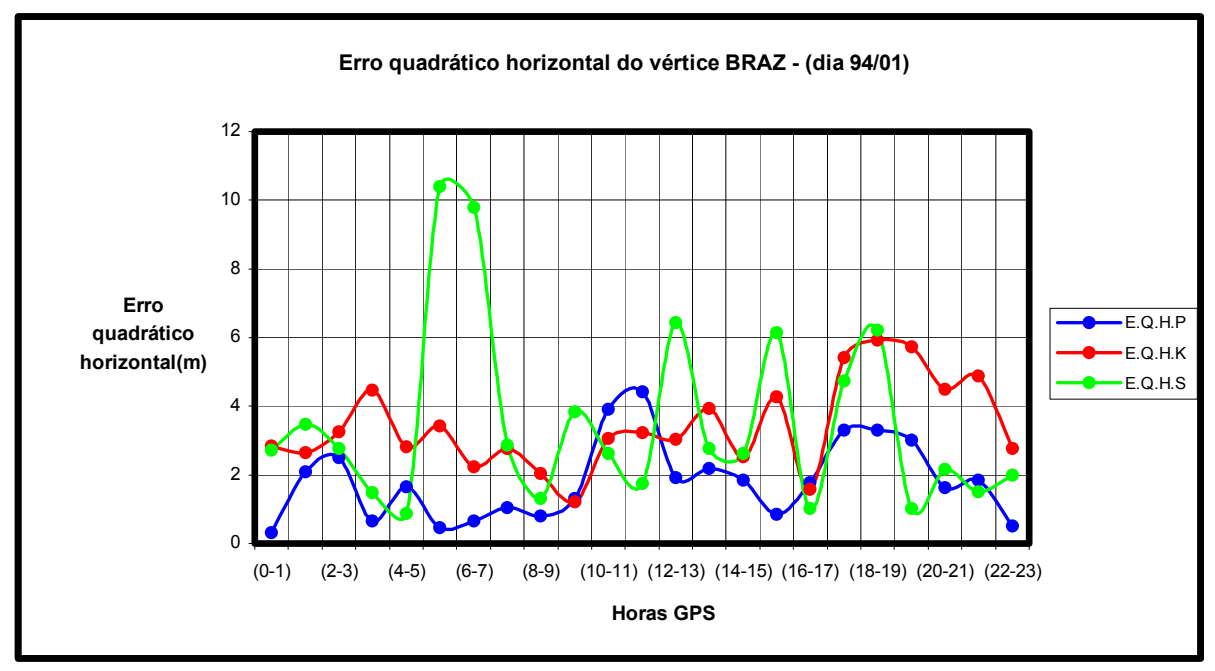

Figura 7.55 - Variação horária do erro quadrático horizontal no posicionamento Single Point do vértice BRAZ - (dia 94/01) 


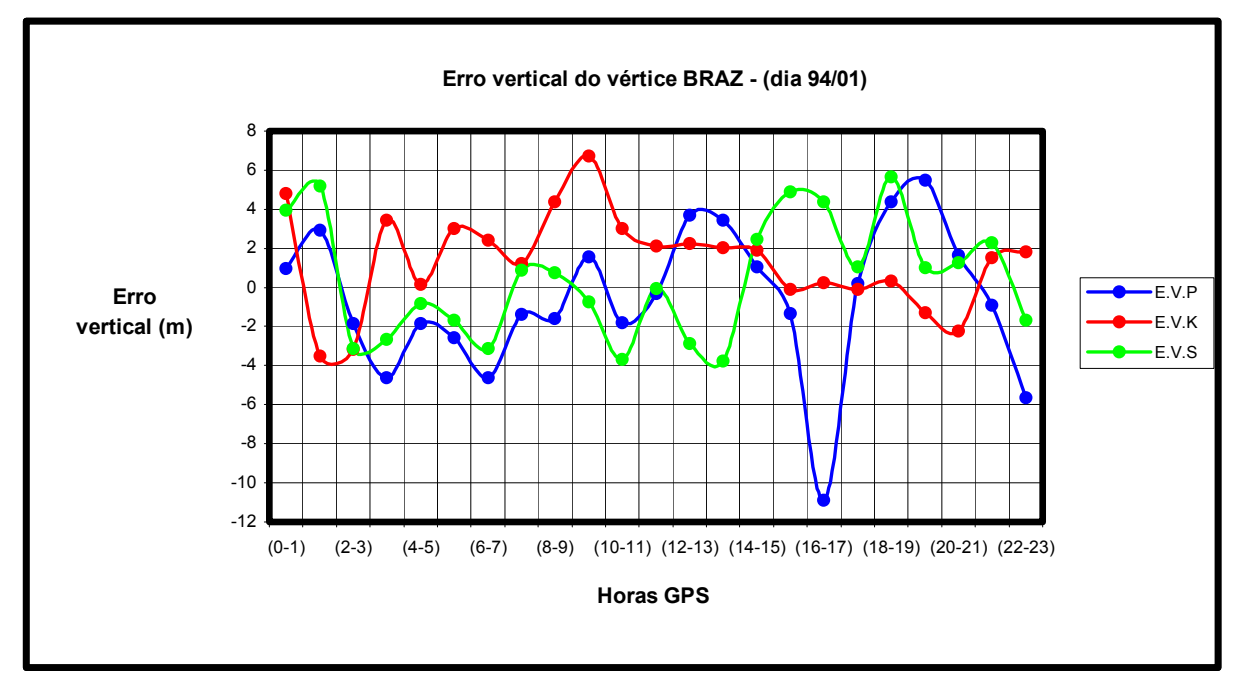

Figura 7.56 - Variação horária do erro vertical no posicionamento Single Point do vértice BRAZ - (dia 94/01)

Tabela 7.42 - Erro quadrático horizontal e erro vertical no processamento Single Point do vértice BRAZ para diferentes modelos ionosféricos - (dia 94/01).

\begin{tabular}{|c|c|c|c|c|c|c|}
\hline \multirow[b]{2}{*}{ Horas } & \multicolumn{3}{|c|}{ Erro Quadrático Horizontal (m) } & \multicolumn{3}{|c|}{ Erro Vertical (m) } \\
\hline & E.Q.H.P & E.Q.H.K & E.Q.H.S & E.V.P & E.V.K & E.V.S \\
\hline$(0-1)$ & 0,314 & 2,848 & 2,712 & 0,976 & 4,796 & 3,942 \\
\hline$(1-2)$ & 2,089 & 2,647 & 3,481 & 2,926 & $-3,532$ & 5,183 \\
\hline$(2-3)$ & 2,505 & 3,245 & 2,773 & $-1,867$ & $-3,170$ & $-3,112$ \\
\hline$(3-4)$ & 0,647 & 4,471 & 1,484 & $-4,610$ & 3,451 & $-2,642$ \\
\hline$(4-5)$ & 1,646 & 2,825 & 0,877 & $-1,842$ & 0,132 & $-0,825$ \\
\hline$(5-6)$ & 0,471 & 3,435 & 10,393 & $-2,572$ & 3,021 & $-1,669$ \\
\hline$(6-7)$ & 0,662 & 2,243 & 9,793 & $-4,604$ & 2,394 & $-3,128$ \\
\hline$(7-8)$ & 1,038 & 2,774 & 2,863 & $-1,389$ & 1,207 & 0,867 \\
\hline$(8-9)$ & 0,799 & 2,046 & 1,315 & $-1,609$ & 4,385 & 0,769 \\
\hline$(9-10)$ & 1,309 & 1,216 & 3,833 & 1,575 & 6,713 & $-0,760$ \\
\hline$(10-11)$ & 3,899 & 3,058 & 2,631 & $-1,822$ & 3,024 & $-3,669$ \\
\hline$(11-12)$ & 4,414 & 3,238 & 1,748 & $-0,328$ & 2,123 & $-0,045$ \\
\hline$(12-13)$ & 1,915 & 3,038 & 6,437 & 3,678 & 2,257 & $-2,881$ \\
\hline$(13-14)$ & 2,190 & 3,944 & 2,780 & 3,419 & 2,009 & $-3,776$ \\
\hline (14-15) & 1,836 & 2,525 & 2,626 & 1,047 & 1,891 & 2,446 \\
\hline$(15-16)$ & 0,857 & 4,271 & 6,155 & $-1,327$ & $-0,102$ & 4,866 \\
\hline$(16-17)$ & 1,778 & 1,590 & 1,010 & $-10,872$ & 0,242 & 4,375 \\
\hline$(17-18)$ & 3,308 & 5,429 & 4,740 & 0,191 & $-0,100$ & 1,042 \\
\hline$(18-19)$ & 3,293 & 5,921 & 6,215 & 4,365 & 0,321 & 5,673 \\
\hline$(19-20)$ & 3,013 & 5,740 & 1,013 & 5,476 & $-1,302$ & 0,990 \\
\hline$(20-21)$ & 1,624 & 4,492 & 2,161 & 1,643 & $-2,232$ & 1,261 \\
\hline$(21-22)$ & 1,846 & 4,875 & 1,518 & $-0,924$ & 1,521 & 2,303 \\
\hline$(22-23)$ & 0,504 & 2,772 & 1,984 & $-5,653$ & 1,817 & $-1,659$ \\
\hline E.M.Q & 1,824 & 3,419 & 3,502 & 2,814 & 2,250 & 2,517 \\
\hline Desvio Padra & $\pm 1,148$ & $\pm 1,275$ & $\pm 2,651$ & $\pm 3,681$ & $\pm 2,482$ & $\pm 3,008$ \\
\hline
\end{tabular}




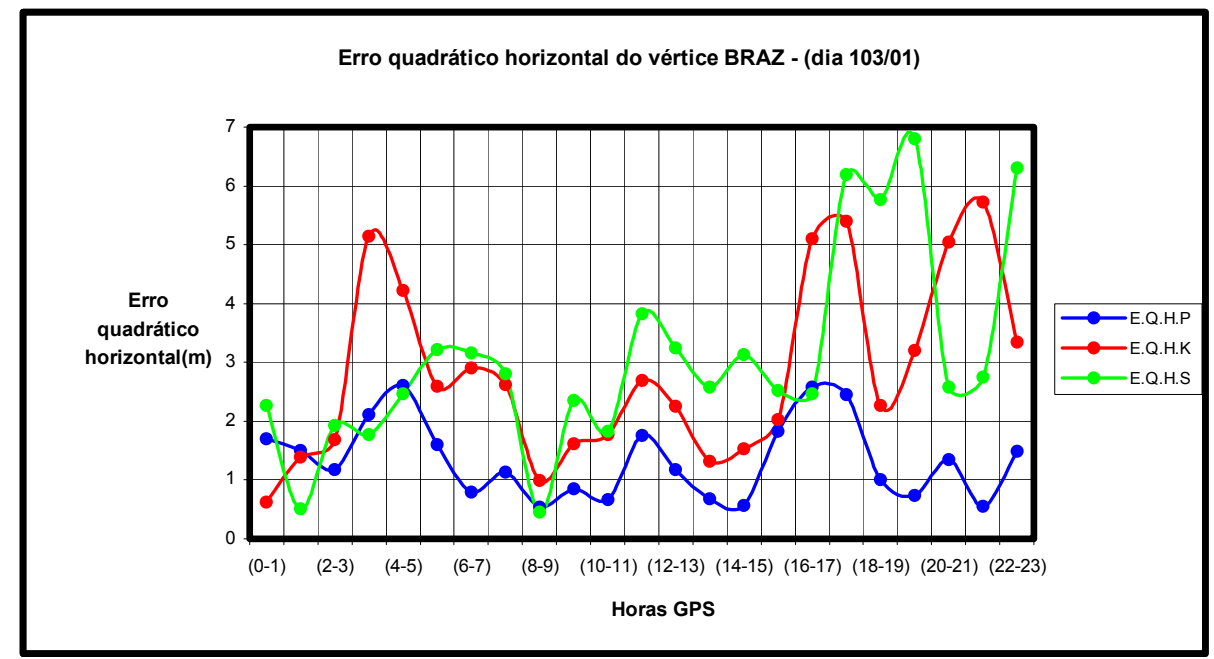

Figura 7.57 - Variação horária do erro quadrático horizontal no posicionamento Single Point do vértice BRAZ - (dia 103/01)

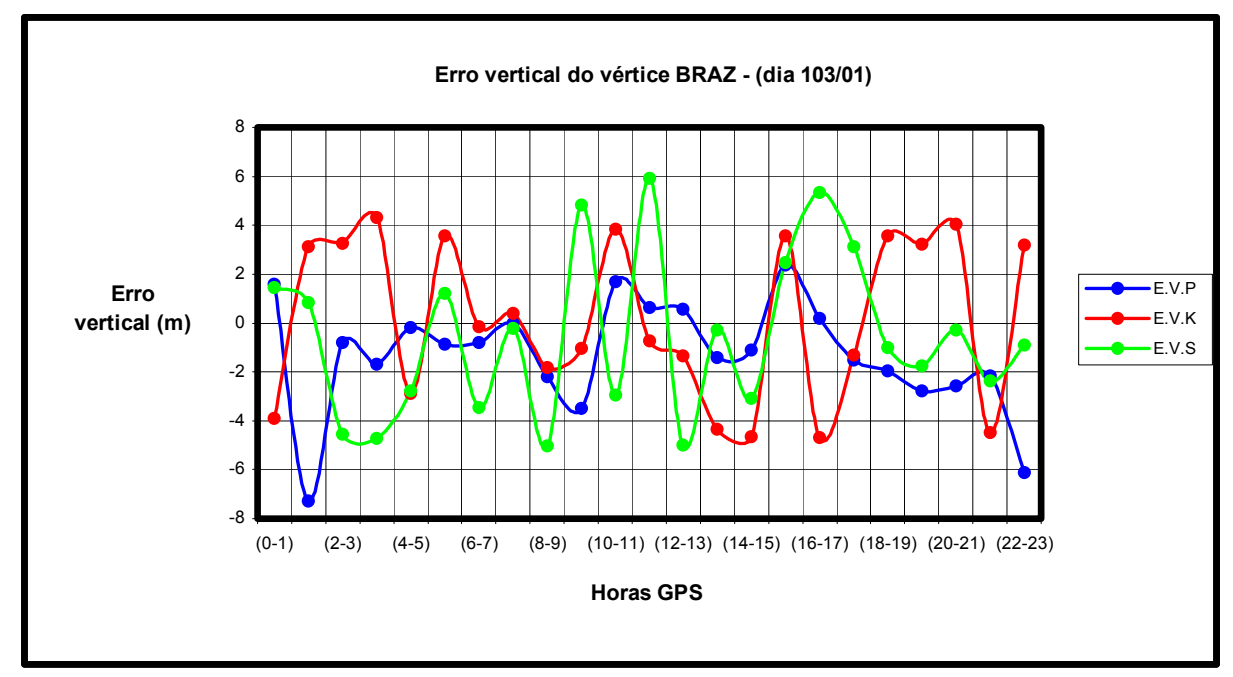

Figura 7.58 - Variação horária do erro vertical no posicionamento Single Point do vértice BRAZ - (dia 103/01) 
Tabela 7.43 - Erro quadrático horizontal e erro vertical no processamento Single Point do vértice BRAZ para diferentes modelos ionosféricos - (dia 103/01).

\begin{tabular}{|c|c|c|c|c|c|c|}
\hline \multirow[b]{2}{*}{ Horas } & \multicolumn{3}{|c|}{ Erro Quadrático Horizontal (m) } & \multicolumn{3}{|c|}{ Erro Vertical (m) } \\
\hline & E.Q.H.P & E.Q.H.K & E.Q.H.S & E.V.P & E.V.K & E.V.S \\
\hline$(0-1)$ & 1,703 & 0,621 & 2,271 & 1,592 & $-3,913$ & 1,436 \\
\hline$(1-2)$ & 1,506 & 1,394 & 0,507 & $-7,277$ & 3,128 & 0,826 \\
\hline$(2-3)$ & 1,177 & 1,690 & 1,928 & $-0,790$ & 3,256 & $-4,571$ \\
\hline$(3-4)$ & 2,106 & 5,143 & 1,777 & $-1,678$ & 4,311 & $-4,728$ \\
\hline$(4-5)$ & 2,600 & 4,218 & 2,461 & $-0,185$ & $-2,890$ & $-2,771$ \\
\hline$(5-6)$ & 1,595 & 2,599 & 3,215 & $-0,872$ & 3,549 & 1,206 \\
\hline$(6-7)$ & 0,790 & 2,904 & 3,164 & $-0,808$ & $-0,168$ & $-3,471$ \\
\hline$(7-8)$ & 1,127 & 2,615 & 2,799 & $-0,023$ & 0,401 & $-0,235$ \\
\hline$(8-9)$ & 0,540 & 0,993 & 0,453 & $-2,195$ & $-1,810$ & $-5,029$ \\
\hline$(9-10)$ & 0,856 & 1,621 & 2,357 & $-3,491$ & $-1,032$ & 4,842 \\
\hline$(10-11)$ & 0,663 & 1,771 & 1,834 & 1,691 & 3,835 & $-2,944$ \\
\hline$(11-12)$ & 1,758 & 2,686 & 3,828 & 0,622 & $-0,732$ & 5,920 \\
\hline$(12-13)$ & 1,176 & 2,255 & 3,248 & 0,568 & $-1,349$ & $-5,012$ \\
\hline$(13-14)$ & 0,675 & 1,316 & 2,585 & $-1,426$ & $-4,342$ & $-0,288$ \\
\hline (14-15) & 0,562 & 1,537 & 3,126 & $-1,119$ & $-4,644$ & $-3,082$ \\
\hline$(15-16)$ & 1,826 & 2,033 & 2,528 & 2,382 & 3,553 & 2,482 \\
\hline$(16-17)$ & 2,581 & 5,100 & 2,461 & 0,192 & $-4,686$ & 5,335 \\
\hline$(17-18)$ & 2,456 & 5,397 & 6,190 & $-1,534$ & $-1,328$ & 3,111 \\
\hline$(18-19)$ & 1,010 & 2,270 & 5,770 & $-1,965$ & 3,582 & $-1,005$ \\
\hline$(19-20)$ & 0,731 & 3,208 & 6,800 & $-2,774$ & 3,225 & $-1,740$ \\
\hline$(20-21)$ & 1,339 & 5,039 & 2,580 & $-2,583$ & 4,026 & $-0,275$ \\
\hline$(21-22)$ & 0,549 & 5,725 & 2,745 & $-2,174$ & $-4,477$ & $-2,361$ \\
\hline$(22-23)$ & 1,493 & 3,340 & 6,303 & $-6,128$ & 3,183 & $-0,906$ \\
\hline E.M.Q & 1,340 & 2,847 & 3,084 & 1,916 & 2,931 & 2,764 \\
\hline Desvio Padrâ & $\pm 0,657$ & $\pm 1,541$ & $\pm 1,689$ & $\pm 2,274$ & $\pm 3,318$ & $\pm 3,314$ \\
\hline
\end{tabular}

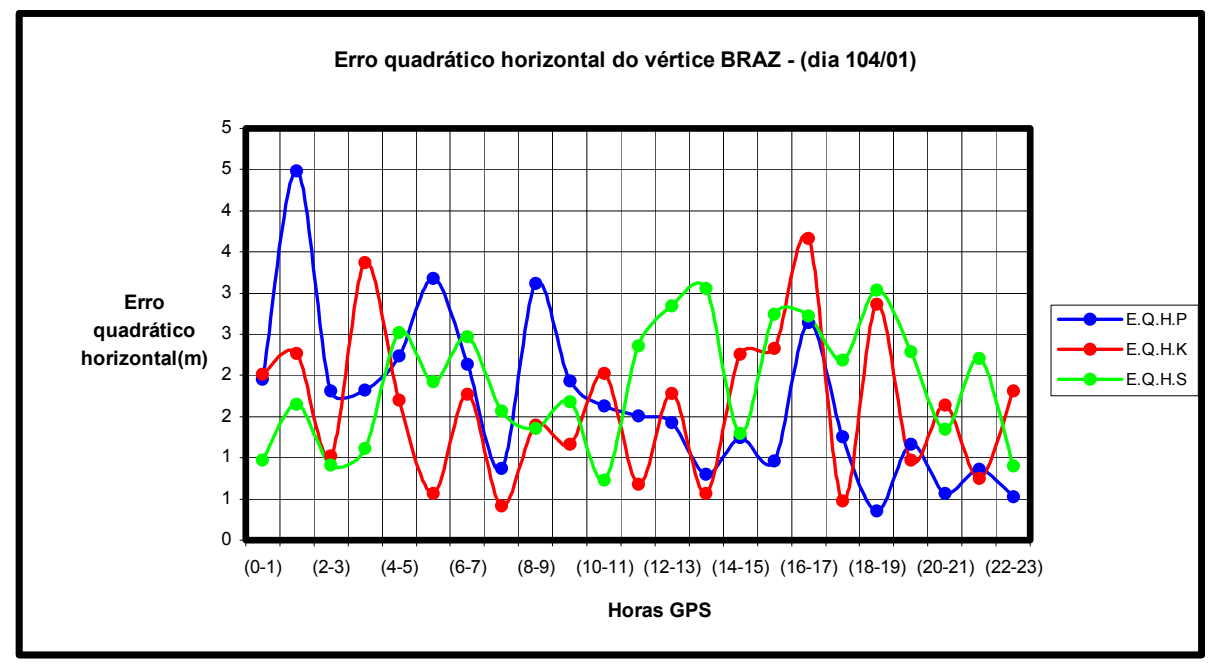

Figura 7.59 - Variação horária do erro quadrático horizontal no posicionamento Single Point do vértice BRAZ - (dia 104/01) 


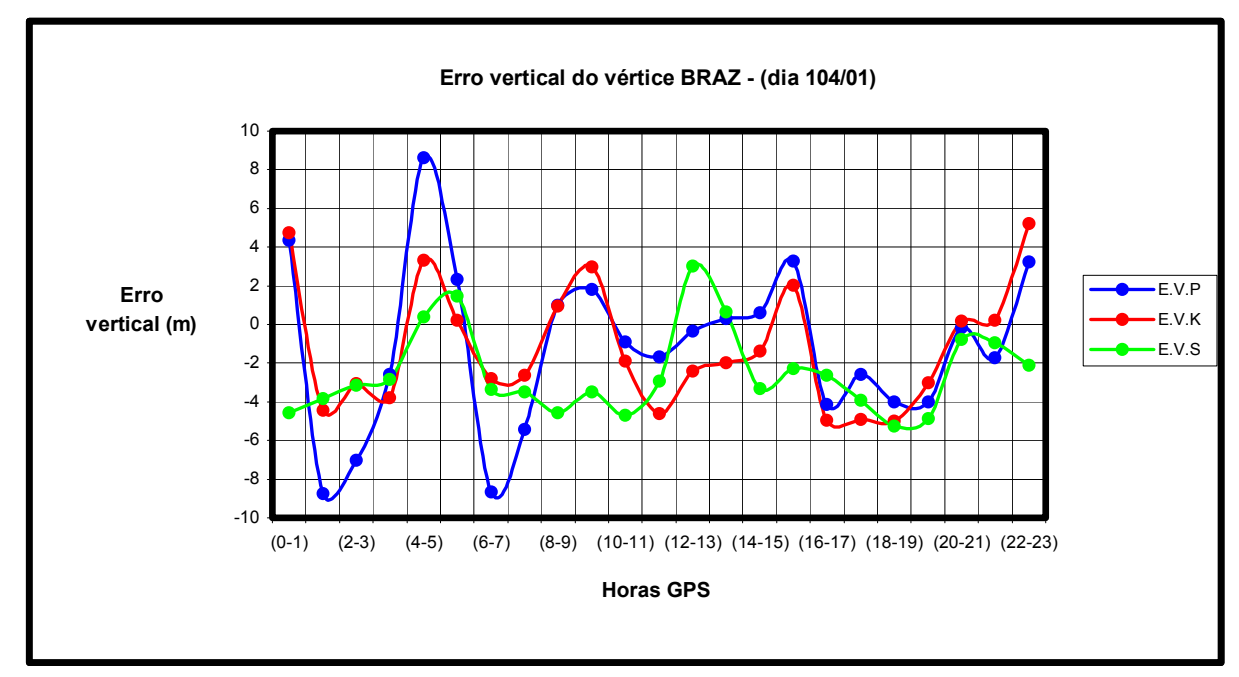

Figura 7.60 - Variação horária do erro vertical no posicionamento Single Point do vértice BRAZ - (dia 104/01)

Tabela 7.44 - Erro quadrático horizontal e erro vertical no processamento Single Point do vértice BRAZ para diferentes modelos ionosféricos - (dia 104/01).

\begin{tabular}{|c|c|c|c|c|c|c|}
\cline { 2 - 7 } \multicolumn{1}{c|}{} & \multicolumn{2}{c|}{ Erro Quadrático Horizontal (m) } & \multicolumn{3}{c|}{ Erro Vertical (m) } \\
\hline Horas & E.Q.H.P & E.Q.H.K & E.Q.H.S & E.V.P & E.V.K & E.V.S \\
\hline $\mathbf{( 0 - 1 )}$ & 1,958 & 2,012 & 0,972 & 4,352 & 4,731 & $-4,581$ \\
\hline $\mathbf{( 1 - 2 )}$ & 4,487 & 2,270 & 1,646 & $-8,735$ & $-4,438$ & $-3,832$ \\
\hline $\mathbf{( 2 - 3 )}$ & 1,810 & 1,027 & 0,916 & $-7,030$ & $-3,049$ & $-3,154$ \\
\hline $\mathbf{( 3 - 4 )}$ & 1,826 & 3,371 & 1,114 & $-2,599$ & $-3,803$ & $-2,826$ \\
\hline $\mathbf{( 4 - 5 )}$ & 2,240 & 1,703 & 2,517 & 8,607 & 3,322 & 0,403 \\
\hline $\mathbf{( 5 - 6 )}$ & 3,177 & 0,564 & 1,924 & 2,319 & 0,202 & 1,468 \\
\hline $\mathbf{( 6 - 7 )}$ & 2,138 & 1,776 & 2,466 & $-8,644$ & $-2,803$ & $-3,354$ \\
\hline $\mathbf{( 7 - 8 )}$ & 0,873 & 0,418 & 1,573 & $-5,437$ & $-2,621$ & $-3,479$ \\
\hline $\mathbf{( 8 - 9 )}$ & 3,115 & 1,398 & 1,361 & 0,985 & 0,929 & $-4,578$ \\
\hline $\mathbf{( 9 - 1 0 )}$ & 1,933 & 1,163 & 1,684 & 1,812 & 2,972 & $-3,496$ \\
\hline $\mathbf{( 1 0 - 1 1 )}$ & 1,632 & 2,020 & 0,726 & $-0,924$ & $-1,915$ & $-4,717$ \\
\hline $\mathbf{( 1 1 - 1 2 )}$ & 1,511 & 0,682 & 2,361 & $-1,678$ & $-4,627$ & $-2,937$ \\
\hline $\mathbf{( 1 2 - 1 3 )}$ & 1,431 & 1,781 & 2,840 & $-0,328$ & $-2,428$ & 3,009 \\
\hline $\mathbf{( 1 3 - 1 4 )}$ & 0,798 & 0,566 & 3,061 & 0,290 & $-1,971$ & 0,667 \\
\hline $\mathbf{( 1 4 - 1 5 )}$ & 1,240 & 2,258 & 1,292 & 0,623 & $-1,370$ & $-3,311$ \\
\hline $\mathbf{( 1 5 - 1 6 )}$ & 0,965 & 2,330 & 2,746 & 3,286 & 2,024 & $-2,282$ \\
\hline $\mathbf{( 1 6 - 1 7 )}$ & 2,637 & 3,659 & 2,726 & $-4,138$ & $-4,955$ & $-2,638$ \\
\hline$(\mathbf{1 7 - 1 8})$ & 1,253 & 0,481 & 2,181 & $-2,608$ & $-4,893$ & $-3,933$ \\
\hline $\mathbf{( 1 8 - 1 9 )}$ & 0,349 & 2,860 & 3,037 & $-3,995$ & $-4,983$ & $-5,251$ \\
\hline $\mathbf{( 1 9 - 2 0 )}$ & 1,165 & 0,969 & 2,291 & $-3,999$ & $-2,999$ & $-4,878$ \\
\hline $\mathbf{( 2 0 - 2 1 )}$ & 0,563 & 1,637 & 1,350 & $-0,172$ & 0,161 & $-0,770$ \\
\hline $\mathbf{( 2 1 - 2 2})$ & 0,861 & 0,752 & $\mathbf{2 , 2 0 5}$ & $-1,713$ & 0,226 & $-0,959$ \\
\hline $\mathbf{( 2 2 - 2 3 )}$ & 0,531 & 1,808 & 0,900 & 3,225 & 5,217 & $-2,131$ \\
\hline E.M.Q & $\mathbf{1 , 6 7 4}$ & $\mathbf{1 , 6 3 1}$ & $\mathbf{1 , 9 0 8}$ & $\mathbf{3 , 3 6 9}$ & $\mathbf{2 , 8 9 7}$ & $\mathbf{2 , 9 8 5}$ \\
\hline Desvio Padrão & $\pm \mathbf{0 , 9 8 8}$ & $\pm \mathbf{0 , 9 0 8}$ & $\pm \mathbf{0 , 7 4 4}$ & $\pm \mathbf{4 , 2 2 7}$ & $\pm \mathbf{3 , 1 6 2}$ & $\pm \mathbf{2 , 1 8 3}$ \\
\hline
\end{tabular}




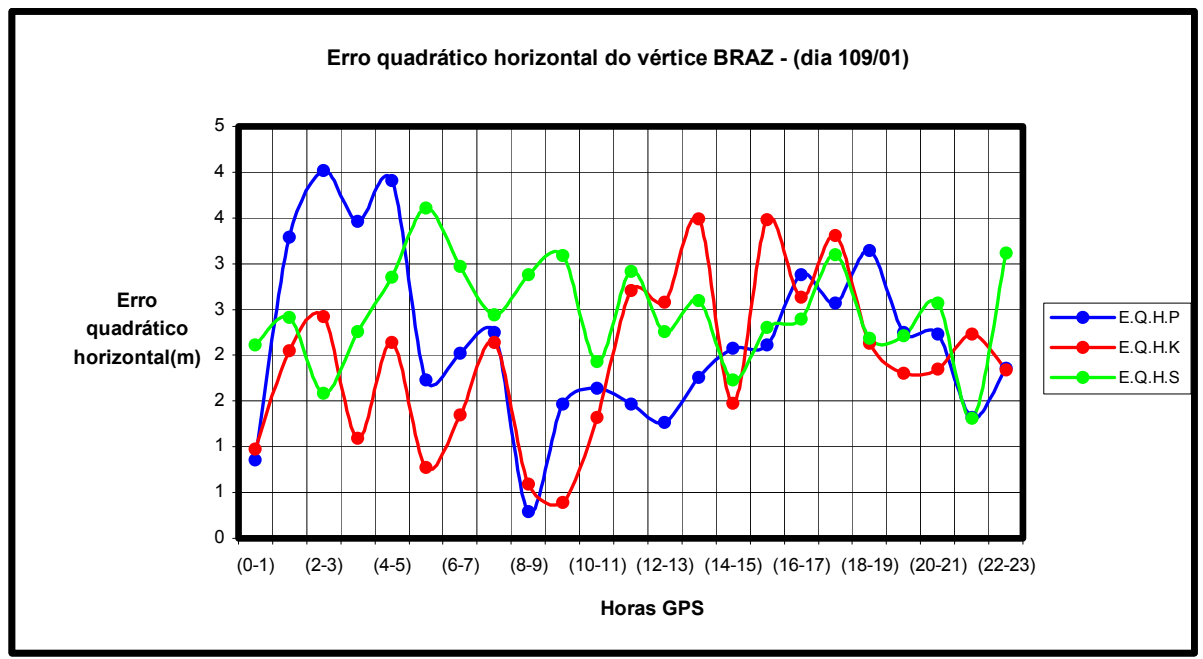

Figura 7.61 - Variação horária do erro quadrático horizontal no posicionamento Single Point do vértice BRAZ - (dia 109/01)

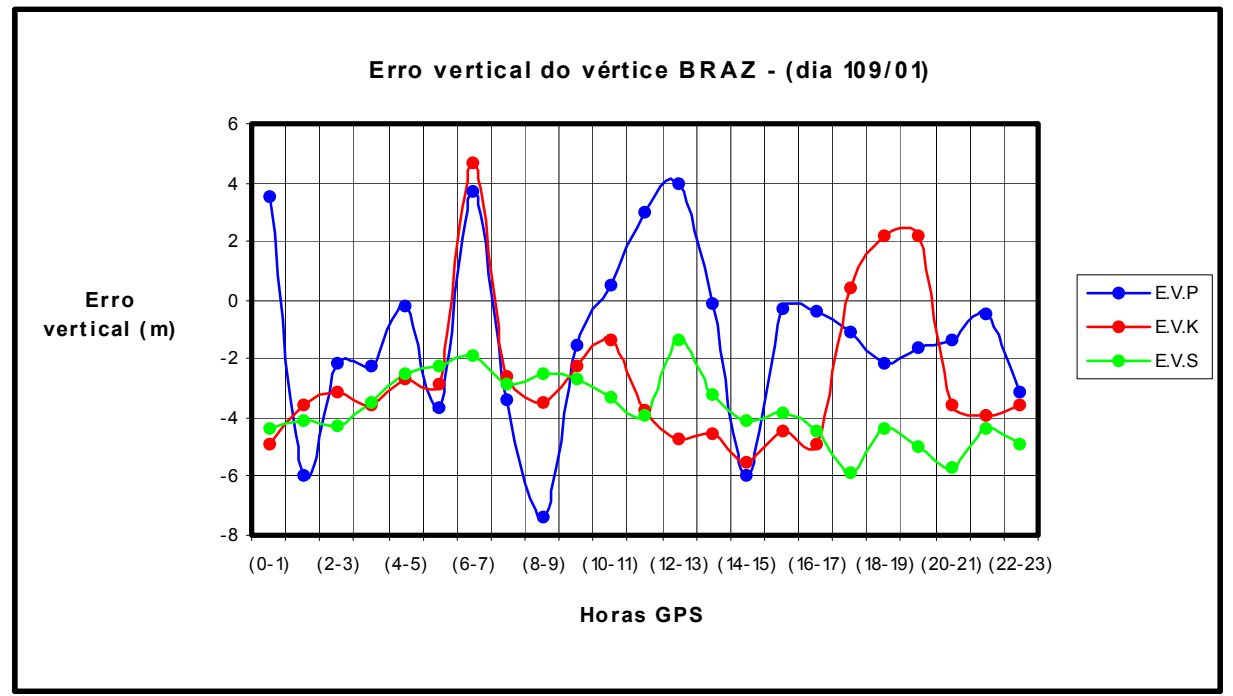

Figura 7.62 - Variação horária do erro vertical no posicionamento Single Point do vértice BRAZ - (dia 109/01) 
Tabela 7.45 - Erro quadrático horizontal e erro vertical no processamento Single Point do vértice BRAZ para diferentes modelos ionosféricos - (dia 109/01).

\begin{tabular}{|c|c|c|c|c|c|c|}
\hline \multirow[b]{2}{*}{ Horas } & \multicolumn{3}{|c|}{ Erro Quadrático Horizontal (m) } & \multicolumn{3}{|c|}{ Erro Vertical (m) } \\
\hline & E.Q.H.P & E.Q.H.K & E.Q.H.S & E.V.P & E.V.K & E.V.S \\
\hline$(0-1)$ & 0,856 & 0,972 & 2,110 & 3,513 & $-4,886$ & $-4,352$ \\
\hline$(1-2)$ & 3,285 & 2,047 & 2,413 & $-5,943$ & $-3,544$ & $-4,144$ \\
\hline$(2-3)$ & 4,016 & 2,424 & 1,587 & $-2,177$ & $-3,141$ & $-4,245$ \\
\hline$(3-4)$ & 3,458 & 1,096 & 2,260 & $-2,197$ & $-3,557$ & $-3,509$ \\
\hline (4-5) & 3,905 & 2,145 & 2,853 & $-0,233$ & $-2,641$ & $-2,526$ \\
\hline$(5-6)$ & 1,732 & 0,779 & 3,611 & $-3,656$ & $-2,851$ & $-2,271$ \\
\hline$(6-7)$ & 2,020 & 1,352 & 2,968 & 3,688 & 4,712 & $-1,845$ \\
\hline$(7-8)$ & 2,249 & 2,142 & 2,437 & $-3,397$ & $-2,600$ & $-2,904$ \\
\hline$(8-9)$ & 0,289 & 0,591 & 2,876 & $-7,415$ & $-3,506$ & $-2,522$ \\
\hline$(9-10)$ & 1,468 & 0,391 & 3,091 & $-1,506$ & $-2,197$ & $-2,707$ \\
\hline$(10-11)$ & 1,643 & 1,323 & 1,935 & 0,476 & $-1,383$ & $-3,283$ \\
\hline$(11-12)$ & 1,464 & 2,704 & 2,912 & 2,992 & $-3,742$ & $-3,940$ \\
\hline$(12-13)$ & 1,266 & 2,581 & 2,255 & 3,929 & $-4,756$ & $-1,319$ \\
\hline (13-14) & 1,762 & 3,485 & 2,592 & $-0,136$ & $-4,566$ & $-3,208$ \\
\hline (14-15) & 2,077 & 1,471 & 1,728 & $-5,982$ & $-5,497$ & $-4,086$ \\
\hline$(15-16)$ & 2,116 & 3,482 & 2,301 & $-0,304$ & $-4,486$ & $-3,851$ \\
\hline$(16-17)$ & 2,882 & 2,630 & 2,399 & $-0,359$ & $-4,898$ & $-4,452$ \\
\hline$(17-18)$ & 2,572 & 3,307 & 3,094 & $-1,111$ & 0,409 & $-5,912$ \\
\hline$(18-19)$ & 3,143 & 2,132 & 2,190 & $-2,168$ & 2,190 & $-4,405$ \\
\hline$(19-20)$ & 2,253 & 1,800 & 2,210 & $-1,587$ & 2,190 & $-4,992$ \\
\hline$(20-21)$ & 2,228 & 1,846 & 2,565 & $-1,377$ & $-3,580$ & $-5,697$ \\
\hline$(21-22)$ & 1,322 & 2,228 & 1,312 & $-0,457$ & $-3,956$ & $-4,402$ \\
\hline$(22-23)$ & 1,862 & 1,844 & 3,117 & $-3,098$ & $-3,591$ & $-4,925$ \\
\hline E.M.Q & 2,168 & 1,947 & 2,470 & 2,509 & 3,429 & 3,717 \\
\hline Desvio Padr & $\pm 0,942$ & $\pm \mathbf{0 , 8 7 3}$ & $\pm 0,549$ & $\pm 3,004$ & $\pm 2,603$ & $\pm 1,182$ \\
\hline
\end{tabular}

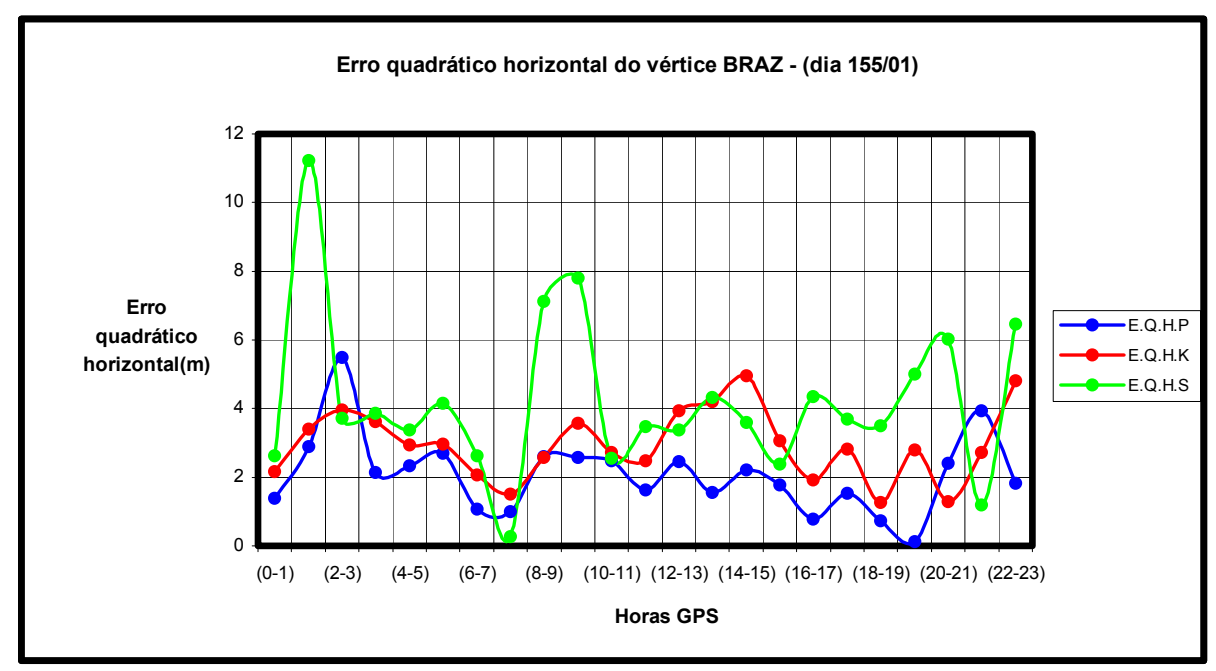

Figura 7.63 - Variação horária do erro quadrático horizontal no posicionamento Single Point do vértice BRAZ - (dia 155/01) 


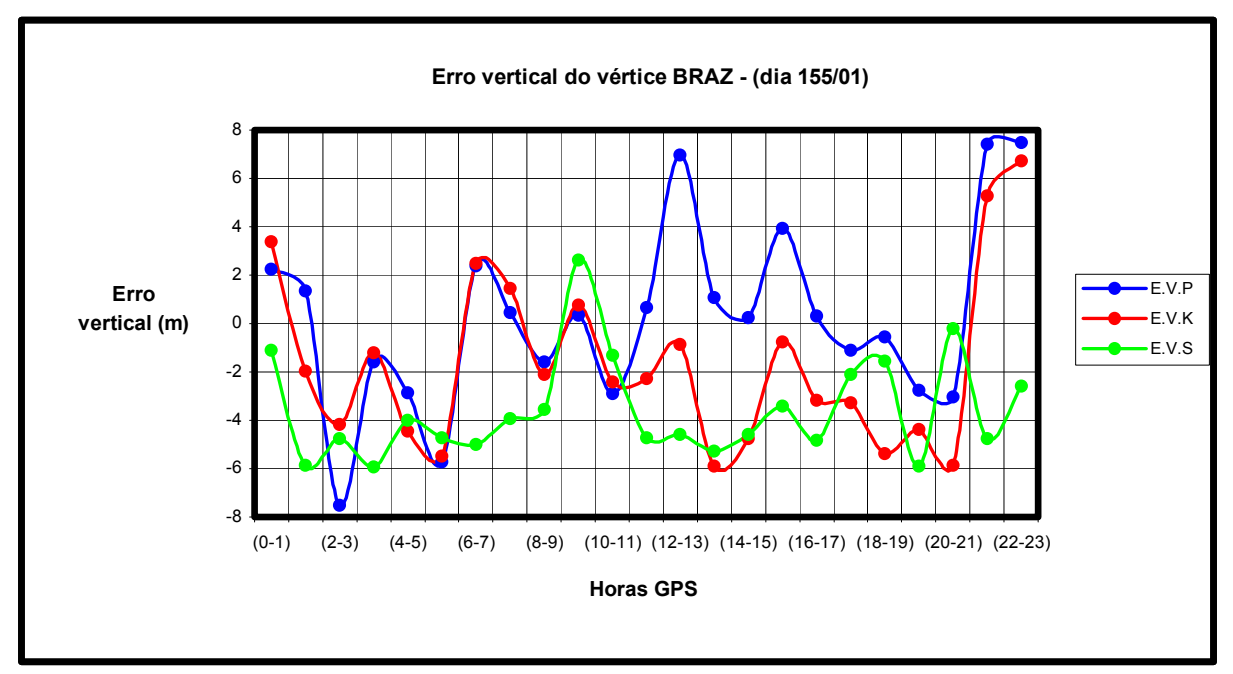

Figura 7.64 - Variação horária do erro vertical no posicionamento Single Point do vértice BRAZ - (dia 155/01)

Tabela 7.46 - Erro quadrático horizontal e erro vertical no processamento Single Point do vértice BRAZ para diferentes modelos ionosféricos - (dia 155/01).

\begin{tabular}{|c|c|c|c|c|c|c|}
\hline \multirow[b]{2}{*}{ Horas } & \multicolumn{3}{|c|}{ Erro Quadrático Horizontal (m) } & \multicolumn{3}{|c|}{ Erro Vertical (m) } \\
\hline & E.Q.H.P & E.Q.H.K & E.Q.H.S & E.V.P & E.V.K & E.V.S \\
\hline$(0-1)$ & 1,386 & 2,171 & 2,628 & 2,246 & 3,373 & $-1,105$ \\
\hline$(1-2)$ & 2,884 & 3,399 & 11,212 & 1,361 & $-1,976$ & $-5,868$ \\
\hline$(2-3)$ & 5,486 & 3,955 & 3,717 & $-7,524$ & $-4,174$ & $-4,757$ \\
\hline$(3-4)$ & 2,141 & 3,620 & 3,859 & $-1,571$ & $-1,196$ & $-5,938$ \\
\hline$(4-5)$ & 2,343 & 2,938 & 3,377 & $-2,866$ & $-4,465$ & $-3,988$ \\
\hline$(5-6)$ & 2,687 & 2,958 & 4,149 & $-5,720$ & $-5,467$ & $-4,710$ \\
\hline (6-7) & 1,060 & 2,068 & 2,631 & 2,380 & 2,478 & $-5,010$ \\
\hline$(7-8)$ & 0,986 & 1,506 & 0,278 & 0,446 & 1,438 & $-3,924$ \\
\hline$(8-9)$ & 2,598 & 2,568 & 7,116 & $-1,572$ & $-2,091$ & $-3,547$ \\
\hline$(9-10)$ & 2,580 & 3,567 & 7,786 & 0,351 & 0,774 & 2,613 \\
\hline$(10-11)$ & 2,481 & 2,720 & 2,558 & $-2,909$ & $-2,408$ & $-1,322$ \\
\hline$(11-12)$ & 1,629 & 2,476 & 3,480 & 0,649 & $-2,275$ & $-4,714$ \\
\hline$(12-13)$ & 2,465 & 3,932 & 3,382 & 6,973 & $-0,872$ & $-4,585$ \\
\hline$(13-14)$ & 1,563 & 4,212 & 4,322 & 1,084 & $-5,897$ & $-5,263$ \\
\hline $\begin{array}{l}(14-15) \\
\end{array}$ & 2,214 & 4,952 & 3,603 & 0,247 & $-4,753$ & $-4,588$ \\
\hline$(15-16)$ & 1,775 & 3,054 & 2,374 & 3,946 & $-0,755$ & $-3,409$ \\
\hline$(16-17)$ & 0,780 & 1,916 & 4,360 & 0,318 & $-3,159$ & $-4,824$ \\
\hline$(17-18)$ & 1,529 & 2,816 & 3,703 & $-1,112$ & $-3,279$ & $-2,087$ \\
\hline$(18-19)$ & 0,732 & 1,260 & 3,494 & $-0,538$ & $-5,367$ & $-1,569$ \\
\hline$(19-20)$ & 0,122 & 2,796 & 4,995 & $-2,755$ & $-4,374$ & $-5,903$ \\
\hline$(20-21)$ & 2,412 & 1,282 & 6,034 & $-3,019$ & $-5,872$ & $-0,202$ \\
\hline$(21-22)$ & 3,932 & 2,730 & 1,182 & 7,402 & 5,269 & $-4,747$ \\
\hline$(22-23)$ & 1,812 & 4,813 & 6,459 & 7,485 & 6,721 & $-2,577$ \\
\hline E.M.Q & 2,069 & 2,944 & 4,204 & 2,803 & 3,410 & 3,793 \\
\hline Desvio Padrão & $\pm 1,129$ & $\pm 1,018$ & $\pm 2,320$ & $\pm 3,799$ & $\pm 3,561$ & $\pm 2,116$ \\
\hline
\end{tabular}




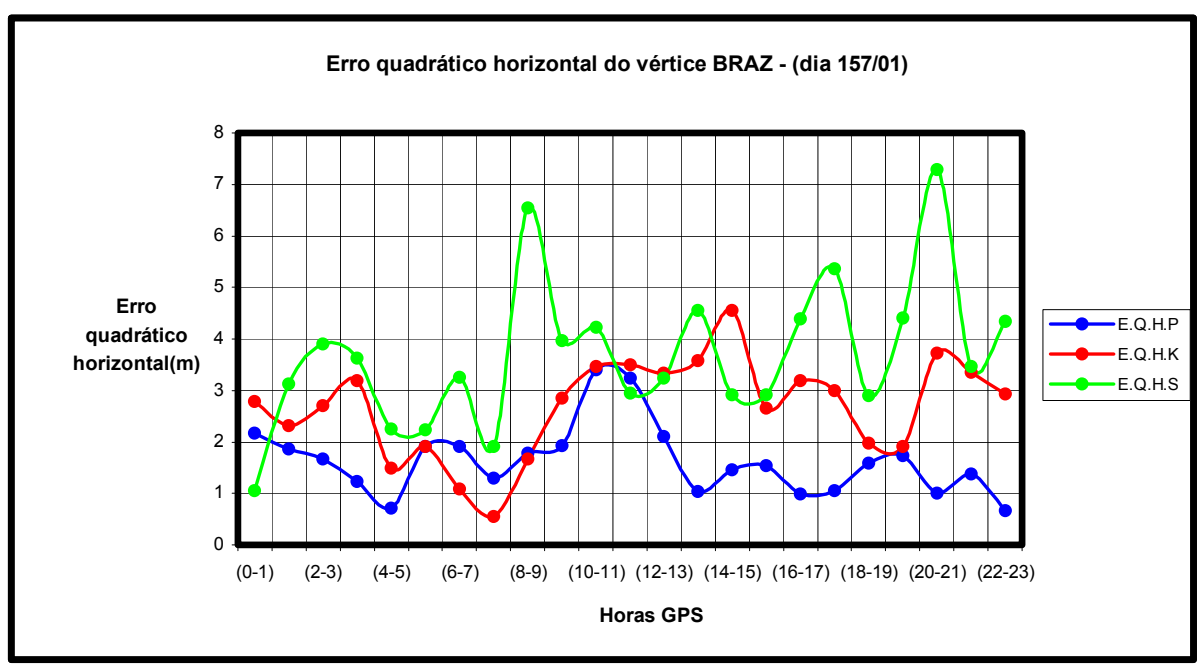

Figura 7.65 - Variação horária do erro quadrático horizontal no posicionamento Single Point do vértice $B R A Z$ - (dia 157/01)

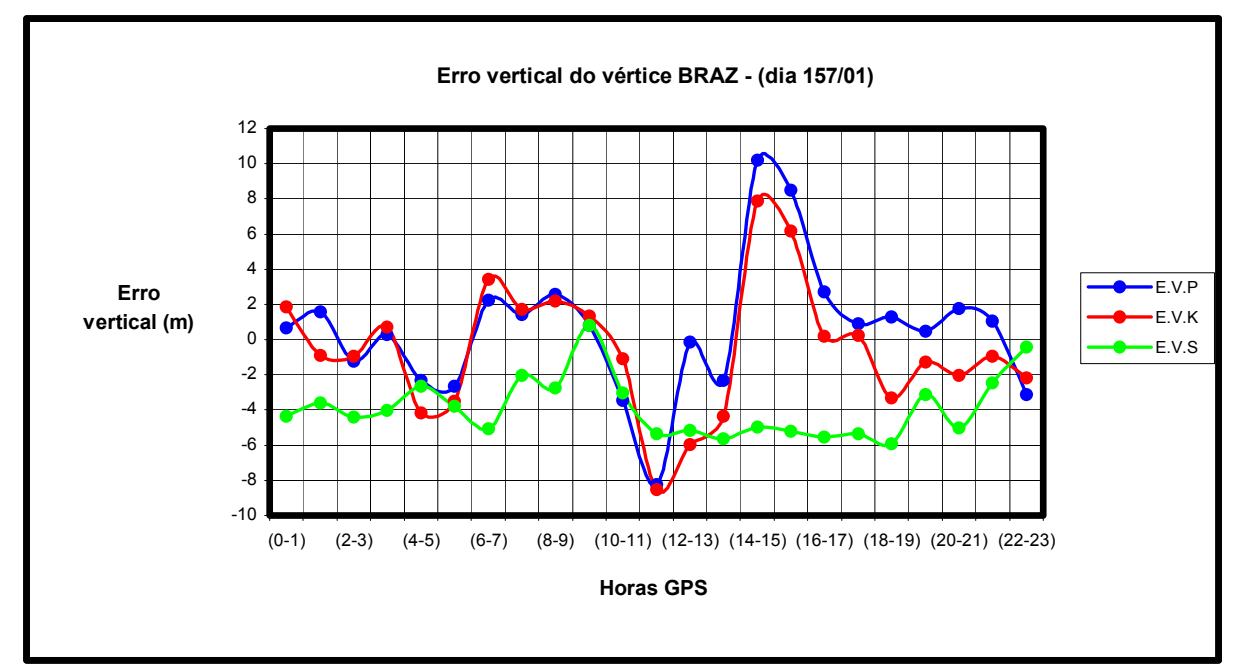

Figura 7.66 - Variação horária do erro vertical no posicionamento Single Point do vértice BRAZ - (dia 157/01) 
Tabela 7.47 - Erro quadrático horizontal e erro vertical no processamento Single Point do vértice BRAZ para diferentes modelos ionosféricos - (dia 157/01).

\begin{tabular}{|c|c|c|c|c|c|c|}
\hline \multirow[b]{2}{*}{ Horas } & \multicolumn{3}{|c|}{ Erro Quadrático Horizontal (m) } & \multicolumn{3}{|c|}{ Erro Vertical (m) } \\
\hline & E.Q.H.P & E.Q.H.K & E.Q.H.S & E.V.P & E.V.K & E.V.S \\
\hline$(0-1)$ & 2,165 & 2,787 & 1,050 & 0,658 & 1,867 & $-4,366$ \\
\hline$(1-2)$ & 1,862 & 2,319 & 3,121 & 1,577 & $-0,910$ & $-3,595$ \\
\hline$(2-3)$ & 1,673 & 2,697 & 3,909 & $-1,239$ & $-0,947$ & $-4,410$ \\
\hline$(3-4)$ & 1,229 & 3,190 & 3,627 & 0,292 & 0,694 & $-4,027$ \\
\hline$(4-5)$ & 0,708 & 1,486 & 2,256 & $-2,299$ & $-4,183$ & $-2,640$ \\
\hline$(5-6)$ & 1,914 & 1,907 & 2,237 & $-2,635$ & $-3,486$ & $-3,766$ \\
\hline$(6-7)$ & 1,909 & 1,090 & 3,250 & 2,227 & 3,409 & $-5,071$ \\
\hline$(7-8)$ & 1,293 & 0,553 & 1,903 & 1,446 & 1,719 & $-2,058$ \\
\hline$(8-9)$ & 1,778 & 1,663 & 6,540 & 2,555 & 2,164 & $-2,733$ \\
\hline$(9-10)$ & 1,924 & 2,842 & 3,964 & 0,808 & 1,316 & 0,790 \\
\hline$(10-11)$ & 3,396 & 3,473 & 4,225 & $-3,467$ & $-1,092$ & $-3,021$ \\
\hline$(11-12)$ & 3,233 & 3,503 & 2,939 & $-8,234$ & $-8,552$ & $-5,349$ \\
\hline$(12-13)$ & 2,111 & 3,332 & 3,233 & $-0,139$ & $-5,947$ & $-5,158$ \\
\hline$(13-14)$ & 1,034 & 3,587 & 4,550 & $-2,295$ & $-4,336$ & $-5,645$ \\
\hline$(14-15)$ & 1,455 & 4,550 & 2,917 & 10,197 & 7,878 & $-4,965$ \\
\hline$(15-16)$ & 1,541 & 2,662 & 2,909 & 8,495 & 6,172 & $-5,198$ \\
\hline$(16-17)$ & 0,982 & 3,192 & 4,390 & 2,703 & 0,179 & $-5,558$ \\
\hline$(17-18)$ & 1,052 & 2,994 & 5,354 & 0,882 & 0,236 & $-5,373$ \\
\hline (18-19) & 1,580 & 1,978 & 2,892 & 1,271 & $-3,292$ & $-5,909$ \\
\hline$(19-20)$ & 1,734 & 1,903 & 4,406 & 0,459 & $-1,287$ & $-3,130$ \\
\hline$(20-21)$ & 0,996 & 3,717 & 7,284 & 1,773 & $-2,030$ & $-5,042$ \\
\hline$(21-22)$ & 1,378 & 3,356 & 3,467 & 1,034 & $-0,956$ & $-2,444$ \\
\hline$(22-23)$ & 0,663 & 2,938 & 4,332 & $-3,105$ & $-2,163$ & $-0,409$ \\
\hline E.M.Q & 1,635 & 2,683 & 3,685 & 2,600 & 2,818 & 3,942 \\
\hline Desvio Padrão & $\pm 0,681$ & $\pm 0,945$ & $\pm 1,412$ & $\pm 3,746$ & $\pm 3,688$ & $\pm 1,729$ \\
\hline
\end{tabular}

\subsubsection{Validação do modelo através de posicionamento relativo - período do outono}

O modelo polinomial, através da metodologia de não corrigir o código $\mathrm{C} / \mathrm{A}$, e sim, através da modelagem, recriar o código $P$, não se mostrou muito eficiente (horizontalmente e verticalmente), se comparado com os modelos de Klobuchar e Standard. Praticamente, durante os sete dias de processamento, a melhora não foi tão significativa em relação ao verão. O dia 109 foi o que apresentou o pior resultado, com erro horizontal do vértice UEPP de $0,604 m \pm 0,513$. Neste dia, o desvio padrão obtido para o erro de interfreqüência do satélite PRN-5, foi de 1,3m, quase o dobro se comparado com o valor médio do período $(0,794 \mathrm{~m})$. Este fato pode ter acarretado este erro para o vértice UEPP. Neste mesmo dia, constatou-se, também, o maior erro horizontal no posicionamento Single Point. 
Os modelos de Klobuchar e Standard mostraram-se bastantes eficientes se comparados com o período do verão. As melhoras foram de 0,200m e 0,400m, respectivamente.

Ao analisar os sete dias de processamento, os valores médios do erro horizontal, foram:

- E.M.Q.H.P $=0,442 m \pm 0,402 m$

- E.M.Q.H.K =0,530m $\pm 0,344 \mathrm{~m}$

- E.M.Q.H.S $=0,548 \mathrm{~m} \pm 0,322 \mathrm{~m}$

O modelo polinomial proporcionou, em média, uma melhora de $0,088 \mathrm{~m}$ e $0,106 \mathrm{~m}$, em relação aos modelos de Klobuchar e Standard, respectivamente.

Em relação ao erro vertical, os valores são semelhantes para os três modelos estudados. Os valores médios para o período foram:

- E.M.Q.V.P $=0,651 \mathrm{~m} \pm 0,789 \mathrm{~m}$

- E.M.Q.V.K $=0,643 \mathrm{~m} \pm 0,777 \mathrm{~m}$

- E.M.Q.V.S $=0,687 \mathrm{~m} \pm 0,819 \mathrm{~m}$

A seguir serão apresentados todos os resultados referentes ao posicionamento relativo, durante o período do outono estudado.

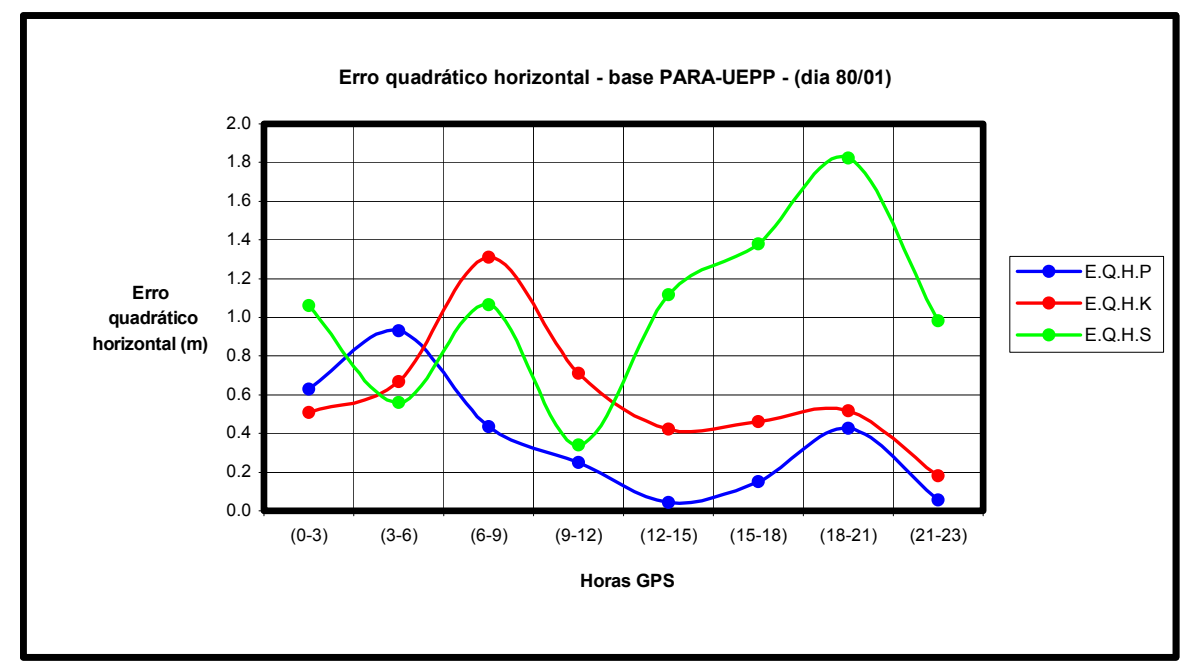

Figura 7.67 - Variação horária do erro quadrático horizontal do vértice UEPP no posicionamento relativo da base PARA - UEPP - (dia 80/01). 


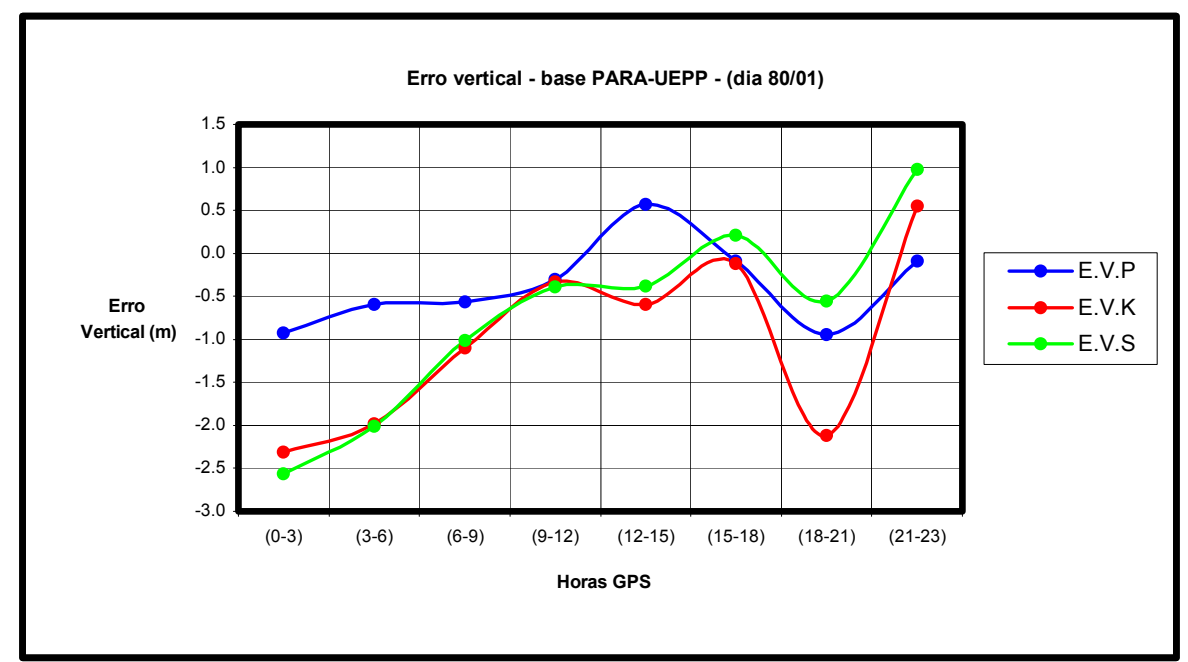

Figura 7.68 - Variação horária do erro vertical do vértice UEPP no posicionamento relativo da base PARA - UEPP - (dia 80/01).

Tabela 7.48 - Erro quadrático horizontal e erro vertical do vértice UEPP no processamento relativo da base PARA - UEPP, para diferentes modelos ionosféricos - (dia 80/01).

\begin{tabular}{|c|c|c|c|c|c|c|}
\cline { 2 - 7 } \multicolumn{1}{c|}{} & \multicolumn{3}{c|}{ Erro Quadrático Horizontal (m) } & \multicolumn{3}{c|}{ Erro Vertical (m) } \\
\hline Horas & E.Q.H.P & E.Q.H.K & E.Q.H.S & E.V.P & E.V.K & E.V.S \\
\hline $\mathbf{( 0 - 3 )}$ & 0,630 & 0,508 & 1,062 & $-0,920$ & $-2,312$ & $-2,560$ \\
\hline $\mathbf{( 3 - 6 )}$ & 0,931 & 0,670 & 0,560 & $-0,593$ & $-1,985$ & $-2,009$ \\
\hline $\mathbf{( 6 - 9 )}$ & 0,434 & 1,311 & 1,063 & $-0,567$ & $-1,097$ & $-1,015$ \\
\hline $\mathbf{( 9 - 1 2 )}$ & 0,251 & 0,710 & 0,342 & $-0,302$ & $-0,334$ & $-0,396$ \\
\hline $\mathbf{( 1 2 - 1 5 )}$ & 0,045 & 0,424 & 1,116 & 0,569 & $-0,590$ & $-0,378$ \\
\hline $\mathbf{( 1 5 - 1 8 )}$ & 0,153 & 0,462 & 1,380 & $-0,091$ & $-0,123$ & 0,211 \\
\hline $\mathbf{( 1 8 - 2 1 )}$ & 0,427 & 0,517 & 1,823 & $-0,942$ & $-2,120$ & $-0,558$ \\
\hline $\mathbf{( 2 1 - 2 3 )}$ & 0,058 & 0,179 & 0,982 & $-0,091$ & 0,553 & 0,974 \\
\hline E.M.Q & $\mathbf{0 , 3 6 6}$ & $\mathbf{0 , 5 9 7}$ & $\mathbf{1 , 0 4 1}$ & $\mathbf{0 , 5 0 9}$ & $\mathbf{1 , 1 3 9}$ & $\mathbf{1 , 0 1 2}$ \\
\hline Desvio Padrão & $\pm \mathbf{0 , 3 0 6}$ & $\pm \mathbf{0 , 3 3 0}$ & $\pm \mathbf{0 , 4 5 6}$ & $\pm \mathbf{0 , 5 0 1}$ & $\pm \mathbf{1 , 0 5 2}$ & $\pm \mathbf{1 , 1 4 1}$ \\
\hline
\end{tabular}




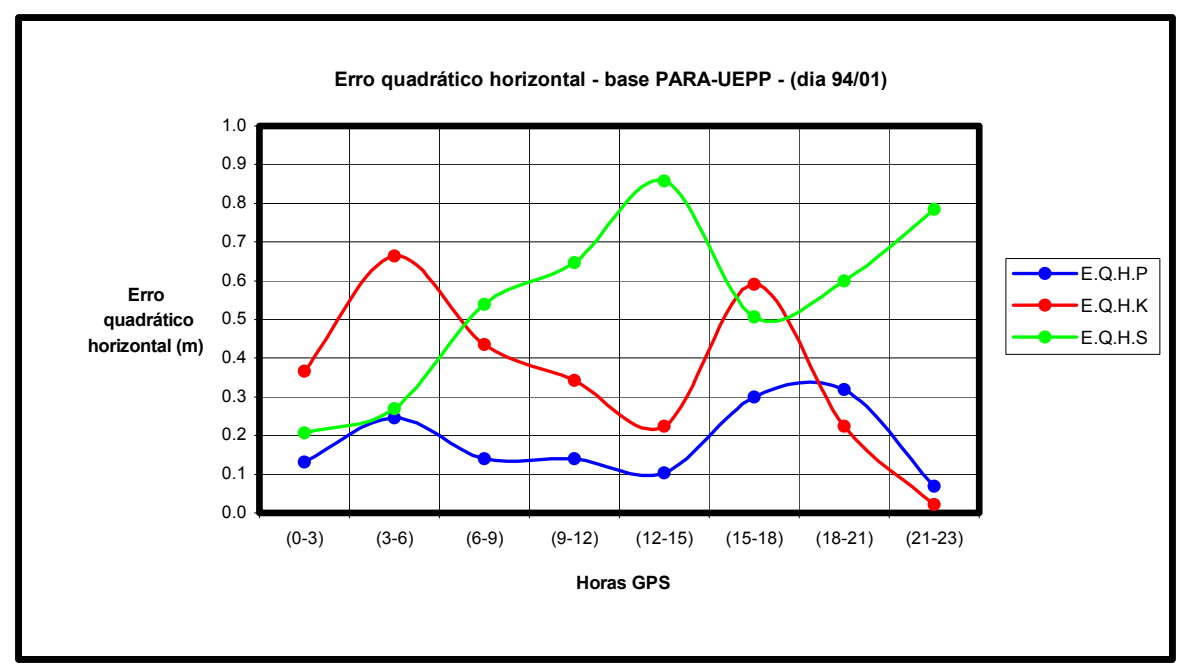

Figura 7.69 - Variação horária do erro quadrático horizontal do vértice UEPP no posicionamento relativo da base PARA - UEPP - (dia 94/01).

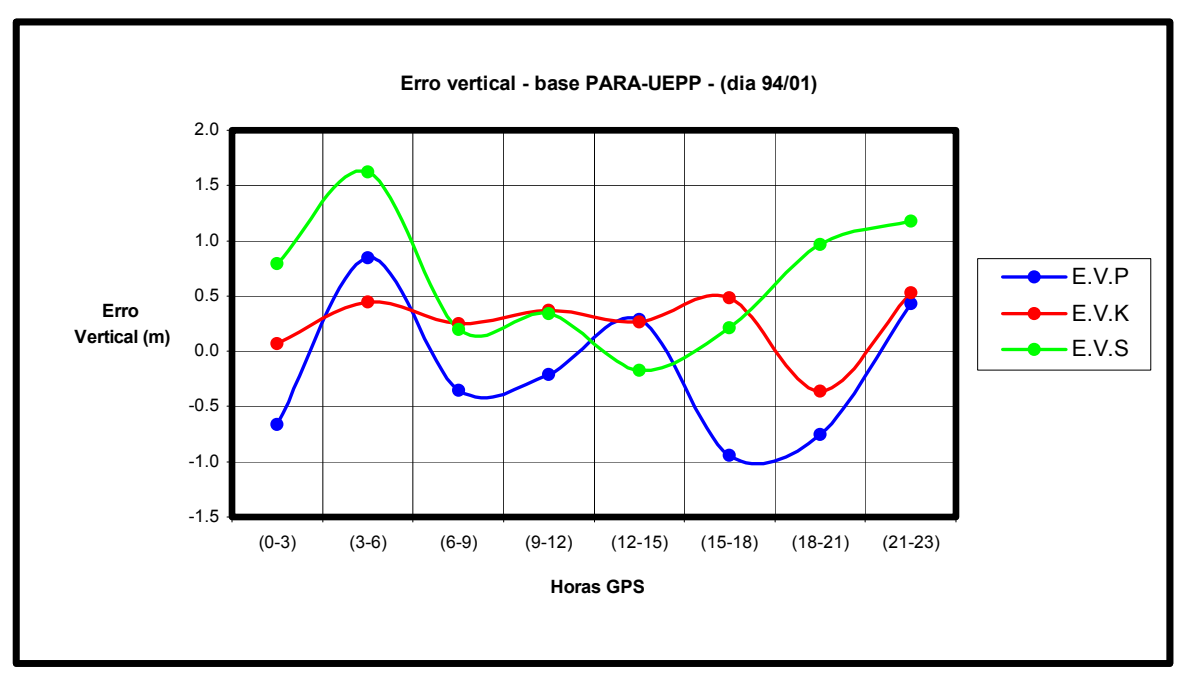

Figura 7.70 - Variação horária do erro vertical do vértice UEPP no posicionamento relativo da base PARA - UEPP - (dia 94/01).

Tabela 7.49 - Erro quadrático horizontal e erro vertical do vértice UEPP no processamento relativo da base PARA - UEPP, para diferentes modelos ionosféricos - (dia 94/01).

\begin{tabular}{|c|c|c|c|c|c|c|}
\cline { 2 - 7 } \multicolumn{1}{c|}{} & \multicolumn{3}{c|}{ Erro Quadrático Horizontal (m) } & \multicolumn{3}{c|}{ Erro Vertical (m) } \\
\hline Horas & E.Q.H.P & E.Q.H.K & E.Q.H.S & E.V.P & E.V.K & E.V.S \\
\hline $\mathbf{( 0 - 3 )}$ & 0,132 & 0,367 & 0,206 & $-0,666$ & 0,070 & 0,793 \\
\hline $\mathbf{( 3 - 6 )}$ & 0,245 & 0,663 & 0,269 & 0,844 & 0,445 & 1,626 \\
\hline $\mathbf{( 6 - 9 )}$ & 0,140 & 0,435 & 0,538 & $-0,354$ & 0,252 & 0,201 \\
\hline $\mathbf{( 9 - 1 2 )}$ & 0,139 & 0,342 & 0,646 & $-0,212$ & 0,373 & 0,341 \\
\hline$(\mathbf{1 2 - 1 5 )}$ & 0,103 & 0,224 & 0,858 & 0,284 & 0,264 & $-0,174$ \\
\hline$(\mathbf{1 5 - 1 8 )}$ & 0,300 & 0,590 & 0,505 & $-0,944$ & 0,485 & 0,214 \\
\hline $\mathbf{( 1 8 - 2 1 )}$ & 0,320 & 0,224 & 0,598 & $-0,751$ & $-0,359$ & 0,970 \\
\hline $\mathbf{( 2 1 - 2 3 )}$ & 0,068 & 0,021 & 0,785 & 0,428 & 0,526 & 1,180 \\
\hline E.M.Q & $\mathbf{0 , 1 8 1}$ & $\mathbf{0 , 3 5 8}$ & $\mathbf{0 , 5 5 1}$ & $\mathbf{0 , 5 6 0}$ & $\mathbf{0 , 3 4 7}$ & $\mathbf{0 , 6 8 7}$ \\
\hline Desvio Padrão & $\pm \mathbf{0 , 0 9 4}$ & $\pm \mathbf{0 , 2 0 8}$ & $\pm \mathbf{0 , 2 2 7}$ & $\pm \mathbf{0 , 6 3 4}$ & $\pm \mathbf{0 , 2 9 0}$ & $\pm \mathbf{0 , 6 0 0}$ \\
\hline
\end{tabular}




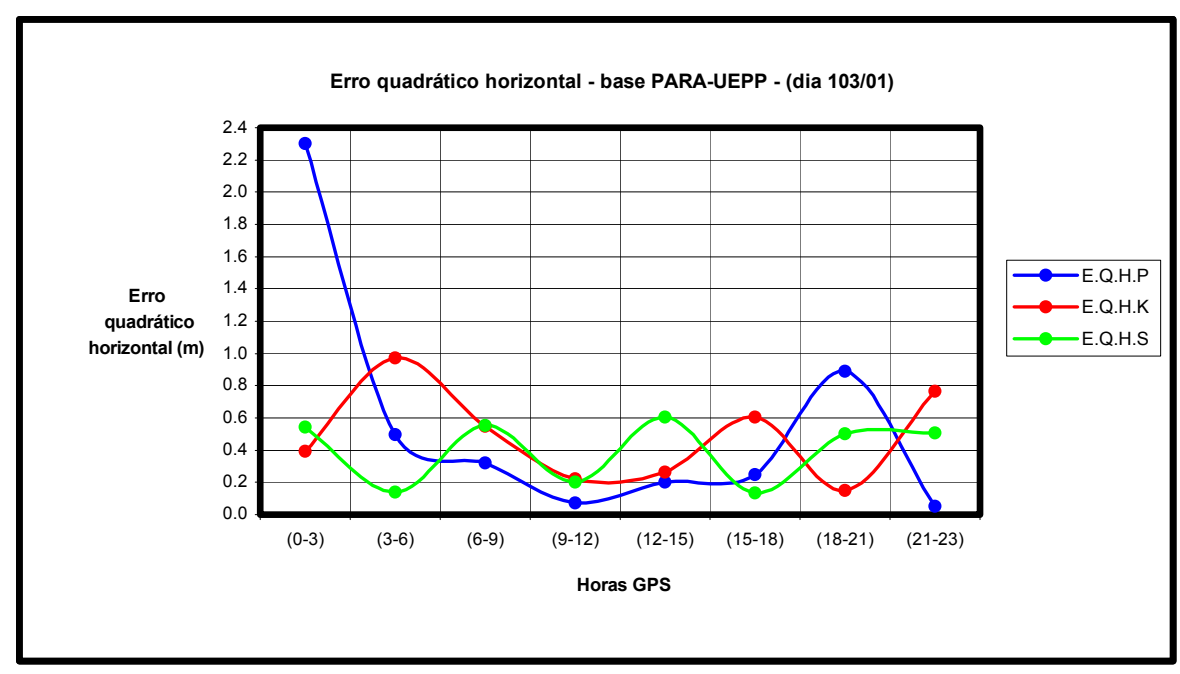

Figura 7.71 - Variação horária do erro quadrático horizontal do vértice UEPP no posicionamento relativo da base PARA - UEPP - (dia 103/01).

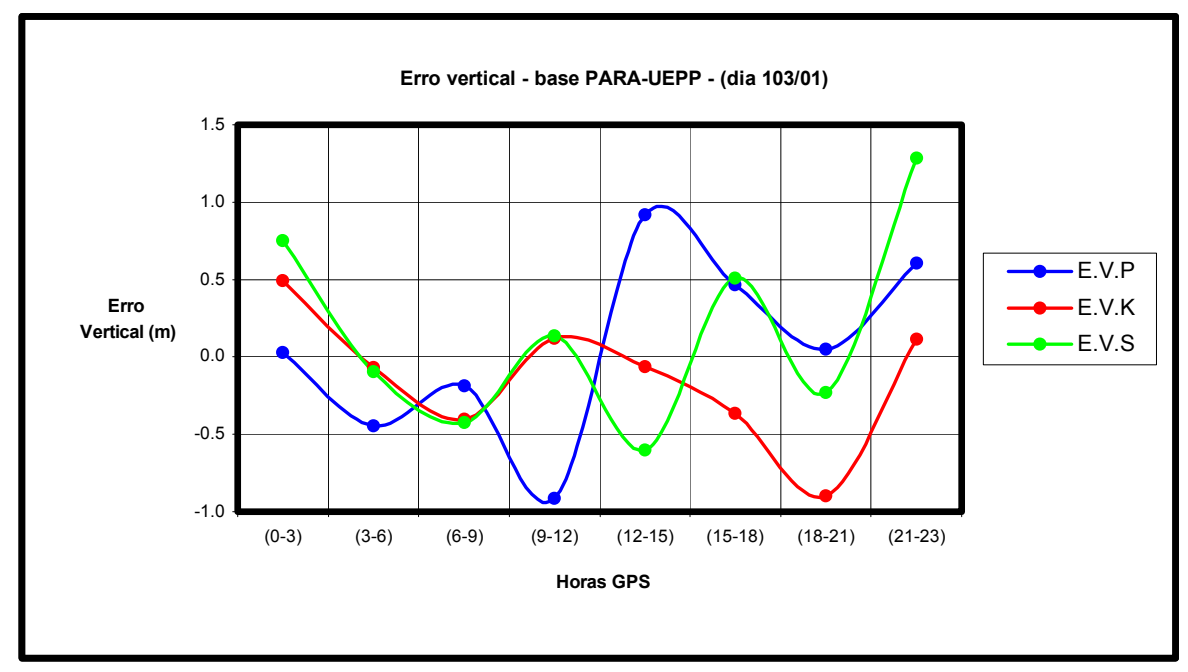

Figura 7.72 - Variação horária do erro vertical do vértice UEPP no posicionamento relativo da base PARA - UEPP - (dia 103/01).

Tabela 7.50 - Erro quadrático horizontal e erro vertical do vértice UEPP no processamento relativo da base PARA - UEPP, para diferentes modelos ionosféricos - (dia 103/01).

\begin{tabular}{|c|c|c|c|c|c|c|}
\cline { 2 - 7 } \multicolumn{1}{c|}{} & \multicolumn{2}{c|}{ Erro Quadrático Horizontal (m) } & \multicolumn{3}{c|}{ Erro Vertical (m) } \\
\hline Horas & E.Q.H.P & E.Q.H.K & E.Q.H.S & E.V.P & E.V.K & E.V.S \\
\hline $\mathbf{( 0 - 3 )}$ & 2,300 & 0,395 & 0,542 & 0,031 & 0,494 & 0,752 \\
\hline $\mathbf{( 3 - 6 )}$ & 0,496 & 0,972 & 0,141 & $-0,447$ & $-0,069$ & $-0,097$ \\
\hline $\mathbf{( 6 - 9 )}$ & 0,322 & 0,550 & 0,553 & $-0,184$ & $-0,400$ & $-0,424$ \\
\hline $\mathbf{( 9 - 1 2 )}$ & 0,073 & 0,224 & 0,202 & $-0,915$ & 0,122 & 0,139 \\
\hline $\mathbf{( 1 2 - 1 5 )}$ & 0,203 & 0,263 & 0,606 & 0,918 & $-0,062$ & $-0,601$ \\
\hline $\mathbf{( 1 5 - 1 8 )}$ & 0,248 & 0,607 & 0,132 & 0,468 & $-0,363$ & 0,507 \\
\hline $\mathbf{( 1 8 - 2 1 )}$ & 0,890 & 0,151 & 0,500 & 0,049 & $-0,898$ & $-0,229$ \\
\hline $\mathbf{( 2 1 - 2 3 )}$ & 0,050 & 0,767 & 0,508 & 0,606 & 0,116 & 1,284 \\
\hline E.M.Q & $\mathbf{0 , 5 7 3}$ & $\mathbf{0 , 4 9 1}$ & $\mathbf{0 , 3 9 8}$ & $\mathbf{0 , 4 5 2}$ & $\mathbf{0 , 3 1 6}$ & $\mathbf{0 , 5 0 4}$ \\
\hline Desvio Padrão & $\pm \mathbf{0 , 7 4 8}$ & $\pm \mathbf{0 , 2 8 6}$ & $\pm \mathbf{0 , 2 0 2}$ & $\pm \mathbf{0 , 5 9 4}$ & $\pm \mathbf{0 , 4 2 1}$ & $\pm \mathbf{0 , 6 4 1}$ \\
\hline
\end{tabular}




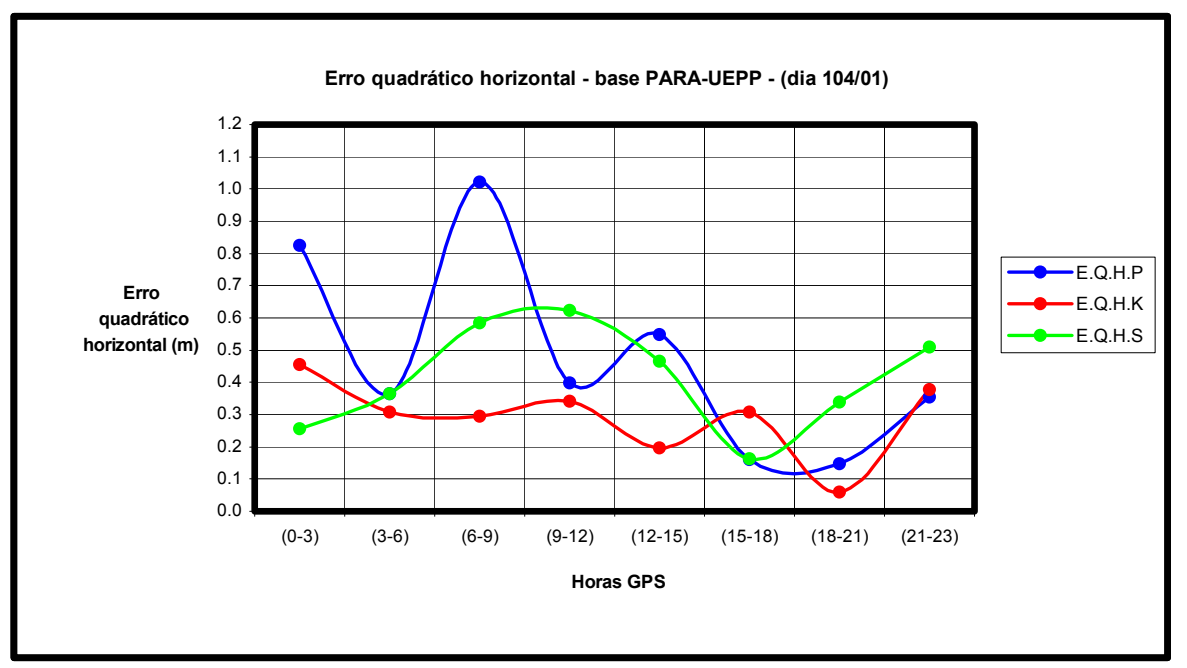

Figura 7.73 - Variação horária do erro quadrático horizontal do vértice UEPP no posicionamento relativo da base PARA - UEPP - (dia 104/01).

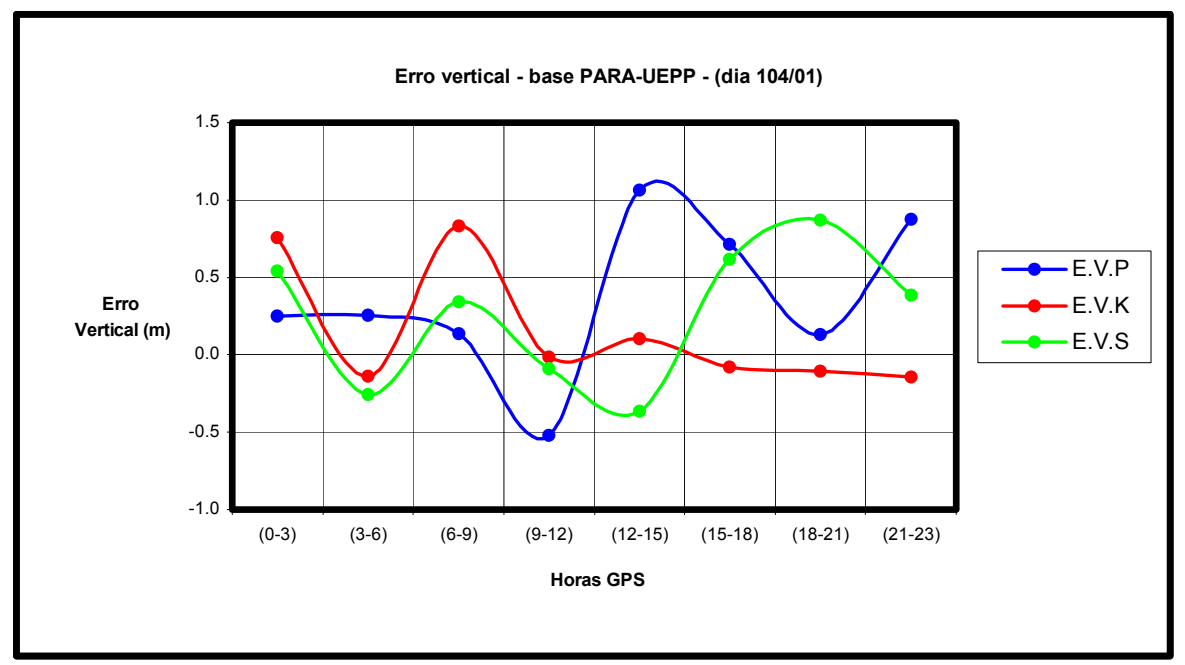

Figura 7.74 - Variação horária do erro vertical do vértice UEPP no posicionamento relativo da base PARA - UEPP - (dia 104/01).

Tabela 7.51 - Erro quadrático horizontal e erro vertical do vértice UEPP no processamento relativo da base PARA - UEPP, para diferentes modelos ionosféricos - (dia 104/01).

\begin{tabular}{|c|c|c|c|c|c|c|}
\cline { 2 - 7 } \multicolumn{1}{c|}{} & \multicolumn{3}{c|}{ Erro Quadrático Horizontal (m) } & \multicolumn{3}{c|}{ Erro Vertical (m) } \\
\hline Horas & E.Q.H.P & E.Q.H.K & E.Q.H.S & E.V.P & E.V.K & E.V.S \\
\hline $\mathbf{( 0 - 3 )}$ & 0,825 & 0,455 & 0,255 & 0,251 & 0,754 & 0,542 \\
\hline $\mathbf{( 3 - 6 )}$ & 0,364 & 0,308 & 0,365 & 0,255 & $-0,139$ & $-0,258$ \\
\hline $\mathbf{( 6 - 9 )}$ & 1,023 & 0,295 & 0,585 & 0,135 & 0,834 & 0,343 \\
\hline $\mathbf{( 9 - 1 2 )}$ & 0,399 & 0,343 & 0,624 & $-0,519$ & $-0,013$ & $-0,089$ \\
\hline $\mathbf{( 1 2 - 1 5 )}$ & 0,549 & 0,195 & 0,467 & 1,066 & 0,106 & $-0,362$ \\
\hline $\mathbf{( 1 5 - 1 8 )}$ & 0,161 & 0,307 & 0,163 & 0,712 & $-0,081$ & 0,619 \\
\hline $\mathbf{( 1 8 - 2 1 )}$ & 0,149 & 0,060 & 0,338 & 0,134 & $-0,104$ & 0,872 \\
\hline $\mathbf{( 2 1 - 2 3 )}$ & 0,355 & 0,377 & 0,509 & 0,875 & $-0,141$ & 0,384 \\
\hline E.M.Q & $\mathbf{0 , 4 7 8}$ & $\mathbf{0 , 2 9 2}$ & $\mathbf{0 , 4 1 3}$ & $\mathbf{0 , 4 9 3}$ & $\mathbf{0 , 2 7 1}$ & $\mathbf{0 , 4 3 3}$ \\
\hline Desvio Padrão & $\pm \mathbf{0 , 3 0 8}$ & $\pm \mathbf{0 , 1 1 9}$ & $\pm \mathbf{0 , 1 6 1}$ & $\pm \mathbf{0 , 5 0 5}$ & $\pm \mathbf{0 , 4 0 5}$ & $\pm \mathbf{0 , 4 4 4}$ \\
\hline
\end{tabular}




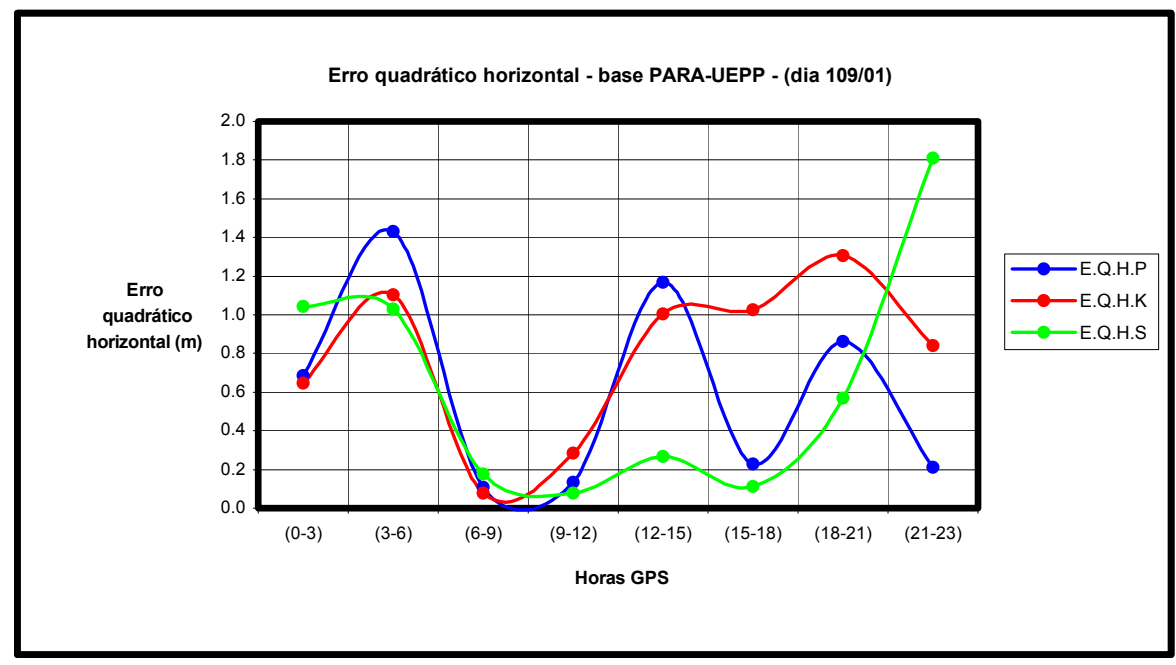

Figura 7.75 - Variação horária do erro quadrático horizontal do vértice UEPP no posicionamento relativo da base PARA - UEPP - (dia 109/01).

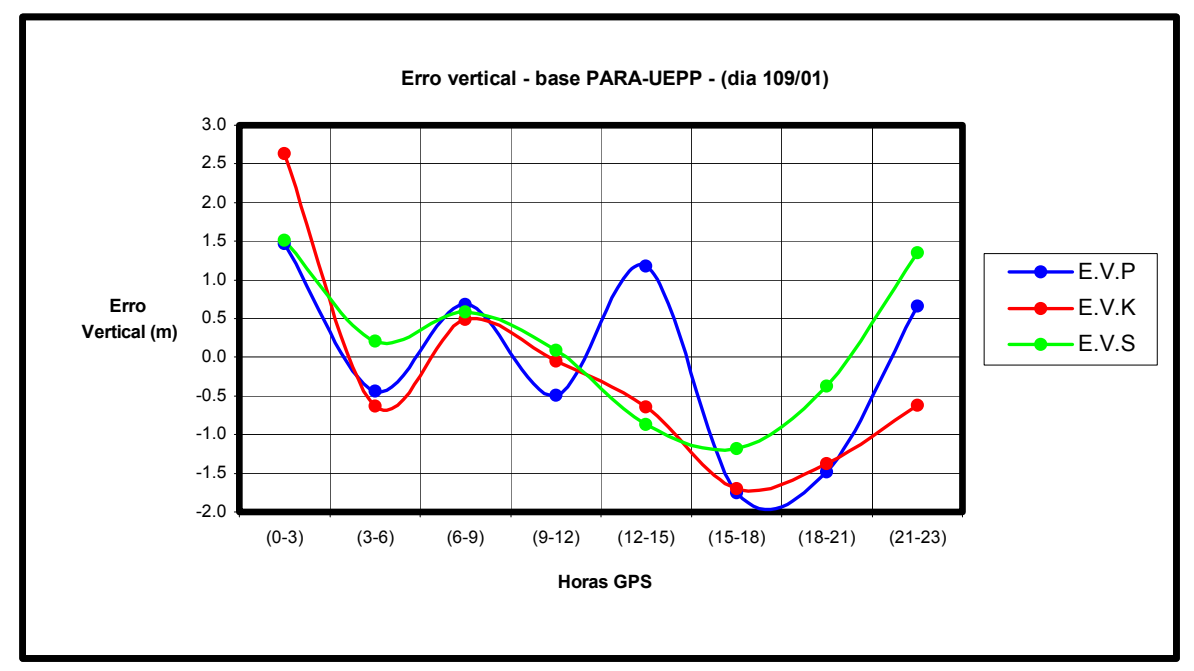

Figura 7.76 - Variação horária do erro vertical do vértice UEPP no posicionamento relativo da base PARA - UEPP - (dia 109/01).

Tabela 7.52 - Erro quadrático horizontal e erro vertical do vértice UEPP no processamento relativo da base PARA - UEPP, para diferentes modelos ionosféricos - (dia 109/01).

\begin{tabular}{|c|c|c|c|c|c|c|}
\cline { 2 - 7 } \multicolumn{1}{c|}{} & \multicolumn{3}{c|}{ Erro Quadrático Horizontal (m) } & \multicolumn{3}{c|}{ Erro Vertical (m) } \\
\hline Horas & E.Q.H.P & E.Q.H.K & E.Q.H.S & E.V.P & E.V.K & E.V.S \\
\hline $\mathbf{( 0 - 3 )}$ & 0.687 & 0.647 & 1.042 & 1.474 & 2.634 & 1.511 \\
\hline $\mathbf{( 3 - 6 )}$ & 1.432 & 1.105 & 1.031 & -0.433 & -0.627 & 0.204 \\
\hline $\mathbf{( 6 - 9 )}$ & 0.106 & 0.076 & 0.178 & 0.686 & 0.484 & 0.587 \\
\hline $\mathbf{( 9 - 1 2 )}$ & 0.133 & 0.285 & 0.079 & -0.491 & -0.046 & 0.095 \\
\hline $\mathbf{( 1 2 - 1 5 )}$ & 1.167 & 1.003 & 0.268 & 1.178 & -0.639 & -0.868 \\
\hline $\mathbf{( 1 5 - 1 8 )}$ & 0.230 & 1.026 & 0.111 & -1.756 & -1.698 & -1.178 \\
\hline $\mathbf{( 1 8 - 2 1 )}$ & 0.864 & 1.308 & 0.568 & -1.480 & -1.379 & -0.372 \\
\hline $\mathbf{( 2 1 - 2 3 )}$ & 0.212 & 0.840 & 1.809 & 0.662 & -0.624 & 1.350 \\
\hline E.M.Q & $\mathbf{0 . 6 0 4}$ & $\mathbf{0 . 7 8 6}$ & $\mathbf{0 . 6 3 6}$ & $\mathbf{1 . 0 2 0}$ & $\mathbf{1 . 0 1 6}$ & $\mathbf{0 . 7 7 1}$ \\
\hline Desvio Padrão & $\pm \mathbf{0 . 5 1 3}$ & $\pm \mathbf{0 . 4 2 4}$ & $\pm \mathbf{0 . 6 1 4}$ & $\pm \mathbf{1 . 2 0 5}$ & $\pm \mathbf{1 . 3 4 7}$ & $\pm \mathbf{0 . 9 6 8}$ \\
\hline
\end{tabular}




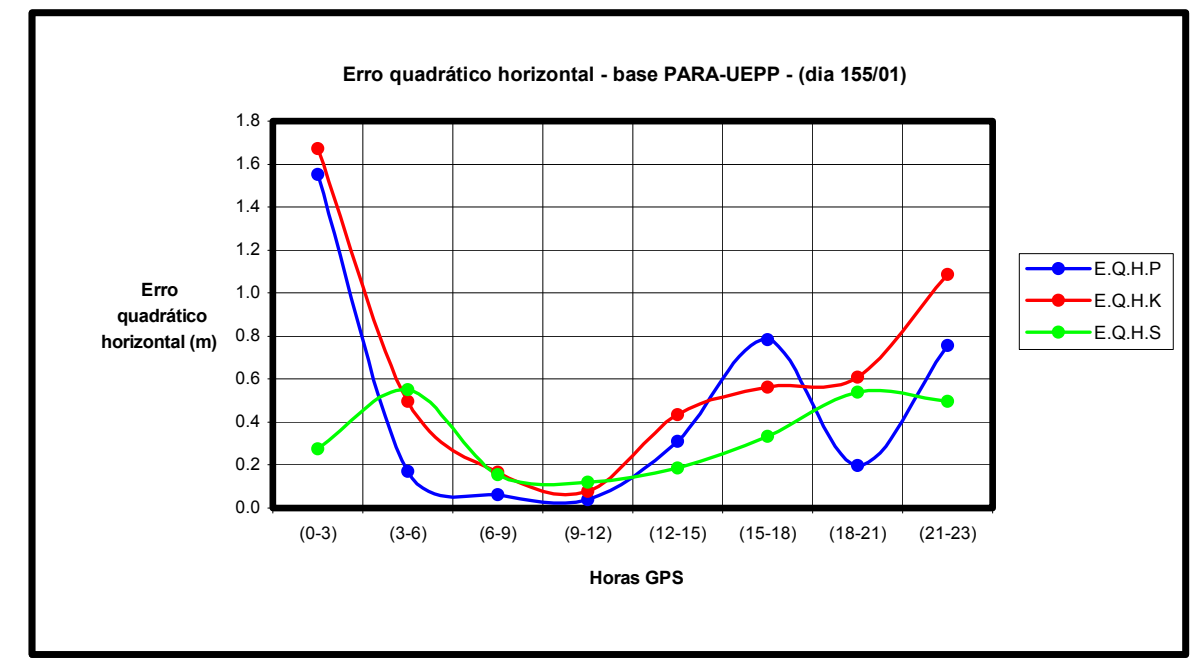

Figura 7.77 - Variação horária do erro quadrático horizontal do vértice UEPP no posicionamento relativo da base PARA - UEPP - (dia 155/01).

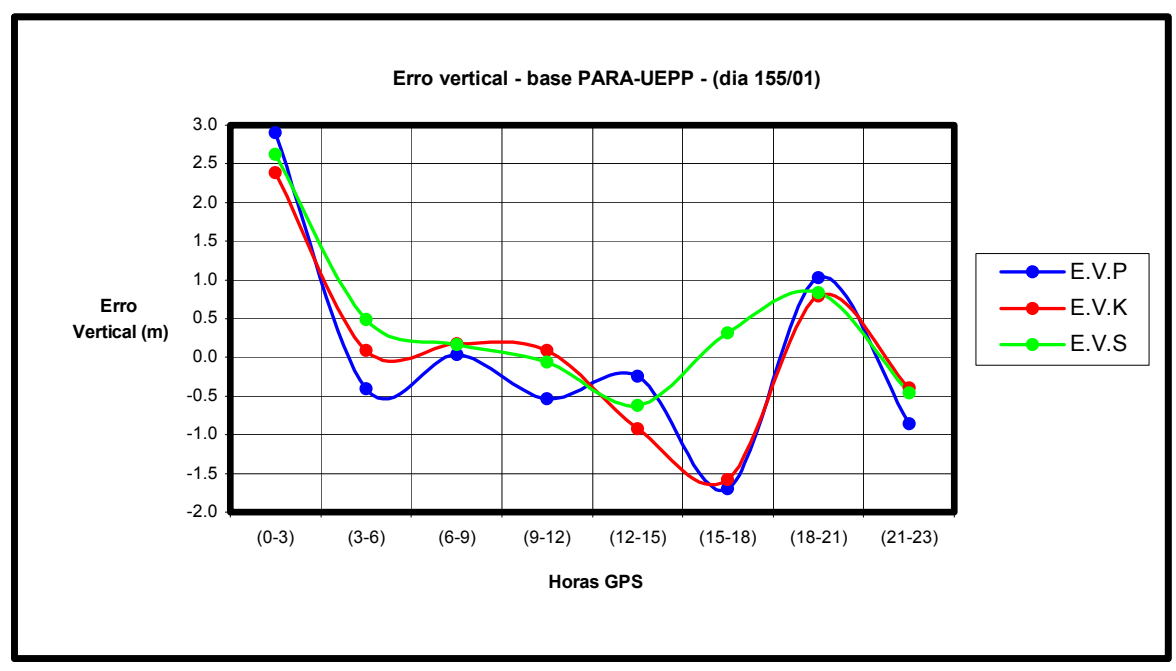

Figura 7.78 - Variação horária do erro vertical do vértice UEPP no posicionamento relativo da base PARA - UEPP - (dia 155/01).

Tabela 7.53 - Erro quadrático horizontal e erro vertical do vértice UEPP no processamento relativo da base PARA - UEPP, para diferentes modelos ionosféricos - (dia 155/01).

\begin{tabular}{|c|c|c|c|c|c|c|}
\cline { 2 - 7 } \multicolumn{1}{c|}{} & \multicolumn{3}{c|}{ Erro Quadrático Horizontal (m) } & \multicolumn{3}{c|}{ Erro Vertical (m) } \\
\hline Horas & E.Q.H.P & E.Q.H.K & E.Q.H.S & E.V.P & E.V.K & E.V.S \\
\hline $\mathbf{( 0 - 3 )}$ & 1,553 & 1,672 & 0,277 & 2,904 & 2,387 & 2,626 \\
\hline $\mathbf{( 3 - 6 )}$ & 0,169 & 0,495 & 0,552 & $-0,405$ & 0,094 & 0,490 \\
\hline $\mathbf{( 6 - 9 )}$ & 0,063 & 0,169 & 0,157 & 0,038 & 0,173 & 0,166 \\
\hline $\mathbf{( 9 - 1 2 )}$ & 0,039 & 0,078 & 0,121 & $-0,535$ & 0,093 & $-0,058$ \\
\hline $\mathbf{( 1 2 - 1 5 )}$ & 0,309 & 0,435 & 0,186 & $-0,246$ & $-0,922$ & $-0,618$ \\
\hline $\mathbf{( 1 5 - 1 8 )}$ & 0,783 & 0,562 & 0,334 & $-1,693$ & $-1,580$ & 0,312 \\
\hline $\mathbf{( 1 8 - 2 1 )}$ & 0,199 & 0,607 & 0,539 & 1,027 & 0,794 & 0,834 \\
\hline $\mathbf{( 2 1 - 2 3 )}$ & 0,756 & 1,085 & 0,498 & $-0,857$ & $-0,392$ & $-0,457$ \\
\hline E.M.Q & $\mathbf{0 , 4 8 4}$ & $\mathbf{0 , 6 3 8}$ & $\mathbf{0 , 3 3 3}$ & $\mathbf{0 , 9 6 3}$ & $\mathbf{0 , 8 0 4}$ & $\mathbf{0 , 6 9 5}$ \\
\hline Desvio Padrão & $\pm \mathbf{0 , 5 2 0}$ & $\pm \mathbf{0 , 5 1 7}$ & $\pm \mathbf{0 , 1 7 6}$ & $\pm \mathbf{1 , 3 9 4}$ & $\pm \mathbf{1 , 1 8 5}$ & $\pm \mathbf{1 , 0 1 4}$ \\
\hline
\end{tabular}




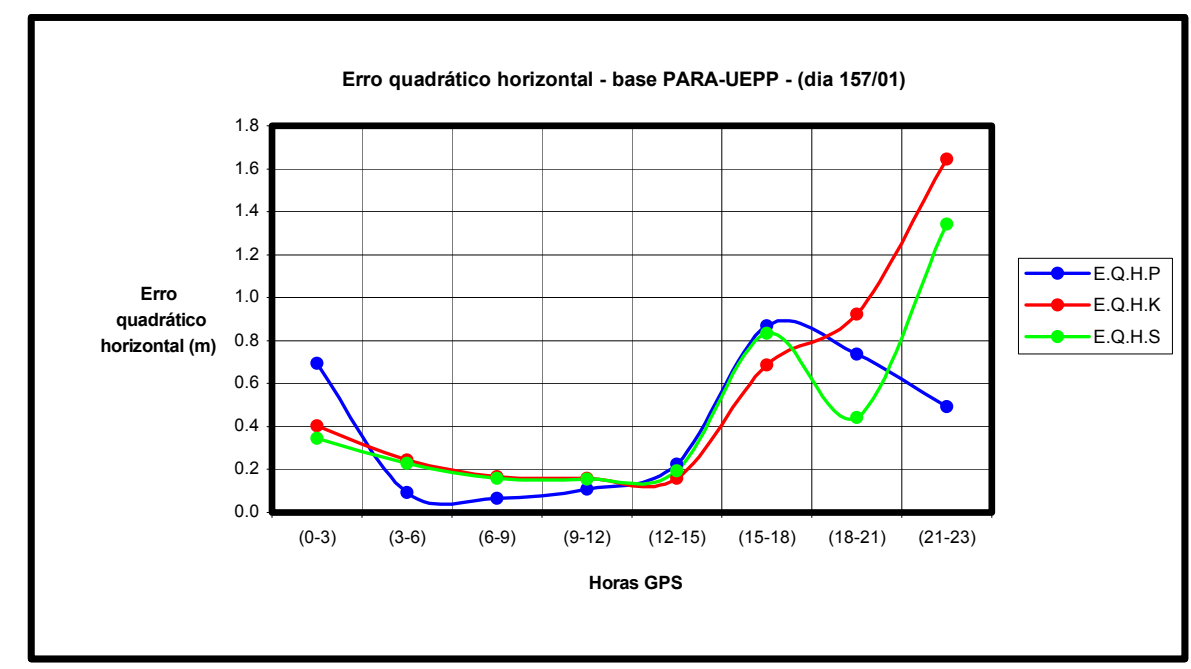

Figura 7.79 - Variação horária do erro quadrático horizontal do vértice UEPP no posicionamento relativo da base PARA - UEPP - (dia 157/01).

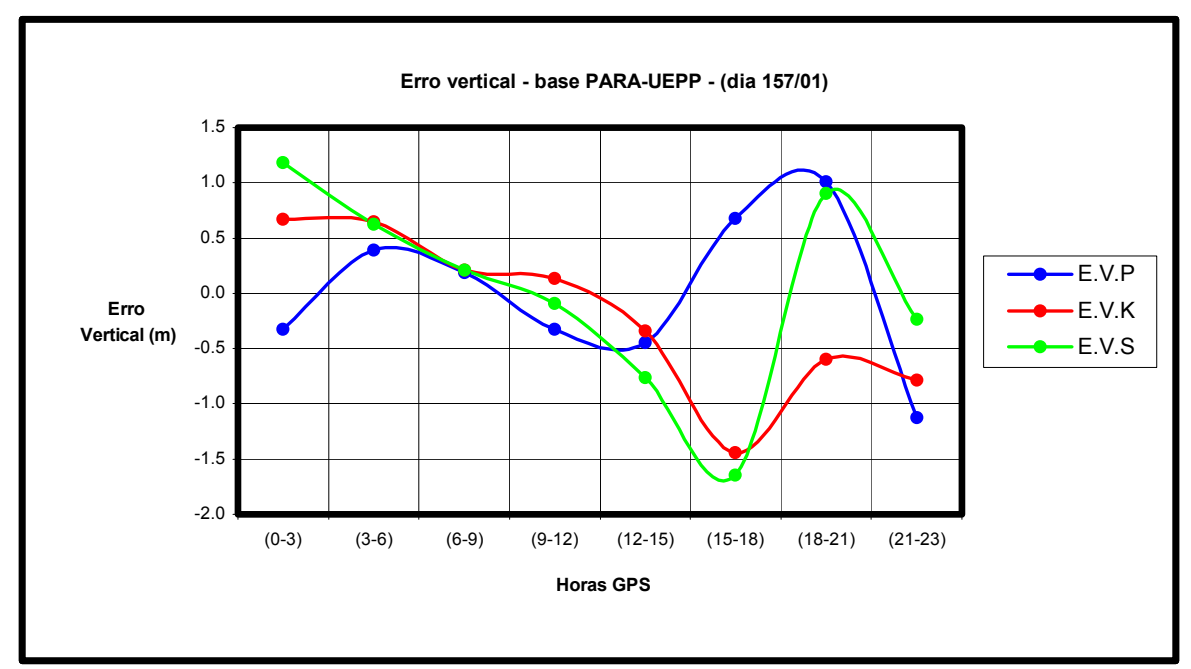

Figura 7.80 - Variação horária do erro vertical do vértice UEPP no posicionamento relativo da base PARA - UEPP - (dia 157/01).

Tabela 7.54 - Erro quadrático horizontal e erro vertical do vértice UEPP no processamento relativo da base PARA - UEPP, para diferentes modelos ionosféricos - (dia 157/01).

\begin{tabular}{|c|c|c|c|c|c|c|}
\cline { 2 - 7 } \multicolumn{1}{c|}{} & \multicolumn{2}{c|}{ Erro Quadrático Horizontal (m) } & \multicolumn{3}{c|}{ Erro Vertical (m) } \\
\hline Horas & E.Q.H.P & E.Q.H.K & E.Q.H.S & E.V.P & E.V.K & E.V.S \\
\hline $\mathbf{( 0 - 3 )}$ & 0,693 & 0,403 & 0,344 & $-0,324$ & 0,674 & 1,186 \\
\hline $\mathbf{( 3 - 6 )}$ & 0,094 & 0,246 & 0,230 & 0,390 & 0,649 & 0,629 \\
\hline $\mathbf{( 6 - 9 )}$ & 0,067 & 0,166 & 0,158 & 0,190 & 0,209 & 0,212 \\
\hline $\mathbf{( 9 - 1 2 )}$ & 0,109 & 0,161 & 0,154 & $-0,327$ & 0,135 & $-0,089$ \\
\hline $\mathbf{( 1 2 - 1 5 )}$ & 0,225 & 0,157 & 0,194 & $-0,443$ & $-0,344$ & $-0,764$ \\
\hline $\mathbf{( 1 5 - 1 8 )}$ & 0,868 & 0,687 & 0,834 & 0,680 & $-1,444$ & $-1,647$ \\
\hline $\mathbf{( 1 8 - 2 1 )}$ & 0,738 & 0,922 & 0,443 & 1,011 & $-0,594$ & 0,905 \\
\hline $\mathbf{( 2 1 - 2 3 )}$ & 0,491 & 1,644 & 1,341 & $-1,124$ & $-0,783$ & $-0,232$ \\
\hline E.M.Q & $\mathbf{0 , 4 1 1}$ & $\mathbf{0 , 5 4 8}$ & $\mathbf{0 , 4 6 2}$ & $\mathbf{0 , 5 6 1}$ & $\mathbf{0 , 6 0 4}$ & $\mathbf{0 , 7 0 8}$ \\
\hline Desvio Padrão & $\pm \mathbf{0 , 3 2 7}$ & $\pm \mathbf{0 , 5 2 4}$ & $\pm \mathbf{0 , 4 2 1}$ & $\pm \mathbf{0 , 6 9 1}$ & $\pm \mathbf{0 , 7 3 9}$ & $\pm \mathbf{0 , 9 2 7}$ \\
\hline
\end{tabular}




\subsection{Coeficientes do modelo referentes ao período do inverno}

Ao analisar os valores dos coeficientes, e ao fazer um comparativo com os valores encontrados no verão e no outono, com exceção do $C_{1}$, os desvios padrão sofreram um aumento significativo. Estes valores estão mais evidentes nos dias 199, 204, 205, 206 e 209, conforme mostram as Figuras $7.84,7.86,7.87,7.88,7.90$ e as Tabelas 7.58, 7.60, 7.61, 7.62, 7.64. Nestes dias, de maior evidência no aumento do desvio padrão, a estação de Manaus participou no processo de ajustamento dos parâmetros. Esta estação está localizada em uma região onde a concentração de elétrons livres na ionosfera é muito elevada, o que pode ter ocasionado esta variação na determinação dos coeficientes.

Ao longo do dia, o comportamento dos coeficientes foi semelhante em relação ao verão e outono. Os coeficientes mantiveram-se constantes até próximo às 17 horas GPS e, após este horário, os mesmos sofreram variações até às 20 horas, intervalo onde a iluminação solar influencia de forma significativa os sinais de rádio.

Através das figuras 7.81 a 7.91 e das tabelas 7.55 a 7.65 , percebe-se o comportamento sazonal da ionosfera, pois os valores encontrados para os coeficientes do modelo permaneceram distintos em relação ao verão e outono.

No que se refere ao ajustamento seqüencial, o índice de rejeição das observáveis foi semelhante aos períodos do verão e outono, de, aproximadamente $33 \%$.

A seguir, serão apresentados todos os resultados do processamento dos coeficientes, no período do inverno estudado.

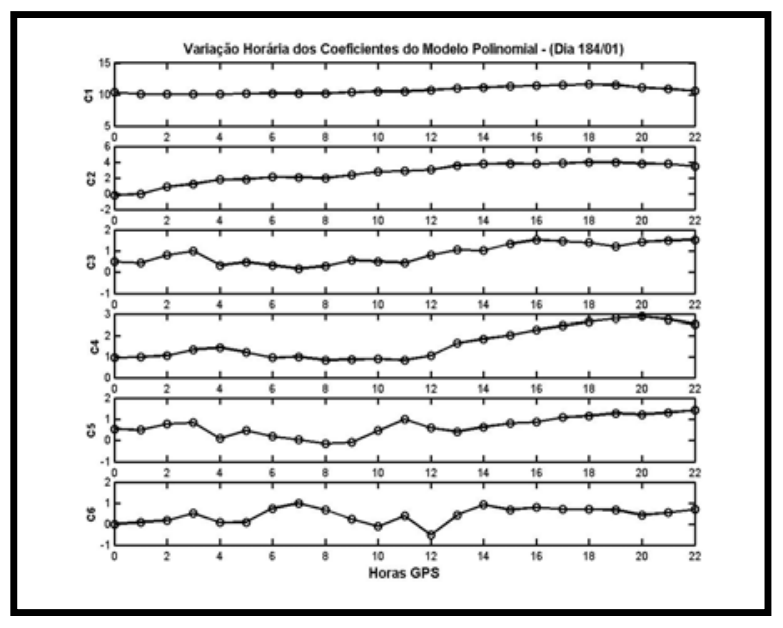

Figura 7.81 - Variação horária dos coeficientes do modelo polinomial (dia 184/01)

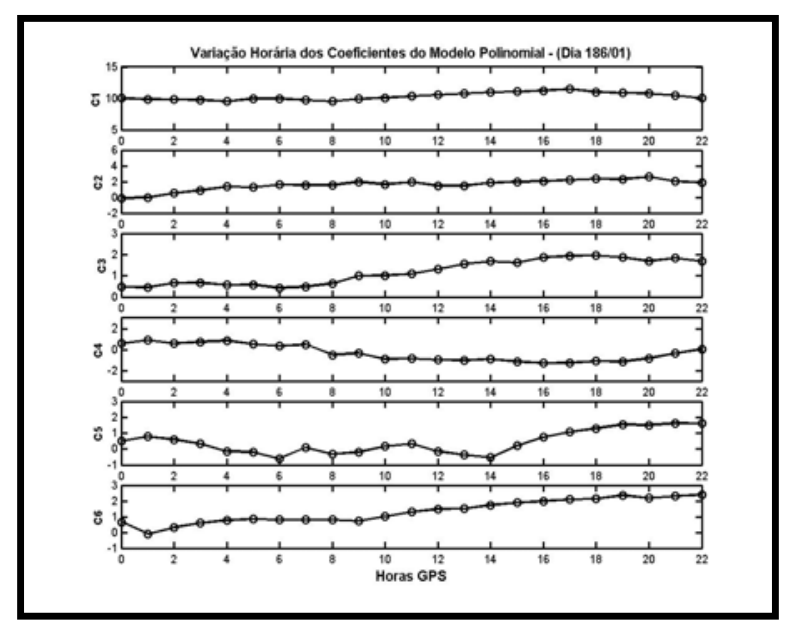

Figura 7.82 - Variação horária dos coeficientes do modelo polinomial (dia 186/01) 


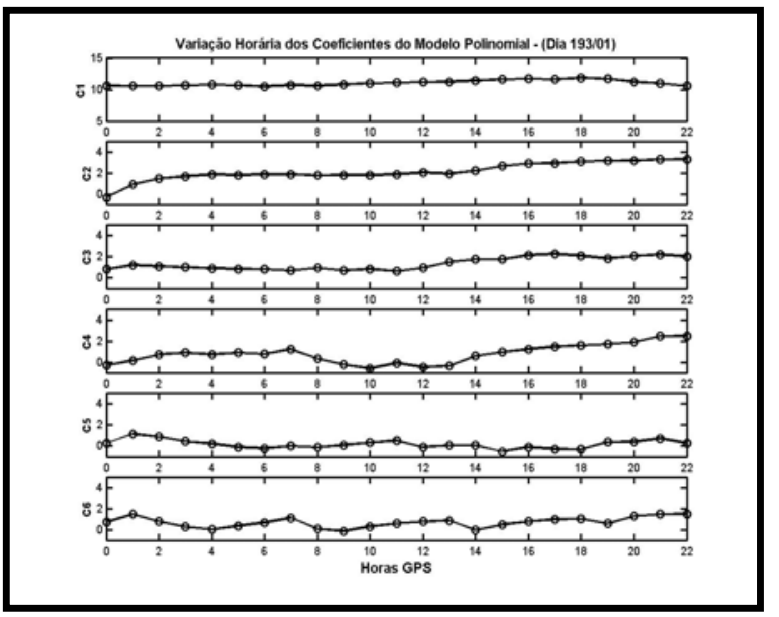

Figura 7.83 - Variação horária dos coeficientes do modelo polinomial (dia 193/01)

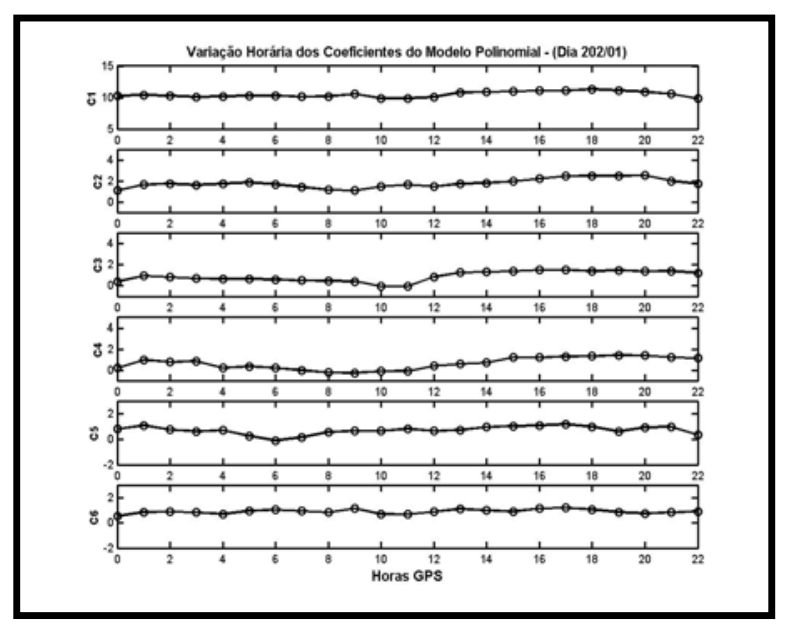

Figura 7.85 - Variação horária dos coeficientes do modelo polinomial (dia 202/01)

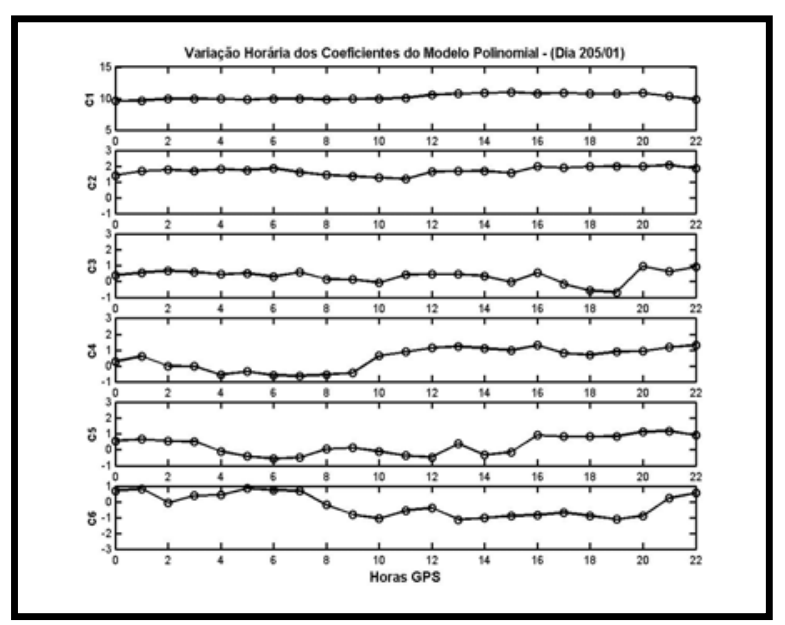

Figura 7.87 - Variação horária dos coeficientes do modelo polinomial (dia 205/01)

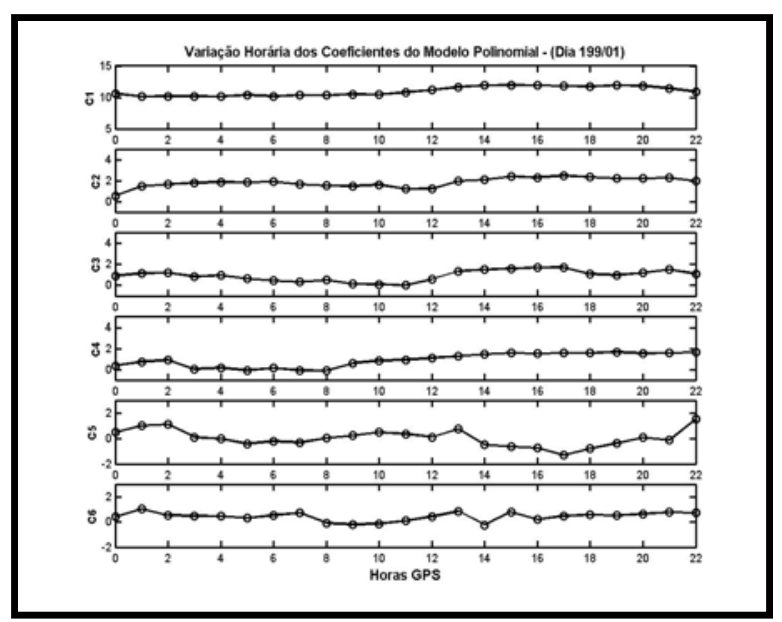

Figura 7.84 - Variação horária dos coeficientes do modelo polinomial (dia 199/01)

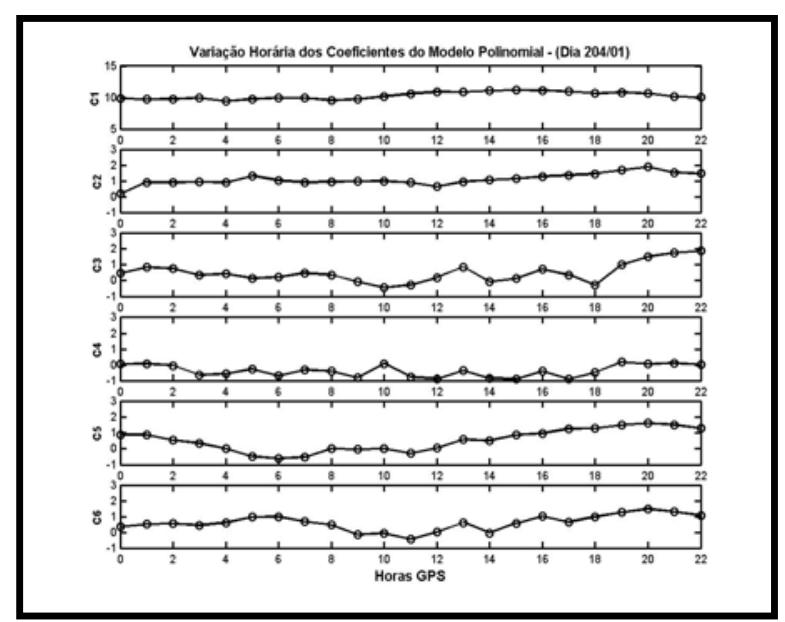

Figura 7.86 - Variação horária dos coeficientes do modelo polinomial (dia 204/01)

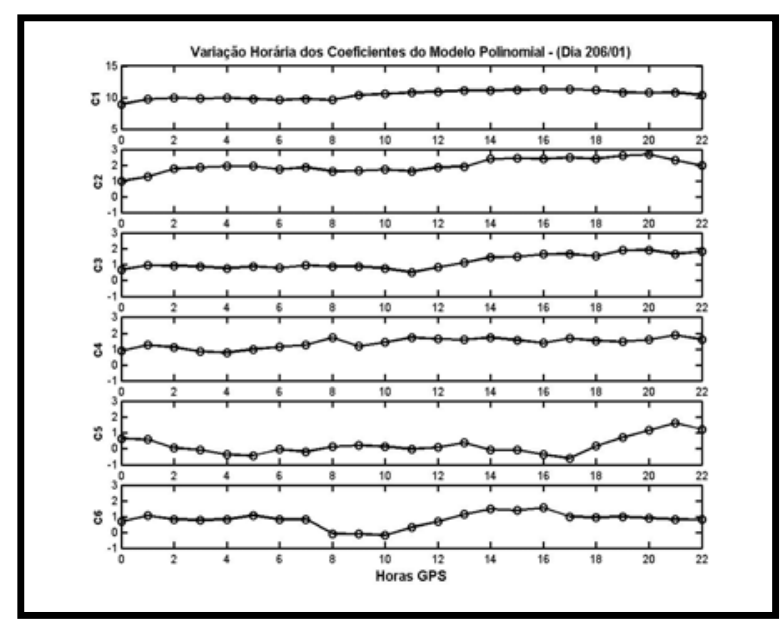

Figura 7.88 - Variação horária dos coeficientes do modelo polinomial (dia 206/01) 


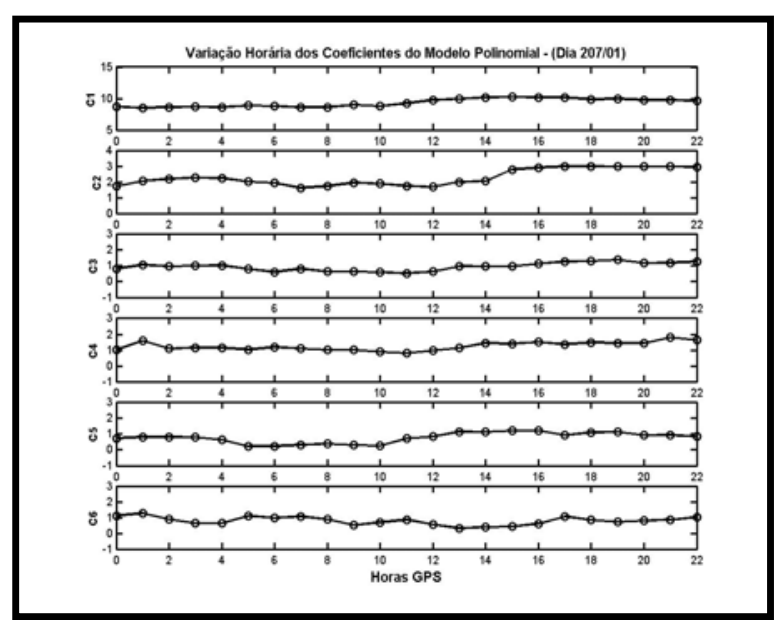

Figura 7.89 - Variação horária dos coeficientes do modelo polinomial (dia 207/01)

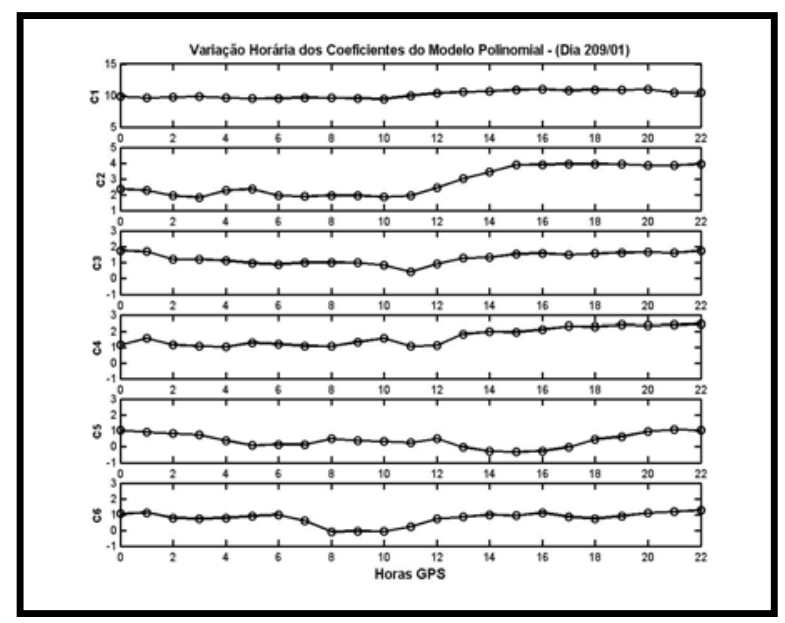

Figura 7.90 - Variação horária dos coeficientes do modelo polinomial (dia 209/01)

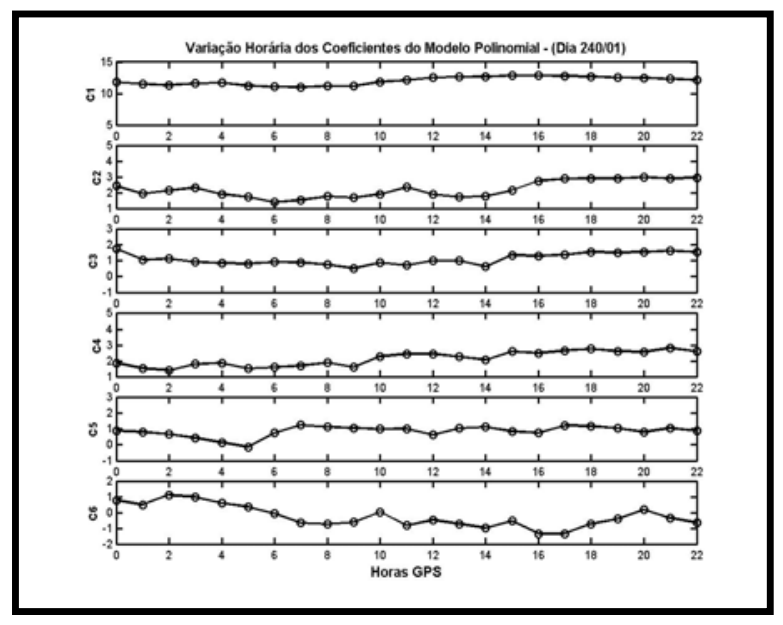

Figura 7.91 - Variação horária dos coeficientes do modelo polinomial (dia 240/01)

Tabela 7.55 - Estatística dos coeficientes do modelo polinomial - (dia 184/01)

\begin{tabular}{|c|c|c|c|c|}
\hline Coeficientes & Valor Médio & Desvio Padrão & Valor Mínimo & Valor Máximo \\
\hline $\mathbf{C}_{\mathbf{1}}$ & 10,647 & $\pm 0,544$ & 10,005 & 11,575 \\
\hline $\mathbf{C}_{\mathbf{2}}$ & 3,162 & $\pm 0,489$ & $-0,198$ & 3,992 \\
\hline $\mathbf{C}_{\mathbf{3}}$ & 0,872 & $\pm 0,473$ & 0,161 & 1,531 \\
\hline $\mathbf{C}_{\mathbf{4}}$ & 1,612 & $\pm 0,750$ & 0,833 & 2,876 \\
\hline $\mathbf{C}_{5}$ & 0,669 & $\pm 0,463$ & $-0,154$ & 1,425 \\
\hline $\mathbf{C}_{6}$ & 0,429 & $\pm 0,373$ & $-0,516$ & 0,985 \\
\hline
\end{tabular}


Tabela 7.56 - Estatística dos coeficientes do modelo polinomial - (dia 186/01)

\begin{tabular}{|c|c|c|c|c|}
\hline Coeficientes & Valor Médio & Desvio Padrão & Valor Mínimo & Valor Máximo \\
\hline $\mathbf{C}_{\mathbf{1}}$ & 10,333 & $\pm 0,582$ & 9,517 & 11,481 \\
\hline $\mathbf{C}_{\mathbf{2}}$ & 1,582 & $\pm 0,399$ & $-0,109$ & 2,595 \\
\hline $\mathbf{C}_{\mathbf{3}}$ & 1,177 & $\pm 0,377$ & 0,429 & 1,963 \\
\hline $\mathbf{C}_{\mathbf{4}}$ & $-0,331$ & $\pm 0,383$ & $-1,291$ & 0,899 \\
\hline $\mathbf{C}_{\mathbf{5}}$ & 0,431 & $\pm 0,323$ & $-0,592$ & 1,629 \\
\hline $\mathbf{C}_{\mathbf{6}}$ & 1,332 & $\pm 0,337$ & $-0,090$ & 2,401 \\
\hline
\end{tabular}

Tabela 7.57 - Estatística dos coeficientes do modelo polinomial - (dia 193/01)

\begin{tabular}{|c|c|c|c|c|}
\hline Coeficientes & Valor Médio & Desvio Padrão & Valor Mínimo & Valor Máximo \\
\hline $\mathbf{C}_{\mathbf{1}}$ & 11,011 & $\pm 0,442$ & 10,490 & 11,830 \\
\hline $\mathbf{C}_{\mathbf{2}}$ & 2,125 & $\pm 0,557$ & $-0,316$ & 3,311 \\
\hline $\mathbf{C}_{\mathbf{3}}$ & 1,342 & $\pm 0,582$ & 0,631 & 2,249 \\
\hline $\mathbf{C}_{\mathbf{4}}$ & 0,790 & $\pm 0,593$ & $-0,571$ & 2,478 \\
\hline $\mathbf{C}_{\mathbf{5}}$ & 0,180 & $\pm 0,397$ & $-0,505$ & 1,158 \\
\hline $\mathbf{C}_{\mathbf{6}}$ & 0,686 & $\pm 0,482$ & $-0,128$ & 1,490 \\
\hline
\end{tabular}

Tabela 7.58 - Estatística dos coeficientes do modelo polinomial - (dia 199/01)

\begin{tabular}{|c|c|c|c|c|}
\hline Coeficientes & Valor Médio & Desvio Padrão & Valor Mínimo & Valor Máximo \\
\hline $\mathbf{C}_{\mathbf{1}}$ & 10,975 & $\pm 0,717$ & 10,114 & 11,928 \\
\hline $\mathbf{C}_{\mathbf{2}}$ & 1,824 & $\pm 0,457$ & 0,562 & 2,477 \\
\hline $\mathbf{C}_{\mathbf{3}}$ & 0,927 & $\pm 0,513$ & 0,013 & 1,712 \\
\hline $\mathbf{C}_{\mathbf{4}}$ & 0,911 & $\pm 0,654$ & $-0,123$ & 1,666 \\
\hline $\mathbf{C}_{5}$ & 0,034 & $\pm 0,667$ & $-1,314$ & 1,523 \\
\hline $\mathbf{C}_{\mathbf{6}}$ & 0,433 & $\pm 0,349$ & $-0,245$ & 1,047 \\
\hline
\end{tabular}

Tabela 7.59 - Estatística dos coeficientes do modelo polinomial - (dia 202/01)

\begin{tabular}{|c|c|c|c|c|}
\hline Coeficientes & Valor Médio & Desvio Padrão & Valor Mínimo & Valor Máximo \\
\hline $\mathbf{C}_{\mathbf{1}}$ & 10,474 & $\pm 0,447$ & 9,837 & 11,316 \\
\hline $\mathbf{C}_{\mathbf{2}}$ & 1,781 & $\pm 0,430$ & 1,076 & 2,513 \\
\hline $\mathbf{C}_{\mathbf{3}}$ & 0,894 & $\pm 0,486$ & $-0,069$ & 1,484 \\
\hline $\mathbf{C}_{4}$ & 0,642 & $\pm 0,574$ & $-0,259$ & 1,417 \\
\hline $\mathbf{C}_{5}$ & 0,713 & $\pm 0,317$ & $-0,098$ & 1,172 \\
\hline $\mathbf{C}_{6}$ & 0,897 & $\pm 0,168$ & 0,537 & 1,180 \\
\hline
\end{tabular}


Tabela 7.60 - Estatística dos coeficientes do modelo polinomial - (dia 204/01)

\begin{tabular}{|c|c|c|c|c|}
\hline Coeficientes & Valor Médio & Desvio Padrão & Valor Mínimo & Valor Máximo \\
\hline $\mathbf{C}_{\mathbf{1}}$ & 10,293 & $\pm 0,570$ & 9,425 & 11,164 \\
\hline $\mathbf{C}_{\mathbf{2}}$ & 1,101 & $\pm 0,365$ & 0,171 & 1,888 \\
\hline $\mathbf{C}_{\mathbf{3}}$ & 0,482 & $\pm 0,611$ & $-0,444$ & 1,858 \\
\hline $\mathbf{C}_{\mathbf{4}}$ & $-0,378$ & $\pm 0,380$ & $-0,887$ & 0,186 \\
\hline $\mathbf{C}_{\mathbf{5}}$ & 0,526 & $\pm 0,699$ & $-0,627$ & 1,604 \\
\hline $\mathbf{C}_{\mathbf{6}}$ & 0,604 & $\pm 0,499$ & $-0,426$ & 1,482 \\
\hline
\end{tabular}

Tabela 7.61 - Estatística dos coeficientes do modelo polinomial - (dia 205/01)

\begin{tabular}{|c|c|c|c|c|}
\hline Coeficientes & Valor Médio & Desvio Padrão & Valor Mínimo & Valor Máximo \\
\hline $\mathbf{C}_{\mathbf{1}}$ & 10,266 & $\pm 0,465$ & 9,594 & 10,950 \\
\hline $\mathbf{C}_{\mathbf{2}}$ & 1,699 & $\pm 0,243$ & 1,188 & 2,069 \\
\hline $\mathbf{C}_{\mathbf{3}}$ & 0,332 & $\pm 0,404$ & $-0,672$ & 0,953 \\
\hline $\mathbf{C}_{\mathbf{4}}$ & 0,470 & $\pm 0,703$ & $-0,638$ & 1,323 \\
\hline $\mathbf{C}_{5}$ & 0,279 & $\pm 0,574$ & $-0,555$ & 1,175 \\
\hline $\mathbf{C}_{\mathbf{6}}$ & $-0,223$ & $\pm 0,732$ & $-1,136$ & 0,838 \\
\hline
\end{tabular}

Tabela 7.62 - Estatística dos coeficientes do modelo polinomial - (dia 206/01)

\begin{tabular}{|c|c|c|c|c|}
\hline Coeficientes & Valor Médio & Desvio Padrão & Valor Mínimo & Valor Máximo \\
\hline $\mathbf{C}_{\mathbf{1}}$ & 10,422 & $\pm 0,686$ & 8,918 & 11,273 \\
\hline $\mathbf{C}_{\mathbf{2}}$ & 1,971 & $\pm 0,429$ & 0,989 & 2,674 \\
\hline $\mathbf{C}_{\mathbf{3}}$ & 1,169 & $\pm 0,442$ & 0,511 & 1,923 \\
\hline $\mathbf{C}_{\mathbf{4}}$ & 1,395 & $\pm 0,321$ & 0,772 & 1,893 \\
\hline $\mathbf{C}_{\mathbf{5}}$ & 0,210 & $\pm 0,555$ & $-0,594$ & 1,616 \\
\hline $\mathbf{C}_{\mathbf{6}}$ & 0,805 & $\pm 0,455$ & $-0,187$ & 1,559 \\
\hline
\end{tabular}

Tabela 7.63 - Estatística dos coeficientes do modelo polinomial - (dia 207/01)

\begin{tabular}{|c|c|c|c|c|}
\hline Coeficientes & Valor Médio & Desvio Padrão & Valor Mínimo & Valor Máximo \\
\hline $\mathbf{C}_{\mathbf{1}}$ & 9,326 & $\pm 0,650$ & 8,507 & 10,259 \\
\hline $\mathbf{C}_{\mathbf{2}}$ & 2,286 & $\pm 0,517$ & 1,612 & 2,998 \\
\hline $\mathbf{C}_{\mathbf{3}}$ & 0,931 & $\pm 0,254$ & 0,522 & 1,352 \\
\hline $\mathbf{C}_{\mathbf{4}}$ & 1,248 & $\pm 0,266$ & 0,792 & 1,799 \\
\hline $\mathbf{C}_{\mathbf{5}}$ & 0,754 & $\pm 0,329$ & 0,226 & 1,198 \\
\hline $\mathbf{C}_{\boldsymbol{6}}$ & 0,795 & $\pm 0,256$ & 0,333 & 1,277 \\
\hline
\end{tabular}


Tabela 7.64 - Estatística dos coeficientes do modelo polinomial - (dia 209/01)

\begin{tabular}{|c|c|c|c|c|}
\hline Coeficientes & Valor Médio & Desvio Padrão & Valor Mínimo & Valor Máximo \\
\hline $\mathbf{C}_{\mathbf{1}}$ & 10,167 & $\pm 0,572$ & 9,429 & 10,981 \\
\hline $\mathbf{C}_{\mathbf{2}}$ & 2,811 & $\pm 0,901$ & 1,829 & 3,950 \\
\hline $\mathbf{C}_{\mathbf{3}}$ & 1,280 & $\pm 0,361$ & 0,419 & 1,751 \\
\hline $\mathbf{C}_{\mathbf{4}}$ & 1,631 & $\pm 0,547$ & 1,002 & 2,442 \\
\hline $\mathbf{C}_{\mathbf{5}}$ & 0,409 & $\pm 0,440$ & $-0,320$ & 1,076 \\
\hline $\mathbf{C}_{\mathbf{6}}$ & 0,764 & $\pm 0,400$ & $-0,099$ & 1,275 \\
\hline
\end{tabular}

Tabela 7.65 - Estatística dos coeficientes do modelo polinomial - (dia 240/01)

\begin{tabular}{|c|c|c|c|c|}
\hline Coeficientes & Valor Médio & Desvio Padrão & Valor Mínimo & Valor Máximo \\
\hline $\mathbf{C}_{\mathbf{1}}$ & 11,996 & $\pm 0,645$ & 11,003 & 12,826 \\
\hline $\mathbf{C}_{\mathbf{2}}$ & 2,210 & $\pm 0,525$ & 1,379 & 2,974 \\
\hline $\mathbf{C}_{\mathbf{3}}$ & 1,109 & $\pm 0,358$ & 0,523 & 1,744 \\
\hline $\mathbf{C}_{\mathbf{4}}$ & 2,147 & $\pm 0,463$ & 1,401 & 2,816 \\
\hline $\mathbf{C}_{\mathbf{5}}$ & 0,845 & $\pm 0,337$ & $-0,140$ & 1,246 \\
\hline $\mathbf{C}_{\mathbf{6}}$ & $-0,256$ & $\pm 0,702$ & $-1,345$ & 1,115 \\
\hline
\end{tabular}

A Figura 7.92 ilustra os valores médios diários dos coeficientes do modelo polinomial, durante alguns dias do inverno.

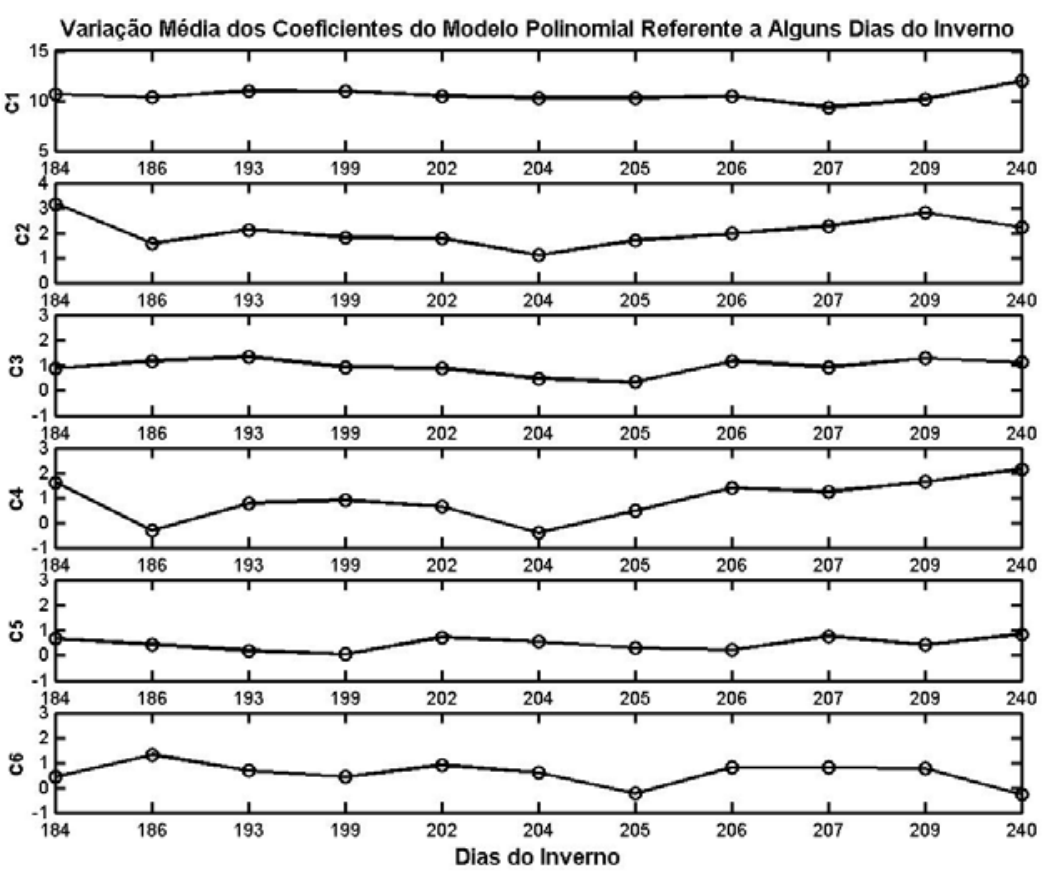

Figura 7.92 - Variação média diária dos coeficientes do modelo polinomial, referente a alguns dias do inverno. 
A Tabela 7.66 ilustra a estatística dos coeficientes neste período do inverno. As colunas "Valor Médio" e "Desvio Padrão" correspondem, respectivamente, a média dos coeficientes e a média dos desvios padrão, em relação aos 11 dias estudados. $O$ valor do desvio padrão do coeficiente $C_{1}$ manteve-se praticamente constante em relação ao verão e ao outono, ao passo que, para os demais coeficientes, o aumento do desvio padrão foi:

- Coeficiente $\mathrm{C}_{2}$ - aumento de $73 \%$ em relação ao período do verão e $30 \%$ em relação ao outono;

- Coeficiente $\mathrm{C}_{3}$ - aumento de $60 \%$ em relação ao período do verão e $97 \%$ em relação ao outono;

- Coeficiente $\mathrm{C}_{4}$ - aumento de $85 \%$ em relação ao período do verão e, $260 \%$ em relação ao outono;

- Coeficiente $\mathrm{C}_{5}$ - aumento de $72 \%$ em relação ao período do verão e $133 \%$ em relação ao outono;

- Coeficiente $\mathrm{C}_{6}$ - aumento de $95 \%$ em relação ao período do verão e $112 \%$ em relação ao outono;

Este aumento do desvio padrão, como dito anteriormente, pode estar relacionado com a participação da estação de Manaus no processo de ajustamento dos parâmetros, uma vez que, a mesma está localizada em uma região, onde a concentração de elétrons livres está muito presente.

Tabela 7.66 - Valores médios dos coeficientes do modelo polinomial referentes a alguns dias do inverno

\begin{tabular}{|c|c|c|c|c|}
\hline Coeficientes & Valor Médio & Desvio Padrão & Valor Mínimo & Valor Máximo \\
\hline $\mathbf{C}_{\mathbf{1}}$ & 10,537 & $\pm 0,575$ & 9,326 & 11,996 \\
\hline $\mathbf{C}_{\mathbf{2}}$ & 2,050 & $\pm 0,483$ & 1,101 & 3,162 \\
\hline $\mathbf{C}_{\mathbf{3}}$ & 0,956 & $\pm 0,442$ & 0,332 & 1,342 \\
\hline $\mathbf{C}_{\mathbf{4}}$ & 0,922 & $\pm 0,512$ & $-0,378$ & 2,147 \\
\hline $\mathbf{C}_{\mathbf{5}}$ & 0,459 & $\pm 0,464$ & 0,034 & 0,845 \\
\hline $\mathbf{C}_{\boldsymbol{6}}$ & 0,570 & $\pm 0,432$ & $-0,256$ & 1,332 \\
\hline
\end{tabular}

A Tabela 7.67 ilustra os valores médios para o erro da portadora $L_{1}$ (erro de interfreqüência), bem como os respectivos desvios padrão médios, referentes ao período do inverno. Se comparados com os períodos do verão e do outono, estes erros mantiveram-se, praticamente, constantes. 
Tabela 7.67 - Valores médios do erro da portadora $L_{1}$ (erro de interfreqüência), devido ao conjunto satélite/receptor, em relação aos dias estudados no inverno.

\begin{tabular}{|c|c|c|}
\cline { 2 - 3 } \multicolumn{1}{c|}{} & \multicolumn{2}{c|}{$(\text { Erro })^{\mathrm{S}}=\left(\left(\mathrm{S}_{\mathrm{P} 2}-\mathrm{S}_{\mathrm{P} 1}\right)+\left(\mathrm{r}_{\mathrm{P} 2}-\mathrm{r}_{\mathrm{P} 1}\right)\right)^{\mathrm{S}}$} \\
\hline Satélites & Valor Médio $(\mathbf{m})$ & Desvio Padrão (m) \\
\hline PRN-1 & 1,136 & $\pm 0,451$ \\
\hline PRN-2 & 1,891 & $\pm 0,520$ \\
\hline PRN-3 & 1,539 & $\pm 0,473$ \\
\hline PRN-4 & 2,188 & $\pm 0,596$ \\
\hline PRN-5 & 2,202 & $\pm 0,460$ \\
\hline PRN-6 & 2,180 & $\pm 0,714$ \\
\hline PRN-7 & 1,955 & $\pm 0,526$ \\
\hline PRN-8 & 1,852 & $\pm 0,513$ \\
\hline PRN-9 & 1,943 & $\pm 0,541$ \\
\hline PRN-10 & 2,380 & $\pm 0,604$ \\
\hline PRN-11 & 1,507 & $\pm 0,420$ \\
\hline PRN-13 & 1,727 & $\pm 0,593$ \\
\hline PRN-14 & 1,495 & $\pm 0,307$ \\
\hline PRN-15 & 1,838 & $\pm 0,437$ \\
\hline PRN-17 & 2,030 & $\pm 0,314$ \\
\hline PRN-18 & 1,741 & $\pm 0,355$ \\
\hline PRN-20 & 1,638 & $\pm 0,474$ \\
\hline PRN-21 & 1,753 & $\pm 0,359$ \\
\hline PRN-22 & 1,543 & $\pm 0,465$ \\
\hline PRN-23 & 1,752 & $\pm 0,416$ \\
\hline PRN-24 & 2,086 & $\pm 0,685$ \\
\hline PRN-25 & 1,665 & $\pm 0,727$ \\
\hline PRN-26 & 2,268 & $\pm 0,603$ \\
\hline PRN-27 & 1,824 & $\pm 0,567$ \\
\hline PRN-28 & 1,781 & $\pm 0,538$ \\
\hline PRN-29 & 1,436 & $\pm 0,363$ \\
\hline PRN-30 & 2,092 & $\pm 0,688$ \\
\hline PRN-31 & 1,515 & $\pm 0,397$ \\
\hline
\end{tabular}




\subsubsection{Validação do modelo através de posicionamento Single Point - período do inverno}

Durante este período, o modelo polinomial mostrou-se o mesmo comportamento no processo de minimização do efeito ionosférico, se comparado com o verão e o outono. Com exceção do dia 184, cujo erro médio quadrático diário foi de 2,1 metros, nos demais dias este erro foi sempre inferior a 1,9 metros.

Durante todo o período do dia, o modelo polinomial proporcionou resultados melhores que o de Klobuchar e o Standard, sempre com variações regulares compreendidas entre 0 e 3,7 metros, inclusive no período de ocorrência de máxima atividade solar, das 17 às 20 horas GPS.

Através da utilização do modelo de Klobuchar, ao analisar o erro médio quadrático horizontal do vértice BRAZ, os resultados encontrados foram semelhantes que no período do outono, com picos superiores a 5 metros em alguns intervalos, como de 0 a 6 e 17 a 20 horas GPS. No dia 184, o modelo proporcionou um erro médio quadrático diário inferior ao modelo polinomial.

Com o modelo Standard, os resultados encontrados foram melhores que no período do verão e do outono, mas sempre com valores superiores, se comparados com os de Klobuchar e polinomial. Em alguns intervalos do dia, constatou-se erros horizontais superiores 8 metros

Ao analisar os sete dias de processamento, os valores médios do erro horizontal, foram:

- E.M.Q.H.P = 1,701m $\pm 0,874 m$

- E.M.Q.H.K = 2,204m $\pm 1,216 m$

- E.M.Q.H.S = 3,227m $\pm 1,379 m$

O modelo polinomial proporcionou, em média, uma melhora de $0,503 \mathrm{~m}$ e $1,526 \mathrm{~m}$, em relação aos modelos de Klobuchar e Standard, respectivamente.

Em relação ao erro vertical, o modelo polinomial também proporcionou melhores resultados que os de Klobuchar e o Standard. Em média, os valores encontrados foram semelhantes ao período do outono. Nos sete dias de processamento os valores médios foram: 
- E.M.Q.V.P $=3,036 \mathrm{~m} \pm 3,690 \mathrm{~m}$

- E.M.Q.V.K = 3,607m $\pm 3,329 m$

- E.M.Q.V.S $=3,492 \mathrm{~m} \pm 2,794 \mathrm{~m}$

A melhora foi, em média, 0,571m e 0,456m, em relação aos modelos de Klobuchar e Standard, respectivamente.

A seguir, serão apresentados todos os resultados do posicionamento Single Point do vértice BRAZ, referentes a alguns dias do inverno.

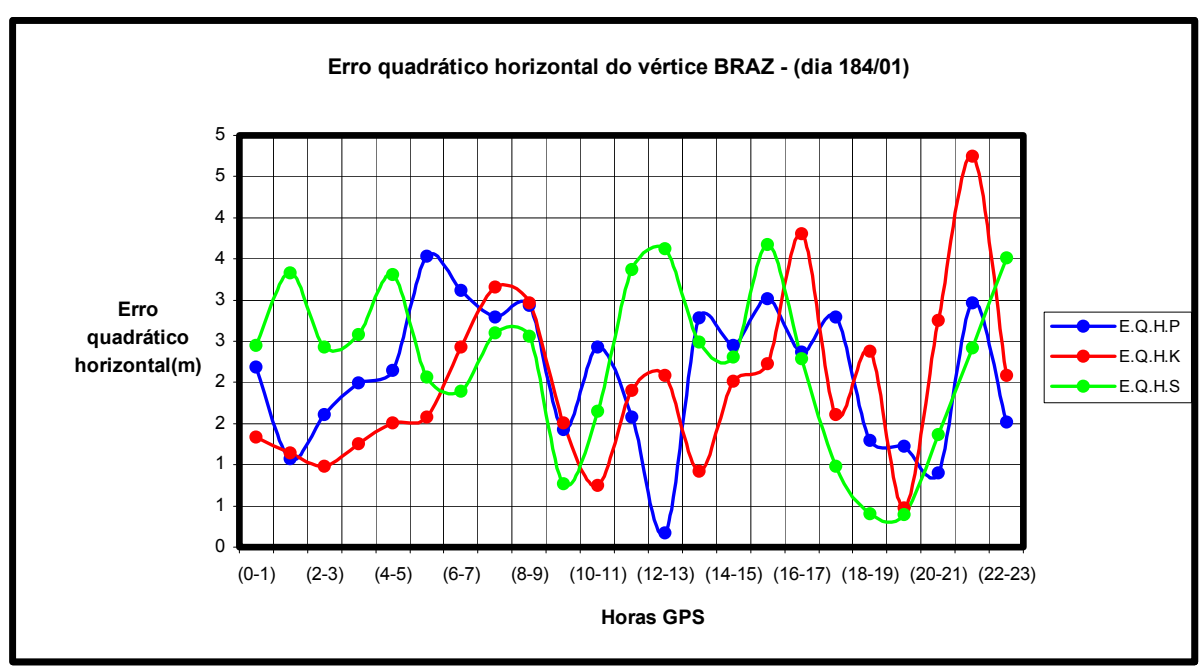

Figura 7.93 - Variação horária do erro quadrático horizontal no posicionamento Single Point do vértice $B R A Z$ - (dia 184/01)

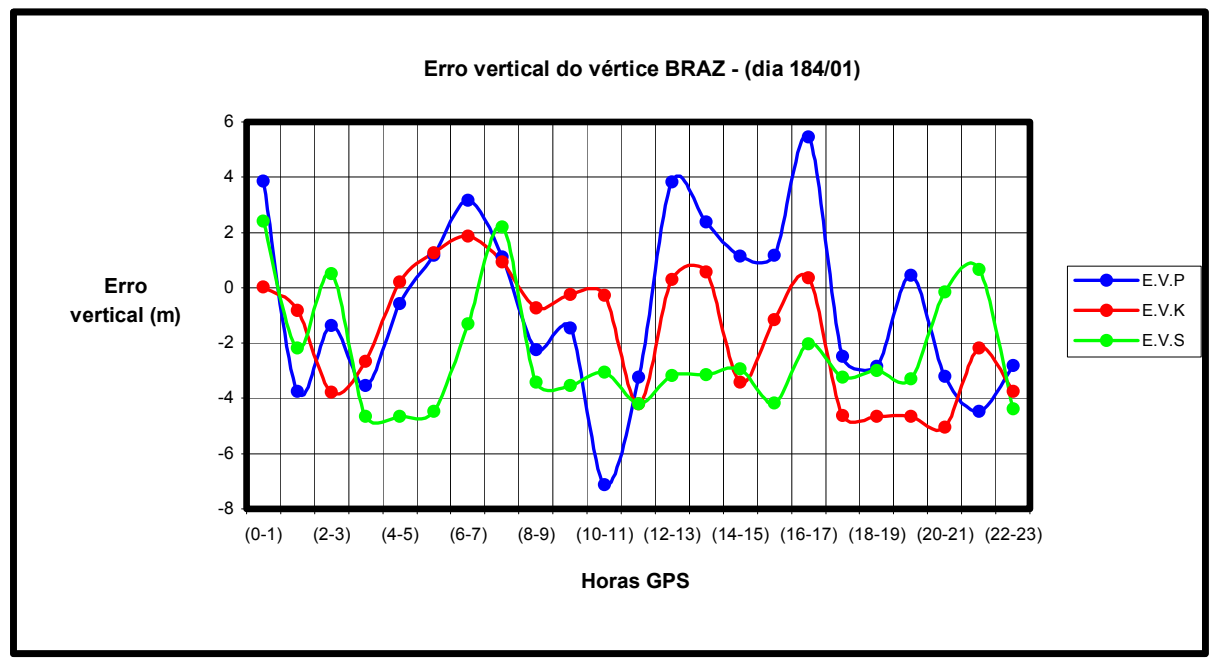

Figura 7.94 - Variação horária do erro vertical no posicionamento Single Point do vértice

$$
\text { BRAZ - (dia 184/01) }
$$


Tabela 7.68 - Erro quadrático horizontal e erro vertical no processamento Single Point do vértice BRAZ para diferentes modelos ionosféricos - (dia 184/01).

\begin{tabular}{|c|c|c|c|c|c|c|}
\hline \multirow[b]{2}{*}{ Horas } & \multicolumn{3}{|c|}{ Erro Quadrático Horizontal (m) } & \multicolumn{3}{|c|}{ Erro Vertical (m) } \\
\hline & E.Q.H.P & E.Q.H.K & E.Q.H.S & E.V.P & E.V.K & E.V.S \\
\hline$(0-1)$ & 2,182 & 1,340 & 2,454 & 3,868 & 0,028 & 2,409 \\
\hline$(1-2)$ & 1,071 & 1,148 & 3,333 & $-3,746$ & $-0,816$ & $-2,181$ \\
\hline$(2-3)$ & 1,607 & 0,982 & 2,425 & $-1,351$ & $-3,765$ & 0,496 \\
\hline$(3-4)$ & 1,995 & 1,252 & 2,581 & $-3,533$ & $-2,650$ & $-4,642$ \\
\hline$(4-5)$ & 2,143 & 1,505 & 3,315 & $-0,563$ & 0,208 & $-4,647$ \\
\hline$(5-6)$ & 3,531 & 1,574 & 2,069 & 1,158 & 1,251 & $-4,473$ \\
\hline$(6-7)$ & 3,113 & 2,431 & 1,892 & 3,155 & 1,878 & $-1,297$ \\
\hline$(7-8)$ & 2,798 & 3,154 & 2,603 & 1,098 & 0,924 & 2,193 \\
\hline$(8-9)$ & 2,936 & 2,961 & 2,556 & $-2,242$ & \begin{tabular}{|l|l|}
$-0,718$ \\
\end{tabular} & $-3,409$ \\
\hline$(9-10)$ & 1,427 & 1,5 & 0,766 & $-1,457$ & $-0,254$ & $-3,548$ \\
\hline$(10-11)$ & 2,431 & 0,745 & 1,646 & $-7,122$ & $-0,283$ & $-3,062$ \\
\hline$(11-12)$ & 1,578 & 1,903 & 3,374 & $-3,245$ & $-4,188$ & $-4,205$ \\
\hline$(12-13)$ & 0,174 & 2,088 & 3,628 & 3,826 & 0,312 & $-3,176$ \\
\hline$(13-14)$ & 2,786 & 0,925 & 2,490 & 2,365 & 0,572 & $-3,153$ \\
\hline$(14-15)$ & 2,451 & 2,010 & 2,305 & 1,129 & $-3,412$ & $-2,944$ \\
\hline$(15-16)$ & 3,020 & 2,231 & 3,678 & 1,178 & $-1,137$ & $-4,158$ \\
\hline$(16-17)$ & 2,373 & 3,803 & 2,292 & 5,443 & 0,353 & $-2,018$ \\
\hline$(17-18)$ & 2,789 & 1,614 & 0,984 & $-2,494$ & $-4,614$ & $-3,224$ \\
\hline$(18-19)$ & 1,294 & 2,379 & 0,406 & $-2,826$ & $-4,655$ & $-2,990$ \\
\hline$(19-20)$ & 1,227 & 0,473 & 0,391 & 0,448 & $-4,640$ & $-3,282$ \\
\hline$(20-21)$ & 0,899 & 2,754 & 1,371 & $-3,217$ & $-5,035$ & $-0,146$ \\
\hline$(21-22)$ & 2,961 & 4,743 & 2,423 & $-4,481$ & $-2,170$ & 0,652 \\
\hline$(22-23)$ & 1,515 & 2,085 & 3,513 & $-2,804$ & $-3,758$ & $-4,388$ \\
\hline E.M.Q & 2,100 & 1,983 & 2,282 & 2,728 & 2,070 & 2,900 \\
\hline Desvio Padrão & $\pm 0,854$ & $\pm 1,014$ & $\pm 0,989$ & $\pm 3,158$ & $\pm 2,237$ & $\pm 2,123$ \\
\hline
\end{tabular}

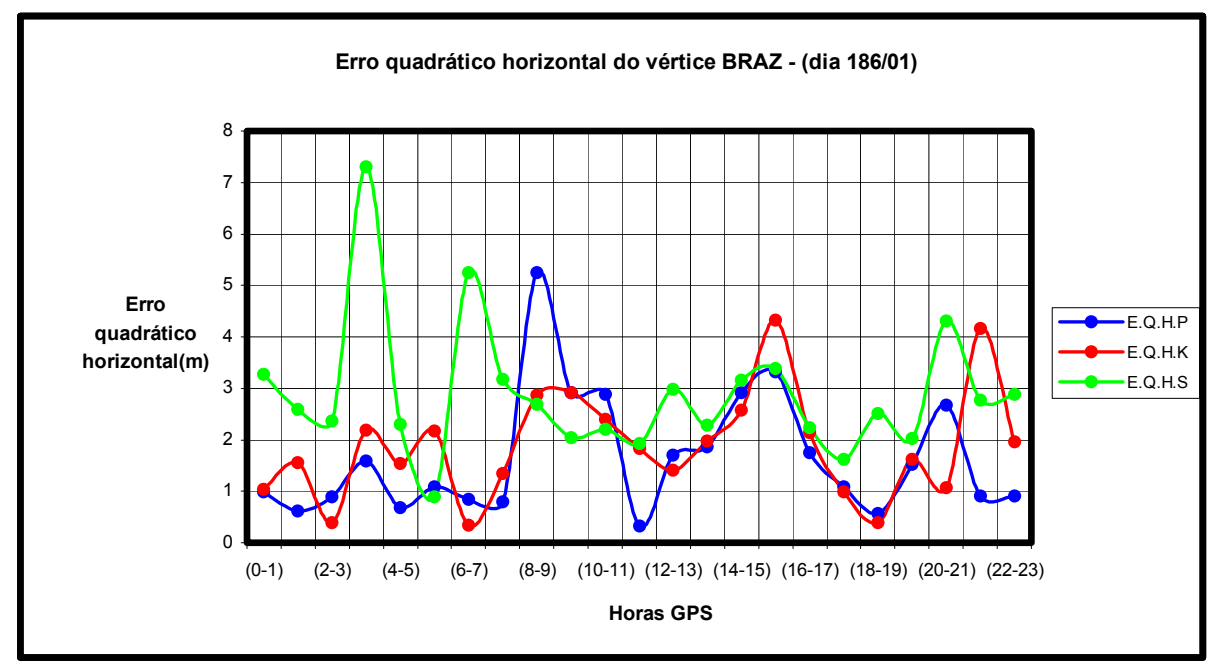

Figura 7.95 - Variação horária do erro quadrático horizontal no posicionamento Single Point do vértice $B R A Z$ - (dia 186/01) 


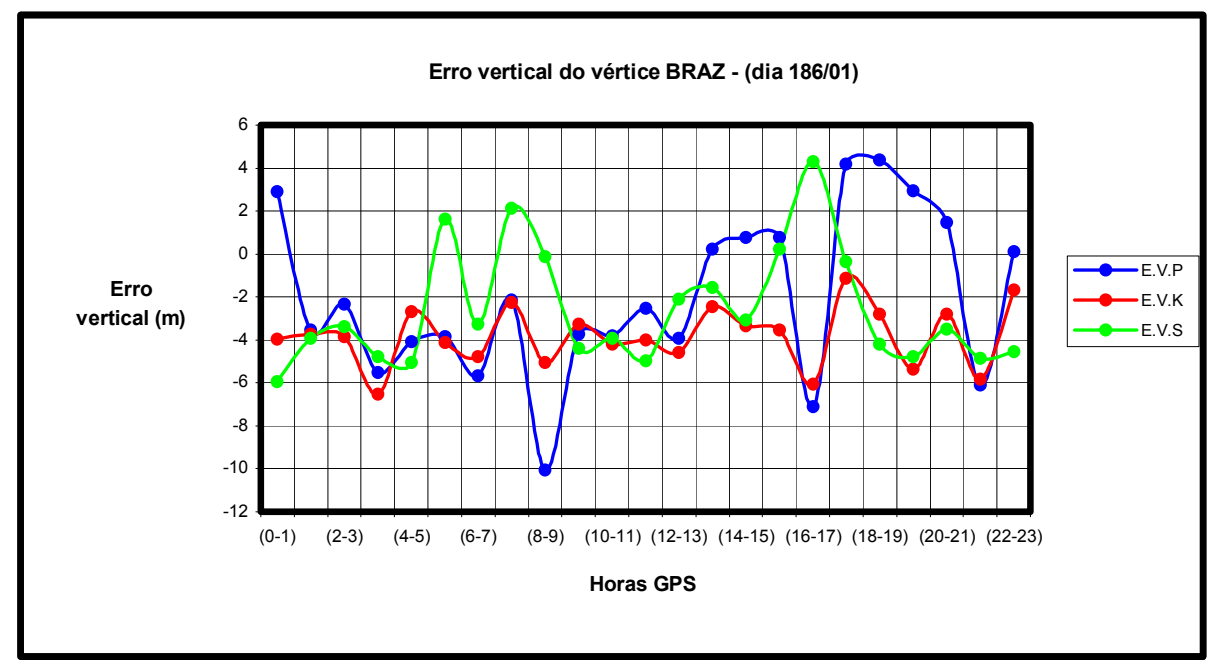

Figura 7.96 - Variação horária do erro vertical no posicionamento Single Point do vértice BRAZ - (dia 186/01)

Tabela 7.69 - Erro quadrático horizontal e erro vertical no processamento Single Point do vértice BRAZ para diferentes modelos ionosféricos - (dia 186/01).

\begin{tabular}{|c|c|c|c|c|c|c|}
\hline \multirow[b]{2}{*}{ Horas } & \multicolumn{3}{|c|}{ Erro Quadrático Horizontal (m) } & \multicolumn{3}{|c|}{ Erro Vertical $(m)$} \\
\hline & E.Q.H.P & E.Q.H.K & E.Q.H.S & E.V.P & E.V.K & E.V.S \\
\hline$(0-1)$ & 0,989 & 1,042 & 3,272 & 2,906 & $-3,987$ & $-5,948$ \\
\hline$(1-2)$ & 0,620 & 1,561 & 2,584 & $-3,558$ & $-3,734$ & $-3,924$ \\
\hline$(2-3)$ & 0,898 & 0,391 & 2,366 & $-2,330$ & $-3,857$ & $-3,396$ \\
\hline$(3-4)$ & 1,587 & 2,186 & 7,299 & $-5,525$ & $-6,513$ & $-4,779$ \\
\hline$(4-5)$ & 0,687 & 1,535 & 2,301 & $-4,081$ & $-2,673$ & $-5,039$ \\
\hline$(5-6)$ & 1,082 & 2,172 & 0,886 & $-3,842$ & $-4,107$ & 1,625 \\
\hline (6-7) & 0,848 & 0,343 & 5,242 & $-5,675$ & $-4,800$ & $-3,254$ \\
\hline$(7-8)$ & 0,786 & 1,340 & 3,175 & $-2,135$ & $-2,270$ & 2,130 \\
\hline$(8-9)$ & 5,250 & 2,869 & 2,681 & $-10,055$ & $-5,047$ & $-0,123$ \\
\hline$(9-10)$ & 2,913 & 2,910 & 2,033 & $-3,743$ & $-3,268$ & $-4,397$ \\
\hline$(10-11)$ & 2,884 & 2,394 & 2,209 & $-3,827$ & $-4,199$ & $-3,919$ \\
\hline$(11-12)$ & 0,327 & 1,828 & 1,929 & $-2,529$ & $-4,006$ & $-4,965$ \\
\hline$(12-13)$ & 1,695 & 1,404 & 2,982 & $-3,918$ & $-4,601$ & $-2,124$ \\
\hline$(13-14)$ & 1,866 & 1,980 & 2,281 & 0,201 & $-2,439$ & $-1,567$ \\
\hline (14-15) & 2,915 & 2,570 & 3,159 & 0,775 & $-3,350$ & $-3,064$ \\
\hline$(15-16)$ & 3,315 & 4,330 & 3,393 & 0,765 & $-3,535$ & 0,214 \\
\hline$(16-17)$ & 1,750 & 2,134 & 2,228 & $-7,112$ & $-6,072$ & 4,302 \\
\hline$(17-18)$ & 1,090 & 0,991 & 1,623 & 4,178 & $-1,157$ & $-0,371$ \\
\hline$(18-19)$ & 0,565 & 0,391 & 2,517 & 4,352 & $-2,791$ & $-4,188$ \\
\hline$(19-20)$ & 1,529 & 1,624 & 2,031 & 2,924 & $-5,383$ & $-4,777$ \\
\hline$(20-21)$ & 2,676 & 1,067 & 4,311 & 1,453 & $-2,822$ & $-3,505$ \\
\hline$(21-22)$ & 0,909 & 4,164 & 2,766 & $-6,118$ & $-5,824$ & $-4,874$ \\
\hline$(22-23)$ & 0,907 & 1,964 & 2,875 & 0,113 & $-1,670$ & $-4,541$ \\
\hline E.M.Q & 1,656 & 1,878 & 2,876 & 3,570 & 3,831 & 3,349 \\
\hline Desvio Padrão & $\pm 1,180$ & $\pm 1,045$ & $\pm 1,310$ & $\pm 3,801$ & $\pm 1,384$ & $\pm 2,702$ \\
\hline
\end{tabular}




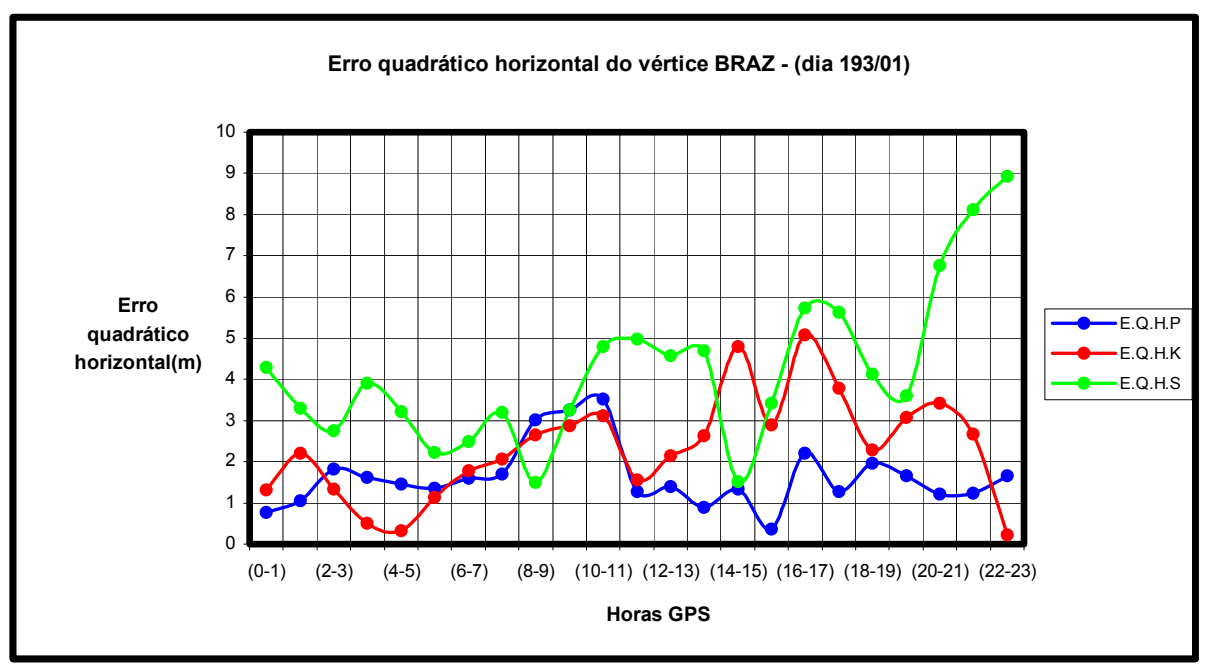

Figura 7.97 - Variação horária do erro quadrático horizontal no posicionamento Single Point do vértice BRAZ - (dia 193/01)

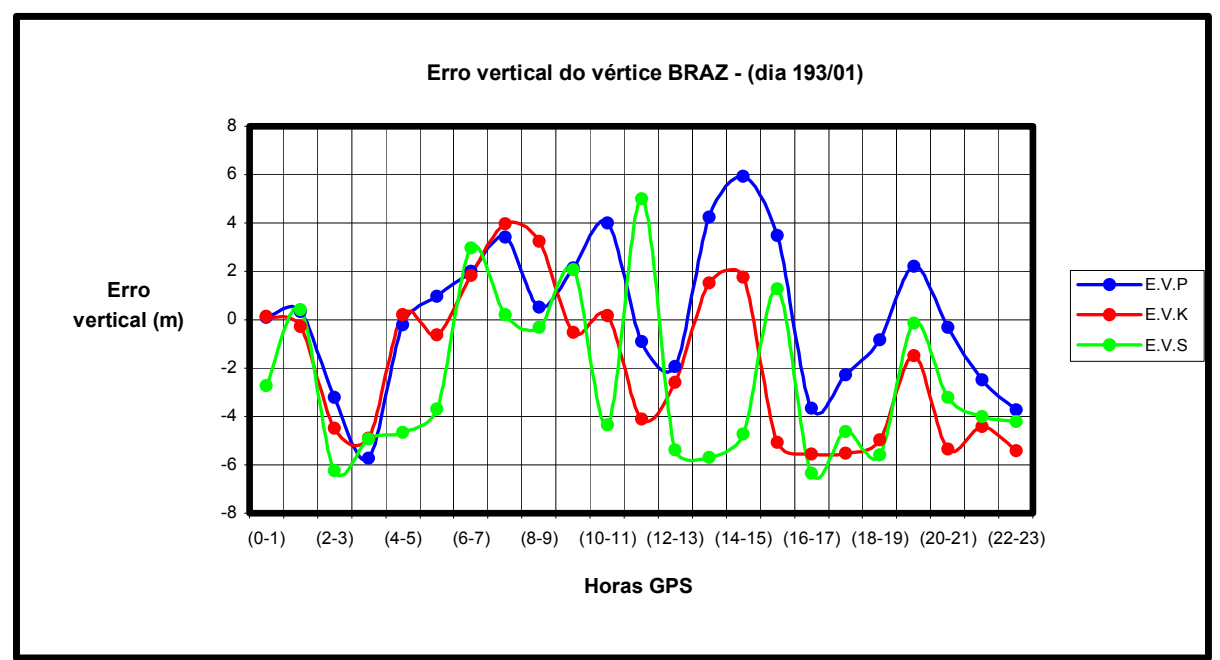

Figura 7.98 - Variação horária do erro vertical no posicionamento Single Point do vértice BRAZ - (dia 193/01) 
Tabela 7.70 - Erro quadrático horizontal e erro vertical no processamento Single Point do vértice BRAZ para diferentes modelos ionosféricos - (dia 193/01).

\begin{tabular}{|c|c|c|c|c|c|c|}
\cline { 2 - 7 } \multicolumn{1}{c|}{} & \multicolumn{2}{c|}{ Erro Quadrático Horizontal (m) } & \multicolumn{3}{c|}{ Erro Vertical (m) } \\
\hline Horas & E.Q.H.P & E.Q.H.K & E.Q.H.S & E.V.P & E.V.K & E.V.S \\
\hline $\mathbf{( 0 - 1 )}$ & 0,773 & 1,312 & 4,284 & 0,104 & 0,140 & $-2,730$ \\
\hline $\mathbf{( 1 - 2 )}$ & 1,056 & 2,196 & 3,303 & 0,338 & $-0,274$ & 0,402 \\
\hline $\mathbf{( 2 - 3 )}$ & 1,825 & 1,328 & 2,756 & $-3,224$ & $-4,473$ & $-6,240$ \\
\hline $\mathbf{( 3 - 4 )}$ & 1,625 & 0,500 & 3,899 & $-5,725$ & $-4,914$ & $-4,918$ \\
\hline $\mathbf{( 4 - 5 )}$ & 1,452 & 0,331 & 3,212 & $-0,197$ & 0,221 & $-4,641$ \\
\hline $\mathbf{( 5 - 6 )}$ & 1,358 & 1,128 & 2,224 & 0,970 & $-0,607$ & $-3,700$ \\
\hline $\mathbf{( 6 - 7 )}$ & 1,601 & 1,788 & 2,495 & 2,010 & 1,821 & 2,957 \\
\hline $\mathbf{( 7 - 8 )}$ & 1,691 & 2,074 & 3,200 & 3,428 & 3,970 & 0,219 \\
\hline $\mathbf{( 8 - 9 )}$ & 3,009 & 2,659 & 1,498 & 0,523 & 3,258 & $-0,295$ \\
\hline $\mathbf{( 9 - 1 0 )}$ & 3,258 & 2,869 & 3,252 & 2,122 & $-0,533$ & 2,058 \\
\hline $\mathbf{( 1 0 - 1 1 )}$ & 3,518 & 3,120 & 4,797 & 4,003 & 0,158 & $-4,328$ \\
\hline $\mathbf{( 1 1 - 1 2 )}$ & 1,270 & 1,566 & 4,976 & $-0,885$ & $-4,115$ & 5,005 \\
\hline $\mathbf{( 1 2 - 1 3 )}$ & 1,391 & 2,155 & 4,568 & $-1,945$ & $-2,586$ & $-5,388$ \\
\hline $\mathbf{( 1 3 - 1 4 )}$ & 0,899 & 2,637 & 4,691 & 4,236 & 1,521 & $-5,703$ \\
\hline $\mathbf{( 1 4 - 1 5 )}$ & 1,339 & 4,794 & 1,524 & 5,928 & 1,761 & $-4,712$ \\
\hline $\mathbf{( 1 5 - 1 6 )}$ & 0,370 & 2,893 & 3,430 & 3,496 & $-5,062$ & 1,266 \\
\hline $\mathbf{( 1 6 - 1 7 )}$ & 2,205 & 5,082 & 5,736 & $-3,669$ & $-5,551$ & $-6,340$ \\
\hline $\mathbf{( 1 7 - 1 8 )}$ & 1,273 & 3,791 & 5,633 & $-2,288$ & $-5,508$ & $-4,629$ \\
\hline $\mathbf{( 1 8 - 1 9 )}$ & 1,969 & 2,291 & 4,124 & $-0,837$ & $-4,952$ & $-5,592$ \\
\hline $\mathbf{( 1 9 - 2 0 )}$ & 1,660 & 3,085 & 3,600 & 2,208 & $-1,467$ & $-0,133$ \\
\hline $\mathbf{( 2 0 - 2 1 )}$ & 1,210 & 3,426 & 6,768 & $-0,326$ & $-5,339$ & $-3,221$ \\
\hline $\mathbf{( 2 1 - 2 2 )}$ & 1,233 & 2,667 & 8,124 & $-2,479$ & $-4,409$ & $-3,999$ \\
\hline $\mathbf{( 2 2 - 2 3 )}$ & 1,662 & 0,233 & 8,929 & $-3,724$ & $-5,427$ & $-4,214$ \\
\hline E.M.Q & $\mathbf{1 , 6 3 7}$ & $\mathbf{2 , 3 4 5}$ & $\mathbf{4 , 2 1 8}$ & $\mathbf{2 , 3 7 7}$ & $\mathbf{2 , 9 5 9}$ & $\mathbf{3 , 5 9 5}$ \\
\hline Desvio Padrão & $\pm \mathbf{0 , 7 5 8}$ & $\pm \mathbf{1 , 2 6 7}$ & $\pm \mathbf{1 , 8 8 5}$ & $\pm \mathbf{2 , 9 7 3}$ & $\pm \mathbf{3 , 1 3 7}$ & $\pm \mathbf{3 , 2 6 5}$ \\
\hline & & & & & & \\
\hline
\end{tabular}

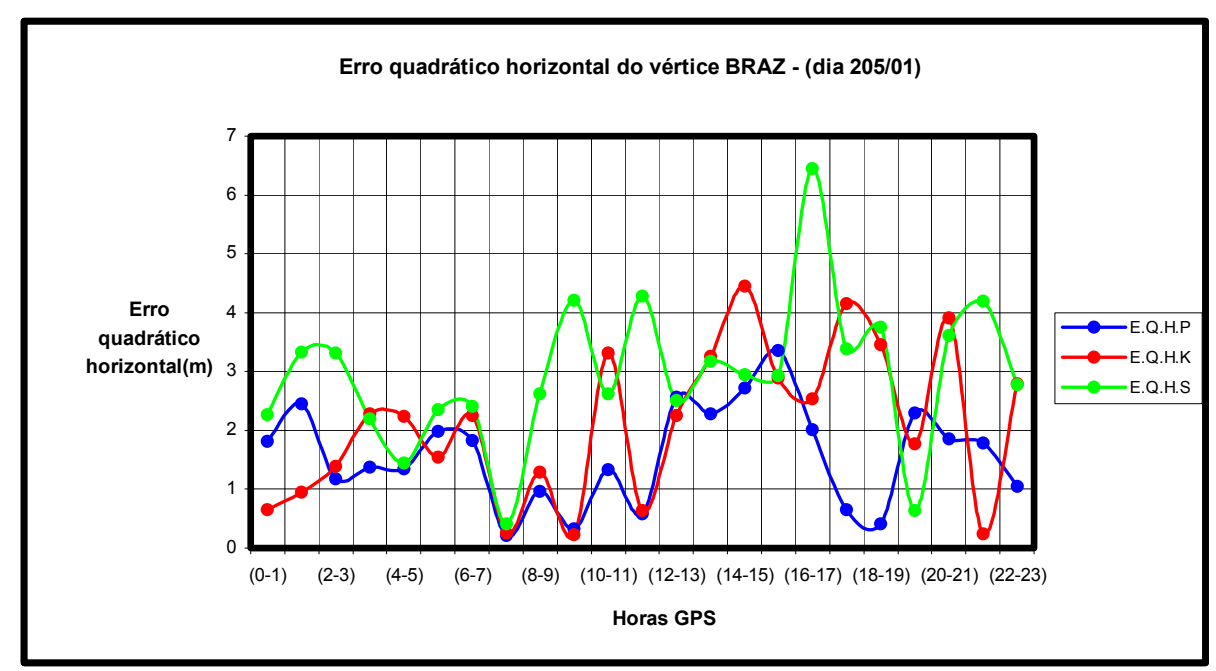

Figura 7.99 - Variação horária do erro quadrático horizontal no posicionamento Single Point do vértice BRAZ - (dia 205/01) 


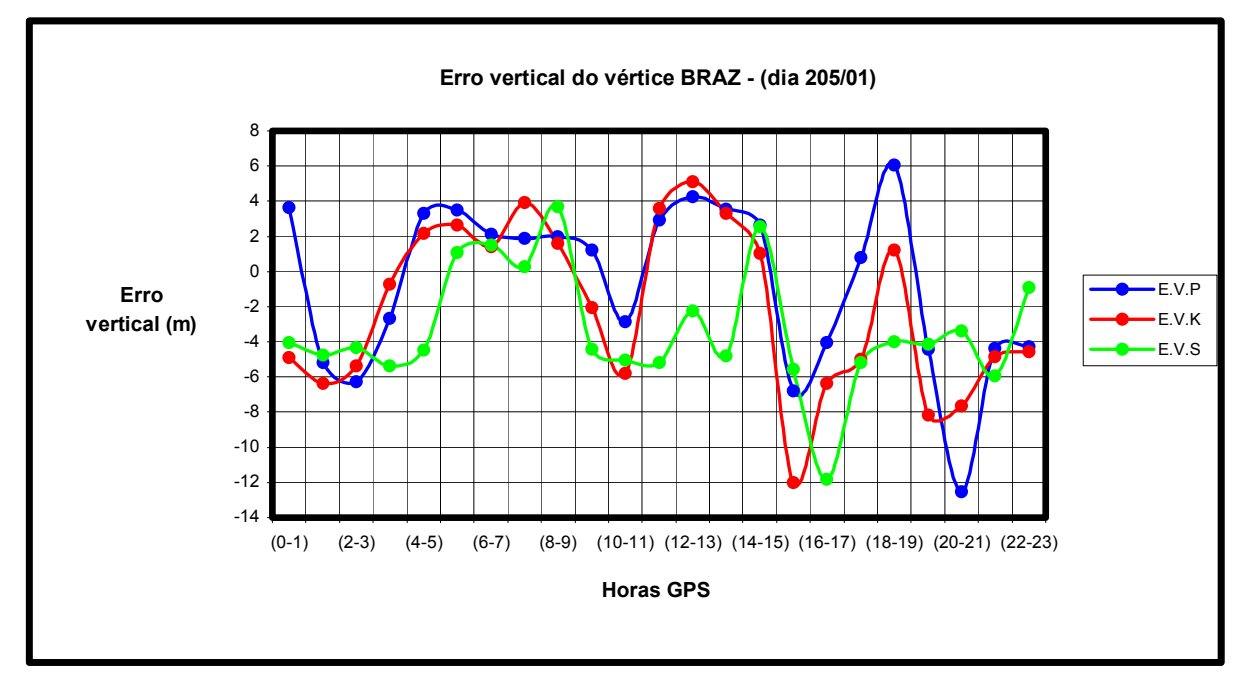

Figura 7.100 - Variação horária do erro vertical no posicionamento Single Point do vértice BRAZ - (dia 205/01)

Tabela 7.71 - Erro quadrático horizontal e erro vertical no processamento Single Point do vértice BRAZ para diferentes modelos ionosféricos - (dia 205/01).

\begin{tabular}{|c|c|c|c|c|c|c|}
\cline { 2 - 7 } \multicolumn{1}{c|}{} & \multicolumn{2}{c|}{ Erro Quadrático Horizontal (m) } & \multicolumn{3}{c|}{ Erro Vertical (m) } \\
\hline Horas & E.Q.H.P & E.Q.H.K & E.Q.H.S & E.V.P & E.V.K & E.V.S \\
\hline $\mathbf{( 0 - 1 )}$ & 1,811 & 0,649 & 2,269 & 3,628 & $-4,895$ & $-4,046$ \\
\hline $\mathbf{( 1 - 2 )}$ & 2,452 & 0,950 & 3,329 & $-5,181$ & $-6,351$ & $-4,732$ \\
\hline $\mathbf{( 2 - 3 )}$ & 1,177 & 1,390 & 3,315 & $-6,268$ & $-5,370$ & $-4,340$ \\
\hline $\mathbf{( 3 - 4 )}$ & 1,374 & 2,286 & 2,200 & $-2,668$ & $-0,743$ & $-5,392$ \\
\hline $\mathbf{( 4 - 5 )}$ & 1,352 & 2,245 & 1,438 & 3,317 & 2,178 & $-4,476$ \\
\hline $\mathbf{( 5 - 6 )}$ & 1,977 & 1,544 & 2,352 & 3,508 & 2,632 & 1,094 \\
\hline $\mathbf{( 6 - 7 )}$ & 1,832 & 2,247 & 2,408 & 2,109 & 1,404 & 1,504 \\
\hline $\mathbf{( 7 - 8 )}$ & 0,215 & 0,260 & 0,411 & 1,871 & 3,909 & 0,252 \\
\hline $\mathbf{( 8 - 9 )}$ & 0,969 & 1,290 & 2,626 & 1,956 & 1,616 & 3,686 \\
\hline $\mathbf{( 9 - 1 0 )}$ & 0,330 & 0,223 & 4,203 & 1,201 & $-2,070$ & $-4,445$ \\
\hline $\mathbf{( 1 0 - 1 1 )}$ & 1,339 & 3,317 & 2,618 & $-2,861$ & $-5,803$ & $-5,019$ \\
\hline $\mathbf{( 1 1 - 1 2 )}$ & 0,588 & 0,644 & 4,281 & 2,922 & 3,585 & $-5,191$ \\
\hline $\mathbf{( 1 2 - 1 3 )}$ & 2,572 & 2,254 & 2,509 & 4,261 & 5,104 & $-2,229$ \\
\hline $\mathbf{( 1 3 - 1 4 )}$ & 2,285 & 3,256 & 3,174 & 3,563 & 3,303 & $-4,823$ \\
\hline $\mathbf{( 1 4 - 1 5 )}$ & 2,715 & 4,455 & 2,947 & 2,640 & 1,036 & 2,537 \\
\hline $\mathbf{( 1 5 - 1 6 )}$ & 3,363 & 2,893 & 2,937 & $-6,795$ & $-12,012$ & $-5,569$ \\
\hline $\mathbf{( 1 6 - 1 7})$ & 2,007 & 2,532 & 6,442 & $-4,056$ & $-6,370$ & $-11,811$ \\
\hline $\mathbf{( 1 7 - 1 8 )}$ & 0,658 & 4,152 & 3,387 & 0,782 & $-5,014$ & $-5,173$ \\
\hline $\mathbf{( 1 8 - 1 9 )}$ & 0,410 & 3,459 & 3,748 & 6,052 & 1,197 & $-4,009$ \\
\hline$(\mathbf{1 9 - 2 0})$ & 2,301 & 1,767 & 0,642 & $-4,426$ & $-8,174$ & $-4,121$ \\
\hline $\mathbf{( 2 0 - 2 1})$ & 1,852 & 3,906 & 3,617 & $-12,538$ & $-7,647$ & $-3,361$ \\
\hline $\mathbf{( 2 1 - 2 2 )}$ & 1,790 & 0,242 & 4,193 & $-4,386$ & $-4,838$ & $-5,949$ \\
\hline $\mathbf{( 2 2 - 2 3 )}$ & 1,046 & 2,788 & 2,772 & $-4,292$ & $-4,572$ & $-0,890$ \\
\hline E.M.Q & $\mathbf{1 , 5 8 3}$ & $\mathbf{2 , 1 2 0}$ & $\mathbf{2 , 9 4 9}$ & $\mathbf{3 , 9 6 9}$ & $\mathbf{4 , 3 4 0}$ & $\mathbf{4 , 1 1 5}$ \\
\hline Desvio Padrão & $\pm \mathbf{0 , 8 3 7}$ & $\pm \mathbf{1 , 2 8 9}$ & $\pm \mathbf{1 , 2 5 9}$ & $\pm \mathbf{4 , 6 7 6}$ & $\pm \mathbf{4 , 7 4 5}$ & $\pm \mathbf{3 , 3 9 6}$ \\
\hline
\end{tabular}




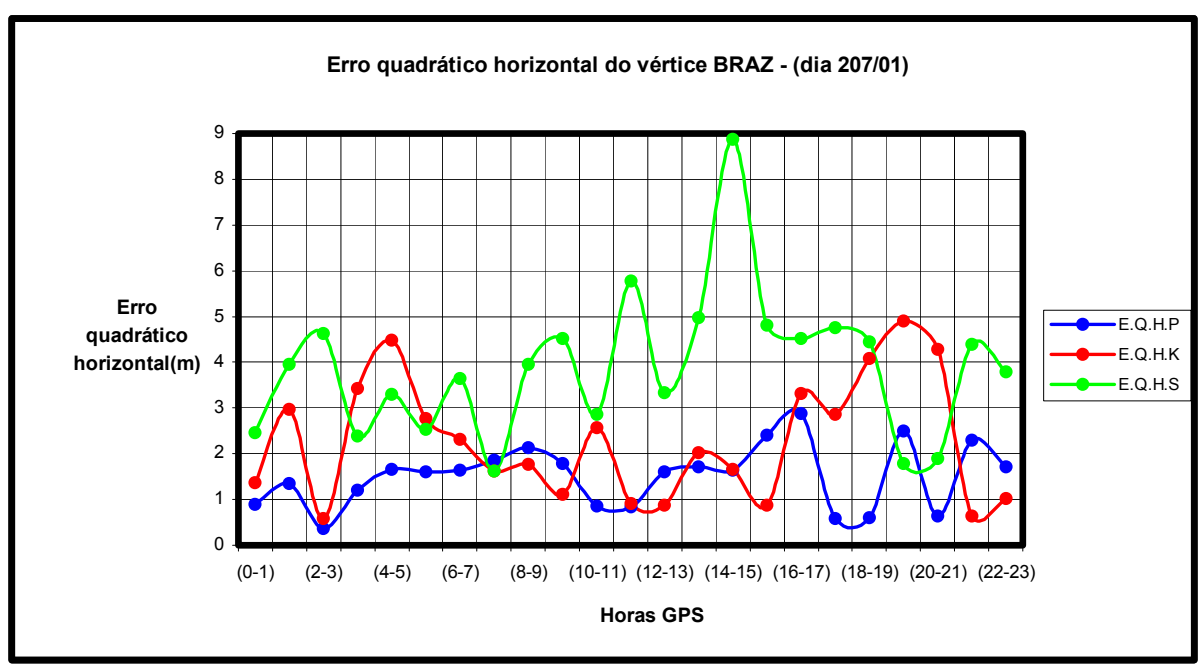

Figura 7.101 - Variação horária do erro quadrático horizontal no posicionamento Single Point do vértice BRAZ - (dia 207/01)

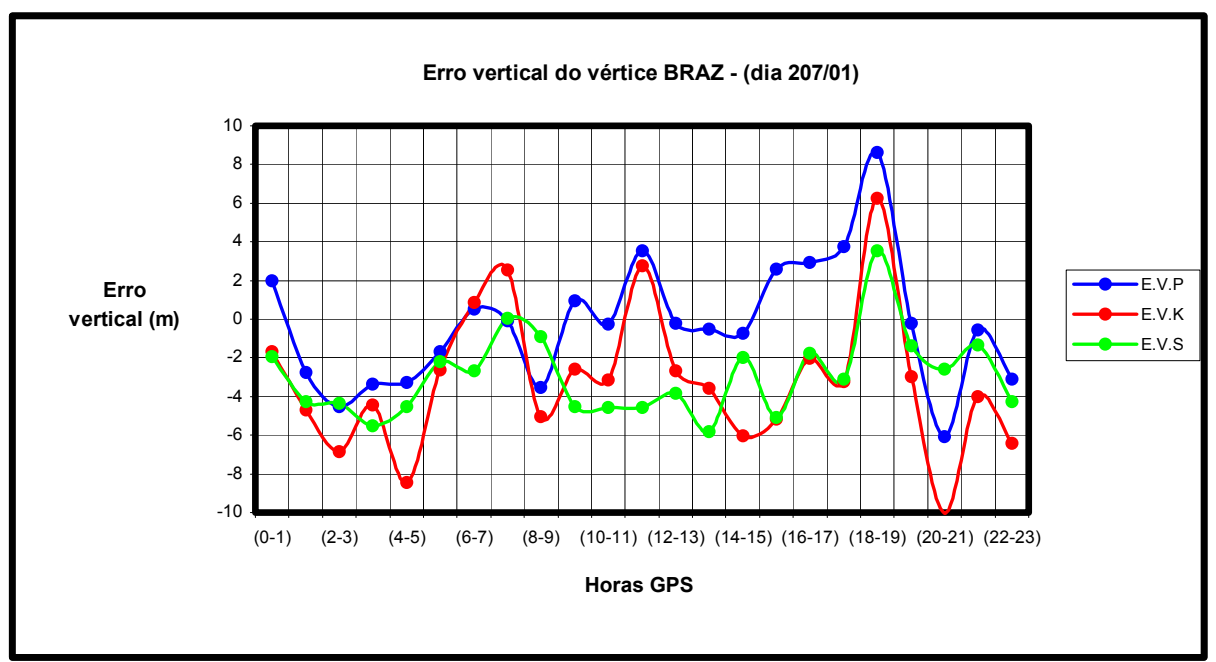

Figura 7.102 - Variação horária do erro vertical no posicionamento Single Point do vértice BRAZ - (dia 207/01) 
Tabela 7.72 - Erro quadrático horizontal e erro vertical no processamento Single Point do vértice BRAZ para diferentes modelos ionosféricos - (dia 207/01).

\begin{tabular}{|c|c|c|c|c|c|c|}
\cline { 2 - 7 } \multicolumn{1}{c|}{} & \multicolumn{2}{c|}{ Erro Quadrático Horizontal (m) } & \multicolumn{3}{c|}{ Erro Vertical (m) } \\
\hline Horas & E.Q.H.P & E.Q.H.K & E.Q.H.S & E.V.P & E.V.K & E.V.S \\
\hline $\mathbf{( 0 - 1 )}$ & 0,891 & 1,365 & 2,459 & 1,974 & $-1,673$ & $-1,937$ \\
\hline $\mathbf{( 1 - 2 )}$ & 1,346 & 2,978 & 3,950 & $-2,761$ & $-4,696$ & $-4,284$ \\
\hline $\mathbf{( 2 - 3 )}$ & 0,359 & 0,578 & 4,621 & $-4,535$ & $-6,851$ & $-4,349$ \\
\hline $\mathbf{( 3 - 4 )}$ & 1,202 & 3,429 & 2,387 & $-3,365$ & $-4,439$ & $-5,504$ \\
\hline $\mathbf{( 4 - 5 )}$ & 1,655 & 4,478 & 3,300 & $-3,260$ & $-8,467$ & $-4,508$ \\
\hline $\mathbf{( 5 - 6 )}$ & 1,608 & 2,775 & 2,525 & $-1,689$ & $-2,636$ & $-2,191$ \\
\hline $\mathbf{( 6 - 7 )}$ & 1,638 & 2,321 & 3,635 & 0,536 & 0,852 & $-2,688$ \\
\hline $\mathbf{( 7 - 8 )}$ & 1,865 & 1,622 & 1,616 & $-0,099$ & 2,527 & 0,043 \\
\hline $\mathbf{( 8 - 9 )}$ & 2,137 & 1,769 & 3,950 & $-3,537$ & $-5,052$ & $-0,886$ \\
\hline $\mathbf{( 9 - 1 0 )}$ & 1,782 & 1,108 & 4,517 & 0,936 & $-2,574$ & $-4,546$ \\
\hline $\mathbf{( 1 0 - 1 1 )}$ & 0,848 & 2,573 & 2,852 & $-0,239$ & $-3,126$ & $-4,586$ \\
\hline $\mathbf{( 1 1 - 1 2 )}$ & 0,831 & 0,904 & 5,779 & 3,551 & 2,773 & $-4,548$ \\
\hline $\mathbf{( 1 2 - 1 3 )}$ & 1,608 & 0,877 & 3,327 & $-0,234$ & $-2,664$ & $-3,858$ \\
\hline $\mathbf{( 1 3 - 1 4 )}$ & 1,712 & 2,017 & 4,967 & $-0,509$ & $-3,586$ & $-5,828$ \\
\hline $\mathbf{( 1 4 - 1 5 )}$ & 1,643 & 1,652 & 8,867 & $-0,731$ & $-6,051$ & $-1,999$ \\
\hline $\mathbf{( 1 5 - 1 6 )}$ & 2,410 & 0,874 & 4,808 & 2,584 & $-5,160$ & $-5,098$ \\
\hline $\mathbf{( 1 6 - 1 7 )}$ & 2,880 & 3,321 & 4,516 & 2,914 & $-2,024$ & $-1,777$ \\
\hline $\mathbf{( 1 7 - 1 8 )}$ & 0,584 & 2,869 & 4,754 & 3,736 & $-3,226$ & $-3,107$ \\
\hline $\mathbf{( 1 8 - 1 9 )}$ & 0,609 & 4,078 & 4,440 & 8,611 & 6,267 & 3,554 \\
\hline$(\mathbf{1 9 - 2 0})$ & 2,505 & 4,893 & 1,792 & $-0,213$ & $-2,980$ & $-1,373$ \\
\hline $\mathbf{( 2 0 - 2 1})$ & 0,642 & 4,276 & 1,886 & $-6,069$ & $-10,029$ & $-2,582$ \\
\hline $\mathbf{( 2 1 - 2 2 )}$ & 2,294 & 0,631 & 4,386 & $-0,554$ & $-4,000$ & $-1,316$ \\
\hline $\mathbf{( 2 2 - 2 3 )}$ & 1,721 & 1,018 & 3,798 & $-3,101$ & $-6,426$ & $-4,261$ \\
\hline E.M.Q & $\mathbf{1 , 5 1 2}$ & $\mathbf{2 , 2 7 9}$ & $\mathbf{3 , 8 7 5}$ & $\mathbf{2 , 4 2 3}$ & $\mathbf{4 , 2 6 4}$ & $\mathbf{3 , 2 5 3}$ \\
\hline Desvio Padrão & $\pm \mathbf{0 , 6 8 1}$ & $\pm \mathbf{1 , 3 2 9}$ & $\pm \mathbf{1 , 5 7 4}$ & $\pm \mathbf{3 , 2 5 1}$ & $\pm \mathbf{3 , 6 7 6}$ & $\pm \mathbf{2 , 1 3 9}$ \\
\hline
\end{tabular}

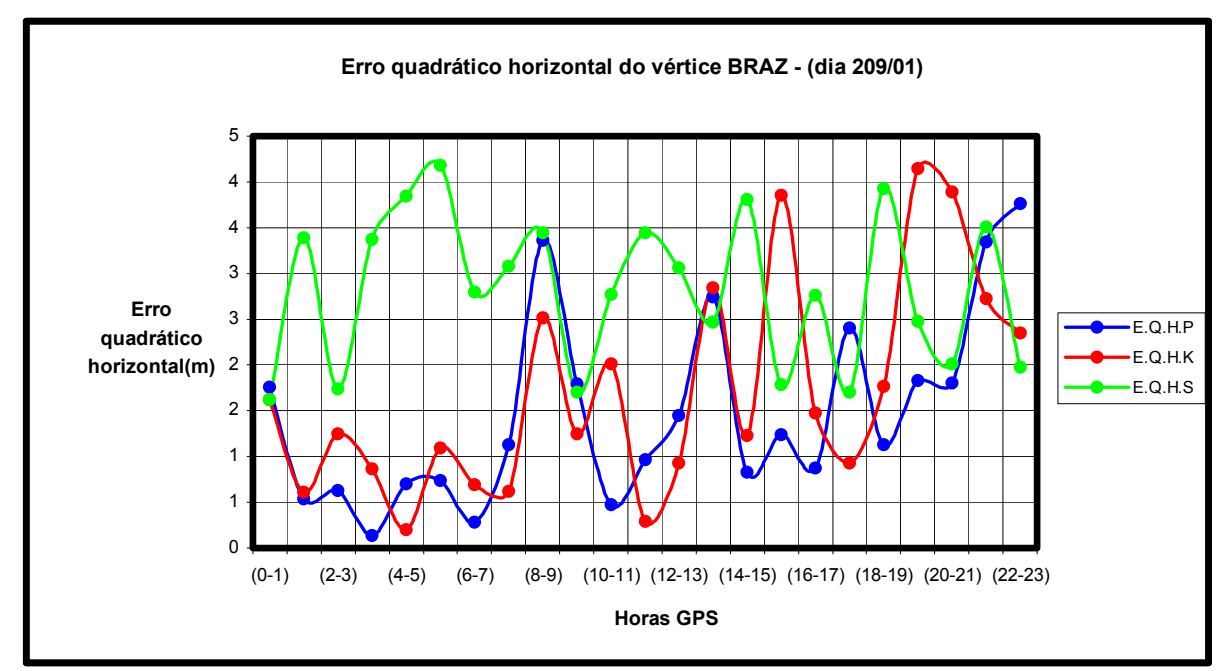

Figura 7.103 - Variação horária do erro quadrático horizontal no posicionamento Single Point do vértice BRAZ - (dia 209/01) 


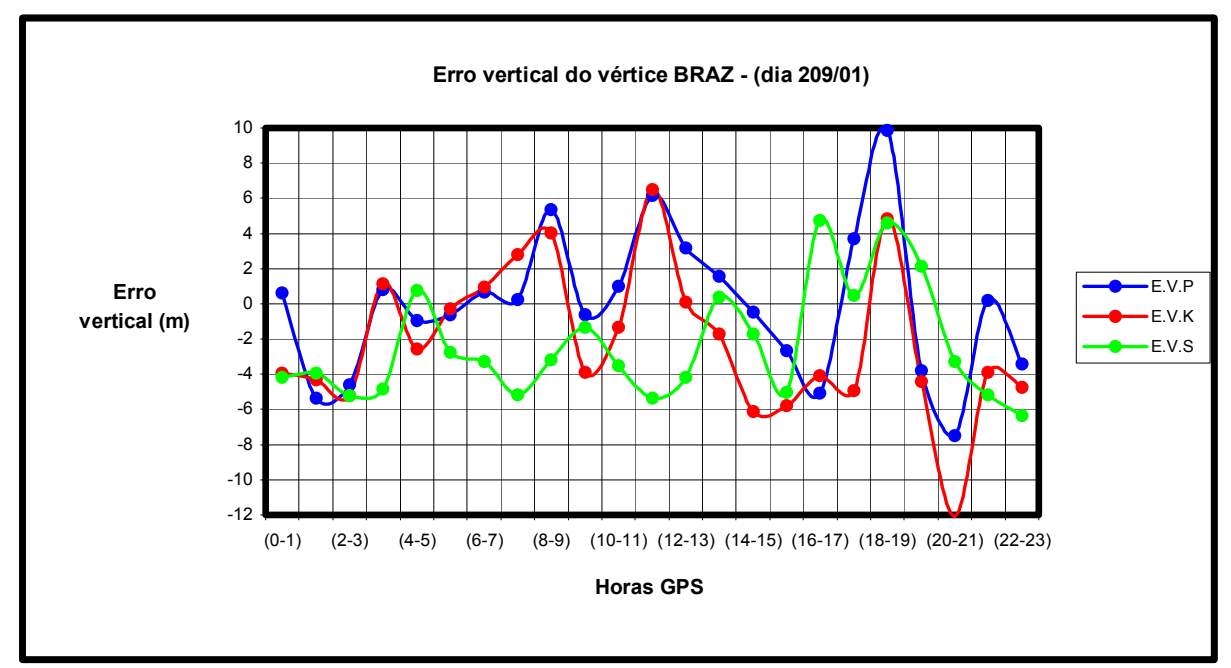

Figura 7.104 - Variação horária do erro vertical no posicionamento Single Point do vértice BRAZ - (dia 209/01)

Tabela 7.73 - Erro quadrático horizontal e erro vertical no processamento Single Point do vértice BRAZ para diferentes modelos ionosféricos - (dia 209/01).

\begin{tabular}{|c|c|c|c|c|c|c|}
\hline \multirow[b]{2}{*}{ Horas } & \multicolumn{3}{|c|}{ Erro Quadrático Horizontal (m) } & \multicolumn{3}{|c|}{ Erro Vertical (m) } \\
\hline & E.Q.H.P & E.Q.H.K & E.Q.H.S & E.V.P & E.V.K & E.V.S \\
\hline$(0-1)$ & 1,756 & 1,620 & 1,620 & 0,620 & $-3,928$ & $-4,178$ \\
\hline$(1-2)$ & 0,538 & 0,613 & 3,390 & $-5,351$ & $-4,300$ & $-3,928$ \\
\hline$(2-3)$ & 0,624 & 1,249 & 1,736 & $-4,592$ & $-5,205$ & $-5,201$ \\
\hline$(3-4)$ & 0,141 & 0,863 & 3,366 & 0,795 & 1,151 & $-4,851$ \\
\hline$(4-5)$ & 0,700 & 0,199 & 3,847 & $-0,971$ & $-2,545$ & 0,769 \\
\hline$(5-6)$ & 0,738 & 1,091 & 4,180 & $-0,619$ & $-0,289$ & $-2,771$ \\
\hline$(6-7)$ & 0,279 & 0,696 & 2,800 & 0,638 & 0,967 & $-3,281$ \\
\hline$(7-8)$ & 1,131 & 0,621 & 3,078 & 0,242 & 2,789 & $-5,160$ \\
\hline$(8-9)$ & 3,365 & 2,511 & 3,445 & 5,340 & 4,034 & $-3,201$ \\
\hline$(9-10)$ & 1,798 & 1,247 & 1,701 & $-0,634$ & $-3,872$ & $-1,321$ \\
\hline$(10-11)$ & 0,473 & 2,013 & 2,772 & 0,972 & $-1,356$ & $-3,501$ \\
\hline$(11-12)$ & 0,961 & 0,293 & 3,445 & 6,136 & 6,504 & $-5,341$ \\
\hline$(12-13)$ & 1,450 & 0,933 & 3,058 & 3,188 & 0,112 & $-4,181$ \\
\hline$(13-14)$ & 2,738 & 2,843 & 2,472 & 1,546 & $-1,705$ & 0,389 \\
\hline (14-15) & 0,833 & 1,227 & 3,804 & $-0,502$ & $-6,112$ & $-1,701$ \\
\hline$(15-16)$ & 1,238 & 3,853 & 1,787 & $-2,655$ & $-5,792$ & $-5,031$ \\
\hline$(16-17)$ & 0,876 & 1,480 & 2,763 & $-5,071$ & $-4,070$ & 4,719 \\
\hline$(17-18)$ & 2,409 & 0,926 & 1,703 & 3,687 & $-4,933$ & 0,472 \\
\hline$(18-19)$ & 1,128 & 1,770 & 3,924 & 9,860 & 4,814 & 4,610 \\
\hline$(19-20)$ & 1,831 & 4,141 & 2,481 & $-3,789$ & $-4,399$ & 2,120 \\
\hline$(20-21)$ & 1,806 & 3,890 & 2,013 & $-7,494$ & $-12,099$ & $-3,281$ \\
\hline$(21-22)$ & 3,340 & 2,728 & 3,504 & 0,187 & $-3,909$ & $-5,191$ \\
\hline$(22-23)$ & 3,762 & 2,349 & 1,977 & $-3,428$ & $-4,747$ & $-6,370$ \\
\hline E.M.Q & 1,475 & 1,702 & 2,820 & 2,970 & 3,897 & 3,546 \\
\hline Desvio Padra & $\pm 1,033$ & $\pm 1,157$ & $\pm 0,822$ & $\pm 4,037$ & $\pm 4,213$ & $\pm 3,168$ \\
\hline
\end{tabular}




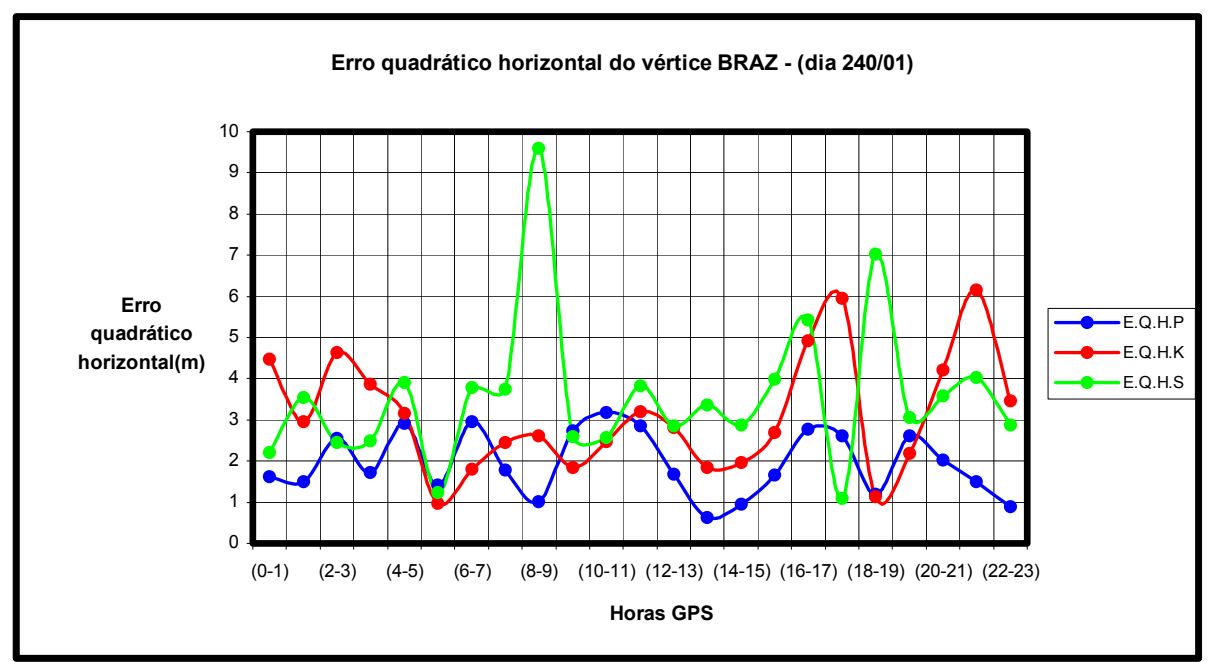

Figura 7.105 - Variação horária do erro quadrático horizontal no posicionamento Single Point do vértice BRAZ - (dia 240/01)

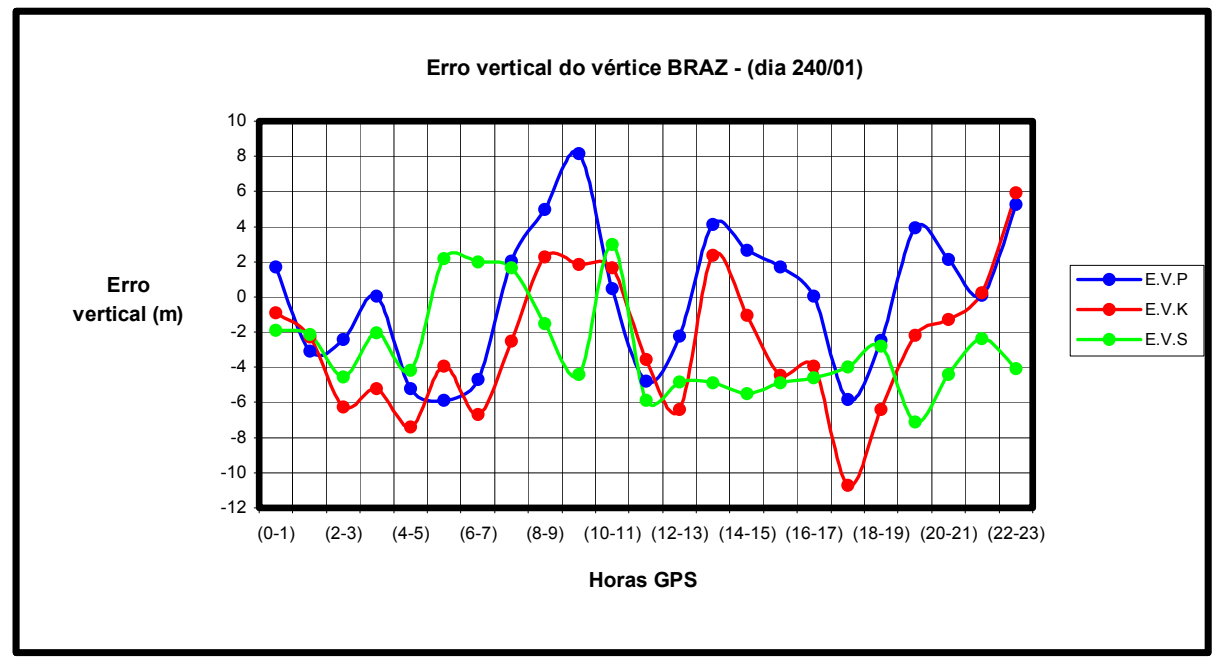

Figura 7.106 - Variação horária do erro vertical no posicionamento Single Point do vértice $B R A Z$ - (dia 240/01) 
Tabela 7.74 - Erro quadrático horizontal e erro vertical no processamento Single Point do vértice BRAZ para diferentes modelos ionosféricos - (dia 240/01).

\begin{tabular}{|c|c|c|c|c|c|c|}
\hline \multirow[b]{2}{*}{ Horas } & \multicolumn{3}{|c|}{ Erro Quadrático Horizontal (m) } & \multicolumn{3}{|c|}{ Erro Vertical (m) } \\
\hline & E.Q.H.P & E.Q.H.K & E.Q.H.S & E.V.P & E.V.K & E.V.S \\
\hline$(0-1)$ & 1,614 & 4,475 & 2,209 & 1,712 & $-0,910$ & $-1,903$ \\
\hline$(1-2)$ & 1,505 & 2,952 & 3,545 & $-3,087$ & $-2,272$ & $-2,143$ \\
\hline$(2-3)$ & 2,550 & 4,645 & 2,440 & $-2,405$ & $-6,242$ & $-4,549$ \\
\hline$(3-4)$ & 1,715 & 3,874 & 2,500 & 0,058 & $-5,217$ & $-2,032$ \\
\hline$(4-5)$ & 2,913 & 3,150 & 3,907 & $-5,220$ & $-7,378$ & $-4,186$ \\
\hline$(5-6)$ & 1,414 & 0,965 & 1,225 & $-5,888$ & $-3,947$ & 2,180 \\
\hline$(6-7)$ & 2,960 & 1,794 & 3,792 & $-4,706$ & $-6,702$ & 1,980 \\
\hline$(7-8)$ & 1,788 & 2,449 & 3,735 & 2,020 & $-2,532$ & 1,643 \\
\hline$(8-9)$ & 1,020 & 2,604 & 9,605 & 4,960 & 2,253 & $-1,530$ \\
\hline$(9-10)$ & 2,737 & 1,833 & 2,587 & 8,174 & 1,848 & $-4,398$ \\
\hline$(10-11)$ & 3,178 & 2,465 & 2,570 & 0,476 & 1,659 & 2,993 \\
\hline$(11-12)$ & 2,857 & 3,193 & 3,833 & $-4,791$ & $-3,541$ & $-5,868$ \\
\hline$(12-13)$ & 1,681 & 2,816 & 2,844 & $-2,226$ & $-6,388$ & $-4,825$ \\
\hline$(13-14)$ & 0,620 & 1,852 & 3,361 & 4,129 & 2,364 & $-4,893$ \\
\hline$(14-15)$ & 0,961 & 1,954 & 2,875 & 2,634 & $-1,059$ & $-5,490$ \\
\hline$(15-16)$ & 1,661 & 2,685 & 3,986 & 1,719 & $-4,473$ & $-4,865$ \\
\hline$(16-17)$ & 2,772 & 4,914 & 5,433 & 0,020 & $-3,947$ & $-4,611$ \\
\hline$(17-18)$ & 2,603 & 5,946 & 1,101 & $-5,830$ & $-10,721$ & $-3,965$ \\
\hline (18-19) & 1,190 & 1,137 & 7,021 & $-2,484$ & $-6,389$ & $-2,814$ \\
\hline$(19-20)$ & 2,613 & 2,192 & 3,063 & 3,953 & $-2,177$ & $-7,098$ \\
\hline$(20-21)$ & 2,017 & 4,213 & 3,578 & 2,125 & $-1,295$ & $-4,399$ \\
\hline$(21-22)$ & 1,504 & 6,163 & 4,020 & 0,086 & 0,223 & $-2,396$ \\
\hline$(22-23)$ & 0,896 & 3,459 & 2,877 & 5,240 & 5,942 & $-4,066$ \\
\hline E.M.Q & 1,946 & 3,119 & 3,570 & 3,215 & 3,890 & 3,688 \\
\hline Desvio Padrão & $\pm 0,773$ & $\pm 1,411$ & $\pm 1,810$ & $\pm 3,935$ & $\pm 3,912$ & $\pm 2,767$ \\
\hline
\end{tabular}

\subsubsection{Validação do modelo através de posicionamento relativo - período do inverno}

O modelo polinomial, se comparado com o período do outono, proporcionou resultados satisfatórios no posicionamento do vértice UEPP. Tanto horizontalmente quanto verticalmente, proporcionou resultados mais eficientes do que com a utilização dos modelos de Klobuchar e Standard.

Através dos gráficos que serão apresentados a seguir, percebe-se que o comportamento dos erros horizontais e verticais é semelhante no período das 0 às 15 horas GPS. Das 15 às 23 horas GPS, através do modelo polinomial, o erro no posicionamento do vértice UEPP reduziu de forma significativa. Isto pode ser verificado durante os 7 dias de processamento. Esta constatação também foi verificada durante as estações do verão e do outono. 
Esta melhora no posicionamento, principalmente no intervalo das 15 às 23, pode estar associado ao fato de se ter recriado um novo código, a possibilitar uma modelagem ionosférica mais eficiente através da solução lono Free.

Neste período do inverno, em média (horizontalmente e verticalmente), o modelo Standard mostrou-se mais eficiente que o de Klobuchar. Isto pode ser verificado através dos valores abaixo:

- E.M.Q.H.P $=0,499 m \pm 0,505 m$

- E.M.Q.H.K =0,676m $\pm 0,606 m$

- E.M.Q.H.S = 0,624m $\pm 0,419 m$

O modelo polinomial proporcionou, em média, uma melhora de $0,177 \mathrm{~m}$ e $0,125 \mathrm{~m}$, em relação aos modelos de Klobuchar e Standard, respectivamente.

Em relação ao erro vertical, os valores médios para o período foram:

- E.M.Q.V.P $=0,477 \mathrm{~m} \pm 0,588 \mathrm{~m}$

- E.M.Q.V.K =0,749m $\pm 0,817 m$

- E.M.Q.V.S = 0,694m $\pm 0,868 \mathrm{~m}$

A seguir serão apresentados todos os resultados referentes ao posicionamento relativo, durante o período do outono estudado.

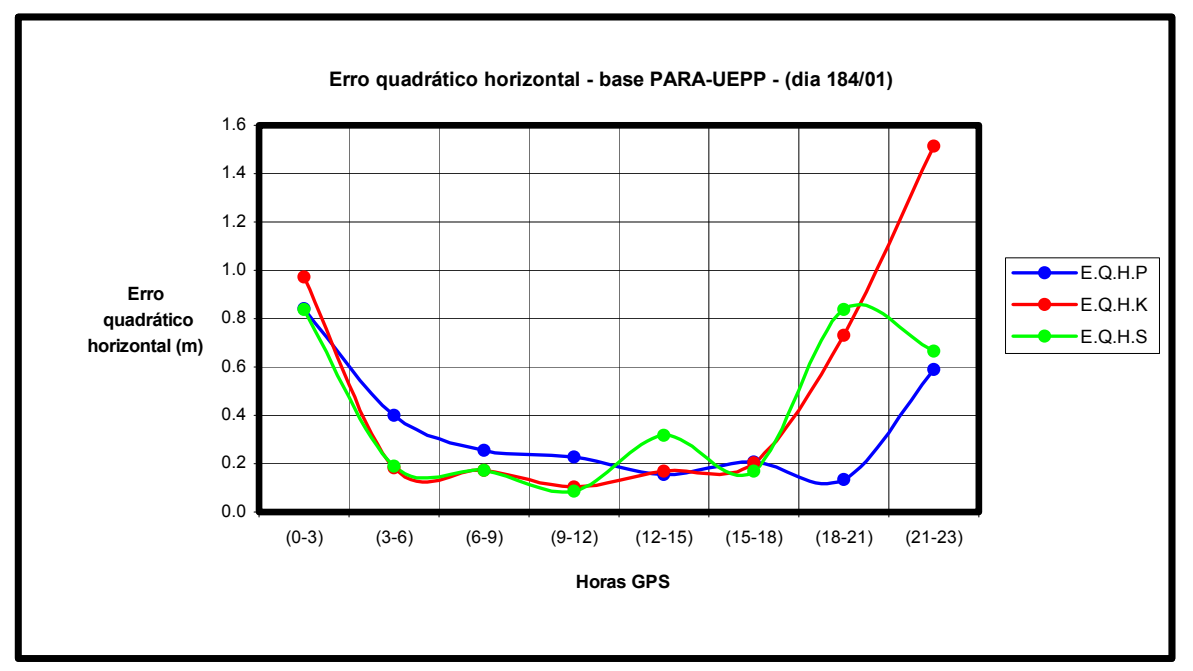

Figura 7.107 - Variação horária do erro quadrático horizontal do vértice UEPP no posicionamento relativo da base PARA - UEPP - (dia 184/01). 


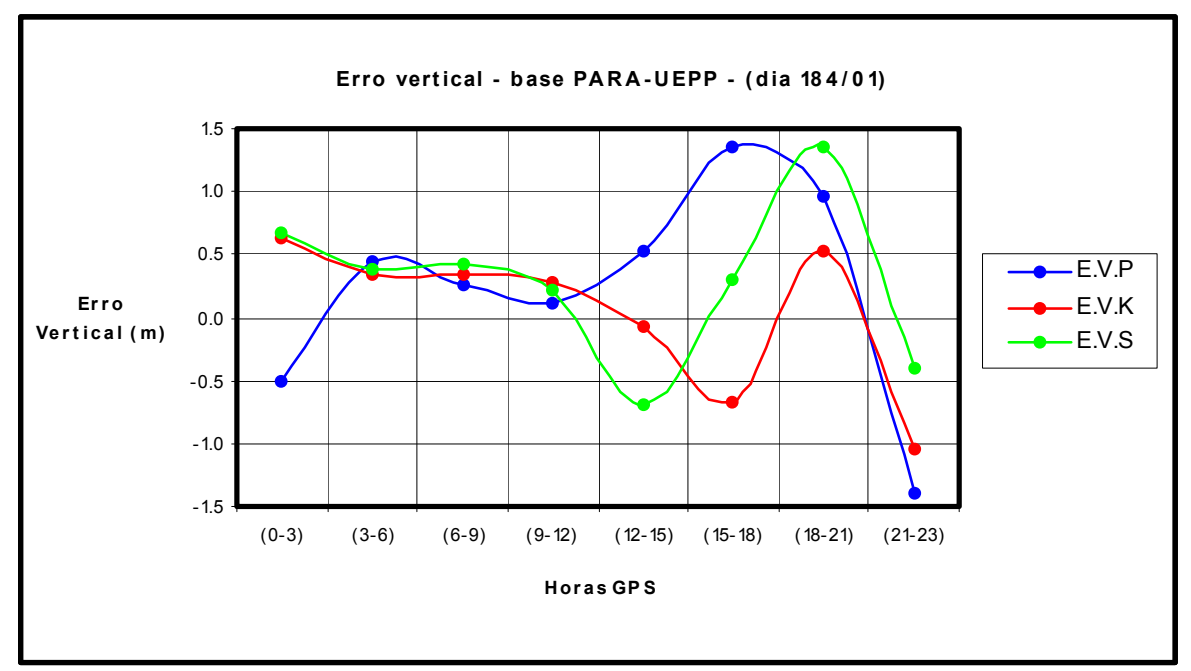

Figura 7.108 - Variação horária do erro vertical do vértice UEPP no posicionamento relativo da base PARA - UEPP - (dia 184/01).

Tabela 7.75 - Erro quadrático horizontal e erro vertical do vértice UEPP no processamento relativo da base PARA - UEPP, para diferentes modelos ionosféricos - (dia 184/01).

\begin{tabular}{|c|c|c|c|c|c|c|}
\cline { 2 - 7 } \multicolumn{1}{c|}{} & \multicolumn{3}{c|}{ Erro Quadrático Horizontal (m) } & \multicolumn{3}{c|}{ Erro Vertical (m) } \\
\hline Horas & E.Q.H.P & E.Q.H.K & E.Q.H.S & E.V.P & E.V.K & E.V.S \\
\hline $\mathbf{( 0 - 3 )}$ & 0,842 & 0,971 & 0,839 & $-0,504$ & 0,635 & 0,673 \\
\hline $\mathbf{( 3 - 6 )}$ & 0,400 & 0,182 & 0,190 & 0,452 & 0,339 & 0,380 \\
\hline $\mathbf{( 6 - 9 )}$ & 0,254 & 0,172 & 0,173 & 0,257 & 0,341 & 0,416 \\
\hline $\mathbf{( 9 - 1 2 )}$ & 0,227 & 0,103 & 0,087 & 0,112 & 0,277 & 0,225 \\
\hline $\mathbf{( 1 2 - 1 5 )}$ & 0,156 & 0,169 & 0,318 & 0,537 & $-0,067$ & $-0,697$ \\
\hline $\mathbf{( 1 5 - 1 8 )}$ & 0,208 & 0,203 & 0,170 & 1,354 & $-0,673$ & 0,292 \\
\hline $\mathbf{( 1 8 - 2 1 )}$ & 0,135 & 0,732 & 0,837 & 0,963 & 0,529 & 1,349 \\
\hline $\mathbf{( 2 1 - 2 3 )}$ & 0,591 & 1,513 & 0,667 & $-1,404$ & $-1,046$ & $-0,405$ \\
\hline E.M.Q & $\mathbf{0 , 3 5 2}$ & $\mathbf{0 , 5 0 6}$ & $\mathbf{0 , 4 1 0}$ & $\mathbf{0 , 6 9 8}$ & $\mathbf{0 , 4 8 8}$ & $\mathbf{0 , 5 5 5}$ \\
\hline Desvio Padrão & $\pm \mathbf{0 , 2 4 8}$ & $\pm \mathbf{0 , 5 1 6}$ & $\pm \mathbf{0 , 3 1 8}$ & $\pm \mathbf{0 , 8 5 9}$ & $\pm \mathbf{0 , 6 0 1}$ & $\pm \mathbf{0 , 6 2 7}$ \\
\hline
\end{tabular}




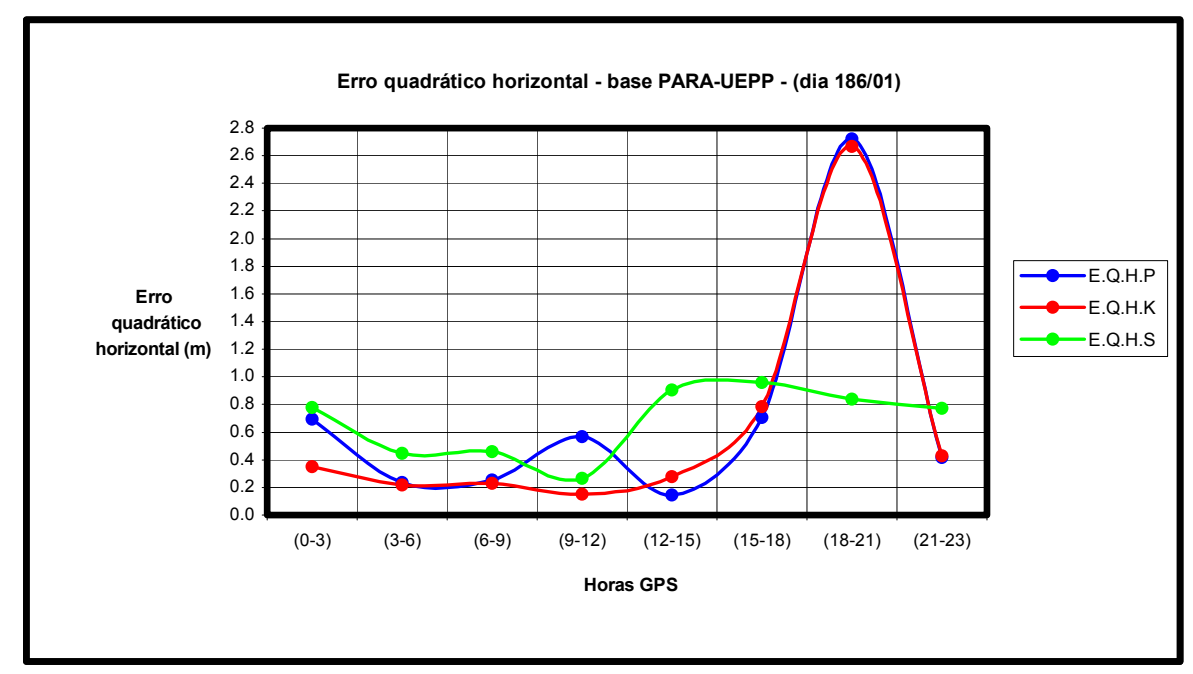

Figura 7.109 - Variação horária do erro quadrático horizontal do vértice UEPP no posicionamento relativo da base PARA - UEPP - (dia 186/01).

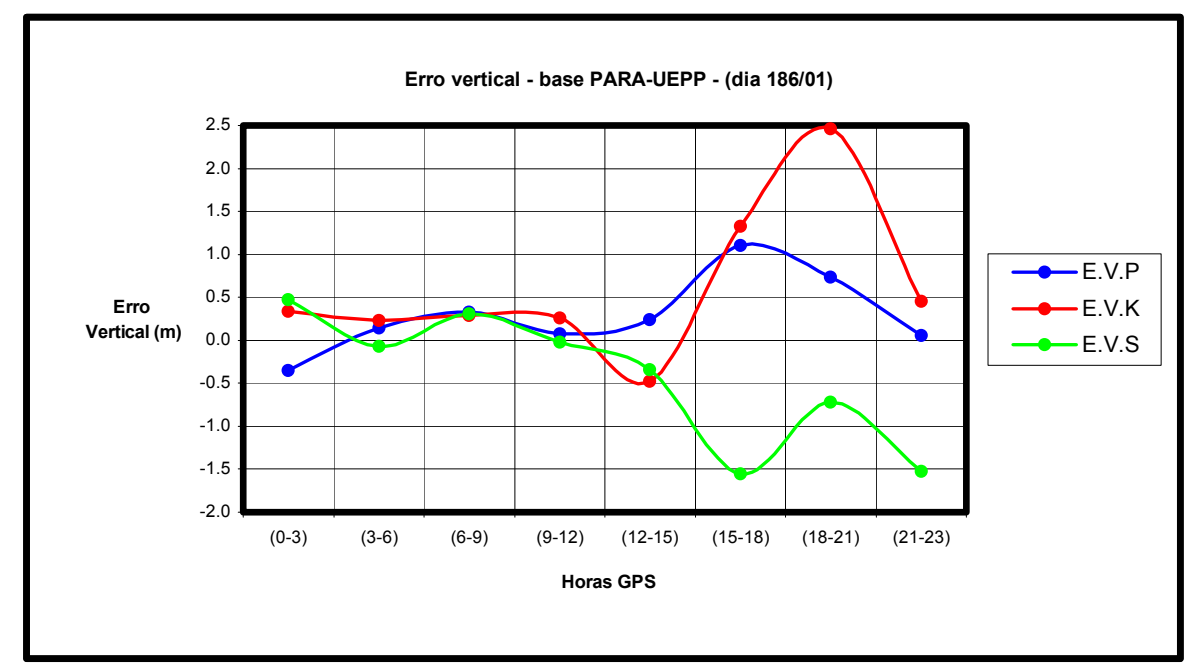

Figura 7.110 - Variação horária do erro vertical do vértice UEPP no posicionamento relativo da base PARA - UEPP - (dia 186/01).

Tabela 7.76 - Erro quadrático horizontal e erro vertical do vértice UEPP no processamento relativo da base PARA - UEPP, para diferentes modelos ionosféricos - (dia 186/01).

\begin{tabular}{|c|c|c|c|c|c|c|}
\cline { 2 - 7 } \multicolumn{1}{c|}{} & \multicolumn{3}{c|}{ Erro Quadrático Horizontal (m) } & \multicolumn{3}{c|}{ Erro Vertical (m) } \\
\hline Horas & E.Q.H.P & E.Q.H.K & E.Q.H.S & E.V.P & E.V.K & E.V.S \\
\hline $\mathbf{( 0 - 3 )}$ & 0,695 & 0,352 & 0,776 & $-0,349$ & 0,336 & 0,470 \\
\hline $\mathbf{( 3 - 6 )}$ & 0,238 & 0,215 & 0,449 & 0,139 & 0,226 & $-0,073$ \\
\hline $\mathbf{( 6 - 9 )}$ & 0,252 & 0,231 & 0,457 & 0,332 & 0,285 & 0,312 \\
\hline $\mathbf{( 9 - 1 2 )}$ & 0,568 & 0,149 & 0,268 & 0,071 & 0,257 & $-0,024$ \\
\hline $\mathbf{( 1 2 - 1 5 )}$ & 0,147 & 0,280 & 0,904 & 0,240 & $-0,475$ & $-0,337$ \\
\hline $\mathbf{( 1 5 - 1 8 )}$ & 0,704 & 0,787 & 0,957 & 1,108 & 1,331 & $-1,555$ \\
\hline $\mathbf{( 1 8 - 2 1 )}$ & 2,720 & 2,668 & 0,840 & 0,739 & 2,459 & $-0,721$ \\
\hline $\mathbf{( 2 1 - 2 3 )}$ & 0,417 & 0,431 & 0,774 & 0,060 & 0,454 & $-1,522$ \\
\hline E.M.Q & $\mathbf{0 , 7 1 7}$ & $\mathbf{0 , 6 3 9}$ & $\mathbf{0 , 6 7 8}$ & $\mathbf{0 , 3 8 0}$ & $\mathbf{0 , 7 2 8}$ & $\mathbf{0 , 6 2 7}$ \\
\hline Desvio Padrão & $\pm \mathbf{0 , 8 3 6}$ & $\pm \mathbf{0 , 8 4 4}$ & $\pm \mathbf{0 , 2 5 2}$ & $\pm \mathbf{0 , 4 4 8}$ & $\pm \mathbf{0 , 8 9 4}$ & $\pm \mathbf{0 , 7 7 5}$ \\
\hline
\end{tabular}




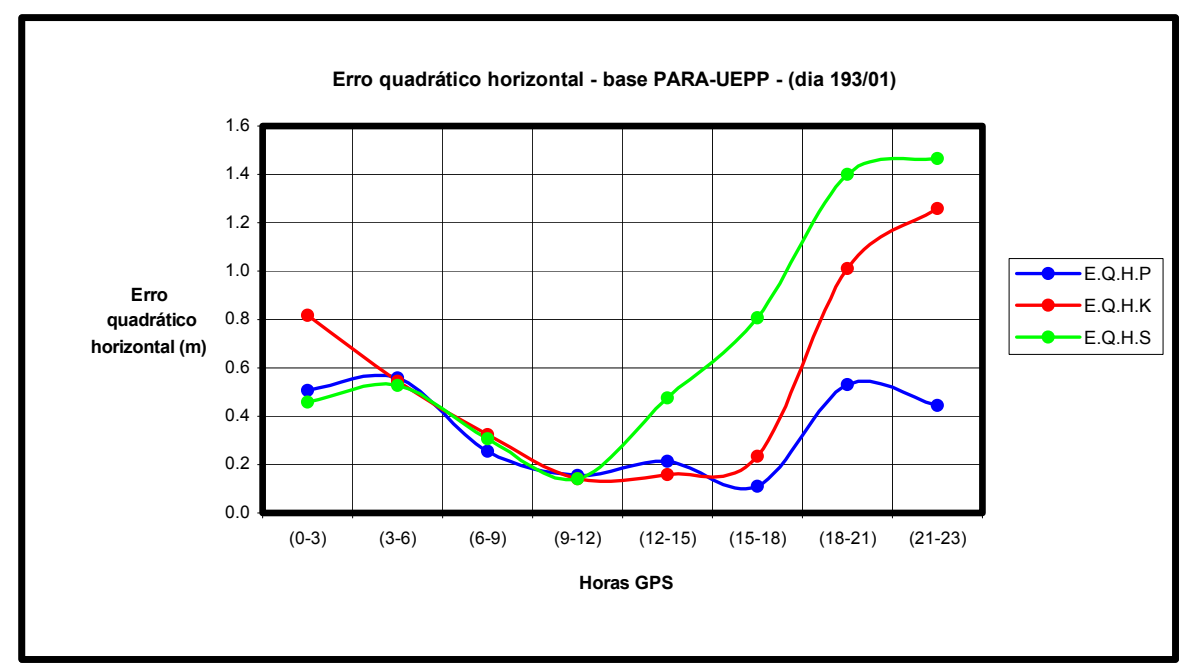

Figura 7.111 - Variação horária do erro quadrático horizontal do vértice UEPP no posicionamento relativo da base PARA - UEPP - (dia 193/01).

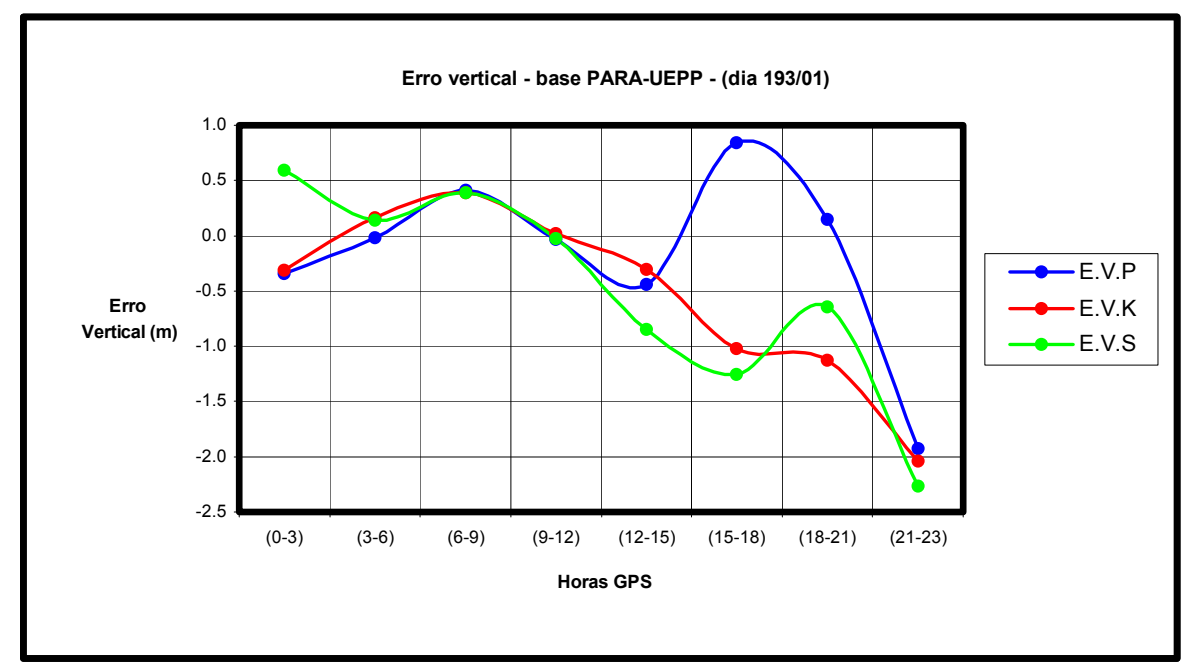

Figura 7.112 - Variação horária do erro vertical do vértice UEPP no posicionamento relativo da base PARA - UEPP - (dia 193/01).

Tabela 7.77 - Erro quadrático horizontal e erro vertical do vértice UEPP no processamento relativo da base PARA - UEPP, para diferentes modelos ionosféricos - (dia 193/01).

\begin{tabular}{|c|c|c|c|c|c|c|}
\cline { 2 - 7 } \multicolumn{1}{c|}{} & \multicolumn{3}{c|}{ Erro Quadrático Horizontal (m) } & \multicolumn{3}{c|}{ Erro Vertical (m) } \\
\hline Horas & E.Q.H.P & E.Q.H.K & E.Q.H.S & E.V.P & E.V.K & E.V.S \\
\hline $\mathbf{( 0 - 3 )}$ & 0,507 & 0,818 & 0,458 & $-0,339$ & $-0,313$ & 0,592 \\
\hline $\mathbf{( 3 - 6 )}$ & 0,557 & 0,545 & 0,529 & $-0,022$ & 0,165 & 0,140 \\
\hline $\mathbf{( 6 - 9 )}$ & 0,254 & 0,324 & 0,306 & 0,410 & 0,390 & 0,389 \\
\hline $\mathbf{( 9 - 1 2 )}$ & 0,156 & 0,142 & 0,142 & $-0,035$ & 0,017 & $-0,027$ \\
\hline$(\mathbf{1 2 - 1 5})$ & 0,213 & 0,158 & 0,477 & $-0,437$ & $-0,307$ & $-0,850$ \\
\hline $\mathbf{( 1 5 - 1 8 )}$ & 0,109 & 0,233 & 0,808 & 0,840 & $-1,025$ & $-1,252$ \\
\hline $\mathbf{( 1 8 - 2 1 )}$ & 0,530 & 1,011 & 1,400 & 0,148 & $-1,127$ & $-0,647$ \\
\hline $\mathbf{( 2 1 - 2 3 )}$ & 0,444 & 1,259 & 1,467 & $-1,929$ & $-2,041$ & $-2,268$ \\
\hline E.M.Q & $\mathbf{0 , 3 4 6}$ & $\mathbf{0 , 5 6 1}$ & $\mathbf{0 , 6 9 8}$ & $\mathbf{0 , 5 2 0}$ & $\mathbf{0 , 6 7 3}$ & $\mathbf{0 , 7 7 1}$ \\
\hline Desvio Padrão & $\pm \mathbf{0 , 1 8 2}$ & $\pm \mathbf{0 , 4 2 4}$ & $\pm \mathbf{0 , 4 9 2}$ & $\pm \mathbf{0 , 8 1 9}$ & $\pm \mathbf{0 , 8 1 2}$ & $\pm \mathbf{0 , 9 6 0}$ \\
\hline
\end{tabular}




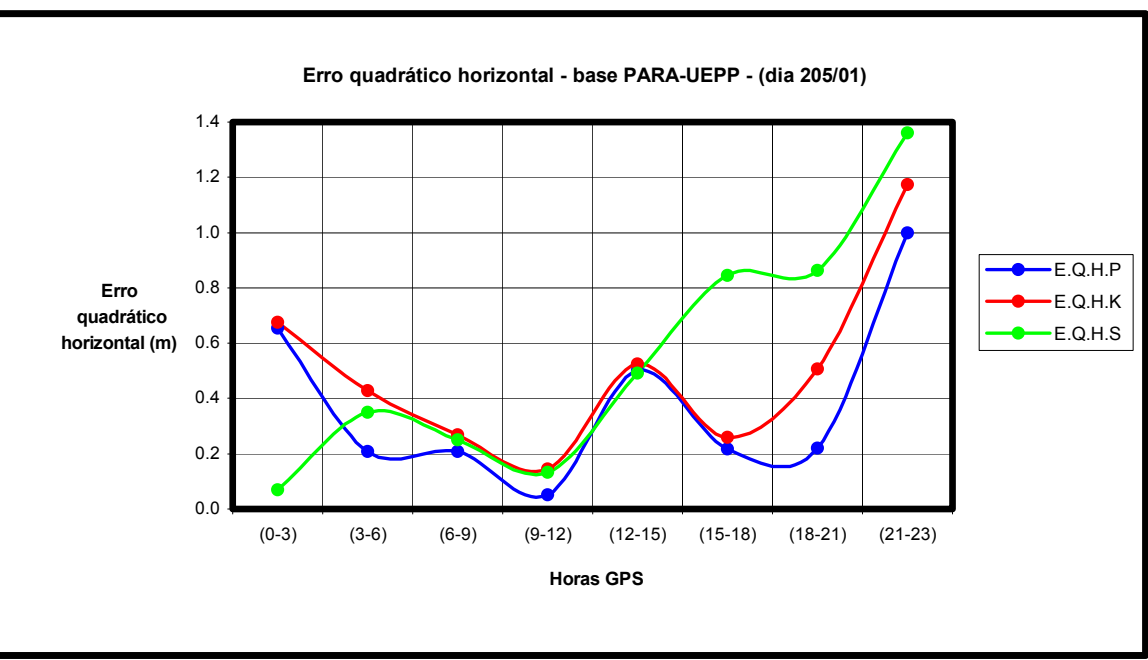

Figura 7.113 - Variação horária do erro quadrático horizontal do vértice UEPP no posicionamento relativo da base PARA - UEPP - (dia 205/01).

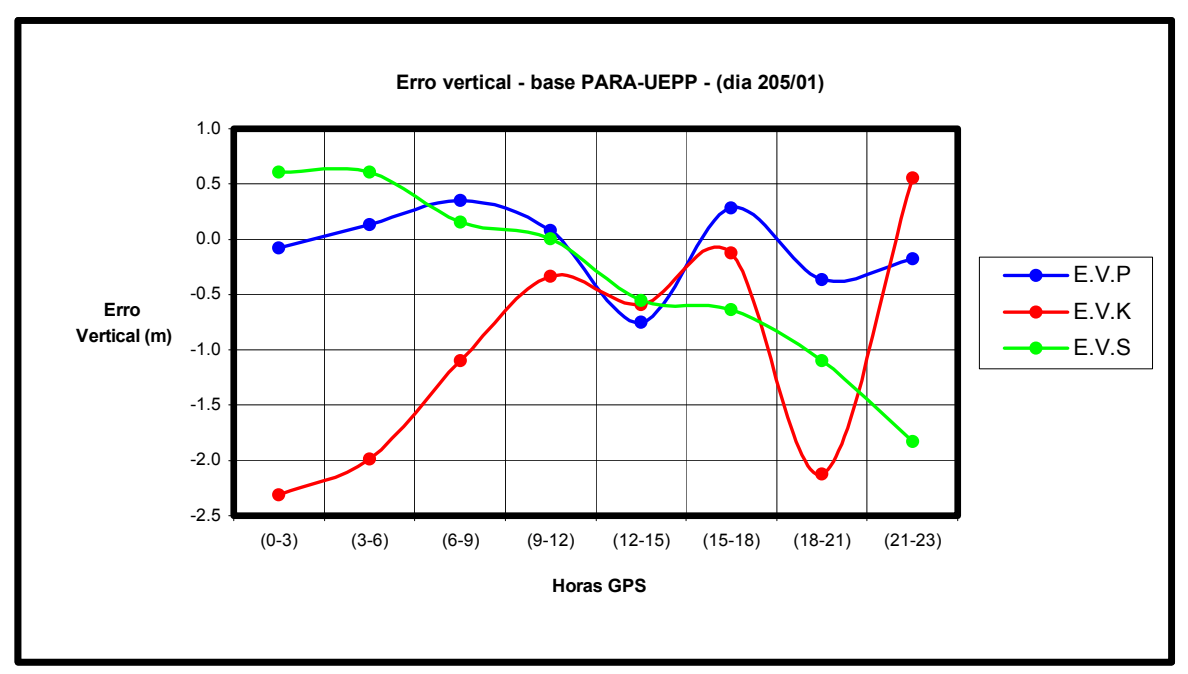

Figura 7.114 - Variação horária do erro vertical do vértice UEPP no posicionamento relativo da base PARA - UEPP - (dia 205/01).

Tabela 7.78 - Erro quadrático horizontal e erro vertical do vértice UEPP no processamento relativo da base PARA - UEPP, para diferentes modelos ionosféricos - (dia 205/01).

\begin{tabular}{|c|c|c|c|c|c|c|}
\cline { 2 - 7 } \multicolumn{1}{c|}{} & \multicolumn{3}{c|}{ Erro Quadrático Horizontal (m) } & \multicolumn{3}{c|}{ Erro Vertical (m) } \\
\hline Horas & E.Q.H.P & E.Q.H.K & E.Q.H.S & E.V.P & E.V.K & E.V.S \\
\hline $\mathbf{( 0 - 3 )}$ & 0,655 & 0,677 & 0,068 & $-0,081$ & $-2,312$ & 0,607 \\
\hline $\mathbf{( 3 - 6 )}$ & 0,207 & 0,428 & 0,350 & 0,131 & $-1,985$ & 0,607 \\
\hline $\mathbf{( 6 - 9 )}$ & 0,208 & 0,267 & 0,250 & 0,354 & $-1,097$ & 0,153 \\
\hline $\mathbf{( 9 - 1 2 )}$ & 0,051 & 0,145 & 0,133 & 0,082 & $-0,334$ & 0,004 \\
\hline $\mathbf{( 1 2 - 1 5 )}$ & 0,499 & 0,525 & 0,491 & $-0,748$ & $-0,590$ & $-0,551$ \\
\hline $\mathbf{( 1 5 - 1 8 )}$ & 0,219 & 0,258 & 0,844 & 0,282 & $-0,123$ & $-0,639$ \\
\hline $\mathbf{( 1 8 - 2 1 )}$ & 0,221 & 0,508 & 0,863 & $-0,363$ & $-2,120$ & $-1,099$ \\
\hline $\mathbf{( 2 1 - 2 3 )}$ & 0,998 & 1,173 & 1,361 & $-0,178$ & 0,553 & $-1,829$ \\
\hline E.M.Q & $\mathbf{0 , 3 8 2}$ & $\mathbf{0 , 4 9 8}$ & $\mathbf{0 , 5 4 5}$ & $\mathbf{0 , 2 7 7}$ & $\mathbf{1 , 1 3 9}$ & $\mathbf{0 , 6 8 6}$ \\
\hline Desvio Padrão & $\pm \mathbf{0 , 3 1 4}$ & $\pm \mathbf{0 , 3 2 2}$ & $\pm \mathbf{0 , 4 4 4}$ & $\pm \mathbf{0 , 3 6 3}$ & $\pm \mathbf{1 , 0 5 2}$ & $\pm \mathbf{0 , 8 5 2}$ \\
\hline
\end{tabular}




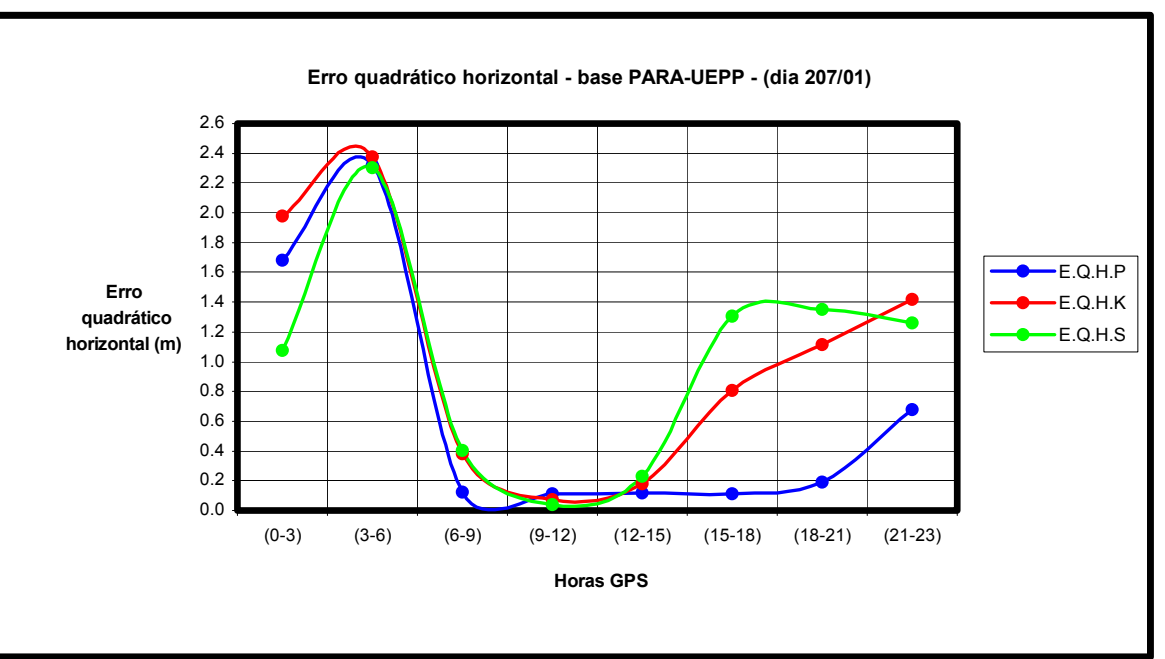

Figura 7.115 - Variação horária do erro quadrático horizontal do vértice UEPP no posicionamento relativo da base PARA - UEPP - (dia 207/01).

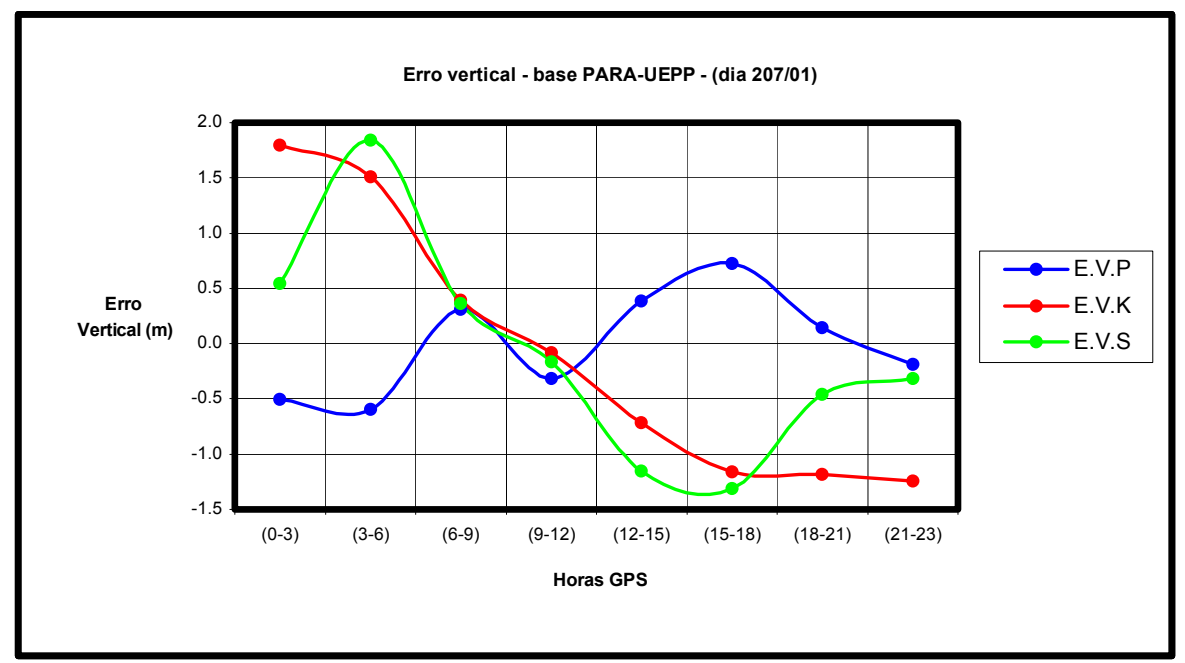

Figura 7.116 - Variação horária do erro vertical do vértice UEPP no posicionamento relativo da base PARA - UEPP - (dia 207/01).

Tabela 7.79 - Erro quadrático horizontal e erro vertical do vértice UEPP no processamento relativo da base PARA - UEPP, para diferentes modelos ionosféricos - (dia 207/01).

\begin{tabular}{|c|c|c|c|c|c|c|}
\cline { 2 - 7 } \multicolumn{1}{c|}{} & \multicolumn{3}{c|}{ Erro Quadrático Horizontal (m) } & \multicolumn{3}{c|}{ Erro Vertical (m) } \\
\hline Horas & E.Q.H.P & E.Q.H.K & E.Q.H.S & E.V.P & E.V.K & E.V.S \\
\hline $\mathbf{( 0 - 3 )}$ & 1.679 & 1.979 & 1.076 & -0.507 & 1.799 & 0.545 \\
\hline $\mathbf{( 3 - 6 )}$ & 2.321 & 2.375 & 2.305 & -0.594 & 1.511 & 1.841 \\
\hline $\mathbf{( 6 - 9 )}$ & 0.124 & 0.381 & 0.405 & 0.308 & 0.390 & 0.360 \\
\hline $\mathbf{( 9 - 1 2 )}$ & 0.109 & 0.072 & 0.038 & -0.315 & -0.083 & -0.164 \\
\hline $\mathbf{( 1 2 - 1 5 )}$ & 0.118 & 0.179 & 0.228 & 0.385 & -0.713 & -1.150 \\
\hline $\mathbf{( 1 5 - 1 8 )}$ & 0.115 & 0.806 & 1.304 & 0.724 & -1.162 & -1.313 \\
\hline $\mathbf{( 1 8 - 2 1 )}$ & 0.191 & 1.113 & 1.351 & 0.143 & -1.186 & -0.457 \\
\hline $\mathbf{( 2 1 - 2 3 )}$ & 0.677 & 1.416 & 1.261 & -0.185 & -1.245 & -0.314 \\
\hline E.M.Q & $\mathbf{0 . 6 6 7}$ & $\mathbf{1 . 0 4 0}$ & $\mathbf{0 . 9 9 6}$ & $\mathbf{0 . 3 9 5}$ & $\mathbf{1 . 0 1 1}$ & $\mathbf{0 . 7 6 8}$ \\
\hline Desvio Padrão & $\pm \mathbf{0 . 8 6 2}$ & $\pm \mathbf{0 . 8 4 3}$ & $\pm \mathbf{0 . 7 4 3}$ & $\pm \mathbf{0 . 4 6 8}$ & $\pm \mathbf{1 . 2 2 1}$ & $\pm \mathbf{1 . 0 1 0}$ \\
\hline
\end{tabular}




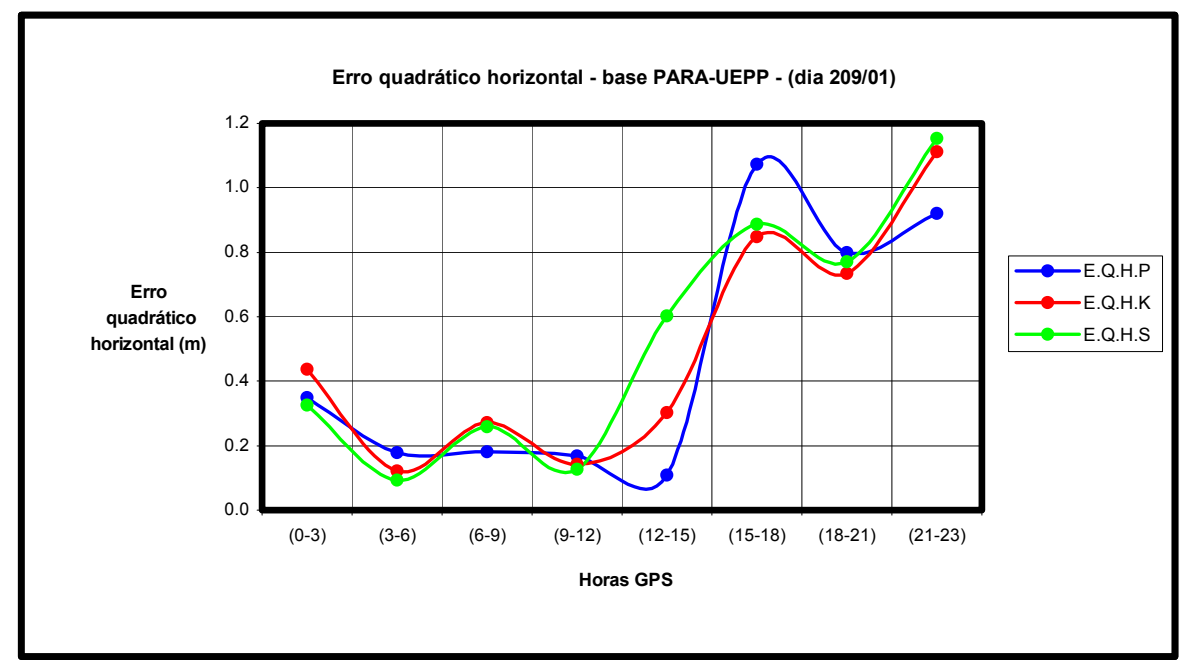

Figura 7.117 - Variação horária do erro quadrático horizontal do vértice UEPP no posicionamento relativo da base PARA - UEPP - (dia 209/01).

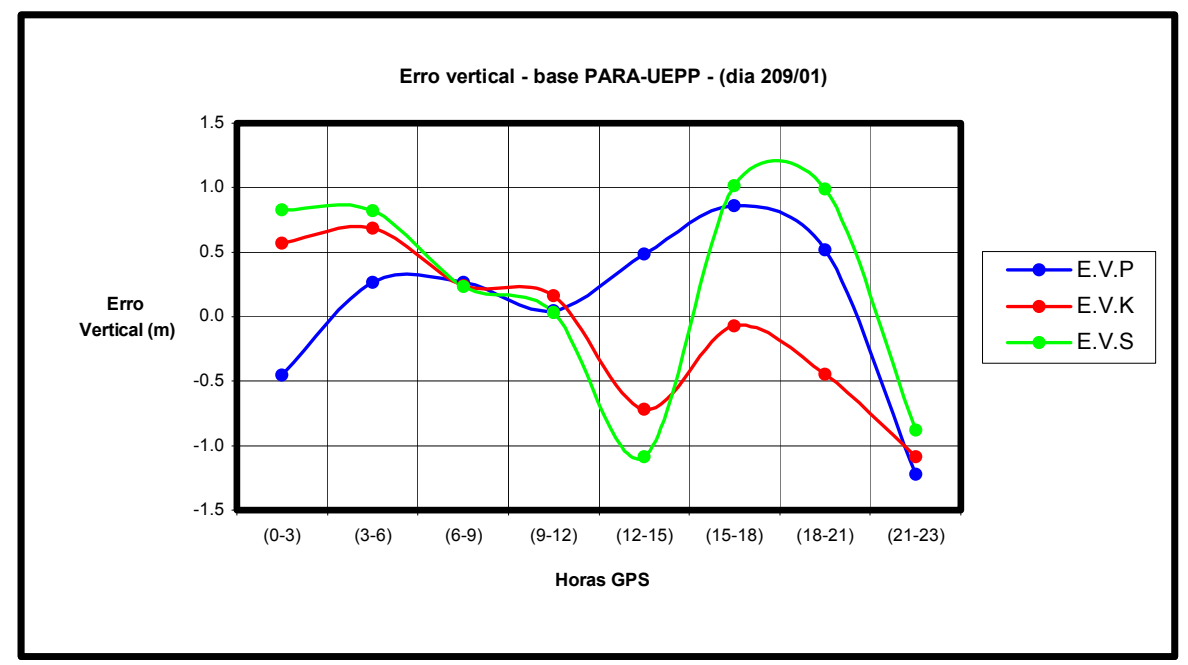

Figura 7.118 - Variação horária do erro vertical do vértice UEPP no posicionamento relativo da base PARA - UEPP - (dia 209/01).

Tabela 7.80 - Erro quadrático horizontal e erro vertical do vértice UEPP no processamento relativo da base PARA - UEPP, para diferentes modelos ionosféricos - (dia 209/01).

\begin{tabular}{|c|c|c|c|c|c|c|}
\cline { 2 - 7 } \multicolumn{1}{c|}{} & \multicolumn{3}{c|}{ Erro Quadrático Horizontal (m) } & \multicolumn{3}{c|}{ Erro Vertical (m) } \\
\hline Horas & E.Q.H.P & E.Q.H.K & E.Q.H.S & E.V.P & E.V.K & E.V.S \\
\hline $\mathbf{( 0 - 3 )}$ & 0,350 & 0,438 & 0,325 & $-0,455$ & 0,570 & 0,825 \\
\hline $\mathbf{( 3 - 6 )}$ & 0,179 & 0,122 & 0,092 & 0,267 & 0,683 & 0,821 \\
\hline $\mathbf{( 6 - 9 )}$ & 0,181 & 0,271 & 0,259 & 0,265 & 0,242 & 0,233 \\
\hline $\mathbf{( 9 - 1 2 )}$ & 0,168 & 0,143 & 0,126 & 0,048 & 0,163 & 0,033 \\
\hline$(\mathbf{1 2 - 1 5 )}$ & 0,109 & 0,303 & 0,604 & 0,488 & $-0,715$ & $-1,086$ \\
\hline$(\mathbf{1 5 - 1 8})$ & 1,074 & 0,848 & 0,887 & 0,860 & $-0,069$ & 1,014 \\
\hline $\mathbf{( 1 8 - 2 1 )}$ & 0,798 & 0,736 & 0,770 & 0,516 & $-0,446$ & 0,989 \\
\hline $\mathbf{( 2 1 - 2 3 )}$ & 0,921 & 1,112 & 1,154 & $-1,223$ & $-1,086$ & $-0,882$ \\
\hline E.M.Q & $\mathbf{0 , 4 7 2}$ & $\mathbf{0 , 4 9 7}$ & $\mathbf{0 , 5 2 7}$ & $\mathbf{0 , 5 1 5}$ & $\mathbf{0 , 4 9 7}$ & $\mathbf{0 , 7 3 5}$ \\
\hline Desvio Padrão & $\pm \mathbf{0 , 3 9 3}$ & $\pm \mathbf{0 , 3 6 2}$ & $\pm \mathbf{0 , 3 8 7}$ & $\pm \mathbf{0 , 6 5 7}$ & $\pm \mathbf{0 , 6 2 3}$ & $\pm \mathbf{0 , 8 3 7}$ \\
\hline
\end{tabular}




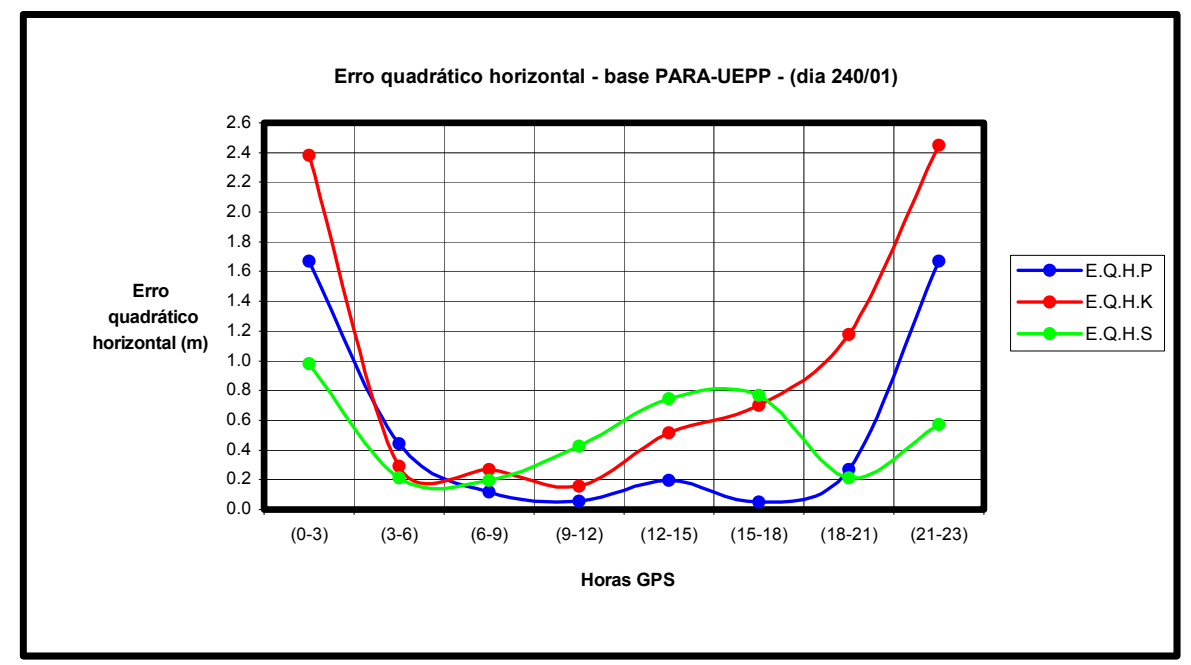

Figura 7.119 - Variação horária do erro quadrático horizontal do vértice UEPP no posicionamento relativo da base PARA - UEPP - (dia 240/01).

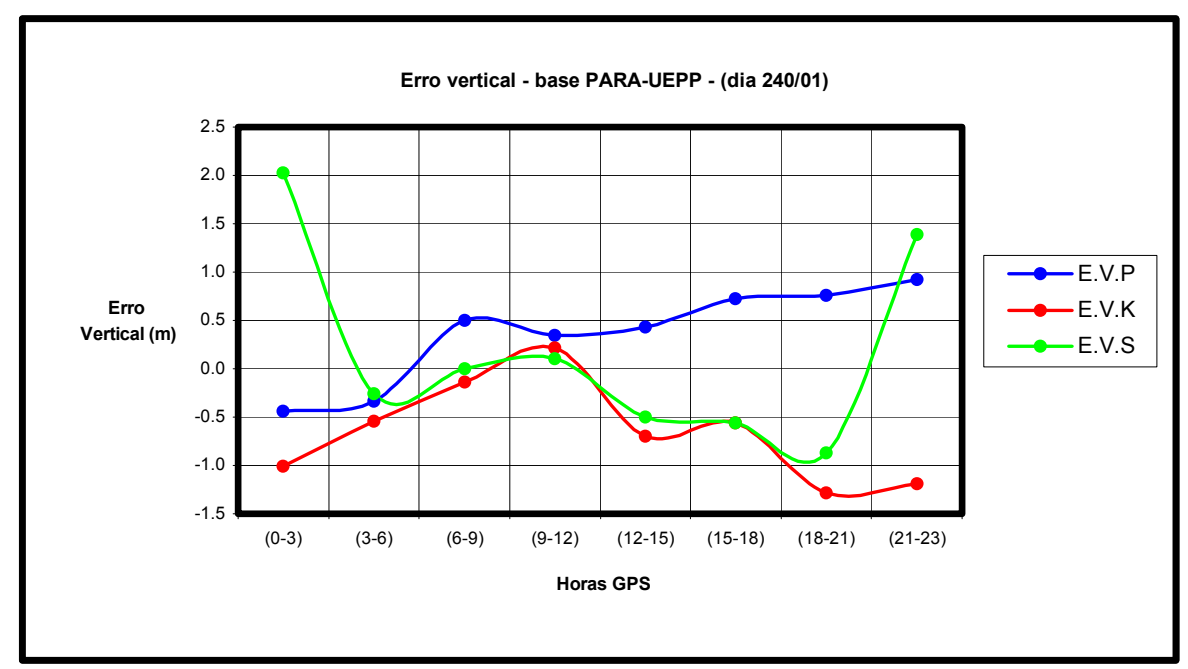

Figura 7.120 - Variação horária do erro vertical do vértice UEPP no posicionamento relativo da base PARA - UEPP - (dia 240/01).

Tabela 7.81 - Erro quadrático horizontal e erro vertical do vértice UEPP no processamento relativo da base PARA - UEPP, para diferentes modelos ionosféricos - (dia 240/01).

\begin{tabular}{|c|c|c|c|c|c|c|}
\cline { 2 - 7 } \multicolumn{1}{c|}{} & \multicolumn{3}{c|}{ Erro Quadrático Horizontal (m) } & \multicolumn{3}{c|}{ Erro Vertical (m) } \\
\hline Horas & E.Q.H.P & E.Q.H.K & E.Q.H.S & E.V.P & E.V.K & E.V.S \\
\hline $\mathbf{( 0 - 3 )}$ & 1,671 & 2,379 & 0,981 & $-0,437$ & $-1,008$ & 2,028 \\
\hline $\mathbf{( 3 - 6 )}$ & 0,441 & 0,292 & 0,213 & $-0,333$ & $-0,547$ & $-0,260$ \\
\hline $\mathbf{( 6 - 9 )}$ & 0,115 & 0,271 & 0,197 & 0,496 & $-0,139$ & 0,001 \\
\hline $\mathbf{( 9 - 1 2 )}$ & 0,054 & 0,158 & 0,425 & 0,345 & 0,218 & 0,106 \\
\hline$(\mathbf{1 2 - 1 5 )}$ & 0,197 & 0,515 & 0,743 & 0,427 & $-0,701$ & $-0,497$ \\
\hline$(\mathbf{1 5 - 1 8})$ & 0,053 & 0,700 & 0,766 & 0,728 & $-0,563$ & $-0,563$ \\
\hline $\mathbf{( 1 8 - 2 1 )}$ & 0,268 & 1,175 & 0,215 & 0,759 & $-1,285$ & $-0,867$ \\
\hline $\mathbf{( 2 1 - 2 3 )}$ & 1,672 & 2,449 & 0,574 & 0,926 & $-1,188$ & 1,384 \\
\hline E.M.Q & $\mathbf{0 , 5 5 9}$ & $\mathbf{0 , 9 9 2}$ & $\mathbf{0 , 5 1 4}$ & $\mathbf{0 , 5 5 6}$ & $\mathbf{0 , 7 0 6}$ & $\mathbf{0 , 7 1 3}$ \\
\hline Desvio Padrão & $\pm \mathbf{0 , 6 9 8}$ & $\pm \mathbf{0 , 9 3 3}$ & $\pm \mathbf{0 , 2 9 9}$ & $\pm \mathbf{0 , 5 0 1}$ & $\pm \mathbf{0 , 5 1 5}$ & $\pm \mathbf{1 , 0 1 4}$ \\
\hline
\end{tabular}




\subsection{Coeficientes do modelo referentes ao período da primavera}

Neste último período de cálculos, ao longo do dia, o comportamento dos coeficientes manteve-se semelhante em relação ao verão, ao outono e ao inverno. Os valores dos mesmos permanecem constantes até próximo às 17 horas GPS e, após este horário, percebe-se variações aleatórias até às 20 horas GPS.

O comportamento sazonal da ionosfera, também fica bastante evidenciado, quando se analisa o valor do coeficiente $C_{1}$, cuja média do período foi de 18,077 . Os valores dos demais coeficientes e suas respectivas variações podem ser verificados através das figuras 7.121 a 7.131 e das tabelas 7.82 a 7.92 .

Novamente, a estação de Manaus participou do processo de ajustamento dos coeficientes. Os valores dos desvios padrão foram semelhantes aos encontrados no período do inverno e maiores que os encontrados nas estações do verão e outono. Este fato, mesmo ao trabalhar com uma modelagem matemática, que propicia uma filtragem das observações, mostra que a concentração de elétrons livres na ionosfera é bastante evidenciada na região Amazônica. Um teste foi realizado no processo de determinação dos parâmetros, sem a presença da estação de Manaus, e constatou-se que, os valores dos desvios padrão foram semelhantes que nas estações do verão e do outono. Este indício pode ser verificado nos valores dos coeficientes referentes ao dia 323 , conforme mostra a Tabela 7.89.

No que se refere ao ajustamento seqüencial, o índice de rejeição das observáveis foi semelhante aos períodos do verão, outono e primavera, de, aproximadamente, $34 \%$.

A seguir, serão apresentados todos os resultados do processamento dos coeficientes, no período do inverno estudado.

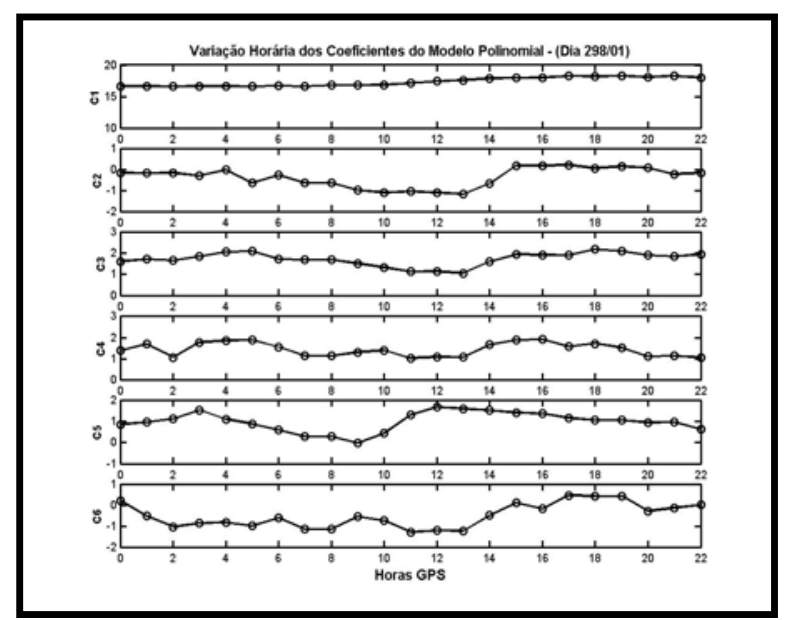

Figura 7.121 - Variação horária dos coeficientes do modelo polinomial (dia 298/01)

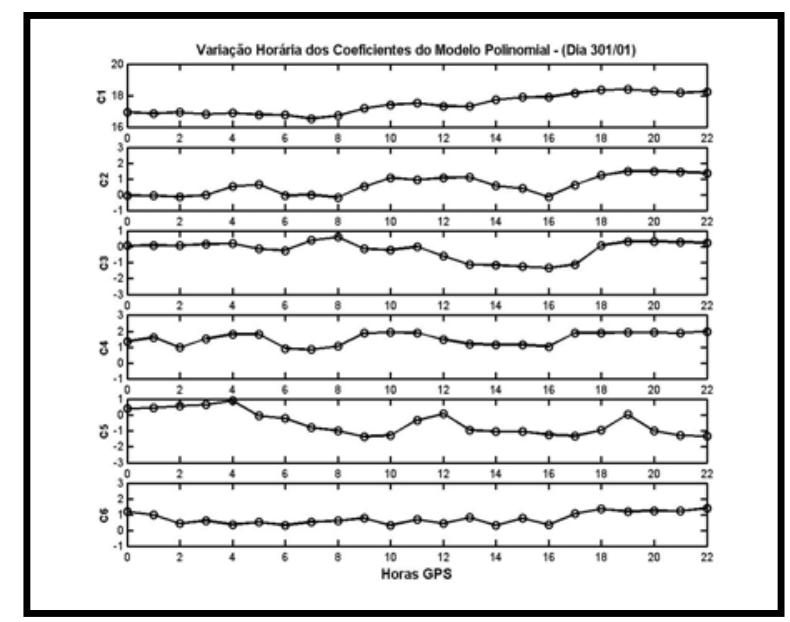

Figura 7.122 - Variação horária dos coeficientes do modelo polinomial (dia 301/01) 


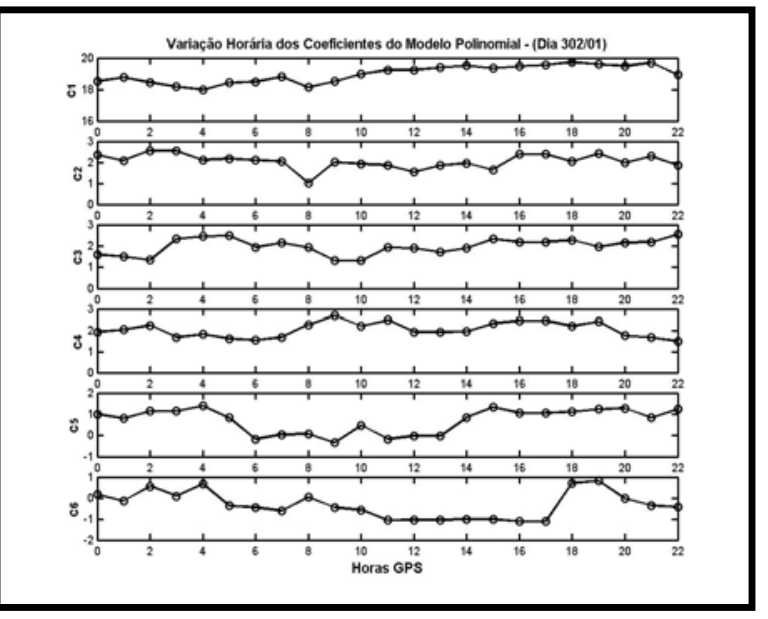

Figura 7.123 - Variação horária dos coeficientes do modelo polinomial (dia 302/01)

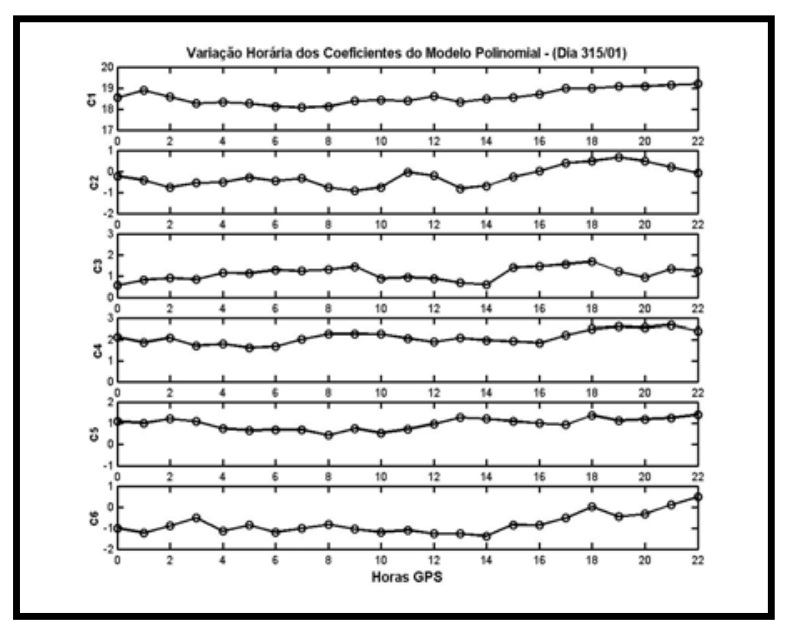

Figura 7.125 - Variação horária dos coeficientes do modelo polinomial (dia 315/01)

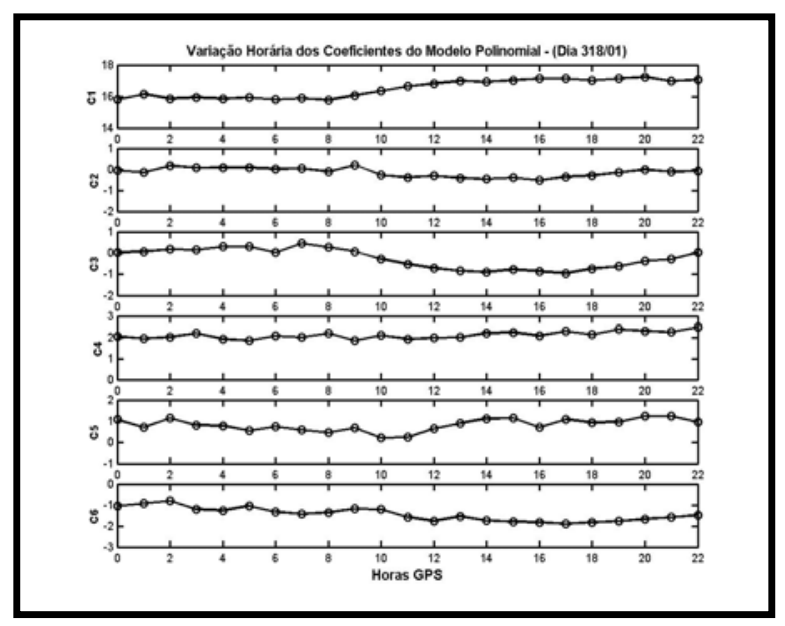

Figura 7.127 - Variação horária dos coeficientes do modelo polinomial (dia 318/01)

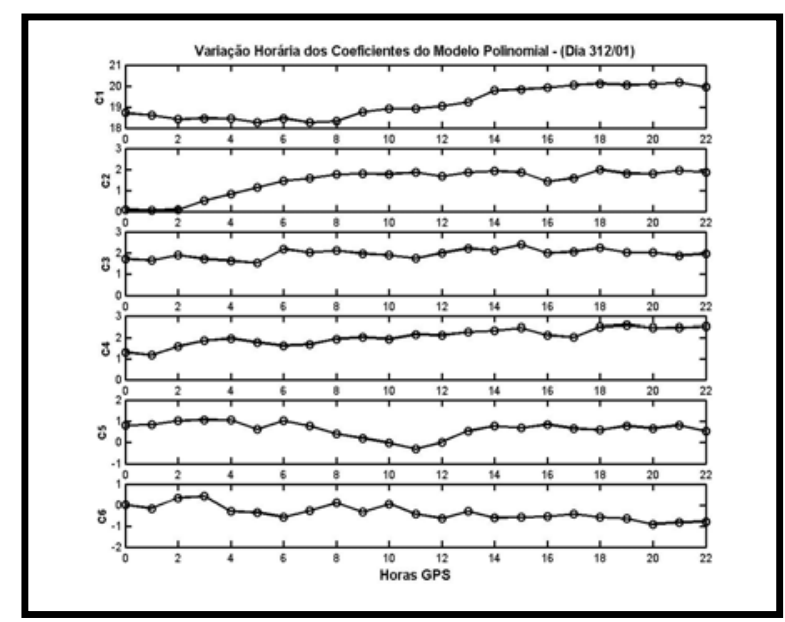

Figura 7.124 - Variação horária dos coeficientes do modelo polinomial (dia 312/01)

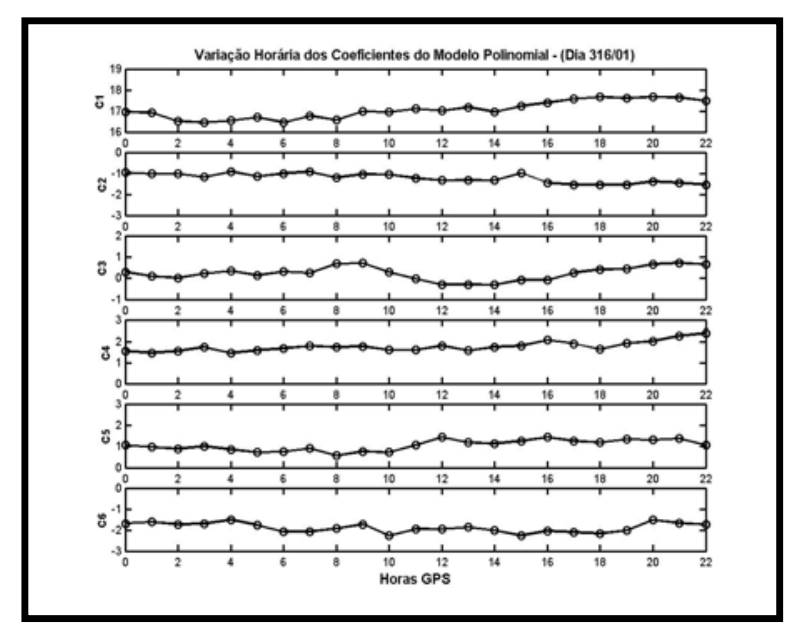

Figura 7.126 - Variação horária dos coeficientes do modelo polinomial (dia 316/01)

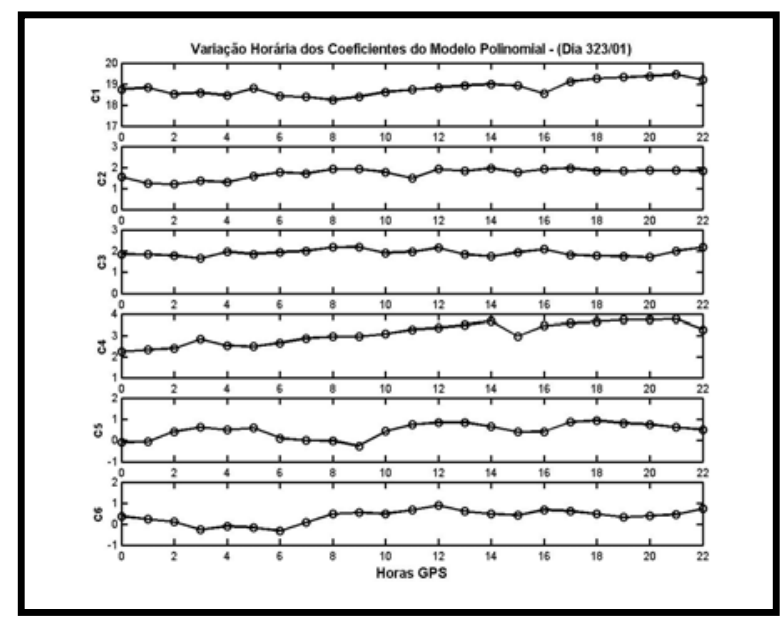

Figura 7.128 - Variação horária dos coeficientes do modelo polinomial (dia 323/01) 


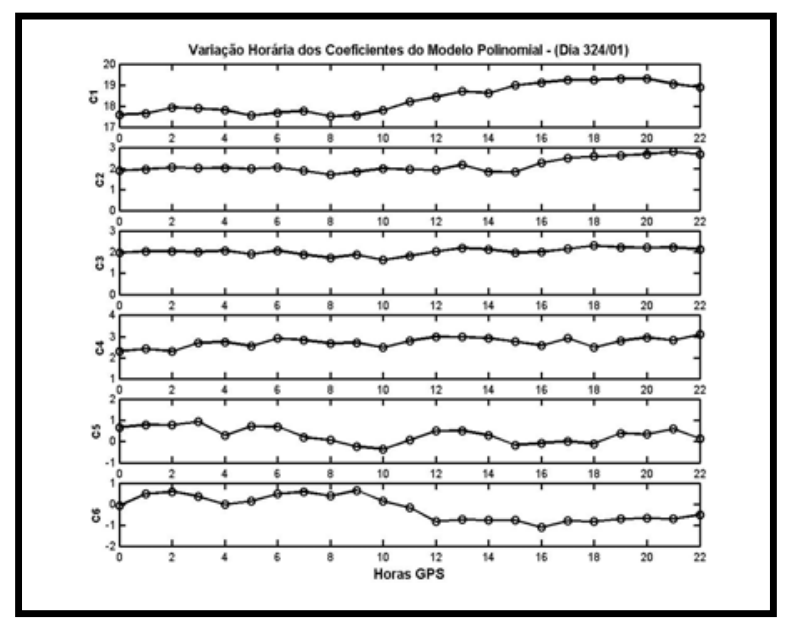

Figura 7.129 - Variação horária dos coeficientes do modelo polinomial (dia 324/01)

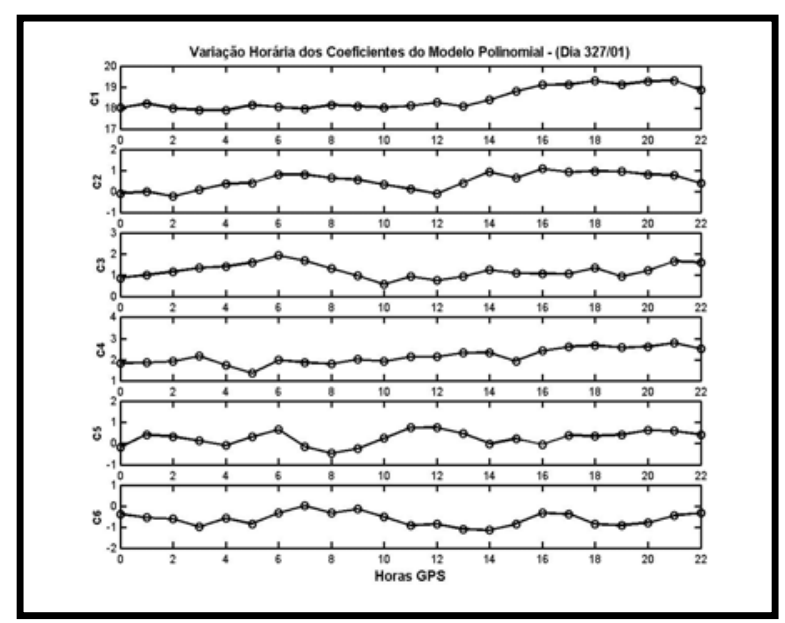

Figura 7.130 - Variação horária dos coeficientes do modelo polinomial (dia 327/01)

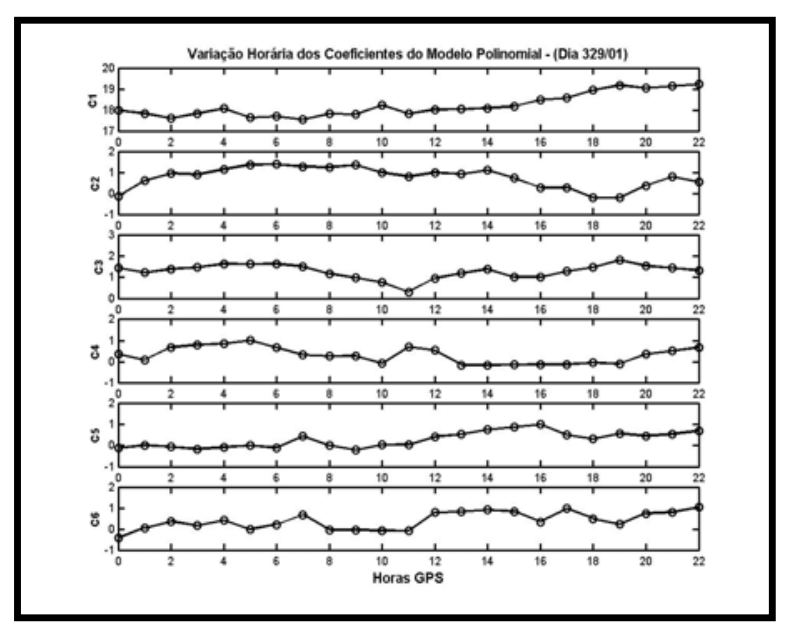

Figura 7.131 - Variação horária dos coeficientes do modelo polinomial (dia 329/01)

Tabela 7.82 - Estatística dos coeficientes do modelo polinomial - (dia 298/01)

\begin{tabular}{|c|c|c|c|c|}
\hline Coeficientes & Valor Médio & Desvio Padrão & Valor Mínimo & Valor Máximo \\
\hline $\mathbf{C}_{\mathbf{1}}$ & 17,329 & $\pm 0,689$ & 16,577 & 18,278 \\
\hline $\mathbf{C}_{\mathbf{2}}$ & $-0,377$ & $\pm 0,468$ & $-1,180$ & 0,218 \\
\hline $\mathbf{C}_{\mathbf{3}}$ & 1,712 & $\pm 0,317$ & 1,048 & 2,178 \\
\hline $\mathbf{C}_{\mathbf{4}}$ & 1,431 & $\pm 0,322$ & 1,027 & 1,910 \\
\hline $\mathbf{C}_{5}$ & 0,980 & $\pm 0,456$ & $-0,034$ & 1,662 \\
\hline $\mathbf{C}_{\mathbf{6}}$ & $-0,505$ & $\pm 0,582$ & $-1,293$ & 0,466 \\
\hline
\end{tabular}


Tabela 7.83 - Estatística dos coeficientes do modelo polinomial - (dia 301/01)

\begin{tabular}{|c|c|c|c|c|}
\hline Coeficientes & Valor Médio & Desvio Padrão & Valor Mínimo & Valor Máximo \\
\hline $\mathbf{C}_{\mathbf{1}}$ & 17,434 & $\pm 0,622$ & 16,532 & 18,388 \\
\hline $\mathbf{C}_{\mathbf{2}}$ & 0,599 & $\pm 0,599$ & $-0,185$ & 1,497 \\
\hline $\mathbf{C}_{\mathbf{3}}$ & $-0,198$ & $\pm 0,596$ & $-1,335$ & 0,596 \\
\hline $\mathbf{C}_{\mathbf{4}}$ & 1,531 & $\pm 0,406$ & 0,840 & 2,000 \\
\hline $\mathbf{C}_{\mathbf{5}}$ & $-0,533$ & $\pm 0,753$ & $-1,370$ & 0,886 \\
\hline $\mathbf{C}_{\mathbf{6}}$ & 0,758 & $\pm 0,370$ & 0,316 & 1,410 \\
\hline
\end{tabular}

Tabela 7.84 - Estatística dos coeficientes do modelo polinomial - (dia 302/01)

\begin{tabular}{|c|c|c|c|c|}
\hline Coeficientes & Valor Médio & Desvio Padrão & Valor Mínimo & Valor Máximo \\
\hline $\mathbf{C}_{\mathbf{1}}$ & 18,977 & $\pm 0,548$ & 17,994 & 19,743 \\
\hline $\mathbf{C}_{\mathbf{2}}$ & 2,052 & $\pm 0,348$ & 1,020 & 2,553 \\
\hline $\mathbf{C}_{\mathbf{3}}$ & 1,982 & $\pm 0,377$ & 1,301 & 2,554 \\
\hline $\mathbf{C}_{\mathbf{4}}$ & 2,034 & $\pm 0,347$ & 1,497 & 2,696 \\
\hline $\mathbf{C}_{5}$ & 0,703 & $\pm 0,575$ & $-0,349$ & 1,387 \\
\hline $\mathbf{C}_{6}$ & $-0,335$ & $\pm 0,631$ & $-1,111$ & 0,825 \\
\hline
\end{tabular}

Tabela 7.85 - Estatística dos coeficientes do modelo polinomial - (dia 312/01)

\begin{tabular}{|c|c|c|c|c|}
\hline Coeficientes & Valor Médio & Desvio Padrão & Valor Mínimo & Valor Máximo \\
\hline $\mathbf{C}_{\mathbf{1}}$ & 19,164 & $\pm 0,725$ & 18,260 & 20,168 \\
\hline $\mathbf{C}_{\mathbf{2}}$ & 1,415 & $\pm 0,643$ & 0,054 & 1,996 \\
\hline $\mathbf{C}_{\mathbf{3}}$ & 1,954 & $\pm 0,214$ & 1,516 & 2,386 \\
\hline $\mathbf{C}_{\mathbf{4}}$ & 2,034 & $\pm 0,390$ & 1,158 & 2,586 \\
\hline $\mathbf{C}_{\mathbf{5}}$ & 0,624 & $\pm 0,356$ & $-0,297$ & 1,059 \\
\hline $\mathbf{C}_{\mathbf{6}}$ & $-0,364$ & $\pm 0,355$ & $-0,907$ & 0,419 \\
\hline
\end{tabular}

Tabela 7.86 - Estatística dos coeficientes do modelo polinomial - (dia 315/01)

\begin{tabular}{|c|c|c|c|c|}
\hline Coeficientes & Valor Médio & Desvio Padrão & Valor Mínimo & Valor Máximo \\
\hline $\mathbf{C}_{\mathbf{1}}$ & 18,583 & $\pm 0,352$ & 18,077 & 19,189 \\
\hline $\mathbf{C}_{\mathbf{2}}$ & $-0,255$ & $\pm 0,462$ & $-0,923$ & 0,663 \\
\hline $\mathbf{C}_{\mathbf{3}}$ & 1,117 & $\pm 0,311$ & 0,565 & 1,689 \\
\hline $\mathbf{C}_{\mathbf{4}}$ & 2,102 & $\pm 0,305$ & 1,623 & 2,685 \\
\hline $\mathbf{C}_{5}$ & 0,975 & $\pm 0,271$ & 0,437 & 1,399 \\
\hline $\mathbf{C}_{6}$ & $-0,799$ & $\pm 0,492$ & $-1,383$ & 0,488 \\
\hline
\end{tabular}


Tabela 7.87 - Estatística dos coeficientes do modelo polinomial - (dia 316/01)

\begin{tabular}{|c|c|c|c|c|}
\hline Coeficientes & Valor Médio & Desvio Padrão & Valor Mínimo & Valor Máximo \\
\hline $\mathbf{C}_{\mathbf{1}}$ & 17,058 & $\pm 0,416$ & 16,446 & 17,667 \\
\hline $\mathbf{C}_{\mathbf{2}}$ & $-1,222$ & $\pm 0,223$ & $-1,544$ & $-0,914$ \\
\hline $\mathbf{C}_{\mathbf{3}}$ & 0,232 & $\pm 0,324$ & $-0,317$ & 0,725 \\
\hline $\mathbf{C}_{\mathbf{4}}$ & 1,769 & $\pm 0,242$ & 1,457 & 2,393 \\
\hline $\mathbf{C}_{\mathbf{5}}$ & 1,055 & $\pm 0,252$ & 0,572 & 1,443 \\
\hline $\mathbf{C}_{\mathbf{6}}$ & $-1,886$ & $\pm 0,225$ & $-2,268$ & $-1,506$ \\
\hline
\end{tabular}

Tabela 7.88 - Estatística dos coeficientes do modelo polinomial - (dia 318/01)

\begin{tabular}{|c|c|c|c|c|}
\hline Coeficientes & Valor Médio & Desvio Padrão & Valor Mínimo & Valor Máximo \\
\hline $\mathbf{C}_{\mathbf{1}}$ & 16,503 & $\pm 0,567$ & 15,782 & 17,239 \\
\hline $\mathbf{C}_{\mathbf{2}}$ & $-0,147$ & $\pm 0,214$ & $-0,526$ & 0,204 \\
\hline $\mathbf{C}_{\mathbf{3}}$ & $-0,263$ & $\pm 0,464$ & $-0,961$ & 0,448 \\
\hline $\mathbf{C}_{\mathbf{4}}$ & 2,108 & $\pm 0,168$ & 1,844 & 2,474 \\
\hline $\mathbf{C}_{\mathbf{5}}$ & 0,826 & $\pm 0,293$ & 0,213 & 1,239 \\
\hline $\mathbf{C}_{\mathbf{6}}$ & $-1,443$ & $\pm 0,317$ & $-1,895$ & $-0,809$ \\
\hline
\end{tabular}

Tabela 7.89 - Estatística dos coeficientes do modelo polinomial - (dia 323/01)

\begin{tabular}{|c|c|c|c|c|}
\hline Coeficientes & Valor Médio & Desvio Padrão & Valor Mínimo & Valor Máximo \\
\hline $\mathbf{C}_{\mathbf{1}}$ & 18,812 & $\pm 0,351$ & 18,247 & 19,466 \\
\hline $\mathbf{C}_{\mathbf{2}}$ & 1,708 & $\pm 0,240$ & 1,203 & 1,966 \\
\hline $\mathbf{C}_{\mathbf{3}}$ & 1,918 & $\pm 0,159$ & 1,642 & 2,192 \\
\hline $\mathbf{C}_{\mathbf{4}}$ & 3,094 & $\pm 0,296$ & 2,724 & 3,765 \\
\hline $\mathbf{C}_{\mathbf{5}}$ & 0,462 & $\pm 0,155$ & $-0,266$ & 0,942 \\
\hline $\mathbf{C}_{\mathbf{6}}$ & 0,354 & $\pm 0,126$ & $-0,323$ & 0,888 \\
\hline
\end{tabular}

Tabela 7.90 - Estatística dos coeficientes do modelo polinomial - (dia 324/01)

\begin{tabular}{|c|c|c|c|c|}
\hline Coeficientes & Valor Médio & Desvio Padrão & Valor Mínimo & Valor Máximo \\
\hline $\mathbf{C}_{\mathbf{1}}$ & 18,338 & $\pm 0,681$ & 17,514 & 19,308 \\
\hline $\mathbf{C}_{\mathbf{2}}$ & 2,135 & $\pm 0,326$ & 1,701 & 2,794 \\
\hline $\mathbf{C}_{\mathbf{3}}$ & 2,022 & $\pm 0,167$ & 1,611 & 2,293 \\
\hline $\mathbf{C}_{\mathbf{4}}$ & 2,731 & $\pm 0,224$ & 2,302 & 3,095 \\
\hline $\mathbf{C}_{\mathbf{5}}$ & 0,301 & $\pm 0,368$ & $-0,354$ & 0,924 \\
\hline $\mathbf{C}_{\boldsymbol{6}}$ & $-0,216$ & $\pm 0,589$ & $-1,121$ & 0,642 \\
\hline
\end{tabular}


Tabela 7.91 - Estatística dos coeficientes do modelo polinomial - (dia 327/01)

\begin{tabular}{|c|c|c|c|c|}
\hline Coeficientes & Valor Médio & Desvio Padrão & Valor Mínimo & Valor Máximo \\
\hline $\mathbf{C}_{\mathbf{1}}$ & 18,437 & $\pm 0,522$ & 17,902 & 19,311 \\
\hline $\mathbf{C}_{\mathbf{2}}$ & 0,497 & $\pm 0,395$ & $-0,246$ & 1,065 \\
\hline $\mathbf{C}_{\mathbf{3}}$ & 1,208 & $\pm 0,331$ & 0,584 & 1,924 \\
\hline $\mathbf{C}_{\mathbf{4}}$ & 2,149 & $\pm 0,368$ & 1,346 & 2,790 \\
\hline $\mathbf{C}_{\mathbf{5}}$ & 0,254 & $\pm 0,336$ & $-0,468$ & 0,760 \\
\hline $\mathbf{C}_{\mathbf{6}}$ & $-0,617$ & $\pm 0,314$ & $-1,144$ & 0,004 \\
\hline
\end{tabular}

Tabela 7.92 - Estatística dos coeficientes do modelo polinomial - (dia 329/01)

\begin{tabular}{|c|c|c|c|c|}
\hline Coeficientes & Valor Médio & Desvio Padrão & Valor Mínimo & Valor Máximo \\
\hline $\mathbf{C}_{\mathbf{1}}$ & 18,208 & $\pm 0,548$ & 17,544 & 19,234 \\
\hline $\mathbf{C}_{\mathbf{2}}$ & 0,760 & $\pm 0,497$ & $-0,212$ & 1,377 \\
\hline $\mathbf{C}_{\mathbf{3}}$ & 1,280 & $\pm 0,336$ & 0,308 & 1,794 \\
\hline $\mathbf{C}_{\mathbf{4}}$ & 0,308 & $\pm 0,384$ & $-0,170$ & 1,000 \\
\hline $\mathbf{C}_{\mathbf{5}}$ & 0,275 & $\pm 0,362$ & $-0,212$ & 0,986 \\
\hline $\mathbf{C}_{\mathbf{6}}$ & 0,400 & $\pm 0,419$ & $-0,429$ & 1,047 \\
\hline
\end{tabular}

A Figura 7.132 ilustra os valores médios diários dos coeficientes do modelo polinomial, durante alguns dias da primavera.

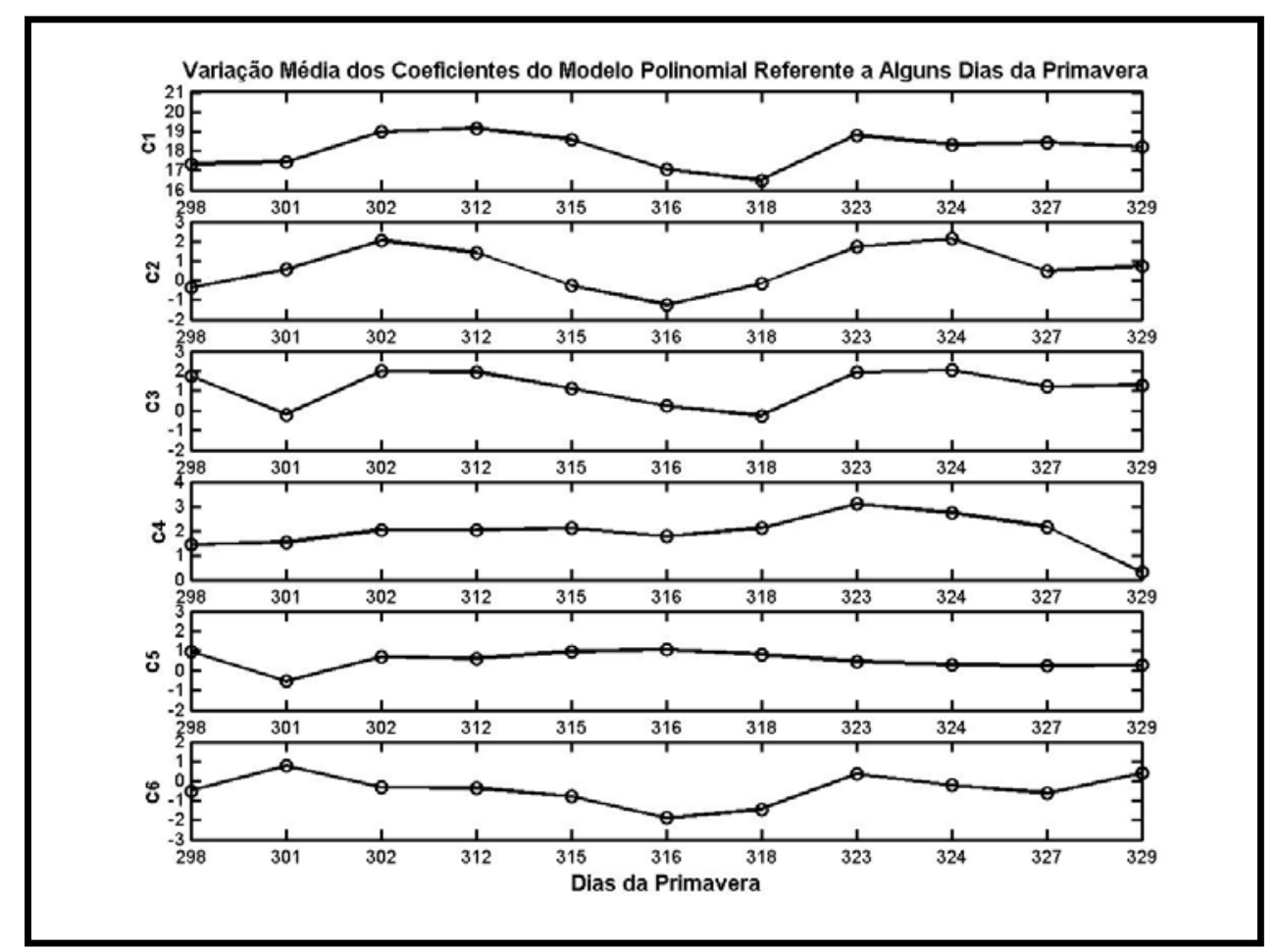

Figura 7.132 - Variação média diária dos coeficientes do modelo polinomial, referente a alguns dias da primavera. 
A Tabela 7.93 ilustra a estatística dos coeficientes neste período da primavera. As colunas "Valor Médio" e "Desvio Padrão" correspondem, respectivamente, a média dos coeficientes e a média dos desvios padrão, em relação aos 11 dias estudados. $O$ valor do desvio padrão do coeficiente $C_{1}$ manteve-se praticamente constante em relação ao verão, ao outono e ao inverno, ao passo que, para os demais coeficientes, o comportamento do desvio padrão foi:

- Coeficiente $\mathrm{C}_{2}$ - aumento de $44 \%$ em relação ao período do verão, $9 \%$ em relação ao outono e diminuição de $17 \%$ em relação ao inverno;

- Coeficiente $\mathrm{C}_{3}$ - aumento de $18 \%$ em relação ao período do verão, $46 \%$ em relação ao outono e diminuição de $26 \%$ em relação ao inverno;

- Coeficiente $\mathrm{C}_{4}$ - aumento de $20 \%$ em relação ao período do verão, $134 \%$ em relação ao outono e diminuição de $35 \%$ em relação ao inverno;

- Coeficiente $\mathrm{C}_{5}$ - aumento de $48 \%$ em relação ao período do verão, $100 \%$ em relação ao outono e diminuição de $14 \%$ em relação ao inverno;

- Coeficiente $\mathrm{C}_{6}$ - aumento de $89 \%$ em relação ao período do verão, $106 \%$ em relação ao outono e diminuição de $3 \%$ em relação ao inverno.

Tabela 7.93 - Valores médios dos coeficientes do modelo polinomial referentes a alguns dias da primavera

\begin{tabular}{|c|c|c|c|c|}
\hline Coeficientes & Valor Médio & Desvio Padrão & Valor Mínimo & Valor Máximo \\
\hline $\mathbf{C}_{\mathbf{1}}$ & 18,077 & $\pm 0,547$ & 16,503 & 19,164 \\
\hline $\mathbf{C}_{\mathbf{2}}$ & 0,651 & $\pm 0,401$ & $-1,222$ & 2,135 \\
\hline $\mathbf{C}_{\mathbf{3}}$ & 1,179 & $\pm 0,327$ & $-0,263$ & 2,022 \\
\hline $\mathbf{C}_{\mathbf{4}}$ & 1,936 & $\pm 0,332$ & 0,308 & 3,094 \\
\hline $\mathbf{C}_{5}$ & 0,538 & $\pm 0,398$ & $-0,533$ & 1,055 \\
\hline $\mathbf{C}_{\mathbf{6}}$ & $-0,423$ & $\pm 0,420$ & $-1,886$ & 0,758 \\
\hline
\end{tabular}

A Tabela 7.94 ilustra os valores médios para o erro da portadora $L_{1}$ (erro de interfreqüência), bem como os respectivos desvios padrão médios, referentes ao período do inverno. Estes erros mantiveram-se praticamente constantes em relação ao verão, ao outono e ao inverno. 
Tabela 7.94 - Valores médios do erro da portadora $L_{1}$ (erro de interfreqüência), devido ao conjunto satélite/receptor, em relação aos dias estudados na primavera.

\begin{tabular}{|c|c|c|}
\cline { 2 - 3 } \multicolumn{1}{c|}{} & \multicolumn{2}{c|}{$(\text { Erro })^{\mathrm{s}}=\left(\left(\mathrm{S}_{\mathrm{P} 2}-\mathrm{S}_{\left.\mathrm{P}_{1}\right)}\right)+\left(\mathrm{r}_{\mathrm{P} 2}-\mathrm{r}_{\mathrm{P} 1}\right)\right)^{\mathrm{s}}$} \\
\hline Satélites & Valor Médio $(\mathbf{m})$ & Desvio Padrão $(\mathbf{m})$ \\
\hline PRN-1 & 1,902 & $\pm 0,638$ \\
\hline PRN-2 & 2,245 & $\pm 0,616$ \\
\hline PRN-3 & 1,762 & $\pm 0,554$ \\
\hline PRN-4 & 2,218 & $\pm 0,675$ \\
\hline PRN-5 & 1,825 & $\pm 0,412$ \\
\hline PRN-6 & 1,855 & $\pm 0,551$ \\
\hline PRN-7 & 2,134 & $\pm 0,602$ \\
\hline PRN-8 & 2,225 & $\pm 0,744$ \\
\hline PRN-9 & 1,820 & $\pm 0,546$ \\
\hline PRN-10 & 2,210 & $\pm 0,621$ \\
\hline PRN-11 & 2,319 & $\pm 0,672$ \\
\hline PRN-13 & 1,958 & $\pm 0,698$ \\
\hline PRN-14 & 1,997 & $\pm 0,659$ \\
\hline PRN-15 & 1,528 & $\pm 0,609$ \\
\hline PRN-17 & 1,625 & $\pm 0,753$ \\
\hline PRN-18 & 1,773 & $\pm 0,561$ \\
\hline PRN-20 & 2,463 & $\pm 0,639$ \\
\hline PRN-21 & 1,544 & $\pm 0,452$ \\
\hline PRN-22 & 1,625 & $\pm 0,487$ \\
\hline PRN-23 & 1,934 & $\pm 0,704$ \\
\hline PRN-24 & 1,886 & $\pm 0,590$ \\
\hline PRN-25 & 1,715 & $\pm 0,664$ \\
\hline PRN-26 & 1,923 & $\pm 0,608$ \\
\hline PRN-27 & 2,631 & $\pm 0,634$ \\
\hline PRN-28 & 2,263 & $\pm 0,726$ \\
\hline PRN-29 & 2,050 & $\pm 0,552$ \\
\hline PRN-30 & 1,737 & $\pm 0,408$ \\
\hline PRN-31 & 2,117 & $\pm 0,561$ \\
\hline & & \\
\hline
\end{tabular}




\subsubsection{Validação do modelo através de posicionamento Single Point - período da primavera}

Neste último período de processamento, contatou-se que os resultados encontrados foram semelhantes que nas estações do verão, outono e inverno. O processamento do vértice BRAZ, através do modelo polinomial, apresentou resultados mais eficientes, se comprados com os modelos de Klobuchar e Standard. Estes dois modelos proporcionaram comportamentos distintos do erro horizontal em relação ao longo do período do dia. Os intervalos das 0 às 6 e das 17 às 20 horas GPS foram os que apresentaram os maiores erros (horizontal e vertical) no posicionamento do vértice BRAZ. Já, através do modelo polinomial, verificou-se que o erro horizontal apresentou um comportamento constante, dentro de uma determinada faixa de valores, durante todo o período do dia. Isto pôde ser comprovado durante as quatro estações do ano estudadas.

Ao analisar os valores médios do período, os valores dos erros horizontais e verticais foram superiores se comparados com os das estações do inverno e do outono. Isto mostra que na primavera a ionosfera influencia os sinais GPS de uma forma mais intensa.

Ao analisar os sete dias de processamento, os valores médios do erro horizontal, foram:

- E.M.Q.H.P $=1,884 \mathrm{~m} \pm 1,027 \mathrm{~m}$

E.M.Q.H.K = 3,171m $\pm 1,738 \mathrm{~m}$

- E.M.Q.H.S $=4,655 m \pm 1,983 m$

O modelo polinomial proporcionou, em média, uma melhora de $1,287 \mathrm{~m}$ e $2,771 \mathrm{~m}$, em relação aos modelos de Klobuchar e Standard, respectivamente.

Em relação ao erro vertical, o modelo polinomial também proporcionou melhores resultados que os de Klobuchar e o Standard. Nos sete dias de processamento os valores médios foram:

E.M.Q.V.P $=2,692 m \pm 3,296 m$

- E.M.Q.V.K = 3,584m $\pm 3,670 m$

- E.M.Q.V.S $=3,510 \mathrm{~m} \pm 3,635 \mathrm{~m}$

A melhora foi, em média, 0,892m e 0,818m, em relação aos modelos de Klobuchar e Standard, respectivamente. 
Através destes valores supracitados, verifica-se que o modelo regional estudado pode ser eficiente nos períodos onde os sinais GPS são afetados de forma intensa pela ionosfera.

A seguir, serão apresentados todos os resultados do posicionamento Single Point do vértice BRAZ, referentes a alguns dias da primavera.

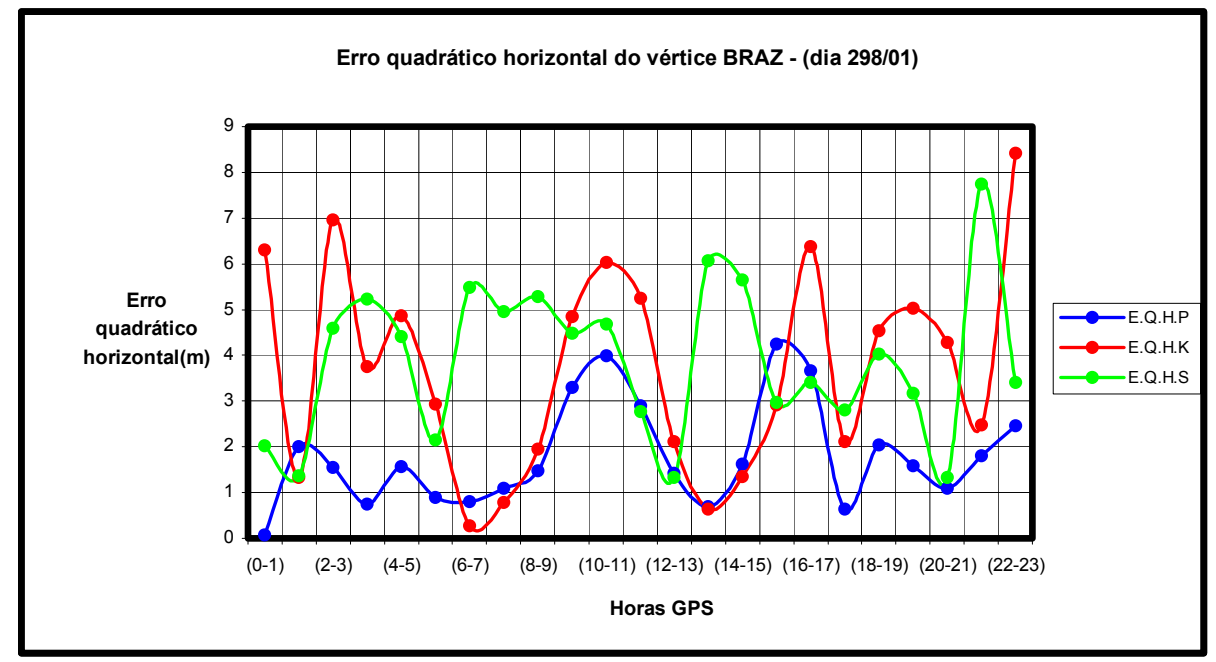

Figura 7.133 - Variação horária do erro quadrático horizontal no posicionamento Single Point do vértice BRAZ - (dia 298/01)

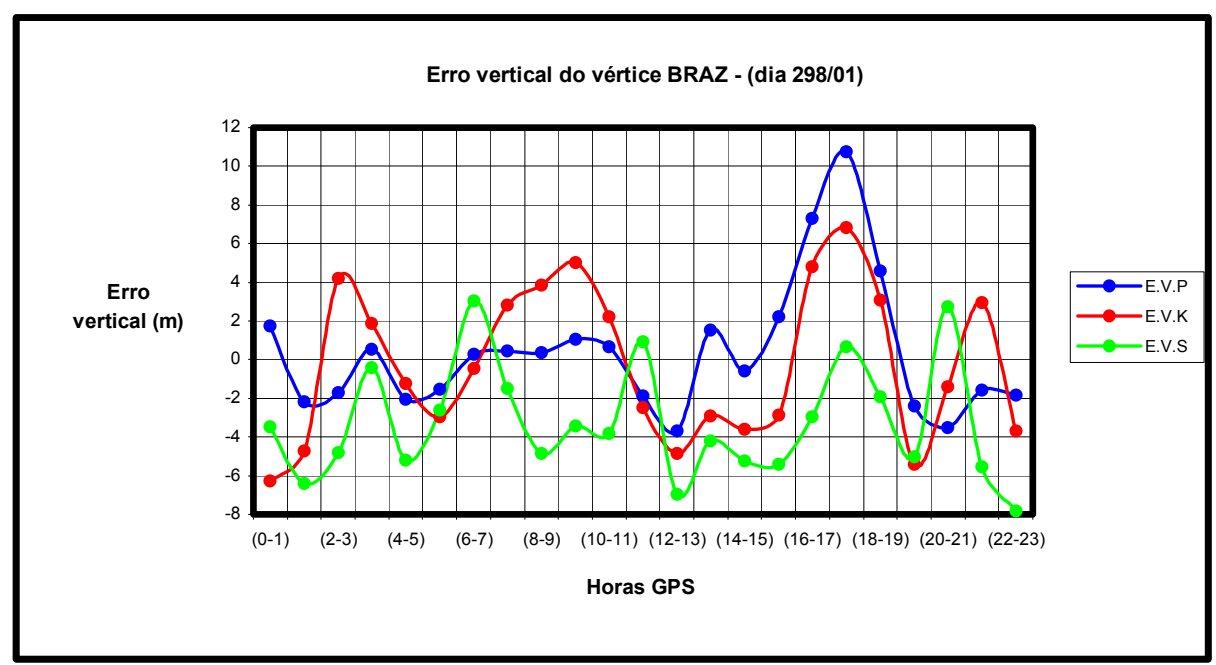

Figura 7.134 - Variação horária do erro vertical no posicionamento Single Point do vértice

$$
\text { BRAZ - (dia 298/01) }
$$


Tabela 7.95 - Erro quadrático horizontal e erro vertical no processamento Single Point do vértice BRAZ para diferentes modelos ionosféricos - (dia 298/01).

\begin{tabular}{|c|c|c|c|c|c|c|}
\hline \multirow[b]{2}{*}{ Horas } & \multicolumn{3}{|c|}{ Erro Quadrático Horizontal (m) } & \multicolumn{3}{|c|}{ Erro Vertical (m) } \\
\hline & E.Q.H.P & E.Q.H.K & E.Q.H.S & E.V.P & E.V.K & E.V.S \\
\hline$(0-1)$ & 0,065 & 6,304 & 2,031 & 1,731 & $-6,277$ & $-3,472$ \\
\hline$(1-2)$ & 2,003 & 1,325 & 1,369 & $-2,166$ & $-4,744$ & $-6,423$ \\
\hline$(2-3)$ & 1,547 & 6,962 & 4,598 & $-1,707$ & 4,203 & $-4,799$ \\
\hline$(3-4)$ & 0,754 & 3,752 & 5,226 & 0,545 & 1,863 & $-0,414$ \\
\hline$(4-5)$ & 1,562 & 4,872 & 4,410 & $-2,056$ & $-1,214$ & $-5,180$ \\
\hline$(5-6)$ & 0,897 & 2,924 & 2,145 & $-1,547$ & $-2,972$ & $-2,594$ \\
\hline$(6-7)$ & 0,809 & 0,280 & 5,479 & 0,265 & $-0,455$ & 3,053 \\
\hline$(7-8)$ & 1,099 & 0,790 & 4,946 & 0,466 & 2,834 & $-1,505$ \\
\hline$(8-9)$ & 1,468 & 1,955 & 5,278 & 0,380 & 3,832 & $-4,863$ \\
\hline$(9-10)$ & 3,296 & 4,850 & 4,487 & 1,066 & 5,032 & $-3,451$ \\
\hline$(10-11)$ & 3,996 & 6,028 & 4,688 & 0,677 & 2,203 & $-3,820$ \\
\hline$(11-12)$ & 2,890 & 5,252 & 2,775 & $-1,876$ & $-2,468$ & 0,912 \\
\hline$(12-13)$ & 1,412 & 2,122 & 1,338 & $-3,685$ & $-4,859$ & $-6,981$ \\
\hline$(13-14)$ & 0,696 & & 6,061 & 1,529 & $-2,894$ & $-4,206$ \\
\hline$(14-15)$ & 1,627 & 1,348 & 5,657 & $-0,595$ & $-3,592$ & $-5,262$ \\
\hline$(15-16)$ & 4,246 & 2,923 & 2,967 & 2,197 & $-2,872$ & $-5,418$ \\
\hline$(16-17)$ & 3,657 & 6,371 & 3,403 & 7,280 & 4,784 & $-2,959$ \\
\hline$(17-18)$ & 0,641 & 2,108 & 2,810 & 10,732 & 6,822 & 0,672 \\
\hline$(18-19)$ & 2,041 & 4,542 & 4,026 & 4,600 & 3,061 & $-1,914$ \\
\hline$(19-20)$ & 1,582 & 5,030 & 3,175 & $-2,408$ & $-5,404$ & $-5,010$ \\
\hline$(20-21)$ & 1,085 & 4,280 & 1,326 & $-3,529$ & $-1,407$ & 2,728 \\
\hline$(21-22)$ & 1,796 & 2,487 & 7,751 & $-1,559$ & 2,940 & $-5,525$ \\
\hline$(22-23)$ & 2,455 & 8,420 & 3,403 & $-1,822$ & $-3,702$ & $-7,830$ \\
\hline E.M.Q & 1,810 & 3,720 & 3,885 & 2,366 & 3,497 & 3,869 \\
\hline Desvio Padrão & $\pm 1,131$ & $\pm 2,253$ & $\pm 1,680$ & $\pm 3,400$ & $\pm 3,913$ & $\pm 2,966$ \\
\hline
\end{tabular}

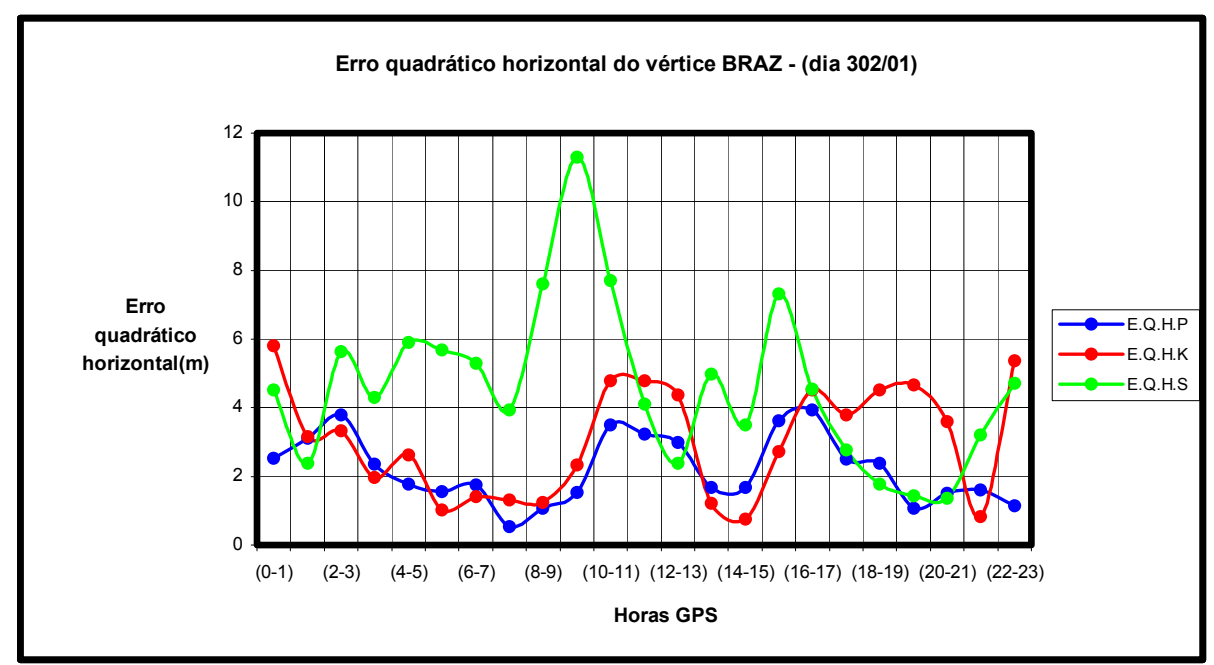

Figura 7.135 - Variação horária do erro quadrático horizontal no posicionamento Single Point do vértice BRAZ - (dia 302/01) 


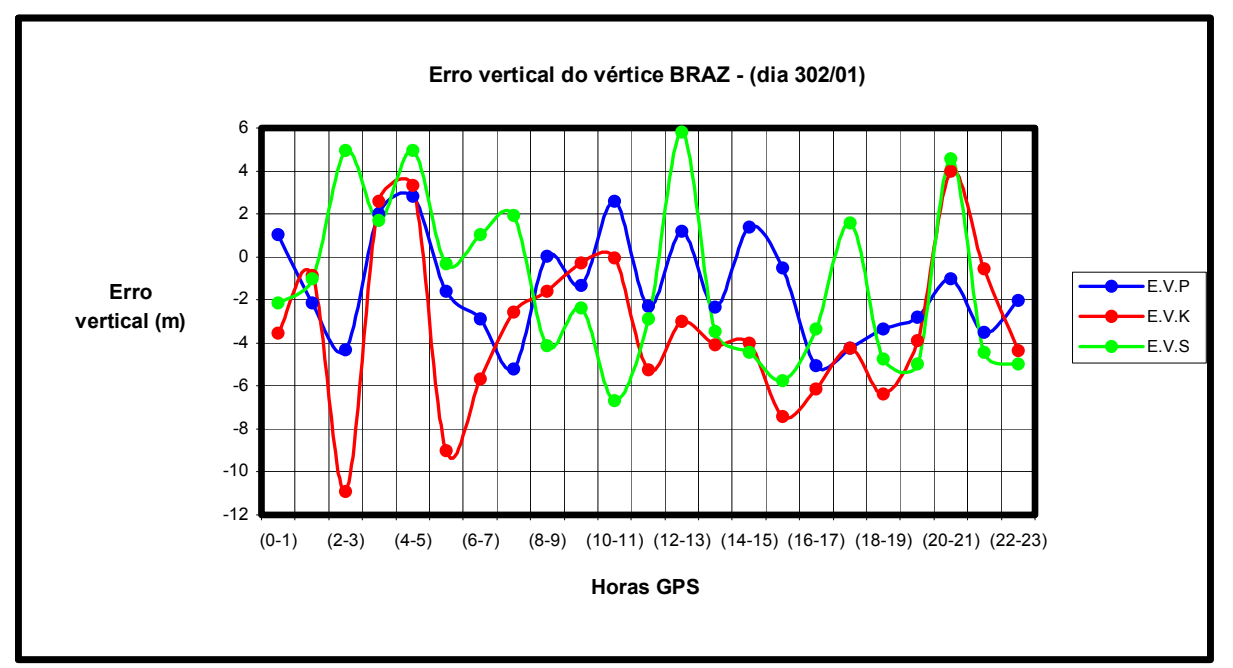

Figura 7.136 - Variação horária do erro vertical no posicionamento Single Point do vértice BRAZ - (dia 302/01)

Tabela 7.96 - Erro quadrático horizontal e erro vertical no processamento Single Point do vértice BRAZ para diferentes modelos ionosféricos - (dia 302/01).

\begin{tabular}{|c|c|c|c|c|c|c|}
\cline { 2 - 7 } \multicolumn{1}{c|}{} & \multicolumn{2}{c|}{ Erro Quadrático Horizontal (m) } & \multicolumn{3}{c|}{ Erro Vertical (m) } \\
\hline Horas & E.Q.H.P & E.Q.H.K & E.Q.H.S & E.V.P & E.V.K & E.V.S \\
\hline $\mathbf{( 0 - 1 )}$ & 2,538 & 5,796 & 4,509 & 1,024 & $-3,550$ & $-2,165$ \\
\hline $\mathbf{( 1 - 2 )}$ & 3,112 & 3,150 & 2,392 & $-2,158$ & $-0,870$ & $-1,022$ \\
\hline $\mathbf{( 2 - 3 )}$ & 3,798 & 3,321 & 5,637 & $-4,303$ & $-10,915$ & 4,953 \\
\hline $\mathbf{( 3 - 4 )}$ & 2,358 & 1,966 & 4,310 & 2,017 & 2,573 & 1,704 \\
\hline $\mathbf{( 4 - 5 )}$ & 1,766 & 2,626 & 5,910 & 2,823 & 3,325 & 4,934 \\
\hline $\mathbf{( 5 - 6 )}$ & 1,544 & 1,022 & 5,673 & $-1,607$ & $-9,030$ & $-0,314$ \\
\hline $\mathbf{( 6 - 7 )}$ & 1,741 & 1,401 & 5,289 & $-2,895$ & $-5,666$ & 1,046 \\
\hline $\mathbf{( 7 - 8 )}$ & 0,526 & 1,307 & 3,934 & $-5,227$ & $-2,578$ & 1,943 \\
\hline $\mathbf{( 8 - 9 )}$ & 1,058 & 1,236 & 7,611 & 0,034 & $-1,602$ & $-4,118$ \\
\hline $\mathbf{( 9 - 1 0 )}$ & 1,537 & 2,333 & 11,288 & $-1,330$ & $-0,269$ & $-2,385$ \\
\hline $\mathbf{( 1 0 - 1 1 )}$ & 3,492 & 4,793 & 7,698 & 2,595 & $-0,058$ & $-6,698$ \\
\hline $\mathbf{( 1 1 - 1 2 )}$ & 3,230 & 4,784 & 4,117 & $-2,287$ & $-5,263$ & $-2,888$ \\
\hline $\mathbf{( 1 2 - 1 3 )}$ & 2,998 & 4,378 & 2,382 & 1,190 & $-3,013$ & 5,807 \\
\hline $\mathbf{( 1 3 - 1 4 )}$ & 1,671 & 1,208 & 4,981 & $-2,351$ & $-4,076$ & $-3,468$ \\
\hline $\mathbf{( 1 4 - 1 5 )}$ & 1,680 & 0,765 & 3,507 & 1,395 & $-3,995$ & $-4,432$ \\
\hline $\mathbf{( 1 5 - 1 6 )}$ & 3,617 & 2,717 & $\mathbf{7}, 307$ & $-0,515$ & $-7,406$ & $-5,736$ \\
\hline $\mathbf{( 1 6 - 1 7})$ & 3,925 & 4,519 & 4,534 & $-5,051$ & $-6,140$ & $-3,367$ \\
\hline $\mathbf{( 1 7 - 1 8 )}$ & 2,504 & 3,796 & 2,781 & $-4,249$ & $-4,232$ & 1,588 \\
\hline $\mathbf{( 1 8 - 1 9 )}$ & 2,390 & 4,528 & 1,767 & $-3,350$ & $-6,380$ & $-4,757$ \\
\hline$(\mathbf{1 9 - 2 0})$ & 1,078 & 4,669 & 1,444 & $-2,824$ & $-3,894$ & $-4,961$ \\
\hline $\mathbf{( 2 0 - 2 1}$ & 1,503 & 3,585 & 1,348 & $-1,009$ & 3,996 & 4,569 \\
\hline $\mathbf{( 2 1 - 2 2 )}$ & 1,604 & 0,827 & 3,208 & $-3,506$ & $-0,564$ & $-4,428$ \\
\hline $\mathbf{( 2 2 - 2 3 )}$ & 1,132 & 5,375 & 4,711 & $-2,037$ & $-4,360$ & $-4,970$ \\
\hline E.M.Q & $\mathbf{2 , 2 0 9}$ & $\mathbf{3 , 0 4 8}$ & $\mathbf{4 , 6 2 3}$ & $\mathbf{2 , 4 2 5}$ & $\mathbf{4 , 0 7 6}$ & $\mathbf{3 , 5 7 6}$ \\
\hline Desvio Padrão & $\pm \mathbf{0 , 9 8 1}$ & $\pm \mathbf{1 , 6 1 4}$ & $\pm \mathbf{2 , 3 4 4}$ & $\pm \mathbf{2 , 4 1 7}$ & $\pm \mathbf{3 , 7 3 1}$ & $\pm \mathbf{3 , 8 4 9}$ \\
\hline
\end{tabular}




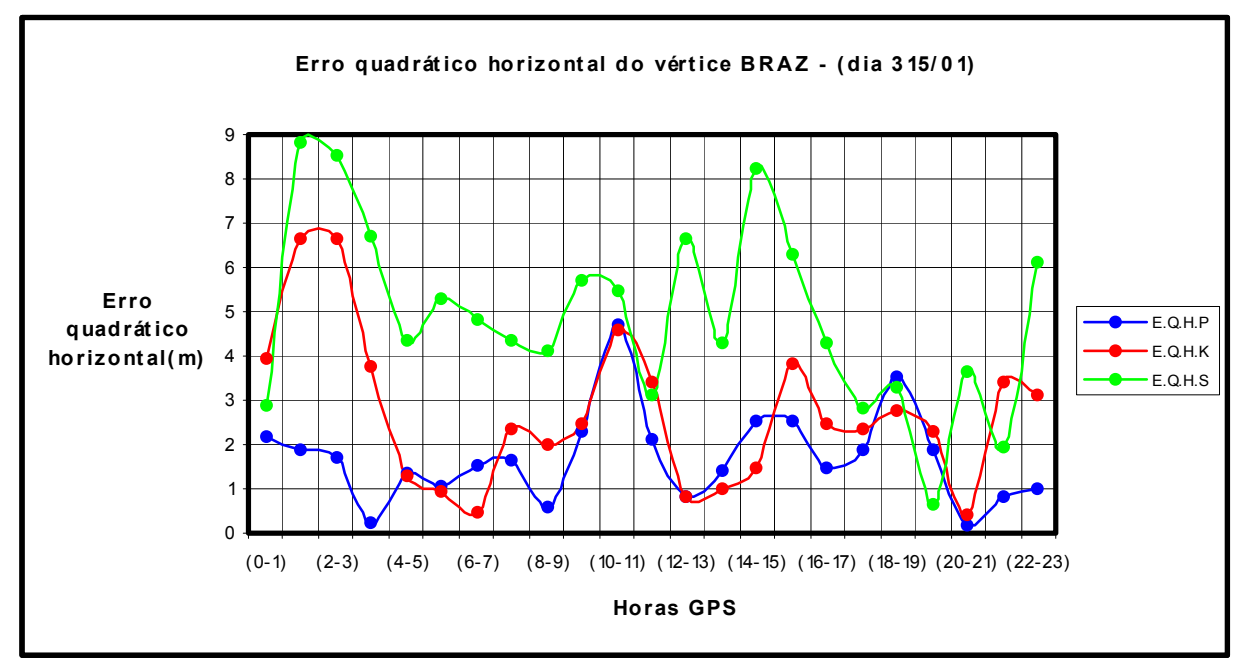

Figura 7.137 - Variação horária do erro quadrático horizontal no posicionamento Single Point do vértice BRAZ - (dia 315/01)

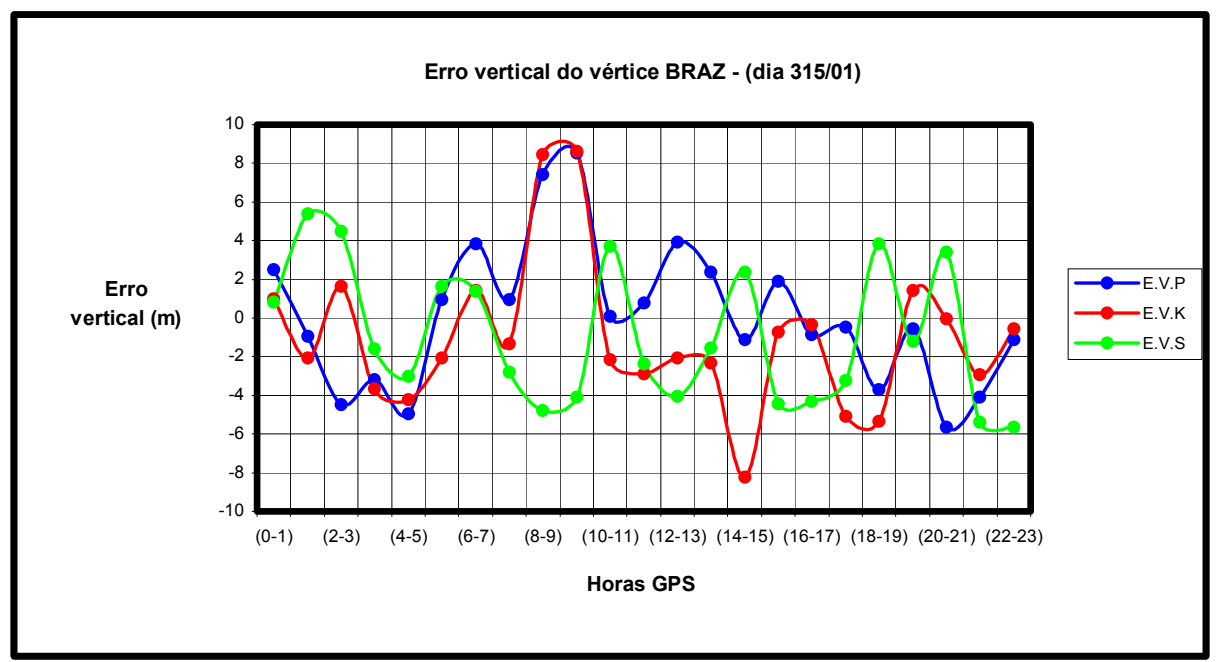

Figura 7.138 - Variação horária do erro vertical no posicionamento Single Point do vértice BRAZ - (dia 315/01) 
Tabela 7.97 - Erro quadrático horizontal e erro vertical no processamento Single Point do vértice BRAZ para diferentes modelos ionosféricos - (dia 315/01).

\begin{tabular}{|c|c|c|c|c|c|c|}
\hline \multirow[b]{2}{*}{ Horas } & \multicolumn{3}{|c|}{ Erro Quadrático Horizontal (m) } & \multicolumn{3}{|c|}{ Erro Vertical (m) } \\
\hline & E.Q.H.P & E.Q.H.K & E.Q.H.S & E.V.P & E.V.K & E.V.S \\
\hline$(0-1)$ & 2,152 & 3,920 & 2,903 & 2,522 & 1,008 & 0,831 \\
\hline$(1-2)$ & 1,876 & 6,618 & 8,805 & $-0,958$ & $-2,053$ & 5,408 \\
\hline$(2-3)$ & 1,700 & 6,621 & 8,544 & $-4,472$ & 1,632 & 4,478 \\
\hline$(3-4)$ & 0,223 & 3,771 & 6,733 & $-3,207$ & $-3,669$ & $-1,597$ \\
\hline$(4-5)$ & 1,357 & 1,273 & 4,351 & $-4,961$ & $-4,235$ & $-3,013$ \\
\hline$(5-6)$ & 1,062 & 0,966 & 5,303 & 0,952 & $-2,074$ & 1,642 \\
\hline$(6-7)$ & 1,551 & 0,452 & 4,842 & 3,840 & 1,433 & 1,398 \\
\hline$(7-8)$ & 1,628 & 2,378 & 4,333 & 0,955 & $-1,356$ & $-2,811$ \\
\hline$(8-9)$ & 0,561 & 1,995 & 4,135 & 7,409 & 8,441 & $-4,772$ \\
\hline$(9-10)$ & 2,280 & 2,494 & 5,693 & 8,530 & 8,641 & $-4,099$ \\
\hline$(10-11)$ & 4,717 & 4,564 & 5,481 & 0,087 & $-2,159$ & 3,698 \\
\hline$(11-12)$ & 2,101 & 3,405 & 3,127 & 0,783 & $-2,902$ & $-2,385$ \\
\hline$(12-13)$ & 0,815 & 0,825 & 6,658 & 3,903 & $-2,074$ & $-4,073$ \\
\hline$(13-14)$ & 1,434 & 1,0 & 4,280 & 2,363 & $-2,346$ & $-1,569$ \\
\hline$(14-15)$ & 2,517 & 1,447 & 8,206 & $-1,101$ & $-8,241$ & 2,381 \\
\hline$(15-16)$ & 2,515 & 3,801 & 6,283 & 1,876 & $-0,754$ & $-4,429$ \\
\hline$(16-17)$ & 1,452 & 2,465 & 4,299 & $-0,871$ & $-0,328$ & $-4,298$ \\
\hline$(17-18)$ & 1,908 & 2,378 & 2,816 & $-0,489$ & $-5,068$ & $-3,252$ \\
\hline$(18-19)$ & 3,538 & 2,749 & 3,319 & $-3,693$ & $-5,339$ & 3,851 \\
\hline$(19-20)$ & 1,875 & 2,296 & 0,620 & $-0,580$ & 1,424 & $-1,202$ \\
\hline$(20-21)$ & 0,192 & 0,404 & 3,639 & $-5,658$ & $-0,061$ & 3,407 \\
\hline$(21-22)$ & 0,843 & 3,402 & 1,936 & $-4,112$ & $-2,924$ & $-5,389$ \\
\hline$(22-23)$ & 0,992 & 3,143 & 6,141 & $-1,114$ & $-0,576$ & $-5,634$ \\
\hline E.M.Q & 1,708 & 2,712 & 4,889 & 2,802 & 2,989 & 3,288 \\
\hline Desvio Padrão & $\pm 1,024$ & $\pm 1,699$ & $\pm 2,079$ & $\pm 3,677$ & $\pm 3,848$ & $\pm 3,537$ \\
\hline
\end{tabular}

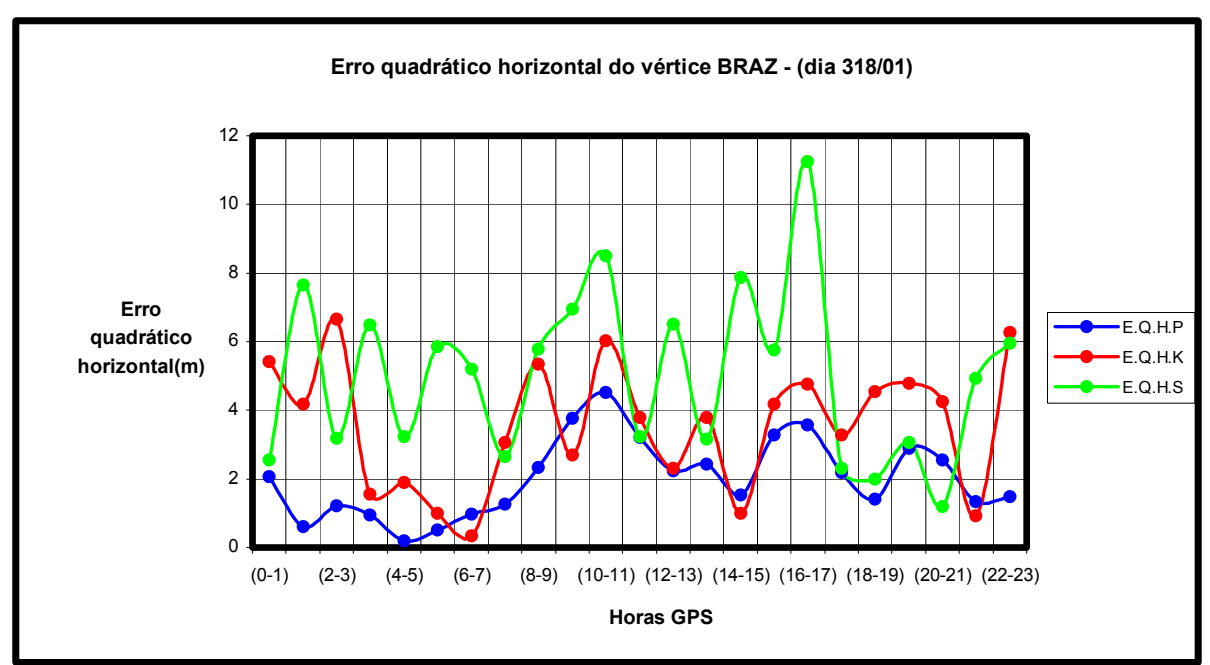

Figura 7.139 - Variação horária do erro quadrático horizontal no posicionamento Single Point do vértice BRAZ - (dia 318/01) 


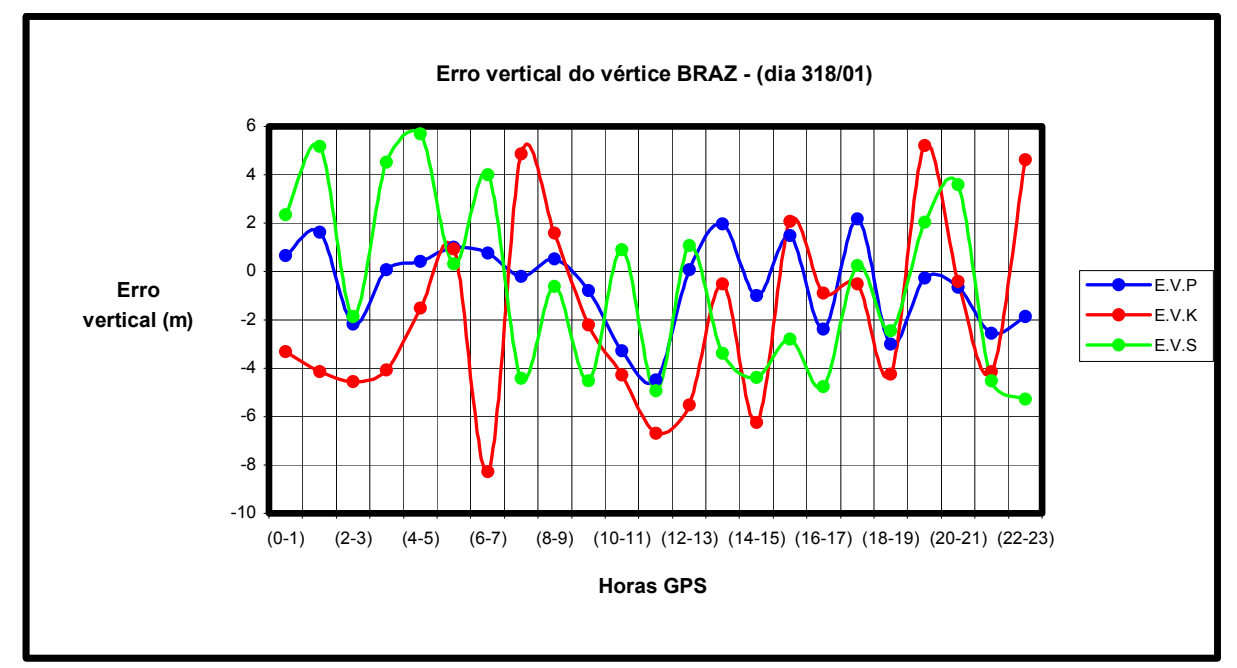

Figura 7.140 - Variação horária do erro vertical no posicionamento Single Point do vértice BRAZ - (dia 318/01)

Tabela 7.98 - Erro quadrático horizontal e erro vertical no processamento Single Point do vértice BRAZ para diferentes modelos ionosféricos - (dia 318/01).

\begin{tabular}{|c|c|c|c|c|c|c|}
\hline \multirow[b]{2}{*}{ Horas } & \multicolumn{3}{|c|}{ Erro Quadrático Horizontal (m) } & \multicolumn{3}{|c|}{ Erro Vertical (m) } \\
\hline & E.Q.H.P & E.Q.H.K & E.Q.H.S & E.V.P & E.V.K & E.V.S \\
\hline$(0-1)$ & 2,075 & 5,419 & 2,553 & 0,644 & $-3,293$ & 2,335 \\
\hline$(1-2)$ & 0,601 & 4,168 & 7,658 & 1,624 & $-4,149$ & 5,184 \\
\hline$(2-3)$ & 1,214 & 6,652 & 3,189 & $-2,175$ & $-4,550$ & $-1,859$ \\
\hline$(3-4)$ & 0,939 & 1,547 & 6,492 & 0,059 & $-4,059$ & 4,528 \\
\hline$(4-5)$ & 0,205 & 1,904 & 3,226 & 0,402 & $-1,502$ & 5,683 \\
\hline$(5-6)$ & 0,509 & 0,998 & 5,861 & 1,015 & 0,933 & 0,309 \\
\hline (6-7) & 0,975 & 0,331 & 5,209 & 0,764 & $-8,265$ & 4,016 \\
\hline$(7-8)$ & 1,254 & 3,065 & 2,642 & $-0,194$ & 4,864 & $-4,415$ \\
\hline$(8-9)$ & 2,329 & 5,348 & 5,783 & 0,516 & 1,573 & $-0,634$ \\
\hline$(9-10)$ & 3,770 & 2,698 & 6,954 & $-0,782$ & $-2,207$ & $-4,528$ \\
\hline$(10-11)$ & 4,514 & 6,032 & 8,491 & $-3,280$ & $-4,271$ & 0,894 \\
\hline$(11-12)$ & 3,215 & 3,798 & 3,240 & $-4,471$ & $-6,698$ & $-4,919$ \\
\hline$(12-13)$ & 2,233 & 2,303 & 6,516 & 0,082 & $-5,523$ & 1,054 \\
\hline$(13-14)$ & 2,435 & 3,800 & 3,153 & 1,952 & $-0,516$ & $-3,370$ \\
\hline$(14-15)$ & 1,533 & 1,000 & 7,877 & $-0,989$ & $-6,254$ & $-4,362$ \\
\hline$(15-16)$ & 3,289 & 4,170 & 5,756 & 1,496 & 2,061 & $-2,803$ \\
\hline$(16-17)$ & 3,569 & 4,768 & 11,257 & $-2,389$ & $-0,889$ & $-4,771$ \\
\hline$(17-18)$ & 2,184 & 3,280 & 2,301 & 2,169 & $-0,501$ & 0,231 \\
\hline$(18-19)$ & 1,407 & 4,540 & 1,989 & $-3,004$ & $-4,236$ & $-2,441$ \\
\hline$(19-20)$ & 2,898 & 4,783 & 3,054 & $-0,282$ & 5,193 & 2,021 \\
\hline$(20-21)$ & 2,559 & 4,240 & 1,198 & $-0,639$ & $-0,405$ & 3,574 \\
\hline$(21-22)$ & 1,346 & 0,914 & 4,935 & $-2,556$ & $-4,150$ & $-4,520$ \\
\hline$(22-23)$ & 1,476 & 6,263 & 5,962 & $-1,861$ & 4,622 & $-5,291$ \\
\hline E.M.Q & 2,023 & 3,566 & 5,013 & 1,450 & 3,509 & 3,206 \\
\hline Desvio Padrão & $\pm 1,140$ & $\pm 1,845$ & $\pm 2,495$ & $\pm 1,809$ & $\pm 3,767$ & $\pm 3,662$ \\
\hline
\end{tabular}




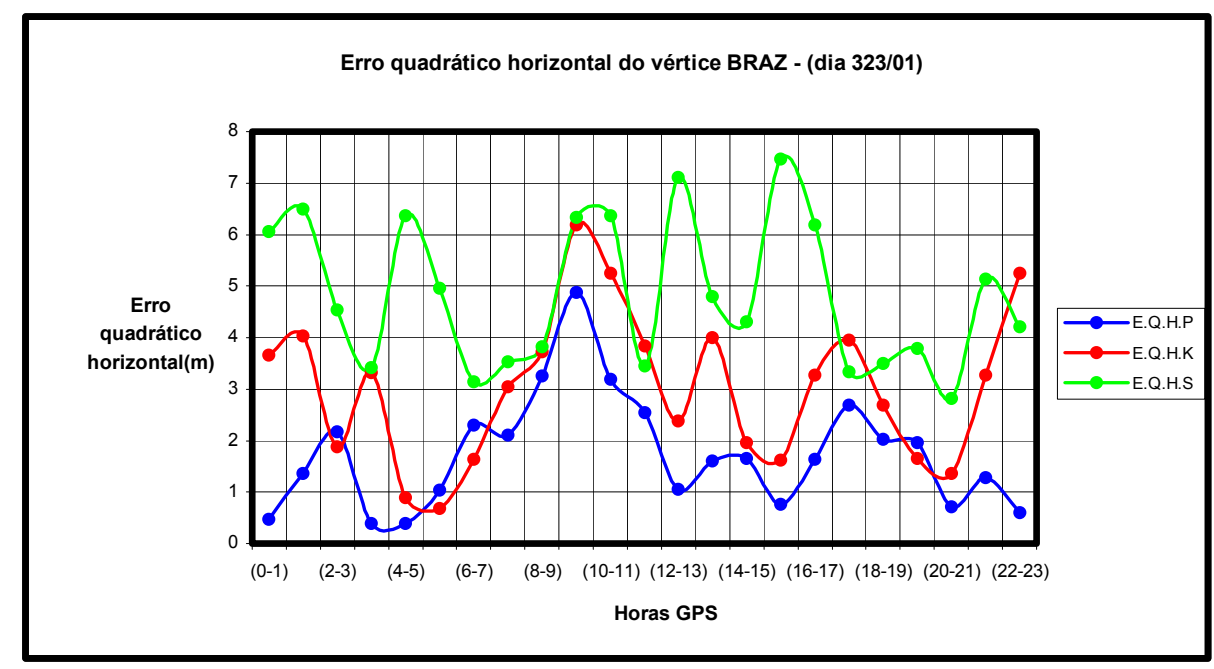

Figura 7.141 - Variação horária do erro quadrático horizontal no posicionamento Single Point do vértice BRAZ - (dia 323/01)

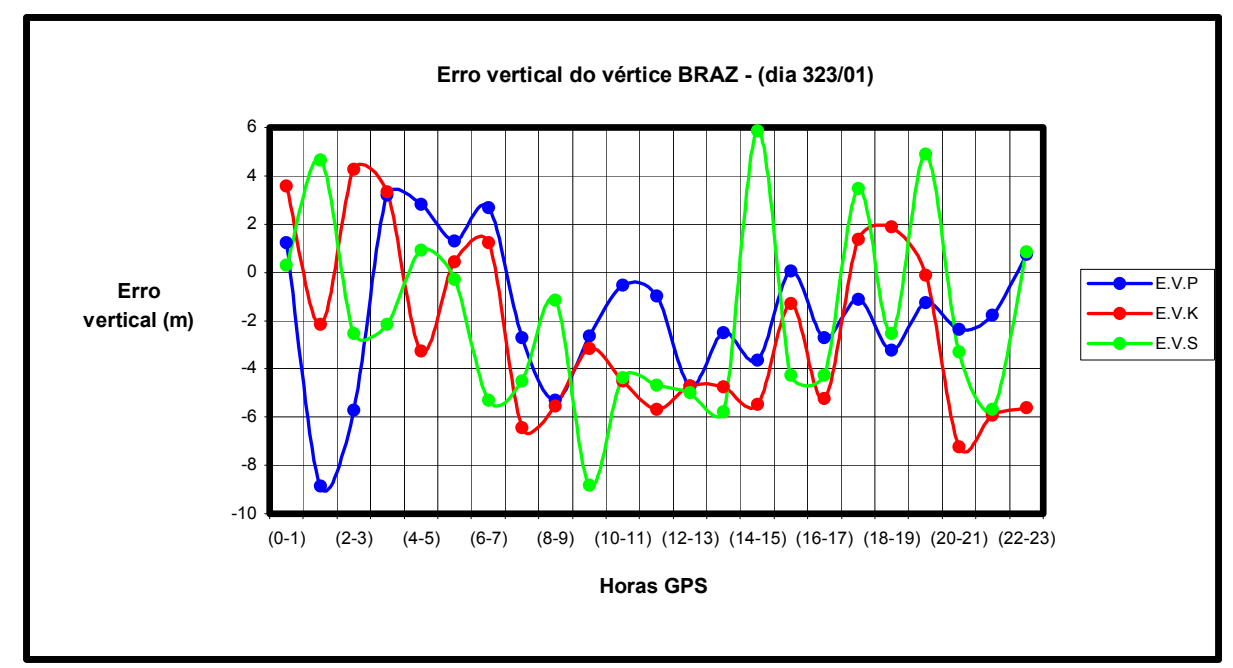

Figura 7.142 - Variação horária do erro vertical no posicionamento Single Point do vértice BRAZ - (dia 323/01) 
Tabela 7.99 - Erro quadrático horizontal e erro vertical no processamento Single Point do vértice BRAZ para diferentes modelos ionosféricos - (dia 323/01).

\begin{tabular}{|c|c|c|c|c|c|c|}
\hline \multirow[b]{2}{*}{ Horas } & \multicolumn{3}{|c|}{ Erro Quadrático Horizontal (m) } & \multicolumn{3}{|c|}{ Erro Vertical (m) } \\
\hline & E.Q.H.P & E.Q.H.K & E.Q.H.S & E.V.P & E.V.K & E.V.S \\
\hline$(0-1)$ & 0,475 & 3,666 & 6,052 & 1,222 & 3,578 & 0,284 \\
\hline$(1-2)$ & 1,357 & 4,029 & 6,502 & $-8,865$ & $-2,172$ & 4,650 \\
\hline$(2-3)$ & 2,166 & 1,885 & 4,526 & $-5,726$ & 4,259 & $-2,520$ \\
\hline$(3-4)$ & 0,392 & 3,320 & 3,423 & 3,198 & 3,323 & $-2,160$ \\
\hline$(4-5)$ & 0,389 & 0,896 & 6,372 & 2,834 & $-3,256$ & 0,914 \\
\hline$(5-6)$ & 1,034 & 0,677 & 4,962 & 1,304 & 0,438 & $-0,302$ \\
\hline$(6-7)$ & 2,302 & 1,640 & 3,137 & 2,688 & 1,226 & $-5,287$ \\
\hline$(7-8)$ & 2,111 & 3,052 & 3,538 & $-2,695$ & $-6,449$ & $-4,518$ \\
\hline$(8-9)$ & 3,263 & 3,727 & 3,824 & $-5,313$ & $-5,532$ & $-1,140$ \\
\hline$(9-10)$ & 4,873 & 6,184 & 6,339 & $-2,631$ & $-3,169$ & $-8,838$ \\
\hline$(10-11)$ & 3,194 & 5,240 & 6,365 & $-0,543$ & $-4,496$ & $-4,367$ \\
\hline$(11-12)$ & 2,549 & 3,834 & 3,445 & $-0,987$ & $-5,685$ & $-4,687$ \\
\hline$(12-13)$ & 1,060 & 2,380 & 7,111 & $-4,707$ & $-4,702$ & $-5,006$ \\
\hline$(13-14)$ & 1,600 & 3,995 & 4,789 & $-2,516$ & $-4,737$ & $-5,771$ \\
\hline$(14-15)$ & 1,652 & 1,952 & 4,305 & $-3,657$ & $-5,467$ & 5,860 \\
\hline$(15-16)$ & 0,760 & 1,615 & 7,473 & 0,045 & $-1,306$ & $-4,262$ \\
\hline$(16-17)$ & 1,631 & 3,278 & 6,183 & $-2,726$ & $-5,234$ & $-4,253$ \\
\hline$(17-18)$ & 2,687 & 3,948 & 3,336 & $-1,135$ & 1,355 & 3,463 \\
\hline$(18-19)$ & 2,025 & 2,689 & 3,495 & $-3,236$ & 1,883 & $-2,539$ \\
\hline$(19-20)$ & 1,961 & 1,644 & 3,781 & $-1,259$ & $-0,121$ & 4,906 \\
\hline$(20-21)$ & 0,708 & 1,352 & 2,822 & $-2,359$ & $-7,240$ & $-3,292$ \\
\hline$(21-22)$ & 1,277 & 3,278 & 5,141 & $-1,783$ & $-5,920$ & $-5,686$ \\
\hline$(22-23)$ & 0,598 & 5,249 & 4,215 & 0,741 & $-5,602$ & 0,851 \\
\hline E.M.Q & 1,742 & 3,023 & 4,832 & 2,703 & 3,789 & 3,720 \\
\hline Desvio Padrão & $\pm 1,097$ & $\pm 1,447$ & $\pm 1,427$ & $\pm 2,958$ & $\pm 3,630$ & $\pm 3,901$ \\
\hline
\end{tabular}

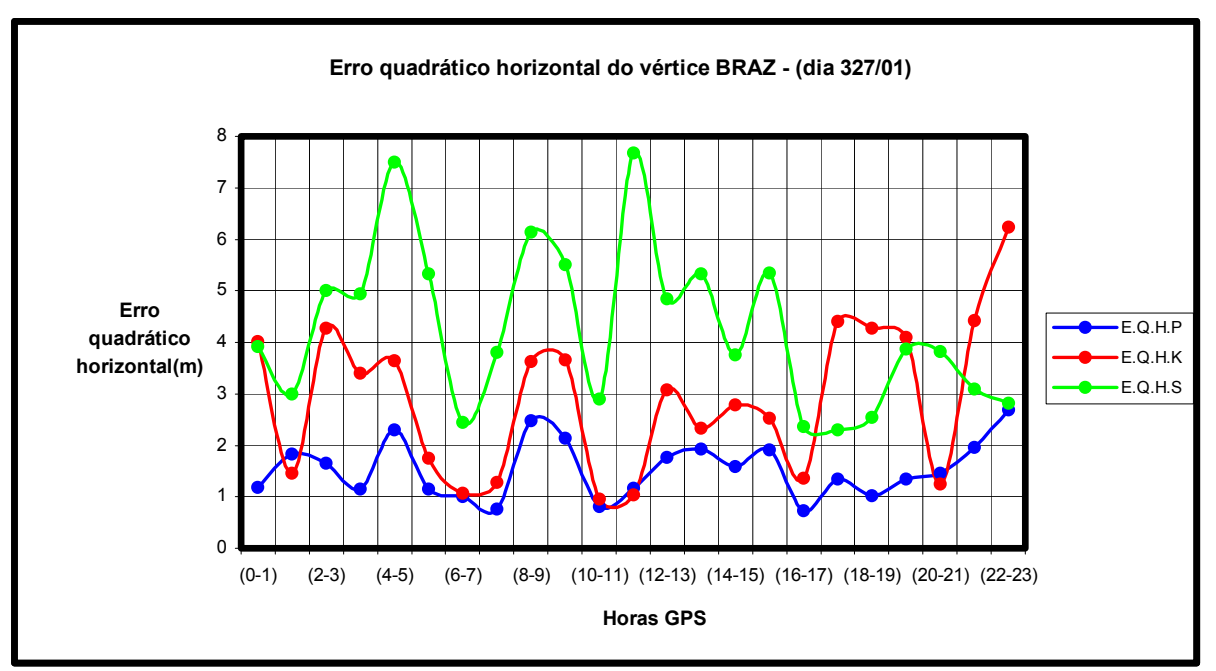

Figura 7.143 - Variação horária do erro quadrático horizontal no posicionamento Single Point do vértice BRAZ - (dia 327/01) 


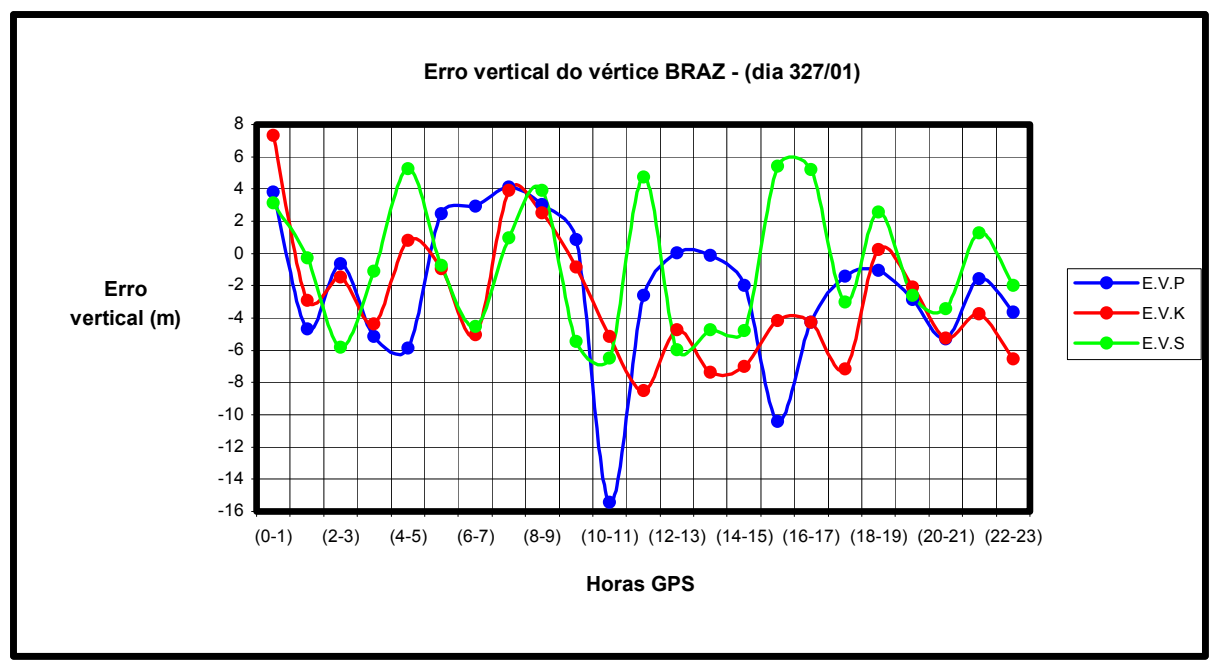

Figura 7.144 - Variação horária do erro vertical no posicionamento Single Point do vértice BRAZ - (dia 327/01)

Tabela 7.100 - Erro quadrático horizontal e erro vertical no processamento Single Point do vértice BRAZ para diferentes modelos ionosféricos - (dia 327/01).

\begin{tabular}{|c|c|c|c|c|c|c|}
\hline \multirow[b]{2}{*}{ Horas } & \multicolumn{3}{|c|}{ Erro Quadrático Horizontal (m) } & \multicolumn{3}{|c|}{ Erro Vertical $(m)$} \\
\hline & E.Q.H.P & E.Q.H.K & E.Q.H.S & E.V.P & E.V.K & E.V.S \\
\hline$(0-1)$ & 1,187 & 4,024 & 3,912 & 3,821 & 7,321 & 3,114 \\
\hline$(1-2)$ & 1,824 & 1,464 & 2,989 & $-4,683$ & $-2,913$ & $-0,281$ \\
\hline$(2-3)$ & 1,650 & 4,279 & 5,006 & $-0,657$ & $-1,442$ & $-5,834$ \\
\hline$(3-4)$ & 1,144 & 3,399 & 4,942 & $-5,140$ & $-4,337$ & $-1,126$ \\
\hline$(4-5)$ & 2,293 & 3,639 & 7,503 & $-5,850$ & 0,786 & 5,233 \\
\hline$(5-6)$ & 1,157 & 1,757 & 5,322 & 2,443 & $-0,970$ & $-0,726$ \\
\hline (6-7) & 1,003 & 1,064 & 2,449 & 2,918 & $-5,016$ & $-4,520$ \\
\hline$(7-8)$ & 0,764 & 1,271 & 3,808 & 4,130 & 3,898 & 0,991 \\
\hline$(8-9)$ & 2,485 & 3,634 & 6,139 & 3,059 & 2,509 & 3,920 \\
\hline$(9-10)$ & 2,143 & 3,659 & 5,513 & 0,855 & $-0,859$ & $-5,468$ \\
\hline$(10-11)$ & 0,807 & 0,951 & 2,894 & $-15,419$ & $-5,126$ & $-6,493$ \\
\hline$(11-12)$ & 1,173 & 1,031 & 7,683 & $-2,590$ & $-8,483$ & 4,755 \\
\hline$(12-13)$ & 1,772 & 3,084 & 4,836 & 0,042 & $-4,702$ & $-5,977$ \\
\hline$(13-14)$ & 1,926 & 2,336 & 5,331 & $-0,130$ & $-7,381$ & $-4,732$ \\
\hline (14-15) & 1,586 & 2,779 & 3,764 & $-1,974$ & $-6,981$ & $-4,775$ \\
\hline$(15-16)$ & 1,911 & 2,534 & 5,351 & $-10,440$ & $-4,155$ & 5,395 \\
\hline$(16-17)$ & 0,732 & 1,368 & 2,357 & $-4,282$ & $-4,261$ & 5,199 \\
\hline$(17-18)$ & 1,352 & 4,404 & 2,298 & $-1,413$ & $-7,155$ & $-3,005$ \\
\hline$(18-19)$ & 1,026 & 4,275 & 2,547 & $-1,041$ & 0,245 & 2,576 \\
\hline$(19-20)$ & 1,348 & 4,101 & 3,869 & $-2,846$ & $-2,096$ & $-2,578$ \\
\hline$(20-21)$ & 1,450 & 1,251 & 3,814 & $-5,317$ & $-5,259$ & $-3,446$ \\
\hline$(21-22)$ & 1,967 & 4,426 & 3,088 & $-1,550$ & $-3,765$ & 1,261 \\
\hline$(22-23)$ & 2,688 & 6,234 & 2,810 & $-3,615$ & $-6,522$ & $-1,967$ \\
\hline E.M.Q & 1,539 & 2,912 & 4,271 & 3,661 & 4,182 & 3,625 \\
\hline Desvio Padrão & $\pm 0,554$ & $\pm 1,452$ & $\pm 1,563$ & $\pm 4,585$ & $\pm 3,918$ & $\pm 4,080$ \\
\hline
\end{tabular}




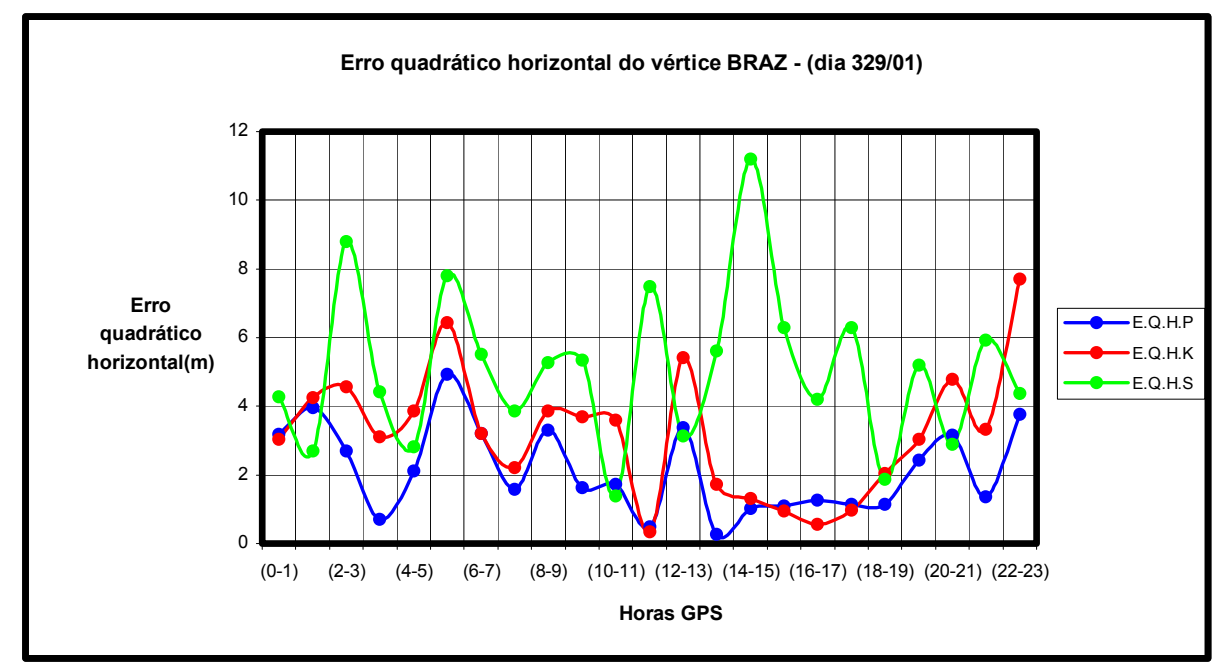

Figura 7.145 - Variação horária do erro quadrático horizontal no posicionamento Single Point do vértice BRAZ - (dia 329/01)

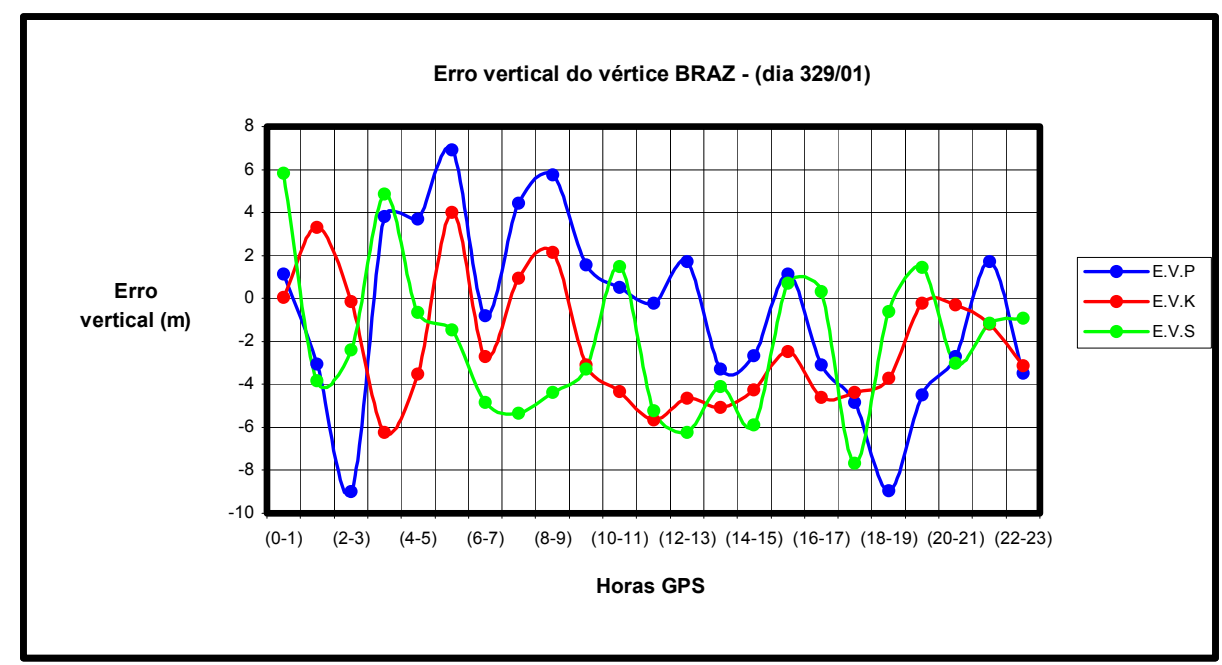

Figura 7.146 - Variação horária do erro vertical no posicionamento Single Point do vértice BRAZ - (dia 329/01) 
Tabela 7.101 - Erro quadrático horizontal e erro vertical no processamento Single Point do vértice BRAZ para diferentes modelos ionosféricos - (dia 329/01).

\begin{tabular}{|c|c|c|c|c|c|c|}
\hline \multirow[b]{2}{*}{ Horas } & \multicolumn{3}{|c|}{ Erro Quadrático Horizontal (m) } & \multicolumn{3}{|c|}{ Erro Vertical (m) } \\
\hline & E.Q.H.P & E.Q.H.K & E.Q.H.S & E.V.P & E.V.K & E.V.S \\
\hline$(0-1)$ & 3,172 & 3,038 & 4,282 & 1,119 & 0,058 & 5,830 \\
\hline$(1-2)$ & 3,971 & 4,251 & 2,694 & $-3,072$ & 3,324 & $-3,817$ \\
\hline$(2-3)$ & 2,694 & 4,557 & 8,786 & $-8,983$ & $-0,149$ & $-2,383$ \\
\hline$(3-4)$ & 0,716 & 3,101 & 4,414 & 3,795 & $-6,250$ & 4,855 \\
\hline$(4-5)$ & 2,114 & 3,851 & 2,820 & 3,711 & $-3,521$ & $-0,668$ \\
\hline$(5-6)$ & 4,923 & 6,434 & 7,795 & 6,900 & 4,011 & $-1,467$ \\
\hline$(6-7)$ & 3,204 & 3,213 & 5,520 & $-0,824$ & $-2,707$ & $-4,849$ \\
\hline$(7-8)$ & 1,583 & 2,203 & 3,858 & 4,442 & 0,933 & $-5,347$ \\
\hline$(8-9)$ & 3,300 & 3,854 & 5,268 & 5,765 & 2,129 & $-4,381$ \\
\hline$(9-10)$ & 1,620 & 3,680 & 5,351 & 1,545 & $-3,092$ & $-3,280$ \\
\hline$(10-11)$ & 1,736 & 3,595 & 1,386 & 0,532 & $-4,331$ & 1,483 \\
\hline$(11-12)$ & 0,489 & 0,331 & 7,488 & $-0,233$ & $-5,637$ & $-5,247$ \\
\hline$(12-13)$ & 3,387 & 5,424 & 3,137 & 1,709 & $-4,664$ & $-6,221$ \\
\hline$(13-14)$ & 0,276 & 1,724 & 5,600 & $-3,270$ & $-5,069$ & $-4,114$ \\
\hline (14-15) & 1,023 & 1,308 & 11,203 & $-2,663$ & $-4,265$ & $-5,890$ \\
\hline$(15-16)$ & 1,092 & 0,943 & 6,286 & 1,114 & $-2,473$ & 0,691 \\
\hline$(16-17)$ & 1,273 & 0,551 & 4,205 & $-3,101$ & $-4,596$ & 0,308 \\
\hline$(17-18)$ & 1,153 & 0,983 & 6,300 & $-4,857$ & $-4,383$ & $-7,659$ \\
\hline$(18-19)$ & 1,140 & 2,048 & 1,872 & $-8,954$ & $-3,712$ & $-0,594$ \\
\hline$(19-20)$ & 2,430 & 3,028 & 5,196 & $-4,482$ & $-0,207$ & 1,453 \\
\hline$(20-21)$ & 3,164 & 4,793 & 2,889 & $-2,716$ & $-0,287$ & $-3,002$ \\
\hline$(21-22)$ & 1,366 & 3,324 & 5,929 & 1,716 & $-1,199$ & $-1,157$ \\
\hline$(22-23)$ & 3,776 & 7,692 & 4,364 & $-3,487$ & $-3,149$ & $-0,903$ \\
\hline E.M.Q & 2,157 & 3,214 & 5,071 & 3,434 & 3,050 & 3,287 \\
\hline Desvio Padr & $\pm 1,260$ & $\pm 1,855$ & $\pm 2,294$ & $\pm 4,224$ & $\pm 2,887$ & $\pm 3,450$ \\
\hline
\end{tabular}

\subsubsection{Validação do modelo através de posicionamento relativo - período da primavera}

Nesta última etapa de processamento de dados GPS, na metodologia relativa, verificou-se que, durante esta estação do ano, o efeito da ionosfera nos sinais GPS ocorreu de uma forma mais intensa que no verão, no outono e na primavera, sendo comprovado através do aumento dos erros horizontais e verticais do vértice UEPP. O maiores erros ocorreram também entre os intervalos das 0 às 6 e das 16 às 23 horas GPS. Mesmo com um aumento dos erros, o modelo polinomial mostrou-se mais eficiente que o de Klobuchar e Standard.

Neste período da primavera, em média (horizontalmente e verticalmente), o modelo de Klobuchar mostrou-se mais eficiente que o Standard. Isto pode ser verificado através dos valores abaixo: 
- E.M.Q.H.P $=0,589 \mathrm{~m} \pm 0,664 \mathrm{~m}$

- E.M.Q.H.K = 1,013m $\pm 0,890 \mathrm{~m}$

- E.M.Q.H.S $=1,243 m \pm 1,042 m$

O modelo polinomial proporcionou, em média, uma melhora de $0,424 \mathrm{~m}$ e $0,654 \mathrm{~m}$, em relação aos modelos de Klobuchar e Standard, respectivamente.

Em relação ao erro vertical, os valores médios para o período mostraram-se semelhantes, com uma pequena melhora quando se utiliza o modelo polinomial. Este fato pode ser verificado através dos valores abaixo:

- E.M.Q.V.P $=1,023 m \pm 1,422 m$

- E.M.Q.V.K = 1,206m $\pm 1,678 m$

- E.M.Q.V.S $=1,270 \mathrm{~m} \pm 1,510 \mathrm{~m}$

A seguir serão apresentados todos os resultados referentes ao posicionamento relativo, durante o período da primavera estudado.

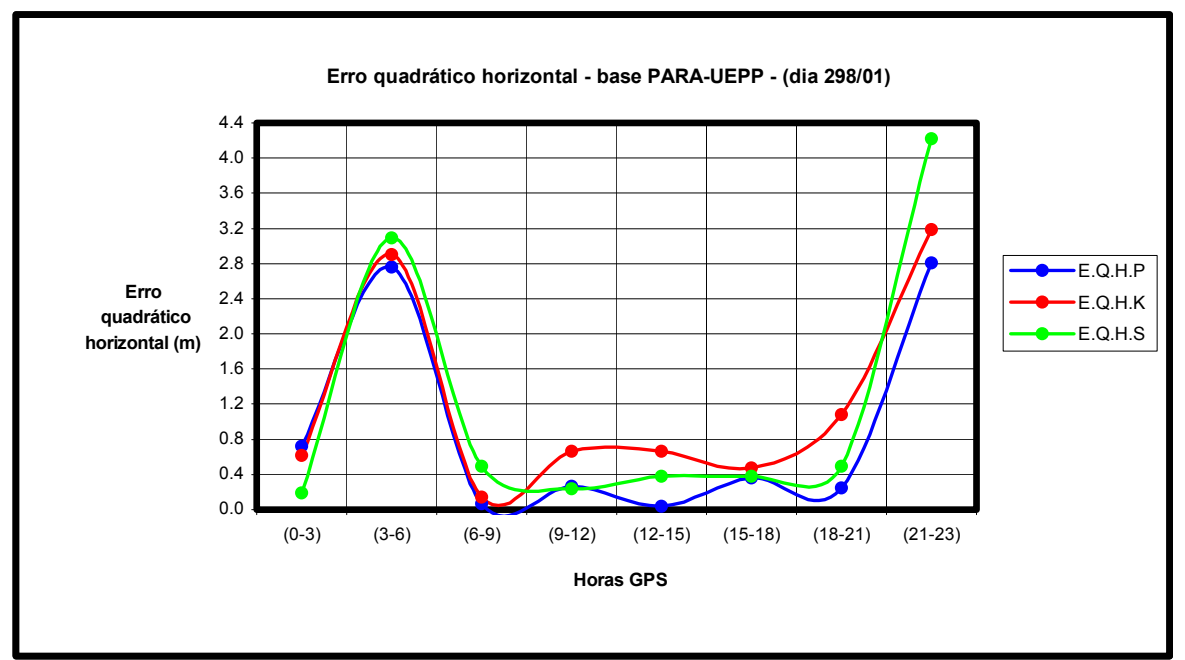

Figura 7.147 - Variação horária do erro quadrático horizontal do vértice UEPP no posicionamento relativo da base PARA - UEPP - (dia 298/01). 


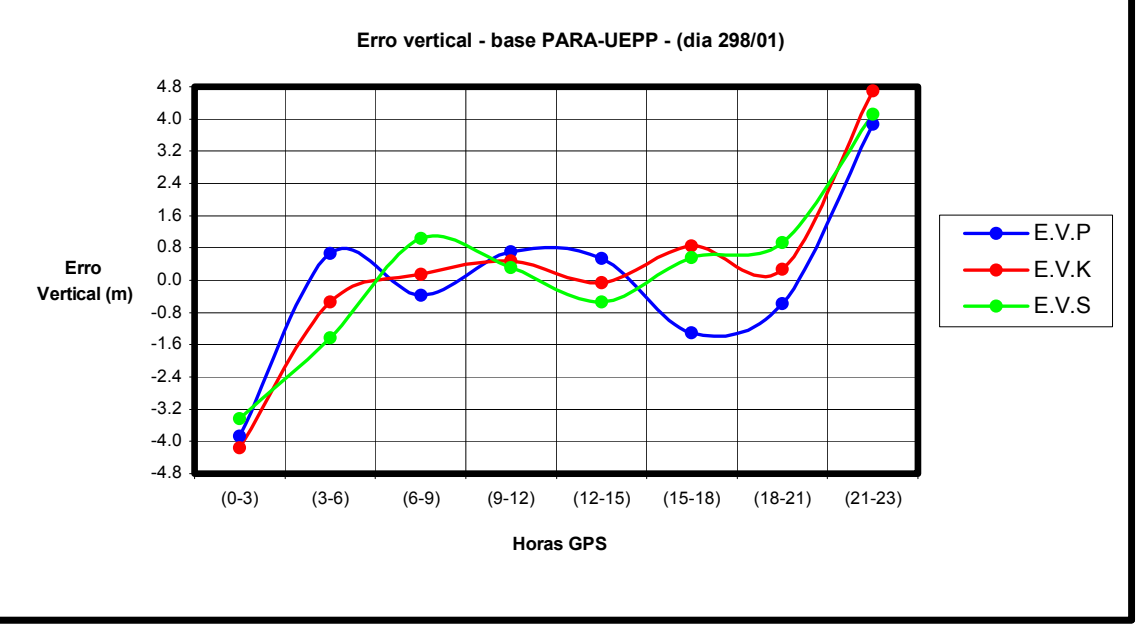

Figura 7.148 - Variação horária do erro vertical do vértice UEPP no posicionamento relativo da base PARA - UEPP - (dia 298/01).

Tabela 7.102 - Erro quadrático horizontal e erro vertical do vértice UEPP no processamento relativo da base PARA - UEPP, para diferentes modelos ionosféricos - (dia 298/01).

\begin{tabular}{|c|c|c|c|c|c|c|}
\cline { 2 - 7 } \multicolumn{1}{c|}{} & \multicolumn{3}{c|}{ Erro Quadrático Horizontal (m) } & \multicolumn{3}{c|}{ Erro Vertical (m) } \\
\hline Horas & E.Q.H.P & E.Q.H.K & E.Q.H.S & E.V.P & E.V.K & E.V.S \\
\hline $\mathbf{( 0 - 3 )}$ & 0,722 & 0,616 & 0,186 & $-3,865$ & $-4,165$ & $-3,444$ \\
\hline $\mathbf{( 3 - 6 )}$ & 2,756 & 2,906 & 3,087 & 0,661 & $-0,540$ & $-1,425$ \\
\hline $\mathbf{6 - 9})$ & 0,071 & 0,145 & 0,496 & $-0,379$ & 0,145 & 1,031 \\
\hline $\mathbf{( 9 - 1 2 )}$ & 0,266 & 0,667 & 0,238 & 0,703 & 0,486 & 0,312 \\
\hline $\mathbf{( 1 2 - 1 5 )}$ & 0,035 & 0,662 & 0,378 & 0,547 & $-0,069$ & $-0,529$ \\
\hline$(\mathbf{1 5 - 1 8 )}$ & 0,358 & 0,474 & 0,378 & $-1,298$ & 0,854 & 0,551 \\
\hline $\mathbf{( 1 8 - 2 1 )}$ & 0,242 & 1,086 & 0,496 & $-0,589$ & 0,270 & 0,941 \\
\hline $\mathbf{( 2 1 - 2 3 )}$ & 2,810 & 3,190 & 4,224 & 3,861 & 4,696 & 4,109 \\
\hline E.M.Q & $\mathbf{0 , 9 0 7}$ & $\mathbf{1 , 2 1 8}$ & $\mathbf{1 , 1 8 5}$ & $\mathbf{1 , 4 8 8}$ & $\mathbf{1 , 4 0 3}$ & $\mathbf{1 , 5 4 3}$ \\
\hline Desvio Padrão & $\pm \mathbf{1 , 1 7 7}$ & $\pm \mathbf{1 , 1 6 1}$ & $\pm \mathbf{1 , 5 5 8}$ & $\pm \mathbf{2 , 1 7 9}$ & $\pm \mathbf{2 , 4 0 2}$ & $\pm \mathbf{2 , 1 7 5}$ \\
\hline
\end{tabular}




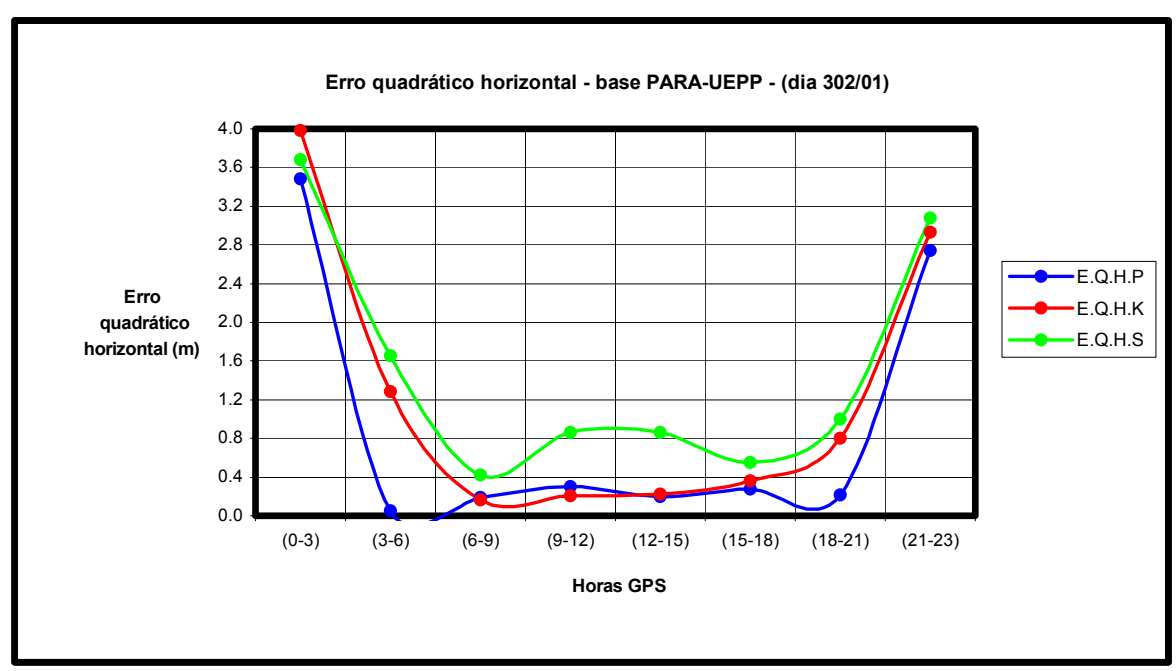

Figura 7.149 - Variação horária do erro quadrático horizontal do vértice UEPP no posicionamento relativo da base PARA - UEPP - (dia 302/01).

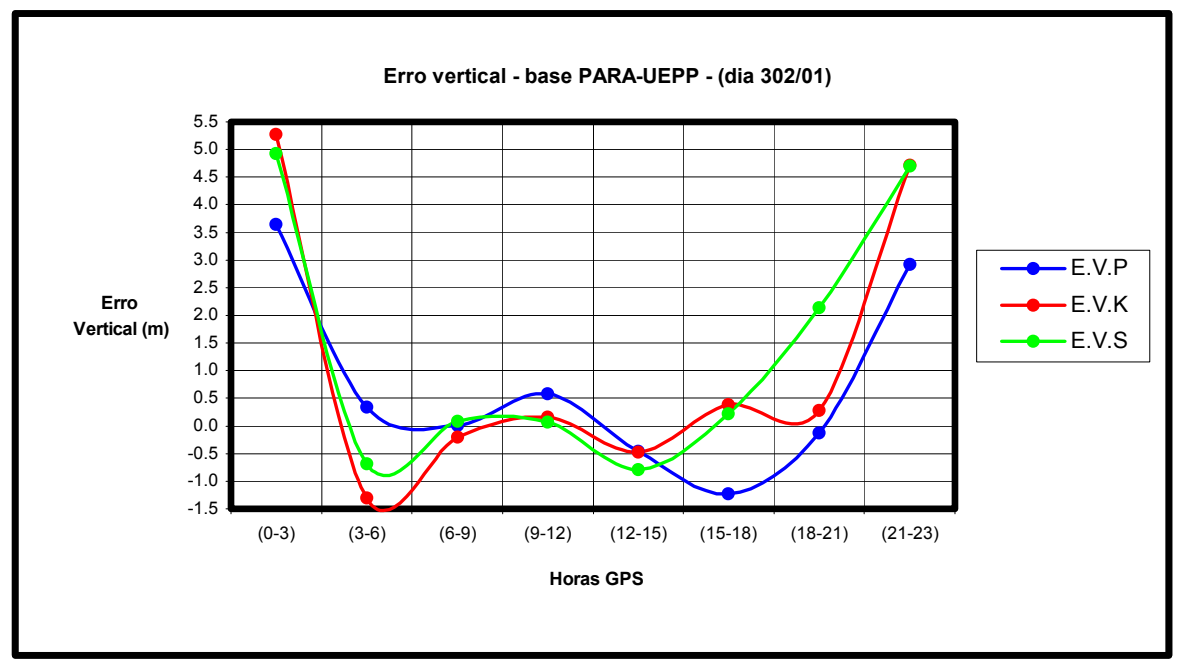

Figura 7.150 - Variação horária do erro vertical do vértice UEPP no posicionamento relativo da base PARA - UEPP - (dia 302/01).

Tabela 7.103 - Erro quadrático horizontal e erro vertical do vértice UEPP no processamento relativo da base PARA - UEPP, para diferentes modelos ionosféricos - (dia 302/01).

\begin{tabular}{|c|c|c|c|c|c|c|}
\cline { 2 - 7 } \multicolumn{1}{c|}{} & \multicolumn{3}{c|}{ Erro Quadrático Horizontal (m) } & \multicolumn{3}{c|}{ Erro Vertical (m) } \\
\hline Horas & E.Q.H.P & E.Q.H.K & E.Q.H.S & E.V.P & E.V.K & E.V.S \\
\hline $\mathbf{( 0 - 3 )}$ & 3,483 & 3,979 & 3,677 & 3,642 & 5,270 & 4,933 \\
\hline $\mathbf{( 3 - 6 )}$ & 0,051 & 1,282 & 1,654 & 0,346 & $-1,310$ & $-0,684$ \\
\hline $\mathbf{( 6 - 9 )}$ & 0,193 & 0,164 & 0,419 & 0,011 & $-0,210$ & 0,080 \\
\hline $\mathbf{( 9 - 1 2 )}$ & 0,299 & 0,208 & 0,859 & 0,589 & 0,166 & 0,062 \\
\hline $\mathbf{( 1 2 - 1 5 )}$ & 0,200 & 0,226 & 0,861 & $-0,461$ & $-0,470$ & $-0,795$ \\
\hline $\mathbf{( 1 5 - 1 8 )}$ & 0,279 & 0,362 & 0,554 & $-1,231$ & 0,386 & 0,218 \\
\hline $\mathbf{( 1 8 - 2 1 )}$ & 0,216 & 0,804 & 1,001 & $-0,132$ & 0,277 & 2,132 \\
\hline $\mathbf{( 2 1 - 2 3 )}$ & 2,740 & 2,928 & 3,079 & 2,926 & 4,709 & 4,693 \\
\hline E.M.Q & $\mathbf{0 , 9 3 3}$ & $\mathbf{1 , 2 4 4}$ & $\mathbf{1 , 5 1 3}$ & $\mathbf{1 , 1 6 7}$ & $\mathbf{1 , 6 0 0}$ & $\mathbf{1 , 7 0 0}$ \\
\hline Desvio Padrão & $\pm \mathbf{1 , 3 6 1}$ & $\pm \mathbf{1 , 4 4 2}$ & $\pm \mathbf{1 , 2 1 8}$ & $\pm \mathbf{1 , 6 9 0}$ & $\pm \mathbf{2 , 4 6 3}$ & $\pm \mathbf{2 , 3 2 7}$ \\
\hline
\end{tabular}




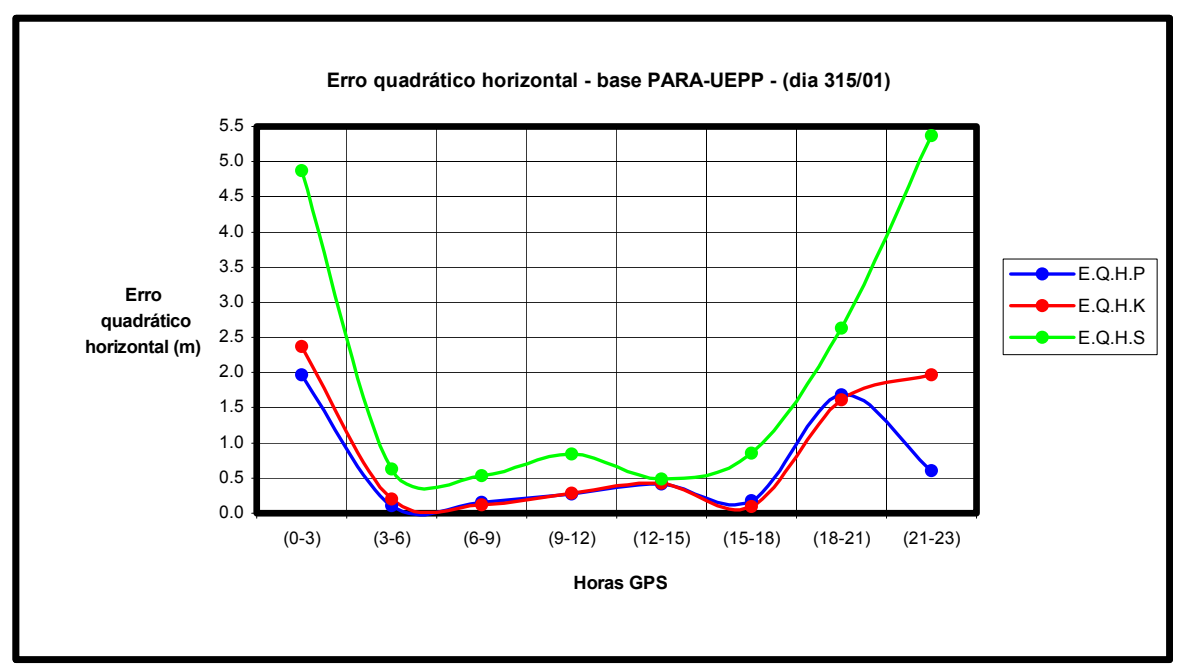

Figura 7.151 - Variação horária do erro quadrático horizontal do vértice UEPP no posicionamento relativo da base PARA - UEPP - (dia 315/01).

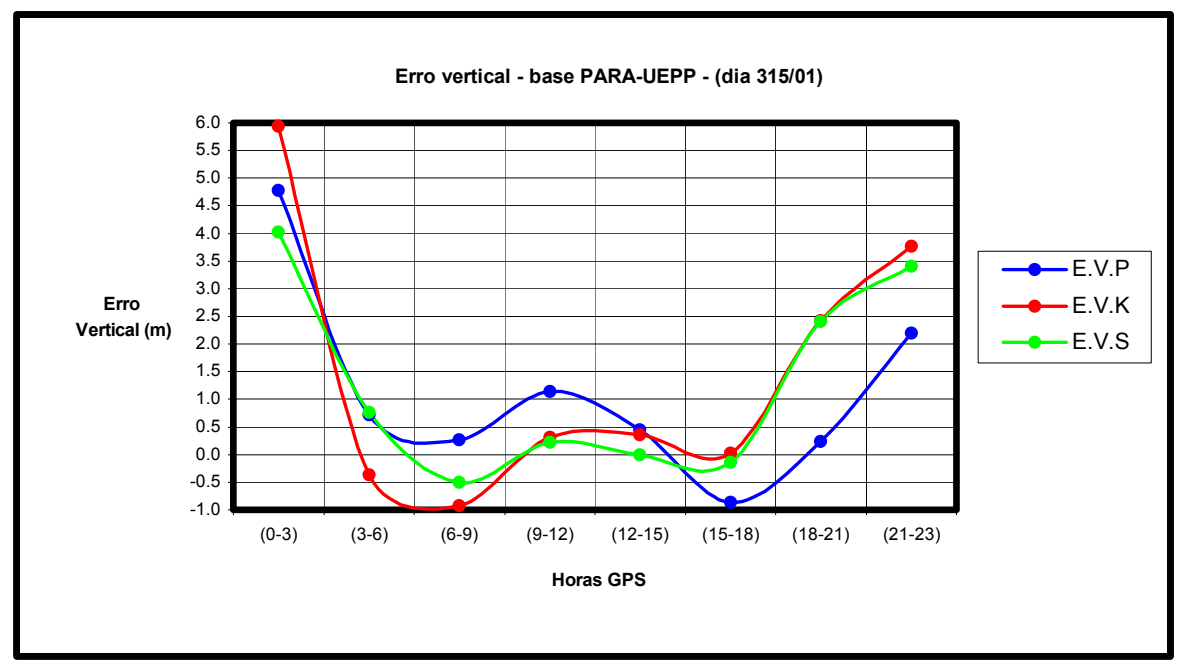

Figura 7.152 - Variação horária do erro vertical do vértice UEPP no posicionamento relativo da base PARA - UEPP - (dia 315/01).

Tabela 7.104 - Erro quadrático horizontal e erro vertical do vértice UEPP no processamento relativo da base PARA - UEPP, para diferentes modelos ionosféricos - (dia 315/01).

\begin{tabular}{|c|c|c|c|c|c|c|}
\cline { 2 - 7 } \multicolumn{1}{c|}{} & \multicolumn{3}{c|}{ Erro Quadrático Horizontal (m) } & \multicolumn{3}{c|}{ Erro Vertical (m) } \\
\hline Horas & E.Q.H.P & E.Q.H.K & E.Q.H.S & E.V.P & E.V.K & E.V.S \\
\hline $\mathbf{( 0 - 3 )}$ & 1,971 & 2,374 & 4,874 & 4,774 & 5,947 & 4,026 \\
\hline $\mathbf{( 3 - 6 )}$ & 0,104 & 0,204 & 0,626 & 0,724 & $-0,369$ & 0,760 \\
\hline $\mathbf{( 6 - 9 )}$ & 0,152 & 0,121 & 0,537 & 0,272 & $-0,928$ & $-0,505$ \\
\hline $\mathbf{( 9 - 1 2 )}$ & 0,270 & 0,284 & 0,836 & 1,144 & 0,312 & 0,224 \\
\hline$(\mathbf{1 2 - 1 5 )}$ & 0,411 & 0,427 & 0,480 & 0,441 & 0,354 & $-0,004$ \\
\hline$(\mathbf{1 5 - 1 8 )}$ & 0,173 & 0,097 & 0,851 & $-0,867$ & 0,022 & $-0,142$ \\
\hline $\mathbf{( 1 8 - 2 1 )}$ & 1,688 & 1,608 & 2,637 & 0,239 & 2,426 & 2,405 \\
\hline $\mathbf{( 2 1 - 2 3 )}$ & 0,609 & 1,970 & 5,365 & 2,194 & 3,763 & 3,402 \\
\hline E.M.Q & $\mathbf{0 , 6 7 2}$ & $\mathbf{0 , 8 8 6}$ & $\mathbf{2 , 0 2 6}$ & $\mathbf{1 , 3 3 2}$ & $\mathbf{1 , 7 6 5}$ & $\mathbf{1 , 4 3 4}$ \\
\hline Desvio Padrão & $\pm \mathbf{0 , 7 3 6}$ & $\pm \mathbf{0 , 9 3 8}$ & $\pm \mathbf{2 , 0 3 5}$ & $\pm \mathbf{1 , 7 1 4}$ & $\pm \mathbf{2 , 3 9 1}$ & $\pm \mathbf{1 , 7 5 5}$ \\
\hline
\end{tabular}




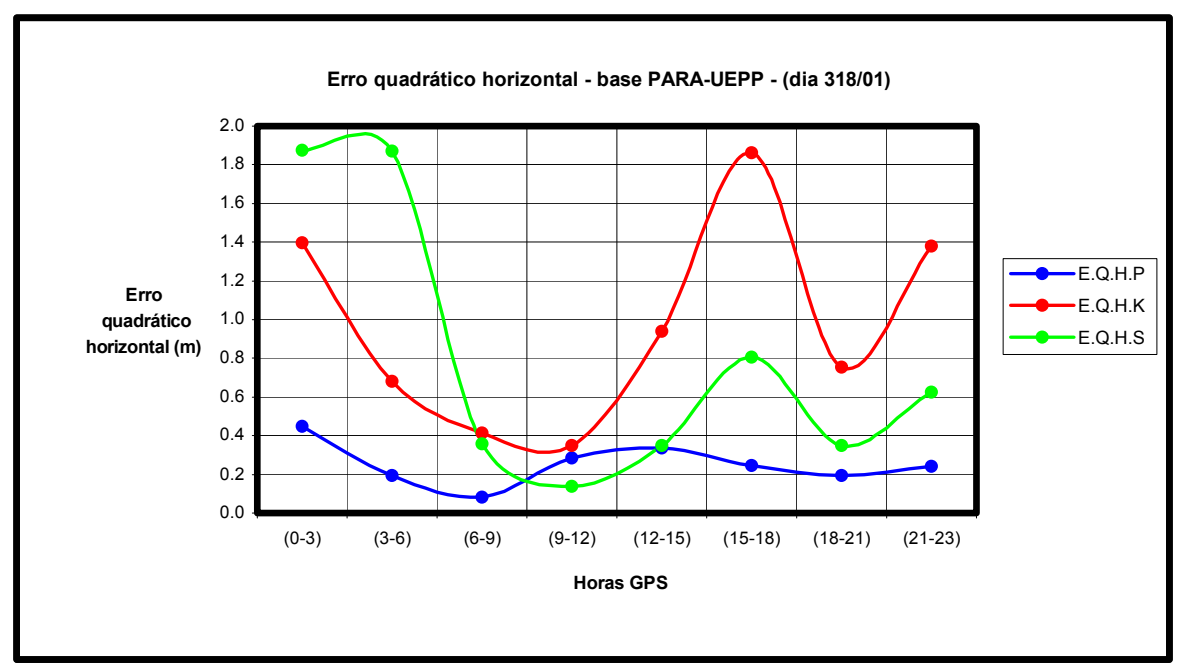

Figura 7.153 - Variação horária do erro quadrático horizontal do vértice UEPP no posicionamento relativo da base PARA - UEPP - (dia 318/01).

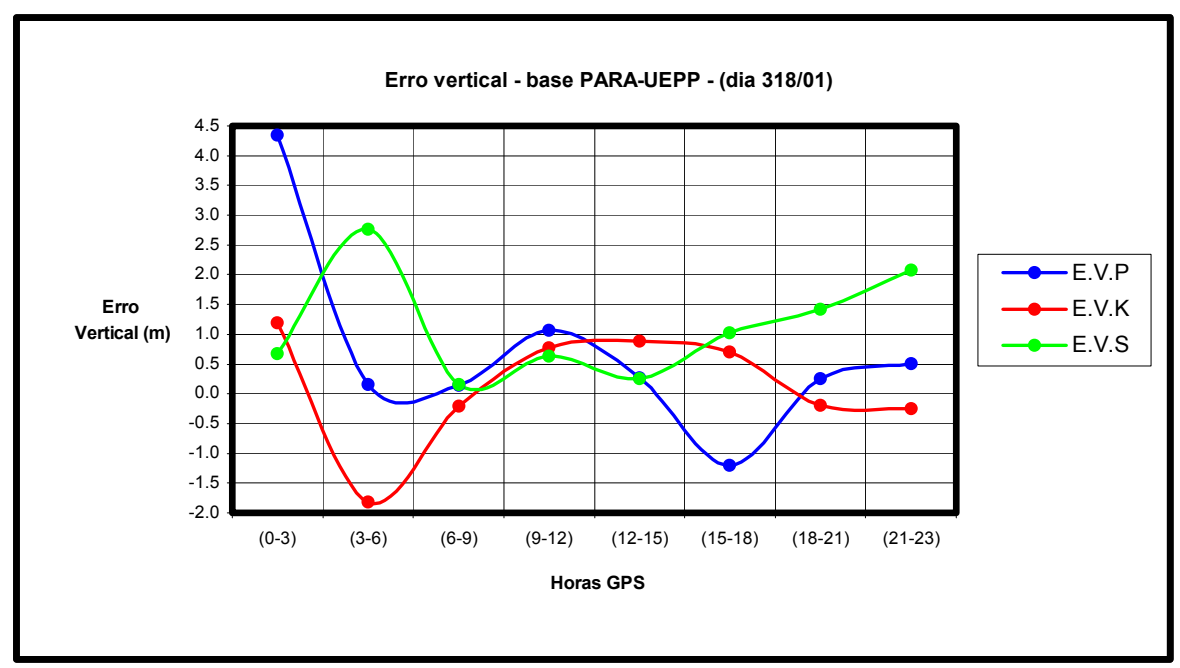

Figura 7.154 - Variação horária do erro vertical do vértice UEPP no posicionamento relativo da base PARA - UEPP - (dia 318/01).

Tabela 7.105 - Erro quadrático horizontal e erro vertical do vértice UEPP no processamento relativo da base PARA - UEPP, para diferentes modelos ionosféricos - (dia 318/01).

\begin{tabular}{|c|c|c|c|c|c|c|}
\cline { 2 - 7 } \multicolumn{1}{c|}{} & \multicolumn{2}{c|}{ Erro Quadrático Horizontal (m) } & \multicolumn{3}{c|}{ Erro Vertical (m) } \\
\hline Horas & E.Q.H.P & E.Q.H.K & E.Q.H.S & E.V.P & E.V.K & E.V.S \\
\hline $\mathbf{( 0 - 3 )}$ & 0,450 & 1,396 & 1,877 & 4,351 & 1,189 & 0,683 \\
\hline $\mathbf{( 3 - 6 )}$ & 0,192 & 0,681 & 1,871 & 0,153 & $-1,813$ & 2,766 \\
\hline $\mathbf{( 6 - 9 )}$ & 0,081 & 0,413 & 0,357 & 0,138 & $-0,208$ & 0,156 \\
\hline $\mathbf{( 9 - 1 2 )}$ & 0,285 & 0,348 & 0,138 & 1,063 & 0,774 & 0,640 \\
\hline $\mathbf{( 1 2 - 1 5 )}$ & 0,336 & 0,941 & 0,350 & 0,269 & 0,882 & 0,252 \\
\hline $\mathbf{( 1 5 - 1 8 )}$ & 0,245 & 1,860 & 0,808 & $-1,207$ & 0,699 & 1,024 \\
\hline $\mathbf{( 1 8 - 2 1 )}$ & 0,196 & 0,753 & 0,349 & 0,251 & $-0,193$ & 1,423 \\
\hline $\mathbf{( 2 1 - 2 3 )}$ & 0,242 & 1,380 & 0,623 & 0,512 & $-0,242$ & 2,083 \\
\hline E.M.Q & $\mathbf{0 , 2 5 3}$ & $\mathbf{0 , 9 7 1}$ & $\mathbf{0 , 7 9 7}$ & $\mathbf{0 , 9 9 3}$ & $\mathbf{0 , 7 5 0}$ & $\mathbf{1 , 1 2 8}$ \\
\hline Desvio Padrão & $\pm \mathbf{0 , 1 0 9}$ & $\pm \mathbf{0 , 5 3 1}$ & $\pm \mathbf{0 , 6 9 5}$ & $\pm \mathbf{1 , 6 1 0}$ & $\pm \mathbf{0 , 9 6 8}$ & $\pm \mathbf{0 , 9 1 3}$ \\
\hline
\end{tabular}




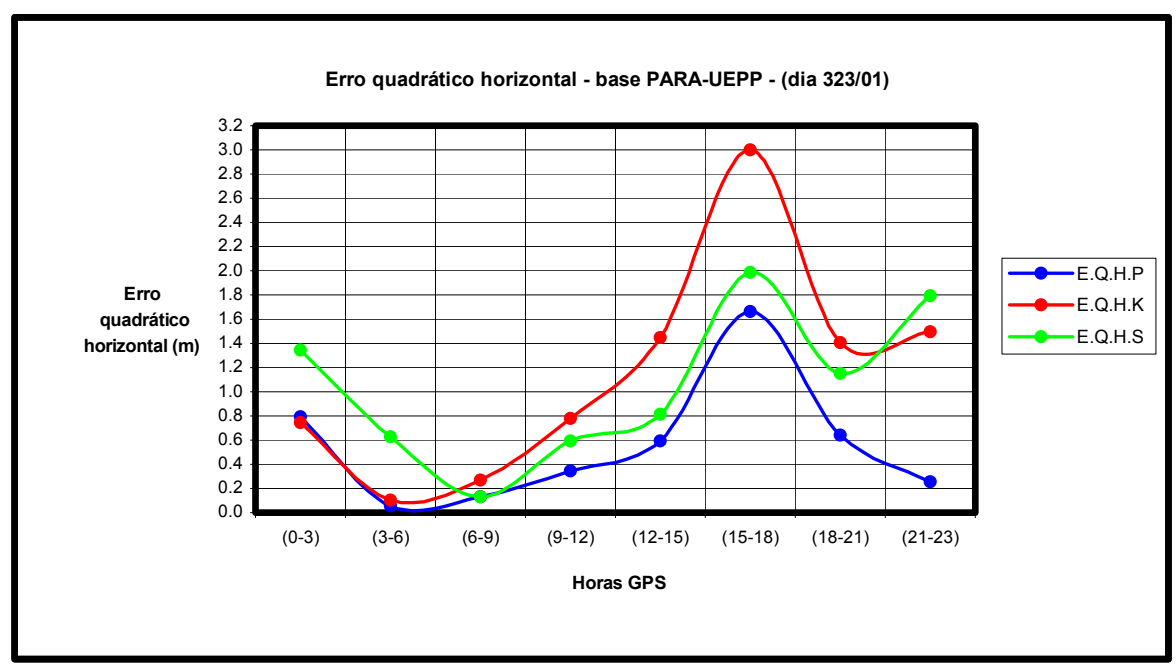

Figura 7.155 - Variação horária do erro quadrático horizontal do vértice UEPP no posicionamento relativo da base PARA - UEPP - (dia 323/01).

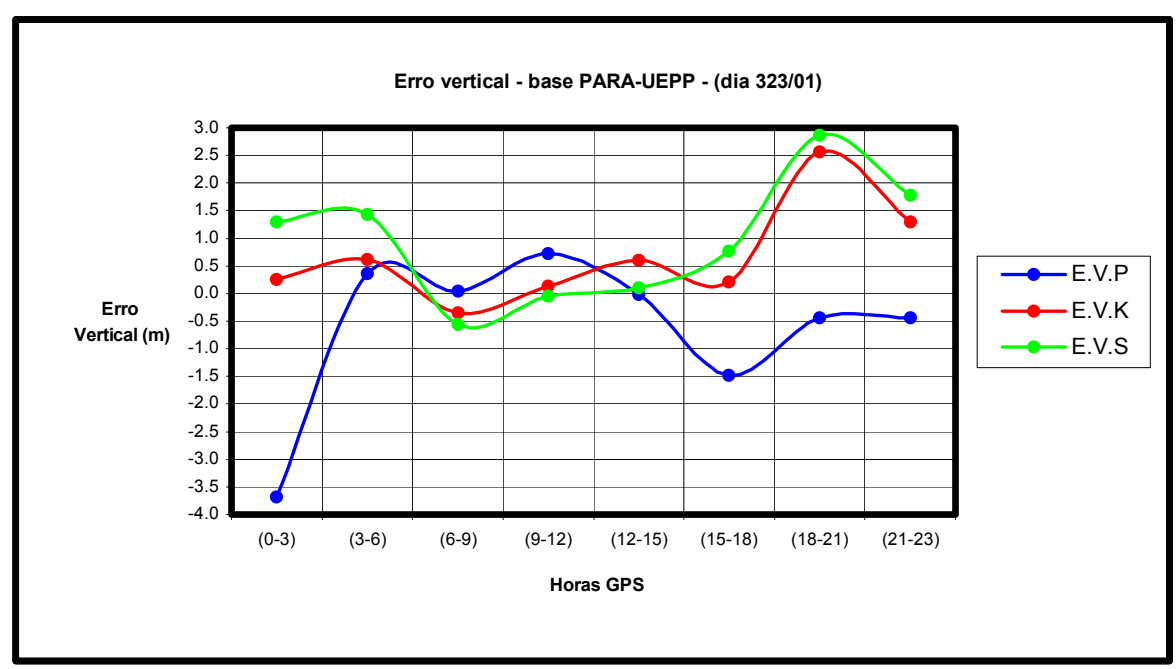

Figura 7.156 - Variação horária do erro vertical do vértice UEPP no posicionamento relativo da base PARA - UEPP - (dia 323/01).

Tabela 7.106 - Erro quadrático horizontal e erro vertical do vértice UEPP no processamento relativo da base PARA - UEPP, para diferentes modelos ionosféricos - (dia 323/01).

\begin{tabular}{|c|c|c|c|c|c|c|}
\cline { 2 - 7 } \multicolumn{1}{c|}{} & \multicolumn{3}{c|}{ Erro Quadrático Horizontal (m) } & \multicolumn{3}{c|}{ Erro Vertical (m) } \\
\hline Horas & E.Q.H.P & E.Q.H.K & E.Q.H.S & E.V.P & E.V.K & E.V.S \\
\hline $\mathbf{( 0 - 3 )}$ & 0,796 & 0,747 & 1,347 & $-3,680$ & 0,255 & 1,294 \\
\hline $\mathbf{( 3 - 6 )}$ & 0,057 & 0,101 & 0,626 & 0,367 & 0,609 & 1,426 \\
\hline $\mathbf{( 6 - 9 )}$ & 0,128 & 0,266 & 0,130 & 0,043 & $-0,344$ & $-0,554$ \\
\hline $\mathbf{( 9 - 1 2 )}$ & 0,348 & 0,779 & 0,591 & 0,721 & 0,136 & $-0,049$ \\
\hline $\mathbf{( 1 2 - 1 5 )}$ & 0,593 & 1,446 & 0,814 & $-0,024$ & 0,597 & 0,108 \\
\hline $\mathbf{( 1 5 - 1 8 )}$ & 1,664 & 3,001 & 1,984 & $-1,481$ & 0,204 & 0,763 \\
\hline $\mathbf{( 1 8 - 2 1 )}$ & 0,643 & 1,409 & 1,152 & $-0,433$ & 2,570 & 2,866 \\
\hline $\mathbf{( 2 1 - 2 3 )}$ & 0,257 & 1,499 & 1,793 & $-0,446$ & 1,301 & 1,784 \\
\hline E.M.Q & $\mathbf{0 , 5 6 1}$ & $\mathbf{1 , 1 5 6}$ & $\mathbf{1 , 0 5 5}$ & $\mathbf{0 , 8 9 9}$ & $\mathbf{0 , 7 5 2}$ & $\mathbf{1 , 1 0 6}$ \\
\hline Desvio Padrão & $\pm \mathbf{0 , 5 1 5}$ & $\pm \mathbf{0 , 9 1 7}$ & $\pm \mathbf{0 , 6 3 4}$ & $\pm \mathbf{1 , 4 0 1}$ & $\pm \mathbf{0 , 9 0 4}$ & $\pm \mathbf{1 , 1 1 6}$ \\
\hline
\end{tabular}




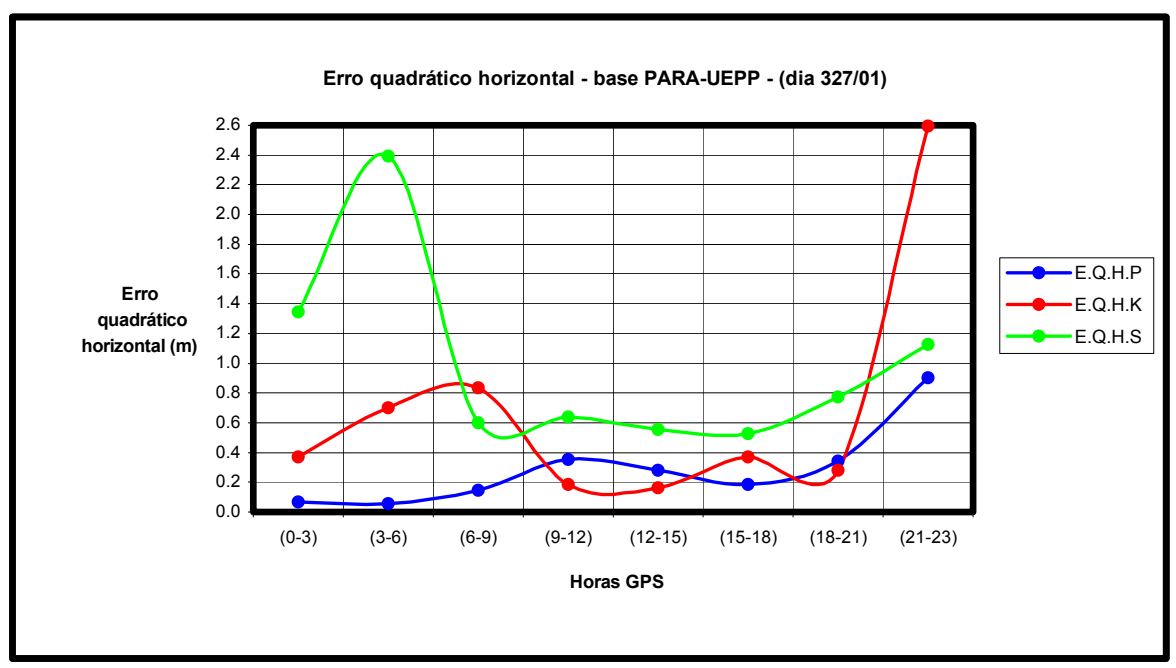

Figura 7.157 - Variação horária do erro quadrático horizontal do vértice UEPP no posicionamento relativo da base PARA - UEPP - (dia 327/01).

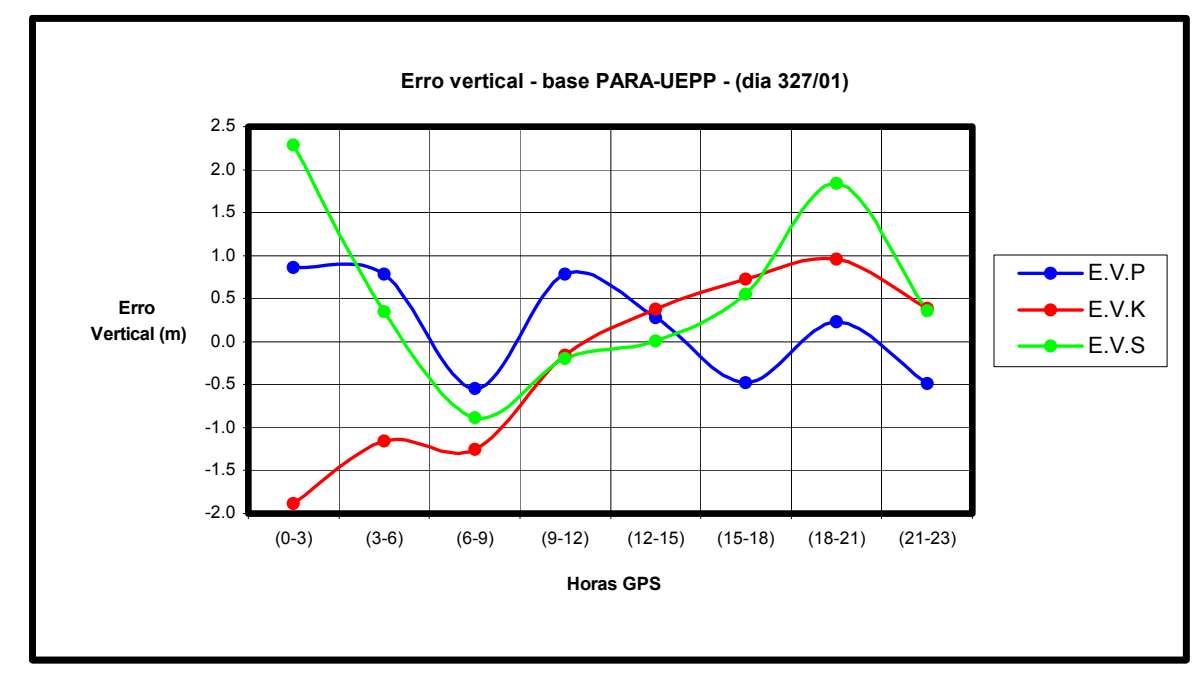

Figura 7.158 - Variação horária do erro vertical do vértice UEPP no posicionamento relativo da base PARA - UEPP - (dia 327/01).

Tabela 7.107 - Erro quadrático horizontal e erro vertical do vértice UEPP no processamento relativo da base PARA - UEPP, para diferentes modelos ionosféricos - (dia 327/01).

\begin{tabular}{|c|c|c|c|c|c|c|}
\cline { 2 - 7 } \multicolumn{1}{c|}{} & \multicolumn{3}{c|}{ Erro Quadrático Horizontal (m) } & \multicolumn{3}{c|}{ Erro Vertical (m) } \\
\hline Horas & E.Q.H.P & E.Q.H.K & E.Q.H.S & E.V.P & E.V.K & E.V.S \\
\hline $\mathbf{( 0 - 3 )}$ & 0,070 & 0,372 & 1,343 & 0,864 & $-1,881$ & 2,291 \\
\hline $\mathbf{( 3 - 6 )}$ & 0,057 & 0,700 & 2,395 & 0,782 & $-1,155$ & 0,348 \\
\hline $\mathbf{( 6 - 9 )}$ & 0,147 & 0,832 & 0,598 & $-0,549$ & $-1,253$ & $-0,881$ \\
\hline $\mathbf{( 9 - 1 2 )}$ & 0,355 & 0,186 & 0,637 & 0,787 & $-0,162$ & $-0,198$ \\
\hline$(\mathbf{1 2 - 1 5 )}$ & 0,278 & 0,162 & 0,553 & 0,281 & 0,373 & 0,010 \\
\hline$(\mathbf{1 5 - 1 8})$ & 0,188 & 0,372 & 0,529 & $-0,474$ & 0,729 & 0,547 \\
\hline $\mathbf{( 1 8 - 2 1 )}$ & 0,342 & 0,278 & 0,772 & 0,230 & 0,962 & 1,843 \\
\hline $\mathbf{( 2 1 - 2 3 )}$ & 0,903 & 2,595 & 1,126 & $-0,487$ & 0,385 & 0,358 \\
\hline E.M.Q & $\mathbf{0 , 2 9 2}$ & $\mathbf{0 , 6 8 7}$ & $\mathbf{0 , 9 9 4}$ & $\mathbf{0 , 5 5 7}$ & $\mathbf{0 , 8 6 2}$ & $\mathbf{0 , 8 1 0}$ \\
\hline Desvio Padrão & $\pm \mathbf{0 , 2 7 2}$ & $\pm \mathbf{0 , 8 0 7}$ & $\pm \mathbf{0 , 6 3 8}$ & $\pm \mathbf{0 , 6 1 1}$ & $\pm \mathbf{1 , 0 5 0}$ & $\pm \mathbf{1 , 0 4 7}$ \\
\hline
\end{tabular}




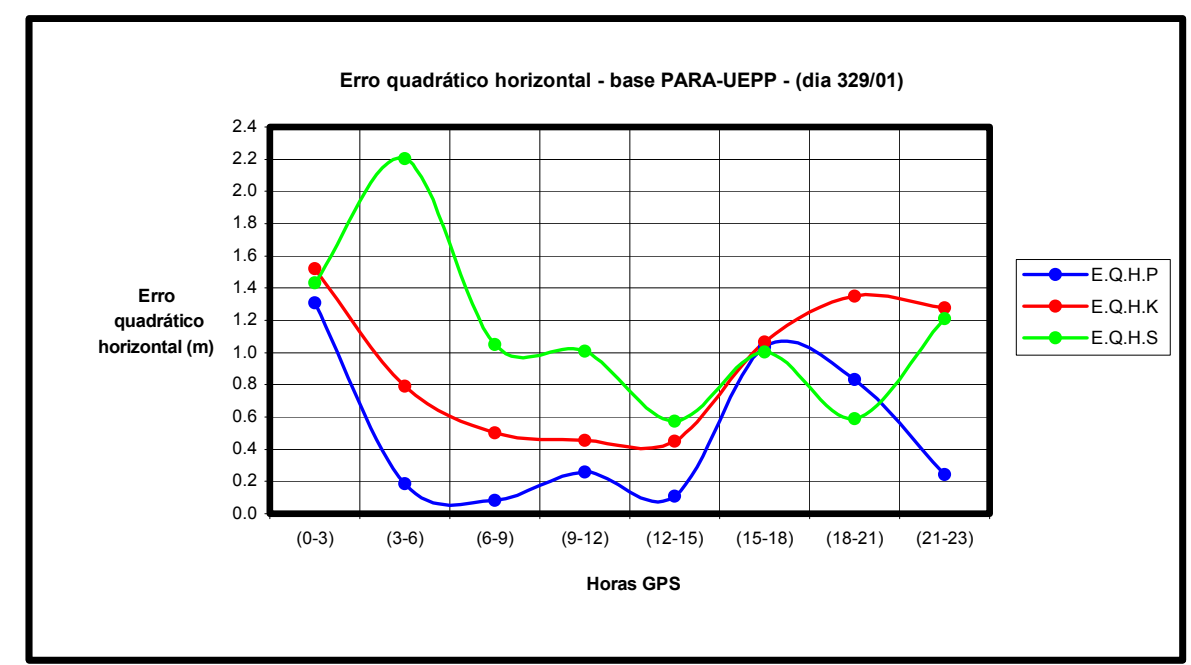

Figura 7.159 - Variação horária do erro quadrático horizontal do vértice UEPP no posicionamento relativo da base PARA - UEPP - (dia 329/01).

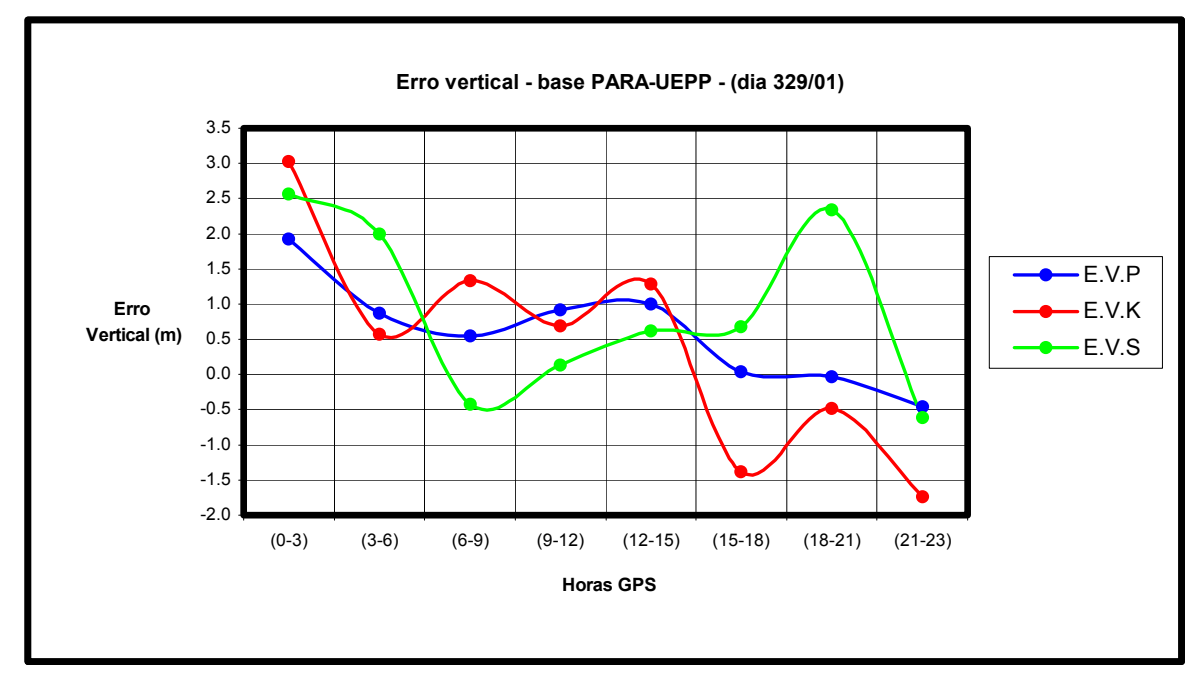

Figura 7.160 - Variação horária do erro vertical do vértice UEPP no posicionamento relativo da base PARA - UEPP - (dia 329/01).

Tabela 7.108 - Erro quadrático horizontal e erro vertical do vértice UEPP no processamento relativo da base PARA - UEPP, para diferentes modelos ionosféricos - (dia 329/01).

\begin{tabular}{|c|c|c|c|c|c|c|}
\cline { 2 - 7 } \multicolumn{1}{c|}{} & \multicolumn{3}{c|}{ Erro Quadrático Horizontal (m) } & \multicolumn{3}{c|}{ Erro Vertical (m) } \\
\hline Horas & E.Q.H.P & E.Q.H.K & E.Q.H.S & E.V.P & E.V.K & E.V.S \\
\hline $\mathbf{( 0 - 3 )}$ & 1,310 & 1,521 & 1,432 & 1,921 & 3,023 & 2,561 \\
\hline $\mathbf{( 3 - 6 )}$ & 0,185 & 0,792 & 2,201 & 0,874 & 0,568 & 1,996 \\
\hline $\mathbf{( 6 - 9 )}$ & 0,085 & 0,502 & 1,052 & 0,549 & 1,332 & $-0,421$ \\
\hline $\mathbf{( 9 - 1 2 )}$ & 0,256 & 0,457 & 1,010 & 0,920 & 0,685 & 0,134 \\
\hline$(\mathbf{1 2 - 1 5 )}$ & 0,107 & 0,448 & 0,572 & 0,996 & 1,281 & 0,625 \\
\hline$(\mathbf{1 5 - 1 8})$ & 1,036 & 1,063 & 1,002 & 0,035 & $-1,388$ & 0,678 \\
\hline $\mathbf{( 1 8 - 2 1 )}$ & 0,834 & 1,350 & 0,591 & $-0,032$ & $-0,485$ & 2,334 \\
\hline $\mathbf{( 2 1 - 2 3 )}$ & 0,242 & 1,279 & 1,212 & $-0,461$ & $-1,739$ & $-0,611$ \\
\hline E.M.Q & $\mathbf{0 , 5 0 7}$ & $\mathbf{0 , 9 2 6}$ & $\mathbf{1 , 1 3 4}$ & $\mathbf{0 , 7 2 4}$ & $\mathbf{1 , 3 1 3}$ & $\mathbf{1 , 1 7 0}$ \\
\hline Desvio Padrão & $\pm \mathbf{0 , 4 7 9}$ & $\pm \mathbf{0 , 4 3 5}$ & $\pm \mathbf{0 , 5 1 9}$ & $\pm \mathbf{0 , 7 4 9}$ & $\pm \mathbf{1 , 5 6 7}$ & $\pm \mathbf{1 , 2 3 9}$ \\
\hline
\end{tabular}


As Tabelas 7.109 e 7.110 ilustram um resumo de todo processamento realizado (Single Point e relativo) durante as quatro estações do ano. Em relação à média do período estudado, constatou-se uma melhora, tanto no posicionamento absoluto quanto no relativo, conforme os valores abaixo:

\section{a) Metodologia Single Point}

- Erro horizontal: o modelo proposto proporcionou uma melhora, em média, de 0,871m (33\%) e 2,459m (57\%) em relação à utilização dos modelos ionosféricos de Klobuchar e Standard, respectivamente.

- Erro vertical: o modelo proposto proporcionou uma melhora, em média, de 1,020m (26\%) e 1,839m (39\%) em relação à utilização dos modelos ionosféricos de Klobuchar e Standard, respectivamente.

\section{b) Metodologia relativa}

- Erro horizontal: o modelo proposto proporcionou uma melhora, em média, de 0,228m (39\%) e 0,389m (47\%) em relação à utilização dos modelos ionosféricos de Klobuchar e Standard, respectivamente.

- Erro vertical: o modelo proposto proporcionou uma melhora, em média, de 0,162m (19\%) e 0,218m (24\%) em relação à utilização dos modelos ionosféricos de Klobuchar e Standard, respectivamente.

Tabela 7.109 - Erro médio quadrático horizontal e erro médio quadrático vertical do vértice BRAZ, referentes aos dias estudados em cada estação do ano (posicionamento Single Point).

\begin{tabular}{|c|c|c|c|c|c|c|}
\hline $\begin{array}{c}\text { Estações } \\
\text { do Ano }\end{array}$ & $\begin{array}{l}\text { E.M.Q.H.P } \\
\qquad(m)\end{array}$ & $\begin{array}{c}\text { E.M.Q.H.K } \\
\text { (m) }\end{array}$ & $\begin{array}{l}\text { E.M.Q.H.S } \\
\qquad(\mathrm{m})\end{array}$ & $\begin{array}{l}\text { E.M.Q.V.P } \\
(\mathrm{m})\end{array}$ & $\begin{array}{l}\text { E.M.Q.V.K } \\
\text { (m) }\end{array}$ & $\begin{array}{l}\text { E.M.Q.V.S } \\
(\mathrm{m})\end{array}$ \\
\hline Verão & $847 \pm$ & $2,934 \pm$ & 5,840 & $2,982 \pm$ & 5,100 & 8,409 \\
\hline Outono & $1,773 \pm 0,939$ & $2,738 \pm 1,179$ & $3,318 \pm 1,671$ & $2,612 \pm$ & 3,112 & 3,269 \\
\hline Inverno & $1,701 \pm 0,874$ & $2,204 \pm 1,216$ & $3,227 \pm 1,379$ & $3,036 \pm 3,690$ & $3,607 \pm 3,329$ & $3,492 \pm 2,794$ \\
\hline Primavera & $1,884 \pm 1,027$ & $3,171 \pm 1,738$ & $4,655 \pm 1,983$ & $2,692 \pm 3,296$ & $3,584 \pm 3,670$ & $3,510 \pm 3,635$ \\
\hline Média & $801 \pm 0,954$ & $2,672 \pm 1,455$ & $4,260 \pm 2,127$ & $2,831 \pm 3,513$ & $3,851 \pm$ & 4,6 \\
\hline
\end{tabular}


Tabela 7.110 - Erro médio quadrático horizontal e erro médio quadrático vertical do vértice UEPP, referentes aos dias estudados em cada estação do ano (posicionamento relativo).

\begin{tabular}{|c|c|c|c|c|c|c|}
\hline $\begin{array}{c}\text { Estações } \\
\text { do Ano }\end{array}$ & $\begin{array}{c}\text { E.M.Q.H.P } \\
(\mathbf{m})\end{array}$ & $\begin{array}{c}\text { E.M.Q.H.K } \\
(\mathbf{m})\end{array}$ & $\begin{array}{c}\text { E.M.Q.H.S } \\
\mathbf{( m )}\end{array}$ & $\begin{array}{c}\text { E.M.Q.V.P } \\
(\mathbf{m})\end{array}$ & $\begin{array}{c}\text { E.M.Q.V.K } \\
(\mathbf{m})\end{array}$ & $\begin{array}{c}\text { E.M.Q.V.S } \\
(\mathbf{m})\end{array}$ \\
\hline Verão & $0,259 \pm 0,247$ & $0,720 \pm 0,726$ & $0,929 \pm 0,836$ & $0,685 \pm 0,800$ & $0,886 \pm 1,293$ & $1,057 \pm 1,416$ \\
\hline Outono & $0,442 \pm 0,402$ & $0,530 \pm 0,344$ & $0,548 \pm 0,322$ & $0,651 \pm 0,789$ & $0,643 \pm 0,777$ & $0,687 \pm 0,819$ \\
\hline Inverno & $0,499 \pm 0,505$ & $0,676 \pm 0,606$ & $0,624 \pm 0,419$ & $0,477 \pm 0,588$ & $0,749 \pm 0,817$ & $0,694 \pm 0,868$ \\
\hline Primavera & $0,589 \pm 0,664$ & $1,013 \pm 0,890$ & $1,243 \pm 1,042$ & $1,023 \pm 1,422$ & $1,206 \pm 1,678$ & $1,270 \pm 1,510$ \\
\hline Média & $\mathbf{0 , 4 4 7} \pm \mathbf{0 , 4 5 4}$ & $\mathbf{0 , 7 3 5} \pm \mathbf{0 , 6 4 2}$ & $\mathbf{0 , 8 3 6} \pm \mathbf{0 , 6 5 5}$ & $\mathbf{0 , 7 0 9} \pm \mathbf{0 , 9 0 0}$ & $\mathbf{0 , 8 7 1} \pm \mathbf{1 , 1 4 1}$ & $\mathbf{0 , 9 2 7} \pm \mathbf{1 , 1 5 3}$ \\
\hline
\end{tabular}




\section{Conclusões e recomendações}

Neste capítulo, além de ser apresentado um resumo do que foi realizado no decorrer de todo trabalho, serão divulgadas as principais conclusões obtidas a respeito dos resultados da pesquisa. Algumas recomendações também serão apresentadas, com o objetivo de desenvolvimento de futuros trabalhos relacionados com o tema em questão.

\subsection{Introdução}

Durante o desenvolver da pesquisa, foram apresentados alguns resultados de trabalhos desenvolvidos, nacional e internacionalmente, cujo tema principal foi a influência da ionosfera nas observáveis GPS.

Apresentou-se, além de uma caracterização da ionosfera e sua influência nos sinais de rádio, um resumo dos principais modelos ionosféricos (pontual e regional), com o intuito de melhoria em posicionamento de pontos com o sistema GPS.

Realizou-se uma abordagem do método de ajustamento de observações seqüencial, aplicado à modelagem ionosférica, através do ajuste dos parâmetros de um polinômio do segundo grau. Para isto, utilizou-se, como medições, as observáveis pseudodistâncias (códigos $\mathrm{C} / \mathrm{A}$ e $\mathrm{P}_{2}$ ) advindas dos arquivos RINEX das estações pertencentes à Rede Brasileira de Monitoramento Contínuo (RBMC). Optou-se em trabalhar com ajustamento seqüencial com o objetivo de filtrar as observações ruidosas envolvidas no problema. No processo de ajuste dos parâmetros realizou-se uma simplificação na modelagem, onde não foram separados os erros de interfreqüência dos satélites e dos receptores.

Os coeficientes do polinômio foram determinados em intervalos de 1 hora, em dias distribuídos nas quatro estações do ano. Procedeu-se desta forma com objetivo de verificar a influência diária e sazonal da ionosfera na determinação dos parâmetros. Para automatização do processo foi desenvolvido um programa em linguagem Visual Basic 5.0 denominado MODEIONO.

Para validação do modelo proposto, a fim de comprovar a hipótese formulada neste trabalho, foram realizados processamentos de informações GPS através das metodologias 
Single Point e relativa. As estações utilizadas no processamento foram BRAZ (Single Point) e, na metodologia relativa, a base formada pelas estações PARA e UEPP. Estas três estações não participaram do processo de ajustamento dos parâmetros do modelo polinomial. O processo utilizado para validação foi comparativo através da análise de erros (horizontal e vertical) processando os pontos BRAZ e UEPP com os modelos de Klobuchar, Standard e o proposto nesta pesquisa. Em relação ao modelo proposto, os critérios foram distintos para os processamentos Single Point e relativo. No Single Point realizou-se correção ao código C/A através do atraso obtido pelo modelo polinomial. Já no método relativo, optou-se em escrever um outro código criando um arquivo RINEX com às observáveis portadora $L_{1}$, código $C / A$ e o código recriado. Este último é função do código $\mathrm{C} / \mathrm{A}$ e do atraso obtido pela modelagem ionosférica. Assim, o vértice UEPP foi processado, fixando as coordenadas da estação PARA, através da solução iono free code.

\subsection{Conclusões}

As conclusões aqui apresentadas foram divididas em duas partes:

a) Conclusões a respeito da estruturação das informações utilizadas na pesquisa

No processo de pesquisa a respeito de quais estações que seriam utilizadas na modelagem ionosférica, constatou-se que as empresas que mantém, no Brasil, redes GPS de monitoramento contínuo (públicas e privadas) não costumam gravar as informações das estações por longos períodos de tempo, como faz o IBGE. Este fato acarretou que não foi possível a utilização de informações GPS, advindas destas estações, na modelagem ionosférica.

Em relação às estações da RBMC, constatou-se que, algumas delas, no período estudado, apresentaram muitas interrupções no processo de armazenamento dos dados.

\section{b) Conclusões a respeito dos resultados encontrados}

O ajustamento seqüencial mostrou ser uma ferramenta eficiente no processo de filtragem das observações ruidosas, ao estimar os parâmetros do modelo polinomial. Foi importante a determinação dos coeficientes em intervalos de uma hora, pois, através desta metodologia, foi possível verificar a influência da ionosfera ao longo do dia na estimativa dos parâmetros. Os maiores picos nos valores dos coeficientes ocorreram entre os intervalos 17 e 20 horas GPS. Esta variação dos coeficientes mostrou o quanto a ionosfera é dinâmica ao 
longo do dia. Assim, ao determinar coeficientes de modelos matemáticos, que tenham por objetivo minimizar os efeitos da ionosfera nas observáveis GPS, é interessante que os mesmos não sejam determinados através de valores médios diários e, sim, em intervalos ao longo do dia. Não foi possível concluir se um intervalo de 1 hora é adequado neste processo. Outros estudos são necessários para responder a esta pergunta.

A participação da estação de Manaus, no processo de ajustamento, proporcionou um pequeno aumento no valor do desvio padrão médio diário dos coeficientes. A influência da ionosfera é bastante evidenciada na região norte de nosso país devido à grande concentração de elétrons livres naquele local, bem como ao efeito da anomalia equatorial. Tal fato pôde ter ocasionado o aumento do desvio padrão dos coeficientes com a participação da estação de Manaus. Com o funcionamento das estações GPS do projeto SIVAM (Sistema de Vigilância da Amazônia), será possível estudar modelos específicos para a região norte do país.

Valores médios distintos dos coeficientes, em relação às estações do ano, mostraram a variação sazonal da ionosfera. Talvez a utilização de modelos matemáticos distintos para cada estação do ano pudesse proporcionar melhores resultados no processo de determinação do atraso ionosférico.

Entre os modelos estudados (Klobuchar e Standard), os resultados encontrados mostraram que a eficiência no processo de redução dos efeitos ionosféricos nas observáveis GPS pode ser melhorada através do estudo de modelos específicos para as condições brasileiras. Isto foi comprovado através do modelo proposto nesta pesquisa. Tanto horizontal quanto verticalmente o modelo de Klobuchar mostrou ser mais eficiente que o modelo Standard, quando aplicado em posicionamento através da metodologia Single Point.

Verificou-se que, no posicionamento Single Point, o modelo proposto proporcionou melhores resultados que o de Klobuchar e o Standard em todo o período do dia, durante as quatro estações do ano. Se comparado com o de Klobuchar, em média, a melhora foi de $33 \%$ e em relação ao modelo Standard a melhora foi de $57 \%$. Diante destes valores salienta-se a importância de se estruturar outras linhas de pesquisa com o intuito de desenvolver modelos matemáticos pontuais e/ou regionais voltados para as condições ionosféricas encontradas no Brasil.

No que ser refere ao posicionamento relativo, verificou-se que os erros horizontais e verticais encontrados com a utilização do modelo de Klobuchar e Standard foram parecidos, de acordo com a média de todo o período estudado. Ao comparar os resultados com a metodologia proposta neste trabalho, a melhora, em média, no posicionamento horizontal, foi de $26 \%$ e $39 \%$, respectivamente, em relação à utilização dos modelos de Klobuchar e 
Standard. Já no posicionamento vertical a melhora foi de $19 \%$ e $24 \%$, respectivamente, em relação aos modelos de Klobuchar e Standard. Pelos resultados conclui-se que a metodologia proposta foi mais eficiente no posicionamento horizontal do que o vertical.

Diferentemente das condições encontradas em alguns países da Europa, Estados Unidos, Canadá, Japão etc, onde a maioria dos usuários possui equipamentos de dupla freqüência, no Brasil a realidade é bem diferente. Com exceção de algumas empresas privadas e instituições de ensino e pesquisa, boa parte dos profissionais brasileiros utiliza equipamentos de simples freqüência em suas atividades de posicionamento. Neste contexto os resultados encontrados neste trabalho podem proporcionar algumas boas perspectivas, no que diz respeito ao desenvolvimento de modelos matemáticos com o objetivo de se recriar o código $\mathrm{P}$ através das informações disponibilizadas pela RBMC. Com isto, é possível realizar posicionamento de pontos utilizando-se modelos mais eficientes através de solução do tipo iono free code.

Por fim, através dos resultados encontrados, a hipótese formulada foi comprovada e um melhor refinamento dos resultados pode ser alcançado através do estudo de outros modelos matemáticos voltados para a realidade brasileira.

\subsection{Recomendações}

Os resultados encontrados, bem como as análises realizadas durante 0 desenvolvimento deste trabalho, deram subsídios para a indicação de algumas recomendações importantes:

- Realizar novos estudos no sentido de reduzir o intervalo de tempo no processo de determinação de parâmetros de modelos ionosféricos regionais;

- Desenvolver modelagens matemáticas específicas para as diferentes estações do ano;

- Sugerir à coordenação de Geodésia do IBGE a divulgação dos arquivos RINEX das estações da RBMC em intervalos de 1 hora e não de 24 horas;

- Desenvolver, em parcerias entre o IBGE e instituições de ensino, estudos no sentido de verificar o comportamento de funcionamento de todas as estações da RBMC e divulgar estas informações pela internet.

- Automatizar o processo de ajuste de parâmetros de modelos matemáticos que têm por objetivo modelar a ionosfera através de linguagens de programação que facilite a divulgação de informações ionosféricas via internet; 
- Conscientizar os órgãos públicos e privados que possuem estações GPS de monitoramento contínuo da importância de manter um banco de dados das cópias dos arquivos RINEX por longos períodos de tempo;

- Estudar modelos matemáticos que caracterizem a ionosfera especificamente para a região norte do Brasil;

- Desenvolver outras metodologias com o objetivo de obter o atraso ionosférico e, conseqüentemente, analisar a possibilidade de recriar um código que seja semelhante ao $\mathrm{P}_{2}$. Neste sentido, recomenda-se estudar outras técnicas como, por exemplo, colocação por mínimos quadrados e redes neurais artificiais. 


\section{Referências bibliográficas}

ANTUNES, C. Método Seqüencial de Ajustamento no Tratamento de Observações GPS. In. Conferência de Cartografia e Geodésia. Faculdade de Ciências da Universidade de Lisboa - FCUL, p. 5-16, 1996.

BEN-ISRAEL, A., GREVILLE, T. N. E. Generalized Inverse: Theory And Applications. Willey And Sons, New York, 1974.

BHATTACHARYA, A. B. et al. Long-Period Fading in Atmospherics During Severe Meteorological Activity and Associated Solar Geophysical Phenomena at Low Latitudes. Annales Geophysicae, Vol. 16, p. 183-188, 1998.

BRILLOUIN, L., SOMMERFELD, A. Wave Propagation and Group Velocity. Academic Press New York, 1960.

BRUNNER, F. K.; WELSCH, W. M. Effects of Troposphere on GPS Measurements. GPS WORLD, p. 42-44, 1993.

BUDDEN, K. G. Radio Waves in the lonosphere. Cambridge: Cambridge University Press, 1966.

CAMARGO, P.O. Modelo Regional da lonosfera Para o Uso em Posicionamento com Receptores GPS de Uma Freqüência. Universidade Federal do Paraná, Tese de Doutorado, Curitiba - PR, 1999.

COCO, D. S. GPS - Satellites of Opportunity for lonospheric Monitoring. GPS WORLD, p. 47-50, 1991.

DABAS, R. S. Ionosphere and its Influence on Radio Communications. RESONANCE, p. 28-43, 2000.

DENARDINI, C. M. Desenvolvimento de um Sistema de Correção de Fase Para o Radar lonosférico de São Luís do Maranhão. Instituto Nacional de Pesquisas Espaciais, Dissertação de Mestrado, São José do Campos - SP, 1999. 
FORTES, L.P.S. Operacionalização da Rede Brasileira de Monitoramento Contínuo do Sistema GPS (RBMC). Instituto Militar de Engenharia, Dissertação de Mestrado, Rio de Janeiro - RJ, 1997.

FONSECA JÚNIOR, E. S. O Sistema GPS Como Ferramenta Para Avaliação da Refração lonosférica no Brasil, Escola Politécnica da Universidade de São Paulo, Tese de Doutorado, São Paulo - SP, 2002.

GEMAEL, C. Introdução ao Ajustamento de Observações: Aplicações Geodésicas. Editora da Universidade Federal do Paraná, Curitiba - PR, 1994.

GIEFER, A. Digital Radio Mondiale Field Trials and Their Impact on System Design. DRM Field Trials, 2001.

GORBUNOV, M. E. Radioholographic Methods for Processing Radio Occultation Data in Multipath Regions. Atmosphere lonosphere Research Division Danish Meteorological Institute, Copenhagen, Denmark, 2000.

HAWK, M. Mid - Latitude Sporadic-E - A Review. http://www.anarc.org/wtfda/sporade.pdf Acessado em 10/08/03.

HOFMANN-WELLENHOF, B.; LICHTENEGGER, H.; COLLINS, J. Global Positioning System Theory and Practice. 2. ed. Springer-Verlag, New York:, 2001.

KAGAN, D. Electromagnetic Waves: Physics 4B Lecture Notes, California State University Chico, p. 1-8, 2002.

KLOBUCHAR, J. A. Ionospheric Time-Delay Algorithm for Single-Frequency GPS Users. IEEE Transactions on Aerospace and Electronic Systems, Vol. 23, n.3, p.325-331, 1987.

KRAKIWSKY, E. J.; BIACS, Z. F. Least Squares Collocation and Statistical Testing. Bulletin Géodésique, Paris, Vol. 64, n.01, p.73-87, 1990.

KUZNETSOV, V. V. et al. Universal Variation of the F2-Layer Critical Frequency and Solar Activity. Earth Planets Space, Vol. 50, p. 57-61, 1998

LEANDRO, R. F., A Influência da lonosfera no Posicionamento GPS Por Ponto Simples. Escola de Engenharia de São Carlos da Universidade de São Paulo, Dissertação de Mestrado, São Carlos - SP, 2003.

LEICK, A. GPS Satellite Surveying. 2. ed., John Wiley \& Sons, New York, 2003.

MANNUCCI, A. J., B. D. WILSON, D. N. YUAN, C. H. HO, U. J. LINDQWISTER, AND T. F. RUNGE, A Global Mapping Technique for GPS-Derived lonospheric Total Electron Content Measurements. Radio Science, Vol. 33, p. 565-582, 1998. 
MOURA, J. O., Pseudo-Inversa Aplicada a Fotogrametria. Universidade Federal do Paraná, Dissertação de Mestrado, Curitiba - PR, 1980.

MONICO, J. F. G. Posicionamento pelo NAVSTAR - GPS: Descrição, Fundamentos e Aplicações. Editora da Universidade Estadual Paulista, Presidente Prudente - SP, 1998.

NEWBY, S. P., LANGLEY, R. B. Tree Alterntative Empirical lonospheric Models - Are They Better than GPS Broadcast Model? In: Proceedings of the Sixth International Geodetic on Satellite Positioning, Colombus, OH, USA, Vol. 1, p. 240-244, 1992.

OSORIO, I. M. T. V. P. O Sistema Global de Posicionamento na Orbitografia de Satélites de Baixa Altitude. Faculdade de Ciências da Universidade do Porto, Tese de Doutorado, Porto - PT, 1992.

PARKINSON, B. W., SPILKER, J. J. Global Positioning System: Theory and Applications. Vol. I, American Institute of Aeronautics and Astronautics, 1996.

PICQUENARD, A. Propagação das Ondas Radioelétricas nos Meios Naturais. Rio de Janeiro, 1974.

POOLE, I. Radio Waves and the lonosphere. ARRL, p. 1-3, 1999.

REMONDI, B. W. Using the Global Positioning System (GPS) Phase Observable fot Relative Geodesy: Modeling, Processing and Results. NOAA, Reprint of Doctoral Dissertation Center For Space Research, University of Texas at Austin, 1984.

ROKHLIN, S. I., BOLLAND, T. K., ADLER, L. Reflection and Refraction of Elastic Waves on a Plane Interface Between Two Generally Anisotropic Media: J. Acoust. Soc., Vol. 79, p. 906-918, 1986.

SCHAER, S. Towards a Combined lonosphere Product. IGS - New Projects \& Applications, http://igscb.jpl.nasa.gov/project, 1998.

SCHAER, S. Mapping And Predicting the Earth's lonosphere Using the Global Positioning System. University of Bern, PhD Thesis, Bern - Switzerland, 1999.

SCHLESINGER, W. H. Biogeochemistry: an Analysis of Global Change. 2nd edition. Academic Press, California, 1997.

SEEBER, G. Satellite Geodesy: Foundations, Methods and Applications. Walter de Gruyter, Berlin, 2003.

SEGANTINE, P. C. L., Estudo do Sinergismo Entre os Sistemas de Informação Geográfica e o de Posicionamento Global. Escola de Engenharia de São Carlos da Universidade de São Paulo, Tese de Livre Docência, São Carlos - SP, 2001. 
SILVA, A. S., GRIPP JÚNIOR, J. Porque o Ajustamento Livre? In. Anais do VII Congresso Nacional de Engenharia de Agrimensura, Salvador - BA, p. 111-113, 1996.

SLAWINSKI, M. A. On Elastic-wave Propagation in Anisotropic Media: Reflection/Refraction Laws, Raytracing, and Travel time Inversion. PhD Thesis, Calgary University, Alberta Canada, 1996.

WEBSTER, I. A Regional Model for Prediction of Ionospheric Delay for Single Frequency Users of the Global Positioning System. University of New Brunswick, MSc. E Thesis, New Brunswick - CA. 1993.

WÜBBENA, G. The GPS Adjustment Software Package GEONAP, Concepts and Models. In: Proceedings of the Fifth International Geodetic Symposium on Satellite Positioning, Las Cruces, New Mexico, Vol. 2, p. 452-461, 1989.

ZENG, X., MACBETH, C. Accuracy of Shear-Wave Polarization Estimates From Near-Offset VSP Data. Canadian Journal Of Exploration Geophysics, Vol. 29, p. 246-265, 1993.

\subsection{Bibliografia complementar}

BAARDA, W. A Testing Procedure for Use in Geodetic Networks. Netherlands Geodetic Commission - Publication on Geodesy - News Series, Vol.2, n.5, 1968.

CAMPOS, M. A., WANNINGER, L., SEEBER, G. Condições lonosféricas Perturbadas e os Sinais GPS. In: Resumos expandidos do $3^{\circ}$ Congresso Internacional da Sociedade Brasileira de Geofísica, Rio de Janeiro - RJ, p. 601-604, 1993.

GEMAEL, C. Geodésia Celeste: Introdução. Editora da Universidade Federal do Paraná, Curitiba - PR, 1991.

GUSTAFSSON, G., N. E. PAPITASHVILI, AND V. O. PAPITASHVILI. A Revised Corrected Geomagnetic Coordinate System for Epochs 1985 and 1990. Journal of Atmospheric and Solar and Terrestrial Physics, n. 54, p. 1609-1631, 1992.

KELLEY, M.C. The Earth's Ionosphere: Plasma Physics and Electrodynamics, International Geophysics Series, Vol. 43, 1989.

KLEUSBERG, A. Ionospheric Propagation Effects in Geodetic Relative GPS Positioning. Manuscripta Geodaetica, Vol.11, n. 4, p.256-261, 1986.

IBGE. Sistema de Referência Geocêntrico para a América do Sul. Relatório final: Grupo de trabalhos I e II / IBGE, Rio de Janeiro - RJ, 1997. 
KLOBUCHAR, J. A. Ionospheric Time-Delay Corrections for Advanced Satellite Ranging System. AGARD Conference Proceedings - Propagation Limitations of Navigation and Positioning Systems, 1977.

KLOBUCHAR, J. A. Ionospheric Effects on GPS. GPS World, p. 48-50, 1991.

KOMJATHY, A.; LANGLEY, R. B. The Effect of Shell Height on High Precision lonospheric Modeling Using GPS. IGS Workshop, Silver Spring, p.193-203, 1996.

MANNUCCI, A. J., WILSON, B. D., YUAN, D. N., HO, C. H., LINDQWISTER, U. J., RUNGE, T. F. A Global Mapping Technique for GPS-Derived lonospheric Total Electron Content Measurements, Radio Science, n. 33, p. 565-582, 1998.

MIKHAIL, E. M. Observations and Least Squares. IEP - A Dun-Donnelley Publisher, New York, 1976.

OLIVEIRA, L. C. Refração Atmosférica nas Medidas Doppler. Universidade Federal do Paraná, Dissertação de Mestrado, Curitiba - PR, 1990.

OSÓRIO, I., OSÓRIO, J. P., REBORDÃO, J. M., TEC Evaluation from GPS Measurements on Board of the Portuguese Satellite PoSAT-1. In: Proceedings 22th ISTS, Morioka, Japan, 2000.

OSÓRIO, I., OSÓRIO, J. P., REBORDÃO, J. M., Ionospheric Studies from GPS Measurements on Board of the Portuguese Satellite PoSAT-1. In: Proceedings of ION Annual Meeting, San Diego, USA, 2000.

RISHHBETH, H., AND O. K. GARRIOT. Introduction to lonospheric Physics, International Geophysics Series, Vol. 14, 1969.

SPILKER JR., J. J., DIERENDONCK, A. J. VAN, Proposed New Civil GPS Signal at 1176,45 $\mathrm{MHz}$. In: Proceedings of the International Technical Meeting of the Satellite Division of the Institute of Navigation. ION GPS, Nashville, Tennessee, USA, 1999.

TEUNISSEN, P. J. G. The Least-Squares Ambiguity Correlation Adjustment: A Method for Fast GPS Integer Ambiguity Estimation. Journal of Geodesy, Vol. 70, p. 65-82, 1995.

WANNINGER, L., Effects of the Equatorial lonosphere on GPS. GPS World, Vol. 5, n. 7, p. 48-54, 1993. 